\title{
CANOES AND CANVAS: \\ THE SOCIAL AND SPATIAL POLITICS OF SPORT/LEISURE IN LATE NINETEENTH-CENTURY NORTH AMERICA
}

\author{
by \\ JESSICA DIANE DUNKIN
}

A thesis submitted to the Faculty of Graduate and Postdoctoral Affairs in partial fulfillment of the requirements for the degree of

\author{
Doctor of Philosophy \\ in \\ History \\ Carleton University \\ Ottawa, Ontario
}

(ㅇ) 2012, Jessica Diane Dunkin 
Library and Archives

Canada

Published Heritage

Branch

395 Wellington Street

Ottawa ON K1A ON4

Canada
Bibliothèque et

Archives Canada

Direction du

Patrimoine de l'édition

395 , rue Wellington

Ottawa ON K1A ON4

Canada
Your file Votre référence

ISBN: 978-0-494-93675-7

Our file Notre référence

ISBN: 978-0-494-93675-7
NOTICE:

The author has granted a nonexclusive license allowing Library and Archives Canada to reproduce, publish, archive, preserve, conserve, communicate to the public by telecommunication or on the Internet, loan, distrbute and sell theses worldwide, for commercial or noncommercial purposes, in microform, paper, electronic and/or any other formats.

The author retains copyright ownership and moral rights in this thesis. Neither the thesis nor substantial extracts from it may be printed or otherwise reproduced without the author's permission.
AVIS:

L'auteur a accordé une licence non exclusive permettant à la Bibliothèque et Archives Canada de reproduire, publier, archiver, sauvegarder, conserver, transmettre au public par télécommunication ou par l'Internet, prêter, distribuer et vendre des thèses partout dans le monde, à des fins commerciales ou autres, sur support microforme, papier, électronique et/ou autres formats.

L'auteur conserve la propriété du droit d'auteur et des droits moraux qui protege cette thèse. $\mathrm{Ni}$ la thèse ni des extraits substantiels de celle-ci ne doivent être imprimés ou autrement reproduits sans son autorisation.
In compliance with the Canadian Privacy Act some supporting forms may have been removed from this thesis.

While these forms may be included in the document page count, their removal does not represent any loss of content from the thesis.
Conformément à la loi canadienne sur la protection de la vie privée, quelques formulaires secondaires ont été enlevés de cette thèse.

Bien que ces formulaires aient inclus dans la pagination, il n'y aura aucun contenu manquant. 
The Department of History recommends to the Faculty of Graduate and Postdoctoral Affairs acceptance of the thesis

CANOES AND CANVAS:

THE SOCIAL AND SPATIAL POLITICS OF SPORT/LEISURE IN LATE NINETEENTH-CENTURY NORTH AMERICA

\author{
submitted by \\ Jessica Diane Dunkin, B.Ed., B.A. Hons., M.A. \\ in partial fulfilment of the requirements \\ for the degree of Doctor of Philosophy \\ James Miller \\ Chair of the Department of History \\ John Walsh, Thesis Supervisor \\ Mary Louise Adams, Queen's University \\ External Examiner
}

Department of History

Carleton University

17 September 2012 


\begin{abstract}
This dissertation explores the social and spatial politics of sport/leisure in the late nineteenth century within the context of the American Canoe Association (ACA). Beginning in 1880, the Association sought "to unite all amateur canoeists for the purpose of pleasure, health, or exploration." Yearly encampments, which brought together enthusiasts from Canada and the United States to sleep under canvas, race canoes, "recreate," and socialize, were central to realizing this mission. The encampments were profoundly meaningful events for many who attended. However, the construction of meaning was contingent upon practices of hierarchy and exclusion. For example, the ACA barred full membership to women, members of the working class, and people of colour, even as it engaged the "other" as labourer at the encampments.
\end{abstract}

I pay particular attention to the ways in which class, gender, and race were mobilized to shape access to and experiences of recreation, but also to the broader effects of the encampments on the lives, livelihoods, and lands of rural whites, Aboriginal people, African Americans, and French Canadians. These were constructed places and communities, and the boundary-work of inclusion and exclusion that characterized them were extensions rather than departures from how place and community were being formed elsewhere. Throughout, this dissertation argues that this seemingly egalitarian and fun-loving organization, which located itself in what its organizers perceived as benign natural landscapes, also participated in a politics of exclusion, displacement, and dispossession at the core of late nineteenth-century liberalism, capitalism, and colonialism. In making such an argument, this dissertation also raises questions about what has historically constituted a "sportscape" arguing the 
space of competition, at least in the case of the ACA regattas, must be studied alongside those spaces of dwelling, administration, work, and travel to which it was connected.

This dissertation is informed by and in conversation with literatures from the history of sport, women's and gender history, the history of tourism, working-class and labour history, and environmental history, and it hopes that specialists in those areas will see not only its indebtedness but also some contributions back to these fields. 


\section{Acknowledgements}

Writing a dissertation is nothing if not a collaborative process. This project owes much to the support and guidance of my teachers, colleagues, and students in the Department of History at Carleton University, but especially to the supervision of Dr. John C. Walsh. I knew from our first meeting in January 2007 as we shared a container of grapes in his office and discussed my future that he would be much more than a supervisor. He has been a wonderful mentor and friend through the good times and the bad. I can only hope that one day I will have the opportunity to offer students the kind of thoughtful and inspiring supervision that $\mathrm{I}$ received as an $\mathrm{MA}$ and $\mathrm{PhD}$ student. I have also had the pleasure of working closely with Dr. Andrew Johnston, from whom I have learned much about American history and culture, teaching, and birds. John and Andrew, alongside Drs. Mary Louise Adams (Queen's), Emilie Cameron (Carleton), and Joanna Dean (Carleton), provided stimulating discussion and trenchant feedback during my defense that will be invaluable as I transform this dissertation into a book. The department's administrative team-Dr. Dominique Marshall, Dr. Jennifer Evans, Dr. James Miller, Joan White, Regina Aulinskas, and Irene Sanna-deserve thanks for the many ways in which they have encouraged and assisted me as I navigated graduate study.

The Carleton History Department is home to a vibrant graduate student community of which I have relished being a part. This dissertation benefitted directly from feedback provided through the Underhill Colloquium and the Living Room Lecture Series, and indirectly from the many informal conversations that took place in the lounge or at Mike's. I have been particularly fortunate to meet David Banoub, Sara Spike, and David Tough. In addition to becoming cherished friends, they have 
provided much in the way of intellectual stimulation and support. My introduction to geography graduate student Bryan Grimwood by Dr. Carter Elwood in the fall of 2008 was serendipitous. This dissertation is so much better for the collaborative work that Dr. Grimwood and I have undertaken since our first meeting.

I had the good fortune of completing my undergraduate degree in the History Department at Trent University, where I was inspired and guided by Finis Dunaway, Janet Miron, Kevin Siena, Dale Standen, and Timothy Stapleton. My decision to attend graduate school was made with the encouragement and support of each of the professors. I am particularly indebted to Dr. Dimitry Anastakis who took me under his wing as an undergraduate student and prepared me so well for graduate school. Long after leaving Trent, Dimitry has continued to support me in myriad ways. I admire him so much as a scholar, a teacher, and a human being.

One of the many pleasures of this project has been archival research. At the New York State Historical Association Library in Cooperstown, NY, with its lovely reading room overlooking Lake Otsego, I wish to thank Sarah, Joanne, and Wayne for their gracious assistance and for making me feel at home. At the Adirondack Museum in Blue Mountain Lake, NY, I am indebted to Hallie Bond and Jerry Pepper for their interest in this project and their help in locating suitable materials. Thanks are also due to the staff at the Mystic Seaport Collections Research Center in Mystic, CT, and the Antique Boat Museum in Clayton, NY. I would also like to thank Mary Margaret Johnston-Miller at Library and Archives Canada for her assistance with photographic materials, and the staff of Carleton's Interlibrary Loan Department, who managed to track down a steady stream of obscure sources for me. The research for this dissertation was enabled by the financial support of the Social Science and 
Humanities Research Council of Canada, the Department of History, and Carleton University.

My family and friends have supported me in myriad ways as I obsessed about coursework, comprehensive exams, proposals and applications, teaching, research, conference presentations, and most recently, writing and revising. An enormous thank you is due to my parents, Stephen Dunkin and Diane Gagne, and their respective partners, Susan Dunkin and Lee Gagne, my brother and sister-in-law, Matthew Dunkin and Victoria Boomgaardt, and my nephew and niece, Griffith and Molly Boomgaardt Dunkin. Graduate school also gave me the opportunity to get to know my uncle, Dr. Thomas Saunders of the University of Victoria, in a new way. I have learned so much from our conservations about teaching, research, and family. In the course of writing this dissertation, I became part of a new family. Thank you Elliot, Audrey, and Peter for making my life more colourful and my days more interesting. Finally, to Paul, your indefatigable support and patience particularly as this project drew to a close was invaluable and by no means taken for granted. Thank you.

I lost three grandparents during the writing of this dissertation. Although they had all lived long full lives, it was nevertheless difficult to say goodbye to this eclectic group of people. I learned so much from them about curiosity, compassion, and resilience, all of which have been invaluable in my teaching and research. This dissertation is dedicated to the memory of Hester Grace Dear Dunkin (1918-1997), Thomas Gilbert Dunkin (1917-2010), Harold Leonard Saunders (1921-2010), and Phyllis Minnie Clendenen Saunders (1929-2011). 


\section{Table of Contents}

$\begin{array}{ll}\text { Abstract } & \text { ii }\end{array}$

Acknowledgements $\quad$ iv

Table of Contents vii

List of Figures viii

Introduction 1

Chapter Two: Organizing 37

Chapter Three: (Dis)Placing $\quad 83$

$\begin{array}{ll}\text { Chapter Four: Navigating } & 119\end{array}$

$\begin{array}{ll}\text { Chapter Five: Governing } & 165\end{array}$

Chapter Six: Placing Domesticity 209

Chapter Seven: Inhabiting $\quad 252$

Chapter Eight: Competing $\quad 299$

Chapter Nine: Producing/Consuming $\quad 354$

$\begin{array}{ll}\text { Conclusion } & 401\end{array}$

Appendix A: Dates and Locations of the Annual Meetings $\quad 408$ and Encampments

$\begin{array}{ll}\text { Bibliography } & 409\end{array}$ 


\section{List of Figures}

1.1 - Map of American Canoe Association Encampments, 1880-1910. 2

2.1 - Area map of the 1895 encampment on Lake Champlain. $\quad 74$

2.2 - Area map of the 1900 encampment on Lake Rosseau.

2.3 - Site map of the 1887 encampment on Lake Champlain. $\quad 78$

2.4 - Site map of the 1901 encampment on Mudlunta Island. $\quad 79$

4.1 - "Muskoka Navigation Steamer 'Medora' at Muskoka Wharf," 1900.

5.1 - H.C. Morse, "Headquarters from Dock," 1897.

5.2 - S.R. Stoddard, "Campers Leaving the Mess Tent," 1889.

5.3 - A.A. Lewis, "Dinner Time in the Mess Tent," 1898.

6.1 - W.A. Rogers, "Headquarters - Secretary ACA Enrolling a Recruit 214 from Squaw Point," 1885.

6.2 - "Official Headquarters," 1886.

6.3 - "A Tent Interior," 1891.

6.4 - "Site of the ACA Camp, Jessup's Neck, Long Island," 1890.

6.5 - S.R. Stoddard, “Toronto Canoe Club Camp," 1889.

7.1 - Cover for Cliff Friend, Give Me a Night in June. $\quad 276$

7.2 - S.R. Stoddard, “Three of the Performers in Seavey's Circus," 1889.

8.1 - S.R. Stoddard, "Start of the ACA Paddling Trophy Race," 1890.

8.2 - Course map from the meet on Stave Island, 1889.

8.3 - George Warder, "Baden-Powel and the Nautilus," 1886.

8.4 - George Warder, "Notus, R.W. Bailey," 1886.

9.1 - George Warder, "Work and Fun in Camp," 1887.

9.2 - "Joe," 1896.

9.3 - "The Sneak-Box Mess: Camp of the Brooklyn Canoe Club," 1887.

10.1 - George Warder, "Packing up - Last day in camp," 1888. 


\section{Chapter One: Introduction}

In June 1880 , the New York Times informed its readers that "to the various political booms, must now be added a canoe boom." The article traced the origins of this canoe boom to the recreational pursuits of John “Rob Roy" MacGregor, a Cambridge-educated lawyer turned social reformer, who, having piloted the waterways of Europe by canoe in 1865 , "stirred up hundreds of his countrymen to follow his example." Although the sport had been "naturalized" in the United States in the early 1870 s with the founding of the New York Canoe Club (1871), its subsequent expansion had been slow because "the American mind was imbued with the belief that a canoe was a 'birch,' and could not by any possibility be anything else." In spite of this impediment, the Times noted, the New York club was growing, others had been founded, and there were now half a dozen canoe builders in the United States.

Only a few months after the article's appearance in the Timed a small group of men gathered at Lake George in the Adirondack Mountains to create a national canoeing organization. ${ }^{3}$ The nascent American Canoe Association (ACA) was intended to bring together canoeists from across the continent, thereby furthering "an interchange of opinion" and increasing "the range of fraternity and good fellowship amongst the knights of the paddle." To this end, the ACA elected to hold a yearly

\footnotetext{
1 "The Canoe Boom," The New' York Times, 19 June 1880. The popularity of the canoe did not well up over night. Rather, it waxed and waned throughout the 1860 s and $1870 \mathrm{~s}$. Some commentators claimed this ambivalence was a function of the solitary nature of the canoe. Others highlighted the failure of the early canoeing regattas (which were anticlimactic at best). There was also a general feeling that the canoe suffered from its associations with Indigeneity. "Paddle and Sail," The New York Timet, 2 August 1878; "Canoeing," Forest and Stream, 2 August 1883.

${ }^{2}$ Here birch signifies the canoe as an "Indian" craft, a point I will return to later in this chapter.

${ }^{3}$ Accounts of the inaugural meeting appear in "The Canoeists' Convention," New York Evening Telegram, 5 August 1880; "The Canoe Congress," Forest and Stream, 12 August 1880; "The Canoe Convention," New York Times, 17 August 1880.

4 "The Canoe Congress," Forest and Stream, 12 August 1880.
} 
encampment. For two weeks each August, canoeing enthusiasts from the United States, Canada, and occasionally Britain gathered to sleep under canvas, race canoes, "recreate," and socialize. Initially these events were held on Lake George. Between 1883 and 1902, however, the annual meetings travelled to various locations in New York, Ontario, and New England. In 1903 the organization established a permanent encampment on Sugar Island in the St. Lawrence River, which remains in use today. ${ }^{5}$

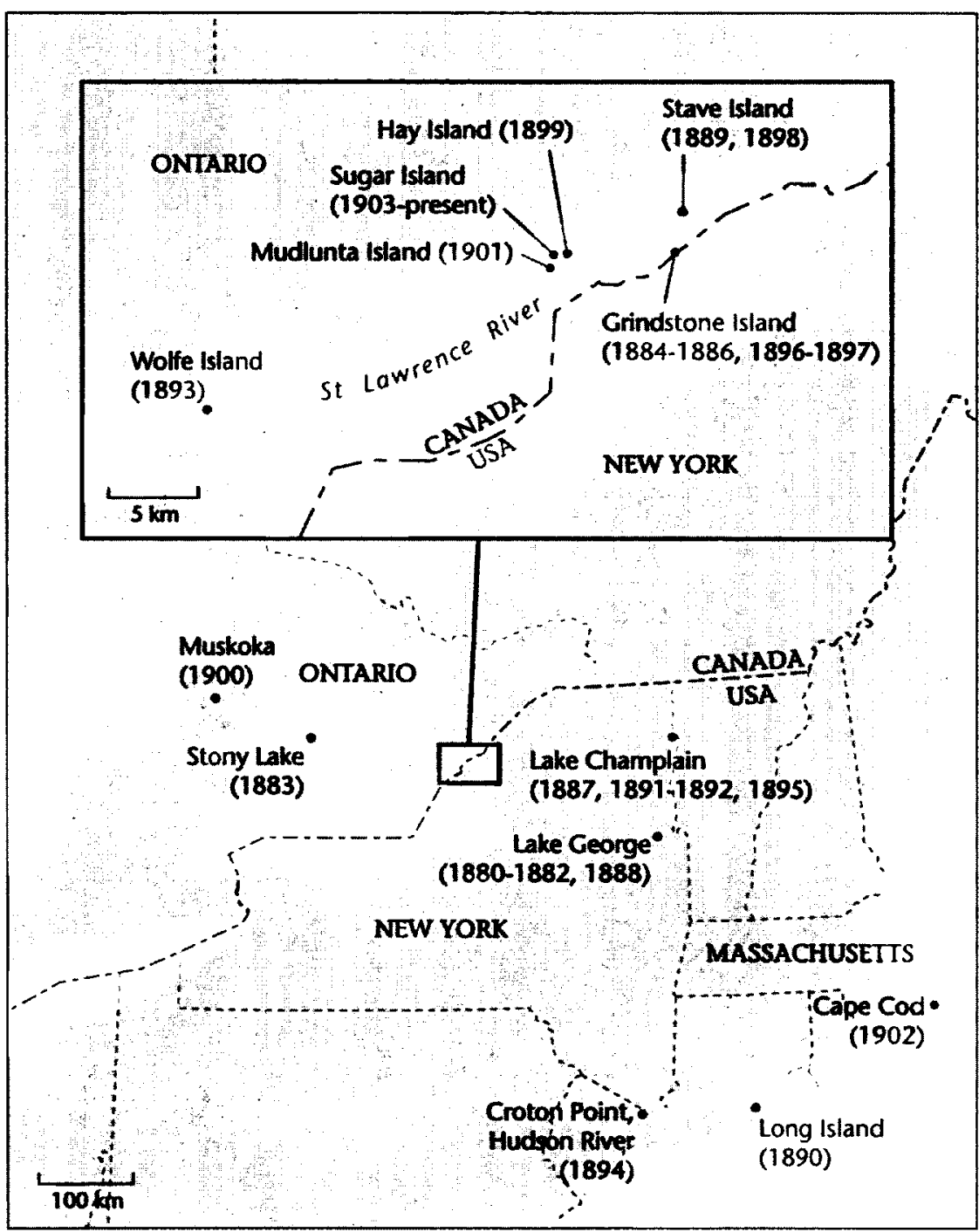

Figure 1.1 - Map of American Canoe Association Encampments, 1880-1910. [Source: Map prepared by Eric Leinberger.]

\footnotetext{
${ }^{5}$ Since I make many references to these locations throughout the dissertation, I encourage the reader to carefully review the map in Figure 1.1.
} 
This dissertation explores in detail the annual meetings and encampments of the American Canoe Association from the organization's founding and first gathering in 1880 until 1910. As a string of temporally and physically bounded events, the meetings provide an excellent opportunity to consider with some depth the entangled processes of community formation and placemaking. My interest in exploring the (re)production of a sporting community and place reflects my contention that power is deployed socially and spatially, and that sport is intimately tied to the politics of everyday life. In the pages that follow, we shall see how sport plays an important role in bolstering and occasionally contesting social and spatial divisions and hierarchies. Indeed, the ACA, a seemingly egalitarian and fun-loving organization that located itself in benign natural landscapes, also participated in a politics of exclusion, displacement, and dispossession at the core of late nineteenth-century liberalism, capitalism, and colonialism. The organization was not just shaped by its surroundings; it was also deeply embedded in and engaged with the unfolding of a modern liberal capitalist society in Canada and the United States. Much as Jarrett Rudy argues that "liberal ideals structured the ritual of smoking," which in turn "served to legitimize beliefs about inclusion, exclusion, and hierarchy," I am convinced of a similar dynamic between liberalism, colonialism, and canoeing. ${ }^{6}$ Play, as we shall see, was (and remains) deeply political.

For much of the twentieth century, historians thought little of leisure as a subject for serious historical inquiry. ${ }^{7}$ Although the history of leisure is now a growing field, sport history in particular continues to be viewed with some suspicion by

\footnotetext{
${ }^{6}$ Jarrett Rudy, The Freedom to Smoke: Tobacco Consumption and Identity (Montreal: McGill-Queen's University Press, 2005), 4.

${ }^{7}$ Peter Bailey, "Leisure, Culture and the Historian: Reviewing the First Generation of Leisure Historiography in Britain," Leisure Studie, 8, no. 2 (1989): 107-127.
} 
scholars outside the field and remains largely incidental to the "mainstream" study of politics, the economy, and society. As Gareth Williams notes, "historians have been slow to appreciate the significance of Anna Karenina's husband's observation that 'sport has a deep value and as is always the case we see only its superficial aspect."'8 Like other critical historians of sport, I contend that the related realms of sport and leisure are not divorced from the power structures that govern society and shape the experiences of daily life; rather, these mutually constitute one another. ${ }^{9}$ It is sport/leisure's ability to appear innocuous and at a remove from broader patterns of social behaviour that is often so central to its power to perform and transform.

I conceive of sporting organizations as active participants in performances of power. In the thesis I am concerned with the effects of these performances on access to and experiences of sport/leisure. Like other organized sports in this period, the ACA welcomed white middle-class men to membership. At the same time it excluded women, members of the working class, and people of colour in various, if uneven, ways. The annual meetings and encampments were central to these performances. Drawing on techniques and technologies consistent with liberal governmentality, the Association worked hard to structure the space and experience of the event, to control access to the site, and to regulate the behaviour of the canoeists. Some at the annual meetings subverted these efforts at control. Bodies in motion could not be managed in ways that bodies on paper could. Moreover, the borders of the encampments were permeable, allowing the coming and going of more people and goods than organizers

\footnotetext{
${ }^{8}$ Gareth Williams, "Popular Culture and the Historians," in Making History: An Introduction to the History and Practices of a Discipline, eds. Peter Lambert and Phillipp Schofield (London: Routledge, 2004), 259.

${ }^{9}$ Donald G. Kyle, Sport and Spectacle in the Ancient World (Oxford: Blackwell, 2007), 5-6; Mark Dyreson, "Sport History and the History of Sport in North America," Journal of Sport Hittory 34, no. 3 (Fall 2007): 405-14.
} 
sometimes wished. Finally, I explore how the effects of these performances were not limited to canoeing enthusiasts, but also extended outward to shape the lives, livelihoods, and lands of rural whites, Aboriginal people, African Americans, and French Canadians.

This study, as I note above, covers the period between 1880 and 1910 . Decisions about beginnings and endings are by no means trivial; they shape the narratives that we as historians offer our readers in enduring ways. ${ }^{10}$ Whereas the starting point is self-evident - the organization was founded and held its first encampment in 1880 - the end-date requires some explanation. The First World War, which is commonly understood as marking the close of the "long nineteenth century," is perhaps the "natural" endpoint for a study of leisure in the Victorian era. ${ }^{12}$ However, in the case of the ACA, the effects of World War I were curtailed, only becoming marked in $1918 .^{13} \mathrm{I}$ might also have elected to end this study in 1902 , the year of the

\footnotetext{
${ }^{10}$ As Jerzy Topolski and Barbara Schrodt observe, "To choose a certain periodisation is to choose a certain coherence," but also to "introduce certain assumptions." Jerzy Topolski, "Periodization and the Creation of Narrative Wholes," Storia della Storiografia, 37 (2000): 12; Barbara Schrodt, "Problems of Periodization in Canadian Sport History," Canadian Journal of History of Sport 21, no. 1 (1990): 65.

${ }^{11}$ Charles Maier equates centuries in the hands of historians to "Procrustes famous bed: the Greek innkeeper either stretched his guests if they were too short or chopped them down if they were too long for the sleeping accommodations that were offered." "By and large," he continues, "historians of the West have stretched the 1800s into the 'long nineteenth century,' extending until World War I." Charles S. Maier, "Consigning the Twentieth Century to History: Alternative Narratives for the Modern Era," American Historical Review' 105, no. 3 (2000): 813. The concept of the "long nineteenth century" is often attributed to Eric Hobsbawm. See, The Age of Revolution: 1789-1848 (New York: New American Library 1962); The Age of Capital, 1848-1875 (New York: Scribner, 1975); The Age of Empire, 1875-1914 (New York: Pantheon Books, 1987).

${ }^{12}$ The centrality of war to periodization in twentieth-century history is discussed in Michael Dawson and Catherine Gidney, "Persistence and Inheritance: Rethinking Periodisation and English Canada's 'Twentieth Century"' in Contesting Clio's Craft: New' Direction, and Debates in Canadian Hittory, eds. Christopher Dummitt and Michael Dawson (Vancouver: University of British Columbia Press, 2008), 55-62.

${ }^{13}$ Even then, the response was limited to the cancelling of the races at the encampment and the decision to not publish a yearbook in 1918. A joint yearbook was issued for 1918-1919 the following year. Ronald Hoffman, "The History of the American Canoe Association, 1880-1960" (PhD Dissertation: Springfield College, 1967), 56. The muted influence of WWI may have reflected the fact that the organization, as much as it was transnational, drew the bulk of its membership from the United States, which did not go to war until 1917.
} 
last mobile encampment of the ACA. However, I was curious about the ways in which a permanent campsite shaped the community of canoeists and the encampment as place. 1910, in other words, allowed me the opportunity to linger with the canoeists while they settled in to their permanent home without necessarily reproducing the mythological importance that was later ascribed to World War I.

No less important are the geographical parameters of this study. Although the organization was referred to as the American Canoe Association, from the outset it was envisioned as being open to canoeing enthusiasts on both sides of the Canada-US border. ${ }^{14}$ Thus, this dissertation is necessarily transnational in its focus. In recent years historians have shown increasing interest in historical processes as they unfold across geopolitical boundaries. Scholars have sought to denaturalize the nation-state as a preordained subject of analysis and to problematize borders as material and imagined entities. ${ }^{15} \mathrm{~A}$ study of the ACA truncated by the border would be woefully inadequate for people, canoes, ideas, and practices moved back and forth across this boundary with varying degrees of ease throughout this period. Sport, leisure, and tourism, while imbued with national particularities, are deeply transnational phenomena. ${ }^{16}$ This is not

\footnotetext{
${ }^{14}$ It was also initially opened to British members, although only a handful ever attended the encampments and most of these were extended honorary membership status.

${ }^{15}$ Sheila McManus, The Line Which Separates: Race, Gender, and the Making of the Alberta-Montana Borderlands (Edmonton: University of Alberta Press, 2005). See, Jeremy Adleman and Stephen Aron, "From Borderlands to Borders: Empires, Nation-States, and the Peoples in Between in North American History," American Hittorical Review 104, no. 3 (1999): 814-841; Steven High, Industrial Sunset: The Making of Nortb America's Rust Belt, 1969-1984 (Toronto: University of Toronto Press, 2003); Paige Raibmon, Autbentic Indians: Episodes of Encounter from the Late-Nineteentb-Century Nortbwest Coast (Durham: Duke University Press, 2005); Benjamin H. Johnson and Andrew R. Graybill, eds., Bridging National Borders in North America: Tranwnational and Comparative Histories (Durham: Duke University Press, 2010).

${ }^{16}$ This is a central contention of Colin Howell's work on sport in the Maritimes, including "Borderlands, Baselines, and Big Game: Conceptualizing the Northeast as a Sporting Region" in New' England and the Maritime Provinces: Connections and Comparitons, eds. Stephen J. Hornsby and John G. Reid (Montreal: McGill-Queens University Press, 2005), 264-279. See also, Bill Parenteau and Richard W. Judd, "More Buck for the Bang: Sporting and the Ideology of Fish and Game Management in Northern New England and the Maritime Provinces, 1870-1900" in New' England and the Maritime Province', 232-251, and
} 
to say that national identities were abandoned within the context of the organization or the meets. On the contrary, the ACA sought to mediate what they saw as national styles with the goal of creating a coherent international canoeing practice. ${ }^{17}$ Nevertheless, there was much that members of the organization shared that transcended national identity, including particular class, race, and gender positions.

Most ACA members and the majority of the campers at the annual meetings were white, middle-class men. Thus, at first glance, an historical treatment of the encampments appears to be a study of masculinity and whiteness. While that is certainly a large part of this story, it is not the whole story. Yes, these events and the ACA, like organized sport more broadly, were dominated by this relatively small but disproportionately powerful group. ${ }^{18}$ However, white middle-class women were extended partial membership in 1882, and allowed to camp out at the meets beginning in 1883. Moreover, working-class and rural whites, as well as African Americans and Indigenous peoples were also present at the encampments. As we shall see, they played crucial roles in the annual meetings, albeit not as members, but instead as workers. Of course, to be in place at the annual meeting was not necessarily to be of the community. Nevertheless, the social scope of this project is much broader than it first appears.

\section{$\mathscr{8}$}

This dissertation began as a history of women's encounters with canoeing in the nineteenth and twentieth centuries. Ultimately, it has been transformed into a history

Cecilia Morgan, 'A Happy Holiday': Englis'b Canadians and Transatlantic Tourism (Toronto: University of Toronto Press, 2008).

${ }^{17}$ The races, for example, were partly about determining what "nationalistic" (Canadian, American, and British being the most prominent) methods of paddling and sailing were "better" or which boats were more efficient, and both of these things were seen as linked to national affiliation.

${ }^{18}$ Although enthusiasts claimed that the canoe was the poor man's yacht, even the simplest of craft remained luxury items, costing upwards of $\$ 25$ in the 1880 s. Serious enthusiasts, but particularly racers spent infinitely more, and often had multiple boats. "Poor Man's Yacht," Forest and Stream, 7 July 1881. 
of the annual meetings and encampments of the American Canoe Association. It was a shift that no one, including myself, could have anticipated, not least because of my firm commitment to women's history. As I began to write what was to be the first chapter of that original project on women and canoe racing, however, I realized what an ambitious task I had laid out for myself. An interdisciplinary workshop on environments and mobility in Canadian history allowed me to focus on one aspect of the research that I had already conducted. Although I had been aware of the ACA prior to this, working through the material I had gathered in repositories in New York and Connecticut revealed some of the potential riches of the topic. I therefore returned to Cooperstown where the bulk of the early ACA archive is held and immersed myself in the world of the encampments. It soon became apparent that this was the story I wanted to tell.

Where I had once been primarily concerned with questions inspired by environmental history and the history of the body, I increasingly approached my research as a social history of sport. While I embraced the new topic of my dissertation, I was admittedly reticent to identify as a historian of sport in part because of the field's relationship to "mainstream" history - even as historians have expanded their notion of suitable historical subjects, sport has remained on the margins - but also because of my own inexperience with sport as a subject of academic study. I quickly found some literature that resonated with my interests in power, space, and place. ${ }^{19}$ Equally important, however, were my experiences teaching the history of sport to

\footnotetext{
${ }^{19}$ These included Patricia Vertinsky and Sherry McKay, eds., Disciplining Bodies in the Gymnasium: Memory, Monument and Modernum (London: Routledge, 2004); Mary Louise Adams, "'Death to the prancing prince': Effeminacy, Sport Discourses and the Salvation of Men's Dancing," Body and Society 11, no. 4 (2005): 63-86; and the collaborative scholarship of Nancy B. Bouchier and Ken Cruikshank that included articles such as "Dirty Spaces': Environment, the State and Recreational Swimming in Hamilton Harbour, 1870-1946," Sport History Review' 29, no. 1 (1998): 59-76.
} 
undergraduate students in history and human kinetics while I was in the writing stages of this project. In their attentiveness and enthusiasm, I saw the powerful appeal of sport, but even more so, the opportunities that sport offered for having conversations about key historical and contemporary questions surrounding gender, sexuality, race, health and the body, the state, and political culture. Not coincidentally, these are the same analytical themes that animate this dissertation, and which are also percolating in the history of sport literature. ${ }^{20}$ Thus, while the thesis addresses a number of historical fields, including gender history, the history of travel and tourism, environmental history, and the history of labour, I also conceive of the dissertation as a history of sport. It is here that I will focus my historiographical discussion.

Most ambitiously, perhaps, this dissertation employs sport as a central category of analysis in order to highlight the productive links that can be made between the study of sport and the study of society, politics, and the economy. I am certainly not the first to make this suggestion. Social historians of sport for decades have sought to make a case for play as a subject of serious scholarly analysis. ${ }^{21}$ In spite of these efforts, the history of sport, in Canada at least, remains a field on the margins of academic history. ${ }^{22}$ In part this is a product of a residual distrust of popular culture as a subject

\footnotetext{
${ }^{20}$ To the authors cited in footnote 19. I would add Susan K. Cahn, Coming on Strong: Gender and Seruality in Twentietb-Century Women's Sport (New York: Free Press, 1994) and Ian Ritchie, "Sex Tested, Gender Verified: Controlling Female Sexuality in the Age of Containment," Sport History Review 34, no. 1 (2003): 80-98.

${ }^{21}$ Alan Metcalfe, Canadian Learns to Play: The Emergence of Organized Sport, 1807-1914 (Toronto: McClelland and Stewart, 1987); Colin Howell, Nortbern Sandlot: A Social Hittory of Maritime Baseball (Toronto: University of Toronto Press, 1995); Bruce Kidd, The Struggle for Canadian Sport (Toronto: University of Toronto Press, 1996); Nancy Bouchier, For the Love of the Game: Amateur Sport in Small-Town Ontario, 1838-1895 (Montreal: McGill-Queen's University Press, 2003). There are some signs of success in this respect as evidenced by contents of both editions of James Opp and John C. Walsh, eds., Home, Work, and Play: Situating Canadian Social Hittory (Don Mills: Oxford University Press, 2006 and 2010).

${ }^{22}$ There are, of course, exceptions. Gillian Poulter's recent monograph on cultures of sport in Montreal in the nineteenth century has reached a wider audience. I hope the same will be true of Mary Louise Adams new book on figure skating. Gillian Poulter, Becoming Native in a Foreign Land: Sport, Vusual Culture,
} 
worthy of scholarly study amongst historians. It is also a reflection of the institutional organization of sport history. History departments rarely advertise or hire historians of sport. Instead, those who study and teach the history of sport overwhelmingly reside in physical education and kinesiology departments. Moreover, in the case of Canada at least, historians of sport are more likely to attend the annual meetings of the North American Society for Sport History (NASSH) than those of the Canadian Historical Association (CHA), and to publish in the field-specific journals of Sport History Review or Journal of Sport History than more widely read journals such as the Canadian Hitorical Review or Histoire Sociale/Social History. ${ }^{23}$ There is little crossover, in other words, between historians of sport and historians of other subjects. This dissertation seeks to bridge the gap between sport history and the broader discipline of history, to "mainstream" sport history in order to show how a study of sport and leisure benefits from and can contribute to our understanding of space/place, political culture, governance, and the history of labour. To that end, therefore, rather than create separate sections to address historiography, sources, and theory, in the pages that follow I weave these threads together. I wish to emphasize the fact that as we work on our histories these are not discrete categories, but rather elements that collide and intersect in different ways to inspire, rebut, and revise our scholarship. I take as my starting point the archive of the American Canoe Association, where this project and my own evolution as a sport historian began.

and Identity in Montreal, 1840-1885 (Vancouver: University of British Columbia Press, 2009); Mary Louise Adams. Artistic Impressions: Figure Skating, Masculinity, and the Limits of Sport (Toronto: University of Toronto Press, 2011).

${ }^{23}$ I do not wish to belittle the important critical scholarship being produced and circulated in the pages of sport studies journals or at the annual meetings of different sports studies associations. Rather, I wish to highlight the apparent divide at an institutional level between the history of sport as part of sport studies and other fields of history. 


\section{\&}

The bulk of the American Canoe Association's historical records are held at the Library of the New York State Historical Association (NYSHA) in Cooperstown, New York, and the Mystic Seaport Collections Research Center (MSCRC) in Mystic, Connecticut. Whereas the former is largely concerned with the early years of the organization, the latter focuses primarily on the ACA in the twentieth century, the exception being minutes for the Annual Meetings, Executive Committee Meetings, and the Board of Governors dating back to 1880 . Although both archives represent the efforts of individual collectors, they are institutional collections. As such, they feature almost exclusively organizational records, such as meeting minutes, and published documents, such as yearbooks and circulars, deliberately made available for consumption both within and beyond the bounds of the ACA. ${ }^{24}$ Wary of how such records can have the effect of becoming uncritically reproduced in our own narratives, I have relied heavily on travelogues, both in the form of books and periodical accounts, to counter the official narrative of the Association that emerges in the NYSHA and MSCRC collections. ${ }^{25} \mathrm{My}$ research also draws extensively on expository journalism. ${ }^{26}$

\footnotetext{
${ }^{24}$ Initially intended as a record of membership, the yearbooks grew to include committee reports, information about the coming meet, summaries of the previous year's regatta, and historical information, such as lists of former commodores, encampment sites, and record holders. Circulars, meanwhile, introduced readers to that year's site, outlined the program for the encampment and regatta, detailed the rules for the camp site and the races, and provided logistical information for travellers and campers. Whereas secretaries produced the yearbooks, circulars were the work of the organizing committees. ${ }^{25}$ To date, I have only uncovered two book-length travelogues pertaining to the encampments: Retaw, Fragment, from the ' 88 Meet (Montreal, 1888), and Florence Watters Snedeker, A Family Canoe Trip (New York: Harper and Brothers, 1892). However, most of the magazine accounts and some of the newspaper articles function more as travel literature than expository journalism. David Spurr refers to this hybrid genre as "literary journalism" because it "combines an immediate historical interest with the complex layering of figurative language that conventionally belongs to imaginative literature." David Spurr, The Rbetoric of Empire: Colonial Discourese in Journalism, Travel Writing, and Imperial Administration (Durham: Duke University Press, 1993), 9.

${ }^{26}$ At the outset, the ACA was a novel institution and the encampments novel events that attracted significant attention in big city dailies and small town papers alike. With time, coverage declined, albeit
} 
Ideally, I would have been able to supplement these sources with more personal accounts, such as diaries and letters. Cecilia Morgan, in her work on transatlantic tourism found that while both public and personal sources "agreed on the general lineaments and structures of their journeys...they did not always concur on the significance and meaning of what they had seen and experienced. ${ }^{27}$ However, to date, I have uncovered few such texts. The two exceptions are memoirs of the meets penned by D.B. Goodsell (1936) and Paul Vernon (1940). ${ }^{28}$ While these were intended for public consumption, it was a very narrow understanding of public, which only included members of the Association. As such, they offer an insider's perspective of the meets rarely available in published sources..$^{29}$ Not incidental or accidental to the archive of the ACA, men produced the majority of the extant material. Women, as we shall see, were not absent from or even in short supply at the annual encampments. Nevertheless, there are few surviving accounts attributable to women..$^{30}$ The challenges of working in such a heavily gendered (and, for that matter, classed and racialized) archive compel some careful methodological choices.

unevenly. By the first decade of the twentieth century, what few accounts of the meets existed were spare, focusing almost exclusively on the results of the races. I attribute the diminishing coverage to the routinization of the encampments and waning interest in canoeing, which by 1910 was being eclipsed by a range of other leisure options. I suspect that many of the newspaper correspondents that covered the early regattas were themselves Association members who were hired temporarily to report on the event, or who had pre-existing ties to a newspaper.

${ }^{27}$ Diarists, for example, "did not participate in antimodern ruminations to the degree that their published fellow tourists did; rather, they celebrated progress wherever they through they saw it and, in turn, lamented its absence in places or people who seemed untouched by its benefits." Morgan, A Happy Holiday, 28-9.

${ }^{28}$ New York State Historical Association (NYSHA), 1.6/2, D.B. Goodsell, A Canoeing Reminiscence (1936); Trent University Archives (TUA), 83-014/2, Paul Vernon, Tales of the ACA, 1940. Both of these accounts emphasize the meaningfulness of the ACA and the encampments to the authors.

${ }^{29}$ For example, they discuss themes such as drinking and sexuality not mentioned elsewhere. That they do so is likely partially a function of their temporal and physical distance from the encampments.

${ }^{30}$ While this disparity is indicative of the cultures of tourism and leisure more broadly, the ACA is anomalous. Cecilia Morgan, for example, notes that "women comprised a significant group amongst anglophone Canadian travel writers." Morgan, A Happy Holiday, 27. 
I conceive of many of these textual sources as travel writing. ${ }^{31}$ For historians, the extensive field of travel writing "constitutes a gold-mine of information about the mental world of tourists," at turns "didactic, fatuous, derivative, self-conscious, and prone to coyness, exaggeration, and overblown rhetoric." ${ }^{.32}$ Much of the work on travel writing has concerned itself with individuals going far afield, Americans in Europe, for example, or European travellers visiting the colonies. What sets the example of the ACA encampments apart is that, in relative terms, the canoeists did not always travel far from home. In some instances, they were playing tourist in their own backyards. Nevertheless, as we shall see, the canoeists employed many of the conventions common to other forms of travel writing. ${ }^{33}$

What is perhaps most remarkable about the ACA collection is the rich photographic archive that once belonged to C. Bowyer Vaux, a member of the ACA from 1880 and, along with his wife Agnes Marion Chipp, a familiar face at the yearly encampments. ${ }^{34}$ Vaux fancied himself a historian of canoeing, publishing a series of articles on the subject in Outing in 1887 and amassing an extensive collection of

\footnotetext{
${ }^{31}$ I have benefitted from the following scholars meditations on travel writing: Sara Mills, Dircourites of Difference: An Analysis of Women's Travel Writing and Colonialium (London: Routledge, 1991); David Spurr, The Rbetoric of Empire: Colonial Discourve in Journalium, Travel Writing, and Imperial Administration (Durham: Duke University Press, 1993); Patricia Jasen, Wild Tbings: Nature, Culture, and Tourism in Ontario, 17901914 (Toronto: University of Toronto Press, 1995); Mary Louise Pratt, Imperial Eyes: Travel Writing and Transculturation, $2^{\text {nd }}$ ed. (London: Routledge, 2008); Morgan, A Happy Holiday.

${ }^{33}$ Here, especially, the lack of women's voices is unfortunate because as Cecilia Morgan notes, women's travel writing, and presumably their experiences as well, "both resembled and differed from men's," although not, of course, because of any natural difference. Morgan, A Happy Holiday, 27.

${ }^{34}$ Vaux was the son of prominent landscape architect, Calvert Vaux, who worked alongside Frederick Law Olmstead in the design of New York's Central Park and Brooklyn's Prospect Park, and an ardent canoeist. He was a long-standing member of the ACA and the New York Canoe Club, and the author of a number of works on the subject of canoeing including C. Bowyer Vaux, Canoe Handling (New York: Forest and Stream Publishing, 1885).
} 
photographs from encampments between 1880 and $1899 .{ }^{35}$ The almost 500 hundred images were produced by commercial photographers, amateurs, and periodical staff. The NYSHA collection also includes a series of scrapbooks created by Fred Saunders that cover the period from $1880-1940$, and personal albums that belonged to Thomas J. Hale (1885-1900), Walwin Barr (c. 1905-unknown), and Leo Friede (c. 19131915). ${ }^{36} \mathrm{I}$ have also accessed images from other sources. Florence Watters Snedeker's travelogue, $A$ Family Journey, for example, includes 37 images, of which 14 are photographs and 13 are line drawings or watercolours. ${ }^{37}$ Periodical accounts also frequently included photographs or drawings from the encampments. ${ }^{38}$

The questions that I asked of this archive, and the ways in which I interpreted the evidence reflect very particular theoretical sensibilities. First and foremost, I sought to read against the grain of these sources, to uncover those narratives that were being obscured or altogether ignored. I paid particular attention to people and practices that seemed out of place or that existed at the margins of these accounts. I also took special care not to reproduce the Association's narrative of itself, seeking instead to interrogate that narrative and to uncover its effects. My reading of this ACA

\footnotetext{
${ }^{35}$ C. Bowyer Vaux, "History of American Canoeing - Part I, 1871-1880," Outing 10, no. 3 (June 1887): 259-269; C. Bowyer Vaux, "History of American Canoeing - Part II, 1879-1883," Outing 10, no. 4 (July 1887): 160-169; C. Bowyer Vaux, "History of American Canoeing - Part III, 1883-1887," Outing 10, no. 5 (August 1887): 395-414. Vaux's photographic collection fills NYSHA, Box 1.1 and 1.2. ${ }^{36}$ NYSHA, Box 1.5 .

${ }^{37}$ Sara Mills suggests that travellers, women and men, incorporated photographs into their travel writing as proof that they went where they said they did. Mills, Discourses of Difference, 113 . Wendy Roy likewise contends that Mina Hubbard "intended her photos to serve as a record of her journey and as concrete evidence of the topography of the countryside through which she travelled and the ethnography of the peoples she encountered." Wendy Roy, "Visualizing Labrador: Maps, Photographs, and Geographical Naming in Mina Hubbard's A Woman's Way tbrougb Unknown Labrador," Studiet in Canadian Literature 29, no. 1 (2004): 17.

${ }^{38}$ Not all of the meets are represented evenly in the photographic archive. For example, there are an abundance of photographs from the 1886, 1887, 1890, and 1891 meets. By contrast, I have yet to uncover photographs of the 1880,1893, and 1896 encampments on Lake George, Brophy's Point, and Grindstone Island respectively.
} 
archive and thus my sense of the encampments was shaped more specifically by theoretical treatments of the concepts of community, space/place, practice, and governmentality.

My understanding of community has been informed by the writing of John C. Walsh and Steven High. Walsh and High emphasize the "cultural and imagined elements" of community, the ways in which community is constituted through the "social spaces of everyday interactions and exchanges," and community as "a social process predicated on relationships. ${ }^{39}$ In particular, they argue that we must "conceive and study community as a social and spatial process," for "social relationships and experiences occur through space, giving that space meaning and value. ${ }^{\prime 10}$ While community has positive connotations - we think, for example, of community development, community ties, community gardens - community is an exclusionary practice as much as an inclusive one. To borrow again from Walsh and High, "The 'production' or 'making' of community through social space is part of the process of 'constructing' difference." ${ }^{.41}$

Walsh and High's emphasis on the spatiality of community belies a deeper belief in the importance of space and place to everyday life. Following Cliff Hague, I understand place as "a geographical space that is defined by meanings, sentiments and

\footnotetext{
${ }^{39}$ John C. Walsh and Steven High, "Re-thinking the Concept of Community," Histoire Sociale/Social History 32, no. 64 (1999): 257, 260, 261. My interest in the entangled processes of community and place dates to my Master's research. Jessica Dunkin, "'The stories we tell': Locating Nature, Gender and Place in the Poetry of Mary Edgar and Glen Bernard Campers" (M.A. Research Essay: Carleton University, 2008), and Jessica Dunkin, "Manufacturing Landscapes: Place and Community at Glen Bernard Camp, 1924-1933," Hìtoire Sociale/Social Hütory 45, no. 89 (2012): 79-113.

${ }^{40}$ Walsh and High, "Rethinking Community," 266, 258. Much of our current thinking on space in social history is informed by feminist geography, which in drawing attention to the "importance of spatial structure in the production and reproduction of masculinist societies," was among the first to highlight the relationship between space and social relations. Gillian Rose, Feminium and Geography: The Limite' of Geograpbical Knowledge (Minneapolis: University of Minnesota Press, 1993), 17.

${ }^{41}$ Walsh and High, "Rethinking Community," 272.
} 
stories rather than by a set of coordinates." ${ }^{12}$ Place, in other words, is space made meaningful. ${ }^{43}$ Place, like community, is "more than a static category, an empty container where things happen. It must be understood as a social and spatial process, undergoing constant change." ${ }^{44}$ Furthermore, placemaking, like community formation, is a deeply political process. Both the boundaries and meanings of place are contested. ${ }^{45}$ My concern with space/place is not limited to the imagined, but also explores the material world that the canoeists helped create. ${ }^{46}$ I have found the related concepts of a "cultural landscape" and "activity arenas" developed by social historians of architecture particularly useful for making sense of the somewhat unconventional built environment of the encampments. "Cultural landscape" refers to "the intersection of the natural landscape with built forms and social life." ${ }^{47}$ A cultural landscape approach thus "lets us see both the ways that institutional priorities shaped the landscape and also how the landscape attempted to shape [individuals] - who may have resisted these efforts." "Activity arenas," meanwhile, are "spaces not necessarily defined by walls and roofs, but created by human action," such as a campfire circle or

${ }^{42}$ Cliff Hague, "Planning and Place Identity," in Place Identity, Participation and Planning, eds. Cliff Hague and Paul Jenkins (New York: Routledge, 2005), 4.

${ }^{43}$ James Opp and John C. Walsh, "Introduction: Local Acts of Placing and Remembering," in Placing Memory and Remembering Place in Canada, eds. James Opp and John C. Walsh (Vancouver: University of British Columbia Press, 2010), 15.

${ }^{44}$ Steven High, "Placing the Displaced Work: Narrating Place in Deindustrializing Sturgeon Falls, Ontario," in Opp and Walsh, Placing Memory, 181.

${ }^{45}$ Doreen Massey, "Places and Their Pasts," History Workubop Journal 39 (1995): 182-92.

${ }^{46}$ As Bill Hillier and Julienne Hanson note, buildings "give shape and form to our material world" and "structure the system of space in which we live and move." Feminist historians of architecture further remind us that buildings function as statements of normative values, "embod[ying] knowledge of social relations" and "taken-for-granted rules that govern relations of individuals to each other and to society." Most concerning are the ways in which "space can be made to hide consequences from us," including "how relations of power and discipline are inscribed into the apparently innocent spatiality of social life." Bill Hillier and Julienne Hanson, The Social Logic of Space (Cambridge: Cambridge University Press, 1984), ix; Daphne Spain, Gendered Space (Chapel Hill: University of North Carolina Press, 1992), 7; Edward W. Soja, Poutmodern Geographies: The Reausertion of Space in Critical Social Theory (London: Verso, 1989), 6.

${ }^{47}$ Abigail Van Slyck, A Manufactured Wildernest: Summer Camps and the Shaping of American Youth, 1890 1960 (Minneapolis: University of Minnesota Press, 2006), xxxi. 
racecourse. ${ }^{48}$ They remind us that as important as the built environment is to social relations so too are the ways in which spaces are understood and used. ${ }^{49}$ To access the production of space and placemaking at the encampments I have made use of maps and descriptions of the campsites. ${ }^{50}$ I have also sought to uncover what the site meant to the campers, to understand how space was imbued with significance and thus transformed into place.

Historians of sport have not been immune to the spatial turn, but its effect has so far been limited. Much of the sport history literature attune to space has focused on more conventional and decidedly urban sporting spaces such as arenas, stadia, and gymnasiums. ${ }^{51}$ The example of the ACA encampments provides a different historical geography. The annual meetings were sites of competitive sport that existed well beyond urban limits, but that were also intimately tied to institutions and practices within the city. Moreover, they were never just spaces of physical activity and competitive sport. People also lived, competed, socialized, and recreated on site. Thus, the annual meetings raise interesting questions about what constitutes a "sportscape," but also about the reach of urban sporting cultures and practices. Furthermore, the

${ }^{48}$ Elizabeth C. Cromley, "Transforming the Food Axis: Houses, Tools, Modes of Analysis," Material History Review' 44 (Fall 1996): 8-22.

${ }^{49}$ This echoes Henri Lefebvre's contention that space is produced through a trilectical relationship between representations of space (the abstract conceptions of professionals and technocrats, imbued with ideology, power, and knowledge and communicated through systems of signs), representational spaces (lived spaces, such as the pub, the city park, and the street corner), and spatial practices (the routes, networks, patterns, and interactions that connect people and places, image and reality). Henri Lefebvre, The Production of Space, trans. Donald Nicholson-Smith (Oxford: Blackwell, 1991 [1974]).

${ }^{50}$ I discuss maps at length in Chapters Two, Three, and Five.

${ }^{51}$ Patricia Vertinsky and John Bale, eds., Sites of Sport: Space, Place and Experience (London: Routledge, 2004); Patricia Vertinsky and Sherry McKay, eds., Disciplining Bodies in the Gymnasium: Memory, Monument and Modernism (London: Routledge, 2004); Russell Field, "Constructing the Preferred Spectator: Arena Design and Operation and Consumption of Hockey in 1930s Toronto," International Journal of the History of Sport 25, no. 6 (2008): 649-77; Mark Stoddart, "Constructing Masculinized Sportscapes: Sküng, Gender, and Nature in British Columbia, Canada," International Review for tbe Sociology of Sport 46, no. 1 (2011): 108-24; Benjamin D. Lisle, "We Make a Big Effort to Bring Out the Ladies': Visual Representations of Women in the Modern American Stadium," International Journal of the Hittory of Sport 28, no. 8/9 (2011): 1203-18. 
ACA encampments were simultaneously ephemeral and enduring. While they only lasted for two weeks and early on at least were mobile and thus not rooted in a particular geographical location, they were still annual events that welcomed the same members back year after year. More than this, they lived long in the campers' place memories.

My thinking about how space was experienced and later remembered at the annual meetings draws upon Michel de Certeau's writing on the relationships between space and practice. This dissertation explores the disciplinary acts that were part of placemaking and community formation, and the efforts made to regulate the behavior of individual canoeists. Yet it is from Certeau that I learned to take seriously the campers' inhabitation of the spaces of the encampment and their negotiation of the community of canoeists. ${ }^{52}$ Certeau maintains that it is through the "dispersed, tactical, and makeshift creativity" of daily practices (his examples include activities such as walking and cooking) that individuals challenge the institutional order and "reappropriate the space organized by techniques of sociocultural production." ${ }^{\text {33 }} \mathrm{His}$ description of the consumer beautifully illustrates this point: “Their trajectories form unforeseeable sentences, partly unreadable paths across a space. Although they are composed with the vocabularies of established languages....and although they remain subordinated to the prescribed syntactical forms..., the trajectories trace out ruses of

\footnotetext{
${ }^{52}$ Certeau's emphasis on the "everyday practices" that occupy "the obscure background of social activity" is best understood vis-à-vis Michel Foucault's work on disciplinary power. Whereas Foucault is concerned with the disembodied gaze directed at, and the power/knowledge practices that are inscribed on, the body of the prisoner as illustrated by the model of the panopticon, Certeau takes as his starting point the "groups or individuals already caught in the nets of discipline." Michel de Certeau, The Practice of Everyday Life, trans. Steven Rendell (Berkeley: University of California Press, 1984), xi, xiv; Michel Foucault, Dücipline and Punisb: The Birth of the Prüon, trans. Alan Sheridan (New York: Vintage Books, 1977).

${ }^{53}$ Certeau, Practice of Everyday Life, xi, xiv.
} 
other interests and desires that are neither determined nor captured by the systems in which they develop. ${ }^{254}$ Certeau's notion of practice calls for a consideration of both the physical forms of practice and the interpretations of behaviour by the actors themselves.

If Certeau has inspired this dissertation's attention to practice, it is Michel Foucault who has shaped my understanding of the regulatory regimes and power relationships in which these practices occurred. Like Foucault, I conceive of power not merely as something held in the possession of elites, but rather as a field of tactics, techniques, and strategies deployed by various actors. Nor do I understand power to be purely repressive; it is also productive. To think of power in this way is to be concerned not with its sources, but its effects. ${ }^{55}$ I have been particularly influenced by Foucault's later writings on governmentality. ${ }^{56}$ Governmentality encompasses "the art and rationality of all forms of governance. ${ }^{57}$ More specifically, it is concerned with the

${ }^{54}$ Certeau, Practice of Everyday Life, xviii. Certeau uses language or the act of speaking to think about other bodily practices, such as walking. Hence, the chapters devoted to walking are entitled "Walking in the City" and "Spatial Stories."

${ }^{55}$ Michel Foucault, Power/Knowledge: Selected Interviews and Other Writing, 1972-1977, ed. Colin Gordon (New York: Pantheon, 1980), 98, 51. This is perhaps the most obvious point of divergence between my work and that of Jarrett Rudy, who I cite above. Even as we share an interest in performances of leisure in the late nineteenth century and their relationship to liberalism, Rudy's Gramsci-inspired construction of liberalism's hegemonic and, thus, coercive relationship to the individual is different than my Foucaultinspired concern for the effects of liberal forms of governance.

${ }^{56}$ Foucault's work on governmentality appeared toward the end of his life, the product of efforts to integrate his earlier thinking on regulation and desire mapped out in Discipline and Punish and The History of Sexuality, Volume 1: An Introduction, trans. Robert Hurley (New York: Random House, 1978). The most important and extensive writings appear in the recently-published lectures that Foucault gave at the Collège de France, especially Security, Territory, Population: Lectures at the Collège de France 1977-1978, trans. Graham Burchell (London: Palgrave Macmillan, 2007), and The Birth of Biopolitici: Lectures at the College de France 1978-1979, trans. Graham Burchell (London: Palgrave Macmillan, 2008).

${ }^{57}$ Simon Gunn, "From Hegemony to Governmentality: Changing Conceptions of Power in Social History," Journal of Social History 39, no. 3 (2006): 708. Foucault defined governmentality as "the ensemble formed by the institutions, procedures, analyses and reflections, the calculations and tactics that allow the exercise of this very specific albeit complex form of power, which has as its target population, as its principle form of knowledge political economy, and as its essential technical means apparatuses of security." Michel Foucault, "Governmentality," in The Foucault Effect: Studiea in Governmentality, eds. Graham Burchell, Colin Gordon, and Peter Miller (Chicago: University of Chicago Press, 1991), 102. 
"conduct of conduct," a term that encapsulates Foucault's concern for the ways in which governance at a macro scale came to be situated in the embodied practices of individual subjects. ${ }^{58}$ Whereas earlier forms of regulation, Foucault argues, employed the fear of physical punishment or of being caught to effect particular ends, a governmental mentality rules through the self-management of desire. The liberal subject is the self-governed subject. Individuals in such a field of governmentality perform in ways that meet state, community, or organizational ends in order to realize personal aspirations for pleasure, success, security, and even a basic sense of fulfillment.

Foucault's thinking on governmentality was truncated by his death in 1984 . However, his ideas have stimulated much critical debate and research. In recent years, sport studies scholars have begun to explore the potentialities of governmentality, particularly in relation to physical education and fitness. ${ }^{59}$ The contributions of historians of sport to this emergent literature have been limited. ${ }^{60}$ Thus, this

\footnotetext{
${ }^{58}$ On the subject of conduct, see Michel Foucault, "The Subject and Power," Critical Inquiry 8, no. 4 (1982): 777-95. With governmentality, Foucault ongoing concern with power shifted to the "critical link... between the governance of the self and government of the state." Foucault's conceived of the state "as a set of practices rather than as an institution or 'apparatus,' as dispersed rather than unitary, and as invested in domains usually associated with civil society, such as sexuality and the family." Michael A. Peters, A.C. Besley, Mark Olssen, Susanne Maurer, and Susanne Weber, eds., Govermentality Studies in Education (Rotterdam: Sense Publishers, 2009), xxix; Gunn, "From Hegemony to Governmentality," 710.

${ }^{59}$ Jin-Kyung Park, "Governing Doped Bodies: The World Anti-Doping Agency and the Global Culture of Surveillance," Cultural Studies $\Leftrightarrow>$ Critical Methodologies 5, no. 2 (2005): 174-88; Younghan Cho, "Broadcasting Major League Baseball as a Governmental Instrument in South Korea," Journal of Sport and Social Isumer 32, no. 3 (2008): 240-54; Louise McCuaig and Richard Tinning, "HPE and the Moral Governance of P/leisurable Bodies," Sport, Education and Society 15, no. 1 (2010): 39-61; Jenny Svender, Hakan Larsson, and Karin Redellus, "Promoting Girls' Participation in Sports: Discursive Constructions of Girls in a Sports Initiative," Sport, Education, and Society (forthcoming).

${ }^{60}$ Exceptions include Jeffrey Montez de Oca, "All-American Sport for All Americans: Collegiate Gridiron as Citizenship Practice during the Early Cold War" (Ph.D. Dissertation: University of Southern California, 2006); Raul Sanchez Garcia and Antonio Rivero Herraiz, "'Governmentality' in the Origins of European Female PE and Sport: The Spanish Case Study, 1883-1896," Sport, Education, and Society (2011): 1-17, and Jürgen Martschukat, "'The Necessity for Better Bodies to Perpetuate Our Institutions, Insure a Higher Development of the Individual, and Advance the Conditions of the Race':
} 
dissertation draws on Foucaultian notions of power, but specifically the idea of governmentality to push the bounds of our current understandings of sport's historical relationship to politics broadly conceived. ${ }^{61}$

Operating from such a theoretical stance, I do not therefore see all of my evidence as "texts" to be deconstructed as "discourse," although I remain interested in the representational qualities of the archive. ${ }^{62}$ In this regard, the power-knowledge effects of materials such as maps, photographs, and even official meeting minutes are all important to how I explain the ways in which the ACA encampments were governed and governable spaces. However, my approach to practice, space, and place as key analytical concepts also requires a more flexible and dynamic reading of the evidence. Specifically, it necessitates a willingness to allow sources, where appropriate, to show what people did, where they did things, how they did them, and what these things meant.

My use of visual sources, in particular, occupies a middle ground between strict realism and images as representation. ${ }^{63}$ In recent years, the study of visual culture has drawn our attention to the many ways in which photographs, while appearing to embody some form of scientific objectivity, are more than "dispassionate reflections of

Physical Culture and the Shaping of the Self in Late Nineteenth and Early Twentieth Century America," Journal of Historical Sociology 24, no. 1 (2011): 472-93.

${ }^{61}$ Much of the existing work at the intersection of sport and politics has focused attention on sport diplomacy or the state's involvement in sport. See, for example, C.E.S. Franks. Michael Hawes, and Donal MacIntosh, "Sport and Canadian Diplomacy," International Journal 43, no. 4 (1988): 665-82; Paul Conlin, "The Cold War and Canadian Nationalism on Ice: Federal Government Involvement in International Hockey During the 1960s," Canadian Journal of the History of Sport 25, no. 2 (1994): 50-68; Dwight Zakus, "A Genesis of the Canadian Sport System in Pierre Trudeau's Political Philosophy and Agenda," Sport Hütory Review' 27, no. 1 (1996): 30-48.

${ }^{62}$ Antoinette Burton, ed., Archive Stories: Facts, Fictions, and the Writing of Hiwtory (Durham: Duke University Press, 2005).

${ }^{63}$ Derek Price and Liz Wells use the work of Susan Sontag and Roland Barthes to represent the two ends of this spectrum. Derek Price and Liz Wells, "Thinking About Photography: Debates, Historically and Now," in Pbotograpby: A Critical Introduction, $4^{\text {th }}$ ed., ed. Liz Wells (London: Routledge, 2009), 27-34. 
historical facts. ${ }^{164}$ On the contrary, they are products of a particular time and place that reflect and reproduce cultural norms and prescriptions. ${ }^{65} \mathrm{My}$ reading of the ACA photographs has been informed by the work of social historians of architecture, such as Annmarie Adams. While cognizant of the many layers of an image, Adams employs photographs to access how individuals occupied and used space, both built and otherwise, in ways that fit with and departed from designers' prescriptions. In this way, documentary and candid photographs can contribute to our understanding of how the ideal meets the real. ${ }^{66}$

\section{$\varnothing$}

This dissertation is not the first account of the early years of the American Canoe Association. In addition to a handful of informal histories that have appeared in periodicals such as Outing and Forest and Stream, there is Ronald Hoffman's 1967 dissertation, "The History of the American Canoe Association," which chronicled the first eighty years of the organization. ${ }^{67}$ Produced while he was a member of the ACA, Hoffman's dissertation is an explicit, if not entirely uncritical, institutional history ${ }^{68}$ Even in its criticism, however, it is imbued with an unwavering belief in the project that is the ACA. That the Association until recently had the dissertation available for

\footnotetext{
${ }^{64}$ Van Slyck, A Manufactured Wilderness, 33.

${ }^{65}$ Two recent examples in the Canadian context are Carol Williams, Framing the West: Race, Gender, and the Pbotographic Frontier in the Pacific Nortbwest (New York: Oxford University Press, 2003); Peter Geller, Nortbern Exposures: Pbotographing and Filming the Canadian Nortb, 1920-45 (Vancouver: University of British Columbia Press, 2004).

${ }^{66}$ See Annmarie Adams, "The Eichler Home: Intention and Experience in Postwar Suburbia," Perspectives in Vernacular Architecture 5 (1995): 164-78, and her Medicine by Design: The Architect and the Modern Houpital, 1893-1943 (Minneapolis: University of Minnesota Press, 2008). See also the closelyaligned methodology adopted in Van Slyck, A Manufactured Wilderness.

${ }^{67}$ Vaux, "American Canoeing, Part II"; Vaux, "American Canoeing, Part III"; W.P. Stephens, "The Past and Future of American Canoeing, 1880-1900," Forest and Stream, 6 January 1900; Hoffman, "American Canoe Association."

${ }^{68}$ See, "Preface," in Hoffman, "American Canoe Association," iii-iv. Hoffman highlights, for example, the organization's poor fiscal management in the 1890s and early 1900s, and suggests that with the purchase of Sugar Island the ACA neglected its responsibility to canoeists nationwide. (40,43-46)
} 
download from its website suggests their approval of its contents and conclusions. Useful for painting the broad strokes of the organization's evolution, Hoffman's dissertation provides little in the way of sociohistorical context and analysis ${ }^{69}$ Rather, it is dominated by long quotations from primary documents, namely published Association literature. Finally, given the centrality of the annual meetings to the ACA, Hoffman's account is spare on the shape or significance of the events to the organization and its members.

My dissertation provides a more comprehensive and nuanced account of the annual meetings and encampments of the ACA between 1880 and 1910 than Hoffman's dissertation. Furthermore, it endeavours to situate the annual meetings in their social and cultural milieu, but also to recall the texture of these events and what they might have meant to those that attended. Perhaps most importantly, however, it offers a critical reading of the Association's first thirty years that considers the organization and encampments as participants in performances of power that reinforced existing social and colonial hierarchies, and facilitated the spread of a divisive and exploitative liberal capitalist order.

Chapter Two, "Organizing," considers two distinct but associated iterations of organizing. First, I explore the creation and administration of the ACA. In order to make sense of the annual meetings, which were efforts to realize the organization's goal of creating a transnational community of canoeists, we must understand the structure and bureaucratic machinations of the Association. Here, I situate the organization and operation of the ACA within the context of the late nineteenth-century voluntary association movement. Second, I describe the yearly practices of planning that the

${ }^{69}$ Hoffman cites no more than a handful of secondary texts. 
organizers and canoeists performed in advance of the encampments. I do so with some brevity as I expand on specific practices in subsequent chapters.

In Chapter Three, "(Dis) Placing," I consider in more detail the different locations that the organization visited in the period between 1880 and 1910. Although I argue more generally that the community of canoeists and the encampment as place were crafted out of repetitive practices and shared experiences rather than the specifics of a given locale, place mattered, which is why some locations were considered more acceptable destinations than others. This chapter does not stop at landscape aesthetics, however. Rather, influenced by postcolonial theory, it maps how hegemonic sporting practices contributed to the displacement and dispossession of Aboriginal people, while also affecting the lives and livelihoods of rural dwellers, on both sides of the CanadaUS border in the late nineteenth century. Finally, this chapter is concerned with the ways in which history, the archive, and popular memory can re-inscribe hierarchies of power, a concern that also appears in Chapter Nine. ${ }^{70}$

The annual meetings of the ACA, like mega-sporting events more generally, required that attendees travel long distances to participate as spectators and competitors. ${ }^{71}$ This travel was not incidental to the event, but central to the experience of attending a meet. Chapter Four, "Navigating," hones in on this travel, and inquires about the ways in which different forms of travel - train, steamer, canoe - shaped

\footnotetext{
${ }^{70}$ In these chapters, my work shares similar concerns as appears in John Bale and Mike Cronin, eds., Sport and Poutcolonialium (Oxford: Berg, 2003); Simon Featherstone, "Chapter Three: Body Cultures," in Postcolonial Cultures (Jackson: University Press of Mississippi, 2005), 65-96; Poulter, Becoming Native.

${ }^{71}$ Here, this dissertation makes a contribution to the emerging field on "sport tourism." On the one hand, it offers a much-needed historical perspective to a subfield which to date has been largely focused on issues of management, rather than critical cultural studies. At the same time, it also seeks to respond to the assertion that "sports tourism has lacked any sustained critical edge." See critiques of the field offered by Laurence Chalip, "The Cogency of Culture in Sport Tourism Research," Journal of Sport and Touritm 15, no. 1 (2010): 3-5, and Paul Dimeo, "Review of Sportu Touritum: Participants, Policy and Providers," Tourism Management 29 (2008): 603.
} 
encounters with the people and places along the way. In Part II, I turn my attention to the local excursions that were prominent components of the encampment experience. These, like journeys to the meets, provided further opportunities for encountering human and physical landscapes, while also participating in the constitution of the encampment as home. This chapter reflects a growing current in tourism studies that complicates travel as an extraordinary event divorced from the everyday. ${ }^{72}$ It suggests further that not only do we remain connected to home in both tangible and intangible ways as we travel, but some forms of travel are explicitly committed to the (re)creation of home.

The attempts of organizers and the Executive Committee to order, discipline, and govern the encampments and the campers is the subject of Chapter Five, "Governing." As we shall see, the ACA deployed tactics of late nineteenth-century state formation to effect particular ways of being amongst the canoeists. These included the organization of the camp landscape, the institution of myriad overlapping lists of rules, and policing. Nevertheless, organizers faced a number of challenges to their ordering, particularly from visitors and alcohol. These challenges, which are the subject of the last part of the chapter, reveal the encampments as contested spaces.

Both Chapters Six and Seven are concerned with how the canoeists inhabited the campsites, and thus, contributed to the production of the encampments as spaces of sport, sociability, and recreation. In Chapter Six, "Placing Domesticity," I pay particular attention to the ways in which the canoeists domesticated the sites through the organization of the encampment and also through decoration. This chapter

\footnotetext{
${ }^{72}$ Adrian Franklin and Mike Crang, "The Trouble with Tourism and Travel Theory," Touritt Studies, 1, no. 1 (2001): 5-22; Bruce Braun, The Intemperate Rainforest: Nature, Culture and Power on Canada', West Coast (Minneapolis: University of Minnesota Press, 2002).
} 
suggests that male domesticity was neither an anachronism nor the sole purview of homosocial spaces, such as the club or navy ship, but was part of cultures of leisure more broadly. Whereas Chapter Six approaches inhabiting in a very literal sense, Chapter Seven, "Inhabiting," employs Michael Haldrup's notion of inhabiting as a mobile practice of being in place to consider how the canoeists participated in the transformation of the campsites from raw space into a meaningful place. ${ }^{73}$ Unlike Haldrup, who limits his understanding of inhabiting to tourists' daily habits, I also consider seemingly extraordinary events, such as minstrel shows and circuses, as expressions of inhabiting. Spectacles, I argue, worked alongside camp regulations, photographs, and accounts of the meet, to reproduce the encampments as spaces of white, middle-class, male sport and recreation.

The greatest spectacle of all at the annual meetings was the regatta, which typically took place during the second week of the encampment. This is the subject of Chapter Eight, "Competing." Following a discussion of amateurism and professionalism in relation to the ACA and the regatta, I consider in detail the organization, delivery, and experience of the annual races. As performative spaces, the regattas played an important role in affirming, reproducing, and defending both the bounds and bonds of community, but also in constructing the encampment as a place of competitive sport with national and international significance. The latter, in turn, was crucial to the ACA's larger project of establishing itself as the definitive canoeing organization in the world. Here as in Chapter Seven, I demonstrate the centrality of the spectacular to everyday life.

\footnotetext{
${ }^{73}$ Michael Haldrup, "Laid-Back Mobilities: Second Home Holidays in Time and Space," Tourium Geograptier 6, no. 4 (2004): 434-55.
} 
In the final chapter, "Producing/Consuming," I explore the encampments as spaces of production and consumption in the Marxist sense of these terms. Not only did the organizers hire people to work at the meets, but campers also purchased goods and services. I am especially concerned with the ways in which labour performed by "others" - women, the working class, African Americans, Aboriginal people, and French Canadians - enabled the encampments to function in ways that they would not have otherwise. The presence of these others at once subverted and reinforced the encampments as exclusively white, middle-class spaces, for these workers, while present, were never admitted on equal footing to the canoeists. Historians of sport have to date largely understood the intersections between sport and labour to mean labour organizing in professional sport or working-class sport and leisure. ${ }^{74}$ As a result, they have overlooked the various forms of work that enabled dominant sporting practices, including organized sport. This chapter seeks to show what kinds of other histories of labour and sport are possible and, I believe, necessary.

My decision to leave the "other" to the end could be interpreted as re-inscribing marginality. To the contrary, I wanted to establish the structure and practices of encampment in order to demonstrate the deep dependencies that these events had on marginalized workers. I also wanted the last word on the subject of the encampments (as far as this work is concerned) to be devoted to the memory of those who have been largely obscured in accounts of the meets. It is, I hope, a palpable reminder of the profoundly divisive world of amateur sport. Sport was not divorced from or a

\footnotetext{
${ }^{74}$ See, for example, Martin H. Blatt and Martha K. Norkunas, eds., Work, Recreation, and Culture: Evalys in American Labor History (New York: Garland Publishing Company, 1996); Lynne Marks, Revivals and Roller Rinks: Religion, Leiwure, and Identity in Late-Nineteentb-Century Small-Town Ontario (Toronto: University of Toronto Press, 1997); Gerald Gems, "Welfare Capitalism and Blue-Collar Sport: The Legacy of Labour Unrest," Retbinking Hütory 5, no. 1 (2001): 43-58.
} 
repudiation of the world of industrial capitalism and liberal government that structured social relations in urban and rural areas across the continent. Rather, it was embedded in, and constitutive of that world, participating directly in (re)enforcing the inequalities of late nineteenth-century society. To place the ensuing chapters in context, I close this introduction with a brief overview of the cultures and landscapes of canoeing in the Victorian era.

\section{$\mathscr{D}$}

The late nineteenth century, as I noted at the outset of this chapter, witnessed an explosion in canoeing as sport, recreation, and leisure. ${ }^{75}$ Most contemporary authors attributed the meteoric rise of canoeing to the aforementioned John MacGregor. ${ }^{76}$ His 1866 bestseller, $A$ Thousand Miles in the Rob Roy Canoe, recounted his travels through the canals and rivers of Europe in a decked craft modeled on kayaks he had seen while visiting North America in $1859 .{ }^{77}$ MacGregor's exploits started a "fashionable craze" in England, where "thousands of gentleman amateurs [took] to the water in imitation," including the Prince of Wales. ${ }^{78}$ A Thousand Miles also found fertile

\footnotetext{
${ }^{75}$ This "canoe boom" was but one manifestation of the expanding sphere of leisure. Whereas earlier in the century, leisure had been viewed with some suspicion, particularly amongst Protestant clergy, by 1900 , it represented a significant component of the daily lives of people across the social spectrum. We can trace the origins of this transformation, in part, to the changes wrought by industrial capitalism. Peter Bailey, "'A Mingled Mass of Perfectly Legitimate Pleasures': The Victorian Middle Class and the Problem of Leisure," Victorian Studies 21, no. 1 (1977): 7-28; David Strauss, "Toward a Consumer Culture: 'Adirondack Murray' and the Wilderness Vacation," American Quarterly 39, no. 2 (1987): 27086.

${ }^{76}$ For accounts of the origins of "modern" canoeing, see "Canoeing," The New York Times, 22 August 1871; "Paddle and Sail," The New York Times, 2 August 1878; "Canoeing in the United States," The New' York Timet, 1 August 1880; "Where Canoes Will Float," New York Times, 2 August 1891; "Annual Canoe Meet," New York Times, 4 August 1895; Hermann Dudley Murphy, "Lovers of the Canoe," Boston Evening Tranucript, 3 August 1909.

${ }^{77}$ John MacGregor, A Thowand Miles in the Rob Roy Canoe: On Rivers and Lakes of Europe (London: Sampson, Low, Marlowe and Company, 1866). MacGregor's book was undoubtedly popular. By 1879 , it was on its fifteenth printing.

${ }^{78} \mathrm{MacGregor}$ also founded the Royal Canoe Club in 1866, and was at the helm of the canoe regatta on the Seine that was one of Britain's contributions to the 1867 Paris Exposition. M.J.D. Roberts,
} 
soil on the other side of the Atlantic, where it was eagerly read, and the Rob Roy canoe adopted and adapted to suit the conditions of North American waterways. ${ }^{79}$ Of course, this narrative of discovery and circulation negates other histories of canoe use for the purpose of sport or leisure within Aboriginal and other Euro-North American cultures, a point I consider in more detail in Chapter Eight.

The most prominent and prolific of the early disciples of "modern" canoeing in North America was William L. Alden, an editor at the New York Timed. ${ }^{80}$ Alden put the resources of the Timed to use to make a name for canoes, penning a number of editorials and articles on the subject in the $1870 \mathrm{~s}^{81}$ As important as Alden's editorials were the travelogues of fellow enthusiasts such as Nathaniel Holmes Bishop and George Washington Sears. ${ }^{82}$ Still others took the gospel of canoeing to the public in different ways, including A.H. Siegfried who gave public lectures on the subject in the $1870 \mathrm{~s}$ and $1880 \mathrm{~s} .{ }^{83}$ Canoeing was also visible in the exhibitionary culture of the

\footnotetext{
"Between Fame and Eccentricity: John 'Rob Rob' MacGregor, Almost Eminent Victorian," History Australia 2, no. 2 (2005): 36-1-36-8.

${ }^{79}$ A Thousand Miles was serialized in Harper's Weekly. William Crowley, Rubton's Rowboats and Canoes: The 1905 Catalog in Peripective (Blue Mountain Lake: Adirondack Museum, 1983), vi.

${ }^{80}$ The importance of print culture in facilitating the canoe boom cannot be understated. A number of early canoeists apart from Alden had connections to publishing including Montgomery Schuyler, who worked for Harper'; Arthur Brentano, a member of the Brentano Family publishing house; and William P. Stephens, who eventually became the chair of the yachting and canoeing department at Forest and Stream. Hoffman, "American Canoe Association," 10-13; Vaux, "American Canoeing, Part I," 264. ${ }^{81}$ Vaux, "American Canoeing, Part I," 262. His work also found print in the pages of Harper's, and later in folio form as The Canoe and the Flying Proa, or Cheap Cruiting and Safe Sailing (New York: Harper and Brother Publishers, 1878). In 1883, he published a work of boys' fiction, The Cruive of the Canoe Club (New York: Harper and Brothers, 1883). Alden was a founding member of the New York Canoe Club. ${ }^{82}$ In 1878. Bishop published an account of an 1874-5 journey from Troy, NY to the Gulf of Mexico, Voyage of the Paper Canoe (Boston: Lee and Shepard, 1878), that became required reading for canoeing enthusiasts in the 1870s. Sears, better known by his penname "Nessmuk" began writing articles about canoe cruising for Forest and Stream in 1880 . He also included canoeing in his treatise on outdoor life, Woodcraft (New York: Forest and Stream Publishing, 1884). Dan Brenan, Robert L. Lyon, and Hallie E. Bond, eds., Canoeing the Adirondacks with Nesumuk: The Adirondack Letters of George Washington Sears (Blue Mountain Lake: The Adirondack Museum/Syracuse University Press, 1993).

83 "Canoeing in the West," Forest and Stream, 24 April 1879; Forest and Stream, 22 April 1880.
} 
period. ${ }^{84}$ In addition to displays at expositions and fairs, such as the Centennial Exhibition in 1876 and the Columbia Exposition in 1893, a group of New York City canoeists organized a Canoeing Exhibition at the Harvard Rooms in May $1886 .{ }^{85}$ Finally, the growth of canoeing was facilitated by the builders who provided the canoes necessary for realizing one's desire to sail or paddle, while also promoting the sport as healthful recreation. Although the canoe building industry was better established in Canada at mid-century, two of the most important builder boosters were Americans: J.H. Rushton (1843-1906) and William P. Stephens (1854-1946) ${ }^{86}$ The virtues and appeal of canoeing, if contemporary enthusiasts are to be believed, were myriad. ${ }^{87}$ Harry Eckford praised canoeing as "all-round exercise," which develops "none of the faculties too much," and ensures "good health without the danger of excess through competition." ${ }^{18}$ This is in contrast with rowing, which E.B. Bronson argued focused on one set of muscles exclusively. ${ }^{89}$ Canoeing was not just

\footnotetext{
${ }^{84}$ See the William English Canoe Company's medals for the expositions in 1876 and 1886 in Peterborough Centennial Museum and Archives (PCMA), 969.45.1, 969.45.2. According to Ted Moores, all of the Peterborough canoe builders were in attendance at 1893 Chicago World's Fair. Ted Moores, "From Forest to Factory: Innovations and Mass Production," in The Canoe: A Living Tradition, ed. John Jennings (Toronto: Firefly Books, 2002), 178. See, also "The Berlin Exhibition," New York Times, 20 March 1880; “America at the Fish Exhibition," New York Times, 30 May 1880. 85 "The Miniature Navy," New' York Times, 25 April 1886.

${ }^{86}$ A consummate self-promoter, Rushton made canoeing visible through his innovative marketing techniques. Bond writes, "He advertised (first locally and then nationally), took exhibits to fairs and expositions, worked closely with his customers, and became a master at the sophisticated practice of getting free advertising by interesting the editors of the sporting press in his work." Stephens, meanwhile, was a founding member of the country's second canoe club, the Jersey Blue, and the author of a small but popular instruction manual, Canoe and Boatbuilding (New York: Forest and Stream Publishing, 1883). By 1903, the manual was on its tenth edition. Hallie E. Bond, Boats and Boating in the Adirondacks (Syracuse: Syracuse University Press, 1998), 86; Vaux, "American Canoeing, Part I," 266.

${ }^{87}$ The canoe was but one of many boats available for recreational uses in this period, and so a case had to be made for the canoe as a craft worthy of attention. It was not enough to sing the praises of the canoe, commentators also highlighted the negatives aspects of other aquatic craft, but particularly the rowboat and the yacht. See, for example, "New Publications: Canoe Voyaging," New York Times, 8 April 1878; W.P. Stephens, "The Charm of Canoeing," The Toronto Daily Mail, 11 July 1881.

${ }^{88}$ Harry Eckford, "Camp Grindstone," The Century Magazine 30, no. 4 (August 1885): 502.

${ }^{89}$ E.B. Bronson, "Rowing and Canoeing. - A Physiological Comparison," American Canoeist 1, no. 2 (March 1882): 12-14. Bronson further opined that having strong arms was the "capital of the
} 
healthy, it was also perceived as regenerative. ${ }^{90}$ An American Canoeist editorial from 1883 maintained that canoeing promised, for the "journalist, professional, or business man," a "delightful, healthful, economical relaxation from duties," an opportunity to restore one's health so as to be able to return to work. ${ }^{91}$ Canoeing also celebrated independence and self-sufficiency. ${ }^{92}$ Orange Frazer argued in the pages of Forest and Stream that the canoeist "is his own motive power and carries with him his house and his provisions, and can afford for the time being to despise the railway train and the hotel. ${ }^{.93}$ One of the chief appeals of the canoe in this regard was that it facilitated an escape from the city. ${ }^{94}$ According to the Times, "as he paddles down the rivers of the

blacksmith," for the "man of intellectual pursuits, the merchant, the financier, the professional man" sound health, endurance, and energy are what was required.

${ }^{90}$ Even as modern life amazed with its new technologies and opportunities there was widespread concern about the frenetic pace of modern life and the threat it posed to human health. The primary concern was neurasthenia, a nervous ailment that physician George Beard argued disproportionately tested the "biological limitations and restraints of [the] highly evolved body" of the white middle-class male. Different forms of recreation and exercise were seen as key components in fighting neurasthenia. See, George M. Beard, American Nervousness: Its Causes and Consequences (New York: G.P. Putnam's Sons, 1881), 3; Gail Bederman, Manlinew and Civilization: A Cultural History of Gender and Race in the United States, 1880-1917 (Chicago: The University of Chicago Press, 1995), 86-7; David Schuster, Neurauthenic Nation: America' Searcb for Health, Happinest, and Comfort, 1869-1920 (New Brunswick: Rutgers University Press, 2011).

91 "Editorials," American Canoeit 2, no. 1 (February 1883): 8.

${ }^{92}$ For white men, in particular, leisure broadly, but sport specifically, provided the independence and self-worth that seemed unavailable in the contemporary world of work. Established notions of manhood, Gail Bederman argues, had been forged in the crucible of "a small-scale, competitive capitalism which had all but disappeared" by the turn of the twentieth century. Instead, "[l]ifelong salaried employment in a large bureaucracy [was] a distinct possibility" for most white middle-class American men in the late nineteenth century. This, in conjunction with a series of economic depressions between 1873 and 1896 , meant "the sons of the middle class faced the real possibility that traditional sources of male power and status would remain closed to them forever." Bederman, Manlines' and Civilization, 12-13; Clark Davis, "The Corporate Reconstruction of Middle-Class Manhood," in The Middling Sorts: Enplorations in the History of the American Middle Claw', eds. Burton Bledstein and Robert D. Johnston (New York: Routledge, 2001), 202.

93 "A Word for Canoeing," Forest and Stream, 4 October 1883. See also, "Paddle and Sail," The New York Times, 2 August 1878; "Canoeing," The New' York Times, 7 April 1872.

${ }^{94}$ The city held an ambivalent place in late nineteenth-century thought. On the one hand, cities were the embodiment of civilization and testaments to human ingenuity and industry. At the same time, they were seen as immoral and unhealthy. This ambivalence is related to a more general ambivalence towards modern life. This ambivalence is palpable in Alan Trachtenberg, "Mysteries of the Great City," in The Incorporation of America: Culture and Society in the Gilded Age (New York: Hill and Wang, 1982), 101-139; William Cronon, "Prologue: Cloud Over Chicago," in Nature', Metropolis: Chicago and the Great West (New York: W.W. Norton, 1991), 5-19. 
continent," the canoeist opens up to himself new vistas and landscapes. ${ }^{95}$ This in contrast with the bicycle, which while "a convenient machine for carrying one around," requires that one "keep to traveled roads and the ways of civilization."

These early proselytizers had a difficult task before them. In the late nineteenth century, the canoe remained tethered in the minds of many white, middle-class Americans (and Canadians too) to the Indigenous cultures to which it owed its very existence. ${ }^{97}$ An 1865 advertisement for Wheeler and Wilson sewing machines is instructive. The advertisement claimed that the company's machines were "the boon of health and independence" for the widow and the seamstress, a welcome alternative to hand sewing, which the author conflates with "carding, spinning, weaving, and grinding corn by hand; padyling a canoe, fishing with bone hook, and inhabiting a hovel." As Aware of the detriment such a relationship posed to their goal of establishing the canoe as a prime leisure choice of the white middle classes, enthusiasts worked hard to re-vision the canoe as a reputable craft, a process I refer to as the "whitening of the canoe." In part, this was a linguistic and conceptual exercise that sought to rhetorically distance the "modern" canoe from its Aboriginal past. An 1880 article, for example, noted, "The canoe of Christian nations has nothing whatsoever in common

\footnotetext{
95 "The Canoe Pastime," The New York Times, 5 May 1872.

${ }^{96}$ Leo Etherington, "Sports of All Sorts," The Deveret New', 4 August 1900.

${ }^{97}$ A review of the canoeing exhibition claimed the "exhibitors propose[d] to remove the impression that canoeing is a barbarous if not a crazy recreation, and to show that it is a sport in every way worthy of civilized and sane human beings." "City and Suburban News," The New York Times, 20 March 1886. 98 "Not Too Late Yet," New York Time, 28 December 1865. Emphasis added.

99 This language borrows from David Roedigger's work on changing understandings of whiteness amongst the American working class. David R. Roedigger, Working Toward Whitenes: How America', Immigranto Became White; The Strange Journey from Elli, Island to tbe Suburbs (New York: Basic Books, 2005). Similar practices were employed to whiten another Native activity in the same period: lacrosse. Poulter notes that promoters did not just civilize the sport, they also sought to civilize the Natives who wished to participate by making them play according to white rules. Poulter, Becoming Native, 125-39.
} 
with the birch canoe of the North American heathen."100 Only a few months later, the Times reiterated their position: "The Indian birch and dug-out, it is true, belong to the canoe group, they are, at best, rude craft, unfit for general cruising, and had long before gone into disuse, and come to be valued only as relics of an uncivilized condition."101 It was also about materially reimagining and reconstructing the "crank" canoe (eg. dugout, birch) using techniques (eg. rib and batten, lap-streak) and products (eg. wood, tin, and copper) associated with modernity, and ultimately with civilization. ${ }^{102}$ As we will see in the coming chapters, the ACA was deeply invested in this project of whitening the canoe. ${ }^{103}$ While the primary focus of this dissertation is not to link the canoe or the practice of canoeing to racism, colonialism, and whiteness, I do point to traces in the archive that are suggestive of these connections. There are others who have capably articulated such relationships primarily in the Canadian context including Jocelyn Thorpe, Bruce Erickson, Andrew Baldwin, Beverly HaunMoss, and Bruce Braun. ${ }^{104}$

The boosters' arguments appear to have gained purchase for the number of canoeists across the country began to grow steadily. Recreational canoeing in the late nineteenth century was a remarkably urban pursuit. Inspired by the broader

\footnotetext{
100 "The Bicycle and the Canoe," The New York Times, 2 June 1880.

101 "Canoeing in the United States," The New York Times, 1 August 1880.

${ }^{102}$ See, Frederic G. Mather, "The Evolution of Canoeing," Outing 5, no. 6 (March 1885): 414-23.

${ }^{103}$ In 1894, the Times claimed, "Little of this development from the canoe of the Indian could have taken place if every canoeist had paddled by himself. It was only through organization and the yearly exchange of new ideas that the evolution of canoeing became possible. The active agent was the American Canoe Association." "Features of the Meet at Croton Point," New York Times, 15 July 1894. ${ }^{104}$ Jocelyn Thorpe, Temagami", Tangled Wild: Race, Gender and the Making of Canadian Nature (Vancouver: University of British Columbia Press, 2012); Bruce Erickson, "Canoe Nation: Race and Gender in the Making of a National Icon" (Ph.D. Dissertation: York University, 2009); Andrew Baldwin, "Ethnoscaping Canada's Boreal Forest: Liberal Whiteness and Its Disaffiliation from Colonial Space," The Canadian Geographer 53, no. 4 (2009): 427-43; Beverly Haun-Moss, "Layered Hegemonies: The Production and Regulation of Canoeing Desire in the Province of Ontario," Topia 7 (Spring 2002): 3955; Bruce Braun, The Intemperate Rainforest: Nature, Culture and Power on Canada's Weat Coast (Minneapolis: University of Minnesota Press, 2002).
} 
association movement, urban enthusiasts came together in clubs. ${ }^{105}$ The first of these was the New York Canoe Club (1871). ${ }^{106}$ By the turn of the century, however, communities large and small on both sides of the border boasted similar organizations that provided physical spaces for enthusiasts to pursue canoeing. Club boathouses and floats enabled canoeists to store and launch their craft. ${ }^{107}$ More than this, however, clubs provided opportunities to socialize with like-minded individuals. ${ }^{108}$ To borrow from C. Bowyer Vaux, "all manner of devices are resorted to continually to make [the club feeling] still stronger - meetings, dinners, regattas, short cruises, camp fires, 'smokers,' lectures, anything, everything, to bring the men together, for then canoe talk always follows." 109

Canoe clubs, like sport more broadly, were largely the preserve of white, middle-class men. ${ }^{110}$ This reflected their financial and social capital, as well as gendered

${ }^{105}$ There was a predilection to organize around one's leisure interests in the late nineteenth century, which was reflective of a broader culture of association in this period. As an 1880 article in the New York Times noted, "the mysterious law of the Anglo-Saxon nature...forbids a man to indulge in any particular sport unless he can induce several other men to join him." Thus, in this period we see a flowering of associations devoted to all manner of sport, recreation, and leisure, including clubs dedicated to birdwatching and mountain climbing, and organizations, which brought together enthusiasts of photography and curling. "A New Society," New York Times, 3 October 1875.

${ }^{106}$ The NYCC while novel was not an anomaly as a sporting club. By 1871 , there were numerous boat, cricket, and baseball clubs in cities throughout the Northeast. Moreover, 1866 marked the beginning of the athletic club movement in New York with the founding of the New York Athletic Club. Later additions included the Manhattan (1876), Harlem (1876), and Staten Island (1877) Athletic Clubs. J. Willis and R. Wettan, "Social Stratification in New York City Athletic Clubs, 1865-1915," Journal of Sport History 3, no. 1 (1976): 45-6.

${ }^{107}$ Although they came in a variety of shapes and sizes from the simple to the grand, most boathouses possessed a section devoted to boat storage with large bay doors opening onto docks or floats, changerooms, dining or ballrooms, and occasionally, smoking rooms, ladies' parlours, and libraries. Some clubs had living quarters on site for a caretaker.

${ }^{108}$ Their yearly calendars reflected this dual identity as social and recreational spaces. Club events included annual regattas, informal competitions, such as Saturday races, and club cruises and excursions, as well as dances, banquets, lectures, and smokers.

${ }^{109}$ C. Bowyer Vaux, "The Canoeing of Today," Outing 16, no. 2 (May 1890): 133.

${ }^{110}$ The early membership of the NYCC is representative of canoe clubs more broadly. Commodore $M$. Roosevelt Schuyler was a merchant (and a cousin of Teddy Roosevelt), Montgomery Schuyler and John Haberton were newspaper editors, G. Livingston Morse and H. Edwards-Ficken were architects, (author, editorial staff of the Herald), Col. C.L. Norton was a soldier and travel writer, A. Cary Smith 
understandings of sporting abilities. ${ }^{111}$ However, canoeing was never exclusively a bourgeois masculine pursuit. Newspapers and magazines such as the New York Timed and Outing occasionally included columns for women canoeists, and most canoe clubs had an associate or honorary member category that enabled women to join, although their participation was often curtailed. ${ }^{112}$ For those without canoes or access to canoe clubs, boat liveries, which were visible on most urban waterfronts in the Northeast by the turn of the century, provided opportunities to take to the water. Liveries such as those at Sunnyside Beach in Toronto and on the Charles River in Boston rented canoes and rowboats at hourly and daily rates. ${ }^{113}$ In doing so, they made canoeing accessible to the wider population of working-class people and immigrants capable of engaging in "cheap amusements," but barred from joining exclusive sporting clubs. ${ }^{114}$

While clubs and liveries were an important part of the nineteenth-century canoeing landscape, they were not the only manifestations of canoeing enthusiasm. Also popular was "canoe cruising," a term that described journeys beyond urban areas

was yacht designer), and J.S. Mosher, M.D. was a health officer. W.P. Stephens, "Memoirs," in New" York Canoe Club-Nortb Shore Yacbt Club Yearbook, 1971; Vaux, "American Canoeing, Part I."

${ }^{111}$ The male body was seen as suited to and capable of strenuous physical activity. Sport remained relatively closed to women in the late nineteenth century because of assumptions about their physical capabilities and anxieties about imperiled femininity, although changing theories of the body and health in the decades around the turn of the century facilitated women's entry into physical education and athletics. Patricia Vertinsky, The Eternally Wounded Woman: Women, Doctors, and Exercive in the Late Nineteenth Century (Toronto: St. Martin's Press, 1990); Helen Lenskyj, "Moral Physiology in Physical Education and Sport for Girls in Ontario, 1890-1930," Proceedings: 5th Canadian Symposium on the History of Sport and Pbyvical Education (Toronto: University of Toronto Press, 1982), 139-50; J.A. Mangan and Roberta J. Park, eds., From 'Fair Sex' to Feminum: Sport and the Socialization of Women in the Industrial and Pout-Induttrial Era (London: Frank Cass, 1987).

112 "The Canoe Pastime," The New York Times, 5 May 1872; "Other Canoeists of the Passaic," The New" York Times, 3 September 1893.

${ }^{113}$ City of Toronto Archives (CTA), Fonds 1244, "Foot of York Steet," 1910; Diane Beasley, "Walter Dean and Sunnyside: A Study of Waterfront Recreation" (M.A. Thesis: University of Toronto, 1995); Dan Miller, "The Charles River Canoe," Wooden Canoe 30, no. 3 (2007): 8-15.

114 Peiss, Cbeap Amusements. 
lasting one or more days that typically married paddling or sailing with camping. ${ }^{115}$ Cruises provided opportunities to escape the urban environments perceived as detrimental to the body, while also engaging in healthful recreation. Certainly canoeists who set out on cruises desired to leave the city behind. ${ }^{116}$ However, it is a misconception that most wished to escape "civilization" altogether. On the contrary, cruising guides reveal how canoeists relied on local people and produce to sustain themselves while on trip: "Living on fish, eggs, and milk — the latter purchased from farmers along the route - the traveler would find the cost of the cruise exceedingly small."117

\section{$\not$}

It was out of this milieu that the American Canoe Association emerged in 1880. Motivated in part by the sporting clubs of the late nineteenth-century city, as well as the wilderness ideal that inspired the middle classes to escape the city, the ACA, as we shall see, was a strange hybrid that married home and away, domestic and wild, public and private. It was also a world that the organization helped to (re)create. In other words, the annual meeting drew on and contributed to the interest in urban canoeing in the form of canoe liveries and canoe clubs, but also wilderness trips or "cruises." More than this, the ACA and its annual meetings reproduced the divisions and hierarchies that characterized late nineteenth-century society. We begin to uncover these connections in the next chapter by considering the formation of the ACA.

\footnotetext{
${ }^{115}$ Cruising was one expression of the wilderness ideal that celebrated the regenerative power of nature for bodies and minds wearied by city living. James Morton Turner, "From Woodcraft to 'Leave No Trace': Wilderness, Consumerism, and Environmentalism," Environmental Hütory 7, no. 3 (2002): 462-84. ${ }^{116}$ See note 94.

117 "The Canoe Trip," New York Times, 8 August 1872.
} 


\section{Chapter Two: Organizing}

In the winter of 1880, readers of Forest and Stream and the New York Times were informed that a "general convention of canoeists" was to be held at Caldwell, N. Y. in early August. The purpose of the event was "to perfect the organization of a national canoe club" and "to take such further action in the interests of the pastime as may be deemed expedient." In addition to the meetings planned for the "canoe congress," the event would feature sailing and paddling races. All enthusiasts were invited to attend, "whether owning canoes or not." The organizers also extended invitations to individuals in England and Canada with an interest in canoeing. Appended to the articles were the names of "well known canoeists," who "all stand in high community," including Charles L. Norton (Commodore of the New York Canoe Club), Charles E. Chase (Commodore of the Jersey City Canoe Club), and Rev. Charles A. Cressy (Landaff, New Hampshire). Those interested in attending were asked to send their names to Nathaniel Holmes Bishop, Esq. ${ }^{1}$

The "first call," as the text of these articles would come to be known, hints at some of the motivations for organizing a "national canoe club," including the promotion of canoeing as a recreational pastime, the bringing together of enthusiasts, and the running of races. Nathaniel Holmes Bishop's personal motivations are equally telling. He envisioned an association, which would be a "forum for tales of cruising and the comparison of camping equipment and canoe models. ${ }^{2}$ Closest to Bishop's heart, however, was the potential for the organization to produce knowledge about the

\footnotetext{
'Forest and Stream, 1 January 1880; "Canoeists to Hold a Convention," New' York Times, 25 February 1880.

${ }^{2}$ Nathaniel H. Bishop, "First Call," as quoted in Ronald Hoffman, "The History of the American Canoe Association, 1880-1960" (Ph.D. Dissertation: Springfield College, 1967), 18.
} 
waterways of the continent. According to one of the organization's unofficial historians, W.P. Stephens, "In all of his travels Mr. Bishop devoted much of his time to the study of the geography and natural history of the regions through which he passed, and, like the father of canoeing, Capt. John MacGregor, he was a firm believer in the canoe as a special instrument for the close and accurate study of a country." All of these sentiments were embodied in the mission statement adopted by the Association in 1883: "Its object shall be to unite all amateur canoeists for the purpose of pleasure, health, or exploration by means of meetings for business, camping, paddling, sailing, and racing; and by keeping logs of voyages, records of waterways, routes, details, drawings, and dimensions of boats, and collections of maps, charts, and books." ${ }^{4}$ Yearly encampments were central to realizing this mission. As one canoeist later noted, “The most valuable feature of the American Canoe Association is its annual meet, bringing together as it does canoeists from all quarters and canoes of all types, affording opportunities for comparisons of the different boats and discussions of their various qualities, besides promoting good fellowship among the constantly increasing body of canoeists."

This chapter considers the theme of organizing in two different, but related ways. In Part I, I explore the origins of the ACA, as well as its administrative structure and organizational practices. My contention here is that in order to make sense of the annual meetings and encampments, we must first understand the Association to which they owe their existence. Part II, by contrast, considers the yearly "organizing" that

\footnotetext{
${ }^{3}$ Stephens went on to note that while Bishop was "a believer in the canoe as a mere means of recreation and healthy sport, he at the same time rated it much higher in the scale of practical utility." W.P. Stephens, "The Past and Future of American Canoeing, 1880-1900," Forest and Stream, 6 January 1900. ${ }^{4}$ Unknown, American Canoe Avsociation Book (New York: Vaux and Company, 1883), 214. Over time the desire to keep logs and amass collections was superseded by racing, socializing, and perfecting the craft. 5 "The Future Camp of the American Canoe Association," Forest and Stream, 4 October 1883.
} 
occurred to bring the meets to fruition. Here, the focus is on the practices of member canoeists and the efforts of the various organizing committees, although the archive is weighted toward the latter.

While I am concerned with the structure and bureaucratic machinations of the ACA, this chapter is by no means an institutional history, not least because it asks different kinds of questions. The most extensive of the existing institutional accounts is Ronald Hoffman's 1967 dissertation, "The History of the American Canoe Association, 1880-1960." Whereas his work emphasizes the progressive internal evolution of the organization and celebrates its geographical and bureaucratic expansion, my concerns are different. ${ }^{6}$ Most importantly, I situate the ACA within a broader sociohistorical context. ${ }^{7}$ In this chapter, in particular, I position the ACA in relation to the nineteenthcentury, middle-class impulse to form associations and clubs that led Alexis de Tocqueville to call the United States a "nation of joiners." ${ }^{8}$ While a canoeing association served different interests than a mutual aid society or a temperance union, both were manifestations of the voluntary association movement. To ignore this fact enables the distancing of sport from the politics of everyday life. And here is the second key difference between this work and that of institutional historians such as

\footnotetext{
${ }^{6}$ For example, Hoffman (like others documenting the organization's early years) celebrates the pioneering efforts of the aforementioned Nathaniel Holmes Bishop without recognizing the ways in which Bishop was motivated by the enthusiasm, expertise, and established social networks of fellow canoeists, as well as the model offered by other boating clubs, sporting organizations, and voluntary associations. Hoffman, "American Canoe Association," 12-5. See, also, C. Bowyer Vaux, "The American Canoe Association, and Its Birthplace," Outing 12, no. 5 (1888): 410-21; "Where Canoes Will Float," New" York Times, 2 August 1891; Stephens, "The Past and Future."

${ }^{7}$ That we can ask such fundamentally different questions about the organization reflects not just different motivations, but divergent historical imaginaries.

${ }^{8}$ Alexis de Tocqueville, Democracy in America, Vol. 1 [1835], ed. Phillips Bradley (New York: Knopf, 1980), 191. De Tocqueville went on to say that "in no country of the world has the principle of association been more successfully used or applied to a greater multitude of objectives than in America." Jeffrey McNairn argues that a similar observation could have been made of British North Americans prior to Confederation. Jeffrey L. McNairn, The Capacity to Judge: Public Opinion and Deliberative Democracy in Upper Canada, 1791-1854 (Toronto: University of Toronto Press, 2000), 67.
} 
Hoffman: my concern for the effects of performances of power such as administrative hierarchies and exclusive membership policies on access to and experiences of sport and leisure.

\section{Part I - Constructing a Transnational Canoeing Community}

\section{Middle-Class Organizing in the Nineteenth Century}

Historians of Canada, the United States, and Great Britain have thoroughly documented the popularity and importance of "voluntary associations" in the nineteenth century. ${ }^{9}$ British historians Catherine Hall and Leonore Davidoff, for example, have identified four overlapping categories of association in this period: philanthropic societies; business and property societies; political societies; and "societies which sought to provide for the cultural, scientific, and educational needs of the middle-class. ${ }^{10}$ Voluntary associations performed a variety of social, cultural, and political functions. For instance, John Gilkeson argues that voluntary associations in Providence, Rhode Island "promoted the social and cultural organization of rapidly growing communities, defined new occupational identities, organized sociability, and provided insurance against sickness and death." ${ }^{\prime 1}$ Don Doyle adds that similar organizations in Jackson, lowa "conferred a certain status" on their members, which in

\footnotetext{
${ }^{9}$ Don Doyle defines voluntary associations as "formally organized social groups...formed to serve specified goals... [and] voluntarily organized and joined (although they may be exclusive)." Don H. Doyle, "The Social Functions of Voluntary Associations in a Nineteenth-Century American Town," Social Science Hittory 1, no. 3 (1977): 333. For broad overviews of the history of voluntary organizations in Canada and the US, see Darren Ferry, Uniting in Meaures of Common Good: The Construction of Collective Liberal Identities in Central Canada, 1830-1900 (Montreal: McGill-Queen's University Press, 2008), and Gerald Gamm and Robert D. Putnam, "The Growth of Voluntary Organizations in America, 18401940," Journal of Interduiciplinary History 29, no. 4 (1999): 51 1-557.

${ }^{10}$ Leonore Davidoff and Catharine Hall, Family Fortunes: Men and Women of the Englist Middle Class, 17801850, rev. ed. (London: Routledge, 2002), 420-21.

$1 "$ John H. Gilkeson, Jr., Middle-Claw Providence, 1820-1940 (Princeton: Princeton University Press, 1986), 9.
} 
turn offered the possibility for social mobility. ${ }^{12}$ Finally, Jeffrey McNairn maintains that voluntary associations contributed to the rise of participatory democracy in Canada, by providing spaces in which "people learned and practiced the norms of reasoned discussion and mutual respect vital to sustained public deliberation." ${ }^{\text {13 }}$ Such characterizations of voluntary societies, as participant institutions in (re)producing community and in the formation of the public sphere, are remarkably positive. There is, however, a darker side to these institutions. For example, Allan Greer and Ian Radforth note that philanthropic and social reform organizations often found "new ways to meddle in the lives of the poor and dependent, all in the interests of social peace and security."14 More broadly, voluntary associations reinforced privileges associated with class, gender, and race. While such institutions were not endemic to the expanding middle class in the nineteenth century, they were key sites through which this class "disseminated their values and defended their class interests. ${ }^{\prime 15}$ Don Doyle, borrowing from Alexis de Tocqueville, argues that it was the "power of meeting" or "the frequent face-to-face contact between men" that enabled

\footnotetext{
${ }^{12}$ Doyle, "Social Functions," 348, 336, 342. On the one hand, voluntary associations "enlarged the number of personal and business contacts," while also fostering the conditions for economic interactions. On the other hand, they enforced "a broad moral discipline," which had implications for business successes.

${ }^{13}$ McNairn, Capacity to Judge, 63. McNairn offers a rather optimistic picture of voluntary associations. He maintains, for instance, that voluntary associations "helped to create and maintain a social space that was relatively autonomous from family, economic production, and the state," a point called into question by the broad overlap between membership in voluntary associations and the occupation of public office that Don Doyle observes in "Social Functions," 336. He also claims that "within [voluntary associations], the hierarchy and fractures of the broader society might be set aside temporarily to allow for a free association of equal members discussing topics of mutual concern." (66)

${ }^{14}$ Allan Greer and Ian Radforth, eds., Colonial Leviatban: State Formation in Mid-Nineteentb-Century Canada (Toronto: University of Toronto Press, 1992), 6.

${ }^{15}$ Gilkeson, Middle-Clav' Providence, 9, 10. For discussions of the importance of associational culture within working-class communities in Canada, see Greg Kealey, Toronto Workers Respond to Industrial Capitalium, 1867-1892 (Toronto: University of Toronto Press, 1991), 98-153; Bryan Palmer, Working Claws Experience: Rethinking the History of Canadian Labour, 1800-1991 (Toronto: McLelland, 1992), 95-100. In the United States, see Herbert G. Gutman, Work, Culture, and Society in Industrializing America: Evsays in American Working-Claw and Social History (New York: Knopf/Random House, 1976).
} 
members of the middle class "to communicate, to identify, and to serve the interests they shared as leaders of local society." ${ }^{16}$ Focusing on the gendered aspects of this privilege, Davidoff and Hall argue that voluntary associations in Britain "redefined civil society" and created "new arenas of social power," by "increas[ing] the confidence of middle-class men and contribut[ing] to their claims for political power." ${ }^{17}$ The result was "a new era in public life which offered very different opportunities to middle-class men and women."18 It was not just women and the working class who were marginalized by this widespread proclivity to organize. Voluntary associations also served "as conduits for the cultural, social, and economic suppression" of Aboriginal people, African Americans, and immigrants. ${ }^{19}$ To be sure, voluntary societies could also be deployed by those on the margins to address "the material inequalities inherent in the governing social order and the symbols and representations of that authority." 20 For the majority, however, liberal claims to equality and inclusion were routinely subverted by practices of hierarchy and exclusion. ${ }^{21}$

In spite of the breadth of this literature, historians of voluntary associations have had little to say about the numerous and popular sporting clubs that were organized in this period, preferring instead to focus their attention on social reform and political institutions. ${ }^{22}$ This suggests a continued belief amongst mainstream historians

\footnotetext{
${ }^{16}$ Doyle, "Social Functions," 342.

${ }^{17}$ Davidoff and Hall, Family Fortunes, 416.

${ }^{18}$ Davidoff and Hall, Family Fortunes, 416, 419.

${ }^{19} \mathrm{I}$ borrow this phrase from Ferry, Meauures of Common Good, 4.

${ }^{20}$ Ferry, Measures of Common Good, 5.

${ }^{21}$ The thrust of Darren Ferry's Measured of Common Good is that voluntary associations "played a critical role in the cultural, socio-political, and economic processes inherent in the construction of a liberal social order in central Canada during the nineteenth century." Ferry, Mea'ures of Common Good, 8.

${ }^{22}$ Ferry, for instance, focuses his attention on 'Mechanics' Institutes, temperance societies, mutual benefit organizations, agricultural societies, the Dominion Grange and Patrons of Industry, and scientific and literary institutions." Ferry, Meawures of Common Good, 10.
} 
that sport is not worthy of serious scholarly attention, but particularly of socio-political analysis. However, as the following discussion of the American Canoe Association makes clear, sporting organizations and other voluntary associations shared members, structures, and values. ${ }^{23}$ Making explicit this connection enables us to see how middleclass sporting associations did more than provide social opportunities or promote particular leisure pursuits. Rather, they, like other voluntary associations of the period, also advanced a liberal social order, reinforced white male privilege, and contributed to the ongoing marginalization of women, the working class, and racialized minorities within the body politic.

In a number of respects, the ACA was representative of late nineteenth-century sporting clubs and associations. It had a bureaucratized system of governance, it promoted the amateur ideal, and it shared a concern for rational recreation and masculine respectability. It also had a direct link to local sport institutions, counting canoe clubs and occasionally athletic clubs among its constituents. ${ }^{24}$ However, the ACA, as an organization that married interests in sport (canoe racing) and recreation (canoe cruising) at a transnational level also diverged from these other forms of sporting associations in its administrative structure and its interests. ${ }^{25}$ For example, aside from the annual meetings, members rarely met face-to-face; there were none of

\footnotetext{
${ }^{23}$ Membership in multiple associations was by no means uncommon. See, Doyle, "Social Functions," 339. This was true of canoeists as well. Paul E. Vernon is representative in this regard. In addition to being a member of the ACA, he held memberships with the Union League Club of New York, the Garden City Country Club, the Royal Geographical Society, and the Kipling Society. "Paul E. Vernon, 87, Set Up Paper Firm," New York Times, 26 June 1957.

${ }^{24}$ Moreover, as I noted in the introduction, the ACA drew on the success of urban canoe clubs, and also contributed to the same. In the wake of the Association's organization in 1880, canoe clubs popped up rapidly around the northeast in particular, but also in other parts of Canada and the United States.

${ }^{25}$ At least in its early years, the ACA sought to satisfy two different constituencies: cruisers (recreationalists) and racers.
} 
the weekly or bi-weekly meetings common amongst local voluntary organizations. ${ }^{26}$

Moreover, as we shall see, the rotation of the Commodoreship between the different regions that constituted the Association, including Canada, meant that officers were routinely drawn from a variety of locales. As a result, the ACA represented not just one set of local circumstances, but a number of them. ${ }^{27}$ Finally, the ACA, in this period, never had a physical headquarters, although there were occasionally efforts to tether the organization's institutional memory (records) to a particular person (librarian or historian).$^{28}$ While it would be erroneous to claim that the ACA was immune to the intersecting currents of urban social reform and local boosterism that shaped amateur athletic associations, the lack of a permanent institutional home and the nature of its administration tempered local concerns. ${ }^{29}$ The ACA, in other words, while never truly a "national" organization did represent a broad geography of interests. $^{30}$

\section{The Organization}

The inaugural meeting of the American Canoe Association, or the National Canoe Club as it was initially known, took place 3-6 August 1880 on Lake George. Small numbers aside, the meet was deemed a success. ${ }^{31}$ The primary goal of the

\footnotetext{
${ }^{26}$ For a discussion of the temporal rhythms of association life, see Doyle, "Social Functions," 347. ${ }^{27}$ Geographers refer to this phenomenon as "translocalism" or "translocality." See, Katherine Brickell and Ayona Datta, eds., Translocal Geograpbies: Spaces, Places, Connections (Burlington: Ashgate, 2011). ${ }^{28}$ The position of librarian was created in 1890 . However, for much of the decade, this person was responsible for little more than the safekeeping of the Association "flags and racing numbers." In 1901, the Executive Committee passed a resolution that made the librarian responsible for keeping copies of the yearbook, and "accounts of cruises and camps as sent to him, as well as "the loose property of the organization." Francis Johnson Burrage, ed., American Canoe As'ociation Yearbook (n.p., 1902), 8.

${ }^{29}$ Bouchier, Love of the Game, 60. Most sporting clubs were firmly emplaced somewhere. This is even true of the purportedly national Amateur Athletic Association in Montreal.

${ }^{30}$ I return to this question of "national representation" below in my treatment of the challenge posed by the creation of the Western Canoe Association.

${ }^{31}$ The only sense of dissatisfaction that comes through in these reports pertains to the size of the first meeting. Organizers had been estimating there would be more than 100 canoes in attendance. In the
} 
gathering - to establish an American canoeing organization - was achieved on the first day. The ensuing days were devoted to a regatta, which drew spectators from the local community and the lakeside resorts. ${ }^{32}$ Of the $30-40$ canoeists in attendance, most were American, although it was a Canadian, Mr. Wallace, who took first place in two of the races. ${ }^{33}$ In the coming years, the Canadian contingent increased exponentially. ${ }^{34}$ The campers pitched their tents adjacent to Nathaniel Bishop's cottage on the eastern side of Lake George ${ }^{35}$ As would become commonplace at subsequent meets, they passed their evenings by the campfire, where "many a rollicking tale of adventure and many an anecdote" were shared. The meet closed with a dinner catered by local hotelier Francis G. Crosby in the dining room of his resort, "at which ladies were present, and speeches were in order." ${ }^{36}$ Forest and Stream concluded that not only did the gathering bring together "all the leading canoeists of this country and of Canada," it also "furthered an interchange of opinion and increased the range of fraternity and good fellowship amongst the knights of the paddle. ${ }^{37}$

end, between 30 and 40 canoeists took part. "City and Suburban News," New' York Times, 20 May 1880; “The Canoe Convention," New York Times, 17 August 1880.

32 "The Canoe Congress," Forest and Stream, 12 August 1880; "The Canoe Convention," New York Times, 17 August 1880; "The Canoe Congress," Forest and Stream, 26 August 1880.

${ }_{33}$ Jamie Benidickson suggests that Canadian canoeists were occupied with other events at the same time, namely the first regatta of the Amateur Oarsmen's Association, "which involved many of Peterborough's leading paddlers as well as members of the host Argonaut club in Toronto." Jamie Benidickson, Idleness, Water, and a Canoe: Reflections on Paddling for Pleasure (Toronto: University of Toronto Press, 1997), 116.

${ }^{34}$ The ACA remained the umbrella organization for Canadian canoeists until 1900, the year the Canadian Canoe Association was founded. While the number of Canadian members declined after 1900, the Northern Division continues to represent Canadian canoeists within the American Canoe Association to this day. Hoffman, "The History of the American Canoe Association," 47; C. Fred Johnston, 100 Years of Champions: The Canadian Canoe Attociation, 1900-2000 (Kingston: Canadian Canoe Association, 2003).

${ }^{35}$ Apparently, hotelier "Mr. F.G. Crosby very generously placed a portion of his hotel lawn at the disposal of the canoeists, for a free camp ground during that meet." "Cruisers and the American Canoe Association," Forest and Stream, 13 December 1883.

36 "The Canoe Congress," Forest and Stream, 26 August 1880.

37 "The Canoe Congress," Forest and Stream, 12 August 1880. 
The newly minted ACA had all the trappings of a nineteenth-century voluntary association, including a constitution, bylaws, a well-defined and hierarchical administrative structure, and a public character. ${ }^{38}$ The constitution and bylaws, which were published and distributed to members as part of the Association yearbook, covered such diverse topics as the definition of a canoe, the amount of the annual dues, regulations for the design and bearing of club and personal signals (flags), and the timing of the annual meeting. ${ }^{39}$ In the fall of 1880 , a second set of rules was developed to govern racing, and in 1886 , a third set was added to structure and regulate the campsite. ${ }^{40}$ Doyle highlights the significance of these bureaucratic routines, arguing that documents of this type "made [voluntary associations] all the more suitable as schools of group discipline and parliamentary procedure," a point I explore in more depth in Chapter Five. ${ }^{41}$

The hierarchical administrative structure of the ACA echoed both the form and some of the nomenclature of yachting clubs and naval squadrons. ${ }^{42}$ At the helm of the organization was the Commodore, who was assisted by a Vice-Commodore, Rear-

\footnotetext{
${ }^{38} \mathrm{My}$ contention is that all of these organizational accessories were an effort to legitimize the organization as the representative of canoeists in the United States and Canada in the late nineteenth century. As Keith Walden notes, "In an economy that put increasing emphasis on managerial and technical expertise, an intensification of formal accreditation was not surprising, but it also served desires for social exclusivity." Keith Walden, Becoming Modern in Toronto: The Industrial Exbibition and the Shaping of a Late Victorian Culture (Toronto: University of Toronto Press, 1997), 24.

${ }^{39}$ Doyle argues that most voluntary associations in the nineteenth century were "rigorously structured by a whole set of specific rules covering everything from the election of officers to the dissolution of the organization." Doyle, "Social Functions," 350. Likewise, the ACA's constitution and bylaws were constantly being enlarged and adjusted to reflect new challenges facing the administration.

${ }^{40}$ St. Lawrence County Historical Association (SLCHA), Camp Circular for Grindstone Island, 1886.

${ }^{41}$ Doyle, "Social Functions," 350.

${ }^{42}$ The nascent organization also derived inspiration from other canoeing institutions, such as the Royal Canoe Club in London (1865) and the New York Canoe Club (1871), which were themselves variously inspired by yachting clubs, naval brigades, sporting clubs, and athletic associations. C. Bowyer Vaux, "History of American Canoeing, Part I," Outing 10, no. 3 (1887): 262; W.P. Stephens, Traditions and Memories of American Yacthing: The 50tb Anniversary Edition (Brooklin: Wooden Boat Publications, Inc., 1989), 96; Mystic Seaport Collections and Research Centre (hereafter MSCRC), Collection 291, Volume 2, Meeting Minutes of the Association, 12 August 1881.
} 
Commodore, and Secretary-Treasurer ${ }^{43}$ These positions, like membership more broadly, were open to canoeists from Canada and the United States. ${ }^{44}$ The roles and responsibilities of the officers were clearly delineated in the constitution and by-laws.

The Commodore, for example, was expected

To preside at the annual meetings of the Association and the [Executive Committee]; to attend the ACA Camp, and to make all preliminary arrangements for the same; to examine and certify for payment all bills presented to the Treasurer; to arrange for the dates of the Division Meets according to Article III...; to visit, if practicable, each of the Division Meets during the year, and to see that all rules and regulations are properly enforced; to pass upon appeals from the decision of ViceCommodores; and he shall have the power to pass on qualification of names whenever published for membership in the official organs. ${ }^{45}$

Practically speaking, the most important role was that of the Secretary-Treasurer, who was responsible for the organization's finances, membership rolls, and the publication of the yearbook. This importance is underscored by the fact that the position of Secretary-Treasurer was the only one with an honorarium, a generous yearly allowance of $\$ 150 .{ }^{46}$ However, election to any office heightened one's status within the Association, and could be used to strength social position outside of the organization as well. ${ }^{47}$

The structural organization of the ACA changed somewhat in the mid-1880s with the establishment of divisions, which separated the membership into smaller units

\footnotetext{
${ }^{43}$ Positions lasted for one term. Although nothing prevented the incumbent from running for a second term, this was not commonplace. That said, a number of the men who were elected Commodore had previously held other officers within the organization. See the "Appendix B: Officers of the ACA, 18801960," in Hoffman, "American Canoe Association," 169-72.

${ }_{44}$ Canadians held the Commodoreship seven times between 1881 and 1910.

${ }^{45} \mathrm{Mix}$, American Canoe Association Yearbook, 47.

${ }^{46}$ The organization instituted the honorarium in 1883. MSCRC, Collection 291, Volume 2, Minutes of the Annual Meeting, 23 August 1883.

${ }^{47}$ Doyle makes a similar argument about voluntary organizations in Jacksonville, lowa in the nineteenth century. Doyle, "Social Functions," 336.
} 
based on geographical location..$^{48}$ Broadly speaking, the re-structuring was for "the convenience of government. ${ }^{\text {"49 }}$ Not only had the organization's membership base expanded rapidly, but there was also a growing realization that it was impractical for most canoeists to attend the annual meet. Divisions, thus, were intended to provide a more local experience-each division was expected to host an annual meet much like the yearly ACA gathering - while also offloading some of the administrative work such as membership applications and the payment of dues. ${ }^{50} \mathrm{~A}$ second motivation appears to have been the growing interest in canoeing in the west in the mid-1880s, but specifically the organization of the Western Canoe Association in 1885 by a group of paddlers that did not feel amply represented by the ACA. ${ }^{51}$ One might read the introduction of divisions as an attempt to entice the WCA into joining the ACA. ${ }^{52}$ One canoeist, for example, opined that the Association was "remodeled on a Federal basis to prevent any more secessions. ${ }^{.53}$ Certainly the WCA's existence undermined the

\footnotetext{
${ }^{48}$ There were five divisions created between 1880 and 1914: the Eastern Division (1886), which included Maine, Vermont, New Hampshire, Rhode Island, Massachusetts, and Connecticut; the Central Division (1886), which included the rest of the United States not covered by the other divisions; the Northern Division (1887), which covered all of Canada; the Atlantic Division (1888), which "was located to include the lower Hudson, Delaware, Susquehanna and Potomac, or the watershed of the Eastern Alleghanies"; and the Western Division (1898), which included the states of Ohio, Indiana, Illinois, Iowa, Michigan, Wisconsin, and Minnesota. See, American Canoeitt (April 1887); W.H.B. McClelland, ed., American Canoe Association Yearbook (n.p., 1916), 30.

49 "Canoe Camp at Muskoka Lake," Rocbester Democrat Cbronicle, 30 July 1900.

${ }^{50}$ Discussions of more localized events were appearing in the official organs as early as 1883 . A note in Forest and Stream opined that "while the great event of the canoeing year will of course be the meet of the Association attended by four or five hundred canoeists, there is still room for the holding of smaller local meets earlier in the season, which would bring together neighbouring clubs, promoting both good feeling and competition among their members, and giving a couple of days' holiday to many who have not time for the ACA meet." "Local Canoe Meets," Forest and Stream, 1 November 1883. See also, Marilyn R. Linton, The Ballast Itland Cbronicles: A Hustory of the Western Canoe Astociation and ILYA Beginnings (Linwood: M.R. Linton, 1994).

${ }^{51}$ C. Bowyer Vaux, "History of American Canoeing, Part III," Outing 10, no. 5 (1887): 408.

${ }^{52}$ This contradicts somewhat Ronald Hoffman's argument that divisions were formed solely to better meet the needs of members. See, Hoffman, "American Canoe Association," 29; MSCRC, Collection 291, Volume 3, Minutes of the Annual Meeting, 7 August 1885, and Meeting of the Executive Committee, 22 August 1886, 27 August 1886, 12 February 1887.

${ }^{53}$ Retaw, Fragmente from the '88 Meet (Montreal, 1888), 8.
} 
ACA's claim to be the representative national body for canoeing enthusiasts. However, much as in federal Canadian politics, there was more interest in this idea from those in the east than from the western canoeists. ${ }^{54}$ It was fourteen years before the Western Canoe Association agreed to join the ACA.

The re-organization of the Association created new administrative positions. While the ACA as a whole remained under the watchful eye of the Commodore and Secretary-Treasurer, each division now elected a Vice-Commodore, Rear-Commodore, and Purser. ${ }^{55}$ The Commodore, Secretary-Treasurer, and representatives from each of the divisions (usually the Vice-Commodore) formed the Executive Committee. ${ }^{56}$ Additional efforts to represent the various constituents of the organization included rotating the Commodoreship and location of the annual meeting between the divisions, although a division could (and did) waive the right to one or both of these privileges. ${ }^{57}$ Although the structural changes were intended to improve the government of the $\mathrm{ACA}$, the introduction of divisions also limited the democratic tenor of the organization. From 1886 onwards, it was not the membership that elected the

\footnotetext{
${ }^{54}$ Roger Gibbins and Loleen Berdahl, "The Roots of Western Alienation," in Weutern Visions, Western Futures: Perspectives on the West in Canada, $2^{\text {nd }}$ ed. (Toronto: University of Toronto Press, 2003), 24-65. ${ }_{55}^{5}$ For all intents and purposes, the Vice Commodore served as the Commodore of his respective division, while the Rear Commodore was his understudy. The purser was the division secretarytreasurer. The Commodore and Secretary were "elected by the Executive Meeting at the camp or a subsequent meeting of that committee," while the Vice and Rear Commodores and pursers were elected by their respective divisional associations. See Mix, American Canoe Avsociation Yearbook, 47-8.

${ }_{56}$ Representation was proportional; divisions were allowed one representative for every 100 members. MSCRC, Collection 291, Volume 3, Meeting of the Executive Committee, 12 February 1887. ${ }^{57}$ MSCRC, Collection 291, Volume 3, Meeting of the Enecutive Committee, 25 August 1887. Before this, there appears to have been an informal practice of electing Commodores from each of the regions in turn. The first four Commodores were from New York (later the Atlantic Division), Cincinnati (later the Western Division), Peterborough (later the Northern Division), and Springfield, MA (later the Eastern Division). Vaux, "American Canoeing, Part III," 396.
} 
Association officers, but the Executive Committee.$^{58}$ The affairs of the majority were now squarely in the hands of a minority, much as in a corporation. ${ }^{59}$

Further administrative change came in 1893 with the creation of a Board of Governors. ${ }^{60}$ The Board, a body charged with overseeing the organization's finances and encouraging fiscal accountability, was but one aspect of the "public character" or "publicity" of the American Canoe Association. ${ }^{61}$ "Public character," the property of being "open and visible to all," was a key feature of middle-class voluntary associations in the nineteenth century ${ }^{62}$ As Davidoff and Hall note, "[m]eetings announced in newspapers, formal constitutions with named patrons and committees, accounts which were published...were the hall-marks of [these] societies," and the ACA was no different. The dates, times, and locations of the annual meetings were publicized in the club's official organs, ${ }^{63}$ as well as in the pages of periodicals across the country. ${ }^{64}$ Minutes were taken at meetings and, as early as 1887, were printed in the Yearbook, and usually in the pages of the official organs as well. The organization's accounts were

\footnotetext{
58 "Canoeing," New' York Sun, 19 August 1897.

${ }^{59}$ Alan Trachtenberg, The Incorporation of America: Culture and Society in the Gilded Age (New York: Hill and Wang, 1982).

60 "Canoeists Adopt a New Policy," New York Times, 5 November 1893. According to Robert J. Wilkin, president of the board of governors for eighteen years, prior to 1894, the ACA was always in debt, so the organization decided to place its financial affairs in the hands of a permanent board of governors, similar to an executive board in a business. In addition to controlling money coming into and going out of the organization, the Board of Governors arranged for yearly audits of the ACA finances. MSCRC, Collection 291, Box 1, Folder 1, Letter from Robert Wilkin to Walwin Barr, 1 September 1926.

${ }^{61}$ Public character is the term used by Davidoff and Hall in Family Fortunet. Patrick Joyce employs publicity in The Rule of Freedom: Liberalism and the Modern City (London: Verso, 2003), pastim.

${ }^{62}$ Davidoff and Hall, Family Fortunes, 419.

${ }^{63}$ From 1882-87, members of the ACA oversaw their own periodical, American Canoeit. Forest and Stream also served as an official organ for much of the $1880 \mathrm{~s}$ and $1890 \mathrm{~s}$. Other periodicals that were designated an official organ between 1880 and 1910, in some cases, only for a year, included Sail and Padzle, Rudder, Atbletic Life, Sail and Sweep, Canoeing, and Fore 'N'Aft. Periodicals such as these provided public forums for the members to praise the organization, to offer suggestions for the meets and regattas, but also to air their grievances. They also contributed to a sense of community amongst the readers. Valerie Korinek makes a similar argument about Chatelaine magazine in Rougbing It in the Suburbs: Reading Chatelaine Magazine in the Fifties and Sixties (Toronto: University of Toronto Press, 2000), 9.

${ }^{64}$ The 1901 election results, for example, were published in the St. Paul Globe, 26 August 1901.
} 
made public through similar means. Further to this, the ACA employed "experts," such as accountants to audit their financial accounts and assess their dealings. ${ }^{65}$ Public character was not just claimed by the leadership, it was also expected by the membership. Consider the following petition submitted to the Executive Committee in 1890 regarding a change in sail rules: "In our opinion the passage, without due publicity, of any rule that antagonizes a considerable number tends to destroy the confidence that has always been placed in the executive committee. ${ }^{n 66}$ On the one hand, publicity, but particularly the publication of the names of elected officers, reinforced the social status of individual members. ${ }^{67}$ On the other hand, this supposed transparency, a trope of liberal political culture, was yet another way in which the organization legitimized its existence and shored up claims to power and influence. “Political legibility," Patrick Joyce argues, "was the condition for the true practice of freedom, for only when all were visible to each, and each to all, could freedom between properly practiced." ${ }^{168}$ As we will see, however, claims to transparency were often little more than that, claims.

The Association's membership rosters were consistent with other voluntary associations in the late nineteenth century. Membership in the ACA was ostensibly

\footnotetext{
${ }^{65}$ The Auditing Committee was appointed in 1885 at the request of Secretary Neide. However, an audit was not conducted in 1885 because the first committee "had not found time." The inaugural audit in 1886 highlighted concerns about the "extremely crude and confused manner in which the accounts [had] been kept." The committee recommended the position of Secretary-Treasurer be filled "by such members as are known to be methodical in business and books." They also suggested that the constitution should be amended such that the accounts would be audited annually and the membership should have free access to the books of the association. "The Executive Committee Meeting," Forest and Stream, 18 November 1886; Forest and Stream, 23 January 1887.

66 "ACA Executive Committee Meeting," Forest and Stream, 20 November 1890. Emphasis added.

${ }^{67}$ Doyle, "Social Functions," 338. "Club membership," according to Amy-Milne Smith, "was one of the visible markers of social identity for men." Amy-Milne Smith, London Clubland: A Cultural History of Gender and Clavs in Late Victorian Britain (New York: Palgrave Macmillan, 2011), 38.

${ }^{68}$ Freedom, as I discuss in Chapter Five, was an important strategy of rule in the late nineteenth century that was adopted by the ACA. Joyce, The Rule of Freedom, 100.
} 
open to "[a]ll persons of respectable character, of any age, who possess a true love of Nature, and are in earnest sympathy with the brotherhood of cruising Canoeists, whether owners of canoes or not." ${ }^{19}$ However, like the amateur athletic associations studied by Nancy Bouchier, the ACA "excluded by design." ${ }^{\text {"70 }}$ For example, one had to be able to afford the initiation fee of one dollar and yearly dues of the same amount to hold membership in the Association..$^{71}$ Although this was a pittance compared to fees charged at other boating and sport clubs in the period - the organization boasted that "the man of little pecuniary means can join us as well as the merchant prince" ${ }^{" 72}$ - it would have represented a day's pay to unskilled manual labourers. ${ }^{73}$ Perhaps more importantly, the Association appeared to offer little to its members beyond an "official" place in the imagined community of canoeists and the opportunity to attend the yearly meets. The latter required at least a week's holiday, the means to travel a great distance, and additional fees, which would have further encouraged those with limited incomes to self-select. $^{74}$

The membership process provided another opportunity to police the boundaries of the Association. ${ }^{75}$ Prospective members had to submit applications to the

\footnotetext{
69 That said, only those who owned canoes could vote at the association meetings or hold office. MSCRC, Collection 291, Box 10, Folder 11, Constitution and By-Law, 1 November 1880.

${ }^{70}$ Bouchier, Love of the Game, 73.

${ }^{71}$ After 1885, annual dues were \$2. "The Association Meet, Regatta Week," Forest and Stream, 13 August 1885; MSCRC. Volume 3, Meeting of the Executive Committee, 7 November 1885.

72 "The Association Book," Forest and Stream, 21 April 1881.

${ }^{73}$ By contrast, in 1880, the Narragansett Boat Club in Providence, Rhode Island charged an entrance fee of five dollars and an annual fee of twenty dollars. Gilkeson, Middle-Class Providence, 142.

${ }^{74}$ The Watertown Daily Times estimated that a trip to the encampment in 1901 could be made for $\$ 30$, and would likely be less than $\$ 50$ for two weeks, including rail fare from New York or Boston. "Preparing for the Canoe Camp," Watertown Daily Times, 6 August 1901. There is also the matter of canoe ownership. Although it was not necessary to have a canoe to attend an encampment, it was certainly encouraged.

${ }^{75}$ Amy Milne-Smith explores in detail the process of election to elite clubs in London in the same period. She demonstrates how elections were at once a private and a public process even within the most
} 
Executive Committee accompanied by a recommendation from a member in good standing, a requirement that reinforced existing social networks. ${ }^{76}$ Following the advertisement of the candidate's name in the official organs of the Association, a practice that allowed the membership to offer feedback, the Executive Committee voted on applications where a three-fifths majority was required for acceptance. ${ }^{77}$ While I have found few instances in which an application for membership was rejected, an example from 1889 is telling. ${ }^{78}$ This case survives because the applicant, Mr. Haag, appealed the Association's decision. According to the meeting minutes of the Executive Committee, Haag was rejected because he was "not a proper person" with neither "the education [nor] the manners of a gentlemen." ${ }^{\prime 79}$ As a result of the appeal, Commodore, Col. H.C. Rogers of Peterborough, Ontario reviewed his case. Concerned that the claims made by the members who had effectively blackballed $\mathrm{Mr}$. Haag were without merit, Rogers gave this group the opportunity to produce evidence to support their allegations. ${ }^{80}$ However, they only re-iterated their initial position and

exclusive and closed clubs of late nineteenth-century London. See, Milne-Smith, "The Black Ball: Looking for the 'Right Sort' of Member," in London Clubland, 35-58.

${ }^{76}$ There are no extant membership applications in the ACA archive, so it is unclear what information the organization asked of applicants.

${ }_{77}$ This is actually relatively low. In some cases in the clubs described by Amy Milne-Smith, a single blackball could kill a membership application.

${ }^{78} \mathrm{I}$ also found mention of a letter being submitted by an unnamed member at an Executive Committee meeting citing "charges of unbecoming conduct against two other members," also unnamed. The issue was read and discussed at the meeting. However, "as the evidence on both sides was not before the committee no action was taken." "The ACA Meet of 1891: Race Week," Forest and Stream, 27 August 1891.

${ }^{79}$ MSCRC, Collection 291, Volume 3, Meeting of the Enxecutive Committee, 23 November 1889. MilneSmith makes clear that social status was of the utmost importance in gaining entrance to a club. However, "an equally important qualification" was "sociability and amiability," because the "type of men who joined determined the character of the club." Milne-Smith, London Clubland, 43-4.

${ }^{80}$ Blackballing was a common practice in social clubs. Amy Milne-Smith argues, "The use of the blackball to declare that a prospective candidate was not worthy of membership in one's society was particularly powerful." Furthermore, "members wielded the black ball for any number of reasons from the trivial to the personal," with politics being a particularly important motivation. Amy Milne-Smith, "Club Talk: Gossip, Masculinity and Oral Communities in Late Nineteenth-Century London," Gender and Huttory 21, no. 1 (2009): 92; Milne-Smith, London Clubland, 46. 
made it clear they were members in good standing. Commodore Rogers responded with the following decision, which appears comparatively generous and inclusive:

I do not wish to offer an interpretation of the word gentleman in Art. III of the constitution, although it certainly means more than male person, and I should be sorry to be the means of admitting to membership in the Association anyone who in thought and in deed did not come within the proper meaning of the term. There may be matters of personal feeling or questions as to social position, which would render it unpleasant for one man to associate with another in the close relationship of a club, but it is one of the advantages of the Association that it is broad enough and strong enough to find a place for men from all parts of the continent, in all ranks, and condition of life, only requiring from its members that they shall be gentlemen in spirit and in conduct. ${ }^{81}$

Haag's case reveals that the term "gentleman" was not merely a substitute for men, but was also informed by ideas of respectability, which as postcolonial historians have made clear, was a deeply classed and racialized ideal. ${ }^{82}$ While Rogers seems to suggest that one could perform this identity, the rest of the Executive Committee appears unconvinced; they ultimately rejected the Commodore's decision. One of the characteristics of the Victorian liberalism described by Patrick Joyce was that it gave the appearance of fairness and objectivity, what Joyce calls the "ethics of governance," but remained influenced by partisan behaviour and in some cases, petty interpersonal feelings. ${ }^{83}$

As a result of such practices, the vast majority of the organization's membership, and thus those in attendance at the annual encampments, were of the middling classes, numbering in their ranks doctors, clergy, lawyers, publishers, and

${ }^{81}$ MSCRC, Collection 291, Volume 3, Meeting of the Executive Committee, 23 November 1889.

${ }^{82}$ See Ann Laura Stoler, "Making Empire Respectable: The Politics of Race and Sexual Morality in Twentieth-Century Colonial Cultures," Cultural Politice' 11 (1997): 344-73; Adele Perry, On the Edge of Empire: Gender, Race, and the Making of Britub Columbia (Toronto: University of Toronto Press, 2001).

${ }^{83}$ See "Chapter 3: The Light of Publicity," in Joyce, The Rule of Freedom, 98-143. 
businessmen.$^{84}$ They were also predominantly men. ${ }^{85}$ Although the initial constitution did not address the question of women members, sport and outdoor recreation remained a largely, although not exclusively, male domain in $1880 .{ }^{86}$ The reference to the "brotherhood of cruising Canoeists" that appeared in the Constitution would have also signalled to women their place (or lack thereof) in the organization. ${ }^{87}$ Nevertheless, women appear to have been interested in joining, for in 1882 an honorary member category was added to the constitution. ${ }^{88}$ This change allowed women to claim membership in the Association and to attend the annual meetings. The terms of their admission, however, underscored women's lesser status. ${ }^{89}$ First, as in contemporary politics, women were prevented from voting or holding office. ${ }^{90}$ As the

\footnotetext{
${ }^{84}$ As the Association's membership lists do not include occupations, it is difficult to determine the exact class background of the various members. However, a random sample of members suggests that most, particularly those who remained involved with the association over a long period of time, were middle class. More prominent members, including the officers, were of the upper reaches of this class. ${ }^{85}$ Here again, there is a precedent in associational culture more broadly. See Lynn Marks, "Mostly Male Worlds: Leisure and Associational Life," in Revivale and Roller Rinks: Religion, Leisure, and Identity in LateNineteentb-Century Small-Town Ontario (Toronto: University of Toronto Press, 1997), 107-39.

${ }^{86}$ See Patricia Vertinsky, The Eternally Wounded Woman: Women, Doctors, and Exercive in the Late Nineteenth Century (Toronto: St. Martin's Press, 1990); Allen Guttmann, Women's Sports: A Hittory (New York: Columbia University Press, 1991); M. Ann Hall, The Girl and the Game: A History of Women's Sport in Canada (Peterborough: Broadview Press, 2002); Andrea L. Smalley, “'Our Lady Sportsmen': Gender, Class, and Conservation in Sport Hunting Magazines, 1873-1920," Journal of the Gilded Age and Progrewive Era 4, no. 4 (2005): 355-80. Smalley's article provides a useful counterpoint to the argument that outdoor recreation, but particularly hunting, was a uniquely masculine pursuit.

${ }^{87}$ This contrasts with the fact that N.H. Bishop, on a number of occasions early in the organization's history, extended membership freely to women. For example, he included the following line in a letter to the editor of Forest and Stream: "All persons can become members - if they possess the spirit and aims of a true canoeist - whether they own a canoe or not. Ladies, as well as young men, can become members." "American Canoe Association," Forest and Stream, 16 September 1880.

${ }^{88}$ Honorary in this case denotes second-class status, although there were honorary memberships also granted to persons of esteem. Many of the first women honorary members were the wives or sisters of full members, although this did not preclude them from being canoeists in their own right. Not only did the regulations stipulate that they had to be "practical canoeists," but six of the eight had canoes listed beside their name. American Canoe Astociation Book, 3.

${ }^{89}$ Darren Ferry notes that "initial attempts to incorporate women and ethnic minorities within voluntary associations were extremely problematic, for despite encouraging the indirect participation of women, men of colour and natives, voluntary associations clearly resisted their participation as equals." Ferry, Measures of Common Good, 16. Ferry's work, in other words, provides an important contrast to McNairn's depiction of voluntary organizations as spaces of inclusive, deliberative democracy.

${ }^{90}$ Women did not receive the right to vote or hold office at the federal level in Canada until 1918 and 1920 respectively. At the provincial level, such rights were granted anywhere between 1916 in the case
} 
organization did not provide an explicit rationale for this decision, we can presume it was considered self-evident that women were not suited to such tasks. Second, whereas male applicants only needed a three-fifths majority for entry into the ACA, women required unanimous support from the Executive Committee. ${ }^{91}$ Third, the constitution allowed for the list of women members to be "revised at any time," effectively enabling the Executive Committee to strike women from the membership rolls at will. ${ }^{92}$ That a similar clause did not exist for male members points to the vulnerability of women's position in the organization. Finally, at the same time that women were officially granted honorary membership status, the membership clause in the constitution was amended so that the word "gentleman" replaced "person," thus entrenching full membership as male. ${ }^{93}$ It was only in 1944 that the Association extended full membership to women. As shall become clear in the chapters that follow, although women were accorded a lesser status in the organization, they were no less enthusiastic canoeists. To borrow from Pauline Johnson, who attended a handful of encampments in the 1890 s, ACA women, "like time or tide... wait for no man, but are as independent, fearless and tanned as any boy in camp." 94

of Manitoba and 1940 in the case of Quebec. However, women in many provinces could vote for school trustees and municipal politicians by 1900 . In the United States, women were granted federal suffrage in 1920. Heather Mclvor, Women and Politico in Canada (Peterborough: Broadview Press, 1996), 86, 77, and Alexander Keyssar, The Right to Vote: The Contested History of Democracy in the United States (New York: Basic Books, 2009), 175.

${ }^{91}$ Again, I have only been able to find one instance where women who had put their names forward for membership were not elected. At a 1908 meeting of the Executive Committee, a motion was carried that "The applications of Miss Addies Rodenstein and Miss Etta K. Thomas for associate membership be laid on the table indefinitely by reason of their ineligibility," although what was meant by ineligibility went unspoken. MSCRC, Collection 291, Volume 4, Meeting of the Executive Committee, 15 August 1908.

${ }_{92}$ Wright, American Canoe Avosiation Yearbook, 7.

${ }^{93}$ MSCRC, Collection 291, Volume 3, Reports of the Annual Meeting, 1884.

${ }^{94}$ Pauline Johnson, "Canoe and Canvas: The A.C.A. Meets in Canadian Waters," Saturday Nigbt, 2 September 1893. 
In addition to being middle class and male, the vast majority of the membership was of Euro-American or -Canadian descent. The notable exception was the aforementioned "Indian poetess," Pauline Johnson, who became an honorary member in $1893 .{ }^{95}$ However, while the annual meeting was racialized as white, it was anything but. Rather, as I explore in more detail in Chapter Nine, the events featured the Aboriginal canoeists who performed for visitors at the 1880 and 1881 meets, the "Coon Band" who entertained campers at the 1890 meet on Long Island, and the AfricanAmerican and French-Canadian men who served as cooks and valets on an ongoing basis. ${ }^{96}$

Finally, a word on age, for the encampments did not feature uniformly individuals from across the generational spectrum. Early descriptions of the encampments emphasized the generational diversity of the Association. For example, the Lowell Daily Courier reassured older canoeists in 1882: "It may be said that [while] canoeing is a manly, invigorating pastime," it is not "by any means monopolized by boys or young men." Rather, the ACA "embraces among its members men of all ages and even ladies. ${ }^{97}$ In practice, most members of the ACA and most campers at the annual meetings were between the ages of 18 and 40, with a smaller constituency of older canoeists. ${ }^{98}$ Children were not absent from the encampments, but particularly in

${ }^{95}$ MSCRC, Collection 291, Volume 3, Meeting of the Executive Committee, 4 November 1893.

${ }^{96}$ See, for example, "The Canoe Congress," Forest and Stream, 22 January 1880; "The Second Day of the Regatta," New York Times, 13 August 1881; S.R. Stoddard, Glimpses of the ACA (Glens Falls, 1890); O.K. Chobee, "Echoes from Stony Lake," The American Canoewt 2, no. 8 (1883): 114; New York State Historical Association (hereafter NYSHA), 1.1/25, "The Sneak-Box Mess: Camp of the Brooklyn Canoe Club," 1887.

97 "About Canoeing," Lowell Daily Courier, 11 May 1882.

${ }^{98}$ Of the 1881 meet, the New York Times reported, "The party is made up of young men and old. There are some youngsters here who are no more than boys, and a nice, manly set of fellows they are, with browned cheeks and arms... There are, too, a number of men whose hair is gray, and they give a happy balance to keep everything moving smoothly." "The Canoe Island Camp," New York Times, 13 August 
the 1880 s and 1890 s, their numbers were limited and they received minimal attention in accounts of the meets. ${ }^{99}$ This changed in the first decades of the twentieth century, as the annual meetings became more clearly family camps. In other words, the early encampments of the ACA, unlike camping more broadly in the late nineteenth century, were not "child-centred experiences."100

The American Canoe Association was largely typical of late nineteenth-century sporting institutions and voluntary organizations. It bore many of the hallmarks of associational life, including rigid rules, a clearly defined hierarchy, and a commitment to respectability. It also served the interests of a narrow portion of the populationwhite, middle-class men — reinforcing their social and political privilege. The ACA through its performance of liberal governance and its exclusivity played a role in constructing the liberal social order in Canada and the United States. This was the same liberal social order that sought to limit the "Other," by restricting women's place in society, expunging Aboriginal people and culture, suppressing the activities of an increasingly and rightfully militant working class, and marginalizing new immigrants. ${ }^{101}$ It was in the yearly encampments that the organization, constituted through these bureaucratic practices, was materialized, by which I mean that the imagined community of canoeists, including its hierarchical structures of authority,

1881. In 1886, the Watertown Herald reported that the "young element...constitutes a majority." "Paddle Your Own Canoe," Watertown Herald, 10 July 1886.

${ }^{99}$ Children receive mention in the following print sources: "Canoeists' Enjoyable Time," Daily Mail and Empire, 9 August 1900; "Opening of the A.C.A. Meet," Boating 2 (1906): 318. They are occasionally visible in photographs of the meets. See, for example, Stoddard, Glimptes of the ACA; "Bathing Beach at Grindstone," in American Canoe Avsociation Yearbook, ed. John R. Blake (Toronto: Bryant Press, 1897), 49; "Camp Group, Hay Island, 1899," in American Canoe Association Yearbook, ed. Herb Begg (New York City: Forest and Stream Publishing, 1900), insert between 46 and 47.

100 J.I. Little, "Life without Conventionality: American Social Reformers as Summer Campers on Lake Memphremagog, Quebec, 1878-1905," Journal of the Gilded Age and the Progresuive Era 9, no. 3 (2010): 299. ${ }^{101}$ Here I am borrowing language if not a theoretical sensibility from Ferry, Measures of Common Good, and Ian McKay, "The Liberal Order Framework: A Prospectus for a Reconnaissance of Canadian History," Canadian Historical Review 81, no. 4 (2000): 617-45. 
became visible to its constituents. In the section that follows, we turn our attention to the preparations necessary for bringing these annual events to fruition.

\section{Part II - Preparing (for) the Encampments and Regattas}

Instead of a small scouting party, self-contained and independent, we bave an army to provide for, and must bave some system, a place prepared in advance, a definite source of supplies, drinking water, sanitary arrangements, transport for a large number of boats and more or less baggage, that rob the meet of its free and extempore cbaracter. ${ }^{102}$

Official preparations for the inaugural encampment on Lake George were relatively limited. Most of Nathaniel Bishop's time was likely spent advertising the meeting, drawing up a regatta programme, and arranging a tent site. By 1910 , the organization of the meet was undertaken by five committees, each headed by a chairman, and consisting of between three and five members. The expansion in the organizational bureaucracy was partly an artifact of those years in the late 1880s and early 1890 s when the encampments drew hundreds of campers. However, it was also a product of the 1883 meet at Stony Lake. Perhaps in an effort to attract visitors from far-flung places, and to keep them comfortable and occupied for two weeks rather than four days, Commodore E.B. Edwards introduced a number of conveniences. ${ }^{103}$ Amongst other things, he set up a camp store and arranged for local farmers to stock it, and he organized steamer transportation from the nearest railway terminus to Juniper Island and built a wharf to accommodate the large boats. In the same period, the

102 "Local Canoe Meets," Forest and Stream, 1 November 1883.

${ }^{103}$ When Edwards fell sick during the encampment, the local paper posited, "He is so zealous in his efforts to make the camp a success that he has probably overexerted himself." "ACA Annual Meeting," Peterborough Daily Review, 14 August 1883. Cecilia Morgan suggests that this obsession with being wellprepared "might be linked to middle-class eagerness for efficiency, made more urgent by a sense of the quickening pace of modernity." Cecilia Morgan, 'A Happy Holiday': Englist Canadiant and Transatlantic Tourism (Toronto: University of Toronto Press, 2008), 25. 
campers' preparations largely decreased. This was the result of an expansion in transportation services, the move to a permanent encampment, and the organization's decision to rent tents, floors, and cots and blankets to campers.

For much of this period, official preparations included appointing an organizing committee, choosing a location, conducting "improvements" on the site, developing a programme for the encampment and regatta, arranging for transportation and food service, and communicating with the prospective visitors. For the canoeists, getting ready for the annual meeting might involve arranging their travel and kit, familiarizing themselves with their destination, and training for races. My discussion of these preparatory practices will be necessarily brief as I explore each of them in more detail in later chapters. However, I bring them together here to highlight the ways in which the meet was not confined to two weeks in August, but was part of a longer temporal rhythm in the canoeists' lives.

Much of the work of preparing the encampments was conducted not by the Association's brass, but by a separate organizing committee(s) appointed at the fall meeting of the Executive Committee. Initially comprised of three members, at least one of whom was local to the encampment site, the organizing committee eventually expanded to include subcommittees devoted to the camp site, regatta, transportation, ladies' camp, and entertainment and music. ${ }^{104}$ It was only with the creation of the Ladies' Camp Committee in 1898 that women were formally involved in the organization of the annual encampment, although the committee chair was always a

\footnotetext{
${ }^{104}$ For the sake of clarity, I will refer to these different subcommittees collectively as the organizing committee or committees, unless I wish to highlight a specific arm.
} 
man. ${ }^{105}$ Most of these committees had members from both sides of the border, yet another attempt to represent the interests of the broader membership and further evidence of the organization's transnational character. ${ }^{106}$

The committee's first official order of business was to choose a campsite. Committees, as I detail in Chapter Three, were inclined towards spaces that embodied romantic aesthetics, while also offering the canoeists a certain range of amenities, including transportation routes and supply chains. The designation of a site was typically performed in the fall, although occasionally it was delayed until the winter. The winter months were more commonly devoted to the surveying of the designated campsite and racecourses, and the acquisition and storage of ice. The latter usually received cursory treatment in accounts of the meetings likely because of its quotidian nature. ${ }^{107}$ Nevertheless, it underscores the dependence that the canoeists had on natural processes such as freeze/thaw. ${ }^{108}$ The practices of surveying, by contrast, received more attention, were celebrated even, likely because as symbols of scientific rationality they underlined the organization's "modern" character. ${ }^{109}$ A note from an

${ }^{105}$ C.V. Schulyer, ed., American Canoe Astociation Yearbook (n.p., 1898), 2.

${ }^{106}$ For example, the organizing/regatta committee for the 1883 regatta at Stony Lake was drawn from Peterborough (Commodore E.B. Edwards, H.T. Strickland), Toronto (Robert Tyson), and New York (William Whitlock). American Canoe Awociation Book, 3.

${ }^{107}$ In 1883, for example, the organizing committee reported, "We have had an icehouse built on the first island and 250 blocks of eighteen-inch ice laid in." "The American Canoe Association in Canada," Forest and Siream, 19 April 1883.

${ }^{108}$ The organizers were also constrained by seasonality in ways that would no longer hold true with the spread of refrigeration technology. See, Lee A. Craig and Matthew T. Holt, "Mechanical Refrigeration, Seasonality, and the Hog-Corn Cycle in the United States, 1870-1940," Explorations in Economic History 45, no. 1 (2008): 30-50. Even with a stocked icehouse, the encampment relied on local farms, in particular, to provide fresh produce. This would lessen over the course of this period, as the organizers tapped into regional supply routes to acquire perishable items. Any breakdown of these routes was borne out in the quality of food on the mess tent table. The 1890 encampment, for instance, was dependent on fresh meat brought from New York. When the boats could not make the journey because of weather, the menu suffered. "The ACA Meet of 1890-II," Forest and Stream, 6 November 1890.

${ }^{109}$ James C. Scott, Seeing Like a State: How Certain Scbemes to Improve the Human Condition Have Failed (New Haven: Yale University Press, 1998); Timothy Mitchell, The Rule of Expertu: Egypt, Tecbno-politicu,

Modernity (Berkley: University of California Press, 2002). 
1891 Regatta Committee Report stresses the importance of the survey to the ACA's reputation: "As the ACA is the head and front of canoeing in this country its record of performance should be in every way standard. That this may be assured it is recommended that the courses, especially the paddling courses be accurately surveyed and the surveying attested." 110

The best account of surveying survives from the Stony Lake meet. ${ }^{111}$ In March 1883, the Canadian members of the committee, E.B. Edwards and Robert Tyson, along with Provincial Land Surveyor James W. Fitzgerald travelled north from Peterborough in a sleigh captained by Joe Vasseur, "a shrewd, good-humored French Canadian, and an excellent teamster." The group also included three local farmers, Mr. McCracken, Mr. Crow, and Crow's son, Willie, who likely served as axe and chainmen for Fitzgerald. ${ }^{112}$ With late winter still all around them, they moved between the snow-covered islands and frozen water of Stony Lake using the compass and chains to take bearings and measurements, and mark off distances. These practices, which made the island and its environs visible and knowable to the organizing committee, enabled Fitzgerald to produce maps of the encampment and racecourses that were later circulated to potential visitors. ${ }^{113}$ In doing so, the organizers were following the very same formula that the government and local land companies had used since the 1820 s to settle this southern edge of the Canadian Shield. ${ }^{114}$ They were

\footnotetext{
${ }^{110}$ MSCRC, Collection 291, Volume 3, Meeting of the Executive Committee, 14 November 1891.

"' Robert Tyson, "Laying Out the Course on Stony Lake," American Canoeit 2, no. 5 (1883): 66-8.

${ }^{112}$ I explore the work of these men and Vasseur in greater detail in Chapter Nine.

113 Nikolas S. Rose, "Governing," in Powers of Freedom: Reframing Political Thought (Cambridge: Cambridge University Press, 1999), 1-60.

${ }^{114}$ John C. Walsh, "Landscapes Of Longing: Colonization And The Problem Of State Formation In Canada West" (Ph.D. Dissertation: University of Guelph, 2001). The map of Stony Lake that

Fitzgerland produced was a seamless fit with the maps being used to colonize the areas surrounding and to the north of Peterborough.
} 
also using the same personnel. James Fitzgerald had been responsible, amongst other things, for surveying the Burleigh Colonization Road (1860-1), which facilitated settlement in the area north of Peterborough. ${ }^{115}$ That some of the visitors to the encampment would later purchase land on Stony Lake for cottages reinforces this connection between tourism and colonization. ${ }^{116}$

The winter months were also used to make travel arrangements. As I discuss in more detail in Chapter Four, the organizing committee aided travel in a number of ways. Briefly, however, circulars provided prospective visitors with route, schedule, and fare information. The committee also arranged reduced fares, facilitated the passage of canoes as freight, and worked with federal customs agencies to ease border crossings. The organizers were more directly involved in coordinating local travel, either arranging for existing steamer service to include the camp wharf in their itinerary, or hiring boats or wagons to complete the last leg of the journey.

Finally, the winter months were devoted to revising the regatta programme and the racing rules, one of the subjects of Chapter Eight. ${ }^{117}$ While most programmes were modeled on the previous year's schedule of events, there were always adjustments to be made based on new technologies, and the success or failure of particular races. New racing rigs also prompted revisions of the rules, as did participants' efforts to bend existing regulations to increase their chances of success, this in spite of the fact that the organization claimed not to encourage or reward winning at all costs.

\footnotetext{
${ }^{115}$ Trent University Archives (TUA), 77-015. James W. Fitzgerald, Report and Diary of Burleigh Road Survey, 1860-1861.

${ }^{116}$ Katharine N. Hooke, From Campsite to Cottage: Early Stoney Lake, Occasional Paper 13 (Peterborough: Peterborough Historical Society, 1992).

${ }^{117}$ The programme for the 1883 meet was "pretty well arranged" by mid-April. "The American Canoe Association in Canada," Forest and Stream, 19 April 1883.
} 
For the canoeists, preparation for the ACA meets was likely part of the more general wintertime preparations they performed in anticipation of the canoeing season. ${ }^{118}$ As one reporter for the Times noted, "Canoeing on the water does not fairly begin until May, but a vast deal of delightful canoeing is now in progress on dry land." 119 Such off-season "canoeing" included varnishing the canoe in the parlour, pouring over catalogues, planning cruises (using maps and timetables), gathering at the boathouse, and taking short cruises when the weather permitted. Presumably, for those who planned to cruise to the annual meeting, the winter months were also the perfect time to gather maps and the accounts of others who had undertaken similar routes, and to engage in imaginative travel.

With the ice off the waterways and the frost out of the ground, the work of "improving" the campsite began in earnest. ${ }^{120}$ The amount and kind of improvements varied from year to year. In addition to clearing underbrush and digging wells, organizers arranged for the construction of paths and the installation of camp infrastructure. ${ }^{121}$ The latter included tent platforms, a wharf, sanitary arrangements, and temporary buildings, such as the camp store and mess tent. ${ }^{122}$ While some of these

\footnotetext{
${ }^{118}$ See, "Winter Work," Forest and Stream, 18 October 1883, for a discussion of the work that needed to be engaged in to ready one's boat for winter, but also the improvements that could be accomplished in the colder months. Pauline Johnson's "Canoe and Canvas" series captures the longing that filled the canoeists' winter months as they waited for the weather and waterways to be amenable to their sails and paddles. McMaster University Archives (MUA), E. Pauline Johnson Fonds, Box 3, Files 6-10, Pauline Johnson, "Canoe and Canvas," The Rudder (March 1895): 34.

119 "The Season for Canoeing," The New' York Times, 25 March 1883; "A Winter Evening's Reverie," Forest and Stream, 11 February 1886.

${ }^{120}$ For a longue durée account of the idea of improvement, see Richard Drayton, Nature'd Government: Science, Imperial Britain, and the 'Improvement' of the World (New Haven: Yale University Press, 2000). 121 "Lake George Meet," Forest and Stream, 28 August 1881; MSCRC, Collection 291, Volume 3, Meeting of the Eniecutive Committee, 23 November 1889; "The ACA Meet," Forest and Stream, 31 July 1890. A newspaper article from the 1890 meet claimed that the Association spent $\$ 1200$ to clear away brush and erect a wharf at Jessup's Neck. NYSHA, 1.2/10, “Canoeing: The ACA Meet," 13 August 1890.

${ }^{122}$ The camp store first appeared in 1883 at the Stony Lake meet. It was one of a handful of permanent structures on Sugar Island. NYSHA, 1.5/6, "ACA Camp Store," 1910.
} 
“improvements" were practical, such as digging a well, as we shall see in Chapter Five, others, such as the impulse to clear underbrush, were ideological.

Members of the organizing and/or executive committees typically travelled to the site for short visits in advance of the meet, as in the case of 1883 , or arrived a few weeks before the opening of the encampment, to oversee these improvements, which as I discuss in Chapter Nine were usually carried out by local labourers. ${ }^{123}$ Commodore Thorn, for example, was in the Thousand Islands as early as 10 July making preparations for the 1904 annual meeting, which was to begin on 5 August. ${ }^{124}$ However, occasionally, the owner of the land hired for the campsite took responsibility for the work. For example, Mr. Scoville, the owner of the 1890 site on Peconic Bay agreed to "clear off all the objectionable underbrush during the early spring and have the grass burned in time to have a fresh crop for August[,]...to fill in a certain objectionable pool, to clear the shore of seaweed and riff-raff and to erect a substantial dock" suitable for a steamboat. ${ }^{125}$ And what of Mr. Scoville's motivations? According to the Camp Site Committee Report, he was part of a local cottagers association who wished to sell off pieces of land in the area. The encampment, he reasoned, would provide a useful showcase to do so. ${ }^{126}$

\footnotetext{
${ }^{123}$ Edwards and other members of the 1883 committee describe their visits in "Correspondence," American Canoeist 2, no. 5 (1883): 59-61; Tyson, "Laying Out the Course"; "American Canoe Association, Peterborough Eaxaminer, 21 June 1883.

124 "In the Thousand Islands," New' York Tribune, 10 July 1904; "Canoe Race," The Evening News, 5 August 1904. Similarly, in 1897, the New' York Herald reported that MacKendrick and his assistants had been on site at Grindstone "for many days" when the camp opened on 6 August. "Canoists [sic] Again in Camp," New York Herald. 7 August 1897.

${ }^{125}$ MSCRC, Collection 291, Volume 3, Meeting of the Executive Committee, 23 November 1889.

${ }^{126}$ J.A. Dodds felt the same way. He leant the Association the Bow Arrow Point site for free in 1887 "in consideration of the advantage of publicity which such use will bring him." "The ACA Meet of 1887," Forest and Stream, 2 June 1887.
} 
Attendees had their own preparations to complete. For example, they had to finalize their travel plans, acquire the necessary equipment, and organize their "outfits." ${ }^{27}$ Consider the following advice given by a Times columnist:

To prepare for camp life, the canoeist must begin early and devote some thought to the work. Besides the careful inspection of his boat..., he has to think of those things necessary to make camping a comfort. A hammock combined with a folding canopy, or, if a woman forms one of the crew, a folding camp bed, take up little room. An 'A,' or wedge, tent must certainly be taken and a folding table and campstools, not forgetting a canteen or luncheon basket, and a camp kit which contains wrought tinned-iron case and cover, forming a frying pan; camp boiling pot, strong wrought-iron fire stove, kettle, two canisters, sugar box, two plates, two teacups and saucers, two knives and forks, two spoons, teaspoons, gridiron, tea strainer, and salt-boxes. These few item take up small room, and are light, and without them camping out becomes a trial, and the pleasures of a day's canoeing are marred by an uncomfortable meal and a bad night's rest. ${ }^{128}$

This brief missive is silent on the matter of cost, although the Times in 1900 offered the following estimations for common items: $\$ 5$ for a wall tent, $\$ 2.50$ for a canvas cot, $\$ 11$ for aluminum tableware, and $\$ 4-5$ for a kerosene stove. ${ }^{129}$ The bourgeois could absorb such costs comfortably, but even these basic amenities could be prohibitive for working-class canoeists.

Canoe clubs also employed the spring and early summer to ready their entries for the regatta. For example, in early August 1884, the New York Sun boasted that the members of the New York Canoe Club were busily preparing for "the various racing events" on Grindstone Island. ${ }^{130}$ Although the organization officially decried the intensive training regimens associated with professional athletes, a point I consider in

\footnotetext{
127 This is the term that canoeists use to describe their "cruising effects."

128 "Annual Canoe Meet," New York Times, 4 August 1895.

129 "Features of Some Seasonable Sports," New York Times, 6 May 1900.

130 "Canoe Sailors in Camp," The New' York Sun, 4 August 1884. The anticipation is captured in other articles, including "Canoeists Going to Sugar Island," Rochester Democrat Chronicle, 18 July 1908.
} 
Chapter Eight, it quickly became apparent that success in the regattas could not be guaranteed without some preparation. By 1885 , the Times contended, "No man who is not an expert has now the slightest chance of winning in a regatta, and the combination of nerve, quickness, and technical skill shown by our best canoe sailors need only be witnessed to convince any one that canoeing is a worthy sister of yachting." ${ }^{131}$

\section{Communicating}

As plans for the annual meeting came together, members of the ACA were kept apprised of developments via the official organs of the association and other prominent periodicals; through circulars, which were printed and delivered to members' homes by post in the spring; and by the yearbook, which was usually produced in late spring or early summer. ${ }^{132}$ Yearbooks, circulars, and the official organs - through membership lists, encampment accounts, and previews of the meets - played a crucial role in constructing the imagined community of canoeists, but also the place of the encampment. The canoeists also contributed to the narrativization of the Association and the encampment as they viewed these texts. To borrow from Roger Chartier, "cultural consumption...is at the same time a form of production, which creates ways of using that cannot be limited to the intentions of those who produce."133

131 "The Canoe Association," New York Time', 25 July 1885.

${ }^{132}$ Announcements for the publication of the yearbook were included in the following issues of Fored and Stream: 21 May 1881, 29 May 1884, 12 July 1888, 16 July 1891. Similar announcements were made in the American Canoeidt. See, for example, "The Association Book," American Canoeist 4, no. 6 (1885): 102. ${ }^{133}$ Roger Chartier, "Culture as Appropriation: Popular Cultural Uses in Early Modern France," in Understanding Popular Culture: Europe from the Middle Ages to the Nineteenth Century, ed. Steven L. Kaplan (Berlin: Mouton, 1984), 234. Certeau also tackles the question of reader agency using the notion of the reader as poacher: "Far from being writers - founders of their own place, heirs of the peasants of earlier ages now working on the soil of language, diggers of wells and builders of houses - readers are travelers; they move across lands belonging to someone else, like nomads poaching their way across fields they did not write, despoiling the wealth of Egypt to enjoy it themselves." Michel de Certeau, The Practice of Everyday Life, trans. Steven Rendell (Berkeley: University of California Press, 1984 [1980]), 174. I prefer 
While the information communicated through these various formats was tailored somewhat depending on space restrictions and the perceived audience, there was significant overlap between the three media. Moreover, organizers perceived them as working together. For example, the circular for the 1902 meet on Cape Cod punctuated the description of the site with the following instruction: "See sketch of Camp Site in Year Book."134 As the circulars were the most exhaustive in their information and would have been received by most members and any non-members who expressed interest in attending the encampment, they will centre this discussion of communicating with the membership. Among other things, the circulars enabled members new and old to imagine the historical geography of the encampment and practices of camp life, while also providing them with the practical information necessary to prepare for the event. They were also endemic to the politics of the ACA and its annual meetings, namely they "sought to educate the eye and also frame the meaning of what people saw and experienced in the landscape even before they saw (or in some cases re-encountered) it." 135

The circulars were likely not the first, nor the only source of information available to the canoeists. The memoirs of ACA members reveal that friends or fellow canoe club members were particularly valuable resources. ${ }^{136}$ A prospective camper might also have read about the ACA encampments in Forest and Stream, Outing, or one

Chartier's reading because it does not dichotomize the reader-writer. Rather, it allows the reader to exist as both consumer and producer.

${ }^{134}$ NYSHA, 1.6/12, Camp Circular for Cape Cod, 1902.

${ }^{135}$ John Walsh has demonstrated how newspapers and programs for Old Home Weeks in the Ottawa Valley in the early twentieth century performed a similar function. John C. Walsh, "Performing Public Memory and Re-Placing Home in the Ottawa Valley, 1900-1958," in Placing Memory and Remembering Place in Canada, eds. James Opp and John C. Walsh (Vancouver: University of British Columbia Press, 2010), 27, 29. I return in more detail to this point in Chapter Five.

${ }^{136}$ NYSHA, 1.6/2, D.B. Goodsell, A Canoeing Reminitcence (1936); TUA, 83-014/2, Paul Vernon, Tales of the $A C A, 1940$. 
of the other prominent weeklies or monthlies that devoted space to the organization in the years covered by this study. The circulars, thus, worked in tandem with other sources of information. The organizers were not only aware of this fact, they exploited it. For example, the circular for the second encampment informed members, "By mailing one dollar to Mr. S.R. Stoddard, Glens Falls, NY, his guide book of Lake George with maps, will be forwarded." ${ }^{37}$ Similarly, the American Canoeist, which reproduced the circular for the 1884 meet in full, directed potential visitors to Grindstone Island to Glimpses of St. Lawrence Summer Life by member Frank H. Taylor for more detailed information about the region. ${ }^{138}$

At their core, the circulars served to situate the encampment in time and space. In addition to indicating the dates and schedule for the meet, most of them included descriptions of the broader situation of the campsite. For example, the 1894 circular noted that the camp at Croton Point on the Hudson River would "be located in a very interesting portion of the River on the northwesterly side of Haverstraw Bay, which is about three miles wide at this point, and gives an opportunity for sailing seldom enjoyed a previous meets. The beach is hard fine sand, free from pebbles or large stones." 139 They also tended to locate and describe the main sites of the camp, such as the Headquarters, Main Camp, Squaw Point, and the Mess Tent. The circular for the 1888 meet at Lake George, for instance, informed canoeists that Squaw Point would

\footnotetext{
${ }^{137}$ MSCRC, Collection 291, Box 23, Folder 2, Camp Circular for Lake George, 1881.

${ }^{138}$ The periodical thought it would be of interest because it contained "maps, charts, and illustrations of all the favourite locales amongst these islands." "Here and There," American Canoeist 3, no. 7 (1884): 103. ${ }^{139}$ MSCRC, Collection 291, Box 23, Folder 2, Camp Circular for Croton Point, 1894.
} 
be situated on the western shore of Long Island, 1/3 mile from the main camp at a "[p]lace where the island is so narrow that canoes can be launched on either side."140

As I consider in more depth in Chapter Three, few if any of the encampments were held in "pristine" wilderness. Occasionally, the longer human history of these sites was alluded to in the descriptions circulated to the canoeists in advance of the meets. For example, the Canoe Islands were described as being "as wild and natural now as they were 50 years ago, when some of the few Indians then remaining in this neighbourhood made them their home. ${ }^{.141}$ Some years, the Indigenous history was employed to entice visitors to the meet. ${ }^{142}$ For example, the 1900 circular explained, "The Camp Site which we have leased for the ACA meet was formerly the meeting point for the Huron tribe of Indians who hunted and fished there before the white man's arrival." 13 As Sharon Wall argues in the case of summer camps, "Reminding children that they walked on what had previously been 'Indian land' was portrayed not as a matter of controversy, as the basis for a critique of colonialism or social redress, but, rather, as a mildly interesting (if unchangeable) anthropological fact." ${ }^{144}$

A common theme in these descriptions was the assumption that "Indians" no longer lived on the land or fished in the surrounding waters. As Mark Simpson notes, the "prospect of Aboriginal disappearance" emerged as "hegemonic common sense" in

${ }^{140}$ MSCRC, Collection 291, Box 23, Folder 2, Camp Circular for Lake George, 1888.

141 "The Canoe Island Camp," New York Times, 13 August 1881. Similar sentiments were used to portray the 1884 site: "The islands in the immediate vicinity of the camp are nearly all unoccupied, and are as innocent of the touch of mankind as when they were the chosen haunts of the predatory Iroquois." Frank H. Taylor, "Grindstone Island and Its Surroundings," Outing 4, no. 1 (1884): 33.

${ }^{142}$ This incorporation of pre-contact aboriginal history as belonging to the history of settler places is also a theme in Walsh, "Performing Public Memory."

${ }^{143}$ Herb Begg, ed., American Canoe Association Yearbook (New York City: Forest and Stream Publishing. $1900), 11$.

${ }^{144}$ Sharon Wall, The Nurture of Nature: Childbood, Antimodernism, and Ontario Summer Camps, 1920-1955 (Vancouver: University of British Columbia Press, 2009), 247. 
the late nineteenth century, serving to "naturalize Native removal, resettlement, and containment." 145 Simpson targets the complicity of the "culture industry" in the dissemination of "the mediatory fiction of vanishing aboriginality," which was, in turn, “instrumental in advancing the material and ideological conditions needed for Native Americans to disappear by the thousands." In other words, the repetition of the rhetoric of disappearance in various cultural forms not only enabled practices of disappearance, but also made them appear to contemporaries as logical and inevitable. The ACA participated in these acts of erasure by continually claiming Native absence or by ignoring the Aboriginal past and present altogether. ${ }^{146}$ Accounts of the 1890 meet on Long Island, for example, are silent on the fact that the encampment was held on the ancestral lands of the Shinnecock, who were presently confined to a reserve on the opposite side of Peconic Bay. ${ }^{147}$ Likewise, Grindstone Island, which hosted the encampment five times between 1880 and 1910, remained an occasional camping ground for the St. Regis Indian Band as late as the $1880 \mathrm{~s} .{ }^{148}$ That accounts of these meets say nothing of these co-inhabitants is perhaps a function of their physical and temporal proximity to the campsites. Only with distance or invisibility could the Indian be properly romanticized.

\footnotetext{
${ }^{145}$ Mark Simpson, Trafficking Subjects: The Politics of Mobility in Nineteentb-Century America (Minneapolis: University of Minnesota Press, 2005), xiv-xv. See also, Jean M. O'Brien, Firsting and Lasting: Writing Indians out of Existence in New England (Minneapolis: University of Minnesota Press, 2010).

${ }^{146}$ As we shall see in Chapter Three, they also participated in a material sense of the dispossession of Indigenous people.

${ }^{147}$ John A. Strong, The Montaukett Indians of Eautern Long Itland (Syracuse: Syracuse University Press, 2001).

${ }^{148}$ Stanley Norcom, Grindstone Island: An Island World Remembered (Self-published, 1993), 170.
} 
A good portion of the circulars was devoted to information about travelling to and from the annual meetings. ${ }^{149}$ Equally prominent were descriptions of the amenities that would be available at the event. Amongst other things, visitors were apprised of the cost of meals at the mess tent, as well as the name and provenance of the individual in charge of board for that year. ${ }^{150}$ Circulars also gave the reader ideas as to how they might spend their time at the meet through the inclusion of sample schedules, descriptions of activities, and occasionally word pictures of camp life. Only rarely were photographs included. More common were maps, which worked alongside the text to enable the canoeists to envision the broader situation of the encampment (area map) and/or the campsite itself (site map). ${ }^{151}$

Scholars have shown a growing interest in maps "as refracted images contributing to dialogue in a socially constructed world." ${ }^{152}$ To borrow from Patrick Joyce, maps are things and "things shape and limit the way actions can be done, and doing affects knowing. Precisely because they are material, things carry meanings at the level of the habitus, the level of implicit and habitual practice." ${ }^{153}$ Maps in conjunction with the text of the circulars organized the landscape of the meets into readily identifiable and consumable pieces - headquarters, wharf, mess tent, camp

\footnotetext{
149 Typically, the transportation section included the schedules and fares of steamers and railways from the most popular points of departure (Boston, New York, Canada), as well as customs details. There might also be instructions about arriving to the campsite by canoe. That the latter option continued to receive mention in the circulars long after this was common practice suggests how the organization imagined, or perhaps more appropriately, idealized itself as a brotherhood of cruising canoeists.

${ }^{150}$ For example, the 1888 circular informed its readers that meals would be provided at a cost of $\$ 1 /$ day by George W. Ferris of the Horicon Lodge, while visitors frequenting the camp store would be operated served by C.A. and E.J. West of Caldwell. MSCRC, Collection 291, Box 23, Folder 2, Camp Circular for Lake George, 1888.

${ }^{151}$ See for example, R. Easton Burns, ed., American Canoe Asvociation Yearbook (Kingston: Daily News Printing House, 1893).

${ }^{152}$ J.B. Harley, The New Nature of Maps: Eways in the History of Cartography (Baltimore: Johns Hopkins University Press, 2002), 53.

153 Joyce, The Rule of Freedom, 41.
} 
store, main camp, Squaw Point - each with its own "conditions of possibility," which afforded particular experiences and precluded others. ${ }^{154}$ While the organizers would have argued that these surveys and maps served practical purposes, as I discuss in more detail in Chapter Five, neither practice was benign. The surveyor, to borrow from J.B. Harley, "replicates not just the environment in some abstract sense but equally the territorial imperatives of a particular political system." ${ }^{155}$ There is another side to this story of maps, however. Jeff Oliver, for example, asks us to consider maps as "things 'of-the-moment,' made for specific purposes but then dispersed and used in other contexts." ${ }^{156}$ More concretely, he argues that "the mapping of northwestern North America was characterized by a far messier, disconnected and contested history than the broad-brushed cultural argument could ever acknowledge." Maps, he continues, "appealed to and colonized minds in certain social arenas, while in others they were contested, their meaning remade." ${ }^{157}$ The maps of the encampments, in other words, were suggestive of certain understandings and practices, but not deterministic.

\footnotetext{
${ }^{154}$ Joyce, The Rule of Freedom, 36.

${ }^{155}$ Harley, New Nature of Maps, 54. Likewise, Joyce argues that "the modern map is essential to power and to the practices of governance." For "to govern," posits Nikolas Rose, "it is necessary to render visible the space over which government is to be exercised." Joyce, The Rule of Freedom, 36; Rose, Powers of Freedom, 36.

${ }^{156}$ For example, "we might ask what were the conditions surrounding their production, and thereafter their use and interpretation? Within which social arenas did maps circulate and to what degree did they influence their users?" Jeff Oliver, “On Mapping and Its Afterlife: Unfolding Landscapes in Northwestern North America," World Archaeology 43, no. I (2011): 68.

${ }^{157}$ Oliver, "On Mapping," 80-1.
} 


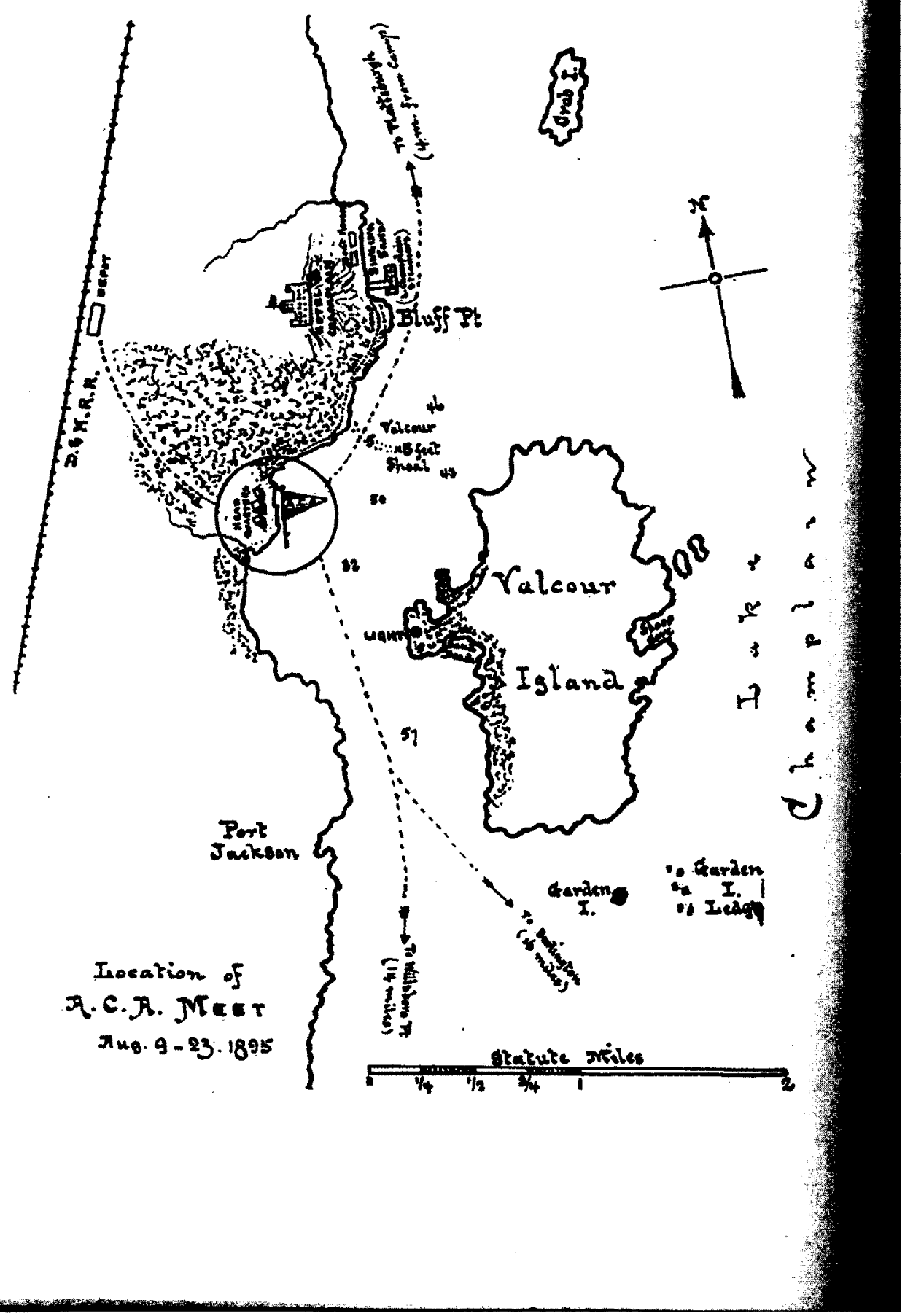

Figure 2.1 - Area map of the 1895 encampment on Lake Champlain. [Source: Charles E. Cragg, ed., American Canoe Association Yearbook (Port Henry: Press of Essex County Publishing, 1895), 10.] 
There was much variation in the maps produced for the encampments. Area maps, such as Figure 2.1, employed a larger scale to indicate the location of the campsite, usually representing the site in relation to urban centres and rail lines or stations. These were often reproductions of maps made for other purposes. ${ }^{158}$ For example, the map in the 1891 Yearbook was borrowed from the Delaware and Hudson Railroad Company. ${ }^{159}$ Similarly, the area map visible in Figure 2.2 and included with the circular for the 1900 meet was a popular cartographic representation of Muskoka originally produced for a tourist guidebook. ${ }^{160}$

By contrast, the site maps were almost always hand-drawn. As only two of the maps are signed, it is difficult to know their origins. ${ }^{161}$ However, we can reasonably assume that they were produced by either a member of the organizing committee or by a surveyor, such as James Fitzgerald. The amount of information that the site maps offered varied. In some cases, they were spare, indicating only the key parts of the campsite such as the Headquarters, Main Camp, the Ladies' Camp, and the racecourses. This is true of Figure 2.3, which depicts the 1887 encampment on Lake Champlain. Other maps were more detailed, such as the representation of the 1901 campsite on Mudlunta Island seen in Figure 2.4. In addition to noting the location of

\footnotetext{
${ }^{158}$ There were exceptions. Area maps for the 1888 and 1893 meets were hand drawn. George W. Hatton and C. Bowyer Vaux, eds., American Canoe Association Yearbook (New York: Nautical Publishing, 1889), xxix; Burns, American Canoe Avsociation Yearbook, 9.

${ }^{159}$ Ralph F. Brazer, ed., American Canoe Association Yearbook (n.p., 1891), insert between 42 and 43. Scholars have linked the railway to tourism and nature. See, for example, "Chapter 1: Creating Tradition: The Roots of National Park Management," in Richard West Sellars, Preserving Nature in the National Parks: A History (New Haven: Yale University Press, 1997): 7-27; Lynda Jessup. "The Group of Seven and the Tourist Landscape in Western Canada," Journal of Canadian Studiev 37, no. 1 (Spring 2002): 144-179.

${ }^{160}$ Picturesque View' and Maps of the Muskoka Lakes, Canada (Toronto: Ralph and Smith, 1893).

${ }^{161}$ Commodore W.G. MacKendrick drew the map for the 1900 meet. Secretary Herb Begg created the map for the following year's gathering. Begg. American Canoe Avsociation Yearbook, 10; Herb Begg, ed., American Canoe Astociation Yearbook (New York City: Forest and Stream Publishing, 1901), 10.
} 
different sites, such as the icehouse, the bathhouse, and the cooking tent, the 1901 map offers descriptions of the landscape. The Squaw Point site, for instance, is described as: "Nicely shaded every tent overlooking river." ${ }^{\prime 62}$ This extra information, which was likely an attempt to sell the location to potential visitors, hints at what constituted an ideal landscape. Finally, site maps named locations in the vicinity of encampment including bays, points of land, and nearby islands. ${ }^{163}$ The map for the 1893 encampment at Brophy's Point, for example, named: Abraham Head, McDonnell's Bay, Knapp's Point, Milton Island. ${ }^{164}$ Such names allude to one aspect of the longer human history that characterized the local landscapes: European settlement.

Of course, maps are "of interest for what they leave out as well as what they put in." ${ }^{165}$ For example, with the exception of the map produced for the 1900 encampment in Muskoka, none of the site maps include representations of the sanitary arrangements. While it is possible that this omission reflects a divide between public and private, sanitation was a very public matter in the late nineteenth century. ${ }^{166}$ Furthermore, as we see in Chapter Six, other ostensibly private spaces, such as tent interiors, were decidedly public at the ACA meets. Also absent from the site maps is any indication of where servants or workers were accommodated, although as I discuss in Chapter Nine, they were an important if largely invisible component of camp life.

\footnotetext{
${ }^{162}$ Begg, American Canoe Association Yearbook (1901), 10. This representational style appears to have been inspired by the previous year's map. Begg, American Canoe Avsociation Yearbook (1900), 10.

${ }^{163}$ If an area map was not included, then the site map usually offered some indication as to the location of the map in relation to local communities. William M. Carter, ed., American Canoe Astociation Yearbook (New Jersey: John L. Murphy Publishing, 1887), 4.

${ }_{164}$ Burns, American Canoe Avoociation Yearbook, 9.

${ }^{165}$ Joyce, The Rule of Freedom, 36.

${ }^{166}$ Megan Davies, "Night Soil, Cesspools, and Smelly Hogs on the Streets: Sanitation, Race, and Governance in Early British Columbia," Hìtoire Sociale/Social History 38, no. 75 (2005): 1-36; Stanley K. Schultz and Clay McShane, "To Engineer the Metropolis: Sewers, Sanitation, and City Planning in Late-Nineteenth-Century America," The Journal of American History 65, no. 2 (1978): 389-411.
} 


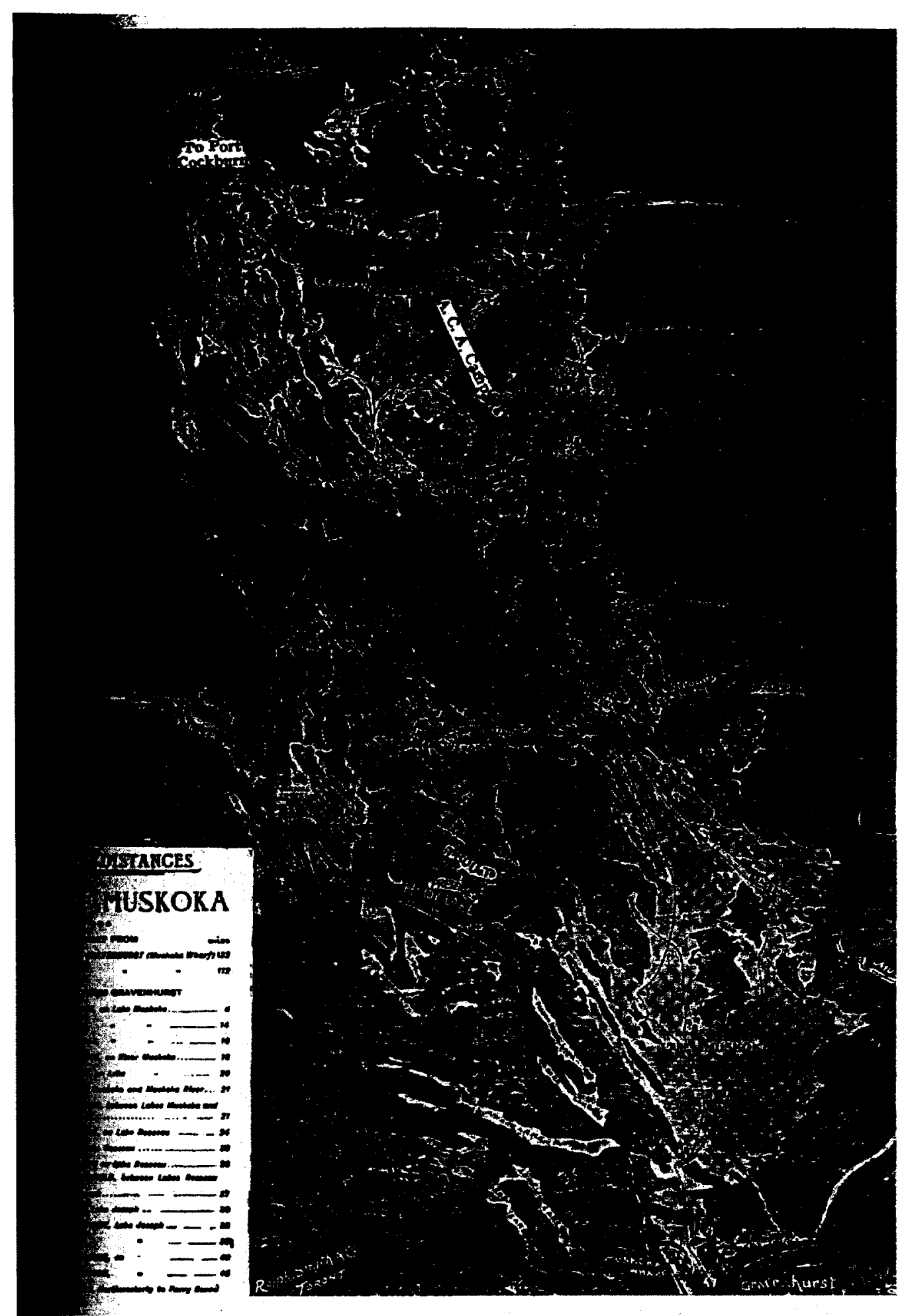

Figure 2.2 - Area map of the 1900 encampment in Muskoka. [Source: Herb Begg, ed., American Canoe Association Yearbook (New York: Forest and Stream Publishing, 1900), 13.] 


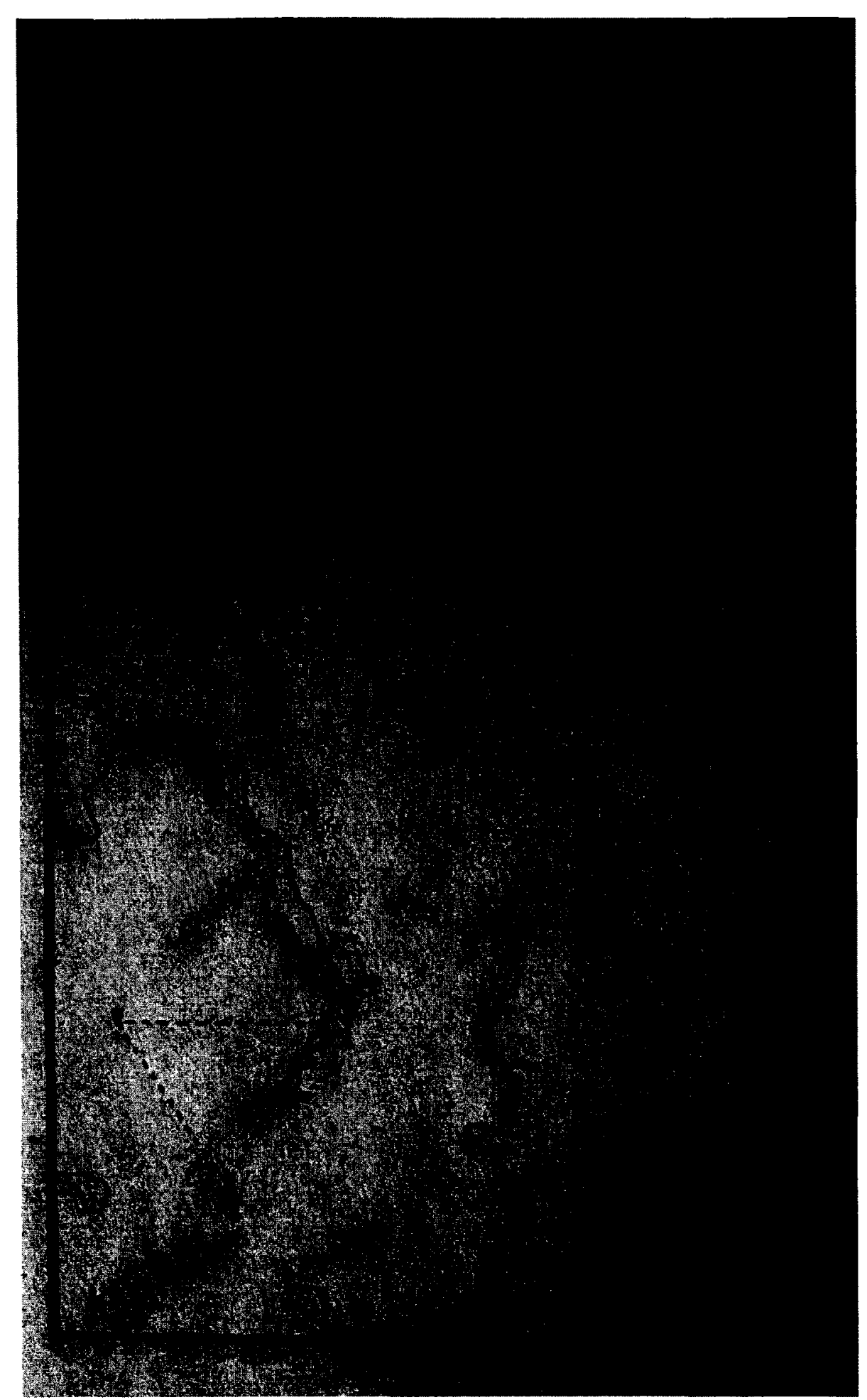

Figure 2.3 - Site map of the 1887 encampment on Lake Champlain. [Source: William M. Carter, ed., American Canoe Asdociation Yearbook (New Jersey: John L. Murphy Publishing, 1887).] 


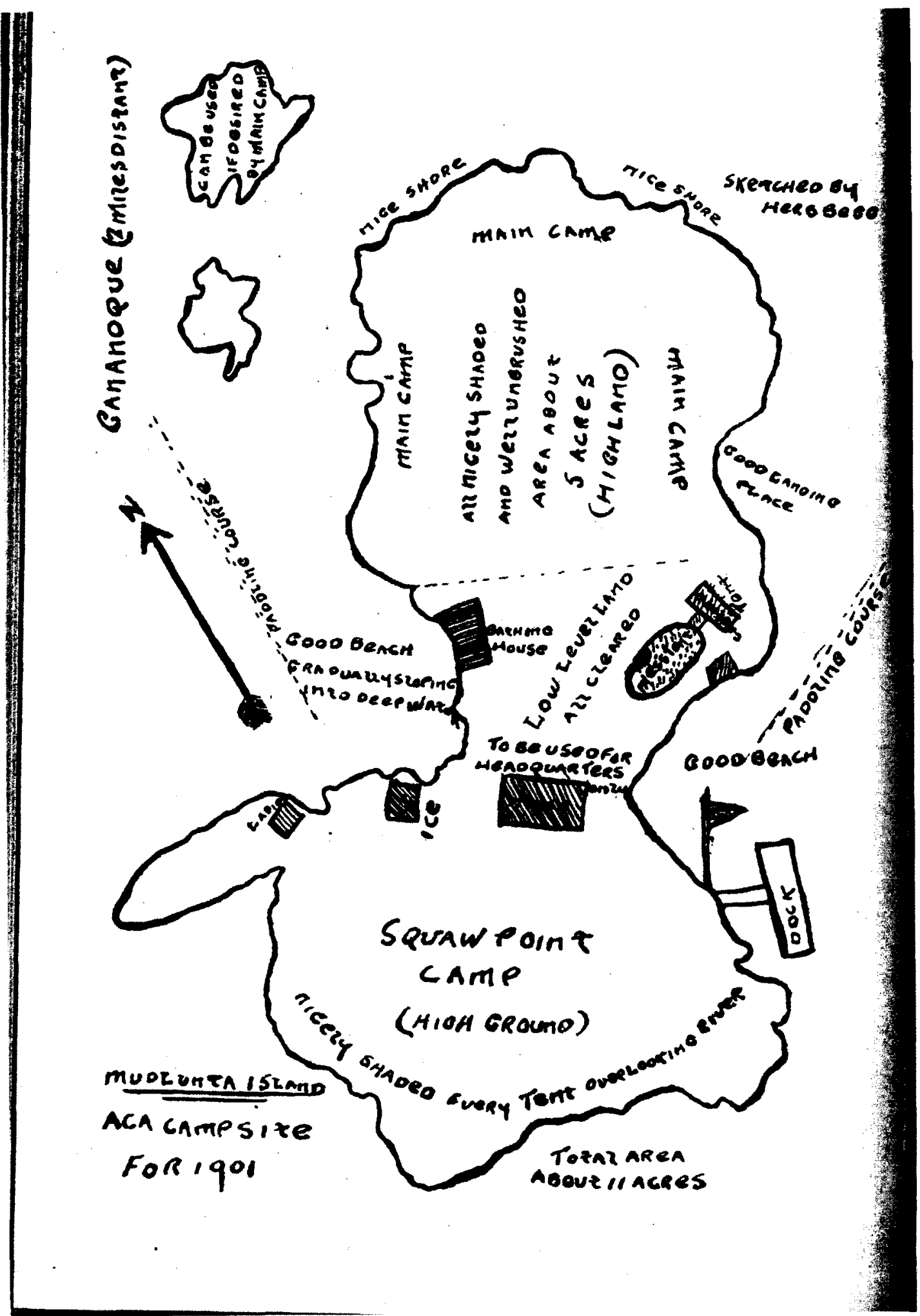

Figure 2.4 - Site map of the 1901 encampment on Mudlunta Island. [Source: Herb Begg, ed., American Canoe Adsociation Yearbook (New York City: Forest and Stream Publishing, 1901), 10.] 
Even as the circulars provided the canoeists with very practical information about travel, accommodations, and food services, they sought to shape the experiences of campers attending the annual meeting by preparing them to "know," "see," and "inhabit" the spaces of the encampment in particular ways. Of course, information about encampment life came from outside the organization, from friends and relatives, as well as books, magazines, and newspapers. These alternative sources may have worked at cross-purposes to the objectives of the organizers, or they may have reinforced organizers' expectations. In either case, campers made choices about what information they assimilated and what was best abandoned, thereby producing understandings of encampment life that were more varied than organizers likely appreciated. ${ }^{167}$

\section{Conclusion}

Founded in 1880 on the shores of Lake George in the Adirondack Mountains, the American Canoe Association was at once a novel institution and an unremarkable one. The first (trans)national canoeing organization in the world, it was of a piece with other voluntary associations of the late nineteenth century, including political societies, philanthropic institutions, and arts and science associations. All shared similar institutional structures, values, and practices. Sporting clubs and associations, like other voluntary institutions, were never only about the things they purported to be about, in this case, canoeing, fresh air, and socializing. Rather, they were also about

\footnotetext{
${ }^{167}$ As Cecilia Morgan notes, "Guidebooks, travelogues, and newspaper and periodical articles about tourist sites helped shape these tourists' sense of what could be entered, traversed, and known. Yet their accounts make it clear that...they also brought their own needs, fantasies, and desires to bear on the meanings that they attributed to such attractions. These were not uncomplicated processes." Morgan, $A$ Happy Holiday, 15.
} 
reproducing particular social, cultural, and political values, and ultimately, about replicating and reinforcing white, middle-class, male privilege to the exclusion and detriment of women, Aboriginal people, African Americans, and the working class.

The encampment, as the most important event in the organization's calendar, was central to the Association's reproduction of power and privilege. Although the event only occupied two weeks in August, preparations began long before the canoeists stepped onto the wharf, and the memory of the event lingered well after the last tent had been packed away. My attention to the details of preparation in the second half of this chapter and in the chapters that follow reflects a contention that the entwined process of placemaking and community formation so central to the ACA encampments began before the opening cannon was fired. Official preparations were largely the purview of the organizing committee, although individual canoeists/campers also participated in "organizing" by learning about the destination, preparing their duffle, and arranging for travel, which in some cases included planning a canoe cruise. The official information distributed by the organizing committee and that which was gathered by enthusiastic campers as they readied themselves for the annual meeting were important catalysts in imagining and constructing the encampment as a social and physical space, which in turn shaped the canoeists' experiences of place and community. This dialogue between official descriptions, ancillary accounts, and canoeists' own imaginings represented an important part of the ongoing and contested process of placemaking, just as disputes over access to the organization served to shape the community of canoeists. Neither of these processes was geographically dislocated. Rather, they were rooted in specific places. In the next chapter, I consider the different locales and campsites in greater detail, using 
contemporary sources to offer some sense of the historical and material landscapes that visitors to the meets encountered and that the ACA, however fleetingly, sought to govern. 


\section{Chapter Three: (Dis)Placing}

In 1880, it was assumed that the annual meeting of the American Canoe Association would remain at the Lake George site in perpetuity. In the fall of that year, charter members Nathaniel Bishop, Nicholas Longworth, and Lucien Wulsin purchased three islands in the lake's centre for a permanent encampment. ${ }^{1}$ Early accounts of the Canoe Islands, as they would come to be known, were positive. The New York Times, for instance, pronounced them "as delightfully situated for a Summer camping-ground as any place imaginable. They are out of sight from everywhere, and hardly a house is to be seen." By 1882 , however, a number of complaints had been leveled at the Lake George site. ${ }^{3}$ The main island was deemed too small for the burgeoning organization and the racecourses, which remained off the shore of the Crosbyside Hotel, were thought to be too far from the islands. ${ }^{4}$ There were also concerns that the wind was unsuited to sailing and the journey to Lake George was unnecessarily arduous. ${ }^{5}$ As one visitor noted, "Many and bothersome were the portages from railway to steamer, from steamer to railway, from railway car to express wagon, from wagon to boat; many were the lifts; many were the bumps and jolts and scratches that the canoes had to endure," and presumably their owners as well. ${ }^{6}$

\footnotetext{
1 "Cruisers and the American Canoe Association," Forest and Stream, 13 December 1883; "The 1884 Meet of the A.C.A.," Outing 3, no. 6 (1884): 464-5.

2 "The Canoe Island Camp," New' York Times, 13 August 1881.

${ }^{3}$ See C. Bowyer Vaux, "History of American Canoeing, Part III," Outing 10, no. 5 (1887): 396. There were, of course, contradictory opinions. According to Forest and Stream, Lake George was a wonderful location, easily accessible with good rail service and courses, which had already been surveyed. "The Future Camp of the American Canoe Association," Forest and Stream, 4 October 1883.

${ }^{4}$ The canoeists either had to paddle or sail the four miles to Crosbyside from the Canoe Islands or, in 1882, be towed by a hired launch. "Lake George Meet," Forest and Stream, 25 August 1881; New York State Historical Association (NYSHA), 1.5/1, "Camping on Canoe Island," Truth, c. 1881; C. Bowyer Vaux, "History of American Canoeing, Part II," Outing 10, no. 4 (1887): 396.

5 "The American Canoe Association," Forest and Stream, 16 August 1888; "Of Interest to Canoeists," The Springfield Republican, 29 July 1891.

6 "The 1884 Meet of the A.C.A.," Outing 3, no. 6 (1884): 464-5.
} 
Finally, there was a growing sense that the members of the Association had become "amusers for hotel crowds."” An invitation from the newly-elected Commodore E.B. Edwards to hold the 1883 meet in the Kawarthas (north of Peterborough, Ontario) provided the perfect opportunity for the Association to test another location. ${ }^{8}$ The Stony Lake meet was deemed a success, and so the Executive Committee, with the support of a large majority of the membership, decided to try a third site rather than return to Lake George. This marked the beginning of 20 years of mobile encampments, during which time the Association visited a variety of locations in Ontario, New York, and New England. It was only in 1903 that the organization settled into a permanent encampment on Sugar Island in the St. Lawrence River. ${ }^{9}$

This chapter brings to the fore the relationship between sport/leisure and geography. Specifically, it reflects my contention that place matters. The encampments were not located just anywhere; as we shall see, they were chosen (and debated over) for specific reasons that speak to several of the larger themes animating this dissertation. These contests over the placing of the encampments resonated beyond the narrow confines of the meetings. As Edward Said reminds us, every act of possession is an act of dispossession, and the case of the ACA encampments is no different. ${ }^{10} \mathrm{As}$ the organization occupied islands and points of land on the St. Lawrence River, in the

\footnotetext{
${ }^{7}$ Vaux, "American Canoeing, Part III," 400. As J.I. Little has noted, by the late nineteenth century, resort hotels had come "to be associated with the very decadence and formality that modern middle-class families were shunning in their desire to experience for a few weeks an idealized rural lifestyle." J.I. Little, "Life without Conventionality: American Social Reformers as Summer Campers on Lake Memphremagog, Quebec, 1878-1905," Journal of the Gilded Age and the Progrestive Era 9, no. 3 (2010): 284. ${ }^{8}$ Vaux, "American Canoeing, Part III," 397.

${ }^{9}$ The annual meeting of the ACA has met there ever since, with the exception of 1926, 1944, and 1945. In 1926, the annual meeting was held at Turtle Island on Lake George. In 1944 and 1945, the meet was cancelled as a result of the war. Ronald Hoffman, "The History of the American Canoe Association. 1880-1960" (Ph.D. Dissertation: Springfield College, 1967), 163-8.

${ }^{10}$ Edward Said, Culture and Imperialism (Toronto: Random House, 1993), 7.
} 
Adirondacks, and on Long Island, to name just a few of the locations, it contributed to ongoing programmes of displacement targeting both Aboriginal inhabitants and white settlers. The organization, in other words, was complicit in a larger imperial project well underway on both sides of the border in the late nineteenth century that sought to isolate and, ultimately, to assimilate and/or eradicate the continent's Indigenous peoples. ${ }^{11}$ This programme was paralleled by a colonizing tourist industry that transformed spaces of production into spaces of consumption, that wrote local lives and livelihoods out of the landscape, and replaced them with more convenient and profitable fictions. ${ }^{12}$ Given the number of encampment locations, I largely restrict my commentary to the case of Sugar Island, the site of the organization's permanent encampment. Nevertheless, many of the principles and effects of occupation and displacement have parallels in the other locations.

Sport history, like other subfields in the discipline, has not been immune to the spatial turn. Increasingly, scholars like Patricia Vertinsky and Russell Field are employing geographical frameworks to make sense of the history of sport. ${ }^{13}$ While

\footnotetext{
${ }^{11}$ On colonial projects targeting Aboriginal people in Canada, see Cole Harris, Making Native Space: Colonialium, Reithtance, and Reserves in Britust Columbia (Vancouver: University of British Columbia Press, 2002), and John Milloy, A National Crime: The Canadian Government and the Retidential School System (Winnipeg: University of Manitoba Press, 1999). For the United States, see David Wallace Adams, Education for Extinction: American Indians and the Boarding School Experience, 1875-1928 (Lawrence: University Press of Kansas, 1995), and Gray S. Whaley, Oregon and the Collapse of Illabee: U.S. Empire and the Traneformation of an Indigenow World (Chapel Hill: University of North Carolina Press, 2010). ${ }^{12}$ Ian McKay, Quest of the Folk: Antimodernium and Cultural Selection in Twentieth-Century Nova Scotia (Montreal: McGill-Queen's University Press, 1994); Dona Brown, Inventing New England: Regional Tourium in the Nineteentb Century (Washington: Smithsonian Institution Press, 1995); Thomas G. Andrews, "'Made by Toile'? Tourism, Labor, and the Construction of the Colorado Landscape," Journal of American Huttory 92, no. 3 (2005): 837-63.

${ }^{13}$ Patricia Vertinsky, "A 'Sense of Place': Reading the Landscape of Sporting Life," International Sport Studiet 23, no. 1/2 (2001): 11-23; Patricia Vertinsky and John Bale, eds., Sites of Sport: Space, Place and Experience (London: Routledge, 2004); Patricia Vertinsky and Sherry McKay, eds., Disciplining Bodies in the Gymnavium: Memory, Monument and Modernism (London: Routledge, 2004); Russell Field, "Constructing the Preferred Spectator: Arena Design and Operation and Consumption of Hockey in 1930s Toronto," International Journal of the History of Sport 25, no. 6 (2008): 649-77. This work has been influenced by the pioneering geographer of sport, John Bale, whose work includes Spart, Space and the
} 
important, this chapter suggests that it is not enough to chronicle how spaces of sport were constructed in both material and cultural ways. We must also link the production of sporting spaces to the broader politics of place, which I understand as space made meaningful. ${ }^{14}$ Among other things, we must trace the effects of emplacement. ${ }^{15} \mathrm{How}$, in other words, have emplacement and placemaking within the context of sport served to displace and dispossess? Here, I call for a postcolonial reading of sport/leisure that has some parallels with Gillian Poulter's work on sporting cultures in nineteenth-century Montreal. ${ }^{16}$ Whereas Poulter is focused almost exclusively on acts of cultural appropriation - she considers, for example, the ways in which Aboriginal sports and sporting spaces were reimagined as indigenous white Canadian practices and locations - this chapter interrogates the appropriation of space and place, and in doing so highlights the physical and psychical displacement effected by white middle-class practices of sport and leisure. ${ }^{17}$ Such a reading moves beyond the simplistic assertion of sport/leisure as benign play to explore how dominant recreational practices have served to delimit, displace, and dispossess the "other." As we shall see, the ACA encampments, in spite of their apparent ephemerality, contributed in different ways to

City (London: Routledge, 1993); Landscapes of Modern Sport (Leicester: Leicester University Press, 1996); and Sport. Geograpby, $2^{\text {nd }}$ ed. (New York: Routledge, 2002). Bale has also been an important proponent of postcolonial theory in sport studies. See John Bale and Mike Cronin, eds., Sport and Postcolonialum (Oxford: Berg, 2003).

${ }^{14}$ James Opp and John C. Walsh, "Introduction: Local Acts of Placing and Remembering," in Placing Memory and Remembering Place in Canada, eds. James Opp and John C. Walsh (Vancouver: University of British Columbia Press, 2010), 15.

${ }^{15}$ This concern for the effects as opposed to sources of power is inspired by Michel Foucault, Power/Knowledge: Selected Interview's and Other Writing, 1972-1977, ed. Colin Gordon (New York: Pantheon, 1980).

${ }^{16}$ Gillian Poulter, Becoming Native in a Foreign Land: Sport, Visual Culture, and Identity in Montreal, 1840-1885 (Vancouver: University of British Columbia Press, 2009).

${ }^{17}$ Poulter's book is (perhaps unconsciously) about sport and the crafting of spatial identities. Although she foregrounds the construction of national identity through sport, her book is very much about Montreal as place. That she is less concerned with displacement may reflect the city's historical context. By the mid-nineteenth century, Montreal had largely been dispossessed. 
these entwined processes of marginalization. My reconstruction of the historical geographies of the ACA meetings is sensitive to the ways in which history itself can reinscribe and naturalize the dispossession of aboriginality, contributing to the displacement of both people and memory. ${ }^{18}$

\section{$\underline{\text { Part I - To Stay or Go? }}$}

The decision to abandon the Canoe Islands in 1882 prompted the American Canoe Association to adopt a policy of mobile encampments. A mobile encampment was appealing for a number of reasons. For members, it provided opportunities to visit new locations. As Canadian canoeist Vincent Clementi articulated in the March 1884 issue of the American Canoeist, "There is no doubt that the establishment of a permanent camp would be beneficial." But, he continued, "it should not be lost sight of that, when we go from home for a holiday in the summer...we like to visit various localities, and pick up new ideas or 'notions,' as I like to call them."19 Clementi's comments suggest that for some members of the Association part of the attraction of a mobile encampment was the "discovery" of new sites each year, a sentiment that evokes imperial nostalgia. ${ }^{20}$ For the organization, a steady rotation of campsites had the potential to attract new adherents, a fact that was amply proven at the 1883 Stony Lake meet. As only members could erect tents on Juniper Island and compete in the

\footnotetext{
${ }^{18}$ John C. Walsh, "Performing Public Memory and Re-Placing Home in the Ottawa Valley, 19001958," in Placing Memory and Remembering Place in Canada, eds. James Opp and John C. Walsh (Vancouver: University of British Columbia Press, 2010), 36-9, 40-4.

19 "A Permanent or Movable Camp," American Canoeitt 3, no. 2 (1884): 31 . Similarly, Forest and Stream highlighted, "there is a disposition on the part of some to vary the meeting place each year, their argument being that, having but two or three weeks each year, they do not wish to spend them in the same place." "The Association Camp," Forest and Stream, 11 October 1883.

${ }^{20}$ Antoinette Burton, "Introduction: On the Inadequacy and the Indispensability of the Nation," in After the Imperial Turn: Thinking With and Through the Nation, ed. Antoinette Burton (Durham: Duke University Press, 2003), 6-7.
} 
races, membership numbers spiked in the months leading up to the 1883 event. $^{21}$ As of August there were 450 members registered, a $200 \%$ increase from the previous year. ${ }^{22}$ While many of these individuals did not renew, their dues had been paid and it allowed the ACA to boast about their burgeoning membership rolls. ${ }^{23}$

Even as mobile encampments had their advantages, it was both expensive and time-consuming to find and establish new camps every year. Moreover, for some, the mobile meet recalled the lives of the oarsmen, who "go on the road posting themselves before rival hotels." ${ }^{24}$ Mobility amongst athletes, in other words, was associated with professionalism, which as we will see in Chapter Eight was the bane of respectable middle-class sporting enthusiasts in the late nineteenth century. ${ }^{25}$ Discussions of a permanent home for the annual meeting occurred intermittently through the 1880 s and 1890 s. $^{26}$ Supporters, which included the editors of Forest and Stream, argued that a permanent encampment would enable the organization to invest in improvements such as landings, storehouses, and stakeboats that would make for a more comfortable and efficient operation. ${ }^{27}$ Furthermore, it would allow the organization to develop advantageous relationships with local transportation and supply companies, the

\footnotetext{
${ }^{21}$ See the accounts in Mystic Seaport Collections Research Center (MSCRC), Collection 291, Volume 2, Record Book of the Secretary of the ACA, 1881-1893.

${ }^{22}$ See MSCRC, Collection 291, Volume 2, Annual Meeting, 22 August 1883; "The Association Races at Stony Lake," Forest and Stream, 6 September 1883.

${ }^{23}$ Forest and Stream reported, "Many Canadians who joined in 1883 only did so in order to attend the camp at Stony Lake, and have since dropped out." "Canoeing in 1884," Forest and Stream, 11 December 1884 .

24 "The Association Camp," Forest and Stream, 11 October 1883. Rowing was notorious for its association with professionalism. See "On Canada," American Canoeitt 2, no. 1 (1883): 1.

${ }^{25} 1$ explore the tensions between amateurism and professionalism in more detail in Chapter Eight.

${ }^{26}$ MSCRC, Collection 291, Volume 2, Meeting of the Encecutive Committee, 13 November 1883; Meeting of the Executive Committee, 4 November 1893. On at least one occasion, the Executive solicited opinions on the subject from the membership. See the January 1884 issue of American Canoeitt.

${ }^{27}$ This theme of comfort was reiterated in a letter from Orange Frazer: "If greater variety is needed it can be had in cruising by different routes to and from the meet. Only in a permanent camp can the greatest comfort be assured. Some scout the idea of making a comfortable camp, as being foreign to our guild. No true canoeist crucifies himself unnecessarily simply because he can." "The ACA Camp," Foreat and Stream, 1 November 1883.
} 
benefits of which could be passed onto members. In a more romantic sense, Forest and

Stream claimed, a permanent encampment could be "a part of a man's life that he looks both backward and forward to with increasing pleasure each summer," akin to the farm of his youth or his alma mater. A "short halting place," in other words, "whence one departs younger, stronger, and better."${ }^{28}$

On a handful of occasions, a committee was struck to investigate the feasibility of acquiring land for a permanent encampment, but with no visible result. ${ }^{29}$ In 1894 , the Association held a vote to gauge support for the idea. The plan was shelved once again, however, when the membership voted overwhelmingly in favour of mobile meets. ${ }^{30}$ Former Commodore C.E. Britton admitted the difficulty of currying support for a permanent encampment in 1901: "It has taken some years to work them up to a fixed place, many preferring the Bohemian mode of moving from place to place. ${ }^{\text {"31 }}$ In spite of such opposition, another committee was appointed to search for a permanent encampment in $1900{ }^{32}$ This time, they fulfilled their mandate by purchasing an island on the St. Lawrence River from the Dominion Department of Indian Affairs (DIA).$^{33}$ The fact that this committee appears not to have consulted the membership may go some way in explaining their relatively rapid success.

\footnotetext{
28 "The Association Camp," Forest and Stream, 11 October 1883. This position underscores the emotional and mnemonic power of place for some.

${ }^{29}$ See, for example, MSCRC, Collection 291, Volume 2, Meeting of the Executive Committee, 13 November 1883; MSCRC, Collection 291, Volume 3, Meeting of the Executive Committee, 4 November 1893.

${ }^{30}$ The membership was given three options: one permanent campsite, two-four permanent campsites, or continue on with the current system. With the exception of one vote for $2-4$ permanent sites, the group was unanimously in favour of sticking with the current system. MSCRC, Collection 291, Volume 2, Annual Meeting, 25 July 1894; Meeting of the Executive Committee, 12 November 1894.

${ }^{31}$ Library and Archives Canada (LAC), RG10, Vol. 2718, File 144, 001-53, Letter from C.E. Britton to Hon. J.A. Smart, 6 February 1901.

${ }^{32}$ MSCRC, Collection 291, Volume 4, Meeting of the Executive Committee, 20 October 1900.

${ }^{33}$ MSCRC, Collection 291, Box 23, Folder 5, Brief Synoputh of the Hiwtory of St. Laurrence Island, 30 September 1933; LAC, RG10, Vol. 2718, File 144, 001-53. As I discuss further in the final section of this chapter, it is significant that the Sugar Island transaction was carried out between the ACA and DIA.
} 
The purchase of Sugar Island in 1901 brought to an end the era of the mobile encampment that characterized the first two and a half decades of the ACA's annual meetings. Not all were in accord that a permanent site was the best idea for the organization. Some members preferred to visit different locales every year. For others, the decision to settle in the St. Lawrence was a clear statement about the organization's allegiances to those in the east. ${ }^{34}$ Certainly, the Sugar Island meets were never as well attended as gatherings in the 1880 s and 1890 s. However, the move to a permanent encampment by no means signalled the event's demise. The ACA still gathers annually on Sugar Island.

\section{Part II - Choosing a Site}

Prior to the acquisition of Sugar Island, the task of choosing a campsite was a central, if largely unregulated component of preparations for the annual meeting. Following the formation of divisions in 1886 , there was a schedule of the general vicinity, if not an exact location, for the meets. ${ }^{35}$ This directive aside there was no official criterion for choosing a location. ${ }^{36}$ Rather, the Executive Committee heard site suggestions and supporting arguments at their fall meeting and then a vote was taken. Campsite recommendations were welcomed if only occasionally solicited from the general membership. ${ }^{37}$ They arrived to the Executive Committee in a variety of ways. Some sent their proposals by mail, including members of the Brockville and Toronto

\footnotetext{
${ }^{34}$ Hoffman, "American Canoe Association," 40.

${ }^{35}$ Divisions, as I noted in the previous chapter, rotated their right to the meet and the Commodoreship. However, they could and did waive these privileges.

${ }^{36}$ This is particularly surprising given the Association's penchant for order and due process.

${ }^{37}$ A note in a September 1889 issue of Forest and Stream encouraged "persons who may know of any suitable place" for the following year's encampment "convenient to New York...to notify Messrs. Stanton or Stephens." "ACA Meet of 1890," Forest and Stream, 12 September 1889.
} 
Canoe Clubs who submitted letters outlining the suitability of Grenadier Island in the St. Lawrence River to be read at the 1884 meeting in Albany, NY. ${ }^{38}$ Others such as C.M. Shedd who desired a saltwater location for the 1887 meet wrote letters to the editors of the official organs, in this case, Forest and Stream. ${ }^{39}$ Still others attended the Executive Committee meeting in person to make a case for their chosen site. General Robert Shaw Oliver of the Mohican Canoe Club in Albany, for instance, was present at the 1885 and 1886 meetings to argue for Bow Arrow Point on Lake Champlain. ${ }^{40}$ Although his initial proposal, which was accompanied by "maps and tracings of the region showing the relative position to principle railroads and steamer points," was not successful, his 1886 campaign was. The 1887 meet was held at Oliver's beloved Bow Arrow Point. If a site was not agreed upon at the meeting, the Executive Committee charged the organizing committee to investigate particular locations and report back to them. In this case, the location was announced in the wintertime.

Even though there was no official criterion for choosing a campsite, not just any location would do. ${ }^{41}$ For example, there was a general feeling that the campsite should be accessible and well serviced, while still "far enough away from hotels and summer travel destinations to preserve the privacy and independence of the camp." ${ }^{\prime 42}$ Hotels were one of the new spaces of luxury and consumption born of the fruits of industrial

\footnotetext{
${ }^{38}$ MSCRC, Collection 291, Volume 2, Meeting of the Executive Committee, 4 October 1884.

39 "A Site for a Saltwater Meet," Forest and Stream, 4 November 1886. For other examples, see Frank H. Taylor, "The Thousand Islands," American Canoewt 1, no. 10 (1882): 147-8; William Whitlock, "The Next Camp," American Canoeiwt 2, no. 8 (1883): 116.

${ }^{40}$ MSCRC, Collection 291, Volume 3, Meeting of the Envecutive Committee, 7 November 1885, and Meeting of the Executive Committee, 13 November 1886.

${ }^{41}$ An excellent example of the rationale for one particular site can be found in debates over the 1890 camp, which was ultimately held on Long Island, New York. MSCRC, Collection 291, Volume 3, Executive Committee Minutes, 23 November 1889.

42 "The 1884 Meet of the A.C.A.," Outing 3, no. 6 (1884): 464-5. The difficulties of finding a balance between accessibility and seclusion is well articulated in "The ACA Meet of 1888: The Camp and the Association," Forest and Stream, 6 September 1888.
} 
capitalism. As such, they were at once symbols of "American capitalist potential" and, for many in the middling classes, emblems of "consumption and entitlement." ${ }^{43}$ For some members, proximity to hotels and resorts had the potential to undermine the organization's claim to middle-class respectability. ${ }^{44}$ Accessibility meant more than having ample transportation routes at hand, it also meant proximity to the border. ${ }^{45}$ Within a few years of the organization's incorporation, rising Canadian membership meant that the ideal camp was one held close to the Dominion. ${ }^{46}$ However, in Canadian waters and on inland lakes were two different things. Although the Stony Lake (1883) and Muskoka (1900) camps were certainly enjoyed, there was a sense that they were too far from the clubs on the eastern seaboard that furnished the Association with the bulk of its membership. This sentiment was manifested in the dismal attendance numbers at the 1900 meet: only 175 of the ACA's almost 4000 members came to Muskoka. ${ }^{47}$ More appropriate were sites in the borderlands such as those on the St. Lawrence River. Finally, accessibility referred to the ability of the organizers to acquire the necessary goods. The 1890 encampment long served as a cautionary tale of inadequate supply lines. ${ }^{48}$

\footnotetext{
${ }^{43}$ Molly Berger, Hotel Dreams: Luxury, Technology and Urban Ambition in America, 1829-1929 (Baltimore: Johns Hopkins University Press, 2011), 7.

${ }_{44} \mathrm{I}$ explore the import of respectability in more detail in the next chapter.

${ }^{45}$ The report of the 1890 Campsite Committee suggested that Jessup's Neck on Long Island was a good location because transportation was convenient from both New York and New England. MSCRC, Collection 291, Volume 3, Report of the Camp Site Committee, 23 November 1889.

46 "The Association Races at Stony Lake," Forest and Stream, 6 September 1883.

${ }^{47}$ Hoffman, "American Canoe Association," 63. Poor attendance was not limited to inland Canadian encampments. A similar situation plagued the 1902 encampment on Cape Cod. The Camp Site Committee Report for that year is riven with the Chairman's frustration. Apparently, the site had been chosen to appeal to those from away, but most who attended were from the Eastern Division. The chairman claimed that had he known this, a site would have been chosen that was more attractive to eastern members. MSCRC, Collection 291, Volume 4, Report of the Camp Site Committee, 1902.

${ }^{48}$ People and supplies, including foodstuffs, had a difficult time arriving at the encampment. "The ACA Meet of $1890-$ II," Forest and Stream, 6 November 1890.
} 
Equally important to location were aesthetics; the site had to be attractive.

What was meant by attractive, however, is somewhat perplexing. For example, within the same breath, the 1900 camp in Muskoka was praised for being picturesque and derided for being too rough. ${ }^{49}$ More congenial to the membership were the "cultivated" sites of Grindstone Island in the St. Lawrence River and Long Island on Lake George. The 1888 circular described the latter as "delightfully wooded with cedars and other trees, and yet afford[ing] ample clear, open ground and grassy glades for camping. ${ }^{150}$ Wild but not too wild appears to have been the consensus. ${ }^{51}$ In the canoeists' aesthetic preoccupations, we see tensions between the two competing touristic sensibilities of the nineteenth century, both of which were expressions of romanticism. The first, the sublime "entailed a new appreciation of natural phenomena" previously "regarded as unpleasantly frightening, unattractive, or even demonic. ${ }^{n 2}$ The second, the picturesque, referred to a "less spectacular quality of landscape, one that was visually pleasing but lacked the emotional impact of the sublime." ${ }^{53}$ That the canoeists were

\footnotetext{
49 “Canoeists' Enjoyable Time," Daily Mail and Empire, 9 August 1900; D.J. Howell, "The International Canoe Meet," The Canadian Magazine 15, no. 6 (1900): 513-21. Howell claimed, "The camp ground was hardly an ideal location...Around headquarters, which was right up from the pier, and in the ladies camp, the ground was quite rocky and heavily wooded, the western and northerly shores rising rather steeply from the water."

${ }^{50}$ MSCRC, Collection 291, Box 23, Folder 2, Camp Circular for Lake George, 1888. The Grindstone camps literally took place on farmer's fields, although there were small woodlots adjacent to the main camp. NYSHA, 1.1/6-1.1/23, Photographs from Grindstone Island, 1884-6; "Around the Pine Camp Fire," New York Times, 20 August 1893.

${ }^{51}$ Certainly, sites could be reformed, as in the case of Jessup's Neck, whose "wild and roughly wooded shore" required "a great deal of work to be done" in order to "be made fit for a large camp." "American Canoe Association," Forest and Stream, 14 August 1890. See also, "Canoeing," New' York Sun, 6 August 1898. That visitors to the 1890 meet responded positively to the site's appearance suggests that the organizers were successful in their improvements, a subject I return to in Chapter Five. "The ACA Meet of 1890: Jessup's Neck," Forest and Stream, 21 August 1890; "Noteworthy Canoeing Matters," New York Evening Pout, 27 August 1890.

${ }_{52}$ Patricia Jasen, Wild Thingu: Nature, Culture, and Tourism in Ontario, 1790-1914 (Toronto: University of Toronto Press, 1995), 8-9.

${ }^{53}$ Jasen, Wild Thing', 8-9. As James Buzard reminds us, they were not universal terms, but were ways of seeing "culturally coded 'male"." For example, the picturesque was conceived of as "a male art of seeing that could correct and complete what a feminized landscape held forth." James Buzard, The
} 
influenced by romanticism is also evident in their gravitation towards "landscapes endowed with the 'interesting associations' of poetry or romantic history or legends. ${ }^{\mathrm{5} 4}$ These included Lake Champlain, which was a battlefield during the American Revolutionary War (1775-1783), and the St. Lawrence River, which had been a notable site of conflict during the War of 1812, the Upper Canadian Rebellion of 1837 38, and the Fenian Raids of the late 1860s.

Other points of consideration for the organizing committee were more practical, such as the availability of fresh water, and the fees and terms of occupancy. ${ }^{55}$ The experience of the 1890 regatta committee brought into stark relief the importance of good relations with the site's owners. In the pages of that year's circular, the committee revealed that their work had been "seriously complicated by a long and vexatious course of negotiations among the owners. ${ }^{256}$ Racecourses posed a further challenge because the regatta featured both paddling and sailing contests. Whereas paddling races were best conducted on calm water, sailing competitions required wind. In practice, it was difficult to accommodate both types of races successfully. Also important was the topography of the waterfront. Given that many of the campers brought canoes with them and these were used on a daily basis, sites had to be able to house landing stages, wooden constructions designed to provide storage and aid in the

Beaten Track: European Tourism, Literature, and the Ways to 'Culture,' 1800-1918 (Oxford: Clarendon Press, 1993), 16.

${ }^{54}$ Brown, Inventing New England, 202. Patricia Jasen refers to this as the "appreciation of those scenes in which landscape and history....were blended together." Jasen, Wild Thing., 10.

${ }^{55}$ Some years the organization paid to rent the space for the encampment. This was true of the Muskoka encampment. However, most years, the land was free. This was certainly true of the 1887 meet at Bow Arrow Point and the 1890 meet at Jessup's Neck. "The ACA Meet of 1887," Forest and Stream, 2 June 1887; MSCRC, Collection 291, Volume 3, Meeting of the Executive Committee, 23 November 1889; "Secretary-Treasurer's Report," in Herb Begg, ed., American Canoe Adsociation Yearbook (New York City: Forest and Stream Publishing Co., 1901), 60-1.

56 "The ACA Meet: Camp Circular," Forest and Stream, 10 July 1890. 
movement of canoes between water and land. The ideal campsite, thus, had sandy beaches to accommodate the stages.

Given the importance attached to the site, and the organization's proclivities for regulation, it is surprising that there was never any official criterion established for choosing an encampment location. Perhaps officials felt that the bid-style process that they adopted afforded ample oversight. Regardless, their final decision was not entirely without direction. In particular, it was shaped by practical considerations, contemporary aesthetics, and accessibility, broadly understood. All of these, however, were underpinned by the imperial politics of placemaking. The canoeists, in other words, assumed a right to the land and to its transformation that was inspired and enabled by colonial hierarchies. Even though many were conscious of the human histories that preceded their arrival at the camps, these histories were understood as consumable elements of the landscape rather than as a challenge to their right to use the water, land, and wildlife for their own sport and leisure.

\section{Part III - The Campsites}

Between 1880 and 1902, the annual encampment of the American Canoe Association was held at more than fifteen different sites on eight bodies of water. ${ }^{57}$ From its origins amidst the weathered mountains of the Adirondacks to the rocky, wooded shorelines of the Canadian Shield and the deciduous forests of the St. Lawrence Lowlands to the soaring Palisades of the storied Hudson River and the coastal communities of Cape Cod and Long Island, the ACA encampments visited a number of iconic landscapes in northeastern North America in the closing decades of

\footnotetext{
${ }^{57}$ See Appendix A for a list of the exact locations of the meets between 1880 and 1910 .
} 
the nineteenth century. The physical environment of the event, which almost inevitably received mention in the circulars and accounts of the encampments, was more than a backdrop for the annual meeting. It was an integral part of the experience. In what follows, I introduce each of the general areas visited by the annual meetings, paying particular attention to the human histories of these locations, and their histories as tourist sites. This part is intended to set the stage for the final section of this chapter, which considers the politics of displacement that this particular manifestation of sport tourism effected.

Lake George was the site of the inaugural encampment, as well as three of the later encampments (1880-1882, 1888). The lake, which was "a little over 33 miles long, running north and south," and "nearly four [miles] wide at the broadest place," boasted more than two hundred islands, of which three belonged to the ACA. ${ }^{58}$ Although founding member Nathaniel Bishop had a summer residence there ${ }^{59}$ Lake George was also a logical choice because of its location in the Adirondack Mountains, which had been a prime destination for outdoor enthusiasts of various stripes since the 1860s. Encouraged by the travel writing of "Adirondack" Murray and the photographs and guidebooks of Seneca Ray Stoddard, men and women from the eastern seaboard flooded into the area to pass the summer months under canvas or in one of the luxury

\footnotetext{
${ }^{58}$ S.R. Stoddard, Lake George Illustrated (Albany: Van Benthuysen \& Sons, 1882), 31. See also, MSCRC, Collection 291, Box 23, Folder 2, Camp Circular for Lake George, 1881.

${ }^{59}$ According to $C$. Bowyer Vaux, Bishop was one of a number of canoeists who "made Lake George their regular summer residence and kept canoes there." Vaux, "American Canoeing, Part II," 361. Bishop's decision also appears to have been inspired by a regatta that had taken place on the lake the year before. Organized by the Lake George Regatta Association, the event, which was predominantly a rowing regatta, had also targeted canoeists by arranging free entry and transport for boats and their captains to and from the lake. Vaux claims that in the wake of the regatta "the reports of the beauties of Lake George as a good canoeing field spread far and near." "Canoe Regatta at Lake George," The New" York Times, 19 June 1879; "Oarsmen Seeking Laurels," The New York Times, 16 July 1879; NYSHA, 1.6/1 1, Fragment from the '88 Meet (Montreal, 1888); C. Bowyer Vaux, "The American Canoe Association, and Its Birthplace," Outing 12, no. 5 (1888): 410-21.
} 
hotels. ${ }^{60}$ By 1880 , Lake George was home to numerous resorts, including the "architecturally noteworthy" Fort William Henry Hotel (built in 1854-5), the "wellknown...but short-lived" Fort George Hotel (built in 1873-4, burned in 1888), and the "venerable" Crosbyside House (built in 1850), as well as a number of private summer residences. ${ }^{61}$

Although early tourists to the area constructed the Adirondacks as an untouched wilderness, it was home to a diverse if scattered local population. With the end of the American Revolution, the area, which had once served as the borderlands between the Huron and Algonquin to the north and the Iroquois to the south, was populated by a "variety of newcomers," including Indigenous refugees from New England, French Canadians, and Yankees from Vermont. ${ }^{62}$ Census records and settler accounts from the late nineteenth century locate Native inhabitants near Saranac Lake, Indian Lake, and Long Lake, while reports from the ACA archive suggest there was also an Aboriginal encampment at Caldwell on the southern tip of Lake George. ${ }^{63}$ Although the census listed most of the inhabitants, Native and otherwise, as farmers, occupational plurality was a more likely reality for the residents. Beginning in the 1860s, tourism provided opportunities for men to work as guides and for women "to

\footnotetext{
${ }^{60}$ David Strauss, "Toward a Consumer Culture: 'Adirondack Murray' and the Wilderness Vacation," American Quarterly 39, no. 2 (1997): 270-86; Jeffrey L. Horrell, Seneca Ray Stoddard: Transforming the Adirondack Wilderness in Text and Image (Syracuse: Syracuse University Press, 1999). Bryant Franklin Tolles argues that it was in Lake George that "tourism in the Adirondack region originated and the first foundations of a substantive hospitality industry were firmly established." Bryant F. Tolles, Jr., Resort Hotel of the Adirondack:: The Arcbitecture of a Summer Paradise, 1850-1950 (Lebanon: University Press of New England, 2003), 30.

${ }^{61}$ Tolles, Resort Hotels, 31, 38, 40. Stoddard's guidebook lists a number of cottages and summer homes on the lake belonging to clergy, doctors, artists, and the like. Stoddard, Lake George Illuwtrated.

${ }^{62}$ Karl Jacoby, Crimes Againut Nature: Poachers, Squatters, Thieves, and the Hidden Hìtory of American Convervation (Berkeley: University of California Press, 2001), 20-1.

${ }^{63}$ Jacoby, Crimes Against Nature, 20-21; "The Canoe Congress," Forest and Stream, 22 January 1880; Florence Watters Snedeker, A Family Canoe Trip (New York: Harper and Brothers, 1892), 33. There appear not to have been official native reservations in the Adirondacks as in other areas visited by the ACA, such as Long Island or Muskoka.
} 
bring their domestic skills as cooks and housekeepers into the marketplace." ${ }^{164}$

However, the tourist industry also placed further pressure on local resources and introduced new class divisions. With the creation of a national park in 1892, the region came more closely under the control of lawmakers and conservationists. ${ }^{65}$

The first Canadian encampment and the first meeting away from Lake George was held on the Stony Lake (1883), just north of Peterborough, Ontario. ${ }^{66}$ Situated at the confluence of the Canadian Shield and the St. Lawrence Lowlands in the "long chain of lakes and water stretches known as the Trent Waters," the lake boasted two distinct landscapes: on the north shore, the rugged granite characteristic of the Shield, and to the south, a smooth shoreline dominated by deciduous forest. ${ }^{67}$ From the turn of the eighteenth century, Stony Lake fell within Mississauga territory. Under pressure from the Crown, the group surrendered their land in $1818 .{ }^{68}$ Eleven years later, they were relocated to three reservations, one of which, Mud Lake (now Curve Lake), was just north of Stony Lake. ${ }^{69}$ The relocation of the Mississauga made way for more intensive white settlement in the area around Peterborough.

The development of Stony Lake for tourism did not begin in earnest until the turn of the twentieth century. ${ }^{70}$ Before that time, a traveller was more likely to see the faces and dwellings of farmers and lumberjacks on the lake's shores, although it was

${ }^{64}$ Jacoby, Crimes Against Nature, 26.

${ }^{65}$ Jacoby, Crimes Against Nature, 27. The latter point is the subject of Chapters Two and Three of Crimed Against Nature, 29-78.

${ }^{66}$ For a broad overview of Stony Lake's development as a tourist destination/cottaging community, see Christine Bentham and Katharine Hooke, From Burleigh to Boschink: A Community Called Stony Lake (Toronto: Natural Heritage/Natural History, 2000).

67 "Stony Lake - Letter from Commodore Edwards," American Canoewt 1, no. 10 (1882): 154.

${ }^{68}$ Robert J. Surtees, "Land Cessions, 1763-1830," in Aboriginal Ontario: Historical Perspectives on the First Nations, eds. Edward S. Rogers and Donald B. Smith (Toronto: Dundurn Press, 1994), 113.

${ }^{69}$ Bentham and Hooke, From Burleigh to Boscbink, 15.

${ }^{70}$ There are discrepancies in the spelling of the lake. Within the same document, you might see Stony or Stoney. I have chosen the former for the sake of consistency. 
occasionally a destination for settler outings. ${ }^{71}$ Susanna Moodie, for example, describes canoeing on the lake in Rougbing It in the Busb. ${ }^{72}$ For this reason, Commodore E.B.

Edwards forewarned visitors in 1883, "Though easily accessible, Stony Lake is

removed from the sophistications of civilizations. Visitors to it must expect no summer resort hotels, no ball-rooms, banquets, or brass bands, but a backwoods campingground, with paddling and fishing for amusements in the daylight, and the song or tale around the camp-fire at night." ${ }^{\text {"73 }}$ Steamer service had only just started when the 1883 encampment took place, and options for accommodations beyond a tent site were few. ${ }^{74}$ Thus, the meet drew attention to the lake as a potential holiday site. Some of the ACA campers even purchased pieces of land on Stony Lake, upon which they later erected cottages and summer homes. ${ }^{75}$ Although the original inhabitants of the area had been sequestered on reserves by this point, early cottagers "recall Native women paddling from cottage to cottage with quill baskets and beadwork."

Between 1880 and 1902, just under half of the encampments took place in the Thousand Islands, the portion of the St. Lawrence River stretching between Kingston and Prescott. The St. Lawrence, which serves as the border here between Ontario and New York, offered a transnational location for a transnational organization. No less than five of the encampments were held on Grindstone Island $(1884-6,1896-7) .{ }^{77}$ The

\footnotetext{
${ }^{71}$ Vaux claims, "it had been the custom for years of many canoeists about Peterborough and Lakefield to establish permanent camps on Stony Lake and adjacent waters, where vacations could be spent paddling, shooting and fishing." Vaux, "American Canoeing, Part III," 397.

${ }^{72}$ See "Chapter V: A Trip to Stony Lake," in Susanna Moodie, Roughing It in the Busth, $2^{\text {nd }}$ ed. (London: Richard Bentley, 1852), 84-102.

73 “"The Meet," American Canoeist 2, no. 6 (1883): 79-83.

74 "Letter from Commodore Edwards," 154.

${ }^{75}$ Katharine Hooke argues that the ACA meet prompted the "rapid development of cottaging on Stoney Lake" and made Juniper Island "a mid-lake meeting spot." Katharine N. Hooke, From Campsite to Cottage: Early Stoney Lake, Occasional Paper 13 (Peterborough: Peterborough Historical Society, 1992).

${ }^{76}$ Bentham and Hooke, From Burleigh to Boscbink, 16.

${ }^{77}$ Grindstone was the most visited of any of the destinations apart from Sugar Island.
} 
Association also visited Stave Island $(1889,1898)$, Wolfe Island (1893), Hay Island (1899), and Mudlunta Island (1901). As in other locations, by the 1880s, most of the Aboriginal people that once occupied the islands in the St. Lawrence had been moved to reserves. The local Mississauga occupied the Alnwick Reserve in Northumberland County, while the transnational St. Regis-Akwesasne Reserve near Cornwall, Ontario was now the official home of the region's Mohawk people. ${ }^{78}$ The latter group, because of its position on the St. Lawrence, was well established in the river's burgeoning tourist industry as boat captains and souvenir vendors by the time of the first ACA meet on Grindstone Island. ${ }^{79}$

"Panoramic river cruises" on the St. Lawrence were in vogue in the first half of the nineteenth century. According to Patricia Jasen, “the islands' endless variety and intricacy, their constant juxtaposition of rough and smooth enhanced by the delicate play of light upon water, foliage, and rock, satisfied the most demanding standards of picturesque taste." ${ }^{100}$ Developments in transportation infrastructure such as "the expansion of steamer service and the introduction of rail travel turned the St Lawrence panorama into a mass tourist attraction. ${ }^{" 81}$ By the 1870 s, such mobile vacations were increasingly passed over for more settled affairs. ${ }^{82}$ At the turn of the century, islands on

\footnotetext{
${ }^{78}$ There had been a permanent Mohawk settlement at St. Regis since the 1770s and 1780s. Surtees, "Land Cessions," 94.

${ }^{79}$ See Chapter 3, "Wilderness Panorama," in Jasen, Wild Things, 55-79.

${ }^{80}$ Jasen, Will Tbinga, 59.

${ }^{81}$ Jasen, Will Things, 66. An article describing the location of the 1884 meet on Grindstone Island made an explicit connection to the location's long history as a tourist destination: "The daily steamer, which leaves Clayton upon the arrival of the connecting express train from Niagara Falls, passes down the wild and storied rapids of the St. Lawrence, and brings her passengers safely to Montreal before sunset, by a route which has now became a great highway of pleasure travel between the West and the mountain and sea-shore resorts of New England." Frank H. Taylor, "Grindstone Island and Its Surroundings," Outing 4, no. 1 (1884): 29-33.

${ }^{82}$ David Stradling suggests that the Thousand Islands "became a fashionable resort in the 1870 s, after George Pullman...purchased an island and built a summer home. The publicity generated by Pullman's arrival in 1871 helped create the 'Rush of 1872,' when hotels were overflowing and residents took in
} 
the Canadian and American side of the river were "dotted with fashionable hotels, cottages, camp grounds, and the mansions of American millionaires. ${ }^{183}$ The ACA encampments, in other words, were one of a number of holidaying excursions taking place among the Thousand Islands in the decades around the turn of the century, many of which were serviced by local labour. ${ }^{84}$ However, the Thousand Islands were never just a tourist destination. A number of the larger islands such as Grindstone and Wellsley were farmed and "small-scale processing industries and metal-fabricating plants" were common sights in communities on both shores by the $1880 \mathrm{~s}^{85}$

To the south and west of the Thousand Islands was another popular destination of the ACA, Lake Champlain, which the Association visited four times (1887, 1891-2, 1895) ${ }^{86}$ Lake Champlain sat immediately to the north of Lake George; a narrow strip of land that accommodated the town of Ticonderoga separated the two bodies of water. Lake Champlain was perhaps best known for its involvement in the War of 1812. According to a contemporary guidebook, it was the site of "one of the most brilliant naval feats" of that conflict, "the defeat and capture of nearly the entire British

paying guests." David Stradling, The Nature of New York: An Environmental History of the Empire State (Ithaca: Cornell University Press, 2010), 88.

83 Jasen, Wild Tbings, 77.

${ }^{84} \mathrm{Jasen}$ 's work makes clear that there was not a singular experience of the Thousand Islands after 1880. Rather, "different islands and different parts of islands, took on distinct meanings in this new resort culture." Jasen, Wild Things, 77.

${ }^{85}$ Gregory S. Kealey, Workers and Canadian Hittory (Montreal: McGill-Queen's University Press, 1995), 249. In Brockville, for example, the James Smart Manufacturing Company, which Kealey argues "dominated the local economy of the 1880s," was engaged in the production of stoves and lawnmowers. (272) Across the river in Ogdensburg, "substantial activity flourished in the extractive industries of sandstone quarrying, cooper, iron, and zinc mining," and in the "manufacturing complements of meatpacking plants and lumber mills." Morton Schoolman and Alvin Magid, Reindustrializing New' York State: Strategies, Implications, Challenged (Albany: State University of New York Press, 1986), 132.

${ }^{86}$ The encampment in 1887 was held at Bow Arrow Point, the 1891 and 1892 encampments took place at Willsborough Point, and the 1895 meet was held on Bluff Point. 
fleet by Commodore McDonough. ${ }^{187}$ By 1887, the year of the first Lake Champlain encampment, Fort Ticonderoga was but a shadow of its former glory, so much so that travel literature from the period urged tourists to visit the "most picturesque old ruin. ${ }^{188}$ Nevertheless, the fort loomed large in popular memory, as did other sites on the lake with connections to the conflict, including Crown Point and Plattsburgh. ${ }^{89}$ Although flanked to the west by the Adirondack Mountains and to the east by the Green Mountains, the lake's shorelines were characterized not by steep cliffs, but by agricultural land. The busy steamer service on the lake served these farm families, as well as local industries and the resort hotels that had been developed to house the growing numbers of tourists. The former included lumber mills, marble quarries, and magnetite mines, while the latter included the eponymously named Hotel Champlain (built in 1890), and the Fort Ticonderoga Hotel (built in 1840). ${ }^{90}$

The first of two encampments to be held on saltwater was the 1890 meet at Jessup's Neck, a small point of land on Peconic Bay on the eastern end of Long Island. ${ }^{91} \mathrm{~A}$ guidebook from 1889 described the island as a "long narrow strip of land...studded with many delightful and popular summer places, easily accessible from

\footnotetext{
${ }^{87}$ Louis M. Babcock, Our American Resorts: For Health, Pleasure and Recreation (Washington: National News Bureau, 1883), 124.

${ }^{88}$ Babcock, Our American Resorts', 124.

${ }^{89}$ See, William Henry Harrison Murray, Lake Champlain and Its Shores (Boston: De Wolfe, Fiske, and Co., 1890).

90 "From Vergennes to Lorna Island," Forest and Stream, 24 May 1883; Murray, Lake Champlain, 231-235; John C. Smock, "Geologico-Geographical Distribution of the Iron Ores of the Eastern United States," Engineering and Mining Journal 37 (1884): 217; Charles H. Possons, Lake George and Lake Champlain (Glens Falls: Chas. H. Possons, 1887), 110.

${ }^{91}$ Although there was a desire to have saltwater encampments, they were considered impractical: "The tide and facilities for obtaining fresh water for a large camp are serious difficulties, besides which some inland point, like the Thousand Islands, is more central for a majority of canoeists, who come from all directions, many from Canada." Hermann Dudley Murphy, "Lovers of the Canoe," Boston Evening Tranucript, 3 August 1909.
} 


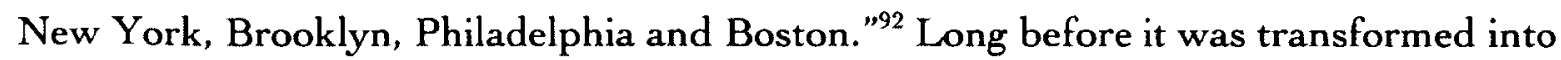
a fashionable tourist destination, Long Island had been inhabited by Algonquian peoples, specifically the Shinnecocks and Montauks on the eastern tip. The arrival of European settlers in the mid-seventeenth century had a profound impact on both groups. However, contrary to the assumption that by the nineteenth century the two communities had all but disappeared, there remains an Aboriginal presence on the island to this day. ${ }^{93}$ At the time of the 1890 encampment, there were two reservations on the eastern end of Long Island: one for the Montauk at the tip of the island and a second near to Southampton for the Shinnecock. Families living in these communities, like their white neighbours, were mostly farmers and fishers whose produce appeared on the dinner tables of nearby New York City. ${ }^{94}$ The extension of the Long Island Railroad to Southampton in 1870 made the eastern tip of the island a mere two-and-ahalf-hour train ride from the city, and prompted the development of resort tourism, as well as the construction of summer homes, which disrupted local economies and communities. ${ }^{95}$

The soaring palisades of the Hudson River provided the backdrop for the 1894 meet at Croton Point. It was here, Richard H. Gassan argues, that tourism in the United States was born in the 1810s as a result of "a confluence of historical accidents, including the valley's proximity to the most rapidly growing financial center in the United States, its remarkable scenery, and its geographical position as a waterway that

\footnotetext{
${ }^{92}$ Bushrod W. James, American Resorts (Philadelphia: F.A. Davis, 1889), 37-8.

${ }^{93}$ John A. Strong, The Montaukett Indiant of Eastern Long Island (Syracuse: Syracuse University Press, 2001).

${ }^{94}$ Marilyn E. Weigold, The Long Island Sound: A History of Its People, Places, and Environment (New York: New York University Press, 2004), 69-71, 74-9.

${ }^{95}$ Cynthia V.A. Schaffner and Lori Zabar, "The Founding and Design of William Merrit Chase's Shinnecock Hills Summer School of Art and the Art Village," Wintertbur Portfolio 44, no. 4 (2010): 307.
} 
connected some of the country's most sought-after destinations. ${ }^{\text {"96 }}$ The Hudson River came to be associated with the American Grand Tour, an imitation of the European Grand Tour that "took visitors up the Hudson to Albany, across New York to Niagara, into Canada - with visits to Montreal and Quebec - and back through New England, sometimes with a stop at the White Mountains." ${ }^{\text {"97 }}$ The Grand Tour was inspired by a desire for "scenery that could rival the European picturesque in its aesthetic value and in its wealth of romantic association." Along the banks of the Hudson, a waterway immortalized in ink and paint by James Fenimore Cooper and Thomas Cole, "unfolded the whole gamut of picturesque imagery: wild mountains and gentle valleys, quaint farms and tidy villages, nature mixed with culture in everchanging configurations. ${ }^{\prime 98}$ Because of its close proximity to New York City, the Hudson had since the 1870 s also provided numerous destinations for canoeing enthusiasts heading out on weekend cruises. ${ }^{99}$ In addition to being a touristic waterway, the Hudson, like the Erie Canal, was also a working river that serviced the many industries and towns along its shores. Canoeists travelling to the 1894 meet by train or boat would have found it hard to miss the sights and smells of the brickmaking industry on the river's shores that employed between seven and eight thousand workers in 130 manufactories. ${ }^{100}$

\footnotetext{
${ }^{96}$ Richard H. Gassan, The Birtb of American Tourim: New York, the Hudson Valley, and American Culture (Amherst: University of Massachusetts Press, 2008), 2.

${ }^{97}$ Cindy S. Aron, Working at Play: A Hittory of Vacations in the United States (New York: Oxford University Press, 1999), 131. The American Grand Tour included both "natural" sites, like Niagara Falls, and "cultural" sites, such as the hotels of Saratoga Springs. David Stradling, "We Are Still in Eden: Romanticism, Tourism, and the Power of Culture," in The Nature of New York, 76-105.

98 Jasen, Wild Things, 58.

99 "Canoe Contest on the Hudson," New York Timer, 31 May 1884; "Racing in Canoes," The New York Times, 30 May 1885; "Racing in Canoes," New' York Times, 31 May 1887; "Canoeists in Camp," The New' York Times, 4 October 1891.

${ }^{100}$ George V. Hutton, The Great Hudson River Brick Industry: Commemorating Tbree and One Half Centuries of Brickmaking (Fleischmann: Purple Mountain Press, 2003). Photographs of the 1894 encampment also
} 
Although it developed later as a tourist destination than its more southerly counterparts, by the turn of the century, Muskoka (1900) "was by far the most popular destination in Ontario for holidays of any length, and its reputation was still growing." ${ }^{101}$ Located 150 kilometres north of Toronto, the region boasted the lakes, windswept pines, and rugged shorelines characteristic of the Canadian Shield. The Robinson Treaty of 1850 deposed the Ojibway that had heretofore occupied the north and eastern shores of Lake Huron to make way for white industry and settlement. ${ }^{102}$ In the middle decades of the nineteenth century, a good portion of the shorelines of the Muskoka lakes were re-made by the axe and plow, lumbering being infinitely more successful than agriculture as a result of the abundance of rock that underlay the thin layers of nutrient-poor soil. The islands, however, remained largely wooded and thus attractive to the "eager but ill-equipped nature seekers" who travelled north from Toronto. ${ }^{103}$ As in other locales, the arrival of the railway to Gravenhurst in 1875 prompted a rapid increase in the number of visitors. ${ }^{104}$ Most stayed in the newly completed resorts like the Royal Muskoka or the Windermere, or built their own cottages. ${ }^{105}$ By 1900 , the year of the ACA encampment, the region was firmly established as a desirable summer destination for bourgeois travellers. As the lumber industry moved north, and farming became increasingly untenable, most local people

indicate that the camp was in sight of warehouses. NYSHA, 1.4/6, "Signal Station in Front of Camp Headquarters," 1894, 1.5/4, Thomas J. Hale's Scrapbook.

${ }^{101}$ Jasen, Wild Things, 116.

${ }^{102}$ Robin Jarvis Brownlie, A Fatberly Eye: Indian Agent, Government Power, and Aboriginal Resistance in Ontario, 1918-1939 (Don Mills: Oxford University Press, 2003), 4-5.

${ }^{103}$ Patricia $J$ asen argues that settlement and tourism developed not in that order, as was common in most locales, but in tandem. Jasen, Wild Things, 117.

${ }^{104}$ Jasen, Wild Tbings, 120.

${ }^{105}$ Despite its position as a seminal tourist destination in Ontario, with the exception of Jasen, little has been written on the early years of Muskoka tourism, particularly early cottaging. Peter Stevens' dissertation tackles the question of postwar cottaging in the region. Peter A. Stevens, "Getting Away from It All: Family Cottaging in Postwar Ontario" (Ph.D. Dissertation: York University, 2010). 
were drawn into the tourist industry both directly and indirectly. Although Ojibway title to the land had been extinguished, Aboriginal communities existed at Bala and Rama, and the Muskoka Lakes remained important sites for subsistence activities, such as hunting and fishing, as well as for the sale of Indigenous crafts. ${ }^{106}$

Cape Cod (1902), the second of the two saltwater encampments and the site of the last ACA meet before the move to Sugar Island, offered visitors a markedly different landscape to the meets in Muskoka (1900) and on Mudlunta Island (1901). Stunted trees, long grasses, and undulating sand dunes constituted the visual landscape, while the waves rolling in from the North Atlantic dominated the aural one. The fishing and shipbuilding industries that had long supported the local population began a steady decline in the mid-nineteenth century, a trend that was mirrored in manufacturing by the turn of the twentieth century. ${ }^{107}$ Although the Cape had all the building blocks for a successful tourist industry, including "sublime landscapes, native legends, the tales of weather-beaten 'old salts,"' and adequate transportation services, it was "regarded as a kind of New England outback, inhabited by unschooled savages with almost no contact with the outside world." ${ }^{108}$ The easterly tip of Massachusetts was not entirely foreign to travellers, having been the subject of Henry David Thoreau's posthumously published Cape $\operatorname{Co\partial }(1865) \cdot{ }^{109}$ However, Thoreau's characterization of the Cape as the "most uninviting landscape on earth" was not

\footnotetext{
106 Jasen, Wild Things, 117; Peggy J. Blair, Lament for a First Nation: The Williams Treaties in Soutbern Ontario (Vancouver: University of British Columbia Press, 2008); "Our History," in Wabta Mobaw'ket. Accessed 9 April 2012: wahtamohawks.ca/?page_id=12. Testimony describing land use practices by Anishnaabeg in "cottage country" can be found in LAC, RG10, Vol. 2328, File 67071-1 and Vol. 2329, File 67071-2.

${ }^{107}$ Lewis M. Alexander, "The Impact of Tourism on the Economy of Cape Cod, Massachusetts," Economic Geograpby 29, no. 4 (1953): 320-6.

${ }^{108}$ Brown, Inventing New England, 11, 202, 204.

${ }^{109}$ Henry David Thoreau, Cape Cod (Boston: Ticknor and Fields, 1865).
} 
altogether flattering and tourism was sluggish until the interwar period. ${ }^{110}$ It would take the automobile to transform Cape Cod into the tourist mecca it is today.

Many of the locations visited by the ACA were either established vacation spots when the organization set up their encampment or were well on their way to becoming just that. Changes in transportation, increased leisure time, more disposable income, and a shift in perceptions of leisure and nature all underpinned these transformations. ${ }^{111}$ However, none of these locations was ever just a tourist destination. As Karl Jacoby notes of the Adirondacks, "It was a place of abandoned farms and of grand new estates, where daily rhythms were set by commercial timber operations and by subsistence agriculture, by wage labor and by household chores, by summer tourism and by winter trapping, foraging, and lumber camps." ${ }^{112}$ Such economic and social richness characterized these other locations as well, although as we will see, particularly in Chapter Nine, this was rarely visible to the canoeists in part because of the work of the contemporary tourism industry, but also because of Victorian bourgeois cultures of seeing that rendered invisible other lifeways.

\section{Part IV - Sugar Island and the Politics of (Dis)Possession}

With the purchase of Sugar Island in 1901 and the official occupation in 1903, the ACA no longer had to engage in the yearly practice of choosing and preparing a site. Instead the committee could turn their attention to the seemingly more manageable task of maintenance. Similarly, for most members, the return to Sugar Island each year was characterized not by learning a new place, but by re-familiarizing

\footnotetext{
${ }^{110}$ As quoted in Brown, Inventing New' England, 202.

${ }^{11}$ Brown, Inventing New England; Aron, Working at Play.

112 Jacoby, Crimed Again't Nature, 28.
} 
themselves with an old one. Although little was said of the island's longer history at the time of purchase, Sugar Island was no terra nulliw. Prior to European contact, it had been part of the territory of the St. Lawrence Iroquois, which stretched from presentday Quebec City to Lake Ontario. ${ }^{113}$ Epidemics and conflicts between this group and the confederated Five Nations Iroquois to the south resulted in a regime change in the late sixteenth century. ${ }^{114}$ By the nineteenth century, Sugar Island and neighbouring isles fell within the Mississauga territory, although the circumstances of the group's movement into the area are uncertain. ${ }^{115}$ According to the archive of the Department of Indian Affairs (DIA), Sugar Island and "other islands in the immediate vicinity were surrendered to the Crown by the Indian owners on the $19^{\text {th }}$ June, 1856 in order that such disposition might be made of the property as would be in the best interests of the Indian owners." ${ }^{116}$ From the viewpoint of the band, however, this settlement had only applied to mainland territory. Thus, there remained "a number of unceded islands located in the Bay of Quinte, South Bay, and Lake Ontario, and between Kingston and 'Guananoque,"' which, in the 1880 s, the community continued to use for fishing. ${ }^{117}$

\footnotetext{
${ }^{113}$ Bruce Trigger, "The Original Iroquoians: Huron, Petun, and Neutral," in Aboriginal Ontario: Historical Perspectives on the First Nations, eds. Edward S. Rogers and Donald B. Smith (Toronto: Dundurn Press, 1994), 45.

${ }^{114}$ Trigger, "The Original Iroquoians," 45, 52.

${ }^{115}$ It is not clear how or when they came to occupy the Thousand Islands. Peggy Blair argues that as "white men rapidly depleted the fish and game in their ancient hunting and fishing grounds, many of the Mississauga and Chippewa First Nations were forced to leave their seasonal villages for locations further from populated areas." In a number of cases, bands "resettled themselves on reserves either adjacent to lakes or on islands, where they could fish." This may also explain why the Aboriginal groups which had occupied the islands in the St. Lawrence River ended up on a reserve in Northumberland County. Blair, Lament for a Firut Nation, 44.

${ }^{116}$ LAC, RG10, Vol. 2718, File 144, 001-53, Letter from J.C. Caldwell, Director of Indian Lands and Timber, to Allan Leja, 4 October 1932. Presumably, Caldwell is drawing from the Canadian Indian Treaties and Surrenders, which states: "The principal members of the Mississauga tribe of the Alnwick, surrendered for sale for the benefit of the tribe, all and singular, those islands lying and situated in the Bay of Quinte, in Lake Ontario, Willis' Bay and in the River St. Lawrence called 'Thousand Islands' which have not heretofore been granted or patented by the crown," as part of Surrender 77 . This text was published in 1891 after the Mississauga voiced their dissent with the original treaty.

117 Blair, Lament for a First Nation, 43-4, 79.
} 
Initially the Crown, wishing to open the land to white settlement and use, pushed the Alnwick Band, as well as other First Nations in the region, to surrender any remaining land forthwith. ${ }^{118}$ Later, they merely denied the existence of unceded territory. Thus, at the same time that the ACA was meeting in the St. Lawrence, the Mississauga were caught in a land claims dispute over the very islands that the organization occupied. ${ }^{119}$ More recently, Sugar Island had sheltered white inhabitants. James MacDonald, the keeper of the Jack Straw and Narrows lighthouses, and his family occupied the island from 1827 until sometime in the mid- $1880 \mathrm{~s}^{120}$ According to a DIA report, McDonald claimed "to have purchased this and some other Islands from Indians." ${ }^{121}$ The island also had more temporary residents. In 1885, George Keys of Lansdowne applied to the Department of Indian Affairs for the right to pasture his cattle on the island, suggesting it was no longer occupied by the MacDonalds at this time. ${ }^{122}$ Others used the land for similar purposes, though not always with permission. ${ }^{123}$

\footnotetext{
${ }^{118}$ Blair, Lament for a First Nation, 44.

119 The Band passed a resolution in 1884 in which "it expressed its willingness to surrender almost all of these non-reserve lands for the sum of $\$ 80,000$ " with the proviso that it kept "the fishing islands in the Bay of Quinte, the St. Lawrence, and Rice Lake, as well as 'any other islands belonging to the said Band' for their own exclusive use." Nine years later the Crown finally responded by rejecting the claim "on the basis that the First Nations had already been compensated for all their surrender lands in the 1818 treaties." Blair, Lament for a First Nation, 79-80.

${ }^{120}$ An affidavit signed by his son John claimed that the elder MacDonald had taken possession of Sugar Island in 1827, and lived on the island until his death in 1867. During this time, twenty acres of the Island was cleared and cultivated. John was born on the island in 1839, and lived there until their house was destroyed by fire, although no date is given for this event. A similar affidavit is included by William McDonald, born in 1937. LAC, RG10, Vol. 2718, File 144, 001-53, Report on Sugar Istand, 13 May 1885; Letter from Caldwell to Leja, 4 October 1932; Affidavit uigned by Jobn McDonald, 5 April 1901.

${ }^{121}$ See the report appended to LAC, RG10, Vol. 2718, File 144, 001-53, Letter from George Keys to Department of Indian Affairs (DIA), 29 April 1885. Later, the Department reported that it did not recognize the claim of McDonald's heirs to Sugar Island.

${ }^{122}$ The report that followed Keys' request noted that part of the island, which was "very prettily situated," was cleared. It also noted the existence of a barn "erected by the government some years ago." Letter from Key, to DIA, 29 April 1885.

${ }^{123}$ See Letters from A.B. Cowan (Indian Land Agent) to Department of Indian Affairs dated 16 June 1886, 5 July 1886, 24 July 1886, 19 May 1888, 16 May 1891 in LAC, RG10, Vol. 2718, File 144, 001-53.
} 
Beginning in 1894, the DIA began to receive requests for Sugar Island from interested buyers. That the Department had anticipated such requests is evident in their decision to have the area surveyed by Charles Unwin in January $1873 .{ }^{124}$ Susan Smith claims that islands around Gananoque and Rockport were purchased for summer retreats as early as that year, although it would be two decades before Sugar Island was sold. ${ }^{125}$ The DIA awarded possession of the island twice in 1894, but in both instances the recipients lost title for failure to comply with the terms of sale. ${ }^{126}$ The Indian Affairs archive is silent on the island's fate until 6 February 1901 when the Department received a purchase request from Charles Edwin Britton of the American Canoe Association. In his letter, Britton noted that "heretofore the camp has been a moveable one," and "it would be a good thing for the St. Lawrence and the neighbouring towns to get them permanently fixed here." ${ }^{27}$ Britton's plea reveals the Association's dependency on local labour, a point I return to in Chapter Nine, as well as the broader economic impact that the encampment had on local communities. The annual meeting, he claimed, "gives employment to our labouring men, boatmen, tent makers, etc. and also largely increases the patronage of our River Boats and in many

\footnotetext{
${ }^{124}$ Letter from Caldwell to Leja, 4 October 1932. Accounts of Unwin's progress can be found in LAC, RG10, Vol. 1899, File 1969, and RG10, Vol. 1879, File 1032. Further surveys and land valuations were conducted in the 1880s and 1890s. See, Susan W. Smith, A History of Recreation in the Thousand Islands (Parks Canada, 1974).

${ }^{125}$ Smith, Recreation in the Thow and Islands.

${ }^{126}$ The first came from Robert W. Deane of Toronto, Ontario, who was awarded the Island on 10 July 1894, and subsequently lost his right for not complying with the terms. The island was sold again later that year to George Millar of Ottawa, ON. Only two years later, however, the sale was cancelled when Millar was found to be in arrears. LAC, RG10, Vol. 2718, File 144, 001-53, Letter from Deputy Superintendent General of Indian Affairs to Robert W. Deane, 9 August 1894; LAC, RG10, Vol. 2718, File 144, 001-53, Letter from Hayter Reed to Haldane Millar, 8 October 1896.

${ }^{127}$ Letter from Britton to Smart, 6 February 1901. He claimed the attendance was from 200 to 300 people. Writing to Clifford Sifton, he increased his estimate: "annual attendance of the Association" was "no mean sum as from 3 to 400 members are present at every annual meet." LAC, RG10, Vol. 2718, File 144, 001 -53, Letter from C.E. Britton to Hon. Clifford Sifton, 19 February 1901. The letter to Sifton also claimed that the Association would raise the value of neighbouring islands.
} 
other ways increases business on the River." The benefits did not end here, for if the camp were to be located in Canada, "all supplies must be purchased here or pay duty... [and] in either case Canadians will reap the benefit." Finally, he suggested that the fact that the association attracts men from as "far west as St. Paul Minn... and the middle states," means that the meet "advertises our country over a vast extent of country." 128

However compelling Britton's economic arguments may have been, it soon came to light that four years earlier the Department had agreed to allow Dr. Bowen, of Gananoque, Ontario, to "have charge of the Island, he having agreed to look after it." ${ }^{29}$ What ensued was a battle between Bowen and the ACA for rights to the island, a contest in which both parties circulated petitions to residents of Gananoque and the surrounding area to demonstrate support for their possession of the land. ${ }^{130}$ In the end, the Department awarded the island to the ACA. ${ }^{131}$ Minister Clifford Sifton appears to have been swayed by the organization's influence and the potential benefit to the local area. In a letter to J.A. Smart, he revealed, "I think it is an advantage to all the people

\footnotetext{
${ }^{128}$ In a later letter to Clifford Sifton, Britton included a copy of the Association yearbook so that the Minister of the Interior could see the "list of membership and also the territory covered by the Association." "You will find," he continued, "that is a large and influential affair." Letter from Britton to Sifton, 19 February 1901. In both letters, he made clear that the Association was comprised of gentleman and ladies. In the letter to Sifton, he added that they are all "amateur sportsmen (nothing of a Professional...is admitted as you will see by enclosed application)."

${ }^{129}$ Internal correspondence suggests that Department was initially amenable to Association's request. LAC, RG10, Vol. 2718, File 144, 001-53, Letter from J.A. Smart to Mr. MacLean, 9 February 1901. LAC, RG10, Vol. 2718, File 144, 001-53, Letter from Unknown to the Secretary, 11 February 1901. It's not clear whether or not Bowen had the rights of a prior applicant because he appears not to have officially leased the island. However, John McDonald, in his 1901 affidavit, claims to have "dispensed of all [his] right Title and interest in the said island to George Henry Bowen" in the mid 1890s. LAC, RG10, Vol. 2718, File 144, 001-53, Affidavit vigned by Jobn McDonald, 5 April 1901. A similar statement is included in an affidavit by John McDonald's brother, William.

${ }^{130}$ Amongst other things, Bowen claimed that he had received the blessing of the McDonald family.

131 They also awarded sale on four other smaller islands in the vicinity of Sugar Island with the understanding that the organization would not build upon them.
} 
on the Canadian side to have the Canoe Association established on Sugar Island, as they hold an annual camp and spend a large amount of money every year."132

The ACA no doubt celebrated their acquisition of Sugar Island. As I noted at the outset of this chapter, however, to possess is to dispossess, for "the earth is in effect one world, in which empty, uninhabited spaces virtually do not exist. Just as none of us is outside or beyond geography, none of us is completely free from the struggle over geography. That struggle is complex and interesting because it is not only about soldiers and cannons but also about ideas, about forms, about images and imaginings." ${ }^{133}$ This brief history of Sugar Island reveals a series of dispossessions that began with the colonial state's purchase of the islands in the St. Lawrence and removal of the Mississauga to the Alnwick Reserve, and continued with the loss of title on the part of Dr. Bowen.

Although the members of the ACA did not physically expel the Mississauga from their land, their purchase of the island was enabled by technologies of imperialism such as treaties and reserves and colonial institutions like the Department of Indian Affairs. Moreover, the funds from the purchase were used to maintain these colonial relations, to only deepen the effect of aboriginal displacement. Consider the following excerpt from the "patent" for Sugar Island: "WHEREAS the Lands hereinafter described are part and parcel of those set apart for the use of the Mississaugas of Alnwick Indians. And Whereas We have thought fit to authorize the sale and disposal of the Lands hereinafter mentioned, in order that the proceeds may be applied to the benefit, support and advantage of the said Indians, in such a manner

\footnotetext{
${ }^{132}$ LAC, RG10, Vol. 2718, File 144, 001-53, Letter from Clifford Sifton to J.A. Smart, 17 June 1901.

${ }^{133}$ Said, Culture and Imperialium, 7.
} 
as We shall be pleased to direct from time to time."134 Although the ACA was not directly involved in the initial displacement of the Mississauga, their desire for and purchase of Sugar Island was part of the impetus behind the initial acquisition of such land on the part of the state, and the confinement of Native people to reservations. Underpinning all of these practices was the assumption of Aboriginal inferiority and white superiority. ${ }^{135}$

The canoeists were not ignorant of their participation in displacing the original inhabitants. An account of the 1891 meet described the encampment as follows: "a small colony of white tents greet the eye where years before the poor Indian pitched his wigwam and feasted his eyes upon the same grand scenery that now delights the canoeists and indeed the modern canoe now on the shore would turn those old time campers 'green with envy' for here we behold the finest specimen of the canoe."136 However, few appear to have any qualms about it. This should not surprise us. From the vantage point of white North Americans in the late nineteenth century, the extinction of the continent's indigenous peoples was all but assured. This point was made directly in the Watertown Re-Union shortly after the sale of Sugar Island: "The island is one of the original ground ceded by the Canadian government ceded to a certain Indian tribe to be used by them and their children forever. The tribe has since become extinct, or nearly so, and the islands are not inhabited by the descendent of the tribe. The government, however, cannot by its own prescribed limitations sell the islands, but as it is practically in control, it leases them, as in the present instance with

\footnotetext{
${ }^{134}$ MSCRC, Collection 291, Box 7, Folder 1, Patent for Sugar Island, 1901.

${ }^{135}$ Reginald Horsman, Race and Manifett Destiny: The Origins of American Racial Anglo-Saxonism (Cambridge, Mass.: Harvard University Press, 1981): 58-9.

136 "The Canoe Meet," The Troy Nortbern Budget, 16 August 1891.
} 
Sugar Island, for a term of 99 years for a certain consideration. ${ }^{.137}$ It was inconceivable that such a traditional and savage people could survive in the modern world, despite evidence to the contrary.

The ACA further secured their newfound possession with a name. Although I have referred to the island they purchased from the Department of Indian Affairs as Sugar Island, it had a number of other monikers. According to J.C. Caldwell, Director of Indian Lands and Timber in the 1930s, "Officially the Island has always been generally referred to as St. Lawrence Island." ${ }^{138}$ Locally, it was known as MacDonald's Island, an allusion to the family that had previously occupied, if not owned, the island. The island also presumably had a Mississauga name and Iroquois ones as well, although these have been lost to the historical record. Upon purchase, the Association was adamant that the island be officially known as Sugar Island on all government documents, including the surveyor's map. As Catherine Nash has noted, "In light of the paramount significance of language as a marker of collective identity, these naming processes [are] practices of cultural erasure in which the newly named and mapped places were appropriated as the indigenous cultures were subordinated." ${ }^{139}$ The desire to have the name recognized on a map added a further layer of legitimation. To borrow from Ken Brealey, 'Objectively, of course, maps do not 'do' anything; it is the actors and institutions making them that do the 'doing'. Subjectively, however, maps do 'do' a great deal. They effectively inscribe and transmit the terms of reference in which

\footnotetext{
137 "Sugar Island for a Home," Watertown Re-Union, 29 June 1901.

${ }^{138}$ Letter from Caldwell to Leja, 4 October 1932.

${ }^{139}$ Catherine Nash, "Irish Placenames: Postcolonial Locations," Transactions of the Institute of British Geographers 24, no. 4 (1999): 460.
} 
concepts of space and territory (and the cultures within them) are formulated,

evaluated, rhetoricized, and 'memorized' for subsequent generations." 140

The organization officially obtained the land in 1901. However, the first annual meeting at Sugar Island did not take place until 1903. Over the next few years, the organization or its members acquired all of the islands adjacent to Sugar Island from Indian Affairs, in order to "to keep [them] in the very best hands." ${ }^{411}$ By 1907 , the Board of Governors could declare that the ACA now felt "entirely free now from any outside interference that heretofore has been somewhat anticipated by those in authority." ${ }^{42}$ Ronald Hoffman argues that Sugar Island “provided a permanent location around which members could rally and hold meets," while also offering "inexpensive camping and water front activities to the members." ${ }^{43}$ Of greater interest to me are the ways in which the purchase of Sugar Island shaped the community of canoeists and the encampment as place. For example, Hoffman argues that after 1903, the annual encampment became "primarily an eastern meet and not a national one."144 While I do not doubt the truth of this statement, it suggests that the ACA at an earlier date did in some way represent the interests of canoeists from coast to coast.

Moreover, it obscures continuities in the kinds of people that were welcomed to the encampments. If anything, with the purchase of Sugar Island, the encampments became more exclusive.

There is a postscript to this story of the sale of Sugar Island. In 1930, members of

\footnotetext{
${ }^{140}$ Ken G. Brealey, "Mapping them 'out': Euro-Canadian Cartography and the Appropriation of the Nuxalk and 'Ts'ilhqot in First Nations' Territories, 1793-1916," Canadian Geograpber 39, no. 2 (1995): 141.

${ }^{141}$ LAC, RG 10, Volume 3044, File 236, 725-147, Letter from C.E. Britton to J.D. McLean, 16 July 1903.

${ }^{142}$ MSCRC, Collection 291, Volume 4, Board of Governor's Report, 1 October 1907.

${ }^{143}$ Hoffman, "American Canoe Association," 40.

${ }^{144}$ Hoffman, "American Canoe Association," 40. Of course, this line of argumentation assumes that at one time the organization was indeed representative of national interests.
} 
the Association "re-enacted" the "purchase of Sugar Island from the Indians." In front of an audience of ACA members, two "white traders" negotiated with four "Indians." The latter, which included a "Squaw," a "Brave," a "Chief," and "a Medicine Man," were clothed in stereotypical and historically inaccurate indigenous dress: blankets wrapped around them, multi-coloured face paint, and in the case of the Chief, a headdress common to the Plains people, not the local Mississauga or Iroquois. Photographs of the performance depict the two traders passing a rifle and a bottle of alcohol to the Indians. The caption reads: "The bottle of rum finally closed the deal." Fred Saunders, who was responsible for the scrapbook featuring the images, referred to the re-enactment as "typical ACA campfire entertainment." 145

\section{Conclusion}

Between 1880 and 1910, the annual meetings of the American Canoe Association travelled to upwards of fifteen sites in Ontario, New York, and New England. There were important differences between the sites, including the topography, local land use patterns, and the degree to which they were engaged in the tourist trade. However, there were also notable similarities. Few were wild. Rather, these locations had long histories as landscapes of subsistence, market activity, and leisure. Although Aboriginal people continued to be part of the diverse local populations and economies, their position had long been under attack by assimilative colonial policies. More recently, tourism had begun to displace and reconfigure the livelihoods and practices of white settlers as well, even as it ostensibly offered opportunities for economic gain and engagement in the wider social world.

\footnotetext{
${ }^{145}$ NYSHA, $1.5 / 3$. Saunders played the role of Chief in this entertainment.
} 
The ACA was complicit in these complementary colonizing projects, not least through their occupation of land, which dispossessed other inhabitants. ${ }^{146}$ In this chapter, I focused on two manifestations of displacement embodied in the examples of Stony Lake and Sugar Island. In the first instance, the ACA's presence on Juniper Island marked the area as a white landscape of leisure. ${ }^{147}$ It also drew the attention of bourgeois canoeists to a seemingly uninhabited wilderness. Some of these canoeists purchased plots of land on the lake, thereby undermining the supposed wildness of the area and precipitating the colonization of the Kawarthas through cottaging. The dispossession effected by the purchase of Sugar Island is more concrete. The archive holds a title of sale, which transferred the land from the DIA to the ACA on a specific date. Although these examples of dispossession proceeded differently, their consequences were the same. The lifestyles and livelihoods of both local indigenous peoples and settlers were irrevocably transformed, as were their ties to and uses of the land, all in the name of play.

The annual meetings, as this chapter makes clear, took place at out-of-the-way if not entirely wild spots in northeastern North America. The members of the ACA, by contrast, were predominantly city dwellers, calling urban locales such as Springfield, Philadelphia, Montreal, Ottawa, and New York City home. Thus, travel to the meets,

\footnotetext{
${ }^{146}$ Such complicity would come to characterize sport tourism more generally as the twentieth century gathered steam. David Whitson and Donald Macintosh, "The Global Circus: International Sport, Tourism, and the Marketing of Cities," Journal of Sport and Social lvoues 20, no. 3 (1996): 278-95; Maurice Roche, Mega-Events and Modernity: Olympics and Expos in the Grow'th of Global Culture (London: Routledge, 2000); Helen Jefferson Lenskyj, Inwide the Olympic Industry: Power, Politics, and Activitm (Albany: State University of New York Press, 2000); Helen Jefferson Lenskyj, The Best Olympic, Ever? Social Impacts of Sydney 2000 (Albany: State University of New York Press, 2002); Jules Boykoff, "The Anti-Olympics," New' Left Review' 67 (2011): 41-59.

${ }^{147}$ It also marked the island as a canoeing place. In 1887, the Northern Division of the ACA held their first annual meeting on Juniper Island. With the establishment of the Stony Lake Cottagers Association, Juniper Island became the site of yearly regattas featuring cottagers. Bentham and Hooke, From Burleigh to Boucbink, 19-21.
} 
which could take anywhere from an afternoon to a week, was an important part of the experience of attending an encampment. In the next chapter, we shall explore what was involved as the organization and campers prepared for and embarked on travel from their urban homes to the distant annual meetings. 


\section{Chapter Four: Navigating}

In July 1891, Florence Watters Snedeker, her husband, Rev. Charles Henry, and their eldest son, Karl, then aged seven, left their home in Poughkeepsie, New York, for the American Canoe Association meeting at Willsborough Point on Lake Champlain. ${ }^{1}$ The three Snedekers travelled together in a single canoe, a decked craft they had christened Gernegross and loaded down with their camping outfit of "tins, tents, rubber beds, [and] blankets." ${ }^{2}$ During the first part of the journey, which took the family along the Hudson River and Champlain Canal past Albany and Troy, they alternated paddling with barge travel and tows from riverboats and shoreline animals. ${ }^{3}$ At Glens Falls, the Snedekers placed their boat on a cart and passed along the corduroy road to Lake George, which they traversed over a number of days with a sail hung from an improvised "sapling mast." Arriving at the village of Ticonderoga, the family engaged a vegetable seller to convey Gernegross by wagon through town to Lake Champlain. After a few days rest on the southern end of the lake, they finally reached their destination by way of Burlington, Vermont on the steamers Vermont and

\section{Cbateauguay.}

Florence Watters Snedeker's travelogue, which appeared in print as $A$ Family Canoe Trip in 1892, is at once representative of meet narratives and distinct from other accounts. On the one hand, A Family Canoe Trip highlights the complex of motive

\footnotetext{
${ }^{1}$ Florence Watters Snedeker, A Family Canoe Trip (New York: Harper and Brothers, 1892). Florence Watters Snedeker was an accomplished author prior to her death in 1893. Her husband, Charles Henry Snedeker, was a Methodist minister. Emily C. Hawley, Annale of Brookfield, Fairfield County, Connecticut (Brookfield: E.C. Hawley, 1929).

${ }^{2}$ Snedeker, A Family Canoe Trip, 1.

${ }^{3}$ Shortly after their journey began, they were invited to load their canoe onto a river barge. Conscious of the strong north wind that was staring them down, they gladly accepted. Later they were offered or solicited similar assistance from other boat people travelling along the canal, as well as from animal drivers on the shoreline. Snedeker, A Family Canoe Trip, 2, 24, 123.

${ }^{4}$ Snedeker, A Family Canoe Trip, 37.
} 
technologies that underpinned long distance travel to the encampments. It also draws attention to the varied experiences engendered by different routes and mediums of travel, the diverse landscapes to which travellers were exposed, and the "social" nature of travel in the period. However, in contrast with other accounts, it offers a more detailed description of "getting there and away," being particularly notable for the attention paid to the natural and human landscapes which the family encountered. It is all the more unique as the product of a woman's pen. Even though women were well represented at the encampments from 1883 onwards, very few wrote publicly about their experiences.

This chapter employs Snedeker's travelogue and others like it to consider the theme of navigating within the context of the ACA encampments. I borrow the concept from Michael Haldrup's writing on second home holidays (cottaging) in contemporary Denmark. Haldrup conceives of navigating as one aspect of a complex of tourist mobilities that also includes inhabiting (the practice of home making) and drifting (the pleasure of movement). "To navigate," Haldrup writes, “means to depart from the places of the well-known and to set course towards points and places at which arrival is anticipated. It is as this objective is realized that the movement gains its meaning. Hence, navigation requires a rigorous organization of time and space, in which places to visit are planned in advance, possible routes considered and times of arrival scheduled." ${ }^{\prime 5}$ Haldrup uses navigating to make sense of sightseeing day trips that holidaying families engaged in while at their second home. However, the concept can be extended to include the long distance travel that took Danish families from their

\footnotetext{
${ }^{5}$ Michael Haldrup, "Laid-Back Mobilities: Second Home Holidays in Time and Space," Tourimn Geographies 6, no. 4 (2004): 447.
} 
first home to the second, and likewise, brought the canoeists from the city to the encampment. Both long-distance travel and excursions were structured modes of movement that required planning and organization. Both also had clear destinations and included travel through largely unfamiliar landscapes.

This chapter has two related preoccupations. In parts one and two, I consider how the canoeists, with the aid of the organizing committee, prepared for travel and made their way to the meets. As we shall see, not all navigations to the ACA meetings were the same. Long-distance travel by train, steamer, and canoe each produced unique kinds of experiences and encounters. Rather than conceiving of this travel as a "precondition for performing tourism," I argue that it was central to the experience of the encampment. ${ }^{6}$ Getting there and away was as foundational to attending an ACA meet as watching the races or sleeping in a tent. In this respect, I problematize any characterization of tourist travel as an empty space that precedes the "real" tourist experience at the destination. "Time spent traveling is not dead time that people always seek to minimize;" rather, "activities occur while on the move." In part three, I turn my attention to the myriad excursions - day trips, fishing trips, picnics - that the canoeists participated in during the first week of the annual meeting and to the ways in which these forms of navigating were part of inhabiting and knowing the encampment. Excursions familiarized the canoeists with local landscapes, albeit in different ways depending on the mode of transport and the "destination." They also took the canoeists away from the campsite for a brief period, which later enabled them to return "home," a concept that will re-emerge in Chapter Six.

\footnotetext{
${ }^{6}$ Haldrup, "Laid-Back Mobilities," 434.

${ }^{7}$ Kevin Hannam, Mimi Sheller, and John Urry, "Editorial: Mobilities, Immobilities and Moorings," Mobilities 1, no. 1 (2006): 12-3.
} 
It is a truism in the transportation literature that different forms of travel afford different kinds of experiences. Mobility scholars have nevertheless tended to focus their attention on a single form of movement, such as walking, airplane travel, or cycling. ${ }^{8}$ This chapter, by contrast, situates three different technologies of travelcanoe, train, and steamer-alongside one another in order to highlight variations in experience and meaning. Transportation historians have also tended to emphasize the role of epochal technologies such as trains and steamships, privileging these over more "mundane" or invisible technologies such as paddles, shoes, and canoes. ${ }^{9}$ As Phil Macnaghten and John Urry note, "such objects or mundane technologies sensuously extend human capacities into and across the physical world," thereby enabling certain practices while precluding others. ${ }^{10}$ The section on the canoe therefore asks what affordances and limitations this seemingly mundane craft engendered.

Finally, this chapter also demonstrates that travel is almost never an isolated social experience, but is undertaken in the presence of others, be they family, friends or strangers. As Mark Simpson notes, mobility is fundamental to the politics of everyday life, a "mode of social contest decisive in the manufacture of subjectivity and the determination of belonging. ${ }^{\prime 11}$ The evidence presented in this chapter thus counters the tendency in much mobility theorizing toward the figure of the nomad, an isolated and

\footnotetext{
${ }^{8}$ See, for example, "Part I: Practices," in Tim Cresswell and Peter Merriman, eds., Geographies of Mobilities: Practices, Spaces, Subjects (Burlington: Ashgate, 2011), 19-96.

${ }^{9}$ Mike Michael's work on walking boots is an excellent case in point. Mike Michael, "These Boots are Made for Walking...: Mundane Technology, the Body, and Human-Environment Relations," Body and Society 6, no. 3-4 (2000): 107-26.

${ }^{10}$ Phil Macnaghten and John Urry, "Bodies of Nature: Introduction," Body and Society 6, no. 3-4 (2000): 8.

"Mark Simpson, Trafficking Subjectu: The Politics of Mobility in Nineteentb-Century America (Minneapolis: University of Minnesota Press, 2005), xiii. Simpson refers to this as the "politics of mobility," the "contestatory processes that produce different forms of movement, and that invest these forms with social value, cultural purchase, and discriminatory power." (xiii-iv)
} 
"remarkably unsocial being...unmarked by the traces of class, gender, ethnicity, sexuality, and geography." 12 The travelers we shall meet in this chapter were, both by intent and happenstance, in constant contact with one another and with countless others who either helped them get to where they were going or whom they met along the way.

\section{$\underline{\text { Part I - Travel Plans }}$}

Travel in the northeastern United States and eastern Canada evolved rapidly over the course of the nineteenth century. Early on, roads of dubious quality were used for local transit, while riverboats of varying description enabled long distance travel. The arrival of the railroad in the 1830 s and 1840 s did not displace boats, but rather "extended freight traffic into regions that were not accessible to waterways." 13 By the late nineteenth century, much of the northeastern United States and Ontario/Quebec had been overlaid with a complex network of rail and steamship lines. This network was developed to move the raw materials and products of industrial capitalism, although it also allowed growing numbers of travellers to seek out new sights, sounds, and experiences. The emergence of travel agencies and the proliferation of guidebooks aided these travellers in navigating what was often a complicated and inconsistent

\footnotetext{
${ }^{12}$ This chapter is, thus, in some small way, a response to Cresswell's call to complicate the figure of the nomad. Tim Cresswell, On the Move: Mobility in the Modern Weatern World (London: Routledge, 2006), 5354. Cresswell cites as evidence of this particular formulation of the nomad: Walter Benjamin's flâneur, Michel de Certeau's Wanderımänner, Gilles Deleuze and Felix Guattari's nomad.

${ }^{13}$ Wolfgang Schivelbusch, The Railway Journey: The Indutrialization of Time and Space in the Nineteenth Century (Berkeley: University of California Press, 1986), 95. Between 1865 and 1890, the number of railroad miles in the United States alone increased by more than four times. John F. Stover, American Railroada (Chicago: University of Chicago Press, 1997), 134.
} 
system of transport. ${ }^{14}$ Despite the increasing numbers of people crisscrossing the continent for pleasure, leisure travel remained the privilege of upper- and middle-class whites. ${ }^{15}$ Travel, to borrow from Karen Jones, "is not a flimsy term encapsulated by leisure, freedom, romance, and adventure nor an incontrovertible badge of American national identity. Instead it is a complex process harbouring distinct social, racial, pedagogic, and class functions." 16

After 1883, a dedicated transportation committee was responsible for facilitating member travel. Via circulars, yearbooks, and the official organs, the committee provided the canoeists with schedule and fare information for routes linking the campsite to cities throughout the Northeast. ${ }^{17}$ The transportation committee also arranged for concessions from the railways and occasionally from steamship lines. ${ }^{18}$ That these concessions usually applied only to first-class travel underscores the privileged circumstances of the members. ${ }^{19}$ The committee was more directly involved

\footnotetext{
${ }^{14}$ As James Buzard rightfully reminds us, it is a mistake to assume that new technologies entirely displaced old ones, but also that a stable and coherent system of transport had developed by the late nineteenth century. On the contrary, a complex of different individuals and corporations responsible for transporting goods and people worked "with varying degrees of efficiency," making travel across large distances "apt to very complicated." Within this context, Buzard refers to travel agencies and guidebooks as "enabling institutions." James Buzard, The Beaten Track: European Tourim, Literature, and the Ways to 'Culture,'1800-1918 (Oxford: Clarendon Press, 1993), 40-1, 47-77.

${ }^{15}$ Patricia Jasen, Wild Things: Nature, Culture, and Tourwm in Ontario, 1790-1914 (Toronto: University of Toronto Press, 1995), 20-2.

${ }^{16}$ Karen Jones, "Review of Trafficking Subjecti," Engliwb Studiev in Canada 31, no. 4 (2005): 237.

${ }^{17}$ Early on and those years when the encampment was held "off the beaten track," these were necessarily more detailed, describing, for instance, how one would transfer between the train and steamer, or offering contact information for carting a canoe along a portage. Mystic Seaport Collections Research Center (MSCRC), Collection 291, Box 23, Folder 2, Camp Circular for Lake George, 1881.

${ }^{18}$ The Transportation Committee for the 1887 meet on Lake Champlain also arranged for the free use of canals, provided that "two or more canoes...lock through at one time." "Transportation to Bow Arrow Point," Forest and Stream, 28 July 1887.

19 "A.C.A.," American Canoeist 4, no. 6 (1885): 87-8. The most common railway discount was full fare to the meet and one-third return in lieu of a full round trip fare. MSCRC, Collection 291, Box 23, Folder 2, Camp Circular for Lake George, 1888; F.L. Dunnell, ed., American Canoe Avsociation Yearbook (New York: n.p., 1890), 22; New York State Historical Association (NYSHA), 1.6/1 1, Camp Circular for Sugar Istand Meet, 1904.
} 
in organizing transportation between the railway terminals and the campsite. ${ }^{20}$ Some years, this involved asking local steamers to adjust their existing routes and/or schedules to accommodate the encampment. In 1888 , for example, the Champlain Transportation Company agreed to have a steamship meet the train at Caldwell and bring its passengers to Long Island for 25 cents. ${ }^{21}$ In other years, the Association hired a steamboat for the purpose of ferrying their members back and forth to the railway station, as in the case of the 1897 encampment when the ACA chartered Pastime to ply the waters between Clayton and the campsite on Grindstone. ${ }^{22}$ Almost without exception, the ACA passed the cost for this convenience on to the canoeist, and in some years, they used the chartered craft to generate revenue..$^{23}$

It was not just people that needed to travel from city to campsite, but things as well and evidence suggests that few of the campers, men or women, were minimalists. ${ }^{24}$ According to the Daily Mail, the baggage for the 1900 Toronto Canoe Club delegation, which consisted of forty members, required "three large freight cars. ${ }^{25}$ The transportation of canoes posed a particular challenge ${ }^{26}$ Railroad companies and freight

\footnotetext{
${ }^{20}$ There was a growing sense among members that such arrangements were a necessity. This was particularly true after the 1887 meet on Lake Champlain, which received horrible reviews from canoeists for transportation. Still, in 1891, Forest and Stream noted, "Absolute quick transit for the last five miles of the long journey to camp is something of the first importance, but which has been seldom realized." "The ACA Meet," Forest and Stream, 25 August 1887; "The ACA Meet of 1891," Forest and Stream, 20 August 1891.

${ }^{21}$ MSCRC, Collection 291, Box 23, Folder 2, Camp Circular for Lake George, 1888. A similar arrangement was made for the 1895 meet at Bluff Point on Lake Champlain. NYSHA, 1.6/11, Camp Circular for Bluff Point, 1895.

22 "Outing for Canoeists," New' York Sun, 1 August 1897.

${ }^{23}$ C.V. Schulyer, ed., American Canoe Avsociation Yearbook (n.p., 1898), 39.

${ }^{24}$ Some commentators tried to claim that women brought significantly more baggage then men, including Forest and Stream: "What with many charges and recalcitrant baggage men, [the canoeist's] cares are great, but they are nothing to those of a man who in an unlucky hour promises to convey a party to Squaw Point." "The Meet of 1886," Forest and Stream, 26 August 1886.

25 "Canoeing: Opens This Morning," Daily Mail and Empire, 3 August 1900.

${ }^{26}$ Most canoeists brought one canoe with them if any at all, although there were exceptions. M.F. Johnson, for example, brought "three different paddling canoes" to the 1884 meet on Grindstone Island because he wanted to compete in all of the paddling races and you needed different boats to do so.
} 
enterprises were notorious for mistreating canoes, not surprising given the size and shape of the craft. ${ }^{27}$ In 1884 , a janitor for a New York club was made to ride in the special car at the forward end of the train to keep watch over the members' canoes. ${ }^{28}$ The following year, a canoeist returning home from the Grindstone Island meet "rode in the baggage car from Clayton to Utica, keeping a close watch on his canoe" to ensure its integrity ${ }^{29}$ There were also ongoing concerns about cost. An 1881 article in Forest and Stream claimed that canoeists were frequently overcharged for their boats because the railway and express companies mistook them for the heavier rowboats or the longer racing shells. ${ }^{30}$ Thus, the transportation committee simultaneously attempted to reduce or eliminate fares for transporting canoes to the annual meeting and to educate railroad companies (and by extension canoeists) about the right way to transport a canoe. ${ }^{31}$ While they were largely successful on the first front - most years the cost of transporting canoes to the meets was waived by transportation companies ongoing complaints about railroad service and the handling of canoes suggest the latter was a losing battle. ${ }^{32}$ It is likely for this reason that so many clubs or divisions arranged private transport for their canoes. ${ }^{33}$

\footnotetext{
Canoeists, in other words, employed creative forms to resist Association regulations. C. Bowyer Vaux, "History of American Canoeing, Part III," Outing 10, no. 5 (1887): 406.

${ }^{27}$ It was commonplace for the canoeists to discover their canoes had been damaged in transit. See, "Canoe, Camp and Camera on Lakes George and Champlain," Lowell Daily Courier, 29 August 1882. 28 "Canoe Sailors in Camp," New York Sun, 4 August 1884.

29 "Personal," Utica Morning Herald, 18 August 1885.

30 "Transportation of Canoes," Forest and Stream, 21 July 1881.

${ }^{31}$ This was seen as an issue that affected more than just ACA members travelling to the meets; it was a systemic problem. In 1888, the ACA struck a Committee on Railways Transportation to address such concerns. "Report of the Committee on Railways Transportation," Forest and Stream, 21 June 1888. ${ }^{32}$ For example, see "Homeward from Stony Lake," Forest and Stream, 19 February 1885; "The Great Canoe Meet," Outing 9, no. 2 (1886): 164-6.

${ }^{33}$ In 1887, for instance, the Brooklyn Canoe Club hired Captain $M$. Knowlton to transport its members canoes from New York City to Plattsburgh on the canal boat, $C$.W. Woodford, at a cost of $\$ 1.50$ per canoe. Similarly, in 1904, the Atlantic Division arranged for a baggage car to transport "canoes to and from Clayton free of charge," although the car was loaded and unloaded at the owner's expense. The
} 
Transportation companies appear to have been amenable to the ACA's requests for discounts and revised schedules. Occasionally, they went out of their way to accommodate the Association. In 1892, for instance, the Delaware \& Hudson Railway built a temporary station and installed a telegraph operator near to the Willsborough Point campsite. ${ }^{34}$ While some railroad and steamer companies saw an economic benefit in accommodating the ACA and its members, this was not always the case. ${ }^{35}$ For example, the Lake Champlain Transportation Company reportedly made stops at the Willsborough Point meet in 1891 "with great reluctance." ${ }^{36}$ Similarly, in 1883 , the New York Central Railways frustrated the Association's planning efforts by declining to make arrangements in advance of the meet. ${ }^{37}$ It is possible that concessions were not always lucrative for the railways, particularly before the organization was well established or in later years when attendance at the encampment had declined. ${ }^{38}$ When the ACA felt they had been treated unfairly, they could (and did) direct their members to other companies. For example, when the Rome, Watertown, and Ogdensburgh Railway refused to lower their rates for canoeists travelling to the 1883 meet, members were encouraged to travel via the Utica or Black River lines. ${ }^{39}$

Central and Eastern Division had made similar arrangements. "Transportation to Bow-Arrow point," Forest and Stream, 14 July 1887; NYSHA, 1.6/11, Camp Circular for Sugar Island, 1904.

${ }^{34}$ "Now for a Big Canoe Meet," New' York Times, 31 July 1892.

${ }^{35}$ Railroads, in particular, played an important role in promoting vacationing more broadly, a point I explore more fully in the next section. See, also, Cindy S. Aron, "Chapter 2: Summer Hotels are Everywhere...: A Flood of Vacationers," in Working at Play: A Hiwtory of Vacations in the United States (New York: Oxford University Press, 1999), 45-68.

36 "The ACA Meet of 1891," Forest and Stream, 20 August 1891.

37 "Driftings," American Canoeitt 2, no. 4 (1883): 59.

${ }^{38}$ Some years, the railways protected themselves by including stipulations in their discounts. The Long Island Railroad agreed to provide the standard one and one-third fare concession as long as a minimum of fifty members travelled on their rail line. In 1907, the reduced fare was "based on attendance of one hundred or more." F.L. Dunnell, ed., American Canoe Ausociation Yearbook (New York: n, p., 1890), 67; MSCRC, Collection 291, Box 23, Folder 2, Camp Circular for Sugar Istand, 1907.

39 "Driftings," American Canoeitl 2, no. 7 (1883): 104. 
Regardless of the location of the camp, some members of the transnational organization had to cross an international boundary on their way to the meets. As with other aspects of travel, organizers sought to ease border crossing by making advance arrangements with the respective customs agencies. At issue in most cases was not the movement of bodies, but rather of goods normally subject to duty. Organizers sought to secure free entry for the members' canoes and camping outfits. ${ }^{40}$ As with travel discounts, campers were generally assured this privilege provided they had a certificate of membership signed by the secretary. ${ }^{41}$ A number of the later meets including the Sugar Island gatherings had customs officers on site for the duration of the encampment, a convenience that saved the canoeists both time and travel..$^{42}$ This officer appears to have been a local person appointed by the state. For example, Michael Delaney, the farmer from whom the Association rented the Grindstone Island campsite, was appointed "inspector of customs" for the 1885 encampment. ${ }^{43}$ The work of the organizing committee certainly had practical advantages for the canoeists. However, in some cases, such preparations also served to limit or discipline travel choices. For example, having arranged for the "palatial steamer

\footnotetext{
${ }^{40}$ Similar courtesies were not extended to all boaters. Yachter J. Arthur Brand of the Minima Yacht Club of England, had to pay $\$ 48$ duty to bring his boat, Spruce IV, to the United States in 1895 . "Tuning Up Spruce IV," The New York Sun, 15 September 1895.

41 "The Meet," The American Canoeit 2, no. 6 (1883): 79-83. The circular for the 1893 meet included a stipulation that such canoes and kits would be provided with free entry provided they returned to their country of origin within 30 days. R. Easton Burns, ed., American Canoe Avsociation Yearbook (Kingston: Daily News Printing House, 1893), 11.

${ }^{42}$ References to onsite customs officials appear in, "City and Vicinity: Briefs," Watertown Re-Union, 8 July 1885; "The Tenth Annual Meet of the American Canoe Association," Sail and Paddle 7, no. 9 (1889): 198-204; "Around the Pine Camp Fire," New' York Times, 20 August 1893; MSCRC, Collection 291, Box 23, Folder 2, Camp Circular for Sugar Istand, 1907; NYSHA, 1.6/1 1, Camp Circular for Sugar Island, 1910.The role of the officer is succinctly described in the 1907 circular.

43 "City and Vicinity: Briefs," Watertown Re-Union, 8 July 1885. Delaney's appointment echoes a broader reality of nineteenth-century state formation, namely that the influence of the state was uneven as a result of local conditions and personnel. See, for example, Bruce Curtis, The Politicus of Population: State Formation, Statititict, and the Censte' of Canada, 1840-1875 (Toronto: University of Toronto Press, 2001), and Karl Jacoby, "Part I," in Crimes Against Nature: Squatters, Poaches, Thieves, and the Hidden History of American Contervation (Berkeley: University of California Press, 2001), 11-75.
} 
Puritan" to ferry members to the 1884 meet at Grindstone Island, the organizing committee decreed that no other steamer would be permitted to land at the camp wharf without a permit. ${ }^{44}$ Similarly, at the 1907 meet, a single steamboat was arranged to meet the train at the Clayton dock on the morning of 10 August and to return passengers to the same on 24 August. In this case, organizers appear to have been less concerned with controlling access to the encampment, although this may have been a consideration, than with "encouraging" members to stay for the full two weeks. ${ }^{45}$

While responses to the yearly arrangements were largely positive, the canoeists were not always satisfied with the work that the transportation committee performed. The 1887 meeting is a good case in point. Forest and Stream claimed the meet was plagued by the worst transportation arrangements in the organization's history. ${ }^{46}$ First, there were only two trains per day arriving from Albany/New York City. Second, the steamer Maquam only made one trip to camp daily, and the train was usually so late as to miss it. As a result, most of the visitors had to pass a night unexpectedly in Plattsburgh. ${ }^{47}$ Accounts of the meets indicate the travellers were forthcoming with their dissatisfaction.

To be clear, while the work of the organizing committee was intended to facilitate individual travel plans, it did not stand in for them. Assuming their clubs (or divisions in later years) had not made any special arrangements, individual canoeists interested in attending the encampments still had to identify which lines they could/would take, on what days and at what times, and purchase their passage. They

44 "The ACA Meet," Forest and Stream, 10 July 1884.

${ }^{45}$ MSCRC, Collection 291, Box 23, Folder 2, Camp Circular for Sugar Island, 1907. As I explore in more detail in Chapter Seven, this was an ongoing concern for the organization.

${ }^{46}$ The 1887 meet served as an exemplar of poor travel arrangements for later meets. See, for example, "The ACA Meet of 1888: The Camp and the Association," Forett and Stream, 6 September 1888.

47 "The ACA Meet," Forest and Stream, 25 August 1887. 
also had to prepare their luggage, and make arrangements for their baggage and canoes. Finally, they had to transport themselves from home to the station or wharf. To do so, they drew heavily on the meet circulars and transportation details provided by the organizing committee. However, as I suggested in Chapter Two, canoeists could make use of other sources of information to plan for and embark on the journey to the encampment, including guidebooks. ${ }^{48}$

Guidebooks, a subgenre of travel literature that appeared in North America in the mid-1820s, were well-established components of touristic practice by the late nineteenth century. ${ }^{49}$ These texts, particularly in North America, (in)formed how travellers moved and saw the "new spaces of the expanding nation. ${ }^{.50}$ As both "literal and imaginative guides," they helped "to define explicitly what tourism was, where in America in happened, and how to do it." ${ }^{\text {I5 }}$ Guidebooks "preceded the tourist, making the crooked straight and the rough places plain for the tourist's hesitant footsteps; they accompanied the tourist on the path they had beaten, directing gazes and prompting responses. ${ }^{152}$ In other words, they afforded certain touristic experiences and interpretations, while precluding others. David Michalski captures this sentiment perfectly: "Like a map, a guidebook can open and close roads; it can both shield and

\footnotetext{
${ }^{48}$ MSCRC, Collection 291, Box 23, Folder 2, Camp Circular for Lake George, 1881.

${ }^{49}$ Prior to this, travel literature predominantly consisted of personal accounts of travel, gazetteers, and geographies. Richard H. Gassan, The Birth of American Tourwsm: New' York, the Hudson Valley, and American Culture (Amherst: University of Massachusetts Press, 2008), 70-1; Richard Gassan, "The First American Tourist Guidebooks: Authorship and the Print Culture of the 1820s," Book History 8 (2005): 51-74. American guidebooks bore the imprint of their European predecessors. Particularly influential were books produced by the House of Murray in London and those published by Karl Baedeker \& Sons, of Leipzig, Germany. Buzard, Beaten Track, 65.

${ }^{50}$ Matt Johnston, "National Spectacle from the Boat and from the Train: Moulding Perceptions of History in American Scenic Guides of the Nineteenth Century," University of Toronto Quarterly 73, no. 4 (2004): 1023.

${ }^{51}$ Johnston, "National Spectacle," 1023; Gassan, Birth of American Tourism, 71. Gassan emphasizes the part played by guidebooks in constructing American national identity by defining "for Americans the places that were uniquely theirs." (72).

${ }_{52}$ Buzard, Beaten Track, 67.
} 
reveal possibilities. Not only does the guidebook record, observe, or recommend, it applies force on what it aims to interpret. ${ }^{n 3}$

In addition to the books produced by independent entrepreneurs, such as S.R. Stoddard, a large proportion of the guidebook industry in this period was occupied by texts commissioned by railway and steamship companies. ${ }^{54}$ Alongside schedules of their various lines, such guidebooks also provided narrative descriptions of the routes taken. According to Matt Johnston, transportation guidebooks were to be utilized while the railcar or steamship was in motion. Using the example of Bradbury and Guild's Boston and Worcester and Western Railroads (1847), Johnston provides the following description of the intended use: "If the train is really moving at the brisk pace of forty miles an hour (as the preface claims), the reader is given approximately eight or nine minutes every two pages to correlate his or her position on the route map, identify sites outside the window, and read about the historical events, technological marvels, and aesthetic merits connected with them. ${ }^{n 55}$ Of course, there is often a disparity between prescription and practice, and we can assume that guidebooks were no exception.

Newspapers and magazines could also function as handbooks for the prospective traveller. ${ }^{56}$ In addition to providing detailed accounts of the meets after the fact on a yearly basis, periodicals also frequently previewed the encampment in the spring and early summer. While the majority of these articles were devoted to

\footnotetext{
${ }^{53}$ David Michalski, "Portals to Metropolis: $19^{\text {th }}$-Century Guidebooks and the Assemblage of Urban Experience," Tourist Studied 4, no. 3 (2004): 188.

${ }^{54}$ Railway booklets and guides "offered detailed information on excursion routes, hotels, summer cottages, and farmhouses." Aron, Working at Play, p. 51.

${ }^{55}$ Johnston, "National Spectacle," 1030.

${ }^{56}$ Cindy Aron has similarly noted that "newspapers not only described but helped to foster the growing interest in vacationing." Working at Play, 48.
} 
describing the site, the subject of Chapters Five and Six, sometimes they included details about travelling to and from the meets. For example, Frank Taylor had the following advice for eastern visitors on their way to Grindstone Island: "New England members will probably come via the Ogdensburg \& Lake Champlain R.R., from Rouse's Point to Ogdensburg, which is thirty-six miles below Alexandria Bay, and a good place to take the water. ${ }^{157}$ Occasionally, advice came from early visitors to the site. For example, a "special correspondent" offered the following counsel to travellers attending the 1891 meet at Willsborough Point:

The extremity is a full six miles from the railroad station at Willsborough, and is reached by wagon road from the station. Coming then from the south, it is better not to leave the train at Willsborough, but to keep on to the next station, Port Kent. After leaving the little hamlet from which the point takes its name, the train skirts the head of Willsborough bay, six miles long and a mile and a half wide, until after several minutes' run one can plainly see, opposite, the fine grove of trees which divides the main camp from the ladies tents...Port Kent lies a little north of the point, but it is an easy paddle or sail down to camp if the wind is right, and if it is wrong, a puffing and consequential steamer enables one to disregard it. ${ }^{58}$

In some cases, canoeists preparing for the encampment actively pursued and/or contributed travel information. Publications like the American Canoeist provided the perfect forum for inquiring about getting to and from the meets. In 1882, for example, a Chicago-based canoeist interested in cruising to Lake George petitioned his fellow readers for routes from the Windy City ${ }^{59}$ The following year, Orange Frazer advised canoeists travelling to Stony Lake: "Members entering Canada via Grand Trunk at Detroit, should go to the up-town office on Jefferson Ave, and the agent there will

\footnotetext{
${ }^{57}$ Frank H. Taylor, "Grindstone Island and its Surroundings," Outing 4, no. 1 (1884): 33.

58 "Musquito Fleet," The Salt Lake Herald, 9 August 1891. As so many of the newspaper articles produced about the meet were re-printed in a variety of periodicals, I am assuming rightly or wrongly that this article would have appeared in newspapers closer to the location of the meet.

59 "From Chicago to Lake George," American Canoeist 1, no. 3 (1882): 40.
} 
supply tickets at reduced rates, and a letter to conductors of the road, instructing them to carry canoes, etc., free." He also encouraged his audience to "Exchange [their] American for Canadian money before crossing the border, as US bank-notes are at one per cent discount, and silver coins twenty per cent." ${ }^{60}$

Travelling to the annual meetings began long before the canoeist left home with their trunk and boat in tow, although adjustments to one's travel plans could take place up to the point of departure and, in the case of obstacles, during the journey itself. Travel to the meets invited and often required preparation and planning months in advance. The organizing committee, but particularly the transportation committee, functioned much like a travel agency in this period, arranging for concessions and organizing services such as customs inspectors and travel between the railway terminal and campsites. The practices of preparing for the encampments were also structured by the available travel literature, which included the meet circulars, guidebooks, and periodicals. Canoeists negotiated these various sources of information (and discipline) as they prepared to travel.

\section{Part II - Getting There and Away}

The physical location of the encampment influenced the means and time of travel for those planning their journeys to the meet. There was usually a small contingent of canoeists who resided close to the campsite. Members of the Lake George Canoe Club had a short trip to the 1882 and 1888 meets, ${ }^{61}$ while New Yorkers

60 "Stony Lake," Forest and Stream, 2 August 1883.

${ }^{61}$ The Lake George Club was organized in 1881. "Driftings," American Canoeitt 1, no. 5 (1882): 71. 
were able to commute daily to the 1894 meet at Croton Point ${ }^{62}$ For some, the ACA gatherings were near to summer residences, including Frank Taylor, whose cottage on Round Island was a stone's throw from the Grindstone Island meets. Most visitors, however, had further to go, especially when the encampments were at one of the extremes of the organization's boundaries, such as in Muskoka (1900) or on Cape Cod (1902). Particularly in the early years, it was not uncommon for the trip from home to camp to take two days or more if travelling by rail, and significantly longer by canoe.

As the canoeists travelled from doorstep to campsite, they made use of multiple transportation technologies. While the bulk of long distance journeys were accomplished by "epochal" technologies such as the train and steamer, travelling shorter distances, from railway terminus to steamer wharf for example, involved more "mundane" mediums such as streetcars, stages, wagons, and barges. ${ }^{63}$ These different modes of transport mediated how "places and landscapes [were] sensed and made sense of." ${ }^{164}$ They also invited different social experiences, for, as John Urry reminds us, travel "result [s] in intermittent moments of physical proximity to particular peoples," or co-presence. ${ }^{65}$ In this section, I consider the environmental and social experiences that three of these technologies - canoes, trains, and steamers - engendered as the canoeists made their way to the annual meetings of the ACA and back again.

The journey between home and the encampment was not a "smooth corridor."

Rather it involved the negotiation of multiple intersecting networks of mobility that

\footnotetext{
${ }^{62}$ NYSHA, Box 1.6/2, D.B. Goodsell, A Canoeing Reminucence (1936), 6.

${ }^{63}$ I borrow this language from Michael, "These Boots." The shorter trips involved navigating urban areas, familiar and not, as well as small towns and, in some cases, rural areas.

${ }^{64}$ Haldrup, "Laid-Back Mobilities," 436; David Crouch, "Places Around Us: Embodied Lay Geographies in Leisure and Tourism," Leisure Studie, 19, no. 2 (2000): 63-76.

${ }^{65}$ John Urry, "Social Networks, Travel and Talk," Britwot Journal of Sociology 54, no. 2 (2003): 163.

Emphasis in original.
} 
occupied different scales and moved travellers at different speeds. ${ }^{66}$ Connections between these networks occurred in train stations, at wharfs, on street corners, and at shorelines. Depending on the location of the transition, these nodes could be lively ACA affairs, as in the case of the Muskoka meet in 1900, where members travelling by rail from various points converged at the steamer docks. ${ }^{67}$ Photographs of the wharf in Gravenhurst, including Figure 4.1, depict a "scene of bustle and confusion." In this case, it was not just bodies and baggage that was transferred from the railcars to the steamer, but also the "streamers, flags and burgees" with which the Toronto Canoe Club had decorated their railcar. ${ }^{68}$

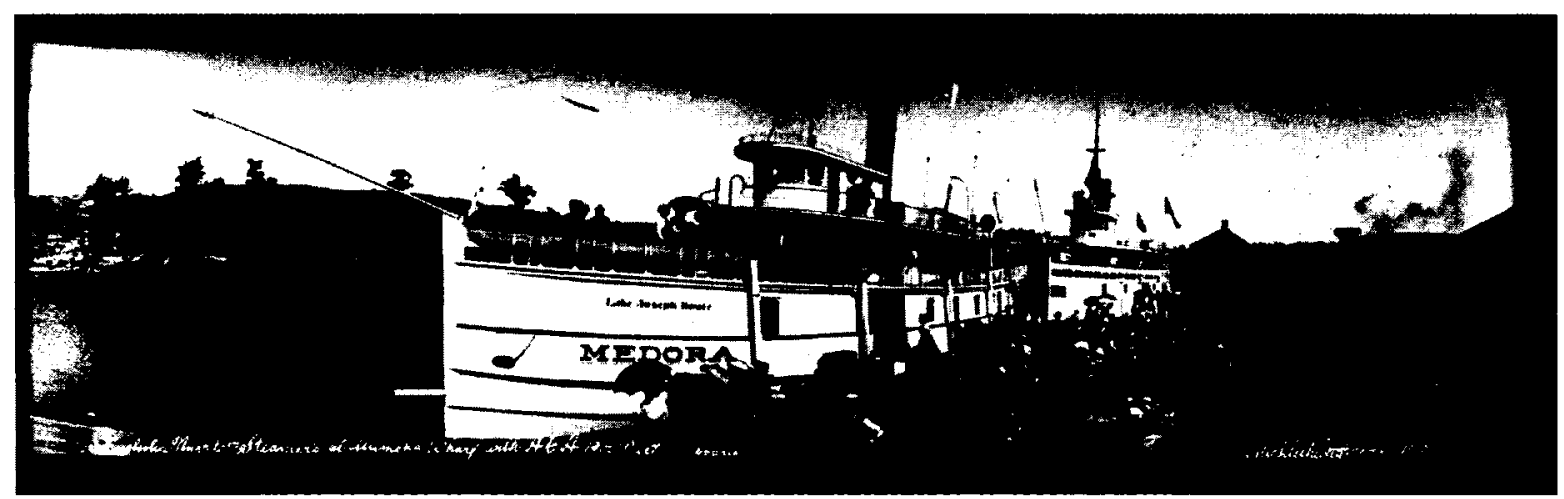

Figure 4.1 - "Muskoka Navigation Steamer 'Medora' at Muskoka Wharf, [Ont.] with American Canoe Association on board, 1900." [Source: LAC, Frank W. Micklethwaite Photographs, PA-068442.]

These points of transition were rarely quick. Consider the following report from a visitor to the 1891 meet at Willsborough Point: "The connection with the trains from the south...is hardly perfect, entailing a wait of nearly five hours at Port Kent. In the hurry and bustle of everyday life, a few hours of serious thought and deliberate introspection, communing with one's self as it were, are never thrown away. At the same time, one would hardly select the string piece of the Port Kent dock on an August

\footnotetext{
${ }^{66}$ Here I am echoing the observations of Hannam, Sheller, and Urry, "Editorial," 12.

${ }^{67}$ D.J. Howell, "The International Canoe Meet," The Canadian Magazine 15, no. 6 (1900): 515.

${ }^{68}$ Howell, "International Canoe Meet," 515.
} 
morning for such mental discipline. ${ }^{\prime 69}$ Delays also happened en route. For example, a broken log boom slowed the steamer carrying the Knickbocker Canoe Club to the 1883 meet on Stony Lake. ${ }^{70}$ Similarly, in 1890, Ford Jones arrived to the Jessup's Neck meet without a tent, bedding or change of clothes because his train had been obstructed by a strike on the New York Rail Road, and he chose not to wait. ${ }^{11}$

The border represented another kind of transition, a threshold as canoeists moved from one national space to another. ACA membership certificates enabled the canoeists to cross the border without having to pay duties, but they did not eliminate wait times and searches. In 1890, O.L. Spaulding, Assistant Secretary in the Treasury Department, reminded the Collectors of Customs at a number of border crossings that "the customary examination should be made" of travellers to the encampments "to prevent any frauds upon the revenue. ${ }^{n 2}$ In theory, the border crossing like other transitions in the journey could go well or poorly. However, I have only uncovered a handful of references to canoeists experiencing difficulties. Most of these are associated with the 1889 meet at Stave Island ${ }^{73}$ According to Forest and Stream, as a result of "abominable Customs regulations," "the passenger from Boston or New York who came by the night express, arriving at Clayton before 7 AM was obliged to wander around the rather prosaic town until noon or later before finding a steamer for camp." Apparently, steamers that departed earlier in the day "were not permitted to

\footnotetext{
69 "The ACA Meet of 1891," Forest and Stream, 20 August 1891. At the 1889 meet at Stave Island, for example, canoeists were forced to wait for half a day because there were no suitable boats to the encampment. In 1890, the wait was "anywhere from six to twenty-four hours." "American Canoe Association Meet," Forest and Siream, 12 September 1889; "The ACA Meet of 1890-1," Forest and Stream, 30 October 1890.

70 "The Stony Lake Meet," Peterborough Examiner, 16 August 1883.

71 "American Canoe Association," Forest and Stream, 14 August 1890.

${ }^{72}$ Forest and Stream, 31 July 1890.

${ }^{73}$ See also "Canoists [sic] Gathering," Rocbester Democrat Cbronicle, 20 August 1896.
} 
land passengers in Canadian territory under penalty of heavy fine., ${ }^{74}$ This example speaks to the particular difficulties posed by the St. Lawrence River, an international waterway. According to a later issue of Forest and Stream, transport between Clayton, Gananoque, and the ACA encampment would be simple if "it were not for the wise and beneficent regulations made by [the US] Government apparently for the annoyance of American citizens." The commentator found particularly frustrating "a law of long standing" that stated "no Canadian vessel is permitted under heavy penalties to call at two American 'ports' in succession." ${ }^{\prime 75}$ The relative ease with which the canoeists appear to have moved back and forth across the border raises questions about the meaningfulness of that boundary for bourgeois recreationalists in the late nineteenth century ${ }^{76}$

\section{Canoe}

Early circulars encouraged members to travel to the meets by canoe. ${ }^{77}$ This was likely a function of the fact that the organization conceived of themselves as an association of cruisers. However, it also fits with the anti-modern impulse characteristic of outdoor recreation in this period. ${ }^{78}$ Canoe travel offered a more "authentic" wilderness experience than modern forms of transportation. Although there is no record of how many people completed the journey from home to the

74 "American Canoe Association Meet," Forest and Stream, 12 September 1889.

75 "Canoeing," Forest and Stream, 23 November 1895.

${ }^{76}$ Similar questions have been raised by scholars of borderlands. See, for example, Sheila McManus, The Line Which Separates: Race, Gender, and the Making of the Alberta-Montana Borderlandy (Edmonton: University of Alberta Press, 2005).

${ }^{77}$ See, for example, NYSHA, 1.6/11, Camp Circular for Stony Lake, 1883.

${ }^{78}$ Alexander Wilson offers a succinct overview of the intersection of leisure and nature on both sides of the border in the pre-World War II era in The Culture of Nature: North American Landscapes from Diuney to the Exxon Valdez (Toronto: Between the Lines Press, 1990), 23-8. See, also Paul Sutter, Driven Wild: How the Fight Against Automobiles Launched the Modern Wildernes Movement (Seattle: University of Washington Press, 2002), 20-3. 
encampment (or vice versa) by canoe, it was never a large number. ${ }^{79}$ More common, but still rare, were the canoeists who paddled or sailed their canoes for a portion of the trip. ${ }^{80}$ Travelling by canoe took significantly longer than by rail or steamer, one reason that it was never wildly popular as a method of transportation to the meets. ${ }^{81}$ However, for those with sufficient time, cruising, as we shall see, afforded opportunities unavailable in mass transport.

Most of these intrepid travellers were men, although not all as the example of Florence Watters Snedeker makes clear. Other women included Mrs. Parmalee of Hartford, Connecticut, who paddled to at least one meet alongside her husband, but attended many more besides. ${ }^{82}$ There were also three women canoeists who were part of the Jabberwock Canoe Club (Springfield, Ohio) cruise to the 1887 meet on Lake Champlain. ${ }^{83}$ It was rare for a canoeist to undertake the trip on his or her own. ${ }^{84}$ More

\footnotetext{
${ }^{79}$ The most prominent example is the Snedeker family whose journey to and from the 1891 meet on Lake Champlain opened this chapter. Dr. Charles A. Neide, of the Lake George Canoe Club, was one of the more consistent cruisers, paddling to or from at least three encampments in the $1880 \mathrm{~s}$. He also used the 1882 meet at Lake George as the jumping off point for the cruise to Pensacola, Florida that he immortalized in The Canoe Aurora: A Cruive from the Adirondacks to the Gulf (New York: Forest and Stream Publishing Company, 1885). R.B. Burchard appears to have made the longest journey by canoe, arriving at the 1886 encampment on Grindstone Island from the Bay of Fundy, a journey of more than 1000 kilometres. Snedeker, A Family Canoe Trip; "Homeward Bound," Forest and Stream, 6 September 1883; "Cruising Notes," Forest and Stream, 10 July 1884; "Cruising Notes," Forest and Stream, 24 July 1884; "The Association Meet," Forest and Stream, 6 August 1885; "The Canoe Meet Ended," New York Times, 28 August 1886.

${ }^{80}$ Typically, this was the last leg between the railway terminus and the campsite, as in the case of the three canoeists who sailed/paddled from Cape Vincent to Grindstone Island in 1886, roughly thirty kilometres. Paul Vernon did the reverse when he paddled his canoe from Brooklyn to the $125^{\text {th }}$ Street Terminal in Manhattan. "The Great Canoe Meet," 166; Trent University Archives (TUA), 83-014/2, Paul Vernon, Tales of the $A C A, 1940$.

${ }^{81}$ Of the eight canoeists who travelled home together from the 1883 meet on Stony Lake, only L.L. Coubert completed the entire journey with Dr. Neide. The rest of the men had to depart at various times, as their work called them back to the city. "Homeward from Stony Lake," Forest and Stream, 19 February 1885.

${ }^{82}$ Given their penchant for canoe travel, it is possible the Parmalees also journeyed to other meets in this way. For example, a note in the Huntingdon Globe, dated 19 June 1884, claimed that "Dr. G.L. Parmelee and wife...expect to travel 2,000 miles this summer in a canoe."

${ }^{83}$ There are only a handful of images from this trip. Beyond the captions, there is very little information about the participants, the route, etc. NYSHA, 1.1/28, Photographs from Lake Champlain, 1887.
} 
common were pairs like Clytie and his companion who canoed to Lake George from Lowell, Massachusetts, in 1882 or a small group like the Jabberwocks. Unlike wilderness canoe trips, which often depended directly on the labour of others, few if any of the groups travelling to the meets by canoe appear to have taken a guide or servants with them. ${ }^{85}$ Finally, most were experienced cruisers, although here too there were exceptions. Clytie and his companion, for example, described themselves as "green." 86

While it was not a rule to do so, those who travelled by canoe carried their "outfit" with them and camped along the way. Florence Snedeker describes the daily task of setting up camp, which included finding "a clearing" and "two trees for the tent. ${ }^{187}$ Likewise, images from the Jabberwock cruise depict the campers cooking together over an open fire and sharing meals. ${ }^{88}$ When the weather was bad or the canoeists desired a more comfortable repose, there were alternatives to tenting. Few of the routes were truly isolated. For example, the pair from Massachusetts took refuge from a storm at the Robert's Rock Hotel on Lake George ${ }^{89}$ Supplies were acquired from stores and farmhouses along the way. The Snedeker family purchased fruit from farm children and treats such as "bananas, peanuts, gumdrops, and root-beer" from the lock stores. ${ }^{90}$ The two Lowell canoeists bought both food and gear, including tin

\footnotetext{
${ }^{84} \mathrm{Dr}$. Neide appears to have cruised from Ballast Island in Lake Erie to the 1885 Grindstone Meet on his own. "The Association Meet," Forest and Stream, 6 August 1885.

${ }^{85}$ Jasen, "Close Encounters," in Wild Things, 133-49. Although Jasen is concerned with Native guides, not all guides were Aboriginal, as the example of the Adirondacks makes clear. Hallie E. Bond, Boats and Boating in the Adirondacks (Syracuse: Syracuse University Press, 1998), 57-67, 164-6.

86 "From Vergennes to Lorna Island," Forest and Stream, 24 May 1883.

${ }^{87}$ Snedeker, A Family Canoe Trip, 27. Her son, Karl, pronounced, "It is nicer to sleep in a farm-house, though it is more fun in a tent." (72)

${ }^{88}$ NYSHA, 1.1/28, Photographs from Lake Champlain, 1887.

89 "From Vergennes to Lorna Island," Forest and Stream, 24 May 1883.

${ }^{90}$ Snedeker, A Family Canoe Trip, 30, 24
} 
dishes, from local stores in Vergennes before departing. One of their first stops once on the water was at a farmhouse to buy milk..$^{91}$

Those canoeing to the meets frequently availed themselves of other forms of transport. They typically did so to overcome some sort of obstacle, to make up time or to avoid inclement weather. Dr. Neide and L.L. Coubert hired a man to carry their canoes between Lake Champlain and Lake George, members of the Stony Lake canoeing party used both trains and steamers to accommodate their rapidly depleting vacation time, and the Snedekers purchased passage on the Vermont and Cbateauugay because of disagreeable weather. ${ }^{92}$ However, the Snedeker family also interrupted their paddling for social reasons. Towing, they claimed, allowed them to become "better acquainted" with their "fellow travellers." ${ }^{93}$ This rationale is consistent with Florence Snedeker's attention in her book to human landscapes. In addition to the "boat people" with whom they travelled up the Hudson, Snedeker introduces us to Dominic Dumas, the Irishman who manned one of the lockstores on the Champlain Canal, and to the "smiling woman" who "ran out, and, with a propriety that savored of genius, waved a teapot in honor of domesticity afloat. ${ }^{194}$ Also appearing in her account are the aforementioned farmers' children, the "dark maidens" of the "Indian encampment" in Caldwell, and Mr. Windham, who accommodated their tents on Lake George when there were no campsites in sight. ${ }^{95}$ However, with the exception of a professor and his wife whom they met at Fort Ticonderoga on Lake Champlain, it is clear that Snedeker

\footnotetext{
91 "Canoe, Camp and Camera on Lakes George and Champlain," Lowell Daily Courier, 29 August 1882.

92 "Cruising Notes," Forest and Stream, 10 July 1884; "Cruising Notes," Forest and Stream, 24 July 1884; Snedeker, A Family Canoe Trip, 80-84; "Homeward from Stony Lake," Forest and Stream, 19 February 1885.

${ }^{93}$ Snedeker, A Family Canoe Trip, 24.

${ }^{94}$ Snedeker, A Family Canoe Trip, 19-23.

${ }^{95}$ Snedeker, A Family Canoe Trip, 30, 33, 42.
} 
did not view these acquaintances as equals, but rather as curiosities. It is no coincidence that her account is akin to an ethnography of rural upstate New York. As Joan Pau Rubies has shown, "the description of peoples, their natures, customs, religious, forms of government, and language," both in a systematic form and as series of "subjective musings," has been deeply embedded in travel writing since the sixteenth century ${ }^{96}$ More than this, the late nineteenth century was awash in anthropological inquiry, a function of the triumph of evolutionary thinking. ${ }^{97}$ The World's Fairs described by Robert Rydell were one of the more popular manifestations of the public culture of anthropology. ${ }^{98}$

Snedeker's account raises questions about the social experience of travelling by canoe. Clearly cruising offered particular kinds of opportunities to interact with others. In addition to intersecting with the trajectories of other travellers, "cruisers" made contact with local people offering both goods and services. The fact that most of the accounts highlight meeting others suggests that this was an important aspect of the experience, although not necessarily a positive one. As I have just illustrated, travellers not infrequently looked with amusement and curiosity at local peoples. There are also the interpersonal dynamics of the cruisers themselves to consider. How did the canoeists interact with one another while they cruised? Did they tire of each other's company? Did they feel isolated? An 1892 article in the New York Times noted, "the one difficulty in this 'tandem' cruising is to get a thoroughly sympathetic and congenial

\footnotetext{
${ }^{96}$ Joan Pau Rubies, "Travel Writing and Ethnography," in The Cambridge Companion to Travel Writing, eds. Peter Hulme and Tim Youngs (New York: Cambridge University Press, 2002), 242, 258.

${ }^{97}$ George W. Stocking, Victorian Antbropology (New York: Free Press, 1987); Lee D. Baker, From Sarage to Negro: Antbropolegy and the Conetruction of Race, 1896-195-1 (Berkeley: University of California Press, 1998).

${ }^{98}$ The Midway at the 1893 Chicago World's Fair, for example, was "hailed as a 'great object lesson' in anthropology by leading anthropologists." Robert Rydell, All the World's a Fair: Visiond of Empire at American International Exposition, 1876-1916 (Chicago: University of Chicago Fair, 1987), 40.
} 
companion." The author hinted at the intimacy and potentially fraught terrain of such an experience when they suggested that a "lifelong friend may become almost one's enemy after a few days of this cruising life." ${ }^{\prime 99}$

It is difficult to provide precise answers to these questions because of the fragmented nature of these accounts. Presumably, there was an intimacy to the canoe trip experience because of the size of the group and the length of the trip. We can also reasonably assume that interactions between the canoeists were informed by the material circumstances of travel. Whereas tandem canoes and paddling facilitated social intercourse, single canoes and sailing made it more difficult. ${ }^{100}$ While some canoeists welcomed the solitude, others thought canoeing a lonely activity for this reason. ${ }^{101}$ Amongst mixed-sex parties, gender played a prominent role in shaping interactions. Women participated in canoe trips, but rarely as equals with their male companions. ${ }^{102}$ In tandem canoes, they were often relegated to the bow of the boat, while men took charge of steering. They were also dissuaded from any of the "heavy lifting" such as portaging, although most of the ACA cruisers, men and women, appear to have availed themselves of the labour of others to cross between bodies of water on their way to the meets.

Travelling to the meet by canoe also engendered particular kinds of environmental experiences. In part, this was because canoes were open, offering few

\footnotetext{
99 "Women as Canoeists," New York Times, 10 August 1892.

${ }^{100}$ Paddling allowed for greater control of the craft, but also the potential to stay close to other boats that were part of the group.

101 "Paddle and Sail," The New York Times, 2 August 1878. According to the author, "The canoe is too lonely to be popular. Most people are gregarious. They like rowing together in a long boat, or sailing in a yacht."

${ }^{102}$ Meg Stanley, "More Than Just a Spare Rib But Not Quite a Whole Canoe: Some Aspects of Women's Canoe-Tripping Experiences, 1900-1940" in Using Wilderness: Esvays on the Evolution of Youtb Camping in Ontario, eds. Bruce E. Hodgins and Bernadine Dodge (Peterborough: The Frost Centre for Canadian Heritage and Development Studies, 1992), 51-60.
} 
places to escape from a hot sun or driving rain. They were also small and sat close to the water, making them susceptible to high winds and waves. Canoeists frequently commented on the wind and rain that impeded their progress, in some cases, leaving them "wind-" or "storm-bound."103 It was not just weather that dictated the shape of a journey; canoes were also at the mercy of larger craft. On his trip from the Brooklyn Canoe Club to the train station in northeast Manhattan in anticipation of the 1893 meet, Paul Vernon gave wide berth to the ferryboats ("the waves the paddle wheels made danced the canoe around more than was pleasant") and the "formidable" ships at anchor in the harbor ( $\mathrm{a}$ "change of tide might cause them to swing"). ${ }^{104}$

Canoeists' environmental experiences were further mediated by their means of locomotion: sail or paddle. Provided there was ample wind, the former enabled the canoeist to cover distance more quickly, while the latter provided greater control of the craft. ${ }^{105}$ Both sails and paddles "sensuously extended" the canoeists' capacities "into and across the physical world," producing particular configurations of body, technology, and environment. ${ }^{106}$ It was through the shifting tension in the ropes held in calloused hands and the resistance of the water felt through paddles that canoeists came to know the paths they travelled on their way to the meet. Travelling by canoe, in other words, was characterized, in part, by physical strain and accommodation. Writes Florence Watters Snedeker, "Paddling on, we thought of weariness; then forgot it,

\footnotetext{
103 "From Vergennes to Lorna Island," Forest and Stream, 24 May 1883; "Homeward from Stony Lake," Forest and Stream, 19 February 1885.

${ }^{104}$ Vernon, Tales of the ACA.

${ }^{105}$ Most, but particularly the American canoeists who were known for sailing, switched back and forth between sails and paddles depending on the conditions, so these were not isolated experiences. The Snedekers, for example, tended to paddle, although on Lake George, they covered some of the watery terrain with the aid of an improvised sail. Similarly, Neide usually sailed, but when faced with poor wind, he took up a paddle.

${ }^{106}$ MacNaghten and Urry, "Bodies of Nature," 8.
} 
and, an hour after, found ourselves fresh again. That is the advantage of paddling.

There is no strain. The muscles soon play themselves to the rhythm. Each day there is less effort in the lazy motion, until one fancies one might fall asleep, and still keep paddling on." ${ }^{107}$ Snedeker's comment also hints at the different embodied ways of knowing the environment that the practices of canoeing afforded.

While sailing tended to be faster than paddling, the pace of travel in a canoe was slower than that of the train and steamer. Some of the consequences of this are captured in the following account of travel to the 1886 meet on Grindstone Island:

[T] he sterns of our canoes are finally allowed to slide off the end of the Cape Vincent pier, and our sails are spread for a twenty-mile sail down the St. Lawrence, which at this point is so wide, that we barely make out the cattle on either bank, as we jump the waves in the current...So we scud, passing one island after the other until, with the sun, the wind goes down, and forces us to paddle the last few miles between little rocky territories, bristling with evergreens and rocks, around which lap defiantly the clear waters of this wonderful river. ${ }^{108}$

Here, we see how the slow pace of the canoe afforded the time to optically and aurally consume one's surroundings: to make note of the cows, to see and hear the waves lapping on the shoreline. For this reason, it is likely not a coincidence that accounts of canoe travel place a greater emphasis on the natural, cultural, and social landscapes in which the canoeists found themselves at various points in their journey.

Those who travelled to the meet in canoes did not just have the time to make close observation of the landscape, they also had the freedom to stop in ways that other travellers did not. Accounts are littered with reports of visiting local sites of interest. Clytie and his companion stopped off at Crown Point and Fort Ticonderoga, both

\footnotetext{
${ }^{107}$ Snedeker, A Family Canoe Trip, 23.

108 "Great Canoe Meet," 166.
} 
remnants of the War of 1812 , while crossing Lake Champlain. ${ }^{109}$ The Snedeker family paid visits to a lumber mill in Glens Falls and an iron mine near Plattsburgh. ${ }^{110}$ Snedeker described the latter as a "place of huge chimneys, of smoke, of crazy plank walks, of miners' dwellings, of saloons, of rushing machines, of a black, evil pit in the centre, and white doves fluttering up from it like souls out of purgatory." 111 The canoeists also took breaks to perform more mundane tasks. Images from the Jabberwock cruise, for instance, show the canoes drawn together like a raft for lunch. ${ }^{112}$ Likewise, partway through their trip, Clytie and friend spent a "pleasant forenoon...occupied in lounging about, reading, writing and taking pictures." ${ }^{113}$ Train

While travel by canoe was certainly romantic, it was an impractical mode of transport for the majority of ACA members. Most commonly, the campers availed themselves of the growing network of rail lines to arrive at the encampments. Train travel, like airplane and automobile travel, has received extensive attention from scholars. Wolfgang Schivelbusch and Michael Freeman, for example, have explored

109 "From Vergennes to Lorna Island," Forest and Stream, 24 May 1883.

${ }^{110}$ Snedeker, A Family Canoe Trip, 56, 68.

${ }^{11}$ Snedeker, A Family Canoe Trip, 74-79. Both John Sears and Cindy Aron have documented the nineteenth century appeal of "industrial tourism," a practice that "turned everyday...industry and workplaces into tourist sights." Sears argues that for "the nineteenth-century tourist [Mauch Chunk] presented a moving panorama in which human ambition seemed splendidly embraced by nature's wealth and power." Aron suggests further that "work places served to reinforce American's belief in their countrymen's ingenuity and technological expertise," and may have also helped to ease tensions "produced by the idleness of vacationing," by maintaining a connection, however ephemeral and "inauthentic," to work. Aron, Working at Play, 133, 145; John F. Sears, Sacred Places: American Tourist Attractions in the Nineteenth Century (New York: Oxford University Press, 1989), 191-208. See also, William Littmann, "The Production of Goodwill: The Origin and Development of the Factory Tour in America," in Constructing Image, Identity and Place: Perspectives in Vernacular Architecture, IX, eds. Alison $\mathrm{K}$. Hoagland and Kenneth A. Breisch (Knoxville: University of Tennessee Press, 2003), 71-84.

${ }^{112}$ NYSHA, 1.1/30, "Lunch Below the Sagamore, Lake George," 1887.

113 "From Vergennes to Lorna Island," Forest and Stream, 24 May 1883. Similarly, Neide and Coubert, faced with the prospect of sailing in high winds, chose to "remain in town and enjoy [them] selves in the mild dissipation of having our photographs taken and reading novels." "Homeward from Stony Lake," Forest and Stream, 19 February 1885. 
how the coming of the railroad re-shaped experiences of time and space in the nineteenth century. ${ }^{114}$ On the one hand, railways offered up "new vistas," expanding the potential spaces for consumption by the leisured classes. ${ }^{115}$ At the same time, trains "annihilated and differentiated space," allowing passengers to cover longer distances in relatively short periods of times, but also to compare various landscapes and thus better appreciate environmental difference. ${ }^{116}$ Others have highlighted the very particular kinds of views that railcars afforded, which further shaped how travellers encountered the landscapes outside of the car. Matt Johnston has observed that the speed of the train offered a "shearing, tangential view," while the large glass windows provided a frame akin to paintings. This is in contrast to the panoramas made possible by the openness of the canoe and certain spaces of the steamer. ${ }^{117}$

A number of these observations are confirmed in accounts of travel to the ACA encampments. For example, the succession of views is encapsulated in the following description of travelling from New York to Muskoka in 1900:

The trip is one of unsurpassed beauty and interest...Such a diversity of scenery could hardly be equaled in a trip of the same length anywhere else on the continent. From New York the route was across the fertile farming lands of New Jersey, through the picturesque Delaware, Lehigh, and Wyoming Valleys - the Switzerland of America - then along the peaceful and placidly flowing Susquehanna and across the beautiful lake region of Central New York to Niagara and its majestic wonders. Then came the quiet shores of Lake Ontario, a glance at the bustling City of Toronto, and a dash across the rich farming lands of Ontario into the wild and rugged beauties of Muskoka. ${ }^{118}$

\footnotetext{
${ }^{114}$ Schivelbusch, The Railway Journey; Michael Freeman, Railway, and the Victorian Imagination (New Haven: Yale University Press, 1999).

${ }^{115}$ Freeman, Railway'4, 7; Schivelbusch, The Railway Journey, 36.

${ }^{116}$ Freeman, Railways, 23, 80.

117 Johnston, "National Spectacle," 1028.

118 "Canoeists' Annual Meet," New York Times, 26 August 1900. Emphasis added.
} 
Here, we see how trains highlighted changing landscapes, and in the process, informed travellers' perceptions of the variety in rail-side environments. ${ }^{119}$ Equally remarkable are the allusions to the speed of the train, which support Schivelbusch's contention that train travel prevented any significant depth of engagement with the landscapes glimpsed through the plate glass windows. In the cocoon of the railway car, the smells and sounds of the passing landscape were all but absent, while the train's speed curtailed visual perception, permitting only the "broadest outlines of the landscape" to be grasped..$^{120}$ That said, train travel did not offer a disembodied experience, void of sensual encounters, but rather a differently embodied experience. Even in the late nineteenth century, rail travel could be quite uncomfortable. ${ }^{121}$ Describing a trip to Lake George in 1883 by way of the newly opened railway, a New York Times staffer remarked, "The locomotive had the asthma, and, I guess, the black vomit, too, from the way she covered us all with cinders." ${ }^{122}$ It was also not uncommon for train cars to be unbearably hot in the summer months, just as the canoeists were making their way to a meet. $^{123}$

The experience of going by train depended on when one travelled. Sleeping cars, for instance, allowed the "tired and run-down business man" to leave behind "the hot and dusty city at night," and wake up the following morning "really on the river." ${ }^{24}$

\footnotetext{
${ }^{119}$ We find a similar situation in C. Bowyer Vaux's account of his trip to the 1881 meet at Lake George: "The train ascended the grade up the watershed of the Hudson and neared the ridge, the 'great divide' between the valleys of the Hudson and St. Lawrence." C. Bowyer Vaux, "The American Canoe Association, and Its Birthplace," Outing 12, no. 5 (1888): 414-5.

${ }^{120}$ Schivelbusch, Railway Journey, 53-55.

${ }^{121}$ As Aron notes, although promotional literature "stressed the ease of train travel," it could be an "arduous experience." Aron, Working at Play, 51.

122 "Resting at Lake George," New' York Times, 13 July 1883. In the same article, the author laments an earlier age when stage travel was the norm.

${ }^{123}$ Aron, Working at Play, 51.

${ }^{124}$ C. Bowyer Vaux, "Canoe Meet at the Thousand Islands," Outing 14, no. 5 (1889): 345 . Overnight travel was certainly an option for those travelling from New York to the St. Lawrence meets. For
} 
In contrast with the "succession of views," overnight travel reinforced the annihilation of space and time; sleep, after all, is an unconscious state of being. The experience was also dependent on how one travelled. The original American car, which "consisted of a single large compartment with seats on either side of a center aisle," was envisioned as a social leveller because it brought people of different classes, races, and genders into contact. ${ }^{125}$ By the 1880 s, however, specialty and extra-fare cars, which provided comfortable seating and sleeping berths, enabled well-heeled travellers to distance themselves from "others," namely the working class and people of colour. Assuming that the members took advantage of the discounts arranged by the transportation committee, they would have travelled to the meets in first class.

Even within the confines of a Pullman car, one could come up against difference. ${ }^{126}$ Some canoe clubs avoided such situations by arranging for private cars. In 1900, for example, the forty delegates of the Toronto Canoe Club travelled in a private car decorated with "streamers, flags, and burgees" to the wharf at Gravenhurst. ${ }^{127}$ After 1886, the divisions often made similar arrangements. ${ }^{128}$ While

example, trains left New York for the 1884 meet at Grindstone at $6.50 \mathrm{pm}$ and arrived at Oswego at $7.50 \mathrm{am}$. Passengers were also given the option to depart at $8.30 \mathrm{am}$ and arrive at $9.55 \mathrm{pm}$. Presumably, in the latter case, they would have had to stay overnight at a hotel on the river's edge.

${ }^{125}$ Amy Richter, Home on the Rails: Women, the Railroad, and the Rise of Public Domesticity (Chapel Hill: University of North Carolina Press, 2005), 66.

${ }^{126}$ Richter, Home on the Rails, 51-52; Aron, Working at Play, 51.

127 "Canoeists' Annual Meet," New' York Times, 26 August 1900; "Canoeing: Opens This Morning," Daily Mail and Empire, 3 August 1900. In some cases, likely when numbers warranted it, clubs banded together to make such arrangements. For example, the Massachusetts clubs hired a "vestibuled [sic] Pullman train" to travel between Boston, Worcester, Springfield, and Clayton for the 1908 meet at Sugar Island, while the New York clubs that attended the 1900 meet in Muskoka, "occupied an entire train, fitted with sleepers, dining and parlor cars." NYSHA, Box 1.6/11, Camp Circular for Sugar Island, 1908; "Canoists [sic] Leave for Camp," New York Herald, 4 August 1900.

${ }^{128}$ For example, the Atlantic Division arranged for a "special sleeping car" to transport its members northwards in 1907. Typically, it was only the more populous divisions that made such arrangements. The camp circular for the 1907 meet made this clear: "As it seems improbable that a sufficient number of members will start from any one point in the Central, Western or Northern Divisions, no effort has been made to arrange special accommodations other than reduced rates." MSCRC, Collection 291, Box 23. Folder 2, Camp Circular for Sugar Island, 1907. 
organizers could cite convenience, we might also read these shared cars, like the desire to have the encampments in out-of-way places, as part of the ACA's efforts to insulate itself from others. In terms of experience, shared cars likely differed from the typical first-class railway journey, which scholars have argued was more likely to be characterized by isolation and anonymity than social engagement. ${ }^{129} \mathrm{~A}$ transportation circular from the 1898 meet argued, "The pleasure of being amongst ACA friends on this private car has always been one of the delights of going to camp." ${ }^{130}$ In 1884 , the New York Sun reported that "as the train bearing the New York delegates rolled out of the Weehawken depot, the notes of a bugle were heard, and the club broke into its chorus":

A little canoe down the bay;

Good-bye, my lover, good-bye.

It bore the flag of the A.C.A;

Good-bye, my lover, good-bye. ${ }^{131}$

Shared cars, in other words, were likely more interactive and lively affairs.

Official arrangements aside, most canoeists travelled to the meets with other enthusiasts. This was certainly true of women, who did not travel in the late nineteenth century on the same terms as men. ${ }^{132}$ They would have, almost without exception, made the trip with family members or a chaperone. ${ }^{133}$ Even Pauline Johnson, who had spent much of the winter and spring of $1892 / 1893$ performing for audiences across

\footnotetext{
${ }^{129}$ Richter, Home on the Raile, 55.

130 NYSHA, 1.6/12, ACA Atlantic Divisions, "Instructions to Members Attending the ACA Meet at Stave Island," 1898.

131 "Canoe Sailors in Camp," New York Sun, 4 August 1884.

${ }^{132}$ Richter, Home on the Rails, 37. See also, Casey Blanton, "Victorian Women Travelers: Mary Kingsley," in Travel Writing: The Self and the World (New York: Routledge, 2002), 44-58.

${ }^{133}$ See, for example, "American Canoe Association Meet: Tenth Annual," Forest and Stream, 22 August 1889; "Musquito Fleet," The Salt Lake Herald, 9 August 1891.
} 
Ontario, travelled to the 1893 meet at Brophy's Point with her mother. ${ }^{134}$ Although trains were, according to Amy Richter, increasingly a public space in which women could maintain their respectability, to do so required vigilance. ${ }^{135}$ While accounts of travel say very little of the preparations undertaken in the hours leading up to departure, Richter argues that "a women's negotiation of public life began at home when she decided what to pack and how to dress for her journey. Good preparation could mitigate fears and troubles that accompanied a woman on her journey and help recreate the protections of the private sphere. ${ }^{.136}$ Etiquette books provided explicit instructions for such preparations.

Contrary to those who travelled by canoe, the ACA members who went by train said very little about their activities en route. Presumably, they used the time to catch up with their companions or to anticipate the coming meet. Certainly other travelogues in Forest and Stream highlight the anticipatory nature of such travel, including the following excerpt the "Canoeing" section of the magazine: "Once seated in the cars and disencumbered of our luggage, we fell to talking over our journey, and refreshed ourselves with several bottles of ginger ale." ${ }^{137}$ The canoeists may have also taken the opportunity to observe strangers in the car, which Richter argues was one of the chief amusements of train travel in the period. ${ }^{138}$ Railroad guides also provided

134 "This An Ideal Canoe Camp," The World, 20 August 1893. Johnson delivered 125 performances in 50 Ontario towns and villages between October 1892 and May 1893. Marilyn J. Rose, "Emily Pauline Johnson," in The Dictionary Of Canadian Biograpby Online. Accessed 2 December 2011: http://biographi.ca/009004-119.01-e.php?id_nbr=7476.

${ }_{135}$ Richter, Home on the Rails, 4. Amongst other things, women were advised to be as inconspicuous as possible both in their dress and decorum, to develop the capability to surreptitiously perform the necessary private acts of hygiene in public, to be covertly aware of the other companions in their car, and to be discerning in their conversation choices. See, "When Spheres Collide: Women Travelers, Respectability, and Life in the Cars," in Richter, Home on the Rails, 32-58.

${ }^{136}$ Richter, Home on the Rails, 40-1.

137 "Around Lake Champlain," Forest and Stream, 7 July 1892.

${ }^{138}$ Richter, Home on the Rails, 48-9. 
opportunities to "sightsee" as they train rolled onwards, although its possible that some travellers agreed with railroad commentators that reading while the car was in motion could have deleterious effects. ${ }^{139}$ For those travelling with their canoes, the trip was punctuated by the transfer points characteristic of nineteenth-century train travel. ${ }^{140}$ For three men headed to the 1884 meeting on Grindstone Island, each transfer point found them outside the car with the baggage personnel negotiating the stowing of their canoes. While they were able to "induce" the clerks at the first two transfer points to pack their canoes, at the final stop in Cape Vincent, the three men were informed that neither the canoes nor the canoeists would be permitted to board the train for the last leg of the journey. They had to travel the twenty miles from Cape Vincent to the camp by sail. ${ }^{141}$

\section{Steamer}

Steamboats represented an earlier era in transportation, although they continued to dot the continent's waterways into the twentieth century. ${ }^{142}$ While railway travel has provided much fodder for the imagination of academic transportation historians, significantly less has been written about the experience of short- and medium-distance travel by steamboat. James Armstrong and David M. Williams argue that the role of the steamship in the history of popular recreation and tourism has been

${ }^{139}$ Johnston, "National Spectacle."

${ }^{140}$ An article in Forest and Stream postulated that it was "not an unusual thing to make six or eight transfers on the way to camp, some at night." "The Meet of 1886," Forest and Stream, 26 August 1886.

141 "Great Canoe Meet," 164. Two canoeists from New York travelling to the same meet did not trust the baggage handlers either. They "hurried to the baggage car at every change" to transfer their boats from one train to the next. "Paddle Your Own Canoe," Forest and Stream, 30 June 1887.

${ }_{142}$ The first steamboat voyage in the United States took place in 1807. Johnston, "National Spectacle," 1025. Andrew Watson's work on supply lines reveals the ongoing importance of steam transportation on the Mukoka Lakes into the twentieth century. Andrew Watson, "Mobility and Sustainability: Lakeside Supply Networks in the Age of Steamboat Navigation, Muskoka Ontario, 1880-1930" (Paper presented at Environments of Mobility in Canadian History, 13-14 May 2011). 
sadly neglected because of an overemphasis on the railway. ${ }^{143} \mathrm{~J} . \mathrm{I}$. Little further argues that historians have tended to conflate the passenger experiences of steamers and trains. Little's work on the tourist industry on Lake Memphremagog suggests that "as steamers zig-zagged between small settlements, resort hotels, and even the docks of the wealthy estate owners," they provided "ample opportunity for passengers who were so inclined to develop a spiritual affinity with their scenic surroundings." He also suggests that steamers boasted a "convivial atmosphere."144 Both of these observations ring true for ACA travel as the following two examples neatly illustrate. In 1881, C. Bowyer Vaux and his companions left the "hot, dusty, and work-a-day city of New York on the Albany night boat." As the boat made its way up the Hudson River, the group "sat on the deck till late in the night, and saw one of the finest auroras that had been seen for years." ${ }^{145}$ In the second example, the steamer was a site of hijinks. D.B. Goodsell recalled of the journey to the 1890 meet, "Harry Quick and Oxholm amused themselves and others too, by throwing pitchers of water into each others staterooms on the journey out. Sleep there was not." 146

In a few cases, longer journeys were made by steam ship. The Rochester canoeists, for instance, chartered a steamboat to convey them from that city to the Grindstone Island meet of $1884 .{ }^{147}$ Similarly, canoeists from Yonkers travelled to the

\footnotetext{
${ }^{143}$ James Armstrong and David M. Williams, "The Steamboat and Popular Tourism," The Journal of Transport History 26, no. 1 (2005): 61-76.

${ }^{144}$ J.I. Little, "Scenic Tourism on the Northeastern Borderland: Lake Memphremagog's Steamboat Excursions and Resort Hotels, 1850-1900," Journal of Historical Geograpby 35, no. 4 (2009): 717, 739.

${ }^{145}$ Vaux, "Its Birthplace," 414.

${ }^{146}$ Goodsell, A Canoeing Reminicence, 2.

147 “The Association Meet," Forest and Stream, 21 August 1884.
} 
1890 meet at Jessup's Neck on the steamer Sbinnecock. ${ }^{148}$ By the late nineteenth century, however, most long distance travel to the annual meetings was undertaken by train. Nevertheless, given that the majority of the encampments were located on islands or points of land not accessible by road, the last stage of the journey from railway terminus to the campsite was almost invariably undertaken by steamship, unless one canoed. ${ }^{149}$

Over longer distances, the steamer was likely akin to a rail car. However, as the means by which the canoeists traveled from railhead to campsite, steamers played an important role in (re)introducing canoeists to camp life in three ways: as material reminders of earlier experiences, as social spaces, and as sites for viewing local landscapes, but most importantly the gathering panorama of the encampment. First, some years, the steamer itself was part of the canoeist's re-acquaintance with camp life because it was the same boat that brought the canoeists to the site in successive years. For example, the Valeria plied the waters between Gananoque, Clayton, and the ACA encampment in $1898,1901,1904,1905$, and $1906 .{ }^{150}$ Likewise, there was the material culture of the steamers. Florence Watters Snedeker made the following observation upon boarding the steamer Chateauguay in 1892: "There was no need now to ask, Whither bound? Canoes filled the passageways, and young men in knickerbockers and blazers swarmed everywhere." ${ }^{\prime 151}$ Whereas on trains, canoes and camping outfits were

\footnotetext{
${ }^{148}$ Whether they realized it or not, the name of this boat was drawn from the Aboriginal people who had long inhabited the eastern tip of Long Island, and who, as I noted in Chapter Three, were now largely confined to a reserve near to Southhampton.

${ }^{149}$ The length of such journeys ranged between a few miles and 21 miles in the case of the Muskoka meet in 1900. "Canoe Camp at Muskoka Lake," Rocbester Democrat Chronicle, 30 July 1900.

${ }^{150}$ NYSHA, 1.2/28, "Steamer Valeria at ACA Camp Dock," 1898; 1.3/6, "SS Valeria Arriving at Camp Dock," 1905; 1.5/1, "ACA Meet and Camp," 1906; 1.6/11, Camp Circular for Sugar Island, 1904;

"Canoeists' Annual Camp," New York Times, 11 August 1901.

${ }^{151}$ Snedeker, A Family Canoe Trip, 84.
} 
stowed away in the baggage car, on steamers, they lined the corridors and, in some cases, were spread across the railings. They were, in other words, visible reminders of the boat's destination and the passengers' recreations.

Second, steamers served as important sites of social interaction in advance of arriving at the encampment. It was their journey on the steamer Chateauguay that truly introduced the Snedeker family to camp life. Shortly after boarding, the family struck up a conversation with a young couple from Canada who had attended the previous year's meet. Amongst other things, Florence used the opportunity to inquire about whether there were "many ladies" at the events and "what kind of people" the members were. ${ }^{152}$ After disembarking, the couple gave the Snedekers a tour of the encampment, pointing out sites of interest and introducing them to others. ${ }^{153}$ In many respects then, the steamer marked the beginning of the encampment proper. An account of the Muskoka meet noted that once the crowd that had gathered at the wharf in Gravenhurst was on the boat, "the camp had fairly begun." 154 Of course, steam ships did more than introduce the canoeists to others of their kind. Because they often served multiple constituencies, steamers also brought canoeists into contact with local people. Snedeker recalled that her family waited for and travelled on the "steamboat in company with a party of farmer folk, the women very natural and lovable in oldfashioned gowns and bonnetfuls of preposterous buttercups and poppies." ${ }^{\prime 15}$ Here again, while steamers may have provided opportunities for travellers to encounter

\footnotetext{
${ }^{152}$ Snedeker, A Family Canoe Trip, 84.

${ }^{153}$ Snedeker, A Family Canoe Trip, 88-90.

${ }^{154}$ Howell, "International Canoe Meet," 515.

${ }^{155}$ Snedeker, A Family Canoe Trip, 119. She distinguishes the more authentic farm folk from the "race of summer boarders" who occupied the hotel. She presents the latter as stiff and formal and anachronistic. Here again, we see the social distance that separated the canoeist traveller from local people.
} 
difference, these experiences likely did little more than reinforce established ideas about the other.

Finally, part of the romance of steam travel was that it was often from the deck of a steamship that a camper first glimpsed the encampment. An attendee at the 1884 encampment on Grindstone Island described seeing the "smooth brown hill," the "tops of clustered trees peeping over the hill," and the "fringe of gleaming white tents along the base of the hill," as the "steamer Puritan emerged form the Cut, a narrow, rocky strait leading northward from...Wellesley Island." ${ }^{156}$ As Tim Youngs argues, "The way we imagine places is not simply a private, individual affair and our responses to them when we visit them are not independent but are mediated by the culturally constructed representations we have previously encountered. ${ }^{1157}$ Visitors to the encampments were primed to encounter the campsite from the water. Year after year, accounts of the meets featured descriptions of this scene similar to that which follows: "The visitor coming from Clayton, four miles distant, sees first, on turning the point of the island, a hill rising gradually from the water, facing the east, at the foot of which is the main part of the camp, some forty tents of all colors, many large ones among them, being pitched here. Each tent or group of tents has one or more large flag poles, flying the Stars and Stripes, British ensign, A.C.A. flag, and various club flags." ${ }^{" 158}$ That there is remarkably little variation in these descriptions suggest that the various encampments, regardless of location, had similar aesthetics. However, it may also reflect the existence

156 “The 1884 Meet," American Canoeist 3, no. 8/9 (1884): 114.

${ }^{157}$ Tim Youngs, Travel Writing in the Nineteentb Century: Filling in the Blank Spacet (London: Anthem Press, 2006), 2. Youngs is drawing on Said here.

158 "A.C.A. Camp," Forest and Stream, 14 August 1884. See also, Columbine, "A Visit to the American Canoe Association," The Young Friend's Review' (1886): 67; "Canoeists in Camp," New York Times, 9 August 1890. 
of a shared understanding of what an ACA camp was and what it should look like in spite of material realities.

Complaints about steamer travel were fewer than those voiced about rail travel, though steamships were not immune from criticism. This was true of the boat that carried members of the Yonkers Canoe Club to the 1890 meet. D.B. Goodsell recalled, "Our canoes were placed or rather thrown overboard and allowed to drift ashore. We found them on the beach full of seaweed and sand. Next day in camp, there were exhibited a number of wooden canary cages containing fiddler crabs which were labeled 'Exhibit from Steamer Shinnecock."159

Although the canoeists employed multiple transportation technologies as they made their way to the annual meeting, most made use of a canoe, train, and/or steamer. As I have shown each of these modes of transportation provided particular kinds of encounters with passing landscapes, environments, and people. They also afforded different experiences of time and space. Travel as these examples make clear was not dead time, but rather was filled with socializing, observing, and encountering new people and places, albeit in different proportions and forms depending on the mode of transport. In part three, I explore how two of these modes, the canoe and the steamer, facilitated local excursions undertaken after arriving at the encampment.

\section{$\underline{\text { Part III - Local Excursions }}$}

The first day or two in camp were usually occupied with getting settled, a process I consider in greater detail in Chapters Six and Seven. The rest of the first week, however, was filled with social and recreational activities, including excursions

\footnotetext{
${ }^{159}$ Goodsell, A Canoeing Reminiscence, 2.
} 
to local sites of interest. As they visited these sites, the ACA members were performing nineteenth-century tourism. To borrow from Cecilia Morgan, "travel was a performed art: it was stylized, it was self-conscious, and it involved a repertoire that was repeated and reiterated, albeit with various levels of negotiation." ${ }^{160}$ Haldrup argues that daytrips, in particular, “derive their meaning through the 'collection' of particular places passed en route, in the form of souvenirs, photographs and vistas." ${ }^{161}$ Following on this, I contend that cruises and day trips, as part of navigating and collecting local environments, provided the canoeists with a wider field of vision of the encampment. Excursions also played an important role in producing and inhabiting the campsite landscape by allowing the canoeists to leave the campsite for a short period of time and ultimately to return "home" again. As with long distance travel, excursions were made possible by a variety of mobile technologies. For the most part, however, it was steamers and canoes that enabled the canoeists to realize their desires to consume local landscapes. ${ }^{162}$ As with long distance travel, these boats shaped how landscapes were "sensed and made sense of." 163 Their relative speed and openness made them ideal craft for sightseeing. Steamers, in particular, were favoured for the "conviviality" described by J.I. Little.

The excursions had a variety of destinations, which dovetailed with dominant tourist practices in the late nineteenth century. ${ }^{164}$ They included "natural" sites such as

\footnotetext{
${ }^{160}$ Cecilia Morgan, 'A Happy Holiday': English Canadians and Transatlantic Touriwm (Toronto: University of Toronto Press, 2008), 15-6.

${ }^{161}$ Haldrup, "Laid-back Mobilities," 447. Emphasis in original.

${ }^{162}$ Photographic evidence of these excursions includes NYSHA, 1.1/4, "All Ready for a Cruise," 1883;

1.1/10, "Steamer Magic at ACA Camp," 1885; 1.1/37, "A Thousand Island Sight-Seeing Trip," 1889. In this last photograph, two of the men have musical instruments in hand.

${ }^{163}$ Haldrup, "Laid-back Mobilities," 436.

${ }^{164} \mathrm{Hal}$ K. Rothman, "Selling the Meaning of Place: Entrepreneurship, Tourism, and Community Transformation in the Twentieth-Century American West," Pacific Historical Review 65, no. 4 (1996): 526.
} 
the always popular Au Sable Chasm, "a wonderful gorge of two miles, which the Ausable River [had] cut through the sandstone cliffs" bordering Lake Champlain. ${ }^{165}$ At the 1883 meet, meanwhile, the canoeists hiked to the top of Blue Mountain, "an overland tramp of 4 miles." ${ }^{166}$ While most of these excursions had a single identifiable destination, in a few instances the outing was intended to offer a cross-section of the local landscapes, such as a canoe cruise through the Thousand Islands. ${ }^{167}$ The same ethos that inspired the organizing committee to locate encampments in places that were wild, but not too wild, also compelled Association members to visit natural sites of interest. ${ }^{168}$ Patricia Jasen argues that the desire to frequent wild places was stimulated by the "emergence of the 'picturesque' and the 'sublime' as major aesthetic categories; the rising importance of landscape as an element of taste; growing links between the concepts of landscape, nationalism, and history; and a deepening fascination with aboriginal peoples." ${ }^{169}$ Sites such as the Chasm and Bala Falls embodied the sublime aesthetic, which included "scars on the earth's surface such as mountains and ravines, and other gloomy or violent phenomenon such as cascading waters, bleak moors, dark

165 "The ACA Meet," Forest and Stream, 25 August 1887; "Canoeists Go On Cruises," New York Times, 12 August 1895. The description for Au Sable Chasm comes from M.F. Sweetser, Soutbwestern New' Hamupbire (Boston and Maine Railroad, 1890), 38. Stoddard referred to the Chasm as "Yosemite in miniature." S. R. Stoddard, Lake George and Lake Champlain: A Book of Today, $20^{\text {th }}$ ed. (Glens Falls, 1890), 115.

166 "Stony Lake Canoe Congress," Peterborough Examiner, 23 August 1883.

${ }^{167}$ The following bulletin appeared for an excursion during the $1889 \mathrm{meet}$ at Stave Island: "The fleet will cruise down the Lost Channel, between Hill and Club Islands, through Wellesley lake and through the Gut to Lyndock light. The Dorotby steam yacht will accompany the fleet and tow it back to camp from Lyndock light. Lunch will be taken en route at the Commodore's orders. Paddle and sail at pleasure." "The Tenth Annual Meet of the American Canoe Association," Sail and Paddle 7, no. 9 (1889): 199. ${ }_{168}$ Romanticism, a product of the eighteenth and nineteenth centuries, refers to the tendency "to value feeling and imagination," "to extend or transfer feelings formerly associated with religious experience to the secular realm," and, finally, "to imbue 'wild nature' with new meaning and value." Jasen, Wild Thing, 7 . ${ }^{169}$ Jasen, Wild Things, 7. 
forests, and thunderstorms." ${ }^{\text {"70 }}$ Picturesque nature, by contrast, displayed "variety, intricacy, roughness, and the quality of being paintable." The vistas afforded by encampments in the Thousand Islands, as I noted in Chapter Three, "satisfied the most demanding standards of picturesque taste."171

The canoeists also visited "historical" sites. While Fort Ticonderoga was a popular destination at the camps on Lake Champlain, canoeists at the 1894 meet at Croton Point likely visited the "Old Van Cortlandt Manor." ${ }^{" 12}$ Located on the roadway between the Point and Sing Sing, the mansion was a veritable treasure trove of American history. The basement still contained the "old embrasures" through which cannons "belched forth loads of grape and canister" during the Revolution, a glass cabinet in the parlor housed thirty-two metal buttons from the coat of Pauling of Sleepy Hollow fame, and in the library sat a small mahogany desk that once belonged to De Witt Clinton. ${ }^{173}$ "Heritage tourism," Hal Rothman argues, "emerged as part of the fin-de-siècle effort by American elites to define a cultural heritage for themselves apart from the European legacy that they had long revered and sought to emulate, yet to which they felt inferior." ${ }^{\text {174 }}$ Cindy Aron argues that visiting historic spots also provided travellers with "a way to reaffirm their connection to American's past and to

${ }^{170}$ Jasen, Will Thing, 8.

${ }^{171}$ Jasen, Wild Things, $59,9$.

${ }^{172}$ As I noted in Chapter Three, guidebooks from the period referred to the "ruins" or "remains" of the fort, and pointed out its "crumbling walls," hinting at its romantic appeal to tourists. See, for example, Charles H. Possons, Lake George and Lake Champlain (Glens Falls: Chas. H. Possons, 1887), 105. As Jasen notes, "the romantic sensibility, especially when infused with nationalism, encouraged an appreciation of those scenes in which landscape and history, especially in the form of ruins and graveyards, were blended together." Jasen, Will Tbing, 10.

173 "The Old Van Cortlandt Manor," New York Times, 22 July 1894. The article concluded, "The canoeists can find plenty to interest them on this historic point if they wish to look for it, for it is all historic ground, full of Revolutionary traditions."

${ }^{174}$ Rothman, "Selling the Meaning of Place," 526. 
validate their belief in America's future. ${ }^{175}$ The appeal of such destinations likely also reflected the antimodern orientation of the canoeists' cultural sensibilities. Excursions to historical sites, like the impulse to camp out, may have fulfilled a desire to return to an earlier age. ${ }^{176}$

Some of the excursions were less about sightseeing than they were about socializing. Some years, for example, the canoeists were invited to the residence or summer home of a member or friend of the Association. At the 1884 meet on Grindstone Island, for example, Frank Taylor bid the canoeists to pass the day at his cottage on Round Island. ${ }^{177}$ In other instances, they were invited to events in local communities. At the 1885 meet on Grindstone Island, a group of canoeists attended a lacrosse match in Brockville. ${ }^{178}$ In 1891 and 1900 respectively, invitations were received from the Lake Champlain Yacht Club located in Burlington and the Muskoka Lake Association at Beaumaris to attend and participate in their annual regattas. ${ }^{179}$ Occasionally, the destination was the steamer itself. This was true of the moonlight cruises offered at the 1884 and 1899 meets. ${ }^{180}$

In addition to the handful of formal excursions that were arranged during the first week, the canoeists also engaged in more informal outings, which took them varying distances. Picnics, leisurely paddles, and fishing trips in the general vicinity of

\footnotetext{
${ }^{175}$ Aron, Working at Play, 132.

${ }^{176}$ T. Jackson Lears, No Place of Grace: Antimoderniwm and the Transformation of American Culture, 1880-1920 (Chicago: University of Chicago Press, 1994 [1981]). One could argue that as the canoeists travelled across space to arrive at the campsite from home, they also thought they were travelling back in time. ${ }^{177}$ About sixty or seventy canoes took up his offer arriving in time for a lunch. Reports of the meet noted, "A pleasant evening was spent, enhanced by the music of the Utica band," before the canoeists retired to the Round Island Hotel for dancing. "The 1884 Meet," 115.

178 "The Association Meet," Forest and Stream, 6 August 1885.

179 "Fun for the Canoeists," New York Times, 21 August 1891; "At Canoe Association's Camp," New York Tribune, 6 August 1900. The former was followed by dinner at Van Nest House in Burlington, and a ball at the clubhouse. "The ACA Meet of 1891: Race Week," Forest and Stream, 27 August 1891.

180 "The 1884 Meet," 115; "The Races at Gananoque," Montreal Gazette, 16 August 1899.
} 
the camps were common occurrences. Images from a number of meets show groups of canoeists exploring nearby shorelines or sharing a picnic lunch. ${ }^{181}$ Other outings took the canoeists farther afield. The visitors to the 1900 camp on Lake Rosseau benefitted from the "kindness of some cottagers" who placed "their launches at the disposal of the campers for a cruise through Lake Joseph," the smallest of the three Muskoka lakes. ${ }^{182}$ Likewise, Paul Vernon recalled visiting Kingston, "a good paddle from the camp," quite often at the 1893 meet on Wolfe Island. ${ }^{183}$ According to Charles Sweester, a prominent guidebook author at mid-century, the "most interesting places to see" at Kingston were "the fortifications, including the forts on both Henry and Frederick Points, with the Martello towers and long wooden bridge; the Provincial Penitentiary, and the two Colleges." ${ }^{184}$ The "military and naval defenses," he argued, were "second only to Quebec." 185 Vernon writes that he and his friends "visited the sites," suggesting they took in the fortifications and perhaps the college. Beyond this, the group also tried (unsuccessfully) to visit the penitentiary. They were informed that, "to secure the privilege of a temporary visit inside a relative was necessary."

As the canoeists visited local sites of interest, they were rarely alone. The photograph from the 1896 meet on Grindstone Island is instructive. It depicts a mixed-

\footnotetext{
${ }^{181}$ For example, NYSHA, 1.2/1. "Picnic Lunch on a Cruise," 1888; 1.5/6. Scrapbook of Walwin Barr, 1905date unknown. Picnics also appear in textual accounts of the meets: "The ACA Meet," Forest and Stream 23 August 1883; "Snips from Snaps at the '89 Meet," Forest and Stream, 19 September 1889; "The ACA Meet of 1892," Forest and Stream, 8 September 1892.

${ }^{182}$ Howell, "International Canoe Meet," 518.

${ }^{183}$ A note in the New York Times also indicated that the first week "was given up exclusively to social enjoyment trips to Kingston, and fishing excursions." "Around the Pine Camp Fire," New' York Times, 20 August 1893.

${ }^{184}$ Charles Humphreys Sweester, Book of Summer Resorts: A Complete Guide for the Summer Tourit (New York: Evening Mail Office, 1868), 11.

${ }^{185}$ Sweester, Book of Summer Resorto, 11.

${ }^{186}$ TUA, 83-014/2, Paul Vernon, Tales of the $A C A, 1940$. The motivations behind and practices associated with visits to prisons and asylums in captured in Janet Miron, Prisont, Asylums, and the Public: Institutional Visiting in the Nineteentb Century (Toronto: University of Toronto Press, 2011).
} 
sex group of excursionists stopped in a small cove. There are four canoes in the foreground, two of which are occupied. Behind the canoes, in various positions on a low rock face amidst the trees, bushes, and mosses that adorn it, are four more women and two more men. ${ }^{187}$ The environments of the meet, in other words, were not just natural and cultural landscapes, they were social ones as well, produced (and consumed) through one's proximity to others.

\section{Conclusion}

The canoeists did not just travel to the encampment; they also travelled back home again. For the most part, they left as they had arrived, "in all sorts of conveyances - carriages, sloops, their own canoes, the Transportation Committee's launch, and the steamboat." ${ }^{\prime 18}$ However, just as on the way there, the route home was not always direct. As Forest and Stream noted at the close of the 1884 meet on Grindstone Island, "some sailed on down the river to cruise further, some scattered among the islands, and others started direct for home." ${ }^{189}$

Travel, to re-state Haldrup's point, involves a "rigorous organization of time and space." 190 This was particularly true of the ACA meets, which took place at out-ofthe-way locations and necessitated the movement of people and bulky luggage across long distances. Travel of this sort entails "a multiplicity of objects such as maps, clocks and guidebooks, etc. to provide images and knowledge against which the knowledge gained en route can be matched up." ${ }^{191}$ Transportation circulars, railway schedules,

${ }^{187}$ Blake, American Canoe Avsociation Yearbook, 72.

188 "Noyac Bay is Deserted," New York Times, 24 August 1890.

189 "The Association Meet," Forest and Stream, 21 August 1884.

${ }^{190}$ Haldrup, "Laid-Back Mobilities," 447.

${ }^{191}$ Haldrup, "Laid-Back Mobilities," 447. Emphasis in original. 
route maps, tourist guidebooks, and periodical accounts were all objects engaged in preparing for and travelling to an ACA encampment. These did more than provide practical advice about the journey, they also shaped how the canoeists imagined and encountered the landscapes, physical and social, through which they travelled.

Canoeists employed a variety of transportation technologies to arrive at the encampments. While the objective of the various craft - to transport people and freight from point $A$ to $B$ - was the same, they offered different environmental and social experiences. For instance, the experience of train travel, which shielded travellers from the elements and distanced them from the passing landscapes, was in marked contrast to going by canoe, which placed bodies in close contact with their environments and gave cruisers time to optically and aurally consume their surroundings. In many respects, steamer travel offered some combination of the two. Steamships travelled more slowly than trains and provided open spaces from which to consume the passing landscapes unimpeded. However, if the canoeists were confronted with inclement weather, they could take themselves inside, away from the wind, rain, or cold. Each of the three main forms of transport also engendered particular social experiences, by enabling certain kinds of interactions between the canoeists, other tourists, and local people. The time required to travel to the meet by canoe encouraged intimacy. It also enabled travellers time to themselves in ways that a railcar did not. In the instances where the canoeists hired railcars or steamers for their exclusive use, interactions with those outside of the ACA were circumscribed, reinforcing the exclusivity of the organization.

Navigating was not limited to travel to and from the meets. Once at the encampments, canoeists could take to the local waterways and visit natural, historical, 
and industrial sites of interest. Waterfalls, dilapidated fortresses, and working mines all drew the attention of the canoeing excursionists. In their desire to sightsee, but also in their choice of destinations, the canoeists were performing contemporary touristic roles that were the product of romanticism, consumerism, and cultural nationalism.

In order to consider these two forms of navigating alongside one another, we have necessarily skipped over a number of important practices that preceded chronologically the excursions discussed here. These include the physical and cultural work that was performed to ready the campsite for the canoeists and the canoeists for the campsite, and the canoeists' domestication of the campsite upon arrival to the meets. It is to these subjects that we turn our attention in Chapters Five and Six, respectively. 


\section{Chapter 5: Governing}

In 1890, the New York Timed remarked that the American Canoe Association encampments are "managed as strictly as is a military post or a yachting squadron, and everything has to be done decently and in order." Three years later, the Times once again made a connection between the armed services and the ACA's annual meetings: "It is all very prim and military on the grassy open [at Brophy's Point], and one would expect to see a regiment of red coats line up and salute." 2 Such assessments were not limited to the pages of the Times. ${ }^{3}$ A reporter for the New York Sun compared the 1885 camp on Grindstone Island to "army life at Peekskill," a military academy on the Hudson River. ${ }^{4}$ Similarly, Canadian poet Pauline Johnson, who attended a handful of meetings in the 1890 s, observed that the camps were run on a "semi-military basis." In part, such references reflect the number of military officers and yachtsmen attracted to the organization. ${ }^{6}$ The 1885,1889 , and 1893 encampments were all under the direction of military men: General Robert Shaw Oliver of Albany, New York, later Assistant Secretary of War (1903-1913); Lieutenant-Colonel H.C. Rogers of Peterborough,

\footnotetext{
1 "The Canoe Men in Camp," New York Times, 17 August 1890.

2 "Around the Pine Camp Fire," New York Times, 20 August 1893.

${ }^{3}$ For similar references, see "The Association Meet," Forest and Stream, 6 August 1885; "Pleasant Time at the Canoe Camp," New York Sun, 20 August 1896; "Rowing," Utica Observer, 19 August 1897; D.J. Howell, "The International Canoe Meet," The Canadian Magazine 15, no. 6 (1900): 518; "Canoemen Gather at the 1000 Islands," Watertown Re-Union, 15 August 1903.

4 "Canoeing at Thousand Islands," New York Sun, 9 August 1885. Peekskill Military Academy operated from 1833 to 1968. Samuel J. Rogal, The American Pre-College Military School: A Hïtory and Comprebenuive Catalog of Institution, (Jefferson: McFarland \& Company, 2009), 180.

${ }^{5}$ McMaster University Archives (MUA), E. Pauline Johnson Collection, Box 3, File 1-5, Pauline Johnson, "The American Canoe Association at Grindstone Island," The Rudder (1896): 355-8.

${ }^{6}$ In 1897, the New' York Times went so far as to suggest that the canoeists form a signal reserve similar to the one being organized by the New York Yacht Clubs. "It would take very little to make a good signal corps out of the canoe men in case of war. Their knowledge of bays, harbors, inlets, and interior rivers is not excelled by any other outdoor men in the community." "Meet of the Canoeists," New York Timed, 15 August 1897.
} 
Ontario; and Colonel William H. Cotton of Kingston, Ontario. ${ }^{7}$ However, the concern for order was also a function of broader cultural currents in the late nineteenth century. As Keith Walden notes, at a time when "unprecedented rates of industrialization and urbanization seemed to be unraveling a centuries-old fabric of behaviour and belief, concern about the nature and possibility of order lay at the heart of most social endeavour. People in all classes sought assurances that order existed or could be made to exist." 8

Most interestingly, descriptions of the quasi-military air of the encampments frequently appeared alongside references to the "freedom" afforded by the annual meetings. For instance, in the aforementioned article by Pauline Johnson, the performer and poet celebrated the "happy Bohemianism of the Association": "The first week under canvas is a veritable period of lotus eating. You idle through the long, yellow August days, living a happy-go-lucky, vagabondish life, the very memory of which brings a certain care-freeness into your busy afterdays." Similarly, Florence Watters Snedeker, author of A Family Canoe Trip, thought the ACA encampment "the freest place in the world." ${ }^{10}$ Contrary to appearances, these claims to freedom were rooted in efforts to govern. Following Patrick Joyce, "To think about freedom as a mode of ruling people is to consider the absence of restraint as a form of restraint,

\footnotetext{
7 "The Association Meet," Forest and Stream, 6 August 1885. "Around the Pine Camp Fire," New York Timed, 20 August 1893. For the dates of Shaw's service as Secretary of War, see "Placing More Democrats," Boston Evening Trantcript, 17 April 1913. For a brief description of Cotton's military service, see "Obituary: Major Gen. William H. Cotton," New York Timet, 21 April 1914.

${ }^{8}$ Keith Walden, Becoming Modern in Toronto: The Industrial Exbibition and the Shaping of a Late Victorian Culture (Toronto: University of Toronto Press, 1997), 33. In the American context, see Robert Wiebe, The Search for Order, 1877-1920 (New York: Wang, 1967); Robert Rydell, All tbe World's a Fair: Visions of Empire at American International Expositions, 1876-1916 (Chicago: University of Chicago Fair, 1987). 9 Johnson, "Association at Grindstone Island," 1896. For similar references, see Howell, "International Canoe Meet," 513-520; "The A.C.A. Canoe Meet," Outing 11, no. 1 (1887): 95-6.

${ }^{10}$ Florence Watters Snedeker, A Family Canoe Trip (New York: Harper and Brothers, 1892), 87.
} 
which is something of a paradox." Freedom in the context of late nineteenth-century liberalism was, as Joyce and others make clear, something that was increasingly "ruled tbrough," a "formula for exercising power."11

This chapter examines the attempts of organizers and the Executive Committee to order, discipline, and govern the encampments and the campers. ${ }^{12}$ Officers and organizers drew on a repertoire of techniques associated with late nineteenth-century liberal state formation, including surveying and mapping, the government of the self, and policing. In this way, the encampments are an example of the reach of liberal political culture beyond the realm of formal politics. The creation of disciplined citizens was not reserved for schools or museums, but could also be undertaken at sporting events and vacation spots.

In this chapter and again in Chapter Eight, I apply Michel Foucault's concept of governmentality to the sphere of sport/leisure to explore how seemingly benign recreational practices, such as canoeing and camping, served as sites for moulding liberal subjects. "Government," Foucault argued in a 1978 lecture at the College of France, "is the right disposition of things, arranged so as to lead to a convenient end."15 Foucault extended the idea of government beyond political administration to include "problems of self-control, guidance for the family and children, management of the

\footnotetext{
"Patrick Joyce, The Rule of Freedom: Liberalium and the Modern City (London: Verso, 2003), 1. Emphasis in original.

${ }^{12}$ This is what Henri Lefebvre terms representations of space, that is, space as it is conceived by professionals and technocrats, such as planners, engineers, and social scientists, and mediated through systems of signs. Representations, although abstractions, are imbued with ideology, power, and knowledge, which enables them to play an important role in the production of space through social and political practice. Henri Lefebure, The Production of Space, trans. Donald Nicholson-Smith (Oxford: Blackwell, 1991 [1974]).

${ }^{13}$ Michel Foucault, "Governmentality," in The Foucault Effect: Studies in Governmentality, eds. C. Gordon and P. Miller (Chicago: University of Chicago, 1991), 93.
} 
household, directing the soul, etc." ${ }^{14}$ Central to liberal governmental power, or "rule through freedom," is the government of the self, or the conduct of conduct. In the late nineteenth century, liberal governmentality, to return to Patrick Joyce, "depended on inculcating calculation among those who were to be governed, shaping them as, quite literally, democratically accountable, and hence responsible, citizens." ${ }^{\prime 15}$ Where governmentality departs from Foucault's earlier understandings of discipline is that it sought to govern not through the fear of being observed (the premise behind Jeremy Bentham's panopticon), but through desire. ${ }^{16}$ Codes of conduct, thus, are internalized to the point that fulfilling them simultaneously satisfies personal ambitions and governmental desires for public order.

Sport scholars have, in recent years, turned to Foucauldian notions of power to open new lines of inquiry in the field. ${ }^{17}$ Sport historians specifically have tended to focus their attention on Foucault's earlier work on discipline. ${ }^{18}$ Two recent collections co-edited by Patricia Vertinsky, for example, consider a variety of ways in which

\footnotetext{
${ }^{14} \mathrm{~T}$. Lemke, "The Birth of Bio-politics: Michael Foucault's Lectures at the College de France on NeoLiberal Governmentality," Economy and Society 30, no. 2 (2001): 192. Nikolas Rose defines programmes of government as the "complex assemblage of diverse forces (legal, architectural, professional, administrative, financial, judgmental), techniques (notation, computation, calculation, examination, evaluation), devices (surveys and charts, systems of training, building forms) that promise to regulate decisions and actions of individuals, groups, organizations in relation to authoritative criteria." Nikolas Rose, "Governing Advanced 'Liberal' Democracies," in Foucault and Political Reason, eds. Andrew Barry, Thomas Osborne, and Nikolas Rose (Chicago: University of Chicago Press, 1996), 42.

${ }^{15}$ Joyce, The Rule of Freedom, 24. Bruce Curtis succinctly concludes, "In [Foucault's] final formulations of the concept, 'governmentality' referred to the intersection of technologies of power, domination, and meaning making with technologies of the self." Bruce Curtis, "Review of Governmentality and the Mautery of Territory in Nineteentb-Century America," American Historical Review 107, no. 5 (2002): 1562.

${ }^{16}$ As I noted in the Introduction, Foucault's later work on governmentality represented a merging of his earlier thinking on discipline and sexuality.

${ }^{17}$ See, for example, Jennifer Smith-Maguire, "Michel Foucault: Sport, Power, Technologies and Governmentality," in Tbeory, Sport and Society, eds. Joseph Maguire and Kevin Young (Oxford: Elsevier Science, 2002), 293-314; E. Wheatley, "Disciplining Bodies at Risk: Cardiac Rehabilitation and the Medicalization of Fitness," Journal of Sport e' Social Issues 29 (2005): 198-221; P. Markula and R. Pringle, Foucault, Sport and Eaxercuse: Pow'er, Knowledge and Tranuforming the Self (London: Routledge, 2006). ${ }^{18}$ Michel Foucault, Discipline and Punirb: The Birtb of the Priton, trans. Alan Sheridan (New York City: Vintage Books, 1977); Michel Foucault, Power/Knowledge: Selected Interviews and Other Writing, 1972-1977, ed. Colin Gordon (New York: Pantheon, 1980).
} 
spaces of sport were constructed to effect particular kinds of embodied experiences. ${ }^{19}$

This chapter retains an interest in power relations at a more intimate level, while also asking questions about the deployment of power on a broader scale using Foucault's later writing on governmentality described above. ${ }^{20}$ In Part I, my concern is for the ways in which the site was laid out, but also the organizers' prescriptions for how the site was to be used by the canoeists, what we might call, following Henri Lefebvre, spatial practices. I pay particular attention to prescribed gender roles, which were themselves gestures in governance. In Part II, I consider the mechanisms by which the organizers sought to enforce such expectations, or governance on the ground. Their practices ranged between disciplinary power in the form of policing (understood here in the conventional sense of the term and not as Foucault used it to describe a wider programme of surveillance and regulation) and biopower, or government of the self. ${ }^{21}$

Of course, the spaces of the encampment and the canoeists did not always conform to expectations. As we see in Part III, order was constantly under threat by disorder. ${ }^{22}$ Here, I consider two "issues" that according to officials, constantly posed a challenge to campsite order: visitors and alcohol. As a point of clarification, I only hint at the

\footnotetext{
${ }^{19}$ Patricia Vertinsky and John Bale, eds., Sites of Sport: Space, Place and Experience (London: Routledge, 2004); Patricia Vertinsky and Sherry McKay, eds., Disciplining Bodies in the Gymnaium: Memory, Monument and Modernium (London: Routledge, 2004). See also, Mary-Louise Adams, Artistic Imprestions: Figure Skating, Masculinity, and the Limits of Sport (Toronto: University of Toronto Press, 201 1), 8-9; Colin Howell, Blood, Sweat and Cbeers: Sport and the Making of Modern Canada (Toronto: University of Toronto Press, 2001), 107-8.

${ }^{20}$ To date, I have only uncovered a handful of articles on the history of sport and governmentality. Perhaps not surprisingly, both are concerned with physical education and fitness. For example, Raul Sanchez Garcia and Antonio Rivero Herraiz, "'Governmentality' in the Origins of European Female PE and Sport: The Spanish Case Study, 1883-1896," Sport, Education, and Society (2011): 1-17; Jürgen Martschukat, “'The Necessity for Better Bodies to Perpetuate Our Institutions, Insure a Higher Development of the Individual, and Advance the Conditions of the Race': Physical Culture and the Shaping of the Self in Late Nineteenth and Early Twentieth Century America," Journal of Historical Sociology 24, no. 1 (2011): 472-93.

${ }^{21}$ Foucault argued that these are the "two poles around which the organization of power over life [has been] deployed" from the eighteenth century onwards. Michel Foucault, The Hittory of Sexuality: An Introduction, Volume 1, trans. Robert Hurley (New York: Vintage Books, 1990 [1978]), 139.

${ }^{22}$ Walden, Becoming Modern, 33.
} 
ways in which campers' visions for the site and their practices intersected with

organizers' expectations in this chapter, as this is the explicit focus of Chapters Six and

Seven.

\section{Part I - Imposing Order}

Here are camping grounds conducted in a manner to excite the admiration of all who appreciate order and seemliness, dignity, and realization of the surrounding beauties of nature. ${ }^{23}$

In Becoming Modern, Keith Walden shows how, as industrial capitalism and mass immigration reconfigured North American cities in the nineteenth century, the middle classes "became more emphatic about imposing a disciplinary order on space." ${ }^{24}$ While the ACA encampments existed at a distance from towns and cities, the organizers' approach to the campsites was informed by their urban experiences. In particular, their bourgeois Victorian ideologies of space and architecture were shaped by "moral environmentalism," the belief that "natural and built environments exert a profound influence over the ideals and inward capacities of those who experience or inhabit them." ${ }^{25}$ Contemporaries, who equated beauty with morality and goodness, assumed that "beautiful and orderly environments morally influenced human behaviour and thought, and encouraged social uplift." ${ }^{26}$ Such thinking underpinned City Beautiful, a

23 "Thousand Island Boating," New' York Evening Post, 16 June 1906.

${ }^{24}$ Walden, Becoming Modern, 245.

${ }^{25}$ David M. Scobey, Empire City: The Making and Meaning of the New' York City Landucape (Philadelphia: Temple University Press, 2003), 159. In turn, moral environmentalism was grounded in theories of moral psychology and environmental determinism. Xiaobei Chen's work on the childsaving movement offers a useful illustration of the intersections of moral psychology and environmental determinism, although she does not use the term environmentalism explicitly. Xiaobei Chen, "'Cultivating Children as You Would Valuable Plants': The Gardening Governmentality of Child Saving, Toronto, Canada, 1880s-1920s," The Journal of Historical Sociology 16, no. 4 (2003): 460-86.

${ }^{26}$ P.G. Mackintosh, "'The development of higher urban life' and the Geographic Imagination: Beauty, Art, and Moral Environmentalism in Toronto, 1900-1920," Journal of Historical Geography 31 (2005): 689. Mackintosh argues that the concept of moral environmentalism "helps us account for the apparent 
contemporaneous movement with roots in the 1893 Chicago World's Fair that espoused the improvement of urban space through comprehensive city planning and the employment of classical aesthetics. ${ }^{27}$ For ACA organizers, a beautiful and ordered encampment cultivated morally sound and decorous campers.

"Putting the camp in order" meant a number of things to officials. First, it signified the "improvements" to the campground described in Chapter Two such as the clearing of underbrush and the creation of trails. ${ }^{28}$ These improvements made the camp landscapes more aesthetically pleasing for the canoeists by domesticating "wildness." ${ }^{29}$ They also made the sites more habitable. Trails, for instance, facilitated movement around the campsite. However, like sidewalks in the city or paths through a park, they also implied appropriate routes for navigating space. ${ }^{30}$ Second, putting the camp in order referred to the imposition of a physical plan on the chosen landscape. The surveying and mapping technologies described in Chapter Two enabled the reproduction of familiar locations such as the headquarters, mess tent, and, after 1883 , the ladies' camp, on markedly different sites each year, making seemingly unfamiliar locations knowable to returning canoeists. The acts of designation inherent in mapping

exigency adhering to the turn-of-the-twentieth-century impulse to aestheticize physical space in the city." (690).

${ }^{27}$ Mackintosh, "Geographic Imagination," 705. On the City Beautiful Movement, see J. Peterson, "The City Beautiful Movement: Forgotten Origins and Lost Meanings," Journal of Urban Hittory 2 (1976): 415-34; William H. Wilson, The City Beautiful Movement (Baltimore: Johns Hopkins University Press, 1989).

${ }^{28}$ Although commentators did not make these comparisons, such "improvements" echo the tasks undertaken by nineteenth-century settlers, suggesting further linkages between tourism practices and colonization. John C. Walsh, "Landscapes Of Longing: Colonization And The Problem Of State Formation In Canada West" (Ph.D. Dissertation: University of Guelph, 2001).

${ }^{29}$ As I noted in the previous chapter, the ideal encampment was domesticated wildness.

${ }^{30}$ Michel de Certeau, The Practice of Everyday Life, trans. Steven Rendell (Berkeley: University of California Press, 1984 [1980]); Roy Rosenzweig and Elizabeth Blackmar, The Park and the People: $A$ Huitory of Central Park (Ithaca: Cornell University Press, 1992), paisim. 
also bound space to conduct, thereby regulating the possibilities of use. ${ }^{31}$ Third, "putting the camp in order" captured efforts to encourage cleanliness and organization. These are most evident in sanitary arrangements, which typically included the digging of wells, the erection of waterclosets/outhouses, and the promotion of daily clean-ups.

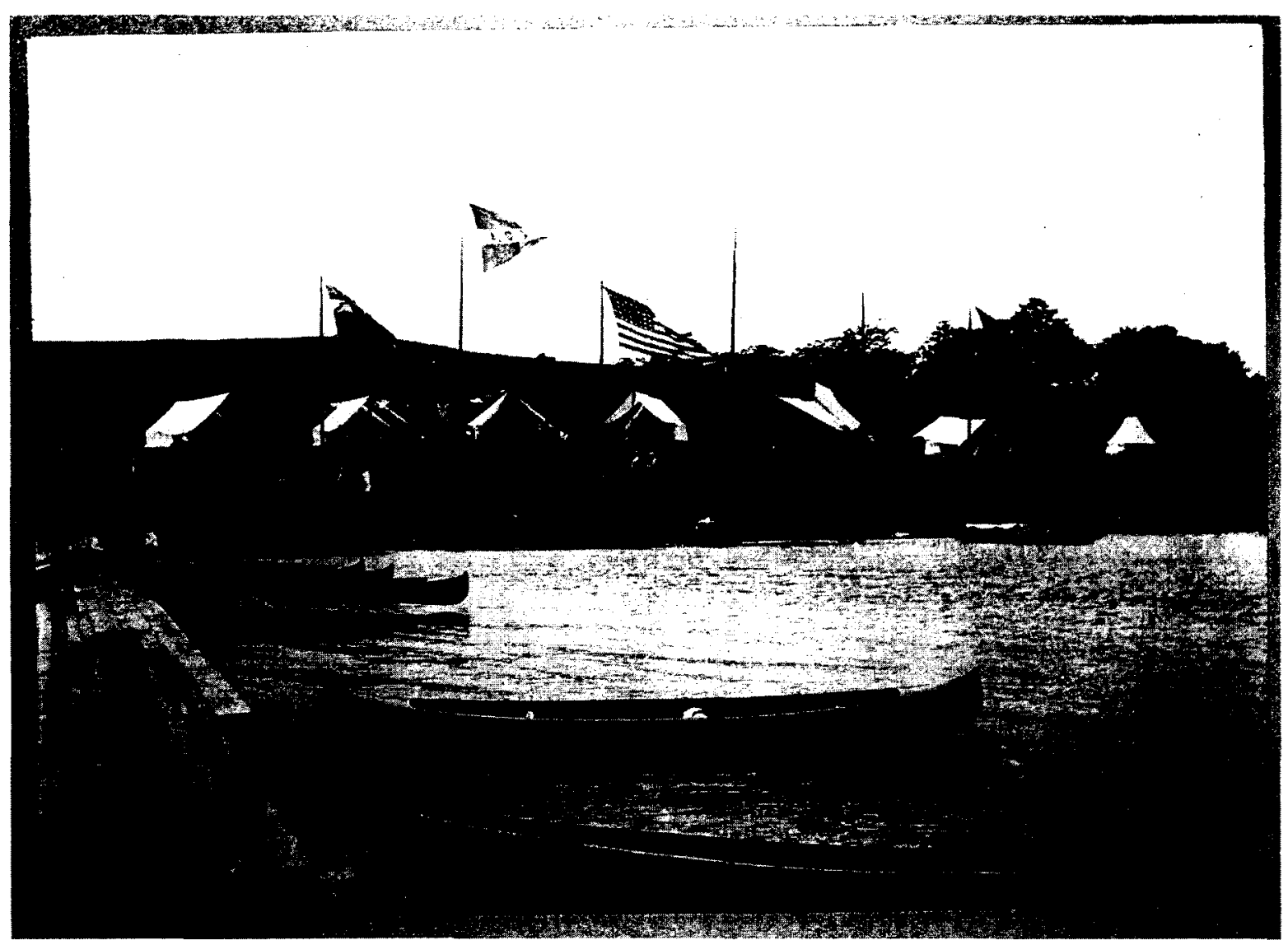

Figure 5.1 - H.C. Morse, "Headquarters from Dock," 1897. [Source: NYSHA, 1.2/26.]

Before turning my attention to the key sites of the encampment - with few exceptions, each of the campsites in this period featured a wharf, headquarters, mess tent, camp store, main camp, women's camp, and waste management sites - a word about the general layout of the annual meetings. Prior to 1902, the physical organization of the encampments changed on a yearly basis, reflecting the topography

\footnotetext{
${ }^{31}$ Joe Hermer, Regulating Eden: The Nature of Order in the Nortb American Parks (Toronto: University of Toronto Press, 2002), 46.
} 
of the site and the intentions of the organizing committee. With the move to Sugar Island, the arrangement of the encampment became more static. As both a mobile and permanent encampment, however, the layout employed by the organizers tended toward a mid-point between "picturesque design principles" in which "pavilions [were] scattered throughout the wooded site in an irregular arrangement designed to complement the natural surroundings," and the straight-line aesthetic of a military encampment captured in Figure 5.1. ${ }^{32}$

\section{Wharf and Headquarters}

For most visitors, members or otherwise, their official introduction to the encampment came at the wharf. ${ }^{33} \mathrm{~A}$ sign at the end of the dock announced to all who landed that the camp was a private one. ${ }^{34}$ As I explore in more detail in the final section of this chapter, the wharf was increasingly under surveillance by camp officials because it represented a primary point of access to the campsite. The headquarters, by contrast, was the organization's practical and symbolic seat of power. It was here that the annual meetings were officially opened with a flag-raising and cannon ceremony, that members and visitors alike came to register, that the bulletin board broadcast the events of the day, and, finally, that the regatta committee announced their decisions in response to fouling complaints (see Chapter Eight). The symbolic importance of the headquarters is evident in its prominence in official and personal photographs of the

\footnotetext{
32 Abigail Van Slyck, "Kitchen Technologies and Mealtime Rituals: Interpreting the Food Axis at American Summer Camps, 1890-1950," Tecbnology and Culture 43, no. 4 (2002): 673-4.

${ }_{33}$ Most years, the wharf was constructed in anticipation of the meet, to accommodate the lake or river steamers that brought the majority of canoeists from the railheads. "ACA Camp," Peterborougb Daily Review, 17 August 1883; "Noyac Correspondence," Sag Harbor Express, 31 July 1890; "Canoeing," New York Sun, 6 August 1898.

34 "Last Days of the River Season," Syracue Evening Herald, 30 August 1896.
} 
encampments. ${ }^{35}$

The landscaping of the headquarters consisted of between three and six tents arranged in a line or semi-circle, as depicted in Figure $5.1 .^{36}$ Ideally, they were of uniform size and shape with the names of the occupants announced via a sign hanging from the tent or painted on the stairs. The Commodore's tent was typically flanked by structures housing the Secretary-Treasurer and Regatta Committee. Other committees and service providers such as customs agents, the camp surgeon, and the postmaster were located in adjacent tents. More than convenience or pragmatism, the arrangement and style of the headquarters tents reflected the organizing committee's commitment to a social order defined as much by rank as function. ${ }^{37}$ Positioned in front of the tents were the camp cannon and tall flagpoles flying the colours of the Association and those of the nations officially represented at the camp. ${ }^{38}$ The flagpoles increased the visibility of the headquarters from points distant. Ideally, the headquarters could see and be seen from all quarters of the encampment. At the 1889 encampment on Stave Island, for example, the headquarters was situated on the highest point of land near the centre of the camp and from this point "six avenues radiated through the camp to the shore, the landings, etc. ${ }^{\text {39 }}$ In practice, this arrangement was not always possible because of the unique topographies of the campsites.

\footnotetext{
${ }^{35}$ Thomas Hale's scrapbook is representative. New York State Historical Association (NYSHA), 1.5/4, "Scrapbook of Thomas Hale," c. 1885-1900.

${ }^{36}$ See, also, "The ACA Meet of 1892," Forest and Stream, 25 August 1892; NYSHA, 1.2/22, Frank H. Foster, "General View of Camp Headquarters," 1892; 1.2/25, "View of Camp from West overlooking Eel Bay," 1897; 1.2/26, H.C. Morse, "Headquarters from Dock," 1897; 1.2/28, A.A. Lewis, "ACA Camp Headquarters," 1898.

37 "Their Campfires Ablaze," New' York Timed, 11 August 1895.

${ }^{38}$ See, "Headquarters from the Dock," in American Canoe Awsociation Yearbook, ed. Thomas H. Stryker (Rome: Press of the Rome Sentinel Company, 1896), 74.

39 "The Tenth Annual Meet of the American Canoe Association," Sail and Paddle 7, no. 9 (1889): 198.
} 
The headquarters was also home to the camp bulletin board, an ACA institution in this period. Photographs from the 1903 meet depict the board as being between eight and ten feet long, and displaying neatly arranged notices of various shapes and sizes. ${ }^{40}$ These notices included the site rules, as well as the schedule of the day. The bulletin board was also used to announce the "orders for the day," to indicate the location of nightly activities, and to offer "racing, cruising and general notices." ${ }^{\text {11 }}$ Apparently, the board also had a lighter side. One post that found its way into the historical record advertised: "For sale cheap, a Bull Terrier Pup, with large capacious jaws, will eat anything, very fond of children." ${ }^{\prime 2}$

\section{Mess Tent and Camp Store}

Whereas the camp headquarters was clearly a space of discipline, the camp mess and store served seemingly more benign purposes: providing for the alimentary needs of the canoeists. ${ }^{43}$ Both were later additions to the camp landscape. In the early years on Lake George, the canoeists cooked for themselves or took meals off-site at the Crosbyside Hotel. However, in 1884, the Delaney family, owners of the Grindstone Island site, opened their home to canoeists desiring a home-cooked meal. The scheme was a success, so the following year an official mess tent, overseen by Mrs. Delaney, was added to the campsite. ${ }^{44}$ Guests wishing to eat at the mess purchased meal tickets

\footnotetext{
${ }^{40}$ John Sears Wright, ed., American Canoe Aveociation Yearbook (n.p., 1904), 10. See, also, 1.5/4, "Bluff Point Lake Champlain," 1895.

${ }^{41}$ St. Lawrence County Historical Association (SLCHA), Camp Circular for Grindstone Island, 1886; Harry Eckford, "Camp Grindstone," The Century Magazine 30, no. 4 (1885): 511; Mystic Seaport Collections Research Center (MSCRC), Collection 291, Box 23, Folder 2, Camp Circular for Lake George, 1888.

42 "Our Trip to the A.C.A. Meet of '93," The Rockwood Review' 1, no. 7 (1894): no pp.

43 The mess was only one of three options for board open to the campers. They could also cook for themselves, or hire a cook for their club. I consider these other options in more detail in the next chapter.

${ }^{44}$ Later messes were run by a variety of people, some of whom had experience in the service industry. For example, Mr. Ferris of the Horicon Lodge Hotel was in charge of the 1888 mess, while the 1891 and
} 
from the Secretary-Treasurer. Most years, three meals a day could be had for one

dollar. ${ }^{45}$ Concerns that people were taking advantage of the system prompted the

Executive Committee to institute a rule in 1890 requiring diners "to show their tickets at the Mess Tent door." ${ }^{46}$

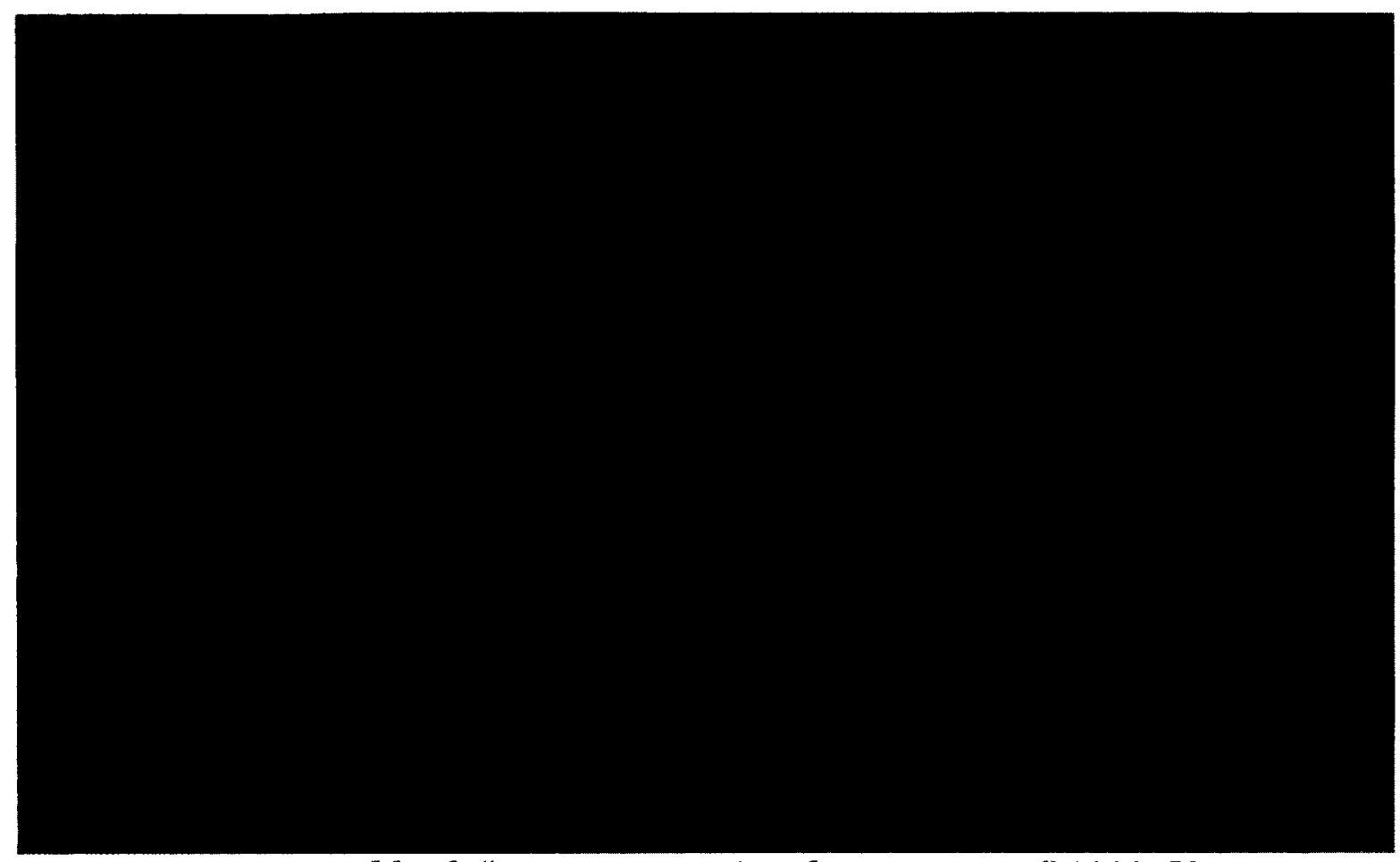

Figure 5.2 - S.R. Stoddard, "Campers Leaving the Mess Tent," 1889. [Source: NYSHA, 1.5/2.]

The mess consisted of a structure that served as a dining room and an attached kitchen for food service preparation visible in the background of Figure $5.2 .{ }^{47}$ Most years, the dining room was a tent, a larger version of the wall tents used by campers for sleeping. However, at the 1896 meet on Grindstone Island, campers took their

1892 messes were supervised by Mr. Otis, the manager of the Willsborough Hotel on Lake Champlain. Mr. D. McElveney of Albany, a professional caterer, oversaw the kitchen on a number of occasions in the 1890s and 1900s. "The ACA Meet," Forest and Stream, 5 July 1888; MSCRC, Collection 291, Box 23, Folder 2, Camp Circular for Willsborough Point, 1892; "Merry Days on the River," Syracuse Daily Standard, 15 August 1897; Charles P. Forbush, ed., American Canoe Avoociation Yearbook (n.p., 1899), 4; William A. Furman, ed., American Canoe Asoociation Yearbook (Trenton: State Gazette Print, 1907), n.p.

${ }^{45}$ The exception was the 1890 meet on Peconic Bay.

${ }^{46}$ MSCRC, Volume 3, Special Meeting of the Executive Committee, 14 August 1890.

${ }^{47}$ The structure on the right in this photograph is likely the camp store. 
meals in an eighty-foot circus tent, and at the 1887, 1891, and 1892 meets, the

canoeists dined in a wood-frame structure similar to the dining halls commonplace at summer camps in the early twentieth century. ${ }^{48}$ Both tents and dining sheds represented points of contact between wildness and civilization. Referring to the 1896 circus tent, for instance, R.B. Burchard noted that on nice days "the canvas wall at one end was removed so that the diners could look upon the water and wooded shores beyond." Although often open to the outside world, as we see in Figure 5.4, meals in the mess tent were served on china on cloth-covered tables adorned with flowers. ${ }^{50}$

Not surprisingly, encampment accounts focus on the quality of the food to the detriment of the facilities available to the cooks in charge of the mess. ${ }^{51}$ This omission likely reflects the fact that the kitchen for urban, bourgeois, late-Victorian sensibilities was "separated from the rest of the house, it was a place that [guests] would never see." ${ }^{52}$ The ACA kitchens, like those at summer camps, were relative simple affairs. They were usually housed in sheds such as that visible in Figure 5.3 and might feature iron stoves or portable baker's ovens. ${ }^{53}$ The exception was the kitchen at the Jessup's Neck meet, which was the "most extensive affair yet seen at a meet." ${ }^{54}$ Although still

\footnotetext{
${ }^{48}$ R.B. Burchard, "Back to Grindstone: The Canoe Camp," Outing 29, no. 2 (1896): 141; "The Annual Canoe Meet," New York Evening Post, 27 August 1887; NYSHA, 1.2/19, "The Mess Pavilion," 1891. A similar pavilion-style mess was used for the 1895 meet on Lake Champlain, although in this case it was erected by the management of the Hotel Champlain. Charles E. Cragg, ed., American Canoe Avsociation Yearbook (Port Henry: Press of the Essex County Publishing Company, 1895), 11.

${ }^{49}$ Burchard, "Back to Grindstone," 141.

${ }^{50}$ I explore this theme more fully in Chapters Six and Seven. Other photographs of the inside of the mess can be seen in NYSHA, 1.2/7, "General Camp Mess," 1890.

${ }^{51}$ I consider what the campers ate in more detail in Chapter Seven.

${ }^{52}$ Elizabeth C. Cromley, "Transforming the Food Axis: Houses, Tools, Modes of Analysis," Material History Review" 44 (1996): 8. Middle-class homes in the late nineteenth century were arranged by zones of use: "the social zones was for the reception of guests and family sociability, the service zone for household work and servants, and the private zone for sleeping and private family activities." In this configuration, cooking "belonged firmly in the service zone."

${ }^{53}$ Van Slyck, "Kitchen Technologies," 675.

54 "ACA Meet," Forest and Stream, 31 July 1890.
} 
within a wood frame structure, it featured an icehouse and storeroom beneath it. It also boasted a "full outfit of ranges, broilers, [and] ovens," that had been acquired from Delmonico's, a venerable New York restaurant, and hot and cold water courtesy of Duparrquet, Moneuse \& $\mathrm{Co}^{55}$ Unfortunately, the appliances appear not to have been used to full effect, for the 1890 meet had notoriously bad food. ${ }^{56}$

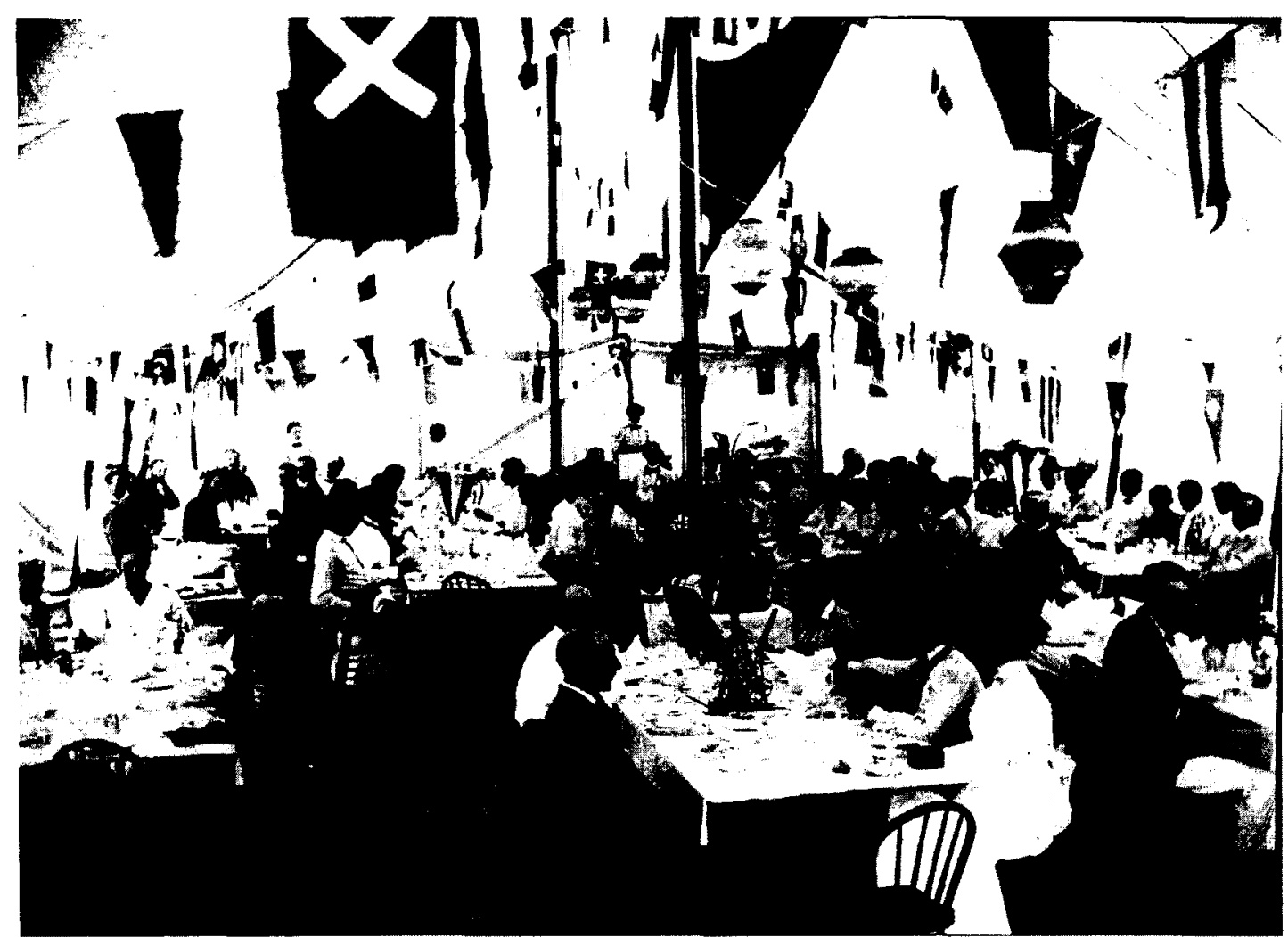

Figure 5.3 - A.A. Lewis, "Dinner Time in the Mess Tent," 1898. [Source: NYSHA, 1.2/27.]

The camp store was introduced in 1883 to provide those canoeists wishing to cook for themselves with the necessary supplies. The camp store, thus, reinforced the organizers' belief that the canoeists should treat the encampment much like a cruise, in which they cooked their own meals and slept in simple tents. Typically run by local

${ }^{55}$ "The ACA Meet: Camp Circular," Forest and Stream, 10 July 1890; "The ACA Meet of 1890-II," Forest and Stream, 6 November 1890. For a brief introduction to Delmonico's, see the entry for the restaurant in Robert E. Weir, Class in America: An Encyclopedia (Westport: Greenwood Press, 2007), 202. 56 "The ACA Meet of 1890-II," Forest and Stream, 6 November 1890. 
merchants or the person in charge of the mess, the camp store featured fresh produce, milk, eggs, and bread. ${ }^{57}$ One might also find coal oil, candles, lanterns, fireworks, stamps, wood, and flags on the store shelves. ${ }^{58}$ Despite the promises of the organizers, the camp store occasionally disappointed, undermining the organizers' desire for selfsufficiency. For example, visitors to the 1889 meet on Stave Island complained that it was difficult to procure staples such as bread and milk. ${ }^{59}$ The camp store at Jessup's Neck in 1890 was better equipped. ${ }^{60}$ Unfortunately, the prices were considered too high. This was particularly irksome because organizers always claimed that goods at the camp store would be available at "city prices." ${ }^{11}$ The example of the camp store suggests that not everyone at the ACA encampments was well off, and that for those who found ways to attend "on the cheap" the promise of reasonably priced produce was a necessity.

The mess tent and camp store were, at once, spaces of "consumption" and spaces of sociability. ${ }^{62}$ While the mess tent's primary function was to feed the canoeists, at others times it served as a chapel, a dance hall, a theatre or a circus tent. ${ }^{63}$ For example, the 1890 circus was held in the mess tent. ${ }^{64} \mathrm{~A}$ few days later, the same tent was "prettily decorated with strings of canoe and Japanese lanterns and festoons of

\footnotetext{
${ }^{57}$ For example, the camp store at the 1888 meet on Lake George was operated by C.A. and E.J. West, grocers from the nearby town of Caldwell. In 1907, mess and camp store were both were placed under the administration of Mr. D. McElveney. MSCRC, Collection 291, Box 23, Folder 2, Camp Circular for Lake George, 1888; See, for example, "The Meet," American Canocitt 2, no. 6 (1883): 79-83.

58 "The Meet," 79-83; SLCHA, Camp Circular for Grindstone Island, 1886; R. Easton Burns, ed., American Canoe Atsociation Yearbook (Kingston: Daily News Printing House, 1893), 10.

59 "American Canoe Association Meet," Forest and Stream, 12 September 1889.

60 "The ACA Meet of 1890 - II," Forest and Stream, 6 November 1890.

61 "The Meet," 79.

${ }^{62}$ This is a theme I return to in Chapter Six.

${ }^{63}$ See, for example, photodocumentation from the 1889 and 1890 meets on Stave Island and Jessup's Neck, NYSHA, 1.2/1-1.2/15. Hybridity was also a characteristic of early summer camp dining pavillions. Abigail Van Slyck, A Manufactured Wilderness: Summer Camps and the Shaping of American Youtb, 1890-1960 (Minneapolis: University of Minnesota Press, 2006), 64.

64 "The Canoe Men in Camp," New York Times, 17 August 1890.
} 
feather grass" and filled with canoeists listening to the "three colored gentlemen from Sag Harbor, who played the guitar, violin, and bones." ${ }^{165}$ These varied uses of the mess tent owed much to the fact that it was one of the few locations on the campsite where a large crowd could gather and be protected from the elements. To an extent, the mess as a multi-use space had parallels in urban dining rooms, which, as Susan Williams notes, were "an appropriate family gathering place in the evening, to read or play games or merely to sit and talk, particularly if [a family] had no other room that presented an alternative to the formality of the parlor." ${ }^{166}$ The store likewise was intended to meet the varied camping needs of the canoeists. However, members could also be found here enjoying a cup of tea, a cold beverage or a conversation with their fellow campers.

\section{Main Camp and Squaw Point}

Prior to 1883 , the annual meeting had been largely if not exclusively a homosocial masculine space. With the exception of "Ladies' Days," women appear to have been absent from the Crosbyside and Canoe Island campsites, although they were certainly in evidence as spectators at the canoe races. The inclusion of a "ladies' camp" at the Stony Lake meet reconfigured the physical and imagined space of the encampment. ${ }^{67}$ What prompted the organization to invite women to camp out at the annual meetings is unclear. Certainly, there appears to have been a degree of enthusiasm on the part of women. When the announcement was made that the 1883

\footnotetext{
65 "Fun for the Canoeists," New York Times, 22 August 1890.

${ }^{66}$ Susan Williams, Savory Suppers and Fasbionable Featt: Dining in Victorian America (Knoxville: University of Tennessee Press, 1996), 53.

67 "Ladies' camp" or "Squaw Point" is somewhat of a misnomer, as the camp also accommodated married couples. Whereas married women had to follow the same rules as single women, men's marital status rendered them immune to the regulations surrounding movement between the two camps.
} 
meet would accommodate female canoeists, parties were quickly formed to attend. ${ }^{68}$ The decision may also have been a response to anxieties about the perceived respectability of the annual meeting; there was a contingent of canoeists that, like O.K. Chobee, thought "visiting canoeists [would] not be tempted to forget their civilization through a lack of refining feminine influence. ${ }^{\prime 69}$ Respectability, which Lynn Marks refers to as an often "vaguely defined but clearly understood category," was an important ideal in the nineteenth century that informed all manner of social interaction. ${ }^{70}$ Manly respectability, which centred on industry, sobriety, piety, compassion, moral turpitude, and an ability to provide for one's family, could be threatened by the absence of women. ${ }^{71}$ Colin Howell, for instance, has documented how baseball promoters in nineteenth-century Atlantic Canada encouraged women's attendance at games believing their presence in the stands "would have a civilizing effect" on what was considered a rowdy pastime. ${ }^{72}$ Similarly, Adele Perry's work on colonial British Columbia has shown how white women were brought to the colony as a result of the belief, however misguided, that they could displace the colony's rough culture with domestic propriety. ${ }^{73}$ It is also possible that women's altered place within the meet was part of, and in some ways anticipated, the shift toward heterosocial

\footnotetext{
68 "The American Canoe Association in Canada," Forest and Stream, 19 April 1883.

${ }^{69}$ O.K. Chobee, "Echoes from Stony Lake," American Canocht 2, no. 8 (1883): 114.

${ }^{70}$ Lynn Marks, Revivals and Roller Rinks: Religion, Leiure, and Identity in Late-Nineteentb-Century Small-Town Ontario (Toronto: University of Toronto Press, 1997), 23.

${ }^{71}$ This list has been adapted from Christopher Anstead's definition of respectable manhood, as cited in Nancy Bouchier, For the Love of the Game: Amateur Sport in Small-Town Ontario, 1858-1895 (Montreal: McGill-Queen's University Press, 2003), 26.

${ }^{72}$ Colin Howell, Northern Sandlots: A Social History of Maritime Baseball (Toronto: University of Toronto Press, 1995), 76. Andrea Smalley likewise argues in the case of hunting that "Male writers and editors...asserted that women's participation would reform hunting, making it a modern, respectable recreation." Andrea L. Smalley, "'Our Lady Sportsmen': Gender, Class and Conservation in Sport Hunting Magazines, 1873-1920," Journal of the Gilded Age and Progreisive Era 4, no. 4 (2005): 364.

${ }^{73}$ See especially Chapter Six in Adele Perry, On the Edge of Empire: Gender, Race, and the Making of Britivb Columbia, 1849-1871 (Toronto: University of Toronto Press, 2001), 139-66.
} 
leisure spaces and practices described by Alan Hunt. ${ }^{74}$

A number of the male canoeists welcomed the change, including a reporter for Forest and Stream, who felt "the camp pleasanter for the presence of ladies who are campers and canoeists." In particular, he applauded their unfailing interest in the sport: "During the races, and some very bad weather, a number of ladies were out in canoes to see the sport, showing just as deep an interest as the men. ${ }^{175} \mathrm{C}$. Bowyer Vaux also defended women's place at the encampment, "Why should the men enjoy the monopoly of the camping pleasures, the freedom, exercise, and sport of canoeing? Girls can swim - some of them - paddle and rest comfortably in tents, and a few of them can actually handle a canoe under sail. It is, after all, only a matter of training and practice. ${ }^{776}$ Finally, Pauline Johnson, on a number of occasions, spoke passionately about the presence of women at the ACA meets, refuting assumptions about their abilities as both campers and canoeists. For example, in 1893 she wrote, "Whatever the canoeing girl may be during the winter seas, she is certainly the most laughter-loving, unconventional sunburnt maiden that the physical culture faddist could desire to see. She joins her brother at the yearly meet as religiously as she wears tans shoes and flannel gowns during her weeks of outing, and, without doubt, canoeing is the coming outdoor pastime for girls." ${ }^{n 7}$

Others were more ambivalent. One unnamed commentator did not want to imagine an encampment without a ladies' camp. However, he was "sure that there were far too many squaws over the ridge at Stave Island." He also felt that "nothing

\footnotetext{
${ }^{74}$ Alan Hunt, "Regulating Heterosocial Space: Sexual Politics in the Early Twentieth Century," Journal of Hittorical Sociology 15, no. 1 (2002): 1-34.

75 "The ACA Meet of 1888: The Camp and the Association," Forest and Stream, 6 September 1888.

${ }^{76}$ C. Bowyer Vaux, "The American Canoe Association, and Its Birthplace," Outing 12, no. 5 (1888): 415.

${ }^{77}$ Pauline Johnson, "Canoe and Canvas: The A.C.A. Meets in Canadian Waters," Saturday Nigbt, 2 September 1893.
} 
could be done in camp without more attention being paid to the necessities of the squaws than the wishes of the canoeists. ${ }^{178}$ In addition to positioning women and canoeists as mutually exclusive categories, this author voiced what was a common concern of male members, that women were somehow undermining the true purpose of the encampment. ${ }^{79}$ One of the organization's secretaries was perhaps the most explicit in his opposition to women on site. In the January 1884 issue of the American Canoeist, Charles Neide issued a sweeping condemnation of the ladies' camp for being "detrimental to the best interests of the Association." ${ }^{80}$ Canoeists were not alone in such feelings. Anxieties about the feminization of culture and everyday life were pervasive in nineteenth-century North America. ${ }^{81}$ Historians have documented how such anxieties contributed to new religious movements like muscular Christianity; organizations such as the Boy Scouts and the Young Men's Christian Association; and recreational spaces like boys' summer camps. ${ }^{82}$

\footnotetext{
78 "Snips from Snaps at the '89 Meet," Forest and Stream, 19 September 1889. A similar sentiment was expressed in a letter to the editor of the New York Tribune in 1890. Portions of the letter were reprinted in the pages of Forest and Stream the following year with the following reply: "We venture the opinion that without the influence of the ladies' camp the meet would lose the attendance of many of the older and steadier members of the ACA, non-girling men at that, who are never seen at Squaw Point." "Address Wanted," Forest and Stream, 17 September 1891.

79 "Snips from Snaps at the '89 Meet," Forest and Stream, 19 September 1889.

80 "A.C.A.," American Canoeitt 2, no. 12 (1884): 189. Such sentiments pervaded canoeing more generally. Charles Norton, for example, claimed that while he had no objection to women canoeists "in the abstract," he felt "the influence of woman...largely adverse to canoeing, and as such should be held strictly in abeyance, unless evidences of the true canoeing spirit are apparent." Charles L. Norton, "Canoes and Canoeists: A Retrospective," Outing 4, no. 2 (1884): 108.

${ }^{81}$ Ann Douglas, The Feminization of American Culture (New York: Knopf, 1977); Michael Kimmel, "Consuming Manhood: The Feminization of American Culture and the Recreation of the Male Body, 1832-1920," Michigan Quarterly Review 33 (1994): 7-36; Gail Bederman, Manlines' and Civilization: A Cultural Huttory of Gender and Race in the United States, 1880-1917 (Chicago: University of Chicago Press, 1996).

${ }^{82}$ Clifford Putney, Muscular Christianity: Manbood and Sports in Protestant America (Boston, Mass.: Harvard University Press, 2003); David I. MacLeod, Building Character in the American Boy: The Boy Scouts, YMCA and Tbeir Forerunners, 1870-1920 (Madison: University of Wisconsin Press, 1983); Leslie Paris, Children's Nature: The Rive of the American Summer Camp (New York: New York University Press, 2008).
} 
The moniker attributed to the newly formed ladies' camp, "Squaw Point," reveals the ambivalent feelings towards welcoming women to the annual meetings. It also underscores the annual meetings as racialized spaces. On the one hand, the nickname further exoticized the space of the women's camp, marking it as "other" to the larger institution of the annual meeting. At the same time, as Susan Joudrey has noted within the context of the Calgary Stampede, "Squaw" was a "derogatory term based on the opposite image of the noble Indian Princess. ${ }^{123}$ Following activist Muriel Stanley Venne, "when a person is called a 'Squaw' she is no longer a human being who has the same feelings as other women. She is something less than other women. ${ }^{184}$ The origins of "Squaw Point" are unclear. However, on a number of occasions the occupants of the ladies' camp tried to have the name changed to "Paradise," suggesting it was imposed on, not adopted by the women members. ${ }^{85}$ The tensions over the naming of Squaw Point further highlight the power of names.

The sites designated for the men's and women's camps reveal the ways in which middle-class notions of respectability in the late nineteenth century were gendered, although, as we shall see in the next chapter, the degree to which men and women began to undermine such conventions suggests a weakening of the ideology. Certainly, the fact that women canoeists were segregated in a separate camp was a reflection of classed notions of respectability. ${ }^{86}$ As Cindy Aron reminds us, middle-class status in

\footnotetext{
${ }^{83}$ Susan L. Joudrey, "The Expectations of a Queen: Identity and Race Politics in the Calgary Stampede," in The West and Beyond: New Perspectives on an Imagined Region, eds. Alvin Finkel, Sarah Carter, and Peter Fortna (Edmonton: Athabasca University Press, 2010), 142.

${ }^{84}$ Muriel Stanley Venne, "The 'S' Word: Reclaiming 'Esquao' for Aboriginal Women," in Unuettled Pauts: Reconceiving the West through Women's History, eds. Sarah Carter, Lesley Erickson. Patricia Roome, and Char Smith (Calgary: University of Calgary Press, 2005), 125.

${ }^{85}$ See, for example, Flip, "The Lake Champlain Canoe Meet," Outing 11, no. 3 (1887): 262.

${ }^{86} \mathrm{On}$ at least two occasions, the organization intended to house the women on a separate island, although this appears not to have happened. "The American Canoe Association in Canada," Forest and
} 
the nineteenth century "rested, in part, on claims to a publicly recognized respectability, a respectability gained by adhering to elaborate and complicated rules of etiquette that governed every minute aspect of life. ${ }^{.87}$ However, it also hints at a desire to "encourage women's entry into socially sanctioned areas" of public life. ${ }^{88}$ Here, Squaw Point had parallels in the ladies' reading rooms described by Abigail Van Slyck, which were "often considered an absolute necessity for encouraging respectable women to venture into the public library." ${ }^{89}$ By the 1880 s, women could for the same reasons also find designated spaces in department stores and banks, in hotels and restaurants, and on steamboats and railroad cars. ${ }^{90}$

The physical location of the two campsites was a testament to the ideological place of men and women in the organization. The men's, or main camp, was typically sited at the heart of the encampment, close to the public spaces of the wharf and the headquarters; its location was a physical reminder of men's favoured position at the core of the Association. Women, by contrast, were situated at the margins of the camp, distant to the headquarters, echoing their lesser status within the ACA. The emplacement of both camps also recalled the separate spheres ideology so popular in the nineteenth century that associated men with public life and women with private,

Stream. 19 April 1883; MSCRC, Collection 291, Volume 3, Meeting of the Executive Committee, 17 November 1888.

${ }^{87}$ Cindy Aron, "The Evolution of the Middle Class," in A Companion to Nineteentb-Century America, ed. William Barney (New York: Blackwell, 2000), 185. Emphasis added.

${ }^{88}$ Abigail Van Slyck, "The Lady and the Library Loafer: Gender and Public Space in Victorian America," Wintertbur Portfolio 31, no. 4 (1996): 223.

${ }^{89}$ Van Slyck, "The Lady," 221.

${ }^{90}$ Susan Porter Benson, Counter Cultures: Sales-women, Managert, and Cuttomers in American Department Stores, 1890-1940 (Urbana: University of Illinois Press, 1986); Katherine C. Grier, "Imagining the Parlor, 1830-1880" in Perspectives on American Furniture, ed. Gerald W. R. Ward (New York: W. W. Norton for the Henry Francis du Pont Winterthur Museum, 1988), 205-39; Carolyn Brucken, "In the Public Eye: Women and the American Luxury Hotel," Wintertbur Porfolio 31, no. 4 (1996): 203-20; Galen Cranz, "Women in Urban Parks," Signe 5, no. 3 (1980 Supplement): S80-5. 
family affairs. ${ }^{91}$

Third, the ideal sites for the two camps reveal the Association's conceptions of appropriate womanhood and manhood. Whereas the main camp was best located out in the open, ${ }^{92}$ organizers sought out wooded and secluded locations for the women's camps. ${ }^{93}$ At the 1889 encampment, for example, Squaw Point was situated "across a narrow bay, and concealed from the main camp by the bluffs. ${ }^{.94}$ At the 1895 encampment, the ladies' camp was located "north of Headquarters, where it is more thickly wooded." 95 That these sites were typically described as "quiet coves" or "a secluded grove" served to further distance Squaw Point from the rest of the campsite. ${ }^{96}$ Not only should men and women be separated, but the weaker sex should also be sheltered and protected. Consider the following description from the 1883 meet on Stony Lake: "It appears that the ladies' camp is sacred ground, not to be lightly profaned, and is kept guarded with oriental exclusiveness. ${ }^{\prime 97}$ The language employed in this example begs a post-colonial reading, as the author simultaneously conjures up images of convents and harems, framing women as both pure and in need of protection, and as objects of desire. Such beliefs were reinforced by the presence of official chaperones in the ladies' camp. Typically, an older woman or couple oversaw

\footnotetext{
${ }^{91}$ Linda K. Kerber, "Separate Spheres, Female Worlds, Woman's Place: The Rhetoric of Women's History," The Journal of American History 75, no. 1 (1988): 9-39.

${ }_{92}$ According to Forest and Stream, "The ideal camp would be a stretch of meadow just above the water and 200 to $300 \mathrm{yds}$ long, surrounded by a grove entirely free from underbrush, where those who wished could camp and where hammocks could be slung in the shade." "American Canoe Association Meet," Forest and Stream, 12 September 1889.

93 "The ACA Meet of 1890 - I," Forest and Stream, 30 October 1890.

94 "The Tenth Annual Meet of the American Canoe Association," Sail and Paddle 7, no. 9 (1889): 198.

${ }_{95}^{9}$ NYSHA, 1.6/1 1, Camp Circular for Bluff Point, 1895.

96 "Canoeists at Lake George," New' York Times, 16 August 1887; "The Canoeists in Camp," New York Times, 22 August 1887; "Canoeists' Annual Meet," New' York Times, 26 August 1900; "The Meet in Muskoka," Daily Mail and Empire, 27 July 1900.

97 "Stony Lake Canoe Congress," Peterborough Examiner, 23 August 1883.
} 
Squaw Point. ${ }^{98}$ For example, Mrs. E.J. Toker was responsible for the ladies' camp in 1884 and $1885 .{ }^{99} \mathrm{Mr}$. and Mrs. Seavey, and Mrs. Bave were charged with seeing that "all [were] made comfortable" in $1890 .{ }^{100}$

Women were not just spatially cloistered, but their movements were temporally constrained as well. As Harry Eckford observed, “Those [women] who honor the meets with their presence are, with their male relatives, assigned quarters in another camp and enjoined not to visit the main encampment till after eight in the morning, when the laziest canoeist is expected to have had his dip, made his toilet and done his toilet." ${ }^{101}$ Some years, women were not to visit the main camp until after ten in the morning. Nor were they to be in the men's camp after six in the evening, unless formally invited and accompanied by a chaperone. Likewise, single men were not to venture into Squaw Point unaccompanied and without invitation. These regulations hint at some of the perceived threats that mixed-sex camping posed to middle-class respectability, not the least of which was bodily intimacy.

The organizing committee was clearly concerned about the location of Squaw Point within the larger encampment. However, they appear not to have spent much time organizing Squaw Point on a micro-level, a fact that only reinforced the otherness of the women's camp. Flip, in her account of the 1887 meet on Lake Champlain, recalled arriving to Squaw Point and there only being "two tents up...to identify the spot." She also took note of the time it took to "find suitable places" for their tents,

\footnotetext{
${ }^{98}$ Flip, “Lake Champlain Canoe Meet," 263; D'Arcy Scott, "The Annual Camp of the American Canoe Association," Mas'ey', Magazine 2, no. 2 (1896): 118.

99 "Obituary," Forest and Stream, 15 October 1885.

100 "The ACA Meet: Camp Circular," Forest and Stream, 10 July 1890; "Fun with Sail and Paddle," New" York Times, 3 August 1890.

${ }^{101}$ Eckford, "Camp Grindstone," 510-1.
} 
suggesting that the organizers had not pinpointed locations in advance of the meet. ${ }^{102}$

The same could not be said of the men's camps. At the 1890 camp at Jessup's Neck,

for example, the organizers laid out two long parallel avenues along the edge of the bluff, connected at intervals by smaller streets. ${ }^{103}$ The result of the organizers' labours recalled the cadastral grid employed by surveyors to rationalize landscapes, in some cases for colonization. ${ }^{104}$ In his work on the New York City grid system, Reuben RoseRedwood argues that it was ordering of the landscape "with Cartesian precision" that provided "the spatial context within which governmental regulation and capital accumulation would be possible." Thus, rationalization of the landscape is a "story about the making of the landscape of modernity." ${ }^{105}$ That the connecting streets at the 1890 encampment "were not as numerous as they should have been" because "some of the campers pitch[ed] their tents in spaces intended to be left open for passage" speaks to the tensions between order and disorder in the camp landscape. ${ }^{106}$ It was not just campers that could upend the committee's system. Some years, the camp landscape

${ }^{102}$ Flip, "Lake Champlain Canoe Meet," 262.

${ }^{103}$ Similarly, at the 1892 meet, visitors were informed, "It is desireable [sic] to preserve one compact and well arranged camp, and members are requested in selecting tent sites to leave a clear road between the water and the first row of tents, and to preserve necessary passageways at convenient intervals between the various groups of tents." "American Canoe Association: Thirteenth Annual Meet," Forest and Stream, 14 July 1892.

${ }^{104}$ See, "Chapter Four: Geography and Citizenship: The Invention of the Ottawa-Huron Tract as a Field for Colonization" in Walsh, Landscapes of Longing, 71-124; James C. Scott, "Nature and Space," in Seeing Like a State: How' Certain Scbemes to Improve the Human Condition Have Failed (New Haven: Yale University Press, 1998), 11-52.

${ }^{105}$ Reuben Rose-Redwood, "Rationalizing the Landscape: Superimposing the Grid upon the Island of Manhattan" (M.A. Thesis: Pennsylvania State University, 2002), 21.

106 "The ACA Meet of 1890 - III," Forest and Stream, 13 August 1890. The organizers approach to locating tents changed over time. At the early encampments on Lake George, the Camp Site Superintendent assigned sites. By the late 1880 s, the organizers were taking a more informal approach. Canoeists were allowed to site their own tents, provided that they had "due regard for the thoroughfares and lines" and the permission of those already in residence. By 1892, the location of the tents once again required official approval, this time from the Camp Site Committee. Finally, in 1912, the Board of Governors passed an official resolution on the subject "[f]or the purpose of maintaining uniformity in the location, construction and alignment of individual campsites." MSCRC, Collection 291, Box 23, Folder 2, Camp Circular for Lake George, 1881, Camp Circular for Lake George, 1888, and Camp Circular for Willsborough Point, 1892; Bancroft L. Goodwin, ed., American Canoe Atvociation Year Book (n.p., 1913). 
also foiled attempts to organize the camp in particular ways. At the 1888 camp on

Long Island, "none of the clubs ha[d] the same compact and well-arranged

encampments that have sometimes been so prominent" because the "topography of the camp," but particularly the "uneven nature of the ground," which "scattered

irregularly" the tents. ${ }^{107}$

\section{Waste Management}

The organizing committee made a number of arrangements and instituted a number of rules to encourage "cleanliness and good order" in camp. They dug wells, which were intended to provide the camp with clean water. They provided outhouses to contain the bodily waste of the campers. ${ }^{108}$ They also carved time out of the official camp schedule for cleaning. The campsite rules stipulated that individual sites were to be put in order by ten every morning. ${ }^{109}$ While campers were responsible for "provid[ing] themselves with the necessary boxes or pails for this purpose," the committee provided for a garbage cart or refuse wagon that circulated the camp to gather waste from individual campsites. ${ }^{110}$ At least in the early years, the garbage cart was the responsibility of the camp police, hinting at the connections between

\footnotetext{
107 "The ACA Meet, Lake George," Forett and Stream, 23 August 1888.

108 There are a handful of references to "sanitary arrangements." See, "Local Canoe Meets," Forest and Stream, 1 November 1883; "The 1884 Meet of the A.C.A.," Outing 3, no. 6 (1884): 464-5; "The ACA Meet: Camp Circular," Forest and Stream, 10 July 1890. The 1890 circular assured visitors, "Particular pains will be taken to have perfect sanitary arrangements." Expenditures for the 1887 meet on Lake Champlain included a line for "three waterclosets" at the cost of \$35.32. "ACA Executive Committee Meeting," Forest and Stream, 17 November 1887. I have only found one other reference to outhouses from the period. "A Permanent Camp," Forest and Stream, 18 December 1890. However, they received mention in a memoir of the encampments: "A novelty in camp [in 1890] was a mimeographed daily newspaper which had a wide circulation. Over the tent was a large sign 'THE DAILY DISTURBER'. Some one removed it to a camp utility building where it remain throughout [sic] the meet a conspicuous object." NYSHA, 1.6/2, D.B. Goodsell, A Canoeing Reminisence (1936), 4. Emphasis added.

${ }^{109}$ MSCRC, Collection 291, Box 23, Folder 2, Camp Circular for Lake George, 1888.

${ }^{110}$ SLCHA, Camp Circular for Grindstone Idland, 1886; MSCRC, Collection 291, Box 23, Folder 2, Camp Circular for Willsborough Point, 1892.
} 
cleanliness and campsite order more broadly. ${ }^{111}$ The organizing committee sought to pass off some of the responsibility for enforcing such regulations to the Club Commanders by reminding them in the circulars that they were responsible for order and cleanliness in their respective camps. Such provisos reinforced the committee's expectations to any who read them. The organizing committee also appears to have appointed a member and "honorary lady member" to oversee the ladies' camps, which we might interpret as further proof of concerns about respectability or as evidence of gendered notions of cleanliness. ${ }^{112}$

Beyond a desire to maintain an aesthetic of order, these activities were also motivated by concerns about health and sanitation, a point that is succinctly captured in the closing line of the 1888 camp rules: "Cleanliness and good order are indispensable for the general health and comfort." ${ }^{113}$ Just as moral environmentalism explained how natural and built space could influence a person's moral well being, it also provided a link between environment and physical health. Linda Nash, for example, has shown how "important perceptions of health were to understanding the natural landscape" in the nineteenth century, but also how efforts to improve local environments were intended "to foster health." 114 While the campsites chosen by the organizers were largely considered healthy, undisciplined campers could undermine their healthfulness with bodily consequence. Nash writes, "nineteenth-century bodies, white and nonwhite, were malleable and porous entities that were in constant

\footnotetext{
${ }^{111}$ SLCHA, Camp Circular for Grindstone Island, 1886.

${ }^{112}$ MSCRC, Collection 291, Box 23, Folder 2, Camp Circular for Lake George, 1888.

${ }^{113}$ SLCHA, Camp Circular for Grindstone Island, 1886.

${ }^{114}$ Linda Nash, Inascapable Ecologies: A Hütory of Environment, Disease, and Knowledge (Berkley: University of California Press, 2006), 5, 72. Rather than accept that such perceptions of landscape are a function of premodern understandings of health, Nash's work seeks to highlight continuities in "concerns over environment and health" between the nineteenth and twentieth centuries.
} 
interaction with the surrounding environment...Consequently, prospective settlers approached new environments with caution, recognizing that the land itself could be either a font of health or a source of illness." 115 Concerns with sanitation likely also reflected a growing preoccupation with waste and waste management in urban environments in the late nineteenth century, which was also related to concerns about health and disease, order and disorder. ${ }^{116}$

As time passed, these "official spaces" - the touchstones of the campsitebecame bound to specific forms of conduct, which migrated with the encampment as it travelled through time and space. ${ }^{117}$ On the one hand, these acts of reproduction made unfamiliar locations knowable place for returning canoeists. However, they also introduced constraints on the canoeists' behaviour, which gave shape to their experiences of the camp. Of course, these were not perfect reproductions. The yearly changes in the organizing committee and the different environmental circumstances of the designated site also shaped the built environment of the encampment. Equally important were the campers. In the next section, I explore in more detail how organizers sought to encourage particular uses of the encampment spaces and discourage others.

\section{Part II - Regulating Conduct}

The regulation of camper conduct was as important to ensuring order during

\footnotetext{
${ }^{115}$ Nash, Inescapable Ecologies, 18. Nash continues here by noting that settlers paid close attention to their bodies' reactions, but also to the appearances of others because both were "important means to understand new places."

${ }^{116}$ George Rosen, A History of Public Health (New York: MD Publications, 1958); Martin V. Melosi, The Sanitary City: Urban Infrastructure in America from Colonial Times to the Present (Baltimore: John Hopkins University Press, 2000).

${ }^{117}$ Hermer, Regulating Eden, 45-6.
} 
the annual meeting as organizing the space of the encampment. In fact, the two were inextricably linked. My understanding and use of the term conduct owes much to Michel Foucault:

Perhaps the equivocal nature of the term conduct is one of the best aids for coming to terms with the specificity of power relations. For to 'conduct' is at the same time to 'lead' others (according to mechanisms of coercion which are, to varying degrees, strict) and a way of behaving within a more or less open field of possibilities. The exercise of power consists in guiding the possibility of conduct and putting in order the possible outcome. Basically power is less a confrontation between two adversaries or the linking of one to the other than a question of government. ${ }^{118}$

Camp officials employed a number of related techniques and technologies of rule designed to match camper behaviour to their expectations: they instituted regulations to govern conduct, they categorized the campers, they arranged the "temporal space" of the encampment with a schedule, and they policed the campground. While some of these were onsite activities, officials did not wait for the annual meeting to begin to make their expectations known. On the contrary, rules and schedules were included in the camp circulars and published in the official organs in advance of the meets. In the event that campers were not familiar with these prescriptions upon arrival to the encampment, copies of the rules and schedules were posted on the bulletin board at the Headquarters. ${ }^{119}$

Three different sets of rules governed encampment life: the constitution and bylaws (which I discussed in Chapter Two), regatta regulations (which I will explore in Chapter Eight), and campsite rules. The organizers and officials often implied that rules were a necessity in order to afford the fun and frivolity that attendees desired.

\footnotetext{
${ }^{118}$ Michel Foucault, "The Subject and Power," Critical Inquiry 8 (1982): 789. Emphasis added.

119 The publicity of the rules is yet another example of the Association's efforts at transparency.
} 
For example, the rules for the 1888 meet concluded as follows: "As these rules are few and simple as possible, the orderly and creditable appearance of the camp is entrusted to the members generally." ${ }^{120}$ This approach echoes Patrick Joyce's observations about the intimate connections between governance and freedom in the late nineteenth century ${ }^{121}$ It also hints at the ways in which organizers sought to encourage community formation amongst the canoeists. The rules were not static; rather, they evolved as new directives were added, others revised, and still others removed. What was considered orderly or disorderly shifted somewhat depending on the year, the site, and Association officials, although never drastically. The rules were also influenced to an extent by member behaviour. For example, in 1888, the Executive Committee, recognizing that the campers would remain awake regardless, extended the hour for quiet from $10.00 \mathrm{pm}$ to $11.30 \mathrm{pm} .{ }^{122}$ However, the fact remains that it was the administration that ultimately determined the rules.

A number of the campsite rules were aimed at curtailing movement within the encampments. For example, they dictated that upon arrival members and visitors alike had to register with the Secretary-Treasurer at Headquarters. After entering their names in his logbook and accepting their camp fees, ${ }^{123}$ the Secretary-Treasurer provided the canoeist with a coloured ribbon to be worn for the duration of the encampment. ${ }^{124}$ The ribbon featured the date of the encampment, the location, and the

${ }^{120}$ MSCRC, Collection 291, Box 23, Folder 2, Camp Circular for Lake George, 1888.

${ }^{121}$ Joyce, The Rule of Freedom.

${ }^{122}$ MSCRC, Collection 291, Volume 3, Meeting of the Executive Committee, 17 November 1888.

${ }^{123}$ Camp fees were one dollar for members until 1904, and two dollars thereafter. MSCRC, Volume 4, Meeting of the Executive Committee, 15 October 1904.

${ }^{124}$ These were not the only badges visible at the campsite. As early as 1884 , canoe clubs began producing their own badges, and unlike the official membership ribbons, these travelled around the encampment as the "men trade them about." One report claimed that most "found their way ultimately to Squaw Point." "The Canoe Men in Camp," New' York Time', 17 August 1890; "The Association Meet," 
status of the camper: member, honorary/associate member or visitor. ${ }^{125}$ These categories shaped participation and navigation while at the encampment. Visitors, for example, were only allowed onsite between the hours of ten and six, unless there was a special event publicly displayed on the bulletin board. The imposition of such categories was of a piece with efforts to rationalize the camp landscape. By dividing the campers up into discrete and seemingly knowable quantities, they could be more easily "surveilled" as they perambulated through the territory of the encampment. ${ }^{126}$ In the case of the ribbons, such badges also served as visible reminders of the campers' place within the encampment (it was literally marked on the body), thereby further promoting particular kinds of conduct. To borrow from Keith Walden, although divisions such as these "were largely appropriated from the logic of common perception, requiring no great exercise of imaginative powers, they did reinforce the legitimacy of many of the cultural divisions of everyday life."127

Other clauses in the rules governed particular activities. For example, members were prohibited from bathing whilst guests were in camp. They were also required to wear "proper bathing costume" at all times. Such regulations were not uncommon in this period for swimming, a subject I return to Chapter Seven. Although it was increasingly seen as a healthful activity worthy of middle-class participation, anxieties remained about mixed-sex swimming parties. ${ }^{128}$

Forest and Stream, 21 August 1884. Images of the encampments show canoeists wearing multiple different ribbons. See, for instance, NYSHA, 1.1/25, "Watching the Trophy Race," 1887.

${ }^{125}$ Examples of the ribbons are exhibited in the Fred Saunders Scrapbooks: NYSHA, 1.5/1.

${ }^{126}$ Stephen Graham and David Wood note that "wherever there has been the creation and enforcement of categories, there has been surveillance." Stephen Graham and David Wood, "Digitizing Surveillance: Categorization, Space, Inequality," Critical Social Policy 23, no. 3 (2003): 227.

${ }^{127}$ Walden, Becoming Modern, 34.

${ }^{128}$ Ken Cruikshank and Nancy Bouchier, for instance, have shown how, prior to World War I, swimmers at Hamilton-area beaches had to be covered from neck to knees, the exception being boys 
The ACA's efforts to regulate camper conduct was not limited to the campsite, although they likely had a greater degree of control over this space. On the contrary, additions to the campsite rules included notes about member behaviour while off-site. In 1888, for example, the camp bulletin board reminded all those who happened past, "The good repute of the ACA must be maintained by those who visit hotels in the neighbourhood." ${ }^{29}$ As with behaviour onsite, the organizers could not be assured that members would comply with their directives. For example, at the 1899 meet on Hay Island, a special meeting of the Executive Committee was adjourned to discuss "disturbances in camp and [the] boisterous conduct of men in camp and at Gananoque." 130 There were clearly concerns as to the kind of message such actions sent to the wider public about the Association.

The various sets of rules worked alongside the camp schedule, which included both daily and weekly elements. In other words, it prescribed when campers were to rise, but also what would take place on Tuesdays. ${ }^{131}$ I explore the contents of the camp schedule in more detail in Chapter Seven. However, of particular interest here is the fact that the weekly schedule always included a Divine Service, overseen either by a local parson or an ordained member. The commitment to holding a weekly service may have reflected genuine devotion, a point I return to in Chapter Seven. However, given that the services were not always well attended, I think we can read the inclusion of the Divine Service, like the organization's public temperance discussed below, as yet

under the age of fourteen. Ken Cruikshank and Nancy Bouchier, "'Dirty Spaces': Environment, the State and Recreational Swimming in Hamilton Harbour, 1870-1946," Sport History Review 29, no. 1 (1998): 67.

${ }^{129}$ MSCRC, Collection 291, Volume 3, Meeting of the Executive Committee, 15 August 1888.

${ }^{130}$ MSCRC, Collection 291, Volume 4, Special Meeting of the Executive Committee, 11 August 1899.

${ }^{131}$ The circular for the 1888 meet offered a particularly detailed schedule. MSCRC, Collection 291, Box 23, Folder 2, Camp Circular for Lake George, 1888. 
another facet of promoting a respectable public image. As Lynn Marks' work on religion and leisure in small-town Ontario makes clear, churchgoing was an important facet of middle-class respectability in the nineteenth century. ${ }^{132}$

In the first decade of the encampments, the daily schedule was communicated using cannons and bugles, much as in military camps. ${ }^{133}$ These were alternately used to awaken the campers, to remind them of mealtimes, to signal the closing of the day, and finally, to call them to bed. At the 1900 meet, there were even daily bugle calls to bring the sick to the camp surgeon. ${ }^{134}$ The liberal use of the bugles earned the camp bugler the title of "dread dignitary," suggesting that such ordering was not always appreciated by the Association's rank and file. ${ }^{135}$ In 1890 , the organization introduced a signal code to communicate with the canoeists. As Pauline Johnson observed, "Twenty-one pennants, of various pattern and color, constituted the signal set adopted by the Association. All business notifications, meetings, weather signals, races and happenings of general interest were announced by a combination of several flags, the minute details of such matters being posted on the bulletin board below." ${ }^{136}$ The signal code worked in tandem with the older practice of bugles and cannons; the bugle would sound every time the signal was changed. ${ }^{137}$ Codebooks were sold at Headquarters so

\footnotetext{
${ }^{152}$ Marks, Revivals and Roller Rinks, 23-5.

133 The New York Sun reported from the 1898 meet on Stave Island, "Bugler Love of the Seventh Regiment, New York City, arrived this morning, and will give the United States Army calls from now on." "Canoeing," New York Sun, 6 August 1898.

${ }^{134}$ Howell, "International Canoe Meet," 518.

${ }^{135}$ Eckford, "Camp Grindstone," 504.

${ }^{136}$ MUA, Box 9, File 27, Pauline Johnson, "Sail and Paddle," The Illutrated Buffalo Exprews, c. 1893. Other references to the new signal system are included in "The Canoeists," Rochester-Democrat Cbronicle, 14 August 1887. As Forest and Stream noted, the signal code only worked with "an open camp" in which the signals could be seen from every point. "The ACA Meet: Race Week," Forest and Stream, 28 August 1890 .

${ }^{137}$ Both the signal officer and bugler were paid camp positions.
} 
that members could decipher the myriad signals. ${ }^{138}$ The sheer volume of signals made the code the target of jokes. For instance, Forest and Stream quipped that the signal officer at the 1890 encampment was "threatened with an attack of nervous prostration" because the code was so lengthy and changed so often. ${ }^{139}$ This temporal ordering of the meet is a near-perfect illustration of E.P. Thompson's "time discipline." ${ }^{140}$ Regardless of whether it stemmed from necessity or a fetish for efficiency, or both, this commitment to the camp schedule was, like the ordering of space at the camps, an exercise in governance.

Ideally, organizers hoped that the campers would, with proper direction, regulate themselves. If this was not the case, the organization had structures in place to "see that the rules [were] complied with." ${ }^{141}$ As early as 1886, order in camp was the responsibility of an "Officer of the Day" chosen from the Executive Committee. The Camp Police, later referred to as "pickets", assisted the Officer of the Day. ${ }^{142}$ Both the Officers of the Day and the Camp Police/pickets wore badges to indicate their position. ${ }^{143}$ Given that the police and pickets were drawn from the general membership, it is reasonable to assume that their effectiveness was uneven. ${ }^{144}$ That

${ }^{138}$ MSCRC, Collection 291, Box 23, Folder 2, Camp Circular for Willsborough Point, 1892. For example, in 1892 , the Association made $\$ 53.25$ from the sale of codebooks. W. B. Wackerhagen, ed., American Canoe Atvociation Yearbook (Albany: Riggs Printing and Publishing, 1892), 40.

139 "The ACA Meet of 1890," Forest and Stream, 21 August 1890.

${ }^{140}$ E.P. Thompson, "Time, Work-Discipline, and Industrial Capitalism," Past and Present 38, no. 1 (1967): 56-97.

${ }^{141}$ SLCHA, Camp Circular for Grindstone Island, 1886.

${ }^{142}$ This linguistic shift took place in 1890. "The ACA Meet of 1890," Forest and Stream, 21 August 1890. All of these terms - officer of the day, police, and pickets - were military sobriquets. Thomas Wilhelm, $A$ Military Dictionary and Gazeteer, rev. ed. (Philadelphia: L.R. Hamersly, 1881). Some of the same terminology was employed at contemporary summer camps. Van Slyck, A Manufactured Wilderness, 131. ${ }^{143}$ SLCHA, Camp Circular for Grindstone Island, 1886. Here again, there are samples of both types of badges in Fred Saunders' Scrapbooks, NYSHA, 1.5/1.

${ }^{144}$ Bruce Curtis and Karl Jacoby make similar arguments about those employed by the nineteenthcentury state to conduct censuses or enforce conservation legislation. Bruce Curtis, The Politicu of Population: State Formation, Statistics, and the Censtus of Canada, $1840-1875$ (Toronto: University of Toronto 
these positions appear to have been farmed out to those who were new to the encampment reinforces this point. ${ }^{145}$

The officers and organizing committee deployed multiple strategies to pursue order in the encampment. In addition to lists of rules, which governed campers' movements and behaviour while onsite, they instituted a strict schedule, which was communicated via bugles and flags; they visibly categorized the campers, so as to more easily monitor their comings and goings, and to remind them of the same; and they appointed a police force, whose responsibility it was to enforce compliance with organization policies. Just as the efforts to physically organize the encampment transformed the campsite into territory, these attempts to discipline the campers transformed them into subjects of rule. In the next section, I consider how these subjects spoke back to the organizers through their conduct.

\section{Part III - Threats to Order}

Camp officials recognized early on the potential of campers to undermine their ambitions for an orderly encampment. Despite their best efforts, the annual meetings were never spaces of perfect order. Rather, order and disorder coexisted within the

Press, 2001); Karl Jacoby, Crimes Against Nature: Poachers, Squatters, Thieves, and the Hidden History of American Contervation (Berkeley: University of California Press, 2001).

${ }_{145}$ D.B. Goodsell recalled his first appointment as a picket at the 1890 meet. He was responsible for the shift between $12.00 \mathrm{am}$ and $4.00 \mathrm{am}$ one night, when rumours were circulating in camp that there were burglars onsite. Goodsell was given orders to "look out for a black sloop" and "report to the officer of the day...every half hour." It was only later that he was told that the situation had been fabricated to keep the "greenhorns" guessing. Goodsell, $A$ Canoeing Reminicence, 3. 
campsite. ${ }^{146}$ In this last section, I consider two aspects of camp life that, from the perspective of the organizers, posed ongoing threats to order: visitors and alcohol.

\section{The Visitor Dilemma}

Trespassers are by no means uncommon, carriages drive into camp and small craft land on the wharf bringing unwelcome guests, most of whom look on the camp as a circus, and gaze into each tent as into the case of the animalo in a menagerie. ${ }^{147}$

The Association was decidedly ambivalent about the presence of visitors on site. On the one hand, visitors represented potential members, confirmed the popularity of the sport and the organization, and legitimized the meets as events. However, they also posed a potential threat to the order of the campsite and the organization. In spite of such ambivalence, "Visitors' Days," or "Ladies' Days" as they were referred to prior to the introduction of Squaw Point in 1883 , were consistent features of the meet schedule from the Association's inception. ${ }^{148}$

Most years, advertisements were posted in area hotels and resorts inviting guests to visit the camp and/or watch the races. ${ }^{149}$ The choice of location for these advertisements hints at the class of visitor desired by the organizers. In some cases, steamer lines or resorts took matters into their own hands and arranged excursions to the campsite, a practice that ACA officials viewed with some concern, likely because

\footnotetext{
${ }^{146}$ Walden makes a similar observation about the Toronto Industrial Exhibitions, events intended to reaffirm order, but which also consistently subverted this ambition ambition. Walden, Becoming Modern, 32-79.

147 "The ACA Meet of 1890: Jessup's Neck," Forest and Stream, 21 August 1890.

${ }^{148}$ 'Ladies" Days were a common occasion at sporting clubs and events, and exhibitions in the late nineteenth century. See, Howell, Nortbern Sandlots, 77; Walden, Becoming Modern, 171.

${ }^{149}$ A sample notice from the 1888 encampment on Lake George is included in NYSHA, 1.6/11. Word also appeared in local and national newspapers. In 1889, for example, the New York Times carried the following notice in the section on the Thousand Islands: "Aug. 21 will be the day on which the camp of the American Canoe Association will be throw open for the inspection of visitors." Following the provision of the location of the meet, the notice concluded with the following comment: "The officers of the association give notice that they will not receive company on any other day than that named." "Sport on the St. Lawrence," New' York Times, 28 July 1889.
} 
they had less control over who might arrive on site. ${ }^{150}$ Also common were church and social reform organizations that used excursions to the encampments as fundraisers. ${ }^{151}$

Although the camp was expected to be in good order at all times, this was especially the case on visitors' days. Canoes were arranged along the pathways in full sail, while the decorated tents had their flaps drawn back ready for their inspection. ${ }^{152}$ At the 1881 encampment, the visitors arrived mid-morning "with their escorts, from the various hotels on the mainland." Boasting "bright dresses and parasols," the women and their companions "went from boat to boat and from tent to tent... The ingenious contrivances in the way of portable stoves, compact camping kits, and all the appliances to which canoeists resort to increase comfort while taking up but little room, were fully explained." ${ }^{153}$ Here again, we see a parallel with the "inspection" and "review" of military troops and quarters by distinguished visitors.

There was, quite clearly, a right and wrong kind of visitor. The Association disdained "the ordinary type of country sightseers, without regard for anything," who arrive on site "armed with lunch baskets and paper parcels" and "[settle] down on the camp and make it their own." ${ }^{154}$ Not only do they "sit and eat in the first tent that [strikes] their fancy," but they "quietly appropriate as souvenirs what little articles pleased their taste, and ask for anything they wanted but did not happen to see." A

150 "The Canoe Men in Camp," New' York Times, 17 August 1890; Rocbester Democrat Chronicle, 13 August 1896.

${ }^{151}$ The Sag Harbor Express, for example, announced in 1890, "an excursion, in aid of the "church debt fund' is to be made to the canoe encampment." Sag Harbor Enxpress, 14 August 1890. The Sag Harbor Corrector claims it was a "Presbyterian affair." Sag Harbor Corrector, 16 August 1890.

152 "The Canoe Meeting," New York Timed, 9 August 1882.

153 "Canoe Convention on Lake George," Rose-Belford's Canadian Montbly and National Review 7, no. 4 (1881): 427.

154 "The ACA Meet of 1890-11I," Forest and Stream, 13 November 1890. 
Times reporter referred to this constituency as the "great unwashed." ${ }^{155}$ By contrast, "visitors from the yachts were always welcomed, and many who came in by carriage or small boat in small parties." ${ }^{156}$ What separated the right and wrong type of visitor then appears to have been class, although presumably the camp was not open to non-white visitors, except as help or entertainment.

The organizers took a number of steps to combat the "problem of outsiders." First, by designating Ladies' Days/Visitors' Days, the organizers implicitly suggested that the encampment at other times was not open to women/outsiders. Second, following the expansion of the encampment to two weeks in 1883, Visitors' Days typically took place on Tuesdays or Thursdays. ${ }^{157}$ The timing of the day, during the week, would have served to discourage the attendance of working-class visitors from nearby towns and cities, who continued to work six days a week in this period and had limited time for holidays. ${ }^{158}$ However, given that the encampments were close to rural areas, it is possible that farm families may have been able to alter their schedule in order to attend. The persistence of concerns about the class of people visiting the encampments suggests a more diverse citizenry was in attendance than the organizers intended. Third, in 1890, the organization relocated the headquarters to the wharf. ${ }^{159}$

\footnotetext{
155 "The Canoe Men in Camp: Some of the Delights at Jessup's Neck," New York Times, 17 August 1890. 156 "The ACA Meet of 1890 -III," Forest and Stream, 13 November 1890.

157 "The ACA Meet: Race Week," Forest and Stream, 28 August 1890; “The ACA Meet of 1891: Race Week," Forest and Stream, 27 August 1891.

${ }^{158}$ In Massachusetts factories, for example, the ten-hour workday was typical in the $1870 \mathrm{~s}$ and $1880 \mathrm{~s}$, although an increasing proportion of businesses required only half days on Saturdays. Most blue-collar workers did not "win" summer vacations until the 1940s. Prior to that, their limited holiday time was likely a mix of civic holidays and company-sponsored holidays. Roy Rosenzweig, Eight Hours for What We Will: Workers and Leiwure in an Industrial City (Cambridge: Cambridge University Press, 1983), 39, 68, 69, 179-80. The situation was similar in Canada. See, Bryan Palmer, "Chapter Five: Merchants of Their Time," in A Culture in Conflict: Skilled Workery and Industrial Capitalism in Hamilton, Ontario, 1860-1914 (Montreal: McGill-Queen's University Press, 1979), and Craig Heron and Steven Penfold, The Worker's Festival: A History of Labour Day in Canada (Toronto: University of Toronto Press, 2005).

159 "The ACA Meet of 1890-I," Forest and Stream, 30 October 1890.
} 
The new site was lauded for being more "accessible" to new arrivals. However, it also increased the officers' abilities to monitor the canoeists' comings and goings and to enforce campsite rules about visitors and fees. Fourth, the introduction of badges in 1885 was also part of efforts to control access to the encampment, making clear who belonged and who did not. ${ }^{160}$ Fifth, with the introduction a camp police force in 1886 , visitors had to produce a "card of invitation" to the police to be allowed access. Finally, the decision to move the camp store in 1907 was also a response to concerns about outsiders on site. That year, the store was relocated from the headquarters on Sugar Island, which was near to the wharf, to the mess tent, which was farther inland. Organizers hoped that the move would eliminate one of the more disagreeable elements of the camp store, namely, that it functioned as a meeting place for outsiders "who had no business being in camp." ${ }^{.161}$ No solution was ever entirely satisfactory. As one observer noted, it was difficult to "keep out the ordinary sight-seer without discourtesy to friends of members, or others who would be welcome in camp." 162 Part of policing the physical edges of the encampments was, like the membership process, about establishing the territorial and social boundaries of the ACA community. Such policing was devoted to ensuring the sovereignty of the site, and to admitting the right sorts of people and barring entry to "others." Such boundaries, however, were by no means impermeable. Undesireable visitors continued to find their way onto the campsite, where organizers claimed they disrupted the perfect order of the meets. More concerning, however, were the disturbances effected

\footnotetext{
${ }^{160}$ The first mention I can find of badges being worn is "Canoeing at Thousand Islands," New York Sun, 9 August 1885. However, discussions about the usefulness of a badge appear in The American Canoeist as early as November 1883.

${ }^{161}$ MSCRC, Collection 291, Box 23, Folder 2, Camp Circular for Sugar Island, 1907. It is not clear from the source who these "outsiders" were: Native people, local folks, troublemakers, etc.

162 "The ACA Meet of 1890: Jessup's Neck," Forest and Stream, 21 August 1890.
} 
by drink, disturbances which were usually the product of member behaviour.

\section{Drunk and Disorderly}

Trees at the 1882 encampment on Lake George were affixed with signs outlining the "RULES To Govern Campers on Lorna Island." The first of these was: "The sale and open use of intoxicating liquors is forbidden on this island." ${ }^{163}$ Likewise, the camp circular for the 1886 meet on Grindstone Island stated rather unequivocally, “There will be NO BAR at the Camp store."164 Four years later, despite requests by the membership that the caterer be allowed to serve beer and wine at meals, the officers voted down the motion $13-4 .{ }^{165}$ This decision was reaffirmed in 1904 when the executive committee passed a motion prohibiting "the public sale of liquor...at camp." ${ }^{\prime 166}$ Journalistic accounts of the meet reinforced the image of the sober ACA constructed through regulations surrounding alcohol. An 1881 article in the New York Times claimed, "There is a strict rule here against the sale or public use of intoxicating liquors and anybody who wants anything to take a drink has to row two miles for it." Similarly, in 1885, Harry Eckford declared that "temperance is not only courted, but indispensable" at the ACA encampments. ${ }^{168}$

The organization's public adherence to temperance should come as no surprise. Temperance, as Craig Heron has noted, was "a cornerstone of middle-class identities" in the late nineteenth century, one of the chief ways in which "growing numbers of

\footnotetext{
${ }^{163}$ Other rules on the sign pertained to fires, the foliage, and graffiti. NYSHA, 1.6/12.

${ }^{164}$ SLCHA, Camp Circular for Grindstone Itland, 1886.

${ }^{165}$ MSCRC, Collection 291, Volume 3, Letter from Commodore Stanton to the Executive Committee, 29 April 1890. Elsewhere, the number is reported as five for and 13 against. "The ACA Meet," Forest and Stream, 22 May 1890.

${ }^{166}$ MSCRC, Collection 291, Volume 4, Meeting of the Executive Committee, 15 October 1904.

167 "The Canoe Island Camp," New' York Times, 13 August 1881.

${ }^{168} \mathrm{He}$ also related an incident in which the Commodore enforced the camp rules by ejecting a man from the encampment who was trying to sell liquor. Eckford, "Camp Grindstone," 511. Emphasis in original.
} 
professionals, business, white-collar workers, master artisans, and their families differentiated themselves...from the rougher elements of the manual workers below them and the decadent aristocracy above." ${ }^{169}$ Other middle-class sport organizations such as the amateur athletic associations described by Nancy Bouchier and the baseball clubs studied by Colin Howell positioned themselves similarly. ${ }^{170}$ However, the fact that the organizers had to make such forceful and public pronouncements in response to requests for alcohol on site suggests that a significant number of canoeists felt that drink was a reasonable part of encampment life.

There is explicit evidence that many canoeists were not tee-totallers while in camp. For example, photographs from the meets not infrequently include bottles of alcohol. ${ }^{171}$ Likewise, D'Arcy Scott's description of a canoeist new to camp included the consumption of alcohol as part of the process of arriving. He depicted the man sitting in front of his tent, "dealing out tin cups of ready-made cocktails, a couple of bottles of which he has been fortunate enough to bring with him." According to Scott, this practice made him "one of the boys. ${ }^{\text {"172 }}$ It was not just men who drank at the ACA meets, but women as well. In 1893, Pauline Johnson expressed her delight with the Vesper Canoe Club campfire at the Brophy's Point meet, but particular the "merry hosts, blazing bonfire and delicious claret cup."173 This finding dovetails with Heron's

${ }^{169}$ Craig Heron, Booze: A Distilled Hiwtory (Toronto: Between the Lines Press, 2003), 60.

${ }^{170}$ Bouchier, Love of the Game, 54, 73; Howell, "Chapter Two: First Innings: Baseball, Cricket, and the Bourgeois Ideal of Healthful Sport," and "Chapter Three: New Players: Baseball and Working-Class Culture," Nortbern Sandlot, 13-36, 37-54.

${ }_{171}$ NYSHA, 1.1/28, George Warder, "Mixed Drinks," 1887; 1.5/4, "Commodore Thorn's Camp," 1889; 1.5/3, "Camp of the Red Dragon Canoe Club," 1906; 1.5/5, Walwin Barr's Scrapbook, 1905-unknown.

${ }_{172}$ Scott, "Annual Camp," 116.

173 Johnson, "Sail and Paddle." Claret was a synonym for red wine in the nineteenth century, an artifact of the once booming trade in red wine from the Bordeaux region in France to England. P.T.H. Unwin, Wine and the Vine: A Historical Geography of Viticulture and the Wine Trade (London: Routledge, 1991): 13, 229-30. 
assertion that not "all the elements of the new middle and upper classes bought into the dry life." To the contrary, some were "quite prepared to accept such vices as drinking, smoking, gambling, and other moral indiscretions provided that those pleasures were not excessive or socially dangerous." ${ }^{\text {"174 }}$ Nevertheless, "the demands of polite respectability redefined 'acceptable' drinking practices," with "moderate consumption in genteel surroundings" emerging as the new ideal. ${ }^{175}$

Paul Vernon's memoirs suggest a gap between such ideals and practices at the ACA meets. He introduces his audience, for instance, to "Lipp," who, many nights, after attending campfires where "hospitality was plentiful," "made his bed for lack of personal transportation ability, by the fire's edge. ${ }^{" 176}$ Vernon also described the evening when "a brewer in camp with his wares posted a general invitation to a party at his tent." Vernon arrived "to find a wild crowd surging around the inside of a ten by twelve tent much enthused by free quantity of cheer for the pleasure of slow assimilation seemed to be outweighed by the desire to reach a volume and a state of inebriety as rapidly as was physically possible, the brewer furnishing the example."177 Apparently, the brewer was not the only one to bring a stockpile of alcohol to the 1893 meet. D.B. Goodsell reported that “Wiser of Prescott...brought...so many cases of Wiser's Canadian whisky that they filled all of one tent except for an aisle in the middle." ${ }^{178}$ The same year, decorated sailor Paul Butler had a "bar tent, which he

\footnotetext{
${ }^{174}$ Heron, Booze, 76.

${ }^{175}$ Heron, Booze, 77.

${ }^{176}$ Trent University Archives (TUA), 83-014/2, Paul Vernon, Tales of the ACA, 1940. Hospitality appears to have been a euphemism for alcohol. It also appears in Retaw, Fragment' from the '88 Meet (Montreal, 1888), 19.

${ }^{177}$ Vernon, Tales of the $A C A$.

${ }^{178}$ Goodsell, A Canoeing Reminiscence, 6. Goodsell also claims that Eddie Sipple brought a Saratoga trunk to the 1896 meet with "nothing in it but glass." (7).
} 
called the Midway." ${ }^{179}$ Some of the organizers' anxieties about alcohol consumption appear to have been well founded, for overconsumption had potentially destructive consequences. On the final night of $1893 \mathrm{camp}$, for example, "a gay group of men not desiring to take home any liquids they had brought with them, drank them all up." Then, "needing wood for a campfire, they appropriated the tent floors," which had previously been sold to the owners of the campsite, and "soon these pine boards were crackling, furnishing plenty of light and heat as they flamed skywards." As if this was not enough, the group then went looking for spectators for their blaze, literally carrying sleeping men out of their tents on their cots to the fireside. ${ }^{180}$

It is likely no coincidence that these more explicit references to alcohol and drunkenness were included in memoirs written long after the fact. Nevertheless, they problematize the myth of the dry meet. The contradictory characterizations of the camp as a dry and wet space are perhaps best explained by concerns about middleclass respectability. Clearly there were some in camp who opposed consumption without qualification, suggesting a personal commitment to sobriety. Paul Vernon, for example, recalls being taken aside after the brewer's party by fellow club member Bob Wilkin, and reprimanded for attending such a gathering. According to Wilkin, who was at least a few years senior, Vernon "would be classed as that kind if [he] was seen at such gatherings." ${ }^{181}$ However, others participated in or condoned a drinking culture so long as it was kept away from the prying eyes of outsiders, suggesting that maintaining appearances trumped temperance. Vernon recalled, for instance, that at a meet on Sugar Island, "social refreshments at camps were taken behind the tents" on

\footnotetext{
${ }^{179}$ Goodsell, A Canoeing Reminiscence, 6.

${ }^{180}$ Vernon, Tales of the $A C A$.

${ }^{181}$ Vernon, Tales of the $A C A$.
} 
account of the visitors. ${ }^{182}$ Behaviour such as this enabled the maintenance of the organization's public claim to respectability. While temperance activists might not have been happy with the situation, as Heron notes, what took place out of sight "was of less concern than the highly visible drinking that still took place in public."183

\section{Conclusion}

Speaking about the Industrial Exhibition, Keith Walden hypothesized, "Perhaps because the grounds were a site where unusual degrees of transgression were permitted, a variety of agencies, both public and private, made special efforts to maintain high standards of rectitude. Among the most prominent were religious groups, temperance advocates, and, of course, the police." 184 The American Canoe Association encampments, as spaces beyond the bounds of everyday existence with their own logics, also invited transgression, if not to the same degree as at the Exhibitions. That said, they were never, at least to my knowledge, the targets of churches, organizations such as the Women's Christian Temperance Union or the police. For the most part, efforts to curtail disorder were undertaken by the on-site administrators. However, in the efforts of the organizers and officials to promote order, we see the values espoused by the three "types" of groups Walden identifies marking the social landscape of the camp. The camp schedule always included a Divine Service on Sundays, and men and women were to interact with the utmost propriety under the watchful gaze of chaperones. Temperance, to borrow from Harry

\footnotetext{
${ }^{182}$ Vernon, Tales of the ACA.

${ }^{183}$ Heron, Booze, 77.

${ }^{184}$ Walden, Becoming Modern, 44.
} 
Eckford, was "to be courted," indispensable as it was to the public respectability of the camp and its campers. Finally, the rule of law was to prevail.

As these examples make clear, claims that the encampments were spaces of freedom obscured the degree to which the site and the campers were objects of governance. As the organizers sought to order the encampments, they drew on the same technologies and techniques of liberal government employed by the state in the same period. Most marked are efforts to rule through desire, what Foucauldians refer to as the conduct of conduct. The annual meetings, in other words, are evidence of the interpenetration of liberal political culture, namely liberal governmentality, and sport/leisure in the late nineteenth century. Of course, in spite of the myriad efforts to construct the encampments as spaces of order, the events were always disorderly at some level, a point that was particularly evident on Visitor's Days and in the evenings.

In this chapter, I explored the encampments as spaces of representation, spaces imagined and enacted by those in positions of power, namely the organizers and the executive committee. In the next two chapters, my concern is with the campsites as lived spaces, produced through the spatial practices of the campers themselves in relation to the structures enacted by the organizers. This desire to juxtapose governance with the practices of everyday life speaks to a more general concern in social history with the dialogic relationship between structure and agency. 


\section{Chapter Six: Placing Domesticity}

As a space of belonging and alienation, intimacy and violence, desire and fear, the bome is invested with meanings, emotions, experiences and relationships that lie at the beart of human life.'

The annual meetings of the American Canoe Association were liminal spaces, distinct from and yet connected to the spaces of home and work. This liminality was reinforced by location - most encampments were on points of land only accessible by water-and their temporal bounds - the encampments occupied a fixed length of time. ${ }^{2}$

Thus, to arrive at the encampment was also to "cross a threshold," which at once linked and separated the interior world of the encampments from the exterior world. ${ }^{3}$ This potentially transformative transition is captured in D'Arcy Scott's description of the 1896 meet on Grindstone Island:

Let us for a moment follow a new-comer, as he arrives in camp, and observe his movements. Landing from the steamer he doesn't look in the least like a canoeist, with his stiff, brown hat and neat, grey suit; but he must be, for the deck hands have just carried out a sort of overgrown coffin case... which turns out to contain his canoe. He has not been on the wharf many minutes when he is taken charge by his friends... Half an hour later we find the same individual decked out in flannels, with tennis shoes and a soft felt or flannel hat decorating his extremities, seated on a half-empty trunk in front of a tent just put up with the assistance of the camp carpenter and many willing and sunburnt hands, dealing out tin cups of ready-made cocktails, a couple of bottles of which he has been fortunate enough to bring with him. He's one of the boys now and has passed the ordeal of arriving in camp. ${ }^{4}$

\footnotetext{
'Alison Blunt and Ann Varley, "Introduction: Geographies of Home," Cultural Geograpbies 11, no. 3 (2004): 3.

${ }^{2}$ Keith Walden makes a similar argument about the spatial structure and temporal structure of the Industrial Exhibitions. Keith Walden, Becoming Modern in Toronto: The Industrial Exbibition and the Shaping of a Late Victorian Culture (Toronto: University of Toronto Press, 1997), 26.

${ }^{3}$ Liminality stems from the Latin word 'limen," meaning thresbold or doorway. Arnold van Gennep, The Rites of Passage (London: Paul, 1960 [1909]). The threshold, to borrow from Renate Dohmen, is a "spatial state of ambiguity," which in the context of a home exists between inner and outer, "an interstitial passage between two states in need of careful negotiation." Renate Dohmen, "The Home in the World: Threshold Designs and Performative Relations in Contemporary Tamil Nadu, South India," Cultural Geographies 11 (2004): 7-25.

${ }^{4}$ D'Arcy Scott, "The Annual Camp of the American Canoe Association," Mas'sey', Magazine 2, no. 2 (1896): 116-7.
} 
Crossing the threshold was about moving from the imagined community of canoeists into the tangible face-to-face community of fellow enthusiasts. On the one hand, this was a conceptual movement. However, as the quotation makes clear, it was also an embodied process that was characterized by a number of practices: physically landing at the wharf; unloading one's baggage from the steamer or canoe; visiting the secretary-treasurer; donning camp clothes; and inhabiting the site by raising and outfitting a tent, and constructing a canoe landing.

In this chapter, I explore these practices of "settling in" to better understand the transformation that campers underwent as they crossed the threshold, but also to make sense of the world they created at the encampments. The canoeists engaged in a number of verbal, mental, and physical acts of domestication most notable in the early days of the meet, but which continued until the last tent was taken down. I conceive of these acts as part of an "exercise of creating a place in the world articulated via the home, that is, fashioning a space of belonging." We might call this the making of domestic place or placing domesticity. Placing domesticity was at once a personal and a public gesture. It was a labour of love, a reflection of the meaningfulness of the experience for the canoeists. Placing domesticity was also a way for the campers to signal the character of the meets to outsiders. It was, in other words, part of the framing of the camps, the regattas, and even canoeing as white forms of "proper" (ie. amateur) sport and recreation.

In many respects this aspect of encampment life is at odds with conventional scholarly understandings of outdoor recreation amongst white middle-class men in the

\footnotetext{
${ }^{5}$ Dohmen, "Home in the World," 23.
} 
late nineteenth century, which suggest that these men fled their homes for the "wilderness" and a temporary life of savagery in order to reinvigorate their masculinity and counter the physically debilitating effects of modern life. ${ }^{6}$ In this chapter, I suggest that men had a more complex relationship to home and domesticity than dominant constructions of Victorian masculinity allow. It is not an argument without precedent. Since the mid-1990s, scholars have paid increasing attention to men's presence within the home, showing how domestic space historically speaking has not been uniformly feminine. ${ }^{7}$ More recently, historians have begun to explore the ways in which men created domestic spaces away from the home in homosocial spaces such as clubs, lodges, and navy ships. ${ }^{8}$ I extend this work on male domesticity to consider homemaking by white middle-class men at leisure in wild environments inspired by, but never truly single-sex spaces. Ostensibly, men went to the wilderness to escape the

\footnotetext{
${ }^{6}$ According to Michael Kimmel, male dominance seemed under threat in this period by women's increasing presence in the public sphere, "the closing of the frontier, rapid industrialization, the decline of the individual farmer and small shopkeeper, and the concomitant rise of mass production and the factory system." Michael S. Kimmel, The History of Men: Evsays in the Hiwtory of American and Britith Masculinities (Albany: State University of New York Press, 2005), 112, 74-7. See, also, Michael Egan, "Wrestling Teddy Bears: Wilderness Masculinity as Invented Tradition in the Pacific Northwest," Gender Forum, 15 (2006). Accessed 19 March 2012: http://www.genderforum.org/issues/genderroomours-i/wrestling-teddy-bears/; Ben Jordan, “'Conservation of Boyhood': Boy Scouting's Modest Manliness and Natural Resource Conservation, 1910-1930," Environmental History 15 (2010): 612-42. This line of thinking owes much to Roderick Nash, Wildernest and the American Mind (New Haven: Yale University Press, 2001 [1967]).

${ }^{7}$ Margaret Marsh, "Suburban Men and Masculine Domesticity, 1870-1915," American Quarterly 40, no. 2 (1988): 165-86; Margaret Marsh, Suburban Lives (London: Rutgers University Press, 1990); Stephen M. Frank, Life witb Fatber: Parentbood and Masculinity in the Nineteentb-Century American Nortb (Baltimore: Johns Hopkins University Press, 1998); John Tosh, A Man's Place: Masculinity and the Middle-Claw Home in Victorian England (New Haven: Yale University Press, 1999); Martin Francis, "The Domestication of the Male? Recent Research on Nineteenth- and Twentieth-Century British Masculinity," The Hütorical Journal 45, no. 3 (2002): 637-52.

${ }^{8}$ Examples of this growing body of work on "exclusively male domesticities outside the home" include Jane Rendell, "The Clubs of St. James's: Places of Public Patriarchy - Exclusivity, Domesticity and Secrecy," The Journal of Architecture 4 (1999): 167-89; Amy Milne-Smith, "A Flight to Domesticity? Making a Home in the Gentleman's Clubs of London, 1880-1914," Journal of Briturb Studies 45 (2006): 796-818; Phillip Gordon Mackintosh and Clyde R. Forsberg, "Performing the Lodge: Masonry, Masculinity, and Nineteenth-Century North American Moral Geography," Journal of Hütorical Geography 35 (2009): 451-72; Quintin Colville, "Corporate Domesticity and Idealised Masculinity; Royal Naval Officers and Their Shipboard Home, 1918-1939," Gender e' History 21, no. 3 (2009): 499-519.
} 
feminine space of the home, not to reproduce it. ${ }^{9}$ And yet, this is just what members of the ACA did, in the presence of and occasionally in conjunction with women.

This chapter hinges on my belief that the encampments for upwards of two weeks functioned as the canoeists' "homes away from home." Home has a multiplicity of meanings and usages. However, as Alison Blunt and Robyn Dowling note, "cutting across the diverse definitions of home used in different frameworks is a recognition that home has something to do with intimate, familial relations and the domestic sphere." ${ }^{10}$ Borrowing from Blunt and Dowling, I define home as "a place/site, a set of feelings/cultural meanings, and the relations between the two." ${ }^{11}$ Of course, "Home does not simply exist, but is made." This "process of creating and understanding forms of dwelling and belonging" has both "material and imaginative elements...People create home through social and emotional relationships. Home is also materially created - new structures formed, objects used and placed." ${ }^{12}$ The encampments were tethered in both material and cultural ways to the world the canoeists ostensibly left behind. The canoeists' urban dwellings were transported to the encampments through objects such as albums, linens, and rugs, but also through the organization of space. Likewise, the experience of the encampments was returned to the city in the form of

\footnotetext{
${ }^{9}$ Even when men engaged in domestic tasks such as cooking historians have distanced such practices from homemaking, or they have invoked the homosociality of their environments to render such practices acceptable. See, for example, Ian Radforth, "The Shantymen," in Labouring Lives: Work and Workers in Nineteentb Century Ontario, ed. Paul Craven (Toronto: University of Toronto Press, 1995), 20477, and Adele Perry, On the Edge of Empire: Gender, Race, and the Making of Britutb Columbia (Toronto: University of Toronto Press, 2001).

${ }^{10}$ Alison Blunt and Robyn Dowling, Home (London: Routledge, 2006), 23.

"Blunt and Dowling, Home, 2. This reflects current trends in researching "home," which has moved beyond "the separation of public and private spheres" to consider "mobile geographies of dwelling, the political significance of domesticity, intimacy and privacy, and the ways in which ideas of home invoke a sense of place, belonging or alienation that is intimately tied to a sense of self. Rather than view the home as a fixed, bounded and confining location, geographies of home traverse scales from the domestic to the global in both material and symbolic ways." Blunt and Varley, "Introduction," 3.

${ }^{12}$ Blunt and Dowling, Home, 23.
} 
flags and photographs. Moreover, camp life contributed to the reimagining of urban domestic space in the late nineteenth century. Following Karen Halttunen's work, it was, in part, through the influence of summer homes and camping that the parlours of middle-class homes were transformed into living rooms, namely as a means of recalling throughout the year the lifestyle afforded by summer haunts. ${ }^{13}$

\section{Settling In}

Most canoeists, as I noted in Chapter Four, arrived at the encampment by steamer. The blast of the boat's horn called those already in camp to gather at the wharf and greet the new arrivals. ${ }^{14}$ At the 1900 meet in Muskoka, "as soon as the gangway was run out there were many joyful meetings. Some of the old campers were literally received with open arms." ${ }^{.15}$ Those years when the wharf was located at a distance from the campsites, the welcome was decidedly different. Not only was the arrival absent of the expected fanfare, but also, as one observer lamented, "one may be in camp two or three days without knowing who of his friends is present. ${ }^{.16}$ The crowd gathered at the wharf usually offered their services to the new arrivals. Canoes and trunks were carried off the boat and loaded onto wagons and carts. ${ }^{17}$ Before they made their way to their campsites, however, the canoeists stopped at the Secretary-

\footnotetext{
${ }^{13}$ Karen Halttunen, "From Parlor to Living Room: Domestic Space and the Culture of Personality" in Consuming Visiont: Accumulation and Display of Goods in America, 1880-1920, ed. Simon J. Bronner (New York: W.W. Norton and Company, 1989), 157-89.

${ }^{14}$ The arrival of a steamship at the dock was "the signal for a grand turnout of the camp." "The Meet of 1886," Forest and Stream, 26 August 1886.

${ }^{15}$ D.J. Howell, "The International Canoe Meet," The Canadian Magazine 15, no. 6 (1900): 515 . Howell suggests that the excitement of arrival was matched by a sense of relief after a long journey.

16 "The ACA Meet of 1891," Forest an $\partial$ Stream, 20 August 1891. Such commentary reinforces the importance of understanding the encampments as social spaces, as much as sporting ones.

17 "The Meet of 1886," Forest and Stream, 26 August 1886.
} 
Treasurer's tent at Headquarters. ${ }^{18}$ A representation of one of these encounters is visible in Figure 6.1.

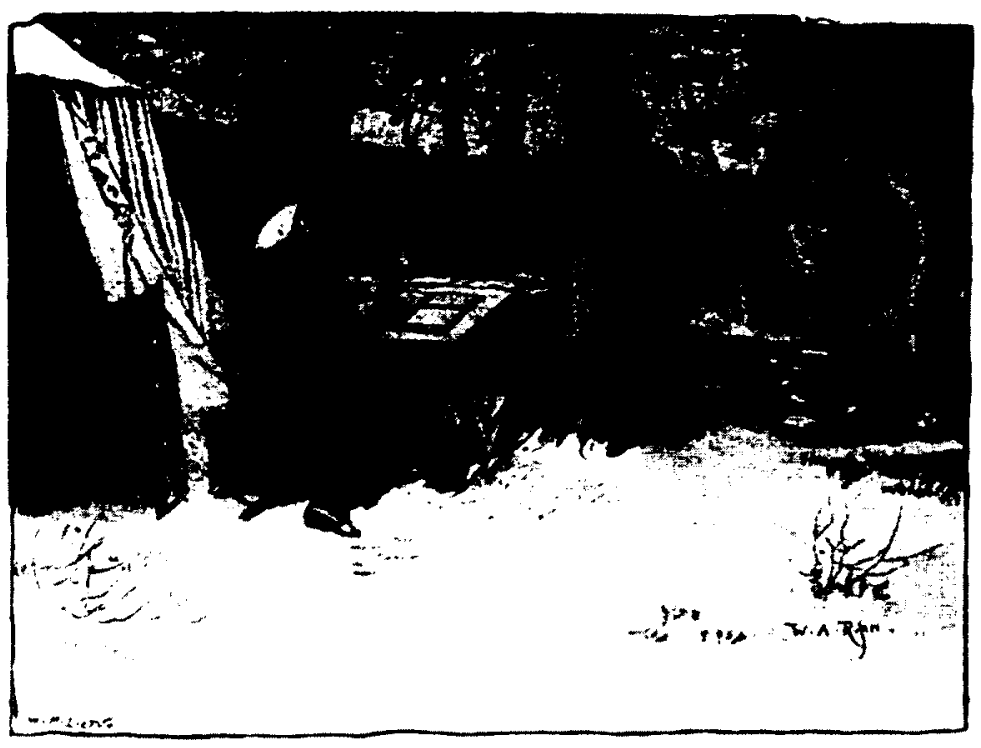

Figure 6.1 - W.A. Rogers, "Headquarters - Secretary ACA Enrolling a Recruit from Squaw Point." [Source: Harry Eckford, "Camp Grindstone," The Century Magazine 30, no. 4 (1885): 510.]

Whereas the wharf and waterfront functioned as the physical threshold of the encampment, enabling embodied passage from the outside to the inside much like a doorway would, the Headquarters was the practical threshold. It was here that the visitor to the encampment was either accepted into the fold and handed a camp badge, or they were turned away. ${ }^{19}$ The importance of this aspect of crossing the threshold should not be understated. It was this process of vetting visitors that made possible the practices of domestication and sociability that defined encampment life for the

\footnotetext{
${ }^{18}$ Here the official registered the new arrivals in his logbook, accepted their camp dues (one dollar until 1904, and two dollars thereafter), and gave them that year's ribbon, which was to be worn for the duration of the encampment. For information about the new dues, see Mystic Seaport Collections Research Center (MSCRC), Volume 4, Meeting of the Executive Committee, 15 October 1904. A close-up photograph of the tent including the log book can be seen in New York State Historical Association (NYSHA), 1.2/1, "The Secretary-Treasurer's Tent at Headquarters," 1889.

${ }^{19}$ The badges featured the dates of the annual meeting, the location, and the status of the camper (member, associate member, or visitor). As I discussed in the previous chapter, these categories shaped the participation and movement of canoeists while at the encampment. The silk ribbons distributed by the Secretary were not the only such objects in circulation at the campsite.
} 
canoeists. However, controlling access to the encampments gave the impression that the space was bounded, even as it was anything but.

Tents

The first order of business once a canoeist had arrived to their respective campsite was to raise a tent. ${ }^{20}$ As the Syracuse Daily Standard noted, "When canoeing at a canoe meet a man is supposed to live in a tent. Even upon Lake George where gorgeous hotels dotted the shores, the canoeists were banded by an unwritten law to live an Indian life...to bring his own tent, pitch it and live in it. ${ }^{21}$ Of course, not all who attended the meets stayed on site or slept in tents. ${ }^{22}$ Some boarded with local families, stayed in cottages near to the campsite, or slept at neighboring hotels. ${ }^{23}$ Still others pulled a canoe up on shore and outfitted it with a tent - the Mohican Canoe Club of Albany, New York was particularly well known for their colourful canoe tents ${ }^{24}$ - or passed the two weeks in a houseboat moored off the headquarters. ${ }^{25}$ For the majority, however, their home away from home for the two weeks of the annual

\footnotetext{
${ }^{20}$ By the $1890 \mathrm{~s}$, members could save themselves the trouble of transporting tents, cots, and blankets to the encampments by renting them from the Association. See, for example, MSCRC, Box 23, Folder 2 , Camp Circular for Sugar Idland, 1907.

21 "Paddling Their Own Canoes on the St. Lawrence," Syracuse Daily Standard, 31 May 1896. Such references to "playing Indian" are infrequent in accounts of the meet, but they are no means absent. Emulation of Aboriginality underpinned outdoor recreation in the late nineteenth century. Philip J. Deloria, Playing Indian (New Haven: Yale University Press, 1998).

${ }^{22}$ While commentators in later years frequently claimed that the organization had departed from its camping roots, "The First Call" included the following note: "There are several excellent hotels at Caldwell, and camp-places will be secured for all who desire them." Ronald Hoffman, "The History of the American Canoe Association, 1880-1960" (Ph.D. Dissertation: Springfield College, 1967), 19.

${ }^{23}$ At the 1883 meet at Stony Lake, for example, a handful of guests had a cottage built on a neighbouring island in advance of the meet. In 1886, the organizers arranged with the Delaney family to accommodate between 18 and 20 boarders during the encampment. In 1906, the Utica Daily Press reported that Mrs. BK Armstrong and Miss Frances A. Armstrong were staying at the Gananoque Inn, while Jesse A. Armstrong attended the annual meet of the ACA. "ACA Annual Meeting," Peterborough Daily Review, 14 August 1883; St. Lawrence County Historical Association (SLCHA), Camp Circular for Grindstone Istand, 1886; "In Brief," Utica Daily Press, 11 August 1906.

24 "ACA Annual Meeting," Peterborougb Daily Review, 18 August 1883. By late 1880s, canoe tents were all but absent at the annual meetings. There was one canoe tent at the 1888 meet on Lake George. "The ACA Meet, Lake George," Forest and Stream, 23 August 1888.

25 "Opening of the A.C.A. Meet," Boating (September 1906): 18.
} 
meeting was a canvas structure held up by a complex amalgam of poles, ropes, and pegs. ${ }^{26}$ As I noted in a previous chapter, the location of one's tent was influenced if not determined by the camp site committee. With the move to Sugar Island, sites became more permanent. ${ }^{27}$

Tents at the early meets were relatively simple affairs. Most were small A-frame structures with a rubber ground sheet that accommodated one or two people. While some campers continued to make use of these compact constructions, the trend was towards larger tents. ${ }^{28}$ In part, this was a matter of convenience; by the 1890 s, it was common for campers to share a tent with fellow club members, family or friends. ${ }^{29}$ However, it also appears to have been a matter of comfort and perhaps of status. Larger tents had more space for entertaining, but also for displaying one's belongings. Although there was certainly variety in the style and shape of tents - a Forest and Stream reporter claimed that "the tents at an ACA meet, like the men who inhabit them, are of all sorts and conditions"-the majority were white canvas A-frames or wall-tents. ${ }^{30}$ Wall tents became particularly popular after the 1886 encampment. Forest and Stream attributed this trend to the influence of English canoeist Warrington BadenPowell, brother to Boy Scout founder Robert Baden-Powell, who attended the Grindstone Island meet with fellow Englishman Walter Stewart. ${ }^{31}$ By the 1890 s, most tents also had a second "room" that served as a parlour. In some cases, this was

\footnotetext{
${ }^{26}$ Tents were yet another way in which the encampments emulated military life. Abigail Van Slyck, "Housing the Happy Camper," Minnesota History 58, no. 2 (2002): 73.

${ }^{27}$ Hermann Dudley Murphy, "Lovers of the Canoe," Boston Evening Transcript, 3 August 1909.

${ }^{28}$ The 1889 meet, for example, featured a wall tent measuring $14 \times 16$ feet. "Some More Snips from and Another Snap at the "89 Meet," Forest and Stream, 24 October 1889.

${ }^{29}$ The Day claimed that it was a "rare thing" for two girls to bunk together in Squaw Point. "Canoeists of America Meet," The Day, 8 August 1898.

30 "Some More Snips from and Another Snap at the '89 Meet," Forest and Stream, 24 October 1889.

31 "The ACA Meet," Forest and Stream, 25 August 1887.
} 
enclosed. ${ }^{32}$ More frequently, however, it was open. ${ }^{33}$ As time passed, tents were also likely to have wooden floors and folding camp cots. ${ }^{34}$ In other words, the canoeists' canvas homes increasingly resembled the very domestic spaces they had left behind. The organizing committee typically arranged for a carpenter to construct the wooden floors in advance of the meet. ${ }^{35}$ However, with few exceptions, campers were responsible for raising their own tents. ${ }^{36}$ In the men's camp, this could be an individual or communal task. Paul Vernon claims to have erected his tent alone at the 1893 meet. ${ }^{37}$ By contrast, Thomas J. Hale's photograph album from the 1890 s depicts members of the Brooklyn Canoe Club over successive years assisting each other in setting up their temporary homes and collectively erecting a club dining tent. ${ }^{38}$ It is less clear what was common practice in the women's camp. The only account to address the matter directly suggests women sat idly by while men did the heavy lifting. ${ }^{39}$ Florence Watters Snedeker is silent on tent raising at the meet. However, she does

32 "Pleasures of the Canoe Camp," New York Times, 22 July 1894.

${ }^{33}$ NYSHA, 1.2/4, "A Typical ACA Squaw Camp," 1890; 1.5/5, Walwin Barr's Scrapbook, 1905-unknown.

${ }^{34}$ Although much of the commentary argues that this shift towards tent floors and cots was underpinned by a desire for comfort, it is also possible that these amenities were so popular because they were considered more healthful. Sleeping bodies were considered to be particularly vulnerable to unhealthy situations. See Lady Mary Anne Barker, The Bedroom and Boudoir (London: Macmillan, 1878). Tent floors and cots removed the sleeping canoeist from the ground, which was believed to emit harmful vapours. They also encouraged the movement of air within and beneath the tents. Circulating air, as Conevery Valencius has shown, was good air. Conevery Valencius, The Health of the Country: How' American Settlers Understood Themuelves and Their Land (New York: Basic Books, 2002), 95-6, 112-3.

${ }^{35}$ At the end of the encampment, the floors were either dismantled and the wood sold, or they were put in storage for the winter months and shipped to the next location the following summer. Either way, the floors represented a costly and labour-intensive process. Thus, one of the arguments for a move to a permanent ACA campsite meant that floors could be erected and rented out to members, which could provide a source of income for organization. MSCRC, Collection 291, Box 23, Folder 2, Camp Circular for Sugar Island, 1907.

${ }^{36}$ Some years, the carpenters also raised the individual tents for the campers. This was certainly true of the 1900 meet in Muskoka. According to the reporter from Forest and Stream, upon arrival to Birch

Point, "those who ordered in advance found their tents ready pitched, with floors and cots." "American Canoe Association: Twenty-First Annual Meet," Forest and Stream, I September 1900.

${ }^{37}$ Trent University Archives (TUA), 83-014/2, Paul Vernon, Tales of the ACA, 1940.

${ }^{38}$ NYSHA, 1.5/4, Scrapbook of Thoma Hale, c. 1885-1900.

${ }^{39}$ Flip claimed to have had "three or four sweet tempered canoeists" to thank for assisting her in erecting her tent at the 1887 meet on Lake Champlain. Flip. "The Lake Champlain Canoe Meet," Outing 11, no. 3 (1887): 262 . 
describe taking part in erecting the family tent on the journey to the meet, and she uses the pronoun "we" when offering advice about tent selection and assembly in the closing chapter of $A$ Family Canoe Trip. Thus, women likely participated in varying degrees. ${ }^{40}$ This fits with women's ambiguous place in outdoor recreation more broadly, which was linked, in part, to contemporary understandings of women's physical (in)abilities. ${ }^{41}$ There is also reason to think that women would have been involved because of Annmarie Adams' work on women and domestic architecture in the late nineteenth century. Women, Adams argues, had a deep knowledge of the inner workings of homes, and were influential in the redesign of domestic space in this period. ${ }^{42}$ It is possible that they would have transferred such knowledge to their canvas abodes.

\section{Fashion}

With the tent up, the canoeist now had an appropriate space to change into their "camp togs." ${ }^{\text {"43 }}$ Clothing, and uniforms in particular, was an important signifier at the annual meetings. It provided another way of representing order, it enabled the canoeists to present themselves as part of a larger whole, and it could be used to signal individuality. ${ }^{44}$ From an analytical perspective, clothing also situated the encampment

\footnotetext{
${ }^{40}$ Snedeker, A Family Canoe Trip, 27, 51, 131-2.

${ }^{41}$ Andrea L. Smalley, "'Our Lady Sportsmen': Gender, Class, and Conservation in Sport Hunting Magazines, 1873-1920," Journal of the Gilded Age and Progressive Era 4, no. 4 (2005): 355-80; Patricia Vertinsky, The Eternally Wounded Woman: Women, Doctors, and Exercive in the Late Nineteentb Century (Toronto: St. Martin's Press, 1990).

${ }^{42}$ Annmarie Adams, Arcbitecture in the Family Way: Doctors, Houses, and Women, 1870-1900 (Montreal: McGill-Queen's University Press, 1996).

${ }_{43}^{43}$ Canoeists did not travel in their campwear, a reflection of norms of middle-class respectability.

${ }^{44}$ Jennifer Craik suggests there is ambiguity in the meaning of uniforms. On the one hand, they "signify order, conformity and discipline." However, they are also "a fetishized cultural artefact embodying ambiguous erotic impulses and moral rectitude." She further distinguishes between the overt and covert lives of uniforms: "the ostensible meanings of uniforms... and the experience of uniforms." The latter, she maintains, is as likely to be characterized by subversion and difference, as by the sameness and unity
} 
in relation to the home spaces that the canoeists had left behind for two weeks, namely, the relatively informal clothing marked the space of the encampment as distinct from the more formal world of middle-class urbanity.

First, clothing played a role in ordering the encampment. ${ }^{45}$ This was particularly true of the officers' uniforms visible in Figure 6.2, which represented the institutional hierarchies of the ACA. The style of official uniforms, like the structure of the organization, was inspired by naval culture and dictated by the Association's Constitution: "The uniform of the officers of the ACA shall be of blue, with the letters ACA embroidered in gold on the collar. The Commodore shall wear three rows of gold lace on each sleeve, the Vice-Commodore two, the Rear-Commodore one." ${ }^{46}$ Jennifer Craik argues that the "adoption and retention of a military-influenced uniform," because of established links to order and discipline, "leant credibility and authority" to contemporaneous organizations, such as the Salvation Army. It is possible that the ACA used uniforms in a similar way, to add legitimacy to their fledgling project of a national canoe organization. ${ }^{47}$ Officer uniforms were not mandatory in camp. At the very least, however, they were worn during ceremonial occasions, which is also when visitors were most likely to be on site. ${ }^{48}$

implied by a uniform. Jennifer Craik, Uniform, Exposed: From Conformity to Tranugression (Oxford: Berg, $2005), 3,5$.

${ }^{45}$ The officer uniforms fall under the category of "military lookalike uniforms," alongside Scouting uniforms. Craik, Uniforms Exposed, 21.

${ }^{46}$ Frederick L. Mix, ed., American Canoe Astociation Yearbook (New York: John C. Rankin Jr., 1888). Interestingly, a note appeared in the 1883 yearbook stating, "It is deemed well to have a nominal uniform, to which members may conform if they wish to do so. It cannot, in the nature of things, be made compulsory for all to wear it. The officers should, however, wear their distinguishing badges." Unknown, American Canoe Avsociation Book (New York: Vaux and Company, 1883), 20.

${ }^{47}$ Craik, Uniforms Exxposed, 45.

${ }^{48}$ The constitution allowed for the "use of uniforms" to be at "the discretion of each officer." Mix, American Canoe Association Yearbook, 50. 


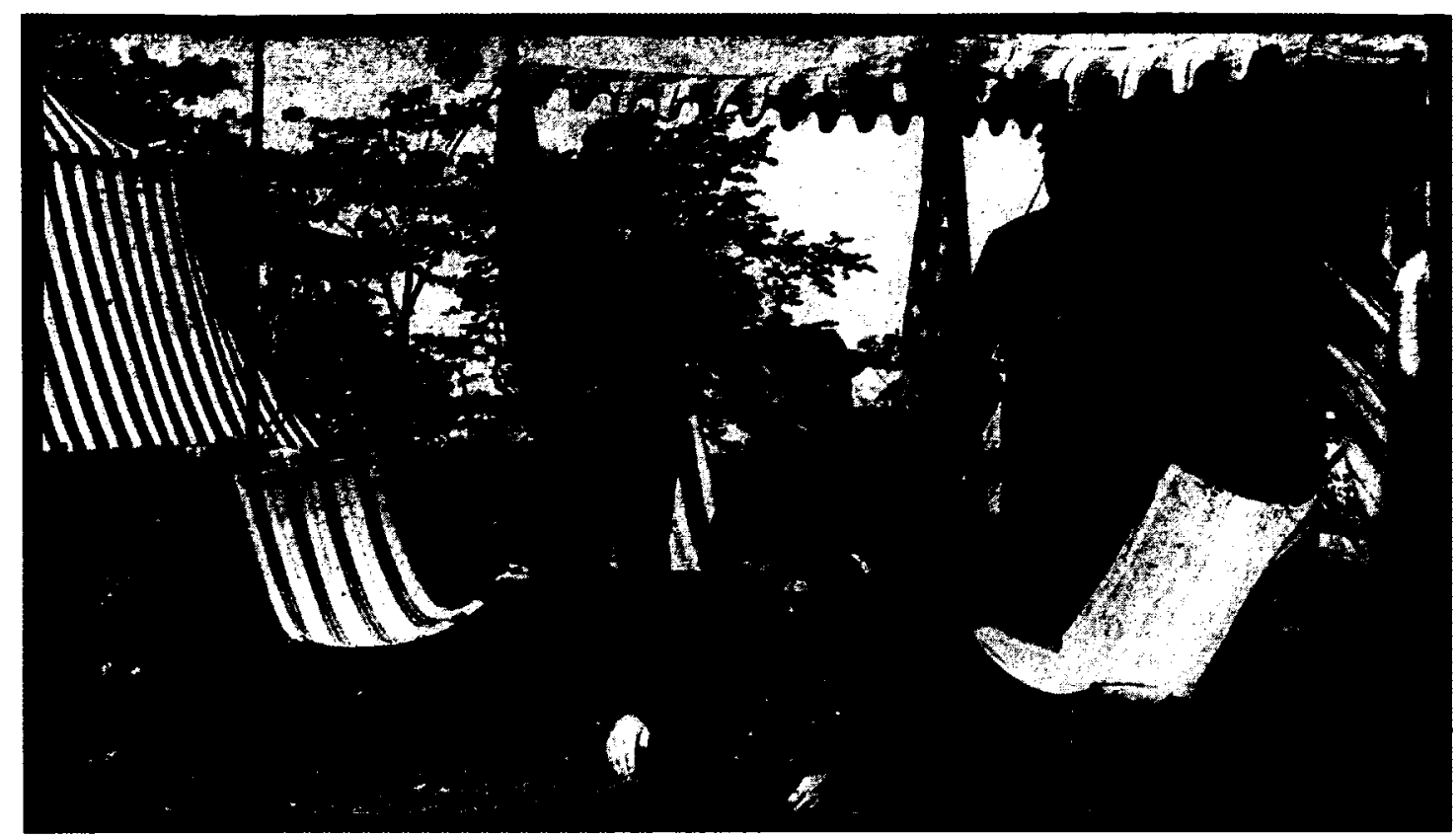

Figure 6.2 - "Official Headquarters," 1886. [Source: NYSHA, 1.1/18.]

The importance attributed to officer's uniforms is evident in Robert J. Wilkin's feeling that too many men were appearing in uniform at the annual meetings. Via Forest and Stream, Wilkin petitioned the "commanding officers of clubs who may attend the ACA camp" to attend not as officers, but as ACA members, which is to say that they should refrain from wearing their "official insignia." To do otherwise, Wilkins argued, would be a mark of "possible discourtesy and thoughtlessness." However, based on Wilkin's own involvement in the Executive Committee in the early 1880s, we might also see his reaction as expressing concern about the threat posed to the ordering of the encampment. Too many commodores, he suggests, would muddle the proper hierarchies and channels of power within the organization. ${ }^{49}$ This example supports Jennifer Craik's contention that "wearing a uniform properly" is "more important than the items of clothing and decorations themselves." ${ }^{50}$ That said, it remains significant

49 "Club Uniforms at the Meet," Forest and Stream, 18 June 1885.

${ }^{50}$ Craik, Uniforms Exposed, 4. 
that the ACA adopted military-inspired uniforms, which have particular connotations about discipline, order, authority, and status. ${ }^{51}$

Second, clothing was used amongst the general membership to signal belonging to a particular club. Full club uniforms were commonplace in the early years of the annual meetings. For example, the "new uniform" of the New York Canoe Club in 1884 consisted of a hunter green Norfolk blouse, knee breeches, long stockings, and a cap of white linen duck embroidered with the club's insignia. ${ }^{52}$ By 1888 , this practice had fallen by the wayside, to the disappointment of some: "While nothing is lost in picturesque effect, the change is rather to be regretted, as the effect of a club uniform was, as in the army, to unite the club, to heighten the esprit $\partial e$ corps, and to induce each club to make the best show that was possible. ${ }^{n 3}$ While full uniforms were no longer common, canoeists did continue to sport clothing such as shirts, sweaters, and hats adorned with a club insignia. This signalled their membership in a particular club. ${ }^{54}$ The allusions made to the sense of community inspired by wearing uniforms reinforce scholarship on clothing's role in the formation and reproduction of community. ${ }^{55}$

Finally, the annual meetings were represented as spaces free of fashionable expectations, the unusual apparel of the canoeists serving as a symbol of the freedoms

\footnotetext{
${ }^{51}$ Craik, Uniformo Exposed, 44.

52 "Canoe Sailors in Camp," New York Sun, 4 August 1884. The precision with which the clubs dictated their uniforms speaks to the "highly specific and deliberately calculated" design of uniforms more generally. Craik, Uniforms Exposed, 7.

53 "The ACA Meet of 1888," Forest and Stream, 6 September 1888. See, also, "The ACA Meet, Lake George," Forest and Stream, 23 August 1888.

${ }^{54}$ Retaw, Fragmento from the '88 Meet (Montreal, 1888), 17-18; NYSHA, 1.2/24, "A Camp Group at Bluff Point," 1895; 1.3/1, "Louis Drake," 1910. Interestingly, one reporter also lamented the shift from "trim and shapely knickerbockers" to "loose and clumsy golf-breeches." R.B. Burchard, "Back to Grindstone: The Canoe Camp," Outing 29, no. 2 (1896): 142.

${ }^{55}$ Diana Crane, Fastion and Its Social Agendas: Class, Gender, and Identity in Clothing (Chicago: University of Chicago Press, 2000).
} 
afforded by encampment life. ${ }^{56}$ As a correspondent for Outing magazine noted, "The rule of dress is to get as far away as possible from conventional patterns, and suit yourself exclusively. ${ }^{\text {"57 }}$ The 1884 camp, for example, boasted a number of "oddities of costume," the most remarkable being the "tall-peaked, sugar-loaf straw hats...ornamented with tassels and broad hat-bands of bright red. ${ }^{\prime 58}$ The 1890 meet was particularly notable for the variations in dress. According to a Times reporter, "Color runs riot in apparel [this year]. Nothing is too bright and no combination too startling for a canoeist to wear, and even a man who walks around in a bright yellow silk nightcap, a scarlet shirt, green knickerbockers, blue stockings, red shoes, and a spotted sash has yet caused a public uprising. ${ }^{159}$ Forest and Stream agreed, claiming that the tendency was "toward grotesque and fantastic costumes," including the man who "cut a rather striking figure in a jersey of open netting over very brown arms and shoulders, and another even taller set off his length by a jersey of horizontal stripes, red and white, surmounted by a red toque." ${ }^{160}$ That the event could offer such apparent freedoms speaks to the success of the organization in establishing the campsite as an ostensibly safe space, an accomplishment that depended on the myriad gatekeeping practices the organization performed. It would be anachronistic to overemphasize the degree to which the canoeists bucked trends and expectations; if photographs of the meets are any indication, most of the men appear to have worn some variation on

\footnotetext{
${ }^{56}$ Crane suggests that one of the consequences of new forms of work in America was the growing import of clothing in signalling rank within the workplace. Thus, the opportunity for the canoeists to abandon convention may have been particularly appealing. Crane, Faubion, 5.

57 "The Great Canoe Meet," Outing 9, no. 2 (1886): 164-6.

58 “The 1884 Meet," American Canoeist 3, no. 8/9 (1884): 113. See, also, "ACA Camp," Forest and Stream, 14 August 1884.

59 “The Canoe Men in Camp," New' York Times, 17 August 1890.

60 "The ACA Meet of 1890-III," Forest and Stream, 13 August 1890.
} 
trousers or knickerbockers, and button down shirts or wool sweaters for much of this period. ${ }^{61}$

Just as the concern for decoration and display amongst presumably male reporters seems anomalous within the context of contemporary gender ideology, so too does their preoccupation with clothing and fashion at the encampment. A commonsense association between women and fashion was well established by the late nineteenth century. ${ }^{62}$ We might explain the eye towards apparel as a recognition of clothing's potential as an expression of the self in an increasingly consumerist society. However, commentary on clothing also appears to have served a regulatory function. Craik distinguishes between "formal prescribed uniforms" (eg. military, ecclesiastical), "quasi-uniforms" (eg. business suits for executives, black dress for funerals), and “informal uniforms" (eg. activists clothing at a demonstration, après-ski wear), although she maintains that all play a role in the construction and mediation of social relations. Particularly interesting is her observation that each category is, in its own way, "managed," the first by "external impositions and codification," the latter two by "other forms of approbation and censure," such as word of mouth and gossip columns. ${ }^{63}$

Perhaps surprisingly, the accounts of the meet pay very little attention to what women were wearing. One exception appeared in 1894 edition of the New York Sun:

The women dress in a variety of styles, ranging from Indian costumes to bloomers, according to their fancy. The canoe girl, as a rule, wears a Tam o' Shanter hat, dark blue serge or flannel dress, with an extremely light skirt, under which are Knickerbockers, heavy stockings, and

\footnotetext{
${ }^{61}$ NYSHA, 1.1, 1.2, and 1.3, Photographs, 1880-1910. See, also, Retaw, Fragmente, 17.

${ }^{62}$ Mary W. Blanchard, "Boundaries and the Victorian Body: Aesthetic Fashion in Gilded Age America," The American Historical Review' 100, no. 1 (1995): 21-50.

${ }^{63}$ Craik, Uniforms Exposed, 17.
} 
rubber-soled shoes. The trousers are not due to the arguments of dress reformers, but to common sense. When a canoe girl capsizes she unhooks and discards her skirt, and can then move freely in righting her little ship. When inside her craft she puts the skirt on again, and when she sails home no one is the wiser. Often the women sail in bathing suits, and are prepared to capsize at any time. ${ }^{64}$

It is worth highlighting the reporter's efforts to distance women's dress choices from "dress reform," a particularly contentious aspect of the women's movement that was gathering steam in the closing decades of the nineteenth century. ${ }^{65}$ Nevertheless, the uniform described above was consistent with changes underway in women's fashion, which were aimed at releasing women from the strictures of Victorian apparel. Pauline Johnson was also attuned to women's clothing at the encampments. Concerned about the message being sent by such clothing, Johnson issued a call-to-arms for women to maintain their "reputation for healthy pastime" by rejecting "fashionable frills." She continued, "for the love of that most blessed of endowments given by your creator, health, don't mimic the cripple or quarrel with your better, most sensible self just because the little goddess fashion is whimsical and at times despises so wickedly the beauty of perfect form and health in the human body." 66

It was men's clothing that emerged as the dominant site of concern for encampment observers. C. Bowyer Vaux observed of the 1888 meet: "One feature of the camp must not be overlooked. The men seemed to think much more of dress than is usual at the meets, no doubt on account of the many ladies who camped on what in

${ }^{64}$ "Canoists [sic] Break Camp," New York Sun, 29 July 1894.

${ }^{65}$ Patricia A. Cunningham, Reforming Women's Faubion, 1850-1920: Politics, Healtb, and Art (Kent: Kent State University Press, 2003).

${ }^{66}$ Pauline Johnson, "Canoe and Canvas: The A.C.A. Meets in Canadian Waters," Saturday Night, 2 September 1893. 
former years was known as Squaw Point. ${ }^{{ }^{67}}$ In this example, we see anxieties resurfacing about the presence of women in camp, but perhaps also about the instability of masculinity. This concern for men's fashion suggests it was a fine line between respectability and the effeminacy associated with the contemporary figure of the dandy. ${ }^{68}$ That such concerns emerged in a wilderness setting, a space seemingly divorced from urban life, is all the more interesting. Given the powerful signals that clothing could emit, it is no wonder that those concerned with the tone and tenor of the organization sought to police fashion, as much as decoration, which is the subject of the next section.

\section{Designing Men and Women}

Once the tent was up and the appropriate clothing put on, the canoeists "moved in" to their temporary homes. As we see in Figure 6.3, the contents of the tents reflected both practical concerns and aesthetic ones..$^{69}$ Rugs and bearskins were spread across the wooden or earthen floors of the tent, a homey defense against dampness and cold. ${ }^{70}$ Canvas folding cots put further distance between sleeping bodies and the floor of the tent, while heavy woolen blankets staved off the cool August nights. Hastily

${ }^{67}$ C. Boyer Vaux, "Canoeing: The Ninth Annual Meet of the A.C.A.," Outing 13, no. 1 (1888): 74. See also Burchard, "Back to Grindstone," 138-43.

${ }^{68}$ In late nineteenth-century Britain, Brent Shannon argues, "antagonism toward effeminate behavior accelerated during an age in which rugged masculinity and athleticism were enthusiastically celebrated by popular culture. Any man who seemed to care too much about his appearance risked accusations that he was weak and womanish." Brent Shannon, "Fashion, Masculinity, and the Cultivation of the Male Consumer in Britain, 1860-1914," Victorian Studies 46, no. 4 (2004): 613.

${ }^{69}$ Textual and photographic accounts of tent interiors can be found in Flip. "Lake Champlain Canoe Meet"; NYSHA, 1.1/27, "Scene Along the Shore," 1887; "Canoists [sic] Break Camp," New York Sun, 29 July 1894; 1.2/18, "Camp of the Mohican Canoe Club," 1891; 1.3/2, "ACA Meet, Sugar Island," 1911. ${ }^{70}$ Van Slyck argues that "given inherited Victorian convictions about the vulnerability of the sleeping body, the tent...was potentially the most treacherous site" at children's summer camps. That said, she further notes that "far from being problematic, tents promised to minimize the boundary between sleepy campers and the camp's healthy, natural setting." Van Slyck, "Housing the Happy Camper," 73; Abigail Van Slyck, A Manufactured Wilderness: Summer Camps and tbe Sbaping of American Youth, 1890-1960 (Minneapolis: University of Minnesota Press, 2006), 103. 
built shelves and "bureaus" provided storage space for clothing, hygiene products, and trinkets. Camp chairs and trunks covered with shawls doubled as seats on those occasions when a canoeist wished to entertain in their quarters. Hanging lanterns provided light, while mirrors affixed to tent poles facilitated grooming or preening. Ice chests kept drinks and foodstuffs cold. Finally, brightly coloured flags, photographs and paintings, canoe paddles, and oriental lanterns personalized the space. ${ }^{71}$

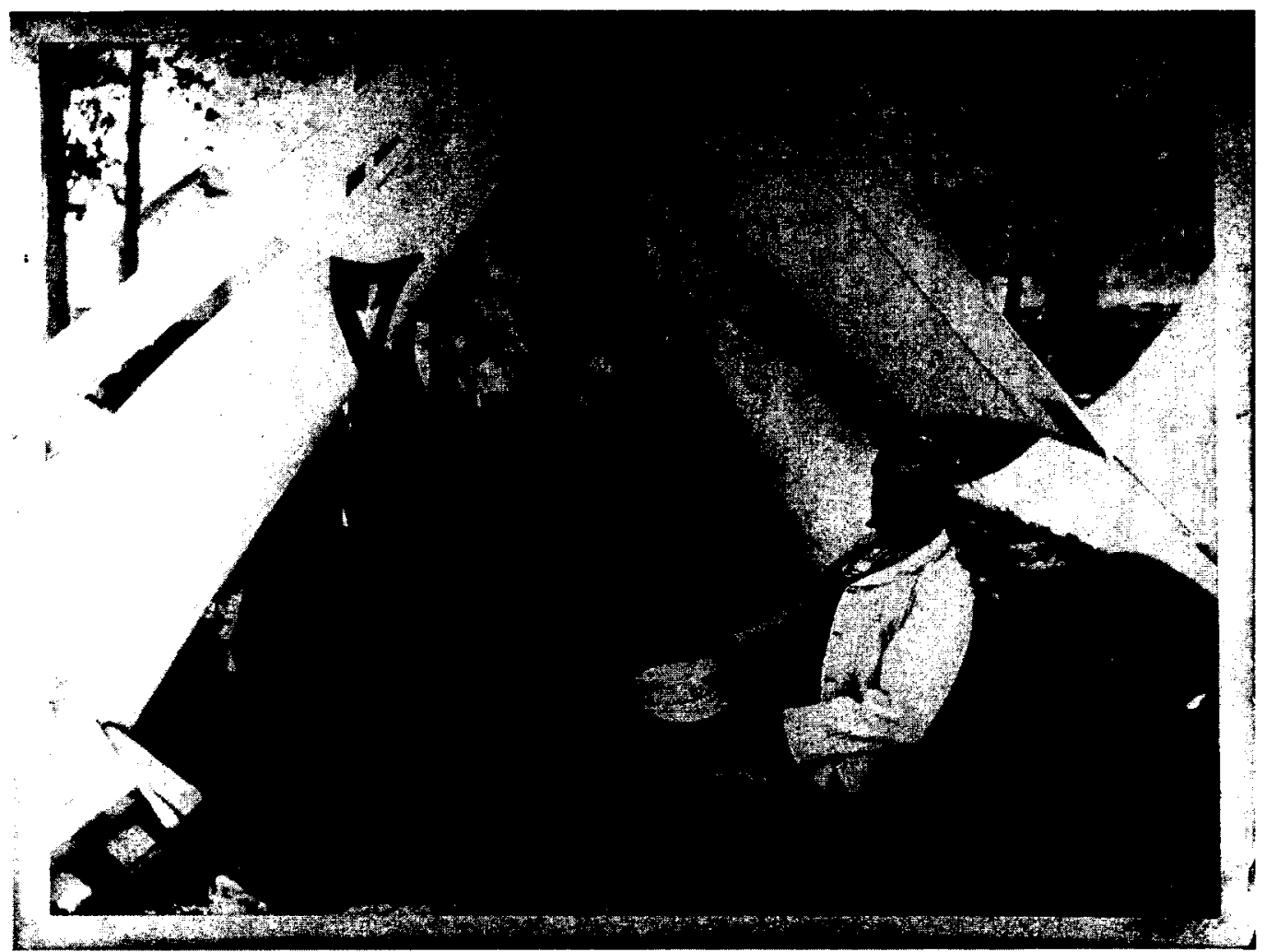

Figure 6.3 - "A Tent Interior," 1891. [Source: NYSHA, 1.2/18.]

For the most part, the canoeists employed conventions of bourgeois Victorian design as they decorated their temporary living spaces. These included artwork and mirrors on the walls, patterned floor coverings, and oriental motifs. In particular, the tent interiors recalled late Victorian parlours, which were constructed as spaces of

\footnotetext{
${ }^{71}$ Good examples of interior decorating can be seen in NYSHA, 1.2/14, "A Typical ACA Squaw Camp," 1890; 1.2/18, "Camp Comfort: A Tent Interior," 1891.
} 
display and increasingly of comfort. ${ }^{72}$ As Gulen Cevik notes, in the late nineteenth century, "The [American] parlour...became a kind of stage upon which the family presented itself to visitors. ${ }^{n 73}$ It was also a space more and more associated with bodily comfort, as is evidenced by the emergence of "cozy" or "Turkish corners" featuring overstuffed chairs and sofas. ${ }^{74}$ Cozy corners, as Karen Halttunen demonstrates, were intended to "invite repose and freedom from conventionality by offering a place to sprawl and lounge at ease. ${ }^{n 5}$

Halttunen's work on the transition from the parlour to the living room raises questions about the relationship between the encampments and urban bourgeois domestic space. Certainly, the decoration of the tents at the encampments dovetailed with contemporary design principles. However, they likely also played a role in reimagining and reorganizing domestic space in the city. Halttunen argues that the "gradual transformation of the highly specialized and intensely private Victorian house into the open and unspecialized twentieth-century house" was underpinned in part by changes in middle-class social life, specifically the informal sociability of life in summer houses and tents. ${ }^{76}$ These spaces, she suggests, frequently boasted a piazza or "outdoor parlor," decorated with "hammocks, large rockers, wicker tables and settees, rugs,

\footnotetext{
${ }^{72}$ Thad Logan, The Victorian Parlour: A Cultural Study (Cambridge: Cambridge University Press, 2001), 36-104.

${ }^{73}$ Gulen Cevik, "American Style or Turkish Chair: The Triumph of Bodily Comfort," Journal of Design History 23, no. 4 (2010): 371. Certainly, contemporary design literature invited the "performance of private life as public spectacle." Jean-Christophe Agnew, "A House of Fiction: Domestic Interiors and the Commodity Aesthetic," in Bronner, Consuming Visions, 140.

${ }^{74}$ Cevik makes the point that these pieces of furniture were not actually Turkish, as "the Turks did not really have freestanding pieces like American couches or chairs." Rather, "Americans called almost any furniture that was overstuffed and comfortable "Turkish'." Cevik, "American Style," 374. On the subject of comfort and the American home, see Katherine C. Grier, Culture and Comfort: Parlor Making and MiddleClass Identity, 1850-1930 (London: Smithsonian Institution Press, 1997).

${ }^{75}$ Halttunen, "Parlor to Living Room," 164-5.

${ }^{76}$ Halttunen, "Parlor to Living Room," 166-7.
} 
decorative screens, and Japanese lanterns. ${ }^{n 7}$ So too did the camps of the ACA, as we see in D'Arcy Scott's account: "In front of the tent is a piazza furnished with rugs, cushions, easy chairs; over the piazza is stretched a fly which gives shade, but does not cut off the breeze. ${ }^{178}$ According to Halttunen, this informal sociability was made possible by the fact that such spaces, unlike urban dwellings, had restricted access. There was "no need for a front hall to exclude the undesirable or a parlor where claims to social position could be made through the formalities of the genteel performance, because those present at the summer had already been screened." ${ }^{79}$ The same was true of canoeists at the ACA meets, who had been vetted during the membership process and again at the registration desks. ${ }^{80}$

Decorating extended beyond the walls of the tent to include the exteriors of the canvas structures and the spaces around the tents. Whereas interior decorating balanced convenience and visual appeal, "exterior decorating" was largely about making the tent and its owner(s) identifiable to those passing by. Exterior decorations might include flags or banners signalling the occupants' nationality or canoe club affiliation; ${ }^{81}$ canoeing paraphernalia such as paddles, sails, and boats, which marked the camper as a serious canoeist; strings of oriental lanterns; and, occasionally, less

\footnotetext{
${ }^{77}$ Halttunen, "Parlor to Living Room," 167.

${ }^{78}$ Scott, "Annual Camp," 117.

${ }^{79}$ Halttunen, "Parlor to Living Room," 168.

${ }^{80}$ The practices of vetting revealed anxieties about the presence of "dangerous others" at the edges of the encampments, but also the vulnerabilities of the encampments' domestic arrangements.

${ }^{81}$ Flags were in evidence in all quarters of the campsites, "from the stars and stripes and British ensign floating from the twin flagstaff at the headquarters camp, and combinations repeated at private camps, to the club burgees and private signals carried by the canoes." "ACA Annual Meeting," Peterborough Daily Review, 13 August 1883. See, also, Columbine, "A Visit to the American Canoe Association," The Young Friends' Review (1886): 67-9; "The Canoe Men in Camp," New York Times, 17 August 1890; Flip, "Lake Champlain Canoe Meet," 262-4.
} 
conventional objects, such as a giant watch or shell designs. ${ }^{82}$

As much as decorating had functional or ornamental ends, it was also a deeply political practice, revealing much about the ways in which the canoeists understood themselves in relation to others, but also hinting at the connections between the realms of leisure, history, culture, economics, society, and politics in the late nineteenth century. Consider, for example, the shell designs that adorned the grounds of the 1890 meet at Jessup's Neck. Visible along the main avenue on Long Island were a Red Dragon, a Puritan Ship, the Treaty Elm, Plymouth Rock, and "other grotesque and picturesque works of art." ${ }^{83}$ The shell designs are interesting for combining club totems such as the Red Dragon with touchstones in early American history. ${ }^{84}$ The latter included the craft that carried the early European settlers (Puritan Ship), the site of the Puritans' landing (Plymouth Rock), and the fabled location of the signing of the "treaty of friendship" between William Penn and the Shackamaxon Delawares (Treaty Elm) that provided the land for the city of Philadelphia. ${ }^{85}$ These historic shell drawings, in other words, recalled and celebrated white settlement. They also provided narrative justification for the presence of white canoeists specifically and white Americans broadly on Native land.

\footnotetext{
${ }^{82}$ An account of the 1898 meet includes a reference to "pine branches" being used to decorate the grounds and tents. "On the St. Lawrence," Utica Sunday Journal, 20 August 1898.

83 "The ACA Meet of 1890: Jessup's Neck," Forest and Stream, 21 August 1890; "The ACA Meet of 1890 - III," Forest and Stream, 13 November 1890.

${ }^{84}$ The Puritan ship was placed in front of the Puritan Canoe Club (Boston, Massachusetts) camp. James Raffan remarks that the club was "curiously named" given that by the 1880 s, the "connection between revelry and canoeing was...well established." James Raffan, Bark, Skin, and Cedar: Exploring the Canoe in Canadian Experience (Toronto: Harper Collins, 1999), 96.

${ }^{85}$ The Treaty Elm was "shrouded in ambiguity," the date, place, and purpose being uncertain. Nevertheless, the tree remains an important symbol. Krause argues, that "On one hand, [it] memorializes a founding Quaker desire for amity between the races; on the other, it testifies to an eventual erosion of that policy-predictably, the triumph in time of racial enmity over amity." Sydney Krause, "Penn's Elm and Edgar Huntly: Dark 'Instruction to the Heart," American Literature 66, no. 3 (1994): 464-5.
} 
Other decorations were equally political. Beginning in 1902, the tents at the women's camp stood under the Squaw Point burgee. Designed by Mrs. Peebles and produced by a sewing bee of "the Squaws" at the Cape Cod meet, ${ }^{86}$ the flag featured a red bust of a stereotypical squaw in profile on a white background, its gaze directed towards the inside of the flag and the letters ACA positioned vertically in decorative script ${ }^{87}$ Despite earlier opposition to the title of Squaw Point, the design and adoption of the flag by members of the women's camp suggests a shift in attitude amongst the associate members, or, at the very least, resignation. The Squaw Point flag was a visible reminder of the very people displaced by the encampments and white settlement more broadly. While it is unlikely that the women of Squaw Point would have thought of their flag in these terms, it is impossible to know given that there is no account of the discussion that took place at the 1902 "pow-wow." Certainly, by the turn-of-the-century, it was possible to "celebrate," or at the very least romanticize, Aboriginal culture in a way that was unimaginable a few decades earlier at the height of the Indian Wars when Native people remained a threat to American westward expansion. ${ }^{88}$ In 1893, however, Frederick Jackson Turner, in his well-known public address delivered at the Columbian Exposition, had declared the frontier closed. ${ }^{89}$ In its wake, "untamed wilderness and untamed people alike appeared to be vanishing." "It was at this historical moment," Paige Raibmon argues, "as political and economic

\footnotetext{
${ }^{86}$ Hoffman, "American Canoe Association," 43.

${ }^{87}$ The identity of the bust is indicated by long, thick braids and a feather extending backwards from the top of its head.

${ }^{88}$ Paige Raibmon, Authentic Indians: Epirodes of Encounter from the Late-Nineteentb-Century Nortbweut Coaut (Durham: Duke University Press, 2005), 124.

${ }^{89}$ Frederick Jackson Turner, "The Significance of the Frontier in American History," Annual Report of the American Historical Astociation for the Year 1893 (Washington: Government Printing Office, 1894), 199. 227. For more information about his appearance in Chicago, see Ray Allen Billington, Frederick Jackson Turner: Hittorian, Teacher, Scholar (New York: Oxford University Press, 1973), 82-131.

${ }^{90}$ Raibmon, Autbentic Indians, 123.
} 
conditions seemed to ensure the disappearance of Aboriginal people and culture, that non-Aboriginal fascination with romantic images of vanishing Indians flourished." ${ }^{91}$

Also commonplace in and around the tents were "Japanese lanterns." While such lanterns, in the absence of electricity, provided lighting for the campers, they were also objects of "orientalism. ${ }^{\text {"92 }}$ As both William Leach and Robert Rydell have shown, department stores and world's fairs frequently boasted decorative arrangements that drew inspiration from the Islamic, Indian, Japanese, and Chinese cultures that constituted "the Orient." ${ }^{193}$ Orientalist landscapes and characters also found their way into novels, film, and commercial theatre. ${ }^{94}$ In part, the appeal of orientalism was that it "hinted at something else, something perhaps not so urbane and genteel, even at something slightly impermissible-luxurious, to be sure, but also with touches of life's underside." ${ }^{\text {95 }}$ John Tchen argues further that "possessing luxuries from 'the Orient' was [also] one means by which well-being came to be measured.

${ }^{91}$ Raibmon, Autbentic Indian, 123. Curtis Hinsley refers to this as the "dehistoricized Indian," a product of the "end of Indian history." Curtis Hinsley, "Zunis and Brahmins: Cultural Ambivalence in the Gilded Age," in Romantic Motives: Evtrays on Antbropological Sensibility, ed. George W. Stocking, Jr. (Madison: University of Wisconsin Press, 1989), 170. As we will see in the coming chapters, First Nations people also provided entertainment opportunities that were associated with romanticism. ${ }^{92}$ Edward Said defines orientalism in three ways: as a field of academic study devoted to "the Orient"; a "style of thought based upon an ontological and epistemological distinction made between 'the Orient' and (most of the time) 'the Occident"; and as a "corporate institution" devoted to "dominating, restructuring, and having authority over the Orient." Edward Said, Orientalium (New York: Vintage Books, 1978), 2-3.

${ }^{93}$ William Leach, Land of Desire: Merchant, Power, and the Rise of a New American Culture (New York: Pantheon Books, 1993); Robert Rydell, All the World's a Fair: Visions of Empire at American International Expositions, 1876-1916 (Chicago: University of Chicago Fair, 1987). See also, John Tchen, New' York Before Chinatown: Orientalium and the Shaping of American Culture, 1776-1882 (Baltimore: Johns Hopkins University Press, 1999). Tchen argues that orientalism was "a cultural phenomenon intrinsic to American social, economic, and political life." (xvi) In New York Before Cbinatown, he chronicles "three overlapping cultural formations of orientalism" in the United States: orientalism newly transplanted from Europe, orientalism "Americanized in the commercial milieu of New York," and orientialism embedded in the politics of the nation. ( $\mathrm{xx}$ )

${ }_{94}^{94}$ William Leach argues that the rapidity with which orientalism spread through all aspects of cultural life lies in the "nearly overnight efflorescence of America's new consumer identities, with their high distributive and marketing demands." Leach, Land of Desire, 107.

${ }^{95}$ Leach, Land of Devire, 104. Leach adds that the appeal and prevalence of orientalism also reveals a sense that something was missing from American culture that could be acquired elsewhere. (105) 
Hence the pursuit of 'life, liberty, and happiness' in this middle-class nation also became the pursuit of consumable luxuries. ${ }^{\prime 96}$ As Said demonstrates, the appropriation of so-called oriental culture was not benign. Rather, orientalism, by presenting the "other" as primitive, uncivilized, and child-like, provided the necessary ideological rationales for Western imperialism. ${ }^{97}$ Imperial expansion was not just underwritten by representations, it was also effected through consumption. Kristin Hoganson's work, for example, shows how as American consumers purchased tropical produce, ostrich plumes, and in this case, oriental lanterns, they were literally "buying-in" to empire. ${ }^{98}$ Their purchasing power, in other words, reinforced and strengthened existing imperialist economic structures.

The appearance of such lanterns at a canoeing encampment signifies the reach of orientalism, but also of late nineteenth-century consumer culture. However, its effect was ambivalent and contradictory. On the one hand, orientalist products, such as lanterns, served to exoticize and further distance the encampment from other spaces of everyday life. At the same time, oriental lanterns connected the encampments to middle-class home spaces, such as the parlour, which was equally likely to have oriental-inspired decorations. ${ }^{99}$ In this way, the presence of the lanterns simultaneously marked the encampments as a transnational and a domestic space, embedded in global networks of capitalist production and consumption. As we shall see in the next

\footnotetext{
${ }^{96}$ Tchen, New' York Before Chinatown, xvii.

${ }^{97}$ Although he developed this line of thought in Orientalium, Said expands on these ideas further in Culture and Imperialism (Toronto: Random House, 1993).

${ }^{98}$ Kristin Hoganson, "Buying into Empire: American Consumption at the Turn of the Twentieth Century," in Colonial Crucible: Empire in the Making of the Modern American State, eds. Alfred McCoy and Francisco Antonio Scarano (Madison: University of Wisconsin Press, 2009), 249.

${ }^{99}$ David Brody, Visualizing American Empire: Orientalism and Imperialism in the Pbilippines (Chicago: University of Chicago Press, 2010), 38-9. Brody argues that the Centennial Exhibition in Philadelphia, in particular, "was a type of sales agent for Oriental spheres that could be bought and appropriated for domestic spheres." Art magazines also provided inspiration for "bringing Asian motifs into the parlour."
} 
chapter, orientalism was not limited to domestic decorations, but was also evident in the spectacles on offer at the meets.

Those with plans to cook for themselves, or who had hired someone else to do so, built spaces for the preparation and consumption of food. Most clubs, for example, erected tents to serve as a dining room. ${ }^{100}$ Canoeists also built brick ovens and campfire circles for cooking. ${ }^{101}$ D'Arcy Scott offered the following description of a "kitchen" at the 1896 meet: "By the side of the tent is a fireplace built of stones, over which hangs a pot on a cross-bar, supported by two upright, forked sticks, where the 'roughing it' camper cooks a meal." ${ }^{102}$ Less common were more formal kitchens, although at the 1884 meet the Deseronto Canoe Club had "a shed of boards for a kitchen with an iron stove set up." ${ }^{\prime 103}$ Some also built tables and benches at which to consume their meals and outdoor shelves to hold their dishes and foodstuffs, or they hired the camp carpenter to do the same. ${ }^{104}$ These tables, like those in the mess tent, were typically covered with linen cloths and adorned with wild flowers or other bits of nature. ${ }^{105}$ Such decorations hint at a desire for gentility at mealtimes. Abigail Van Slyck documents similar practices in summer camps where meal times were important reminders of civilization for campers otherwise encouraged to embrace their inner savage. ${ }^{106}$ Thus, the dining tents, which recalled the dining rooms of Victorian homes, were, alongside the campers' tents, some of the more obvious manifestations of efforts

\footnotetext{
${ }^{100}$ NYSHA, 1.1/5, "Mess Time in the Canadian Camp," 1883; 1.1/16, "Camp of the Brooklyn Canoe Club," 1886. A more informal dining tent is featured in Figure 9.3.

101 "Pleasures of the Canoe Camp," New York Times, 22 July 1894.

${ }^{102}$ Scott, "Annual Camp," 117.

103 "The Association Meet," Forest and Stream, 21 August 1884.

104 "The ACA Meet of 1888: The Camp and the Association," Forest and Stream, 6 September 1888.

105 "The ACA Meet of 1891," Forest and Stream, 20 August 1891; NYSHA, 1.1/5, "Mess Time in the Canadian Camp," 1883; 1.1/16, Camp of the Brooklyn Canoe Club, 1886; 1.1/24, "Camp of the Deowainsta Canoe Club, Rome, NY," 1887.

${ }^{106}$ Van Slyck, A Manufactured Wildernews, 131.
} 
to domesticate the encampment and to cultivate a sense of the place as "home." $107 \mathrm{We}$ might see such practices as public performances of respectability, but they could also be read as personal acts of valuation. The encampments were deeply meaningful to those who attended, and the care and concern with which they ordered the space, and recalled the geographies of home were testaments to their significance.

Descriptions of Squaw Point are overrepresented in accounts of the meets, implicitly reinforcing the already established association between women, domestic space, and decoration. ${ }^{108}$ However, men also participated enthusiastically in decorating their tents. At the 1903 encampment, for example, a reporter for the Watertown ReUnion noted, "Several of the large canoe clubs in Boston, New York and Philadelphia and other large cities have tents of their own where their headquarters are located. These they have decorated very prettily, each vying to excel the others." ${ }^{109}$ Similarly, the New York Timed reported, "the abiding places of the feminine contingent contain more rugs and draperies than those of the masculine element." However, they declared them "no whit neater, and as they are filled with trunks and have no ice chests dug in the ground back of them, with scores of bottles reposing therein, they are not as pleasant in the long run as the men's abodes." ${ }^{110}$ This last example suggests that there may have been different considerations for men and women as they outfitted their

${ }^{107}$ NYSHA, 1.1/27, "Dinner Time in the Mess Tent," 1898.

${ }^{108}$ See, "Pleasures of the Canoe Camp," New York Times, 22 July 1894; NYSHA, 1.2/30, "Visitors at Commodore Thorn's Camp," 1899. Such commentary reflected and contributed to the coding of consumption in the form of decoration as feminine and production as masculine, a powerful binary that continues to shape writing on the history of consumer culture. Mark Swiencicki, "Consuming Brotherhood: Men's Culture, Style and Recreation as Consumer Culture, 1880-1930," Journal of Social History 31, no. 4 (1998): 773-808; Stefan K. Cieply, “The Uncommon Man: Esquire and the Problem of the North American Male Consumer, 1957-63," Gender and History 22, no. 1 (2010): 161-78.

109 "Canoemen Gather at the 1000 Islands," Watertown Re-Union, 15 August 1903.

110 "The Canoe Men in Camp," New York Times, 17 August 1890. See also, "Canoists [sic] Break Camp," New York Sun, 29 July 1894. 
tents, as well as different objects put on display.

Historians have typically understood the appeal of outdoor living in the late nineteenth and early twentieth centuries as "offering the middle-class male an escape from domesticity and the opportunity to reassert his social dominance."111 However, men's participation in placing domesticity at the ACA meets calls such interpretations into question. What's more, unlike those locales where historians have documented male domesticity - lodges, clubs, navy ships - the encampments were mixed-sex venues. How do we explain this seemingly anomalous situation? ${ }^{112}$ Perhaps the encampments, as liminal spaces, were acceptable locations for engaging in domesticity. Certainly, the existence of the threshold gave the impression that the community was bounded and vetted. However, it is also possible that historians have overemphasized the degree to which middle-class men in the late nineteenth century rejected the domestic, a point that Margaret Marsh made more than twenty years ago, but which has only recently garnered the attention of historians with any seriousness. ${ }^{113}$ If this is the case, then it suggests the enduring power of the ideology of separate spheres in shaping historical writing, as much as if not more so than historical experience.

\section{Classifying Tents}

Tents were neither exclusively private nor purely public spaces, but were something in between. Like their bedrooms at home, the tents were intimate spaces in

111 J.I. Little, "Life without Conventionality: American Social Reformers as Summer Campers on Lake Memphremagog, Quebec, 1878-1905," Journal of the Gilded Age and the Progrestive Era 9, no. 3 (2010): 283. 112 The ACA encampments were not entirely unique in this respect. J.I. Little's work on the Lake Mephremagog encampments of American social reformers in the late nineteenth century suggests that their "camping experience...elevated the domestic sphere," rather than trying to do away with it. However, unlike the Mephremagog encampments, which Little characterizes as egalitarian, the ACA meets were not concerned with transforming the social order. Rather, the canoeists' encampments often reinforced the social hierarchies of everyday life. Little, "Life without Conventionality," 283.

${ }^{113}$ Marsh, "Suburban Men." 
which the canoeists dressed and slept. ${ }^{114}$ They were also spaces of sociability, akin to a parlour, used for entertaining friends and neighbors. ${ }^{115}$ Finally, they were public spaces in the sense that they were routinely left open to the outside world. ${ }^{116}$ Photographic and textual accounts of the annual meetings depict the canvas houses with their flaps pulled back, "open to admit the sun and air," their "contents unblushingly revealed to the passer-by." ${ }^{17}$ Even when the canoeists closed their tent flaps, their movements were not necessarily private. Paul Vernon recalled of the 1893 encampment: "Colonel [Cotton] was Commodore that year with a large white tent in the center of camp. We noticed as we went past the first night that the Colonel's candle, as he retired furnished a perfect silhouette on the tent's side of his movements, showing all the actions of change, from his daily garb to the final hop into bed."118 J.I. Little argues that the "minimum of privacy" afforded by tents is evidence of "the communal nature" of camp life. ${ }^{119}$ Shared living, but particularly limited privacy, likely reinforced the bonds of community for better or worse.

In part, the canoeists appeared to have left their tents open for the visual consumption of others. Canadian Aboriginal historian Paige Raibmon has argued that Victorians understood domestic spaces and domestic goods as "material markers of

\footnotetext{
${ }^{114}$ Elizabeth Collins Cromley, "Sleeping Around: A History of Beds and Bedrooms," Journal of Design Hittory 3, no. 1 (1990): 1-17. By the late nineteenth century, most bourgeois homes had two or more bedrooms. Married couples, and older children were typically assured their own rooms.

${ }^{115}$ Photographs from the meets showing campers, of both sexes, scattered in and around tents reinforce this observation. NYSHA, 1.1/5, "Group of Canadian Canoeists," 1883; 1.2/14, "A Typical ACA Squaw Camp," 1890; 1.2/30, "Visitor's at Commodore Thorn's Camp," 1899.

116 The hybridity of these spaces is not unusual. Cromley notes the existence of advice literature on "how to make a bedroom serve additional living needs of the modern woman," but also the development of new kinds of furniture in the mid-nineteenth century that "enabled a single room to do duty as a parlour and as a bedroom." In this configuration, the bedroom is a place to sleep, "to sit and, indeed, to live." Cromley, "Sleeping Around," 10-1.

${ }^{117}$ Columbine, "A Visit," 68.

${ }_{118}$ Vernon, Tales of the $A C A$.

${ }^{119}$ Little, "Life without Conventionality," 282.
} 
civilization," and as windows onto "the individual's soul and the family's moral state." ${ }^{20}$ Certainly, this was true of early Victorians, who saw the "home as a moral force," in which the parlour was "the most important arena for the expression of character." ${ }^{121}$ By the turn of the century, the parlour had been replaced by the living room, which not only collapsed distinctions between public and private, but was also devoted to "personal temperament and its self-expression."122 Given the periodization of the encampments, it is likely that the campers embodied some mix of the two approaches to decoration in their design of their tents. Bedrooms by the late nineteenth century were also "known for their ability to convey individuality." ${ }^{23}$ The bedroom, opined one contemporary design writer, "is the place for one's personal belongings, those numberless little things which are such sure indications of individual character and fancy...the one room where purely personal preference may be freely exercised." ${ }^{124}$ Elizabeth Cromley further emphasizes the degree to which "the expression of individuality" was "an expression constructed out of markers of gender roles." ${ }^{25}$ Thus, we might interpret this transformation of private domestic space into a public spectacle as part of individual self-fashioning made available for public consumption, a way for canoeists to demonstrate their morality, civilization, and perhaps also their gendered personality to fellow campers, but even more importantly to the men and women who passed through the encampment on visitors' days.

The display of tent interiors could also be understood as a demonstration of the

\footnotetext{
${ }^{120}$ Paige Raibmon, "Living on Display: Colonial Visions of Aboriginal Domestic Space," BC Studies 140 (2003): 71 .

${ }^{121}$ Halttunen, "Parlor to Living Room," 158, 160.

${ }^{122}$ Halttunen, "Parlor to Living Room," 181, 188.

${ }^{123}$ Cromley, "Sleeping Around," 8. Emphasis in original.

124 "The Bedroom and its Individuality," Craft tman, 9 February 1906, as quoted in Cromley, "Sleeping Around," 8.

${ }^{125}$ Cromley, "Sleeping Around," 9.
} 
emerging consumerist ethos of the age and the belief that one's identity was intimately tied to their possessions. As William Leach observes in Land of Desire, the closing decades of the nineteenth century witnessed a profound transformation in American society, as capitalism "began to produce a distinct culture, unconnected to traditional family or community values, to religion in any conventional sense, or to political democracy." Rather, this new culture was "a secular business and market-oriented culture, with the exchange and circulation of money and goods at the foundation of its aesthetic life and of its moral sensibility." ${ }^{126}$ It was not just that the "nation moved from life revolving around the local market to the consumer center," but rather, "the idea of how life was properly lived changed." ${ }^{27}$ Consumption was a powerful force in late nineteenth-century North America that was increasingly linked to identity. ${ }^{128}$ As Kristin Hoganson argues, consumerism "helped mark the bounds of inclusion and exclusion that differentiated classes, races, ethnicities, nationalists, and civilization, and it constituted a key terrain in which particular groups struggled over the kind of world in which they wished to live." 129 This consumerist ethos combined with the "growing middle-class preoccupation with the household interior" to produce the belief that one left "his or her imprint" upon a room through "accumulation, selection, and

\footnotetext{
${ }^{126}$ Leach, Land of Desire, 3.

${ }^{127}$ Bronner, Consuming Vision, 1. Consumer culture, according to Richard Wrightman Fox and T. Jackson Lears is "an ethic, a standard of living, and a power structure." Richard Wrightman Fox and T. Jackson Lears, eds, The Culture of Consumption: Critical Essays in American History, 1880-1980 (New York: Pantheon Books, 1983), xii. See, also, Keith Walden, Becoming Modern in Toronto: The Industrial Exbibition and the Sbaping of a Late Victorian Culture (Toronto: University of Toronto Press, 1997), and Donica Belisle, Retail Nation: Department Stores and tbe Making of Modern Canada (Vancouver: University of British Columbia Press, 2011).

${ }^{128}$ Anthropologist Mary Douglas argues that consumption is a "fundamental form of human communication." Mary Douglas and Baron Isherwood, The World of Goods: Towards an Antbropology of Consumption (New York: W.W. Norton, 1979), as cited in Bonner, Consuming Visions, 5.

${ }^{129}$ Hoganson, "Buying into Empire," 249.
} 
placement." ${ }^{\prime 30}$ That this emergent culture was appearing far from the shopping districts of major urban centres in "backwoods encampments" demonstrates the reach of the burgeoning consumer culture.

Finally, the decision to leave the insides of a tent exposed was likely informed by concerns about bodily health. Mariana Valverde has described the symbolic import attached to light, soap, and water by urban moral reformers in the late nineteenth and early twentieth century.$^{131}$ Her concern is with the ways in which these elements functioned as representations of purity, broadly conceived, and thus were linked to moral wellbeing. However, sunshine and fresh air were also commonly associated with physical health. As Daniel Freund has shown, contemporary medical theories posited that sunshine could kill harmful bacteria, while simultaneously providing the necessary energy to promote health. ${ }^{132}$ Equally important to human health was clean air, for bad air (miasma) was commonly understood to carry disease. ${ }^{133}$ The belief in the remedial effects of sunshine and "the hygiene of fresh air" were both expressions of a more common faith in the "redeeming power of nature" to promote physical and moral health. ${ }^{134}$ Such theories often depended on urban/rural and urban/wilderness

\footnotetext{
${ }^{130}$ The ideal, in other words, was a purchased interior. Agnew, "A House of Fiction," 138, 139.

${ }^{131}$ Mariana Valverde, The Age of Light, Soap, and Water: Moral Reform in Englu'b Canada, 1885-1925 (Toronto: University of Toronto Press, 2008 [1991]).

${ }_{132}$ Daniel Freund, "The Battle for a Brighter America: A Social History of Natural Light, 1850-1935," (Ph.D. Dissertation: Columbia University, 2008).

${ }^{133}$ William F. Bynum, Science and the Practice of Medicine in the Nineteenth Century (Cambridge: Cambridge University Press, 1994); Valencius, Health of the Country, 110-7. This concern about bad air also prompted the canoeists to build tent floors, which were believed to, amongst other things, enable air to circulate beneath the tent.

${ }^{134}$ The term "hygiene of fresh air" is taken from Phillip G. Mackintosh and Richard Anderson, "The Toronto Star Fresh Air Fund: Transcendental Rescue in a Modern City, 1900-1915," Geographical Review 99, no. 4 (2009): 540. The latter quotation is drawn from Roy Rosenzweig and Elizabeth Blackmar, The Park and the People: A History of Central Park (Ithaca: Cornell University Press, 1992), 2. The belief in "pure air" and sunshine as important aspects of bodily health is evident in the early tuberculosis therapies and treatment centres, or sanatoria. It was also part of the "fresh air camp" phenomenon, which involved removing working-class and immigrant children from urban environments to pass a
} 
dichotomies, in which urban was coded unhealthy, and rural or wild places healthy.

However, the example of the ACA suggests that the campers' location in wilderness

did not negate concerns about health. There were still good and bad spaces, healthy

and unhealthy. As I demonstrated in earlier chapters, such designations were not fixed,

but shifted across time and space.

Tents did more than straddle the divide between public and private, between healthy and unhealthy. They, much like cabins at children's camps, "represented points of contact between the natural world and domestic space." ${ }^{135}$ In this way, tents defied the "historical geographical process through which nature became scripted as 'the other' to the private space of the bourgeois home in western societies." ${ }^{136}$ In addition to allowing fresh air and sunshine to cross the threshold, accounts of the meets reveal how the boundaries of the tent were constantly breeched by insects and animals. ${ }^{137}$ At the 1890 meet at Jessup's Neck, for instance, the camp was "full of a sort of field mouse, a very tame little animal that $[\mathrm{ran}]$ in and out of the tents and under the tent floors. ${ }^{138}$ Such animals were considered "out of place" and could occasionally be frustrating for the campers - the preponderance of centipedes at the Stony Lake meet

week or two at a pastoral or wilderness setting. Annmarie Adams and Stacie Burke, "Not a Shack in the Woods': Architecture for Tuberculosis in Muskoka and Toronto," Canadian Bulletin of Medical Hitory, 23, no. 2 (2006): 429-55; Sharon Wall, "'All they need is air': Building Health, Shaping Class at the Fresh

Air Camp," in The Nurture of Nature: Cbildbood, Antimodernism, and Ontario Summer Camps, 1920-1955

(Vancouver: University of British Columbia Press, 2009), 102-39.

135 Jessica Dunkin, "Manufacturing Landscapes: Place and Community at Glen Bernard Camp, 1924 1933," Histoire Sociale/Social History 45, no. 89 (2012): 99. See also Leslie Paris, Cbildren's Nature: The Rìe of the American Summer Camp (New York: New York University Press, 2008), 103.

${ }^{136}$ Maria Kaika, "Interrogating the Geographies of the Familiar: Domesticating Nature and Constructing the Autonomy of the Modern Home," International Journal of Urban and Regional Rerearcb 28, no. 2 (2004): 266 . In this way, tents were more akin to the make-shift dwellings erected by settlers and described in Valencius' The Health of the Country than the homes that the canoeists left behind when they travelled to the meet, although the latter was not immune to nature's presence.

${ }^{137}$ At some of the meets, the canoeists erected netted canopies in an effort to keep mosquitoes away from their sleeping bodies. "The Canoe Men in Camp," New' York Times, 17 August 1890.

138 “The ACA Meet of 1890: Jessup's Neck," Forest and Stream, 21 August 1890. 
prompted one canoeist to sleep in his canoe with an impromptu tent overhead rather than remain in his land tent. ${ }^{139}$ Otherwise, the canoeists appear to have largely embraced the porous boundary between inside and outside, between civilization and nature that was so concerning to settlers in the Canadian and American wests in their own makeshift dwellings only a decade or two earlier. ${ }^{140}$

Tents, including the mess tent, were also particularly susceptible to vagaries of climate. Heavy rains during the first week of the 1889 Stave Island meet "searched out the weak places in the tents very effectively." ${ }^{\prime 41}$ The following year, there were a number of severe storms including one on the first Sunday that attacked the mess tent "until the tables were almost afloat." ${ }^{142}$ While such weather impeded the canoeists' activities, it also brought them together. At the latter meet, "as the wind increased" during the storm, "all hands were called on to hold [the mess tent] down. While some of the men held the three large tent poles, others helped by the ladies, held the sides and the roof down. The tent rocked and the top split badly, but by hard work it was saved from total collapse." Storms could also provide welcome excitement. Of course, too many consecutive days of rain could dampen spirits.

Certain kinds of tents were more susceptible than others to rain, including the single-pole pavilion tents with their "striped sides, gaily painted poles and very flat roofs." ${ }^{143}$ However, few could protect against cold and damp. Paul Vernon's memoir hints at the very different experience of sleeping in a tent, which Abigail Van Slyck

\footnotetext{
139 “Tents," Foreat and Stream, 20 December 1883.

${ }^{140}$ Valencius, Healtb of the Country, 94-7.

141 "Some More Snips from and Another Snap at the '89 Meet," Forest and Stream, 24 October 1889.

142 "American Canoe Association," Forest and Stream, 14 August 1890.

143 "Some More Snips from and Another Snap at the '89 Meet," Foredt and Stream, 24 October 1889.
} 
argues were "an abrupt departure from the comforts of home."144 It was certainly a practice to which campers had to become acclimatized. Vernon writes, "Being new to cot life in camp, I turned in the first night directly above the canvas of the cot to find I was damp and cold. As the only warm thing around was the oil lantern, I pulled it in to the dry out the dampness, pulling it up and down on the canvas to ease the chill."145 What Vernon realized was that his body was accustomed to home beds, in which the "heavy hair-filled mattress keeps out the cold." He eventually adapted by layering blankets beneath him on the cot, but not before having a bad night's sleep and burning his foot on the lantern he employed in an effort to warm up his bed.

\section{It Takes a Village}

Although the first campsites were fairly simple affairs, later encampments as Figure 6.4 suggests emerged as small villages. ${ }^{146}$ The organizers typically laid out "streets" to connect the camp's five main sites (wharf, headquarters, mess tent, main camp, and women's camp), but also to act as thoroughfares within the men's and women's camps. ${ }^{147}$ These streets, in other words, encouraged particular routes of movement through the encampment. The streets were often lined with strings of lanterns. One year there were even light posts, some of which boasted electric light, installed along the main road. ${ }^{148}$ The importance attributed to lighting is telling. Although useful in a practical sense for navigating the campsite, light was also

\footnotetext{
${ }^{144}$ Van Slyck, A Manufactured Wilderne's, 101.

${ }^{145}$ Vernon, Taled of the $A C A$.

${ }^{146}$ A reporter for the Peterborough Daily Review remarked that the 1883 campsite had the "appearance of a canvas village." “ACA Annual Meeting," Peterborough Daily Review, 14 August 1883.

${ }^{147}$ This was not the case at all of the meets. Accounts of the 1893 meet at Brophy's Point, for instance, are explicit about the absence of streets. "Around the Pine Camp Fire," New York Times, 20 August 1893. 148 "ACA Camp," Foreut and Stream, 14 August 1884; NYSHA, 1.2/15, "Mending Sails, Canoe Sailors' Row," 1890; “The Canoe Men in Camp," New York Timer, 17 August 1890. Electricity was an anomaly in the camp at least until the late 1890 s if not after.
} 
associated with goodness and purity. Artificial light, in particular, was "routinely viewed as the supreme sign of 'modernity' or 'civilization."'149 Finally, lighting made the spaces of the encampment visible to organizers and members of the camp police force. ${ }^{150}$

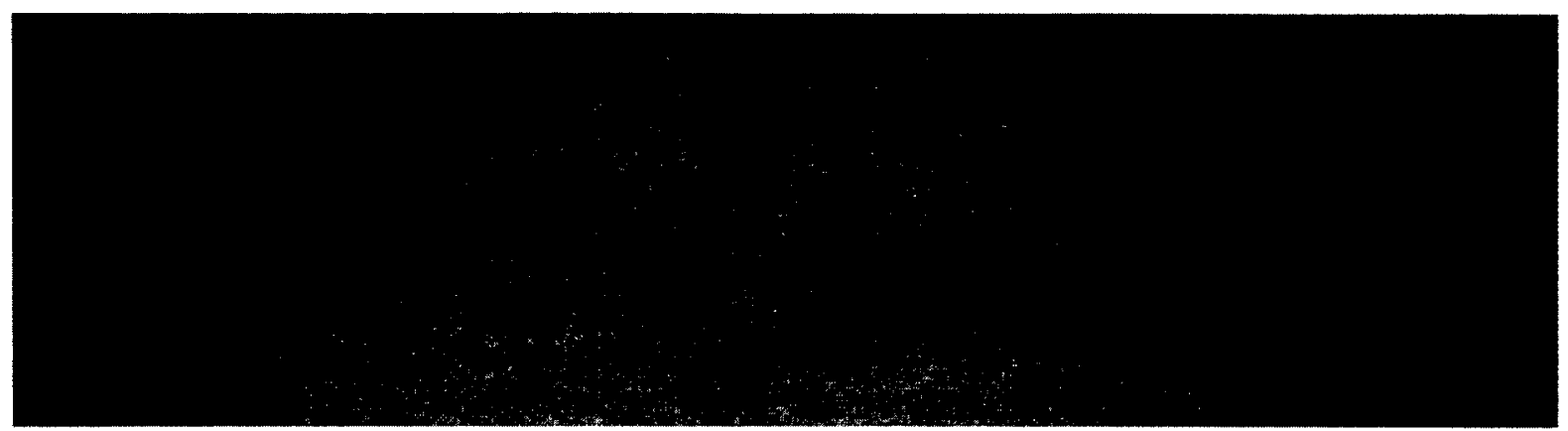

Figure 6.4 - "Site of the ACA Camp, Jessup's Neck, Long Island," 1890. [Source: Forest and Stream, 31 July 1890.]

It was also common practice for the inhabitants to name the streets and to erect signposts like those in Figure 6.5 to this effect. At the 1881 meet at Lake George, for example, the canoeists could stroll down Knickerbocker Avenue, Natural Scenery Avenue or Baxter Street. ${ }^{151}$ At the 1888 meet, "gorgeous signboards" marked Appian Way, Tarpican Rock, and Peanut Hump. ${ }^{152}$ The 1890 boasted the most elaborate street system with signposts pointing the way to Broad Street, Beacon Street, Commonwealth Avenue, Rittenhouse Square, Chestnut Street, Madison Square, Newspaper Row, lanthe Avenue, Queen's Road, King Street, the Esplanade, and

\footnotetext{
${ }^{149}$ Chris Otter, The Victorian Eye: A Political Hittory of Light and Vivion in Britain, 1800-1910 (Chicago: University of Chicago Press, 2008), 1.

${ }^{150}$ I am reminded here of the "morality lights" that school boards and parent-teacher associations installed on school grounds in the postwar era with an end to curbing youth delinquency. Mary-Louise Adams, The Trouble with Normal: Postwar Youtb and the Making of Heterotexuality (Toronto: University of Toronto Press, 1997), 81-2.

151 "The Canoe Island Camp," New' York Times, 13 August 1881. Street names are also mentioned in "At the ACA Camp," Brooklyn Daily Eagle, 13 August 1902.

152 "The ACA Meet, Lake George," Forest and Stream, 23 August 1888; Retaw, Fragments, 13. "Tarpican Rock" likely refers to Tarpeian Rock, which was an infamous execution site in the Roman Empire. Christopher DeRosa, "From the Tarpeian Rock: The Spectacle of Conspiracy in Renaissance Rome" (Ph.D. Dissertation: University of California Berkeley, 1999), 2.
} 
Plaza Place. ${ }^{153}$ The names chosen by the canoeists appear to have a variety of origins. Some referred to particular clubs, such as "Knickbocker Avenue" or "Ianthe Avenue." Others were practical, such as "Newspaper Row," which pointed campers to the office of the "Daily Disturber," the print periodical of the 1890 meet. ${ }^{154}$ Still others reproduced familiar urban locales such as "Madison Square" (New York) and "Rittenhouse Square" (Philadelphia) or thoroughfares such as "Yonge Street" (Toronto) and "Beacon Street" (Boston). ${ }^{155}$ In some cases, the references were tonguein-cheek. "Baxter Street," for instance, was not a historic thoroughfare like Chestnut Avenue in Philadelphia, but rather a common destination for immigrants arriving to New York in the late nineteenth century. It also served as a stock image for social reformers wishing to "capture the horrors of nineteenth century housing before tenement house reform." 156

Postcolonial scholars, as I discussed briefly in Chapter Three, have drawn our attention to the social and ideological power of naming places. To borrow from Catherine Nash, "Linking language and geography, place names, at once both material and metaphorical, substantive and symbolic - read, spoken, mapped, catalogued and written in the everyday intimate and official bureaucratic geographies of road signs, street names and addresses - are all about questions of power, culture, location and identity." 157 Paul Carter, likewise, argues that naming is a form of "spatial punctuation,

153 "The Canoe Men in Camp," New York Times, 17 August 1890; "The ACA Meet of 1890: Jessup's Neck," Forest and Stream, 21 August 1890.

${ }^{154}$ NYSHA, 1.2/11, "Camp of the Ianthe Canoe Club," 1890.

155 "Yonge Street" was mentioned in accounts of the 1889 meet. See, for example, "Some More Snips from and Another Snap at the '89 Meet," Forest and Stream, 24 October 1889.

${ }^{156}$ Elizabeth Fee, Theodore M. Brown, Jan Lazarus, and Paul Theerman, "Baxter Street Then," American Journal of Public Healtb 92, no. 5 (2002): 753.

${ }^{157}$ Catherine Nash, "Irish Placenames: Postcolonial Locations," Tranuactions of the Institute of Britists Geograpbers 24, no. 4 (1999): 457. 
transforming space into an object of knowledge, something that could be explored and read." ${ }^{158}$ Much of this research has focused on state efforts to extend territory and rationalize rule. However, clearly names had import for organizations beyond the state. For the ACA, placenames served to familiarize the landscape, to make it knowable and known, and to domesticate it. ${ }^{159}$ Assuming that place is space made meaningful, naming was also one of the ways in which encampment spaces became places. ${ }^{160}$ To borrow again from Paul Carter, "by the act of place-naming, space is transformed symbolically into a place, that is, a space with a history." ${ }^{161}$ Using street signs to reinforce names also reproduced the geographies of home by overlaying urban material culture and geographies on the natural space of the encampment. These practices also further imbricated the physically separate worlds.

Additional evidence of the village-like atmosphere of the encampments can be seen in the main camp. Here, the ordering of the tents in the men's camp was largely done on the basis of club affiliation. Thus, the Brooklyn Canoe Club or Ottawa Canoe Club camps functioned as "neighbourhoods" within the larger camp. With the move to Sugar Island, these neighbourhoods were inscribed on the landscape in a more enduring way, such that "[e]very locality had its own camp. There was New York Bay with the New York men on one side and the Rochester men at Irondequoit Park on

\footnotetext{
${ }^{158}$ Paul Carter, The Road to Botany Bay: An Exploration of Landacape and Hiwtory (New York: Knopf, 1988), 67.

${ }^{159}$ Wendy Roy makes a similar argument about Mina Hubbard's practices of naming in Labrador: "The toponyms on Hubbard's map contribute to her personalization and domestication of the landscape... By giving public geographic features names that, at least initially, had only private meaning, Hubbard's map takes the public and the outside, and turns it into the private and the inside." "Visualizing Labrador: Maps, Photographs, and Geographical Naming in Mina Hubbard's $A$ Woman's Way tbrough Unknown Labrador," Studies in Canadian Literature 29, no. 1 (2004): 24, 26-7.

${ }^{160}$ James Opp and John C. Walsh, eds., Placing Memory and Remembering Place in Canada (Vancouver: University of British Columbia Press, 2010), 3.

${ }^{161}$ Carter, Botany Bay, xxiv. Naming as place-making and naming as power are not mutually exclusively, but are inter-related.
} 
the other. Behind Irondequoit Park was the Armstrong preserve isolated on a high bluff but nevertheless within snowing distance of every other tent on the island."162 Eventually, these names appeared on maps of the encampment, strengthening the Association's power over the landscape, and adding another layer of legitimacy to the designations.

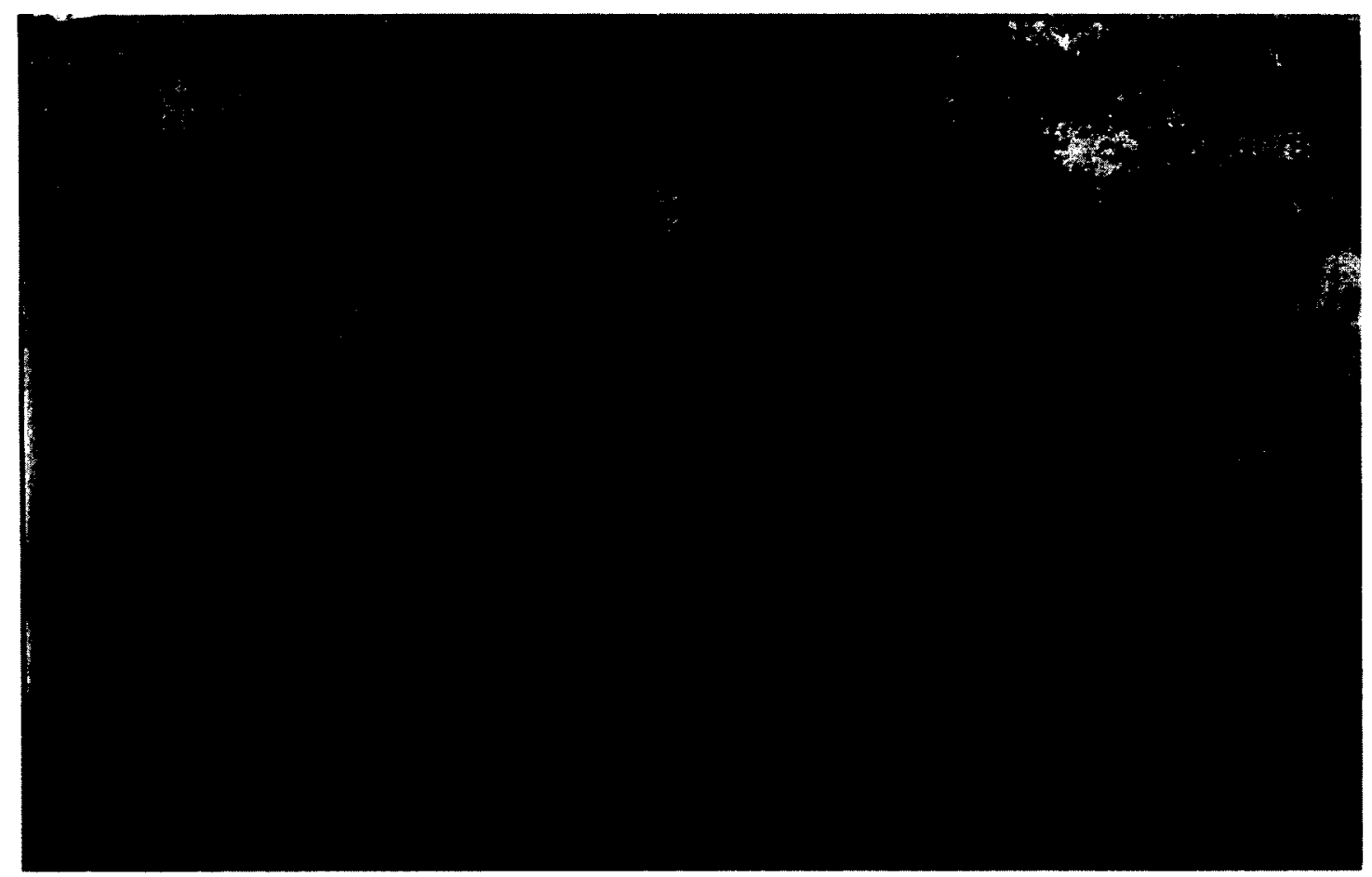

Figure 6.5 - S.R. Stoddard, “Toronto Canoe Club Camp," 1889. [Source: NYSHA, 1.5/2.]

Finally, there was the inclusion of decidedly "civilized" spaces at the encampments such as art galleries and barbershops that reinforced the campsites as villages. For example, two members of the Crescent Canoe Club, of Trenton, New Jersey, established an art gallery at their camp on Grindstone Island in 1884. Visitors to the gallery could glimpse Mssrs. Shrapnel and Humme's "sketches in color of Canadian woods and lakes," including vistas of the previous year's camp. ${ }^{163}$ In 1883 ,

\footnotetext{
162 "Beautiful Sugar Island: New Home of the ACA," Sail and Sweep 2, no. 9 (1903): 364-6. 163 "The Association Meet," Forett and Stream, 21 August 1884.
} 
Captain Clegg's campsite on Juniper Island, which he nicknamed "The Fort," also boasted an art gallery, although its contents went unremarked in the pages of the Peterborougb Examiner. ${ }^{164}$ The presence of barbershops at meets on Jessup's, Lake Champlain, and Sugar Island, to name just a few, also reinforced the urbane air of the encampments. ${ }^{165}$

\section{Complicating Home}

My characterization of the tents as homes away from home would not be foreign to the canoeists. They themselves referred to their canvas abodes using homely nomenclature. For example, Mrs. Fish's tent at the 1894 meet was called "the Bungalow." ${ }^{166}$ At the 1890 meet, one reporter remarked that the tents were "scrupulously clean and kept in a way that a Dutch housewife would envy." ${ }^{67}$ Finally, Retaw noted of the 1888 meet that while "there were many small and unpretentious tents," there were also "a great many the size of a small house, with matched board floors, bright rugs, folding chairs and tables, cot beds, and any quantity of nicknacks." 168 Karen Halttunen argues, "Such tongue-in-cheek identification of the summerhouse piazza as a 'parlor' and its nearby grove of trees as a 'drawing room' was clearly intended to undercut the formality of Victorian middle-class social life."169 However, I think such naming was also about cultivating the encampments as a homeplace. Beyond legitimizing their presence on the sites, conceiving of the encampments as home belied the canoeists' deep attachment to place, although as I

\footnotetext{
164 "Stony Lake Canoe Congress," Peterborough Examiner, 23 August 1883.

165 "The Canoe Men in Camp," New York Timed, 17 August 1890; MSCRC, Collection 291, Box 23,

Folder 2, Camp Circular for Willeborougb Point, 1892; Howell, "International Canoe Meet," 513-20; NYSHA, 1.6/11, Camp Circular for Sugar Island, 1904.

166 "Pleasures of the Canoe Camp," New' York Time, 22 July 1894.

167 "The Canoe Men in Camp," New York Times, 17 August 1890.

${ }^{168}$ Retaw, Fragments, 14.

${ }^{169}$ Halttunen, "Parlor to Living Room," 158.
} 
have suggested elsewhere in this dissertation, this was not a specific physical location as much as a composite notion of the encampment that emerged through social and spatial practices.

Nevertheless, I am wary of overemphasizing the degree to which the tents at the encampments were homely, or the lengths to which the campers went to domesticate the site. To do so would be to ignore the ways in which the encampments and in some cases the campers resisted such characterizations. Consider a photograph from the first Sugar Island encampment in 1903, in which Major and Mrs. Leigh are depicted sitting in front of their tent. The photograph is entitled "At Home?," and unlike other captions in the yearbook, the title was placed in quotation marks. While At Home signals the domestic nature of this particular space, "At Home?" questions this categorization and suggests that tents were not authentically domestic. ${ }^{170}$ Furthermore, not everyone in attendance at the meets was comfortable with the practices of domestication endemic to camplife. ${ }^{171}$ For example, an Outing account of the 1886 meet asserted that "If there is a weak point about this A.C.A., it is that its members are disposed to make themselves altogether too comfortable in their tents on shore, and to lose the practical lessons in camping out, which are emphasized by constantly shifting quarters...Next year we shall expect to see chairs and tables, and in

170 "At Home?," in American Canoe Axtociation Yearbook, ed. John Sears Wright (n.p., 1904), insert between 38 and 39 .

${ }^{171}$ While most indicated their preference for comfort by their actions, there were others who were more explicit: "The canoeists who visit Lake George at this season enjoy a complete immunity from the sufferings ordinarily inseparable from canoeing. They sleep in tents instead of their narrow and coffinlike craft; they paddle and sail when they chose and simply for recreation, without feeling the dread necessity of 'making it ten more miles before sunset,' or of turning out at sunrise in order to paddle in the cool of the day through a pouring rain. They take their meals at the restaurant, and are not harassed by the necessity of 'going for milk,' or of building a fire and booking in a wind that will blow the smoke in their eyes no matter on which side of the fire they may be. Best of all, there is no necessity of washing the frying-pan. Of all the miseries of canoeing the frying-pan is the greatest... Living with this freedom from care the canoeist at Lake George is comparatively a happy man." "The Canoe Meeting," New York Times, 9 August 1882. 
1888 Grindstone will start a row of cottages. Such abuses of camp life can have few attractions for the genuine cruiser." ${ }^{172}$ Two years later, a reporter for Forest and Stream voiced similar concerns. He claimed that the character of the camp had changed "materially over the last three years"; each year the camp was "becoming less primitive and more civilized." ${ }^{173}$ The tents were now "double the size" and frequently furnished with "spring cots, rugs, chairs and tables"; board floors had become a necessity rather than a luxury; and the "large Saratoga [trunk] had replaced the modest camp chest." The 1893 meet at Brophy's Point was particularly infuriating for "old-timers," with its "telegraph office, two pianos, a baggage wagon, a Custom House officer and Postmaster, steamboats making seven trips a day, bait and boats for hire for fishing, a dancing platform, a hotel and restaurant, a steamboat landing, a laundry agent, [and] a daily news service." 174

The fact that the commentators referred to these conveniences as "enervating" or "effeminate" luxuries hints at the complex of ideas that underpinned such anxieties about domestication. Both adjectives suggest that such luxuries undermined one's manliness, albeit in different ways. "Ennervating," for example, makes specific reference to the threat of overcivilization, which was ultimately a concern about racial fitness. ${ }^{175}$ "Effeminate," by contrast, highlights anxieties about the feminization of

\footnotetext{
${ }^{172}$ This comment reveals some of the tensions in the organization between those who identified as cruisers and those who considered themselves racers. "The Great Canoe Meet," Outing 9, no. 2 (1886): 166. That the tents might be transformed into cottages was not altogether impossible. Certainly that had been the fate of Weslyan Grove. Brown, Inventing New England, 78.

173 "The ACA Meet of 1888: The Camp and the Association," Forest and Stream, 6 September 1888.

174 "Around the Pine Camp Fire," New' York Times, 20 August 1893.

${ }^{175}$ Victorians were universally concerned with the threat of neurasthenia, a nervous condition brought on by the demands of modern life. Modern life, they believed, could be quite literally unnerving. David Schuster, Neurathenic Nation: America's Search for Health, Happinet's, and Comfort, 1869-1920 (New Brunswick: Rutgers University Press, 2011).
} 
American culture. ${ }^{176}$ As Gail Bederman's work makes clear, however, these were not isolated concerns. Rather, gender and race were profoundly intertwined in this period within a hegemonic Western paradigm of civilization: "In the context of the late nineteenth century's popularized Darwinism, civilization was seen as an explicitly racial concept," which denoted "a precise stage in human racial evolution - the one following the more primitive stages of 'savagery' and 'barbarism"'-that only applied to whites. ${ }^{177}$ It was also a gendered concept: "One could identify advanced civilizations by the degree of their sexual differentiation....The pronounced sexual differences celebrated in the middle class's doctrine of separate spheres were assumed to be absent in savagery, but to be an intrinsic and necessary aspect of higher civilization."178 Clearly, the domesticity of the camp was never total, and always contested, revealing in particular tensions between idealized masculinity and lived gender roles.

\section{$\underline{\text { Conclusion }}$}

While the canoeists recognized the ACA encampments as temporary, they also went out of their way to domesticate such spaces, to (re)configure the landscape in ways that recalled the homes, towns, and cities that they had left behind. Not only did the campers reproduce the spaces of Victorian homes (kitchens, dining halls, parlours, bedrooms), but they also decorated them accordingly, employing design conventions that drew on objects and styles produced and circulated in the networks of colonial

\footnotetext{
${ }^{176}$ There were more immediate concerns about the feminization of the encampments. Amongst those sounding the alarm, there was a belief not only that such luxuries were dangerous for men, but also that they attracted women, which would further undermine the very masculinity of the camp. See, for example, "Around the Pine Camp Fire," New' York Times, 20 August 1893.

${ }^{177}$ Gail Bederman, Manlinest and Civilization: A Cultural Hwtory of Gender and Race in the United States, 1880 1917 (Chicago: University of Chicago Press, 1995), 25.

${ }^{178}$ Bederman, Manlines and Civilization, 25.
} 
capitalism. They also arranged the encampments to recall the layouts of urban neighbourhoods. In their form, as well as their content, the encampments functioned as homes away from home. As much as the encampments were distanced from the spaces of home and the city, these two realms were also deeply entangled. The rationale behind these desires to domesticate may lie in the cultural meanings attributed to home and domesticity in the late nineteenth century, as well as the rising spectre of consumerism. They may also signal tensions at the heart of modern tourism.

In any case, these practices of homemaking reveal how deeply meaningful the encampments as place, community, and experience were to the campers. They also indicate that the world of recreation was not divorced from larger structures and processes of industrial capitalism and colonialism, but reflected and reinforced the same. Moreover, the practices of domestication, which formed a key part of the encampments calls into question the extent to which outdoor recreation was a rejection of domesticity, particularly for men. To borrow from Martin Francis, "If there was a 'flight from domesticity' in the late Victorian and Edwardian periods, it was unable to claim a monopoly over the masculine imagination, which was characterized by contradictory patterns of desire and self-identification. ${ }^{179}$ Now that we have placed domesticity, we can turn our attention to the ways in which the canoeists inhabited these spaces.

\footnotetext{
${ }^{179}$ Francis, "Domestication of the Male," 642. Francis further destabilizes the accepted chronology of British masculinity a little later: "It might be better therefore to replace the simplistic narrative of a 'flight from domesticity' between 1870 and 1914, followed by a 're-domestication' of the male in the interwar years, by an awareness that men were continually seeking to reconcile and integrate the contradictory impulses of domestic responsibility and escapism, both of which could, at various times, find sanction in the polyphonic voices of popular culture or politics."
} 


\section{Chapter Seven: Inhabiting}

Life at the American Canoe Association encampments was predictable. The morning bugle sounded at $7.00 \mathrm{am}$ to rouse the campers. Half an hour later, the camp gun was fired and the colours run up at headquarters, marking the official start to the day. A morning dip for those who wished to partake was punctuated by breakfast, which, in turn, was followed by time for "house-keeping" and other "camp work." During the first week, the rest of the day might be spent visiting, writing letters, calling at the post office, exploring the campsite or heading out on an excursion. During the second week, races were the order of the day. If the canoeists were on site, lunch was taken at noon in the mess tent or at their campsite, and supper served around six. With a few exceptions, evenings were passed by the campfire. While the flags lowered with the setting of the sun, the day officially ended with the bugle playing taps, after which point, the expectation was for camp-wide silence. Occasionally, the schedule was altered somewhat to accommodate a church service, Visitors' Day, or one of the many spectacles intended to amuse. ${ }^{1}$

In the last chapter, I considered practices of inhabiting in a very literal sense by exploring the ways in which the canoeists domesticated the physical environments of the campsites through material means. In this chapter, I examine how the canoeists inhabited the encampments through their daily activities. Like Michael Haldrup, I conceive of inhabiting not as a stationary activity, but rather as a mobile practice that

\footnotetext{
'A typical day at the annual meeting is described in "ACA Camp," Forest and Stream, 14 August 1884, and Retaw, Fragmenty from the ' 88 Meet (Montreal, 1888), 14-5. Most of the lengthier accounts of the meets include descriptions of the daily and weekly rhythms of encampment life.
} 
involved multiple forms of movement. ${ }^{2}$ The canoeists walked from their tents to the beach to bathe, they bicycled to the mess shed for meals, they paddled along the shoreline to a campfire. ${ }^{3}$ As they moved, they contributed to the transformation of the raw material of the encampment space into a meaningful place. While some of this movement was undertaken alone, many more of the canoeists' "micro-journeys" were carried out with others. ${ }^{4}$ Thus, these quotidian mobilities afforded encounters with the social landscape of the encampment, as well as the physical one. The importance of the former was brought into sharp relief at the 1891 meet at Willsborough Point when the campsite was on a much larger scale than in previous years. ${ }^{5}$ Not only did this mean lengthier travelling times between sites, but, as a reporter for Forest and Stream noted, the dispersed nature of the encampment "interfere[d] greatly with the usual familiar, everyday intercourse of camp life."

Unlike Haldrup, what I classify as inhabiting at the annual meetings is not limited to the canoeists' daily practice, but also includes seemingly extraordinary activities: spectacles. By examining the banal alongside the spectacular, I suggest that the extraordinary was as routine as the quotidian, in large part because, like the daily activities that the canoeists performed, it conformed to temporal patterns established over the course of several encampments. In fact, this chapter makes clear that the event was shaped as much by uses of time as by uses of space. There were daily

\footnotetext{
${ }^{2}$ Michael Haldrup, "Laid-Back Mobilities: Second Home Holidays in Time and Space," Tourum Geograpbies 6, no. 4 (2004): 445.

${ }^{3}$ Not all movements were so utilitarian. The 1890 meet at Jessup's Neck, for instance, was appreciated for the "pleasant walks" afforded by the beaches and woods. "The ACA Meet of 1890: Jessup's Neck," Forest and Stream, 21 August 1890.

${ }^{4}$ I owe this idea of a micro-journey to Bryan Grimwood.

${ }^{5}$ Organizers estimated that the camp was capable of accommodating upwards of 600 people, although only half as many people were likely in attendance. "The ACA Meet of 1891," Forest and Stream, 20 August 1891.

6 "The ACA Meet of 1891," Forest and Stream, 20 August 1891.
} 
rhythms such as wake-up, mealtimes, and campfires. There were weekly rhythms that included visitors' days and church services. Finally, there were yearly rhythms; these enabled the campers to anticipate the time for socializing and recreating in the first week and time for racing or spectating during the second. They could further expect other forms of entertainment such as a minstrel show, a canoe parade, or a circus.

This chapter is thus concerned with two related, but distinct modes of being "in place" and forming community: practice and performance. ${ }^{7}$ In the first half of the chapter, we watch the processes of inhabiting begun in the last chapter and centred on the tent extend outwards across time and space. Here, my concern is with the activities the campers engaged in, as well as their social worlds as they practiced. In the second section, I examine the many spectacles that occurred during the course of the encampments: the illuminated parades, the Commodore's review, historical reenactments, circuses, and minstrel shows. These events brought together large numbers of the campers. In this way, they were a materialization of the imagined community of canoeists. As sites of shared experience, they also reinforced the bounds and bonds of community. ${ }^{8}$ Finally, the spectacles (re)inscribed place, constituting the encampment as hegemonically white, middle-class, and male.

Whereas historians of sport have been attune to the ways in which physical activities and competitions have served to define and strengthen the boundaries of community, they have had less to say about sporting venues and events as places

\footnotetext{
${ }^{7}$ Tim Cresswell and Gareth Hoskins, "Place, Persistence, and Practice: Evaluating Historical Significance at Angel Island, San Francisco, and Maxwell Street, Chicago," Annale of the Aducciation of American Geograpbers 98, no. 2 (2008): 394; John C. Walsh, "Performing Public Memory and Re-Placing Home in the Ottawa Valley, 1900-1958," in Placing Memory and Remembering Place in Canada, eds. James Opp and John C. Walsh (Vancouver: University of British Columbia Press, 2010), 25-56; John C. Walsh and Steven High, "Rethinking the Concept of Community," Histoire Sociale/Social History 32, no. 64 (1999): 255-74.

${ }^{8}$ Walsh and High, "Community."
} 
marked by gender, class, and race. ${ }^{9}$ Two recent exceptions are Patricia Vertinsky's Disciplining Bodies in the Gymnasium and Russell Field's work on spectatorship at Maple Leaf Gardens. ${ }^{10}$ More than just treatments of how sporting spaces seek to discipline experience, both texts also consider how spaces of sport become meaningful through the intersections of social relations and embodied practice. This chapter parallels these works, but in a markedly different kind of sportscape. Whereas Vertinsky and Field focus their attention on more conventional sporting spaces - a gymnasium and a hockey arena - this chapter is concerned with a "cultural landscape" of sport, a term used by architectural historians "to describe the intersection of the natural landscape with built forms and social life."11

Part I - The Practices of Everyday Life

\section{Mess Tents and Meals}

With the tents raised and their baggage unpacked, the canoeists quickly settled into the routine captured in broad strokes in the opening paragraph of this chapter. Much like at summer camps, "rigorously maintained mealtimes gave a clear and consistent structure to each day" at the ACA meets. ${ }^{12}$ Bells and bugles called the campers to the mess for breakfast, lunch, and dinner at the same time each day, or

\footnotetext{
${ }^{9}$ See, for example, Colin Howell, Northern Sandlots: A Social History of Maritime Baieball (Toronto: University of Toronto Press, 1995); Nancy Bouchier, For the Love of the Game: Amateur Sport in Small-Town Ontario, 1838-1895 (Montreal: McGill-Queen's University Press, 2003).

${ }^{10}$ Patricia Vertinsky and Sherry McKay, eds., Disciplining Bodied in the Gymnatum: Memory, Monument and Modernium (London: Routledge, 2004); Russell Field, "Constructing the Preferred Spectator: Arena Design and Operation and Consumption of Hockey in 1930s Toronto," International Journal of the Hittory of Sport 25, no. 6 (2008): 649-77.

${ }^{11}$ Abigail Van Slyck, A Manufactured Wilderness: Summer Camps and the Shaping of American Youth, 1890. 1960 (Minneapolis: University of Minnesota Press, 2006), xxxi. Cultural landscapes are further comprised of "activity arenas," which are "spaces not necessarily defined by walls and roofs, but created by human action." Here, Van Slyck is drawing on Elizabeth C. Cromley, "Transforming the Food Axis: Houses, Tools, Modes of Analysis," Material Huttory Review 44 (1996): 8-22.

${ }^{12}$ Van Slyck, A Manufactured Wilderness, 126.
} 
reminded them to sup at their own tents. Meals offered opportunities for social intercourse. This was particularly true if one was eating in the mess tent, a space that welcomed participants from all corners of the camp regardless of gender, nationality or club affiliation. ${ }^{13}$ Long wooden tables and catered meals afforded, encouraged even, interactions with friends new and old. Of course, the ostensibly egalitarian nature of the mess tent had a limit, restricting equal access to paying members and their approved guests. Presumably servants and staff ate elsewhere, although the archive is silent on this point.

Unlike at summer camps, where "middle-class campers were deeply involved in routine meal preparation," the mess tent at the annual encampments was more akin to a hotel dining room or restaurant where food preparation was undertaken by hired help and hidden from view. ${ }^{14}$ Reflecting this arrangement, the mess was, on a number of occasions, likened to a restaurant. At the 1892 meet, for example, the New York World noted, "The camp mess is really a first-class restaurant." ${ }^{15}$ Conversely, Forest and Stream lamented the fact that at the 1888 meet, "all dined at the mess shed, practically equivalent to a very poor hotel with all the pleasure of camp life carefully extracted."16 Despite efforts at shielding the campers from meal preparation, the boundary between the kitchen and the canoeists was not impermeable. Paul Vernon, for example, observed the unsettling visibility of the byproducts of meal preparation at the 1893 meet: "You met the kitchen first as you approached and unfortunately had to pass the

\footnotetext{
${ }^{13}$ Even in those cases where canoeists cooked for themselves, they often came together in more informal ways to share the responsibilities of cooking. Caspar W. Whitney, "Annual Meet of the American Canoe Association," Harper's Weekly, 2 September 1893.

${ }^{14}$ Van Slyck, A Manufactured Wildernest, 129.

15 "Paddlers Getting Ready," New' York World, 31 July 1892.

16 "The ACA Meet of 1888: The Camp and Association," Forest and Stream, 6 September 1888.
} 
refuse pile which gave a nauseous view of what, at that meal you were to be served."17 Although Vernon does not comment on his olfactory response to the encounter with the refuse pile, we can imagine that it was an equally unpleasant smell.

The mess tent, like the campers' sleeping tents, was a hybrid space, embodying the intimate relationship between nature and culture, and home and away that characterized the encampment more broadly. ${ }^{18}$ As the example of the Stave Island meet visible in Figure 5.3 illustrates, the mess tent often boasted strings of lanterns and flags, linen tablecloths, china dishes, and uniformed servers. ${ }^{19}$ On the other hand, there was rarely a wood floor underfoot, so the canoeists ate with the dirt and grass beneath their feet; small creatures were likely to appear in the dining space; and the wait staff were typically the daughters and wives of local farmers or fishers, presumably with little formal training or experience. The mess tent was a hybrid space in another way as well. As I noted in Chapter Five, the rearrangement of the tables and chairs/benches and the addition of decorations or a stage could transform the dining space into a dance hall, theatre or sanctuary. The mess also frequently served as a destination for rainy day activities. ${ }^{20}$

As with other spaces and aspects of camp life, commentators were ambivalent about the mess tent. While some recognized its usefulness for those busy with racing,

\footnotetext{
${ }^{17}$ Trent University Archives (TUA), 83-014/2, Paul Vernon, Tales of the ACA, 1940.

${ }^{18}$ Abigail Van Slyck has made similar observations about dining pavilions at children's camps in $A$ Manufactured Wildernew, 64-7.

19 "Table linens...became essential elements in any civilized life style by the late nineteenth century." Susan Williams, Savory Suppers and Fasbionable Feasts: Dining in Victorian America (Knoxville: University of Tennessee Press, 1996), 70.

${ }^{20}$ For mention of rainy day activities, see "The Association Meet," Forest and Stream, 6 August 1885, and "Rainy Day Amenities" in S.R. Stoddard, Glimptes of the ACA (Glen Falls, 1890).
} 
for others, the mess, like tent floors and Saratoga trunks, represented overcivilization. ${ }^{21}$ In 1893, for example, a New York Times reporter opined, "The old canoeist had none of these things in camp," referring to the pianos, a baggage wagon, and the "restaurant."22 For this observer, the encampment appears to have taken on the air of a resort, which, as I discussed in Chapter Two, middle-class travellers in the late nineteenth century regarded with some disdain. ${ }^{23}$ Others who opposed the mess did so on the basis of quality. While commentators relished the memory of the "excellent country fare of the Delaney farm," there were a number of less successful attempts at feeding the canoeists, including the "scant provender of 1888" and the "experienced hotel steward," whose previous work at the Rossmore Hotel and Sinclair House in New York City appears not to have aided him in producing edible meals at the 1890 meet. $^{24}$ The mess tent was but one of three options for board open to the campers. They could also cook for themselves, or they could hire a cook and hold a "club mess." Throughout this period, all three options were in evidence at a given encampment, although in varying quantities depending on the year. A Forest and Stream article from the 1888 meet, for example, claimed that "nearly all patronize the mess tent," with only

\footnotetext{
${ }^{21}$ Although this was never suggested in accounts of the meets, for women, "who oversaw and -in households with few servants-participated in the purchase, preparation, and serving of daily meals," the mess tent may have offered a welcome respite from the responsibilities of home. Cindy S. Aron, Working at Play: A History of Vacations in the United States (New York: Oxford University Press, 1999), 57. 22 "Around the Pine Camp Fire," New' York Times, 20 August 1893.

${ }^{23}$ J.I. Little, "Life without Conventionality: American Social Reformers as Summer Campers on Lake Memphremagog, Quebec, 1878-1905," Journal of the Gilded Age and the Progressive Era 9, no. 3 (2010): 284. 24 "The ACA Meet of 1890 - II," Forest and Stream, 6 November 1890; "The ACA Meet of 1888," Forest and Stream, 6 September 1888 . The 1890 mess had the worse reputation to date of any of the meets. The portions were mean, there was an absence of fresh produce, and as D.B. Goodsell noted, "we were in a locality famed for its scallops and shell fish but I cannot remember seeing any at all." New York State Historical Association (NYSHA), 1.6/2, D.B. Goodsell, A Canoeing Reminiwcence (1936), 3; "The ACA Meet of 1890-II," Forest and Stream, 6 November 1890.

${ }^{25}$ I consider the work of such men and women in greater detail in Chapter Nine.
} 
a "handful cook [ing] for themselves," ${ }^{26}$ while in 1894, organizers decided not to offer a mess option at the Croton Point meet. ${ }^{27}$ By the early twentieth century, most campers took their meals in the mess tent on Sugar Island ${ }^{28}$ In the years where the campers had choice, the preference for one method was likely informed by cost, time, and ability. In 1888, Forest and Stream estimated that a canoeist could meet their daily needs for 75 cents, while a good club mess ran upwards of $\$ 2$ per person per day. ${ }^{29}$ By contrast, with the exception of the 1890 meet, the canoeists could get three meals a day from the mess tent throughout this period for one dollar. ${ }^{30}$ The competitive canoeists who used their time to prepare and compete in the races were typically less inclined to cook for themselves, while campers with limited experience in the realm of outdoor living might have chosen to frequent the mess tent for practical reasons. Still others may have had ideological motivations for choosing a personal mess over the camp kitchen such as a desire to "rough it." ${ }^{31}$ Some years, the campers changed strategies mid-way through the meet. This was true of Paul Vernon and members of the Brooklyn Canoe Club. In 1893, "so bad did the commissary become" that they "hired a man from Kingston to feed [them]." ${ }^{\prime 32}$

Interestingly, periodical accounts and memoirs offer little about the actual contents of meals. For this, we must look to the circulars, although as the example of

26 "The ACA Meet, Lake George," Forest and Stream, 23 August 1888.

${ }^{27}$ Mystic Seaport Collections Research Center (MSCRC), Collection 291, Box 23, Folder 2, Camp Circular for Croton Point, 1894. The decision was made by vote of the Executive Committee. They voted $14-3$ in favour of abolishing the camp mess.

28 "Of late years, however, individual cooking has been very rare and almost all have patronized the camp mess." "Canoeists' Annual Camp," New' York Times, 11 August 1901.

29 "The ACA Meet of 1888: The Camp and the Association," Forest and Siream, 6 September 1888.

${ }^{30}$ In 1890, mess tent meals were offered on a sliding scale. "The ACA Meet of 1890-II," Forest and Stream, 6 November 1890.

${ }^{31}$ American Canociut 3, no. 8 (1884): 64.

${ }^{32}$ Vernon, Tales of the $A C A$. 
the 1890 meet made clear, to promise a menu was one thing, to deliver it was another thing entirely. ${ }^{33}$ The proposed menu for the mess tent at the 1888 meet at Lake George featured oatmeal/wheat/hominy, meat, potatoes, bread and butter, and coffee or tea for breakfast. ${ }^{34}$ For dinner, the main meal of the day, the canoeists were to expect soup, meats, vegetables, coffee and tea, and deserts. ${ }^{35}$ Finally, the menu promised suppers consisting of cold meats, bread and butter, hot rolls or griddlecakes, sauce and cake. ${ }^{36}$ If these menus are any indication, then meals served in the mess tents sought to replicate those on offer in middle-class homes in the same period. ${ }^{37}$ In practice, however, there were likely noticeable differences for the consumers because of inconsistent supply lines and the quantity of food that had to be prepared.

Advice given to canoeists intending to cook for themselves over a camp stove or fire also provides some indication of the range of dietary possibilities. One commentator in the 1880 s suggested that a cruiser's breakfast should have "a few good staples," such as meat, eggs, and potatoes, "easily and simply prepared." ${ }^{\prime 38}$ The evening meal was also to be a simpler affair, requiring "little or no cooking, merely coffee and a

33 "The ACA Meet of 1890-II," Forest and Stream, 6 November 1890.

${ }^{34}$ This is one of the few circulars to feature a full menu. That the contents of the previous year's menu are similar suggests that there was a common encampment bill of fare. Specifically, the canoeists were promised meat, eggs, and cakes for breakfast; soups, roasts, and vegetables for dinner; and cold meats and sweets for supper. "The ACA Meet of 1887," Forest and Stream, 2 June 1887.

${ }^{35}$ Not only is the description here more elaborate for the midday meal, but on those occasions where separate prices were provided for the various meals, lunch was the most expensive. For example, at the 1892, dinner was 50 cents, while breakfast or supper were 35 cents. MSCRC, Collection 291, Box 23, Folder 2, Camp Circular for Willoborough Point, 1892.

${ }^{36}$ MSCRC, Box 23, Folder 2, Camp Circular for Lake George, 1888.

${ }^{37}$ Williams, Savory Suppers.

38 "The ACA Meet of 1888: The Camp and the Association," Foreut and Stream, 6 September 1888. One of the ironies of this account is that even as the author laments the overcivilization of the encampments and the increasing reliance on the camp mess, he advises canoeists to bring the following utensils with them: "Frying pan, gridiron, patent broiler, French coffee pot, pails of from one to eight quarts capacity, steam cooker, butcher knife, large form and spoon, carving knife and fork, table cutlery and spoons, plates and dishes of tin or china... wooden plates, Japanese paper napkins, cans of sugar, coffee, tea; also salt and pepper cruets and small articles." The list of foodstuffs he advocated bringing was even longer, including everything from cocoa and Worcester sauce to pineapple and Edam cheese to pickles and marmalade. 
can of soup warmed up, with the aid of cold meats, potato salad, canned lobster or salmon, etc."39 The author agreed that dinner should be "the main meal of the day." Although he did not give any indication as to what kinds of repasts were appropriate, he directed the canoeists to Canoe and Camp Cookery $(1885) \cdot{ }^{40}$ Composed of columns penned by Seneca and published in the pages of Forest and Stream in the early 1880 s, Canoe and Camp Cookery included chapters devoted to the preparation of soups, fish, meats and game, and vegetables. ${ }^{41}$ A number of observations can be made of camp cookery in relation to the typical middle-class meal based on Seneca's text: it depended more heavily on canned goods, including soups and meats ${ }^{42}$; it made use of local game, including fish, squirrels, and pigeons; and it was light on vegetables. ${ }^{43}$ Of course, these are prescriptive documents. It is more likely that those who cooked for themselves, because of the proximity of the camp store with its groceries, canned goods, bread, butter, milk, and eggs, followed a modified "cruising diet." ${ }^{\prime 4}$ Thus, while those who dined in the mess tent reproduced many of the practices and consumed many of the foods common to middle-class meals as they were enjoyed in urban centres, cruisers' ways of cooking and their foodstuffs were different, if not radically so.

39 "The ACA Meet of 1888: The Camp and the Association," Forest and Stream, 6 September 1888. ${ }^{40}$ Seneca, Canoe and Camp Cookery: A Practical Cook Book for Canoewty, Corintbian Sailors and Outerd (New York: Forest and Stream Publishing, 1885). The volume was re-issued in 1893. The original columns often appeared in close proximity to the ACA column in the magazine's pages.

${ }^{41}$ Seneca's suggestions are perhaps more realistic for a camper than the Forest and Stream author: sugar, tea, flour, crackers, lard, rice, bacon, coffee, butter, condensed milk, bread, potatoes, meal, molasses, pepper, pickles, yeast powder, salt. These are to be accompanied by meat and vegetables procured en route. Seneca, Canoe and Camp Cookery, 16.

${ }^{42}$ Canned goods may have been a staple of cruising diets because of their convenience. However, they were not a significant part of middle-class diets more until the 1920s. Ruth Schwartz Cowan, "The 'Industrial Revolution' in the Home: Household Technology and Social Change in the $20^{\text {th }}$ Century," Tecbnology and Culture 17, no. 1 (1976): 8.

${ }^{43}$ The latter, Seneca argued, were too bulky for "the canoeist, whose stowage room is limited." Thus, he limited his commentary to potatoes, "which he most certainly will carry," and green corn, which "he can obtain readily, if his cruise leads him through a farming country." Seneca, Canoe and Camp Cookery, 30. 44 "Stony Lake," Forest and Stream, 28 June 1883. 


\section{“Recreating" Canoeists}

The time between meals was taken up with a variety of activities that brought campers to different locations on and around the encampment site. As I described in Chapter Four, excursions to local sites of interest were a popular way to pass the time during the first week. For those wishing to stay closer to home, however, there were a number of other options, many of which centred on the water or shoreline. These included swimming, fishing, canoeing, and games.

At the early meets, bathing was more common as a practice of personal hygiene than a recreational pursuit. For this reason, it took place early in the morning in areas near to the Main Camp for men, or Squaw Point for women. ${ }^{45}$ Towards the end of this period, swimmers began to appear outside of the official bathing times, but also in common areas of the campsite like the wharf. ${ }^{46}$ An account of the 1896 meet on Grindstone Island, for example, claimed, "Bathing is one of the principal amusements of the men's and women's camps. At all hours the level, sandy beach, which extends far out into the bay, is dotted with human figures in dark bathing suits enjoying a swim or a splash in the waters of the St. Lawrence. ${ }^{m 47}$ Photographs from the period also show mixed-sex groups of campers playing in the water with the camp headquarters in the background.$^{48}$ The evolving place of swimming at the annual meetings echoes

\footnotetext{
${ }^{45}$ A photograph from the 1887 meet by S.R. Stoddard shows two men removing their clothing on the beach, while a third stands by, already disrobed, his back to the camera. NYSHA, 1.1/24, "Camp of the Mohican Canoe Club, Albany, NY," 1887.

${ }^{46}$ By 1890 , "ladies, as well as gentlemen" were being encouraged to bring their bathing suits to the annual meetings, presumably for recreational purposes. Later reports claimed that many took advantage of the clear, warm water at Jessup's Neck. "ACA Meet," Forest and Stream, 31 July 1890; "The ACA Meet of 1890: Jessup's Neck," Forest and Stream, 21 August 1890. 47 "Ready for the Races," Syracuse Evening Herald, 23 August 1896.

${ }^{48}$ NYSHA, 1.2/30, "Camp Dock from the Headquarters," 1899; "Bathing Beach at Grindstone," in American Canoe Astociation Yearbook, ed. Thomas Stryker (Rome: Press of the Rome Sentinel, 1896), 49; "Morning Swim from ACA Camp Book," n.d. There are also a number of swimming photographs in NYSHA, 1.5/6, Walwin Barr Scrapbook, c. 1905-unknown.
} 
transformations underway elsewhere. As Jeff Wiltse demonstrates, swimming was, in the late nineteenth century, a "male activity." ${ }^{\prime 99}$ In North America, it was also associated with "rowdy and indecent plebians," making it an undesirable activity amongst the middle classes. ${ }^{50}$ Modest bathing attire, the development of "proper" swimming facilities, and the emergence of formal swimming clubs all aided in recasting bathing as an acceptable middle-class pursuit. However, anxieties persisted about mixed-sex bathing well into the twentieth century. ${ }^{51}$ That this transformation appears to have taken place earlier at the ACA encampments suggests the events were "safe spaces" that enabled participation in otherwise morally questionable activities.

Also popular at the encampments was fishing. ${ }^{52}$ There appears to have been particularly good fishing at the 1883 encampment on Stony Lake. ${ }^{53}$ The local paper reported that a group of "Waltonites" had brought in an " $18.5 \mathrm{lb}$ Maskinonge. ${ }^{n 54} \mathrm{~A}$ week later, George Fitzgerald landed a $22.5 \mathrm{lb}$ fish of the same species. ${ }^{55}$ It was not just men who took advantage of fishing opportunities. That same year, the Peterborough Examiner reported that, "a young lady [had] covered herself with glory by gatting [sic]

\footnotetext{
${ }^{49}$ Jeff Wiltse, Contested Waters: A Social Huttory of Swimming Pools in America (Chapel Hill: University of North Carolina Press, 2007), 13; Christopher Love, "Swimming and Gender in the Victorian World," in A Social History of Swimming in England, 1800-1918: Splaubing in the Serpentine (London: Routledge, 2008), 19-35.

${ }^{50}$ Wiltse, Contested Waters, 14.

${ }^{51}$ This may stem from the fact that swimming was often associated with nude bathing. Love, Social History of Swimming, 20; Wiltse, Contested Wateri, 9.

${ }^{52}$ Perhaps somewhat surprisingly given the recreational culture of the era, I have only found two references to hunting at the encampments, one in anticipation of the 1883 meet and one following it. "Correspondence," American Canocitt 2, no. 4 (1883): 59-61; "Stony Lake Canoe Congress," Peterborough Examiner, 23 August 1883.

${ }^{53}$ Other references to fishing can be found in: W.S. Buell, "The American Canoe Association - The Meet of '99," Outing 35, no. 1 (1899): 87-9; Goodsell, A Canoeing Reminuicence, 15-6.

54 “The Stony Lake Meet," Peterborough Examiner, 16 August 1883. "Waltonites" refers to those who followed in the footsteps of Izaak Walton, author of The Compleat Angler (1653). Maskinonge likely refers to muskellunge, "large voracious predators that are highly prized as sport fish." William F. Sigler and John W. Sigler, Fisbes of the Great Basin: A Natural History (Reno: University of Nevada Press, 1987), 53. 55 "A Preliminary Business Meeting of the Association," Peterborough Daily Review, 22 August 1883.
} 
a 14 lb. monster." ${ }^{56}$ Women's enthusiasm for and participation in fishing excursions at the encampments likely reflected a broader interest in piscatorial pursuits amongst the "gentle sex" in the late nineteenth century. ${ }^{57}$ Fishing excursions tended to take the campers further afield than bathing, creating opportunities for encountering local landscapes and local people. Occasionally, the canoeists hired resident guides to show them the choicest locales, particularly at the meets on the St. Lawrence River, an area famed in the late nineteenth century for its muskellunge sport fishery. ${ }^{58}$ For some, the fish caught while at camp were purely for sport, while for others, they were a welcome addition to the meals they prepared over their campfires. For example, W.S. Buell claimed that the "fishing in the vicinity [of the 1899 meet] was found to be excellent, and many bass, pike and pickerel were lured and landed, to form substance for the frying pan of the voracious canoeist." 59

Canoes figured prominently as the campers fished and swam, providing a means of accessing good fishing spots away from the campsite or serving as objects of play for swimmers. ${ }^{60}$ However, canoes were also more directly objects of activity. Free time afforded the perfect opportunity to take to the water for a leisurely sail or paddle.

\footnotetext{
56 "The Stony Lake Meet," Peterborougb Examiner, 16 August 1883. Other references to women's fishing exploits appear in "Around the Pine Camp Fire," New York Time, 20 August 1893; "New Mab is Flyer," New York Sun, 22 August 1896; John R. Blake, ed., American Canoe Avvociation Yearbook (Toronto: Bryant Press, 1897), 48.

${ }^{57}$ David McMurray, "Rivaling the Gentleman in the Gentle Art: The Authority of the Victorian Woman Angler," Sport History Review 39, no. 2 (2008): 99-126.

${ }^{58}$ William Knight, "'Our Sentimental Fisheries': Angling and State Fisheries Administration in $19^{\text {th }}$ Century Ontario" (M.A. Thesis: Trent University, 2006), 102.

${ }^{59}$ W.S. Buell, "The American Canoe Association - The Meet of '99," Outing 35, no. 1 (1899): 87. See, also, "Around the Pine Camp Fire," New' York Times, 20 August 1893, and Forest and Stream. 5 September 1896.

${ }^{60}$ Images from the period show individuals dunking the canoes and then piling into the swamped craft. NYSHA, 1.5/6, Scrapbook of Walwin Barr.
} 
Canoes also provided a means of exploring the campsite environs or taking a picnic. ${ }^{61}$

For others, free time was used to tinker with their canoes or to test new rigging. ${ }^{62}$ Still others could be found perched on the shoreline watching a "scrub" or "scratch" race the canoeists' term for an informal contest - or taking part in the same. ${ }^{63}$ At the 1885 meet, for instance, "a scratch trial between a native in a skiff and a canoeist in his canoe" sailed at twilight "interested Camp Grindstone hugely." Early on, such races functioned as opportunities for testing the merits of a particular craft or canoeist. Increasingly, however, the week prior to the meet was used more explicitly for training. ${ }^{65}$

Canoe races were not the only sporting matches to provide amusement during the first week. The canoeists brought other recreational equipment with them such as baseball bats and tennis racquets that they put to use during their free time. ${ }^{66}$ While most of these activities were considered respectable, there is some evidence to suggest that the canoeists engaged in "rough" sport as well. At the 1892 meet, for example, Forett and Stream reported that, during the second week, "[a]fter the return of the men to the headquarters, at 10:30 a couple of bouts with gloves took place, one very amusing one between two men of 139lbs. and 206 lbs., the smaller man being the victor." ${ }^{67}$ That such an encounter took place at night ostensibly away from the prying

\footnotetext{
${ }^{61}$ For picnics, see "The ACA Meet," Forest and Stream, 23 August 1883; NYSHA, 1.2/1, "Picnic Lunch on a Cruise," 1889; Library and Archives Canada (LAC), R2730-1-0-E, "A Group at the American Canoe Association Camp at Gananoque, St. Lawrence River," 1893.

62 "The ACA Meet, Lake George," Forest and Stream, 23 August 1888.

${ }^{63}$ Harry Eckford, "Camp Grindstone," Century Magazine 30, no. 4 (1885): 506; "The Canoe Men in Camp," New York Timed, 17 August 1890; "Canoeing," New' York Sun, 10 August 1899.

${ }^{64}$ Eckford, "Camp Grindstone," 506. I return to this example in Chapter Eight.

65 "Canoe Race," The Evening Newe, 5 August 1904.

${ }^{66}$ NYSHA, "Fun in Camp: A Baseball Game," 1897.

67 "The ACA Meet of 1892," Forevt and Stream, 25 August 1892. I also found mention of "boxing, wrestling or tumbling" in relation to the evening gatherings at the 1898 meet. "Thousands Islands," Brooklyn Daily Eagle, 14 August 1898.
} 
eyes of women or visitors to the encampment makes its existence more understandable.

Boxing in the late nineteenth century had an unsavoury reputation. ${ }^{68}$

Some years, the annual meetings featured more formal sporting events unrelated to canoeing. In 1895, for example, a game of baseball was arranged between the canoeists and guests staying at the nearby Hotel Champlain. There was more than just baseball that day. The event also gave the canoeists an opportunity to engage in one of their favourite pastimes, dressing up. The Timed reported that, "the campers marched to and from the camp in a body with flying banners, and the camp band at their head. The 'camp ambulance corps,' with an appalling array of axes, saws, bottles, and stretchers, was a conspicuous and amusing feature of both the procession and the game. ${ }^{69}$ In 1897 , the meet featured a tennis tournament that pitted the canoeists against each other. ${ }^{70}$ Despite the inroads made by women in canoe racing by this time, a subject I explore in more detail in Chapter Eight, they appear to have only been spectators at these other sporting events.

There was also time devoted to more leisurely forms of social intercourse. Paths around the site invited exploration on foot or bicycle. ${ }^{71}$ The area in front of tents provided the perfect space to learn more about new friends or get caught up with old ones, to share stories about one's canoeing exploits, and to compare recent innovations

\footnotetext{
${ }^{68}$ It was illegal in some parts of the US because of its association with gambling, yet was also promoted by American president, Theodore Roosevelt. Elliot J. Gorn, The Manly Art: Bare-Knuckle Prize Figbting in America (Ithaca: Cornell University Press, 1986); Ryan A. Swanson, "I Never Was a Champion at Anything': Theodore Roosevelt's Complex and Contradictory Record as America's 'Sports President'," Journal of Sport History 38, no. 3 (Fall 2011): 425-446. In the Canadian context, see Kevin B. Wamsley and David Whitson, "Celebrating Violent Masculinities: The Boxing Death of Luther McCarty," Journal of Sport Hutory 25, no. 3 (1998): 420-1.

69 "Canoeists Win at Baseball," New York Times, 15 August 1895.

${ }^{70}$ The Milwaukee Journal, 21 August 1897.

71 "The ACA Meet of 1890: Jessup's Neck," Forest and Stream, 21 August 1890; "Annual Canoe Meet," New' York Times, 4 August 1895; NYSHA, 1.5/4, "Bluff Point, Lake Champlain, NY," 1895; NYSHA, 1.6/19, "Paddling Among the Thousand Islands: Whiling Away the Days at Sugar Island," 1904.
} 
in boating technologies. ${ }^{72}$ On some occasions, the musical instruments that the campers were encouraged to bring for the evening campfires were pulled out and the time was passed singing songs or listening to music. ${ }^{73}$ The headquarters, which functioned as the centre of camp, was also a popular destination when one had little else to do, for a canoeist could always be sure to find a person or people with whom to engage. ${ }^{74}$

During the day, the canoeists spread to the four corners of the encampment and beyond. When night fell, they could usually be found in one place: around the campfire. As Pauline Johnson remarked, "As the last atom of the sun's circle vanishes the sunset gun is heard at headquarters, and you turn to gaze on the myriad tents gathered at your feet, already a blaze of camp-fires here and there. ${ }^{\prime \prime 5} \mathrm{ACA}$ campfires ranged from informal gatherings of friends and acquaintances to formally organized events overseen by the Association and boasting a few hundred guests. ${ }^{76}$ The majority, however, were relatively simple affairs that saw the campers gather together to sing songs and tell stories. ${ }^{77}$ Where possible, the music was enlivened by instruments that had been carried from home to camp. In 1894, for example, the canoeists were backed up by a "old rusty banjo, with no head" and a "three legged piano, that goes out of tune

${ }^{72}$ NYSHA, 1.2/23, “An Afternoon at Squaw Camp," 1894.

${ }^{73}$ NYSHA, 1.1/26, "Camp of the Springfield Canoe Club," 1887; 1.2/6, "A Little Music At the Mohican Camp," 1890; 1.2/18, "Mohican Club," 1891; 1.5/4, "Camp Group Croton Point," 1894.

${ }^{74}$ NYSHA, 1.2/23, "A Meeting at Camp Headquarters Tent," 1894.

${ }^{75}$ McMaster University Archives (MUA), E. Pauline Johnson Collection, Box 3, File 1-5, Pauline Johnson, "The American Canoe Association at Grindstone Island," The Rudder (December 1896): 355-8.

${ }^{76}$ Reports of large campfires are included in "Canoeists Break Camp," New York Sun, 16 August 1884;

"The ACA Meet, Lake George," Forest and Stream, 23 August 1888; "The Canoe Meet," The Troy Nortbern Budget, 16 August 1891 .

${ }^{77}$ Every year a handful of more formal and elaborate campfires featuring different kinds of performers were announced on the camp bulletin board. At the 1891 meet, for example, a fireside performance was organized by the Committee on Entertainments, for which a stage fitted with lanterns for footlights and the Mohican war canoe sail for a curtain was erected "in a grove with noble trees." There in the light of the Chinese lanterns that were strung from the trees and a large bonfire, the audience watched a series of tableaux directed by Lafeyette Seavey. They were also treated to musical numbers by a band of cellos, violins, guitars and mandolins, and also by a guitar and cello duet. The performance was closed with a "touching solo from Mrs. C.V. Schulyer." "Fun for the Canoeists," New York Times, 21 August 1891. 
in the upper notes. ${ }^{78}$ The Association developed a repertoire of songs over the years that came to be associated with encampment life; these drew heavily on the folk melodies of African Americans and French Canadians. ${ }^{79}$ "Alouette" and "En Roulant" were crowd favourites at the 1884 meet on Grindstone Island. ${ }^{80}$ Likewise, the 1890 meet at Jessup's Neck would "long be remembered for its famous 'Coon Band' of three darkies with their 'Watermelon Growing on the Vine."'81

In addition to familiar sounds, campfires usually meant familiar smells, namely pipe smoke and wood smoke. ${ }^{82}$ With respect to the latter, such smells were rooted in place, a reflection of the species of trees indigenous to a particular locale. For example, in 1890 , reports of the meet commented on the pleasant odour of the "beech cedar roots," a testament to the campsite seaside ecosystem. ${ }^{83}$ On the St. Lawrence River, the smell of pine stumps or logs burning were more likely, while Lake Champlain recalled hemlock bows. ${ }^{84}$

For the most part, the campfire programs featured amateur talent from within the ranks. The exception was Pauline Johnson, who, by the mid-1890s, was a well-

\footnotetext{
78 "Our Trip to the A.C.A. Meet of '93," The Rockwood Review 1, no. 6 (1894): n.p. A number of the camp circulars encouraged visitors to the encampment to bring musical instruments with them. MSCRC, Box 23, Folder 2, Camp Circular for Sugar Island, 1907.

${ }^{79}$ Ian MacKay's work on tourism in Nova Scotia in the early twentieth century highlights the appeal of folk music to tourists and anthropologists. See, in particular, "Chapter Two: Helen Creighton and the Rise of Folklore," in Ian McKay, The Quest of the Folk: Antimodernism and Cultural Selection in TwentietbCentury Nova Scotia (Montreal: McGill-Queen's University Press, 1994), 43-151.

80 "The Association Meet," Forest and Stream, 21 August 1884; "Canoeists Break Camp," New York Sun, 16 August 1884. See, also, NYSHA, 1.6/21, "A Reminiscence of Grindstone Island, 1884."

81 "Fun for the Canoeists," New York Times, 22 August 1890; "Tents All Pitched," New' York World, 7 August 1892; Forest and Stream, 1 September 1892. For many years after the 1890 meet, "Watermelon Growing on the Vine," or "Watermellin' Growin' on da Vine" as it was more commonly known, was a campfire favourite. The songs appear in a Camp Fire Song book produced in 1909. See, NYSHA, 1.6/21. The drawing that accompanies "Oh! That Chicken Pie," features four "coons" paddling a canoe. 82 "The Canoe Island Camp," New' York Times, 13 August 1881; "The Meet of 1886," Forest and Stream, 26 August 1886.

83 "The Canoe Men in Camp," New' York Times, 17 August 1890.

${ }^{84}$ D'Arcy Scott, "The Annual Camp of the American Canoe Association," Mavsey's Magazine 2, no. 2 (1896): 118; Florence Watters Snedeker, A Family Canoe Trip (New York: Harper and Brothers, 1892), 112.
} 
established performer in Canadian, American, and British circles. ${ }^{85}$ At the 1893 meet, Johnson recited some of her poetry during the Cataraqui Canoe Club's campfire, which also featured a club orchestra, songs, and camp calls. Johnson, true to form, appeared in front of the audience in "the ornamental garb of a Mohawk maiden." There, amidst the red lights, she "tossed back her long black hair, clinched her hands, and recited her own poem, wherein an Indian wife bids her warrior husband go to war with the whites." According to the New York Times, the effect "was all very stirring and tragic, and the gentle American girls shivered with something more than the chill of the night air. ${ }^{186}$ In addition to her skills as a poet and performer, the audience embraced Johnson's delivery of such lines at a campfire in part because of the cultural associations between "Indians" and campfires. ${ }^{87}$ Campfires were important for more pedestrian reasons as well, namely they brought together the various groups of canoeists. They also provided a space to express "ideas and anxieties that are less easily spoken of in everyday conversation." In this way, campfires served as important sites for the materialization of community, a belief that was at the heart of Ernest Thompson Seton's contemporaneous Woodcraft Movement. ${ }^{88}$

With the appropriate invitations and chaperones, campfires could and did accommodate both men and women. Mixed-sex audiences appear to have been more common for formal campfires, while impromptu affairs tended to be homosocial spaces. The campfire of the Deowainsta Club at the 1896 meet on Grindstone, for

\footnotetext{
${ }^{85}$ Veronica Strong-Boag and Carole Gerson, Padding Her Ow'n Canoe: The Times and Text' of E. Pauline Jobnson (Tekabionwake) (Toronto: University of Toronto, 2000).

86 "Around the Pine Camp Fire," New York Times, 20 August 1893.

${ }^{87}$ Pauline Turner Strong, "Cultural Appropriations and the Crafting of Racialized Selves in American Youth Organizations: Towards an Ethnographic Approach," Cultural Studies-Critical Methodologied 9. no. 2 (2009): 208.

${ }^{88}$ Hallie Bond, Joan Jacobs Brumberg, and Leslie Paris, "A Paradise for Boys and Girlo": Cbildren's Camps in the Adirondacko (Syracuse: Syracuse University Press, 2006), 48.
} 
instance, was explicitly a "Stag function, with songs by the Rome quartet in addition to the usual entertainment. ${ }^{\text {899 }}$ However, occasionally, more formal campfires were declared to be for men only, as in the case of the 1890 Mohican Club campfire, which S.R. Stoddard captured in a flash-enabled photograph.$^{90}$ Similarly, the following year, the Eastern Division hosted a "pipe and beer night" in the main camp. ${ }^{91}$ The decision to host male-only campfires is further evidence of the gendered tensions that characterized encampment life.

More universally mixed-sex venues were dances. ${ }^{92}$ In some cases, the campers were invited out to dances at other locations. For example, at the 1888 meet, a hop was hosted by the nearby Horicon Lodge. ${ }^{93}$ In 1901, the campers "return[ed] to civilization for a brief time" to attend a masked ball at the "fashionable" Gananoque Inn. ${ }^{94}$ Other years, the canoeists organized dances themselves. These were one of the few occasions when the canoeists shed their camp togs for more formal clothing. The Times reporter said of the 1890 hop that the "girls wore their freshest gowns," while "the men were immaculate in white flannels." ${ }^{\prime 95}$ Typically, the ACA dances were held in the mess tent/shed. Decorations, such as club flags, bunting, and Japanese lanterns transformed

\footnotetext{
89 "At the Canoe Camp," New York Sun, 25 August 1896.

90 "The ACA Meet of 1890-III," Forest and Stream, 13 August 1890.

91 "The ACA Meet of 1891: Race Week," Forest and Stream, 27 August 1891.

${ }^{92}$ Dances were events that were held because there were men and women present. They were not part of the early encampments, which as I have noted elsewhere were largely homosocial spaces. That said, the canoemen may have attended dances at local hotels during the early meets on Lake George. 93 "The ACA Meet, Lake George," Forest and Stream, 23 August 1888. Another account of this meet claims that the hops organized each night drew canoeists away from the camp and "lessened the number who took part in the ordinary evening amusements and informal camp-fires that make every night in camp so pleasant." "The ACA Meet of 1888: The Camp and the Association," Forest and Siream, 6 September 1888.

94 "Purchase Sugar Island," Rochester Democrat Chronicle, 16 August 1901; "Canoeists Ready to Race," New York Times, 18 August 1901.

95 "Fun for the Canoeists," New York Timet, 22 August 1890.
} 
the otherwise quotidian dining hall into a space for dancing. ${ }^{96}$ Despite such efforts, the mess tent would never be a proper dance hall. According to the New York Times, dancers at the 1890 meet "gyrating around in fine style one moment would catch the soles of their shoes against a swaying board a member later and dance the next few steps on their knees or necks, while the spectators would laugh unfeelingly." Also noticeable, and remarked upon by the Times reporter, was the rather unfortunate gender disparity amongst the dancers. However distant the encampments were from formal society, it remained unthinkable that men would dance with men. ${ }^{98}$ Typically, local talent serenaded these events. ${ }^{99}$ The 1892 meet had a "genuine country breakdown," featuring local fiddlers, ${ }^{100}$ while an "orchestra of five pieces" from nearby Plattsburgh provided the music for a dance given at the 1895 meet at Bluff Point. ${ }^{101}$ It was not just musicians who came from off-site, but dancers as well. ${ }^{102}$ At the 1887 meet, "the camps and cottages on the neighboring islands [were] called on to supply partners for the canoeists, and they did." 103

As the campfire's flames weakened or the musicians played their final notes, the expectation was that the campers would drift off to their tents. In case they forgot, the

\footnotetext{
96 "Like a Serpent of Fire," New York World, 26 August 1887; "Fun for the Canoeists," New York Timed, 22 August 1890.

97 "Fun for the Canoeists," New York Times, 22 August 1890.

${ }^{98}$ Miners in California and British Columbia, however, were known to do just that. See, Susan Lee Johnson, "Bulls, Bears, and Dancing Boys: Race, Gender, and Leisure in the California Gold Rush," Radical History Review 60 (1994): 25-6; Adele Perry, On the Edge of Empire: Gender, Race, and the Making of Brititb Columbia (Toronto: University of Toronto Press, 2001), 29-30.

${ }^{99}$ At the 1891 meet at Willsborough Point, music for the "impromptu dance" held on the Saturday night was "furnished by the Yonkers men and other canoemen." "The ACA Meet of 1891," Forest and Stream, 20 August 1891.

100 "Sunday at the Canoe Camp," New' York Timet, 8 August 1892.

101 "Dancing at the Camp," New' York Times, 19 August 1895.

102 "Canoeing," New York Sun, 11 August 1899.

103 "Like a Serpent of Fire," New' York World, 26 August 1887.
} 
camp bugler offered one final reminder that the day was done. ${ }^{104}$ Nevertheless, some remained around the campfire, and if accounts are trustworthy, the vast majority of these were men. Forest and Stream claimed it common, for instance, "After the circle [of the campfire] has broken up and the ladies departed... an extra bottle is emptied into the pail of punch on the embers...the songs decrease in melody as they gain in force of expression, and...those stupid tiresome and shameless old reprobates, the camp chestnuts...come out for an annual airing in the darkness." 105 The cover of darkness encouraged behaviour few would categorize as respectable including the consumption of alcohol, which I discussed in some depth in Chapter Four, and the boxing mentioned above. Also popular at nighttime were pranks. ${ }^{106}$ In 1885 , for example, a canoeist returned to his tent to discover "that in his absence his comrades had chased and captured a young calf, which was snugly ensconced in his bed." ${ }^{\prime 107}$ In 1890 , the "night owls," a group of pranksters made their rounds of the main camp, turning over the beds of unsuspecting sleepers. ${ }^{108}$ The "night owls" reappeared at the Brophy's Point meet, where their efforts to play "God Save the Queen" on the whistle of the camp steamer succeeded in keeping their fellow campers from slumber. ${ }^{109}$

Not everyone found such antics amusing. In 1888, a special meeting of the

\footnotetext{
${ }^{104}$ Prior to 1889 , lights out was at ten o'clock. A letter from a former commodore read at the 1888 meeting of the Executive Committee that this too early out was unreasonable. R.W. Gibson suggested moving taps (the signal for bedtime in camp) to a later hour. MSCRC, Collection 291, Volume 3, Meeting of the Executive Committee, 17 November 1888.

105 "The ACA Meet of 1890-III," Forest and Stream, 13 August 1890.

106 The New York Evening Post remarked in 1887, "The practical jokes that the fellows worked on each other were simply countless, and it is safe to say that no set of Sophomores could have begun to keep up with them." "The Annual Canoe Meet," New' York Evening Pout, 27 August 1887.

107 "The Association Meet," Forest and Stream, 6 August 1885.

108 "Noyac Bay is Deserted," New' York Times, 24 August 1890.

${ }^{109}$ Goodsell, A Canoeing Reminiscence, 6. According to Ronald Hoffman, a second band of "high-spirited" canoeists was formed for similar effect following the move to Sugar Island. Known as the "Foggy Dews," the "group was responsible for much of the mischief and tricks that occurred during the early camps." Ronald Hoffman, "The History of the American Canoe Association, 1880-1960" (Ph.D. Dissertation: Springfield College, 1967), 123.
} 
Executive Committee was called to address complaints made against the

Knickerbocker Canoe Club. Although the content of the complaint is not shared, a resolution about "regarding the hours for quiet" was adopted by the Committee and communicated to the offending club. ${ }^{110}$ In order to ensure that the broader community got the message, the committee posted a similar instructional on the bulletin board, an effort at time-discipline that had mixed-results at best. The issue of misbehaving reiterates one of the central arguments of Chapter Five: the encampments were contested spaces, in which the officials' efforts at ordering were not infrequently challenged by the behaviour of the broader membership.

Sundays were quiet days around camp. ${ }^{111}$ In the morning, the space of the mess tent or the area around the headquarters was transformed from a secular space into a sacred place. Although there were only ever two Sundays during the annual encampments, Divine Services were an important part of the yearly ritual of the encampment. ${ }^{112}$ Those years from which reports of the sermons remain suggest that the minister took the opportunity to wax eloquent on the "spiritual" importance of the encampments, broadly defined. The ministers at the 1883 meets, for instance, spoke about the sense of brotherhood that the organization fostered between people of different national backgrounds, as well as the importance of leisure time to an

${ }^{110}$ MSCRC, Collection 291, Volume 3, Special Meeting of the Executive Committee, 15 August 1888.

111 "Some fifty to a hundred canvas tents were erected here and there under the trees, and it being Sunday, nearly all the boys were home." "Holidaying in the West," Quebec Saturday Budget, 7 August 1897.

${ }^{112}$ For example, see "ACA Annual Meeting," Peterborougb Daily Review, 21 August 1883; "Sunday at the Canoe Camp," New York Times, 8 August 1892; NYSHA, 1.1/29, "Divine Service," 1887; 1.2/21, Henry D. Marsh, "Divine Service in Camp," 1891; 1.5/5, Walwin Barr, "Divine Service, Sugar Island," 1907 and 1910. 
individual's health and well-being in the modern age. ${ }^{113}$ For some visitors, the opportunity to worship in the out-of-doors was particularly attractive. Flip, for example, commented on the "services under a big oak tree, with a glorious view of the lake framed by braches of the trees, like a great stained glass window...It was a noble church, this one of ours, without four walls to hedge one's mind in." 114 As I noted in Chapter Five, the services were likely, at least in part, displays of Protestant respectability. They were also, as Flip's comments suggest, deeply meaningful for those with spiritual convictions. However, I also think we can understand the divine service as yet another component of domesticating the encampment space through the reproduction of the spaces and structures of home, and thus, further evidence of the slipperiness of speaking of this travel as "being away."115

\section{Encampment Intimacies}

In Chapter Five, I spoke about the Association's efforts to regulate heterosocial encounters at the annual meetings by organizing the space of the encampment and the schedule in particular ways. Camp officials imposed restrictions on the movements of single men and women, they were housed in separate spaces, and women were frequently accompanied by chaperones. There were, however, contradictory messages in circulation, both in periodical accounts of the meets and in official documents. An Ottawa Citizen article from 1883 listed the "paddling tete-a-tete of the 'merry, merry maiden and the tar"' as one of the "sources of delight...offered and enjoyed" at the

113 "ACA Annual Meeting," Peterborough Daily Review. 13 August 1883; "ACA Annual Meetings," Peterborougb Daily Review', 21 August 1883. In the latter case, the content of their messages represented a sea change from the negative relationship that existed between recreation and religion in the AngloAmerican world earlier in the nineteenth century. Dominic Erdozain, The Problem of Pleasure: Sport, Recreation, and the Criwit of Victorian Religion (Woodbridge: Boydell Press, 2010).

114 "The Lake Champlain Canoe Meet," Outing 11, no. 3 (1887): 264.

${ }^{115}$ The other event which performed a similar function was Commodore Dunnell's tea party.

Photographs of this event appear in NYSHA, 1.2/28, "Commodore Dunnell's Tea," 1898. 
annual meeting, the use of tete-a-tete alluding to the intimacy of the practice. ${ }^{16}$

Similarly, two descriptions of Juniper Island circulated by the organizing committee in advance of the 1883 meet suggest that the site was suited for more than just racing or cruising. The first painted Juniper Island as "a cbarming spot...with a broken and indented coast line forming delightful little coves and nooks" with "smooth water" perfect for a canoe at rest, while the second claimed that "there are so many channels, sudden turns, and secluded nooks [around the island], that weeks may be spent in exploring them without monotony."117 Such language produced a rudimentary geography of intimacy, which was then enriched by the practices of individual canoeists. That campers themselves conceived of the encampments in this way is suggested in Paul Vernon's memoir: "Naturally with a Squaw Camp full of girls and a number of men with more or less leisure on their hands, opportunities of meeting frequently and the poetic charm of a canoe on a moonlight night, romance there was." 118

There was also the influence of the wider symbolic and practical associations between courtship and the canoe in the Victorian era. The Adirondack Museum in Blue Mountain Lake, New York has an extensive collection of boating-related sheet music that includes songs such as "We'll Paddle Our Own Canoe," "Love's Canoe," and "Out in Your Canoe." Even songs without references to boating have canoes on the covers. "Neath The Mellow Midnight Moon," for example, features a man paddling from the stern of a canoe, while a woman holding a Japanese lantern sits in

\footnotetext{
116 "American Canoe Association," Ottawa Citizen, 18 August 1883.

117 Robert Tyson, "Laying Out the Course on Stony Lake," American Canoeist 2, no. 5 (1883): 67; "The Meet," American Canoeit 2, no. 7 (1883): 79. Emphasis added.

${ }^{118}$ Vernon, Tales of the $A C A$. There also appears to be a common sense association between the encampments and romance, evident in the accounts of the meet. For example, The Day described Squaw Point as the place where the "wives, sisters and sweethearts of the canoeists" gather. "Canoeists of America Meet," The Day, 8 August 1898.
} 
the middle of the boat. On the cover for "Give Me A Night in June" seen in Figure 7.1, the canoeists sit in close proximity to one another in their red canoe as the moonlight plays on the water. ${ }^{119}$

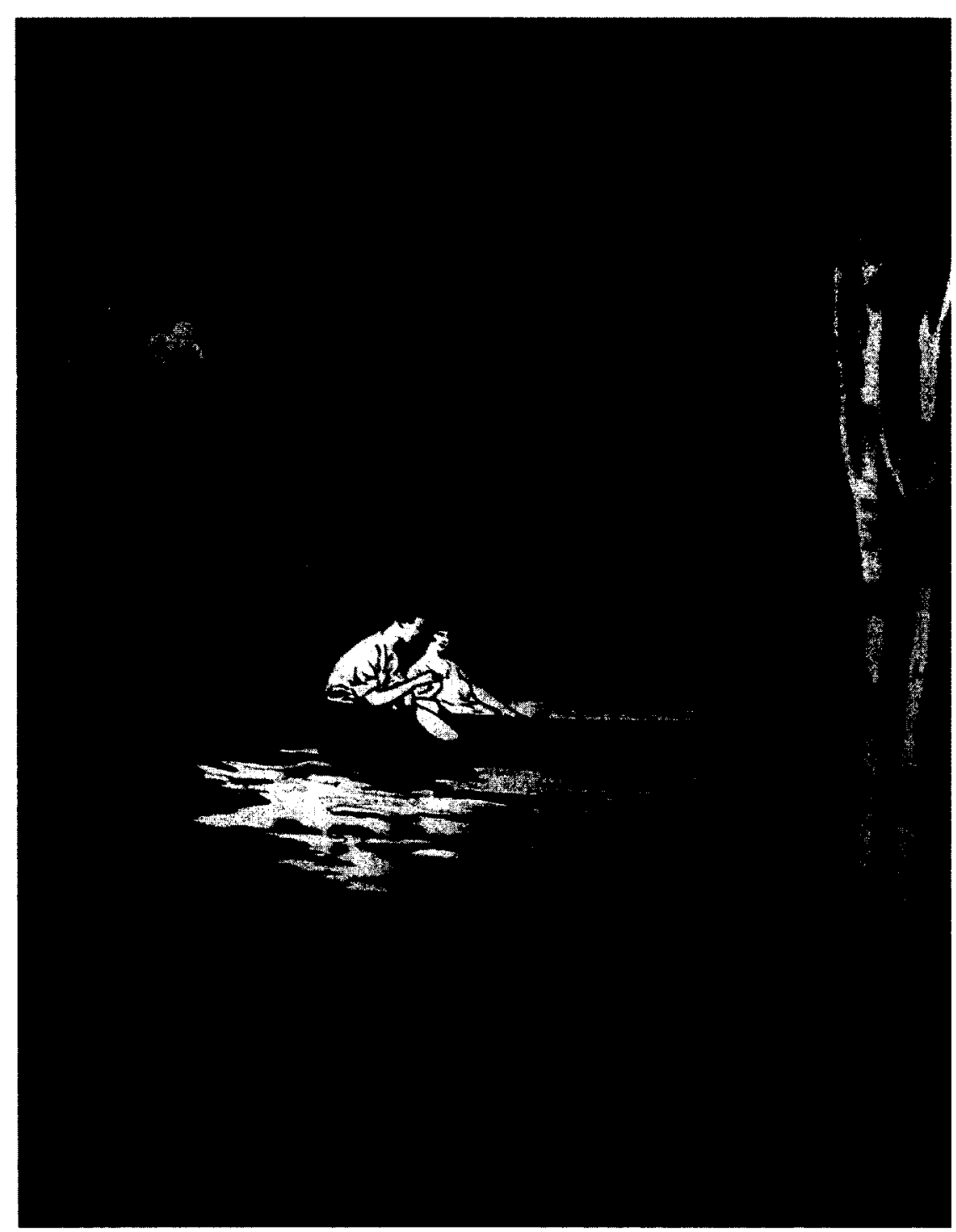

Figure 7.1 - Cover for Cliff Friend, Give Me a Night in June (New York: Jerome H. Remick \& Co., c. 1927). [Source: Adirondack Museum, Sheet Music Collection, Drawer XII, Folder A5.]

Despite the popularity of canoeing motifs, there were parallel anxieties about canoeing and heterosocial leisure, which ironically reinforced links between the craft

${ }^{119}$ Adirondack Museum (AM), Sheet Music Collection, Drawer XII, Folder A5, Cliff Friend, Give Me a Night in June (New York: Jermoe H. Remick \& Co., c. 1927). Although this is from a later period, the museum has boating-related sheet music dating between 1862 and 1949. 
and romance. These reached a high point in Boston in the first decade of the twentieth century, when the Metropolitan Park Commission "prohibited love-making" in canoes on the Charles River. ${ }^{120}$ Both kissing and "reclining side by side" were deemed "obscene or indecent act[s]" worthy of a twenty-dollar fine. ${ }^{121}$ That canoeists rebelled by holding "canoe-ins," in which they lay under blankets in the bottoms of their canoes, suggests the degree to which the canoe was a contested site of heterosocial leisure in this period..$^{122}$

In spite of the ACA's regulations and perhaps inspired in part by popular culture, men and women found ways to spend time together at the encampments. In some cases, they took advantage of ACA sanctioned events like campfires. D.J. Howell, for instance, observed of the 1900 meet, "The uncertain light and the glamour of the night give opportunities for the growth of friendship that the most timid do not neglect." ${ }^{123}$ Howell's account also suggests it was a matter of timing: "The last days in camp are often the most pleasant. The crowd thins out and friendships formed have a chance to deepen." ${ }^{\prime 24}$ In other cases, couples found alternative spaces to meet. At the 1890 meet, for example, the long camp wharf became "quite a fashionable promenade in the evening, being neutral ground between the forbidden precincts of Squaw Point and the main camp." ${ }^{25}$ Canoes were also common sites for heterosocial sociability at the encampments. ${ }^{126}$ Reports of the 1894 meet claim that D'Arcy Scott "gallantly

\footnotetext{
120 "'Canoodling' and Kissing," Hawera and Normanby Star, 14 October 1903.

121 "Penalty for Kissing," Bruce Herald, 26 January 1904.

${ }^{122}$ Thomas A. McMullin, "Revolt at Riverside: Victorian Virtue and the Charles River Canoeing Controversy, 1903-1905," New England Quarterly 73, no. 3 (2000): 482-94.

${ }^{123}$ D.J. Howell, "The International Canoe Meet," The Canadian Magazine 15, no. 6 (1900): 516.

${ }^{124}$ Howell, "The International Canoe Meet," 520.

125 "The ACA Meet of 1890: Jessup's Neck," Forest and Stream, 21 August 1890.

${ }^{126}$ NYSHA, 1.2/3, "View from Squaw Camp," 1889.
} 
[gave] nearly all the young ladies in camp a paddle on the river in his Indian craft."127 Flip's account of the 1887 meet suggests women pursued such encounters, in some cases under the cover of darkness. She describes "the paddle back to [her] own home from the big fire in one of the most comfortable canoes at the camp handled by its owner," as being a particularly pleasurable time, and a reason to attend campfires outside of Squaw Point. ${ }^{128}$ Thus, while much emphasis was placed on keeping men and women apart except under the watchful eye of chaperones, there were clearly opportunities for individuals to avoid the prying eyes of others.

There is evidence of at least a handful of relationships blossoming at the ACA meets. In 1900, the New York Tribune reported the engagement of Miss Clara Britton of Kingston, Ontario, and Louis H. May of New York City, claiming that the two had met "through a fondness in common for outdoor life in the camp of the American Canoe Association in the Thousand Islands." ${ }^{29}$ Clara's sister Mary Alice had married a prominent canoeist, C. Valentine Schuyler, only a few years earlier. ${ }^{130}$ Also married in 1894 were William J. Stewart and Miss Gertrude Fredericks, both residents of Newark, New Jersey, and members of the Ianthe Canoe Club. The New York Sun

\footnotetext{
127 "Pleasures of the Canoe Camp," New York Times, 22 July 1894.

${ }^{128}$ Flip, "The Lake Champlain Canoe Meet," Outing 11, no. 3 (1887): 264. There were other instances of paddling under the cover of darkness. At the 1883 meet, for instance, the first night of the regatta was either passed "around the campfire with songs and yarns of various cruises," or "paddling about the lake by moonlight," in canoes "carrying Chinese lanterns." "The Association Races at Stony Lake," Forest and Stream, 6 September 1883.

129 "Brooklyn's Social World," New York Tribune, 20 May 1900.

${ }^{130}$ Eva L. Moffat, The Ancestors of Daniel Freeman Britton of Westmoreland and Gananoque, 1808-1807 (n.p., 1953), 128; "Canoes and Canoeing," New' York Sun, 11 June 1894. They had attended the 1893 encampment together. According to the $N_{e w}$ York Sun. Schuyler was the first to have his tent pitched at the 1894 meet. "The First Tent at the Canoe Camp," New York Sun, 10 July 1894. It's not clear whether or not Mary Alice attended with him. This was Schuyler's second marriage. He had attended the 1890 and 1891 meets with his first wife; she died 30 June 1892 of consumption. Forest and Stream, 7 July
} 1892. 
reported that the two had attended ACA encampments "for a number of years."131

Finally, Walwin Barr and Gertrude Gard attended at least three meets together prior to their wedding in $1909 .^{132}$

What of homosocial or homosexual encounters? ${ }^{133}$ None of the sources address the subject explicitly, although a few are suggestive including Paul Vernon's memoirs. In his account of the 1893 meet, Vernon refers to a "red headed, blue eyed Irishman" named Sparrow, "who was a plumber." 134 When another canoeist inquired about Sparrow, Vernon mused, "Thus I suppose desiring to reflect on the ancient and honorable vocation of wiping joints and going back for more tools, but little did the Brooklyn Club care and Sparrow[']s wit whether from pipes or fittings, was always welcome." Vernon's account could refer to occupation and class differences, although elsewhere the author claims that Sparrow died a few years later and "left a million dollars," suggesting the Toronto-based canoeist was not an actual plumber. Moreover, Vernon related the following request from Sparrow, which suggests he had something to hide: "Now when you meet the Misses, if she asks, have you been to Toronto, say you have. For last winter, I was out on a glorious party until real late in the morning

\footnotetext{
131 "Canoes and Canoeing," New' York Sun, 11 June 1894. The newlyweds were in attendance for that year's meet.

${ }_{132}$ See, "ACA Weddings," Forest and Stream, 26 June 1909. Gard and Barr were both present at the 1905, 1906, and 1907 meets. It is not clear whether or not they met through the ACA. However, images from Barr's personal album suggest a developing relationship between the young couple over the course of their presence at the Sugar Island encampments. NYSHA, 1.5/6, Scrapbook of Walwin Barr.

${ }^{133}$ Historians have amply discussed the problems with defining sexuality. See, David M. Halperin, "Sex before Sexuality: Pederasty, Politics, and Power in Classical Athens," in Hidden from Hiwtory: Reclaiming the Gay and Lesbian Past, eds. Martin Baumi Duberman, Martha Vicinus, and George Chauncy, Jr. (New York: NAL Books, 1989), 37-53; Leila J. Rupp, "Toward a Global History of Same-Sexuality," Journal of the History of Sexuality 10, no. 2 (2001): 287-302. Michel Foucault defines sexuality as that "great surface network in which the stimulation of bodies, the intensification of pleasures, the incitement to discourse, the formation of special knowledges, the strengthening of controls and resistances, are linked to one another, in accordance with a few major strategies of knowledge and power." Michel Foucault, The History of Sexuality, Volume 1: An Intraduction, trans. Robert Hurley (New York: Random House, 1978), 105-6.

${ }^{134}$ Vernon, Tales of the $A C A$.
} 
and when I was taken to task, I told her you were in town and I had been out with you." Here again, there are multiple possibilities for interpretation. However, taken together and given the tenor of Vernon account, which seems devoted to highlighting the "underbelly" of the encampments, there is a distinct possibility that he was referring to Sparrow's non-normative sexual practices. Even if this is not the case, we must, at the very least, entertain the possibility that the ACA encampments were spaces for heterosexual and homosexual encounters. Certainly, the encampments were, to a certain degree, homosocial spaces and work in the field of gay and lesbian history has shown that same-sex institutions such as boarding schools, prisons, and the navy were important in "fostering same-gender sexual networks." ${ }^{135}$ Moreover, as an encampment that ran for fourteen days and nights, there was presumably ample opportunity for canoeists to engage in "illicit" activities.

As the canoeists went about their daily routines, their movements produced particular activity spaces and connected disparate parts of the camp landscape, giving shape to the encampment as place. Their perambulations through the campsite also brought them into contact with different people, which materialized the community of canoeists. Inhabiting, in other words, was a physical practice, as well as a social one. As the example of sexuality makes clear, such movements were constrained by the specific expectations of organizers and broader notions of middle-class respectability. It was as they negotiated their own desires and social constraints that the campers constituted the community of canoeists and participated in the transformation of the raw material of the campsites into meaningful spaces, or places. Alongside these

\footnotetext{
${ }^{135}$ Steven Maynard, "Rough Work and Rugged Men: The Social Construction of Masculinity in Working-Class History," Labour/Le Travail 23 (1989): 168.
} 
everyday routines and practices of inhabiting were spectacles that, in addition to providing entertainment and excitement, played a complementary role in the processes of community formation and placemaking. It is to these events that we now turn.

\section{$\underline{\text { Part II - Spectacles }}$}

There were usually a handful of spectacular performances during the American Canoe Association encampments intended to educate and amuse the campers. These included "speeches, songs, minstrels, mock trials, exhibitions of strength and skill, the illuminated statue of Liberty, fireworks, camp-fire entertainments, etc." ${ }^{136}$ While at first glance these spectacles appear to be extraordinary events, as we shall see there was repetition from year-to-year. That a number of these spectacles took place in the mess tent, the very space in which the majority of campers ate on a daily basis, further underscores their quotidian nature. Occasionally, these spectacles provided an opportunity for the canoeists to present themselves to "outsiders." ${ }^{\text {"137 }}$ For the most part, however, both the performers and audience members were members of the ACA. ${ }^{138}$ Similarly, while the organizing committee took responsibility for some of these events, member canoeists were as likely to be in charge.

There are multiple ways in which we can interpret the meaning and significance of spectacles. Historians such as Simonetta Falasca-Zamponi, for example, have demonstrated how nation-states utilized spectacles as exhibitions of their power, but

\footnotetext{
${ }^{136}$ C. Bowyer Vaux, "The Canoeing of Today," Outing 16, no. 3 (1890): 215.

137 These were rarely local people, but rather other visitors to the area, such as guests at a nearby resort hotel.

${ }^{138}$ Accounts of the meets emphasize male members engagement by canoeists. However, at least five women performed in Seavey's 1892 tableaux vivants of $A v$ You Like It. Likewise, Thomas J. Hale's scrapbook shows women participating in performances at the Croton Point meet. NYSHA, 1.6/12, "Programme for As You Like It," 1892; "ACA Camp Entertainment Group," 1894.
} 
also to order their citizen-subjects. ${ }^{139}$ Adolf Hitler was particularly cognizant of the power of sport as national spectacle as is evidenced by the 1936 Berlin Olympics. ${ }^{140}$ Daniel Goldstein, in contrast, argues for spectacles as sites of possibility, which the underprivileged employ to contest their marginal place in society. ${ }^{141}$ Given the relative homogeneity of the participants, it is unlikely that these spectacles offered any real challenge to established social hierarchies. However, these were not merely shows of power on the part of the organizers. Rather, campers were active participants in the constitution of the events both as performers and as audience members. ${ }^{142}$ As we shall see, the spectacles served a practical purpose, bringing the canoeists together en masse and making the community visible to itself. Spectacles also provided opportunities for the canoeists to tell stories about themselves to themselves. Thus, they delineated the relationship of the organization and the encampment to the wider social world. Drawing on Don Handelman, I think of these public performances as "locations of community that convey participants into versions of social order in relatively coherent

\footnotetext{
${ }^{139}$ Simonetta Falasca-Zamponi, Fascist Spectacle: The Aestheticu of Power in Mustolini'd Italy (Berkeley: University of California Press, 1997).

${ }^{140}$ Arnd Kruger and William J. Murray, eds., The Nazi Olympicu: Sport, Politics, and Appeasement in the 1930. (Champaign: University of Illinois Press, 2003); Allen Guttmann, "Berlin, 1936: The Most Controversial Olympics," in National Identity and Global Sports Events: Culture, Politics, and Spectacle in the Olympics and Football World Cup, eds. Alan Tomlinson and Christopher Young (Albany: State University of New York Press, 2006), 65-82.

${ }^{141}$ Daniel M. Goldstein, The Spectacular City: Violence and Performance in Urban Bolivia (Durham: Duke University Press, 2004). Goldstein is largely concerned with vigilante lynchings, which he argues are ritual performances contesting the neoliberal state's failure to "protect its citizens from predators." Like the religious processions and fiestas that occur in the same localities, "lynching in Cochamba today can be conceptualized as a kind of spectacle, a visually arresting and attention-getting display by which the invisible and ignored make demands on a state that has shown itself unable or unwilling to provide order and scecurity to their communities." (3)

${ }_{142}$ Mera Flaumenhaft, in her book The Civic Spectacle, asks us to consider "what sort of community of citizen-spectators is formed by the looking together that they do in the theater." Mera Flaumenhaft, The Civic Spectacle: Evitayi on Drama and Community (London: Rowman and Littlefield Publishers, 1994), 1. The plays that are the subjects of Flaumenhaft's monograph were all revisions of well-known myths and histories. She argues that, "by reshaping a story held in common, each author reshapes the community for which he writes."
} 
ways... Their mandate is to engage in the ordering of ideas, people, and things." 143

Finally, the encampment spectacles sought to inscribe place, constituting the

encampment, amongst other things, as a space of order and whiteness.

\section{Performing Order: The Commodore's Review and Illuminated Parade}

The "Commodore's Review," or "Review of the Fleet," was typically held during the second week of the encampment in advance of the regatta. The Commodore organized all of the canoes in camp into divisions and then watched as they paraded in front of camp. ${ }^{144}$ At the 1883 meet, for example, the canoes formed into divisions and then passed by the main camp, where they "wheeled into line facing it. After three cheers for the A.C.A. and a general salute, they again advanced in divisions to the ladies' camp and saluted. The sailors then returned under sail, the others following under paddle, to the main camp, where they closed up to be photographed."145 Commentators frequently remarked on the beauty of the craft moving together across the water, often enhanced by sail adornments. ${ }^{146}$ While most of the participants in the review were men, "some of [the canoes were] 'manned' by ladies." ${ }^{47}$ For Flip, taking part in the 1887 Review was the moment when she "felt [her] self to be a real canoeist":

\footnotetext{
${ }^{143}$ Don Handelman, Modele and Mirrors: Towards an Antbropology of Public Event, (Cambridge: Cambridge University Press, 1989), 15-6.

144 The 1888 Review, for example, was to feature four divisions: tandem paddling canoes; single paddling canoes; cruising sailing canoes; and racing sailing canoes. MSCRC, Collection 291, Box 23, Folder 2 , Camp Circular for Lake George, 1888.

145 “A.C.A. Annual Meeting," Peterborougb Daily Review, 23 August 1883.

${ }^{146}$ At the 1884 meet, for example, visitors saw "New York with the red ball, Toronto a ring of the same color, Knickerbockers a red lozenge, Lake George a red star, Mohicans with a turtle and many others." The most elaborate at that meet were the Springfield canoes, one with "two cherubs painted in colors on the mainsail," another with "an imp swinging in a horseshoe," and still others with "snakes, mermaids and fishes" or "dyed red and yellow or painted fantastically." "The Association Meet," Forest and Stream, 21 August 1884. An example of sail adornments can be found in NYSHA, 1.2/25, H.C. Morse, "Rochester Canoe Club War Canoe 'Huff,'" 1897.

147 "The Association Meet," Forent and Stream, 6 August 1885.
} 
"I joined the fleet in my own little canoe, and paddled my little boat with the rest."148 For contemporary observers, the Review served a number of functions. First, it represented the fleet's "recognition...of the authority of its commodore," reinforcing the social hierarchies of the organization. ${ }^{149}$ Second, as a celebration of canoes and canoeing en masse, it was a visible reminder of the community of canoeists. ${ }^{150}$ Related to this, Flip's account suggests that the Review had the potential to temporarily dissolve gender difference amongst the canoeists, even as it buttressed differences based on boat type. ${ }^{151}$ In this way, these parades were akin to the "demonstrations of human coordination" such as marching drills that were so attractive to organizers and spectators alike at the Industrial Exhibitions as testaments to the "possibilities of order." ${ }^{152}$ Perhaps we might take this point further and suggest that the Review was also a performance of place. In the arrangement of the canoes, the flying of colours, the display of the captains' healthy bodies, and the order of the procession and its rituality, the Review was an observable, linear, and unambiguous display of the virtues of authority, order, discipline, and play that governed the encampments.

A variation on the Commodore's Review, the Illuminated Parade, took place some years at night, occasionally during the regatta, but not necessarily. ${ }^{153}$ The following is the account of the parade from the 1883 meet at Stony Lake:

\footnotetext{
${ }^{148}$ Flip, "Lake Champlain Canoe Meet," 264.

149 "Some More Snips from and Another Snap at the '89 Meet," Forest and Stream, 24 October 1889.

${ }^{150}$ The author of this Forest and Stream article opined that the parade brought "the canoes of the ACA together for once on a friendly footing." "Some More Snips from and Another Snap at the '89 Meet," Forest and Stream, 24 October 1889.

${ }^{151}$ Flip, "Lake Champlain Canoe Meet," 264.

${ }^{152}$ Keith Walden, Becoming Modern in Toronto: Tbe Industrial Exbibition and the Shaping of a Late Victorian Culture (Toronto: University of Toronto Press, 1997), 37.

${ }^{153}$ The illuminated parade also receives mention in: "Canoeists on the St. Lawrence," Utica Daily Prent, 12 August 1898; "Canoeists Enjoying Camp Life," New York Sun, 14 August 1901; "Canoeists in Camp," Syracuse Daily Journal, 9 August 1905.
} 
A magnificent procession of canoes, decorated and illuminated, was held in the evening. Sixty-five canoes, by actual count, illuminated with Chinese lanterns, fastened up on the masts and on ropes, strung the whole length of the boats, were marshaled at the ladies' camp, under the command of Commodore Edwards, and as they slowly made their way in single line up the lake, the sight was beautiful. On their arrival at the main camp, the command was given to pass completely around Otter Island in single file. The blending of colors, motion of the boats, and the reflection of the light from the waters, combined to give effect charming in the extreme. Having completed the circuit of Otter Island, the fleet was formed in a solid square, and proceeded back to the main camp. ${ }^{154}$

Two years later, Vaux remarked that the view from the water "was very fine, [with] strings of many colored lamps along the entire length of the camp," and the movement of the boats along the water from starboard to port creating the illusion of a "fiery snake against a sea of black." 155 The Illuminated Procession, like the Commodore's Review, was an entertaining spectacle and a celebration of order and discipline. In part, the appeal of the procession for the viewers was the canoeists' abilities to control their craft in spite of the challenge of darkness. However, the event was also popular because of the play of light and colour, which recalled transformations associated with the expanding culture of consumption in the late Victorian era. As William Leach's work so convincingly demonstrates, colour, glass, and light were the "arsenal" of the new merchandising strategies, the "visual vocabulary of desire in the late nineteenth century." ${ }^{\prime 156}$ They were not just reserved for store windows, but were also present in "matrix of...urban commercial institutions" that included the opera house, the

154 "What They Did at Stony Lake of An Evening," American Canoeist 2, no. 8 (1883): 125. A similar description can be found in Eckford, "Camp Grindstone," 499.

155 "The Association Meet," Forest and Stream, 6 August 1885. The canoe parade was not the only event to feature light. Also popular were fireworks displays, which featured "blue, red and white fires, rockets, magnesium wires, balloons and Roman candles." C. Bowyer Vaux, "The American Canoe Association, and Its Birthplace," Outing 12, no. 5 (1888): 419. An award was given to Townsend and Amory for the "finest fireworks display" at the 1888 regatta. George W. Hatton and C. Bowyer Vaux, eds., American Canoe Atrociation Yearbook (New York: Nautical Publishing Company, 1889), 15.

${ }^{156}$ William Leach, Land of Devire: Mercbants, Power, and the Rive of a New'American Culture (New York: Pantheon Books, 1993), 103. 
restaurant and hotel, and the amusement park. ${ }^{157}$ If the ACA is any indication, the appeal of light and colour also extended to backwoods encampments. In the

Illuminated Procession, we also see the cultural work performed by Japanese lanterns and described in Chapter Six.

\section{Performing Race: Minstrel Shows}

Minstrel shows were another enduring feature of the ACA meets, a reflection likely of the broader popularity of minstrelsy in the nineteenth century. ${ }^{158}$ For example, a group of Americans at the 1883 meet on Stony Lake "formed themselves into a minstrel troupe, which they named the 'Centipedes,' after the most conspicuous occupants of the camp."159 At the 1890 meet on Long Island, the erection of a stage and the rearrangement of the chairs transformed the circus tent that functioned as the dining hall into a theatre. In the glow of the canoe lanterns that served as footlights, costumed canoeists in blackface delivered jokes about the daily fare and the Pequot quartet charmed the audience with their musical stylings. ${ }^{160}$

Although the performers were members of the Association, they borrowed heavily from the form and content of mainstream minstrelsy. Like their urban

${ }^{157}$ William Leach, "Strategists of Display and the Production of Desire," in Consuming Vwions: Accumulation and Display of Goods in America, 1880-1920, ed. Simon J. Bronner (New York: W.W. Norton, 1989), 99-132.

${ }^{158}$ According to Mel Watkins, minstrelsy was, for more than half of the nineteenth century, "America's pre-eminent form of entertainment." It was particularly popular amongst white, urban Americans in the northern states. Mel Watkins, "Foreward," in Invide tbe Minstrel Mask: Readings in Nineteentb-Century Blackface Minstreloy, eds. Annemarie Bean, James Vernon Hatch, and Brooks Macnamara (Hanover: University Press of New England, 1996), ix; Alexander Saxton, The Rive and Fall of the White Republic: Class Politics and Mass Culture in Nineteenth-Century America (London: Verso, 2003), 165. Minstrel shows were also popular canoe club events in this period. The Toronto Canoe Club, for example, had its own Minstrel Troupe. "The Madison: Toronto Canoe Club Minstrels," The Toronto World, 25 April 1915. ${ }^{159}$ O.K. Chobee, "Echoes from Stony Lake," American Canoeiwt 2, no. 8 (1883): 115.

160 "Fun for the Canoeists," New' York Times, 22 August 1890; "The Minstrel Show" in Seneca Ray Stoddard, Glimpues of the ACA (Glen Falls, 1890). Minstrel shows also receive mention in "ACA Annual Meeting," Peterborougb Daily Revieu", 18 August 1883; "Ready for the Races," Syracuse Evening Herald, 23 August 1896. There are images of canoeists in blackface in Walwin Barr's album: NYSHA, 1.5/5. 
counterparts, the actors arranged themselves in the semi-circle formation introduced by the pioneering Virginia Minstrels. ${ }^{161}$ The ACA shows also boasted an interlocutor, "who was seated in the centre of the company and acted as the master of ceremony," and endmen, who, with "their seemingly endless store of riddles, puns, and one-liners," were known for their "raucous comedy." 162 Finally, the programmes for ACA minstrel shows, like arrangements for mainstream minstrel performances, moved between jokes, tableaux, music, stump speeches, and monologues. ${ }^{163}$

Robert C. Toll argues that the appeal of minstrelsy was that it was "immediate, unpretentious and direct." As "each act_-song, dance, joke, or skit —was a selfcontained performance," a minstrel show could be easily performed and adapted. ${ }^{164}$ Minstrel shows also served a social function, by providing opportunities for audiences facing profound social, economic, and cultural change in the late-nineteenth century a means for expressing "their deepest concerns, anxieties, and needs." However, such shows tended to focus on the "most superficial features and the most striking evidence of these changes," and to "express serious criticism without compelling the listener to take them seriously." ${ }^{165}$ Finally, minstrel shows provided seemingly authentic opportunities for northeastern whites to satisfy their curiosity about black Americans. In Chapter Nine, I explore in more detail what performing may have meant for African Americans at the ACA. However, the vast majority of those who participated in the ministrel show programs at the ACA meetings were white. For this group, minstrelsy offered an opportunity to play the racial other by donning face-paint,

${ }^{161}$ Robert C. Toll, Blacking Up: The Minstrel Show in America (New York: Oxford University Press, 1974), 30-31, 52 .

${ }^{162}$ Toll, Blacking Up, 53.

${ }^{163}$ Stump speech referenced in "ACA Annual Meeting," Peterborough Daily Review', 18 August 1883.

${ }^{164}$ Toll, Blacking Up, 34.

${ }^{165}$ Toll, Blacking Up, 161. 
dressing in "negro" clothing, and performing "blackness" in front of an audience.

Recall, however, that even as the canoeists were ostensibly transgressing the racial divide, they were doing so for an audience of friends, or at the very least familiars, much like children playing Indian at summer camp. ${ }^{166}$ The wharf and headquarters had assured this. Moreover, at any point the performers could remove the black face paint and other markers of racial inferiority.

Rather than destabilize racial hierarchies, then, such performances reinforced the racial privilege of the white performers and spectators and preserved the categories of racial difference. Indeed, the audience was entirely in on the act, understanding the "rules" of black-face and the carefully guarded liminality it provided to both those on and off stage. As Greg Dening has so forcefully demonstrated, it is in the relationships between performers and audiences that meanings get worked out and that storytelling makes it effects felt and known. ${ }^{167}$ For our purposes, then, we might argue that, besides providing familiar, well-known entertainment, these minstrel shows also affirmed campsites as white places.

\section{Seavey's Spectacles}

The most elaborate of the ACA spectacles were performed under the tutelage of Lafayette W. Seavey. ${ }^{168}$ Seavey was a New Yorker best known for his work in the

\footnotetext{
${ }^{166}$ Sharon Wall, "Totem Poles, Teepees, and Token Traditions: 'Playing Indian' at Ontario Summer Camps, 1920-1955," Canadian Historical Review 86, no. 3 (2005): 513-44.

${ }^{167}$ Greg Dening, Performances (Chicago: University of Chicago Press, 1996), 105.

${ }^{168} \mathrm{I}$ have found brief references to other spectacles, but as there is little detail of their contents, it is difficult to know how they fit into encampment life. For example, an 1896 article refers to the funeral of Julius Caesar performed by C. Bowyer Vaux at one of the early Grindstone meets. R.B. Burchard, "Back to Grindstone: The Canoe Camp," Outing 29, no. 2 (1896), 141. See also "Lunched on Top of Flagpole," New' York Tribune, 12 August 1905; "The Association Meet," Forest and Stream, 6 August 1885.
} 
photographic industry, and his involvement in the theatre world as a scene painter. ${ }^{169}$ Although never a formal member of the administration or organizing committee, ${ }^{170}$ after joining the ACA in 1884 , he quickly became the camp's unofficial dramatist and director of amusements. ${ }^{171}$ He also contributed, alongside S.R. Stoddard and George Warder, to the photographic archive of the encampment that is part of the ACA collection at Cooperstown. Those years when he was not in attendance at the meet, his absence was palpable. In 1896, R.B. Burchard opined, "the camp was lacking in the humorous and picturesque spectacular effects and impromptu side-shows of which Mr. Seavey was of old the chief promoter, and that gentleman's genial presence was missed by all who had been present at the earlier meets."172 Seavey appeared to have spared little expense in his spectacles, although it is unclear who funded the displays. For the tableaux of "As You Like It" at the 1892 gathering on Lake Champlain, not only was a small stage built in the grove, but also the "costumes and the little necessary scenery were sent from New York."173 Likewise, the second spectacle at the same meet involved the construction of a large structure measuring seventy feet long and twelve feet high that was later covered with a "painted canvas representing a fort." On

\footnotetext{
${ }^{169}$ Credited with "successfully introducing and making scenic background[s] an indispensable accompaniment to any well-equipped gallery," Seavey also produced painted backgrounds for the theatre. Robert Taft, Photograpby and the American Scene (New York: Dover, 1964), 352-3.

${ }^{170}$ Seavey was stranger to administration, however. He was the Commodore of the Knickerbocker Canoe Club in New York in 1890. "The Canoe Men in Camp," New York Times, 17 August 1890.

${ }^{171}$ From his first trip to an annual meeting in 1884, Seavey had some amusement to offer the canoeists, such as tableaux, campfire programs, balls, minstrel shows and the like. "Canoeists Break Camp," New York Sun, 16 August 1884; "The Canoe Men in Camp," New York Times, 17 August 1890; "New Mab is Flyer," New York Sun, 22 August 1896.

172 "Canoeing," Outing 29, no. 1 (1896): 84. See, also, "New Mab is Flyer," New' York Sun, 22 August 1896.

173 "The ACA Meet of 1892," Forest and Stream, 25 August 1892. A programme for the tableaux is included in NYSHA, 1.6/12.
} 
Thursday evening, Visitors' Day, the fort was lit up with a fireworks display that lasted half an hour. ${ }^{174}$

Four of Seavey's spectacles lingered long in ACA memory. The first took place at the showman's inaugural encampment on Grindstone Island. ${ }^{175}$ Following the last day of races, several hundred campers and visitors gathered on Nob Hill for the performance, which opened with recitations, songs, and instrumental music. The highlight of the show was the arrival of a "band of Indians" in a birchbark canoe. This group presented a series of performances, including "an Indian wedding, funeral, hunt, capture and scalping of a white man, burning a captive at the stake and the war dance." The evening concluded with the singing of "God Save the Queen," presumably a homage to the Canadian hosts. ${ }^{176}$ Whereas most of the evening's performers were canoeists, the account in the New York Sun suggests that the "Indians" were actually Native participants. ${ }^{177}$ Paige Raibmon's work on Aboriginal performances at the Chicago World's Fair in 1893 offers insight into the complex of meanings and misunderstandings that such events engendered. Whereas spectacles provided opportunities for Indigenous performers to contest their absence in contemporary society, and to reaffirm their cultural integrity, for white audiences, such performances routinely reinforced existing stereotypes about the "dying race," and confirmed Aboriginal culture "as a static relic of the past."178

\footnotetext{
174 "The ACA Meet of 1892," Forest and Stream, 25 August 1892.

${ }^{175}$ Burchard remarked that Seavey's "Indian spectacular performances" were "talked of at every camp for ten years." Burchard, "Back to Grindstone," 141.

176 "The Association Meet," Forest and Stream, 21 August 1884.

177 "Canoeists Break Camp," New' York Sun, 16 August 1884.

${ }^{178}$ Paige Raibmon, Authentic Indians: Episodes of Encounter from the Late-Nineteentb-Century Nortbwest Coaut (Durham: Duke University Press, 2005), 73. See, especially, "Chapter Three: Theatres of Contact: The Kwakwaka'wakw at the Fair," 50-73.
} 
The second Seavey spectacle took place at the 1889 meet on Stave Island. ${ }^{179}$ That year, the "large three-pole tent" the organizing committee hired to serve as the mess and visible from within in Figure 7.2 gave the dramatist the idea for a circus. ${ }^{180}$ In anticipation of the spectacle, a "ring was plowed in the sod under the tent, leveled off and 'sawdusted," and "rule benches were constructed around it for the spectators." The list of personalities that appeared in the ring was seemingly endless: "four clowns dressed in pajamas, and appropriately painted"; "Arabs"; "Indians, cowboys"; "Turks, wild men of Borneo, the hairy man, a bear and an elephant." ${ }^{\text {181 }}$ The performances were equally elaborate, featuring "bareback riding, tight-rope walking, gymnastics, contortion acts, bar performances, tumbling, turning, clown business, ringmaster, trick animals, heavy-weight lifting, barrel-turning, handsprings, somersaults, wild men and wild animals, a band, a big four-poled tent, sawdust ring, Deadwood coach, and all."182 The star of the show was "Mlle. Jabberwock" pictured in Figure 7.2, who "in true circus-rider costume, mosquito netting dress and all — barring a heavy mustache - rode a farm-horse, well tired out after a hard day's work." According to Sail and Paddle, the whole affair lasted more than two hours and "kept the large audience in fits of laughter." 183 The event was closed with "taking of a flash-light photograph of the interior of the big tent, audience, band, performers, and all" by S.R. Stoddard. ${ }^{184}$

\footnotetext{
${ }^{179}$ As one of the few locations on the campsite where a large crowd could gather and be protected from the elements somewhat, the mess tent often doubled as a performative space. There is some evidence to suggest that another circus was undertaken at the 1898 meet, which was also held on Stave Island. "At the Canoe Association Camp," New York Tribune, 9 August 1898.

${ }^{180}$ C. Bowyer Vaux, "The Canoeing of To-Day: Second Paper," Outing 16, no. 3 (1890): 215.

${ }^{181}$ Vaux, "Canoeing of To-Day," 216.

182 "The Tenth Annual Meet of the American Canoe Association," Sail and Paddle 7, no. 9 (1889): 200.

183 "The Tenth Annual Meet," 200.

${ }^{184}$ S.R. Stoddard, Glimpsest of the $A C A$ (Glens Falls, 1889). A handful of photographs of the circus can be found in NYSHA, 1.2/3 and 1.2/4.
} 


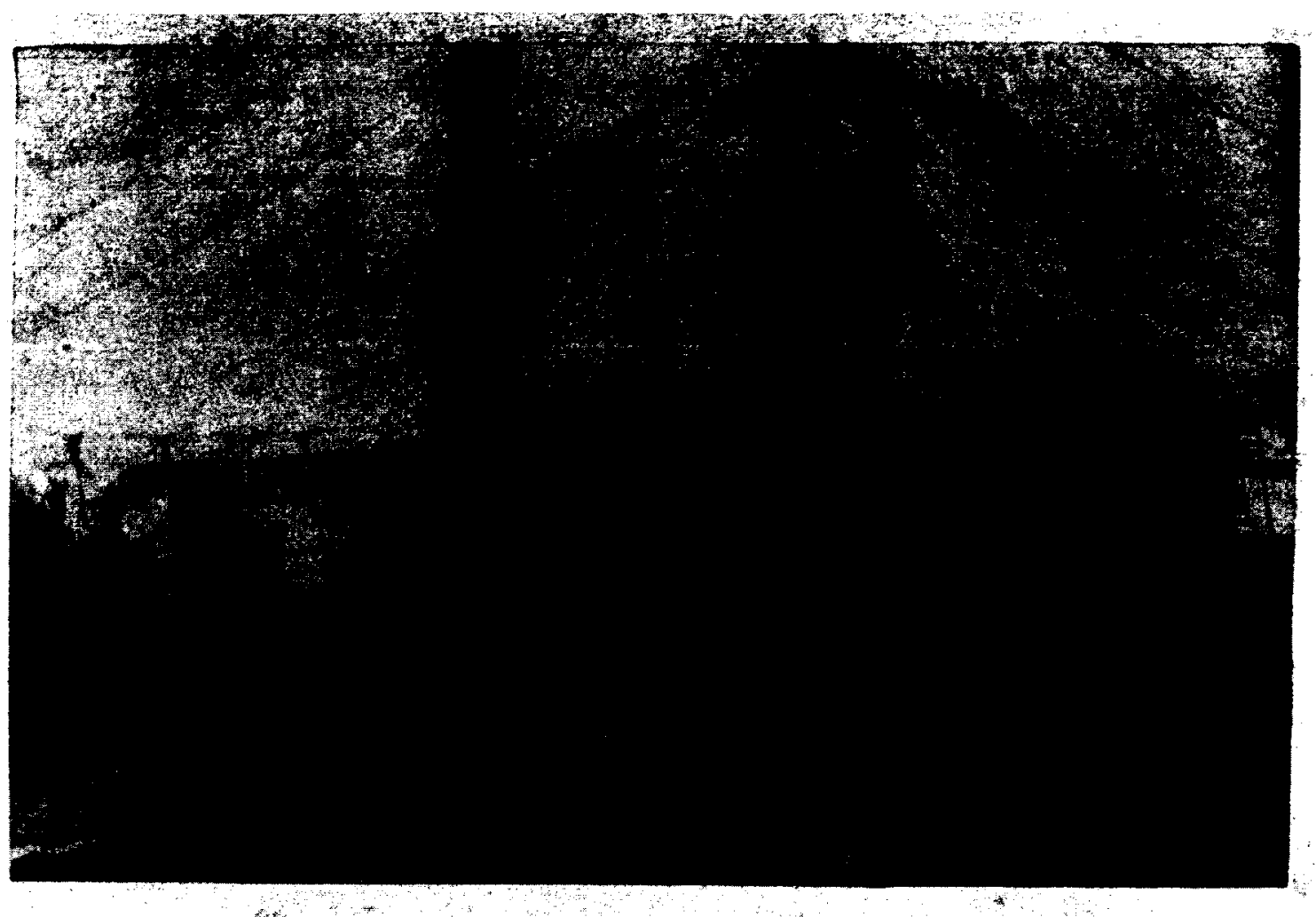

Figure 7.2 - S.R. Stoddard, "Three of the Performers in Seavey's Circus," 1889. [Source: NYSHA, 1.2/3.]

At the Executive Committee meeting in November 1889, former Commodore H.C. Rogers offered the following reaction: "I must enter my appreciation of Mr. Seavey's exertions to promote the enjoyment of the camp. He has, I know, for years employed his time in camp with that end in view, and this year he quite eclipsed all former acts by his unrivalled circus... In my opinion, Seavey outdid Barnum." 185 Rogers' reference to Barnum, a well-known circus promoter in the late nineteenth century, highlights the prominence of the circus in this period. More than an opportunity for amusements, Janet Davis argues that the American circus was "a powerful cultural icon of a new, modern nation-state" that "helped consolidate the

\footnotetext{
${ }^{185}$ MSCRC, Volume 3, Meeting of the Executive Committee, 23 November 1889.
} 
nation's identity as a modern industrial society and world power." ${ }^{186}$ On a more immediate level, circuses "transformed diversity into spectacle." ${ }^{187}$ For example, circus acts "articulated the instability of white racial identity through clownish caricatures of ethnic difference," while simultaneously reinforcing "a shared sense of white privilege" amongst the audience members. In part, audiences came to the circus to "laugh at what they ostensibly were not: preindustrial, slow, bumbling, naive, or savage." ${ }^{188}$ Unlike at travelling circuses, ethnic differences at the ACA event, which was performed by Association members, were put-on by white performers, much like the blackface of the encampments' minstrel shows. As the example of Mlle. Jabberwock makes clear, spectacles like the circus also provided opportunities to transgress gender boundaries. Finally, circuses were also frequently associated with disorder, such as stealing, fighting, conning, and gambling. ${ }^{189}$ Thus, the appeal of the circus may have stemmed at least in part from its unsavoury connotations, even as threats were minimized at the ACA by the gatekeeping performed the wharf and headquarters.

Seavey's third major spectacle took place at the 1891 meet on Lake Champlain during the race for the Pecowisc Cup. As the sailing canoes rounded the buoys, there appeared a "strange and horrible monster." Observers reported that "as he came down, his eyes flashing fire, his huge jaws clashing together, and his many scaly coil rising above the water, the bravest quaked with fear, and the timid sought the shelter of the woods." The monster made its way towards Squaw Point "in search of the beautiful

\footnotetext{
${ }^{186}$ Janet M. Davis, The Circus Age: Culture and Society Under the American Big Top (Chapel Hill: University of North Carolina Press, 2002), 10. Davis makes the point that circuses were of a piece with other visual forms in the late nineteenth century that have already received mention here, including department stores, early motion pictures, world's fairs, and newspapers. (24)

${ }^{187}$ Davis, The Circus Age, 10.

${ }^{188}$ Davis, The Circur Age, 26.

${ }^{189}$ Davis, The Circus Age, 29-31.
} 
maidens which all tradition tells us is the chosen food of dragons and sea serpents."

Some of the canoeists sought to repel the beast with the guns on the cliff, but to no avail. Eventually two canoeists attacked it with "lances and harpoons," finally managing to subdue the monster only a few feet from the ladies camp. The beast, badly injured, was then dragged ashore at the pavilion dock. He measured $100 \mathrm{ft} .{ }^{190}$ Visitors to the meet expressed wonder at the massive creature "swimming along without any visible means of propulsion." ${ }^{191}$ Whereas circuses provided opportunities for trangression, the spectacle of the Lake Champlain monster reinforced the proper of order of things. Faced with the threat to their womenfolk, the men of the ACA rushed to the rescue, killing the beast and ensuring the safety and order of their encampment.

The fourth and final Seavey spectacle, the "Storming of Taku Fort," was realized at the Muskoka meet in $1900 .{ }^{192}$ Midway through the encampment, a fort featuring a "pagoda and quaint turrets," was erected on a "little rocky island near the paddling course" under the direction of "Li Hung Chang" (Seavey). One evening, "allied fleets of war canoes and canoes of lighter draft" appeared on the waterfront, their "crews hurl[ing] a storm of rockets and Roman candles at the fort." ${ }^{193}$ This spectacle appears to have been a recreation of a battle that took place during the Boxer Rebellion only a few months earlier in June 1900. The canoeists were not the only group in this period to recreate scenes from the Boxer Uprising for public

190 "The ACA Meet of 1891," Forest and Stream, 20 August 1891.

${ }^{191}$ Goodsell, A Canoeing Reminiscence, 4.

${ }^{192}$ Images of the spectacle were included in the 1901, 1902, and 1904 Yearbooks. Herb Begg, ed., American Canoe Ausociation Yearbook (New York City: Forest and Stream Publishing, 1901), 37; Francis Johnson Burrage, ed., American Canoe Astociation Yearbook (n.p., 1902), 74; John Sears Wright, ed., American Canoe Awociation Yearbook (n.p., 1904), insert between 30 and 31.

${ }^{193}$ Howell, "International Canoe Meet," 520. 
consumption. ${ }^{194}$ In 1901, William "Buffalo Bill" Cody produced an elaborate reenactment based on this same conflict, entitled "The Rescue at Pekin," as part of his Wild West show. ${ }^{195}$ John Haddad argues that at the core of Cody's spectacle was a contest between civilization and savagery: "Americans viewed the Boxers as barbaric because [they] sought the eradication through violent means of the very things that signified 'progress' in the West - telegraph systems, railroads, mining projects, and Christian missions." 196 Haddad also sees the "The Rescue at Pekin" as a "rite-ofpassage ritual that helped [Americans] reconcile their fondness for their rugged past with their necessary participation in the modern industrial state that America was fast becoming." 197

It is no coincidence that a number of Seavey's spectacles, which were immediately popular and memorable, elicited a sense of dangerous excitement amongst the audience. Any fear they may have felt when confronted with scalping Indians, lake monsters, or savage Boxers existed alongside the knowledge that they occupied a place and community that made such things safe. Not only did they assume the presence of like-minded people, but more importantly people of a similar class and race status, but also the work that went into securing the boundaries the encampment assured them that such performances and trangressions were little more than temporary fantasies. This dual experience of being scared but safe is akin to the encampments as being at

\footnotetext{
${ }^{194}$ The Edison Manufacturing Co. produced a film entitled "Bombardment of Taku Forts, by the Allied Fleets," in August 1900 of the battle, which took place on 17 June 1900.

195 John R. Haddad, "The Wild West Turns East: Audience, Ritual, and Regeneration in Buffalo Bill's Boxer Uprising," American Studie, 49, no. 3/4 (2008): 5-38. For more on William Cody and his Wild West shows, see Louis Warren, Buffalo Bill's America: William Cody and the Wild West Show' (New York: Alfred A. Knopf, 2005); Richard Slotkin, "Buffalo Bill's 'Wild West' and the Mythologization of the American Empire," in Cultures of United States Imperialium, eds. Amy Kaplan and Donald E. Pease (Durham: Duke University Press, 1993), 164-181.

${ }^{196}$ Haddad, "Wild West Turns East," 5-6.

${ }^{197}$ Haddad, "Wild West Turns East," 8.
} 
once away but home.

For the most part, the spectacles at the ACA encampment were expressions of order. The Commodore's Review and the Illuminated Procession, for example, were akin to the precision displays at the Industrial Exhibitions described by Keith Walden. Even those spectacles better suited to the Exhibitions' midway, such as ministrel shows or circuses, did not dismantle the social hierarchies that permeated the organization and encampment life. ${ }^{198}$ If anything they reinforced them by temporarily allowing the participants to don the dress and habits of "the other." That the canoeists could engage in such transgressive behaviour is further evidence of the power of the threshold in constructing the campsites as safe spaces, but also of the shared roles of performer and spectator that characterized encampment spectacles. The spectacles, as events that attracted large numbers of campers, played an important role in constituting the community of the ACA. Specifically, they provided another opportunity for the canoeists to see and be seen, which reinforced their sense of one another. Finally, spectacles were important inscriptions of place at the annual meetings.

\section{Conclusion}

Throughout the two weeks of the American Canoe Association encampments, the canoeists were kept busy preparing and/or consuming meals; socializing with friends new and old; visiting local sites of interest; engaging in recreational activities, such as swimming, fishing, and baseball; and preparing for the races during the second

\footnotetext{
${ }^{198}$ The Midway dates to the 1893 Chicago World's Fair. It married amusement with ethnography through the organization of different "savage" cultures. See, Walden, Becoming Modern, 286-91; Robert Rydell, All the World's a Fair: Viwions of Empire at American International Exasostionu, 1876-1916 (Chicago: University of Chicago Press, 1987), 40-1, 55-68.
} 
week. The routine nature of camp life recalled the quotidian practices of home. The canoeists' participation in these activities of inhabitation made them familiar with the spaces of the campsite, but also with their fellow campers, for better or worse. In other words, going swimming or singing songs around the campfire were not just ways to pass the time or engage in pleasurable activities, they were also opportunities to develop a sense of place and to reinforce the bonds of community through shared experience.

With respect to the spectacles, there are parallels between the encampments and Keith Walden's fairs. The ACA meetings, like the Exhibitions provided a relatively contained space in which to safely explore the "disturbing implications of transgressive behaviour." The encampments, however, appear to have provided opportunities for participation in a way that the fairs did not. The canoeists crossed lines of gender, class, and race as they participated in spectacles at the ACA meetings. Keith Walden argues further that the appeal of spectacle can be explained in part by the fact that "while fairgoers were eager to witness confirmations of order, they also delighted in tinkering with some of the structures that ordinarily bound their lives." ${ }^{199}$ To be sure, such transgressions did not upset the "proper" order of things. To the contrary, spectacles worked alongside camp regulations, photographs, and accounts of the meet, to consolidate the class, gender, and racial privileges of the canoeists. Specifically, they reproduced the community of canoeists as white, middle-class, and masculine, and the encampments as orderly spaces of white, middle-class, and male sport and recreation. This chapter considered a number of spectacles that took place in relation to the ACA

199 Walden, Becoming Modern, 41. 
meets. However, the biggest spectacle of all is yet to come: the regatta. It is to this colourful event that we turn our attention in the next chapter. 


\section{Chapter Eight: Competing}

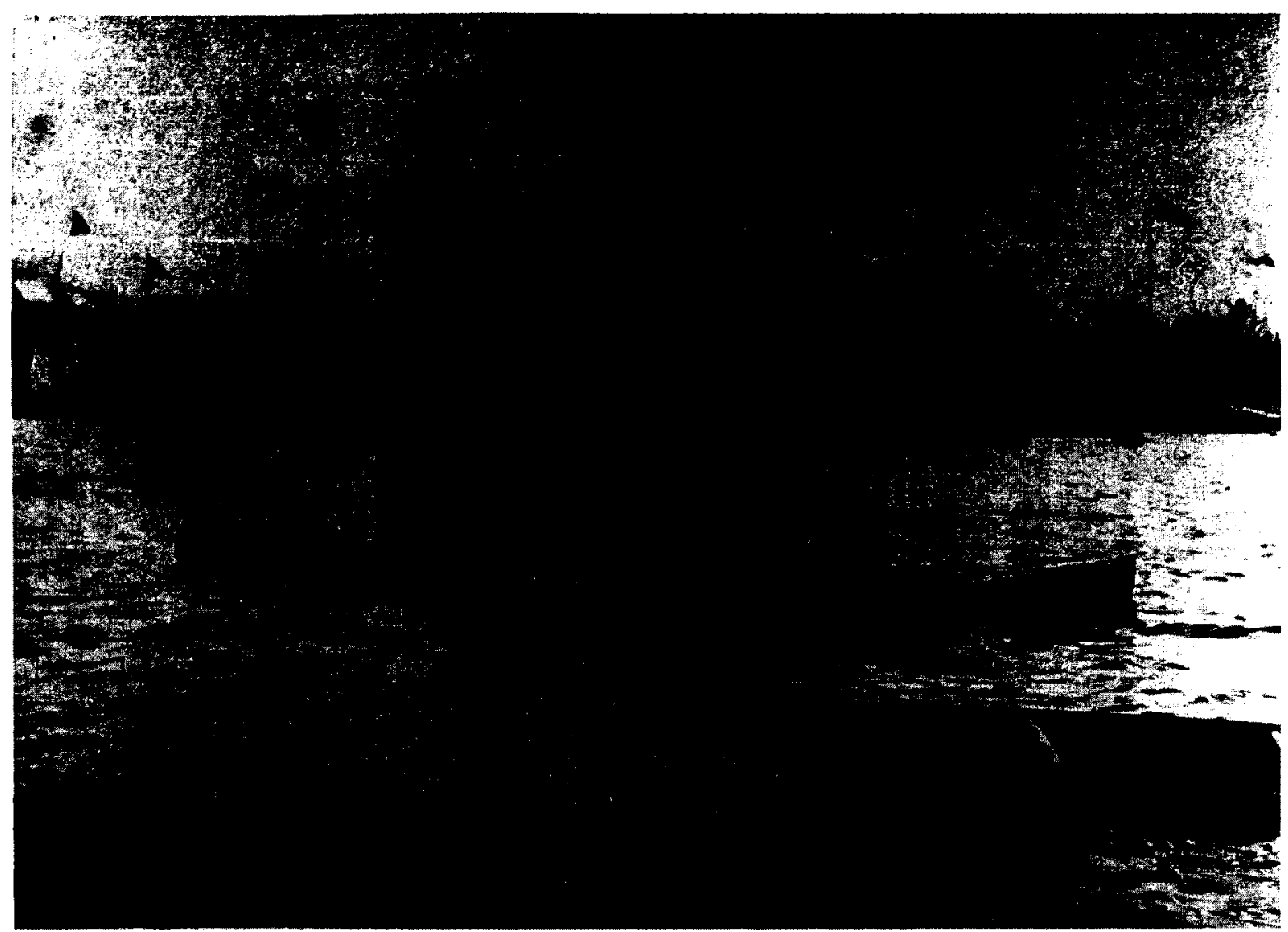

Figure 8.1 - S.R. Stoddard, "Start of the ACA Paddling Trophy Race," 1890. [Source: NYSHA, 1.1/11.]

On the opening day of the canoe races at the 1882 meet of the American Canoe Association, the New York Sun reported, "New arrivals have swelled the number of canoes to 130 , and these, with an immense number of rowboats collected off Crosbyside, present a spectacle full of animation and kaleidoscope changes." ${ }^{\text {The Sun's }}$ choice of words was by no means coincidental; as Figure 8.1 suggests, the biggest spectacle of all at the annual meetings was the regatta. For three or four days, the canoeists turned their attention away from the domestic spaces of the campsite and the recreational spaces of the surrounding waters and woods to focus on the competitive

\footnotetext{
1 "Canoeists on Lake George," New York Sun, 11 August 1882. Emphasis added.
} 
space of the racecourse. ${ }^{2}$ The optic and sonic landscapes of the camp reflected this reorientation with "hundreds of canoes of infinite variety, skiffs, sailing boats, steam yachts...plying and flying in every direction," "flags of every fantastic device" unfurled, "whistles, horns and trumpets...blowing," and "people shouting across the water to one another, and laughing." The whole place, a New Friends' Review article concluded in 1886 , "seemed given over to merry-making." ${ }^{3}$

Bodies and practices also marked the shift in focus from socializing and recreation to competition. According to Pauline Johnson, “men formerly given to immaculate flannels, gay blazers and nobby canvas shoes were arrayed in stingy bathing suits." ${ }^{14}$ Women's dress, by contrast, became more elaborate and decorative bright colours, parasols, and fancy hats being commonplace. ${ }^{5}$ The racers, meanwhile, "spent the morning scrubbing about their respective floats, oiling canoes, polishing centre-boards and getting into good racing shape. ${ }^{16}$ More generally, the races, one observer argued, "did one thing and they did it well; they destroyed the enervating $\partial o l c e$ far niente that had crept over the camp...[T] he whole camp became, if not a hive of industry, at least an accumulation of activity." ${ }^{\prime 7}$ Also visible was the marked increase in the number of bodies on site. Not only did a significant proportion of campers arrive

\footnotetext{
${ }^{2}$ As I noted in the Introduction to this dissertation, the competitive space of the regatta was one of the features of the annual meetings of the ACA that set the encampments apart from similar gatherings under canvas, such as tent meetings and summer camps.

${ }^{3}$ Columbine, "A Visit to the American Canoe Association," The Young Friend's Review (1886): 68.

${ }^{4}$ E. Pauline Johnson, "Princes of the Paddle," Toronto Saturday Night (9 September 1893): 6.

${ }^{5}$ Lorgnette, "A Woman at a Canoe Race," Outing 24, no. 6 (1894): 422. Photographs of the meets also illustrate the transformation of the campers' dress. See, for example, NYSHA, 1.2/8, S.R. Stoddard, "Visitors' Day, Main Dock," 1890, 1.2/20, S.R. Stoddard, "Willsborough Point, Visitors Day," 1891. These visitors' days took place during the regatta.

"Johnson, "Princes of the Paddle," 6.

${ }^{7}$ Retaw, Fragments from the '88 Meet (Montreal, 1888), 24.
} 
just in time for the races, but also the regatta, even in off years, drew spectators from surrounding resorts and communities.

This chapter addresses the regattas in three related, but also distinct ways. First, it situates the yearly races alongside other boating competitions in the nineteenth century, in particular yachting and rowing races, and military regattas. Second, it explores amateurism and professionalism - two well-worn themes in the history of sport - within the context of the ACA regattas. The ACA example reveals both connections to and divergences from other sporting clubs and associations in this period, especially as it involved the ambiguous meanings of "amateurism" and "professionalism," and their relationship to technology. Third, the bulk of the chapter is devoted to the organization, delivery, and experience of the annual races.

Our understanding of these regattas as sporting events is enhanced if we think of them as a performance akin to a stage play. As detailed below, the events had "programmes," which offered cues to the audience (spectators) as to the drama about to unfold between the performers (contestants and officials) on "the stage" (race courses), while the rules imposed on the competitors functioned as a kind of "script," giving shape to the performance. In earlier chapters, too, we have seen how consistently officials staged the meetings through careful planning and administration, and these same practices extended to the races themselves much as they did to other nineteenth-century sporting contests. ${ }^{8}$

\footnotetext{
${ }^{8}$ This approach to historical analysis and interpretation is by no means original. I drew particular inspiration from Greg Dening's artful account of the mutiny on the Bounty. Greg Dening, Mr. Bligh's Bad Language: Pavion, Power and Theatre on the Bounty (Cambridge: Cambridge University Press, 1992). See also, Greg Dening, Performances (Chicago: University of Chicago Press, 1996); Keith Walden, Becoming Modern in Toronto: The Industrial Exbibition and the Shaping of a Late Victorian Culture (Toronto: University of Toronto Press, 1997); John C. Walsh, "Performing Public Memory and Re-Placing Home
} 
Framing the regattas as performed events brings forward a number of important themes from earlier chapters. As in Chapter Five, I am concerned with efforts to discipline and govern the canoeists, albeit within a space of competition. The canoe races reinforce my contention that sporting events and culture can serve as sites of governmental power relationships, an emergent field in the history of sport. ${ }^{9}$ The deployment of technologies and techniques of governance at the regattas normalized similar practices in other aspects of everyday life. Also, as I noted at the outset of this chapter, the regatta was a spectacle akin to the minstrel shows and parades described in Chapter Seven. Like these other performative spaces, it played an important role in affirming, reproducing, and defending both the bounds and bonds of community, making clear who belonged and who did not. The regatta, in other words, was as much a part of the "everyday life" of the encampment as breakfast at the mess tent and taps following the campfire. Finally, as in Chapter Four, I am concerned with technology. However, in this case, the focus is on its relationship to sport and the amateur ideal as opposed to travel. It is here that the example of the ACA departs most notably from existing work on amateurism as a historical phenomenon.

\section{$\underline{\text { Part I-Historical Context }}$}

\footnotetext{
in the Ottawa Valley, 1900-1958," in Placing Memory and Remembering Place in Canada, eds. James Opp and John C. Walsh (Vancouver: University of British Columbia Press, 2010), 25-56.

${ }^{9}$ See, for example, Jeffrey Montez de Oca, "All-American Sport for All Americans: Collegiate Gridiron as Citizenship Practice during the Early Cold War" (Ph.D. Dissertation: University of Southern California, 2006); Raul Sanchez Garcia and Antonio Rivero Herraiz, "'Governmentality' in the Origins of European Female PE and Sport: The Spanish Case Study, 1883-1896," Sport, Education, and Society (2011): 1-17, and Jürgen Martschukat, "'The Necessity for Better Bodies to Perpetuate Our Institutions, Insure a Higher Development of the Individual, and Advance the Conditions of the Race': Physical Culture and the Shaping of the Self in Late Nineteenth and Early Twentieth Century America," Journal of Historical Sociology 24, no. 1 (2011): 472-93.
} 
Canoe racing was not the brainchild of late nineteenth-century bourgeois sports. As Jamie Benidickson has noted, "elements of competitive canoeing were firmly established in aboriginal and fur trade experience." ${ }^{10}$ Although North American Indigenous groups were likely racing canoes long before contact, much of our understanding of canoeing contests amongst Native people and fur traders comes from European observers. Early nineteenth-century travellers like John McTaggart and Anna Jameson captured something of this world in their travelogues. McTaggart, writing in the 1820 s, described "fifty canoes in the smooth broad lake, voyageurs fancifully adorned...as they rapidly lift and dip."1 A decade later, Jameson recounted watching thirty canoes, "each containing twelve [Aboriginal] women and man to steer...[begin a race] with sudden velocity." ${ }^{12}$ Until the late nineteenth century, however, canoe races were an anomaly amongst "gentlemen sports" and uncommon in the urban centres of the industrializing Northeast. ${ }^{13}$ In part, this is because the canoe remained intimately tied to Indigenous peoples, a point I discussed in the Introduction to this dissertation. It is also possible, however, that canoes because of their

\footnotetext{
${ }^{10}$ Jamie Benidickson, Idlenest, Water, and a Canoe: Reflections on Paddling for Pleasure (Toronto: University of Toronto Press, 1997), 110. See also, C. Fred Johnston, "Canoe Sport in Canada: Anglo-American Hybrid?," in Canexus: The Canoe in Canadian Culture, eds. James Raffan and Bert Horwood (Toronto: Betelguese Books, 1988), 59-60.

"John Mactaggart, Tbree Year' in Canada (London: Henry Calhoun, 1829), as quoted in Benidickson, Ideness, 110. In her work on the voyageurs of the late eighteenth and early nineteenth centuries, Carolyn Podruchny documents the importance of play, but specifically, canoe contests to acquiring masculine capital, the measurement of wealth in a community that boasted a non-accumulation ethic. Carolyn Podruchny, Making the Voyageur World: Travelers and Traders in the Nortb American Fur Trade (Toronto: University of Toronto Press, 2006), 184-7.

${ }^{12}$ Anna Jameson, Winter Studies and Summer Rambles in Canada (New York: Wiley and Putnam, 1839), 294.

${ }^{13}$ One of the few exceptions is Peterborough, Ontario where beginning in the 1850 s, wooden canoes were being manufactured and raced on the region's many waterways. Jean Murray Cole, "Kawartha Lakes Regattas," in Nautawgan: The Canadian Nortb by Canoe ${ }^{3}$ Snowisoe, eds. Bruce W. Hodgins and Margaret Hobbs (Toronto: Dundurn Press, 1987), 203-10.
} 
associations with wild spaces vis-à-vis both Aboriginal people and the fur trade were considered "out-of-place" in urban areas.

While canoe races were rare, boating contests in the harbours of cities such as New York, Boston, Montreal, and Halifax were not. For the most part, these regattas featured yachts, skiffs, and rowing shells. Occasionally, however, Native contestants would be called on to perform in a canoe race. An early account of a boating regatta in Halifax described races competed for by $\mathrm{Mi}$ 'kmaq men and women in birch craft. ${ }^{14}$ As at snowshoe races in nineteenth-century Montreal, the "Indian races" at the 1826 regatta were more likely a "crowd-drawing spectacle" than a test of paddling prowess. ${ }^{15}$ Interestingly, while white women's participation in regattas was severely curtailed well into the twentieth century, as this example suggests, it was not uncommon for "Indian races" to feature Indigenous women. ${ }^{16}$ Such scenes were consistent with the complex social hierarchies of the nineteenth century produced through the intersections of gender and race. ${ }^{17}$ That most "Indian races" were run for a purse - a necessity to ensure the participation of Aboriginal athletes - contributed to

\footnotetext{
${ }^{14}$ Halifax Free Prest, 11 July 1826. This particular regatta was organized in celebration of a visit from the Earl of Dalhousie. See also, Halifax Nova Scotian, 29 June 1831; Halifax Nova Scotian, 10 August 1831. C. Fred Johnston hypothesizes that the popularity of the "Indian races...might account for the trend to more small boat races - gigs, wherries, flats and jolly boats," at the Halifax races. Johnston, "Canoe Sport in Canada," 62.

${ }^{15}$ Gillian Poulter, Becoming Native in a Foreign Land: Sport, Visual Culture, and Ientity in Montreal, 1840-1885 (Vancouver: University of British Columbia Press), 28. Poulter also suggests that "Native participation was necessary...to signify the national identity of the occasion," a position that continues to hold true in contemporary mega-events, such as the Olympics. (155) See, for example, Lisa Kilner, "Narrating Indigenous-Settler Histories: Native Cultural Representations at the 1988 Calgary Olympic Winter Games" (M.A. Research Essay: Carleton University, 2009).

${ }^{16}$ Halifar Nova Scotian, 24 August 1836. There are also reports of canoe races between indigenous women at the Peterborough regattas. See Peterborough Examiner, 15 September 1859. See, also, Jameson, Winter Studies, 294.

${ }^{17}$ These have been well documented in a variety of colonial contexts. See, for instance, Adele Perry, On the Edge of Empire: Gender, Race, and the Making of Britub Columbia (Toronto: University of Toronto Press, 2001); Ann Laura Stoler, Carnal Knowledge and Imperial Power: Race and the Intimate in Colonial Rule (Berkeley: University of California Press, 2002).
} 
the "common-sense" associations between professionalism and race in the late nineteenth century, a point I will return to in a moment.

In Canada, early boating regattas were often organized by the local garrison, which as Peter L. Lindsay has shown were "the paramount influence" in the development of organized sport in Canada prior to Confederation. ${ }^{18}$ Later in the nineteenth century, regattas would become the responsibility of boating and canoeing clubs such as the Lachine Boating Club of Montreal or the Banook Canoe Club of Halifax. ${ }^{19}$ Much of the pomp and circumstance of the garrison events lived on in the early regattas of Canadian boating and canoe clubs. At the turn of the century, it was not uncommon for orchestras hired by the host club to establish themselves near to the water, in some cases on floating pavilions, and play through the canoe races. ${ }^{20}$ In the United States, the shape and content of canoeing regattas owed much to rowing culture. ${ }^{21}$ It is no coincidence that commentators often likened the scene of an ACA race day to that of a regatta on the Thames or Charles Rivers. ${ }^{22}$ Both places were, by the 1880 s, firmly established in the American imaginary as sites of rowing races. ${ }^{23}$ Also influential was the sport of yachting. First organized in the US in the 1840 s, yachting

\footnotetext{
${ }^{18}$ Peter L. Lindsay, "The Impact of Military Garrisons on the Development of Sport in British North America," Canadian Journal of Hittory of Sport and Physical Education 1, no. 1 (1970): 33. Benidickson concurs, "the military contributed an administrative structure that could readily be adapted to the organization of an event such as a regatta." Benidickson, IDlenest, 111.

19 Johnston, "Canoe Sport in Canada," 63-4.

${ }^{20}$ At Ottawa-area regattas, for example, the band of the $43^{\text {rd }}$ Duke of Cornwall's Own Rifles, and Berry's and Valentine's orchestra were usually responsible for providing musical entertainment during the races. "Canoeing," Ottawa, 21 July 1900; "Canoeing," Ottawa Citizen, 28 July 1902; Ottawa Daily Citizen, 27 July 1903; "Canoeing," Ottawa Citizen, 6 July 1906.

21 "The A.C.A. Canoe Meet," Outing 11, no. 1 (1887): 95-6; "Discussed in Canoe Camp," New' York Times, 15 August 1892.

${ }^{22}$ See, for example, "Along the St. Lawrence," New, York Tribune, 28 July 1901.

${ }^{23}$ Rowing races were being run on the Charles River in Boston as early as the $1840 \mathrm{~s}$, and the first Harvard-Yale boat race took place in 1852. Of course, rowing in the United States owed much to Britain. Charles A. Peverelly, The Book of American Pastimes (New York: Self-Published, 1866), 117; Christopher Dodd, The Story of World Rowing (London: Hutchinson, 1991), 217.
} 
clubs and regattas were a common feature of urban harbours along the eastern seaboard by the late nineteenth century. ${ }^{24}$ The creation of the ACA's International Challenge Cup in 1886 was directly inspired by the America's Cup, the pinnacle of nineteenth-century yachting races. ${ }^{25}$

\section{Part II - The Amateur Ideal}

Sport in the nineteenth century was shaped by an ongoing and vociferous

debate over amateurism and professionalism, and canoeing was no exception. ${ }^{26}$

Whereas the professional was seen to be motivated by economic or personal gain, the amateur ostensibly played for the love of the game. ${ }^{27}$ Mary Louise Adams has shown, for example, how English ice skaters in the mid-nineteenth century perceived competition as the "bane of true amateurism." ${ }^{28}$ As a result, skating enthusiasts "initially rejected the idea of competitions because they thought it unseemly for gentlemen to compete against their peers. ${ }^{29}$ While the members of the ACA were not

\footnotetext{
${ }^{24}$ W.P. Stephens, Traditions and Memories of American Yactbing: The 50 th Anniversary Edition (Brooklin: WoodenBoat Publications, Inc., 1989), 1-5.

${ }^{25}$ John Rousmaniere, The America'd Cup 1851-1983 (London: Pelham Books, 1983).

${ }^{26}$ Key texts on amateurism in Canada, the United States, and Great Britain include: Alan Metcalfe,

"The Growth of Organized Sport and the Development of Amateurism in Canada, 1807-1914," in Not Just a Game: Evsay, in Canadian Sport Saciology, eds. Jean Harvey and Hart Cantelon (Ottawa: University of Ottawa Press, 1988), 33-50; Alan Metcalfe, "The Meaning of Amateurism: A Case Study of Canadian Sport, 1884-1970," Canadian Journal of the History of Sport 26, no. 2 (1995): 33-48; Bruce Kidd, The Struggle for Canadian Sport (Toronto: University of Toronto Press, 1996); S.W. Pope, "Amateurism and American Sports Culture: The Invention of an Athletic Tradition in the United States, 1870-1900," International Journal of the Hiwtory of Sport 13, no. 3 (1996): 290-309; Nancy Bouchier, For the Love of the Game: Amateur Sport in Small-Town Ontario, 1838-1895 (Montreal: McGill-Queen's University Press, 2003); Dilwyn Porter and Stephen Wagg, eds., Amateurism in British Sport: It Matters Not Who Won or Lout? (London: Taylor and Francis, 2007).

${ }^{27}$ According to Lincoln Allison, amateur is a French word that signals "action or consumption arising from taste rather than instrumental self-interest." Lincoln Allison, Amateurism in Sport: An Analysis and a Defence (London: Frank Cass, 2001), 3. Allison argues further that amateurism was variously a response to commercialism and professionalism in the eighteenth and nineteenth centuries.

${ }^{28}$ Mary Louise Adams, Artwitic Impressions: Figure Skating, Masculinity, and the Limits of Sport (Toronto: University of Toronto Press, 2011), 168.

${ }^{29}$ Adams, Artivtic Impressions, 128, 168.
} 
opposed to competition, they retained concerns about its potential consequences. As one commentator writing in 1894 noted, "the great problem in racing is to make the sport interesting and popular, to induce men to work for the prize, and yet prevent such a rapid and unhealthy development as will lead a few men to give all their time and labor to securing every prize and shut out the great majority from the benefits that always follow from a general and open competition." ${ }^{30}$ As rowing, yacht racing, and canoeing in England had all succumbed to the scourge of professionalism, it seemed only a matter of time before canoeists in North America would face a similar reality.

Of course, some claimed that the sport of canoeing was immune to professionalism, including a reporter for the New York Times:

The 'professional' element, which has so often converted boat-races and base-ball matches into pretexts for gambling, cannot intrude itself among canoeists for a 'professional' canoeist is as impossible as a professional player of 'I spy.' To be a canoeist a man must have that true love of nature and outdoor work which will enable him to regard the labor, inconveniences, discomforts, and occasional dangers of a canoe cruise as part of a delightful sport. The 'professional' is ready to work for money, but not for the mere pleasure of working, and there is not the slightest danger that he will ever be found in the cock-pit of a canoe. ${ }^{31}$

A few years later, Harry Eckford offered a similar assessment of the sport, arguing that canoeing could withstand "the gangrene of professionalism" because "professionals can make no money at these regattas, not even in the paddling races." ${ }^{\text {"32 }}$ However, even as they claimed canoeing impervious, such writers were acknowledging the ever-present spectre of the professional. Much as over-civilization lurked at the edges of encampment life threatening to jeopardize the rejuvenating atmosphere of the

30 "Features of the Meet at Croton Point, on the Hudson," New" York Times, 15 July 1894.

31 "A Year's Work," New' York Timer, 8 June 1881. See also, Cruiser, "The 'Musquito' Fleet," The Gloversville Daily Leader, 14 August 1891; Caspar W. Whitney, "Annual Meet of the American Canoe Association," Harper', Weekly, 2 September 1893.

${ }^{32}$ Harry Eckford, "Camp Grindstone," The Century Magazine 30, no. 4 (1885): 502. Eckford's pathologization of professionalism reveals the depth of anxieties surrounding playing for pay. 
annual meeting, professionalism was an ongoing concern for those committed to the amateur ideal. Even Eckford admitted that in "the 'crack' sailors" so admired by spectators at the ACA regatta "we see the tendency toward professionalism."33

Given the celebratory attitudes toward professionalization in the world of work in the late nineteenth century, what was so concerning about professionalism in sport $?^{34}$ In part, concerns about the spread of industrial capitalism, but specifically the transformation of the world of work, fueled this opposition. ${ }^{35}$ At one level, sport/leisure was to function as a haven from an individual's vocational toils. ${ }^{36}$ Professionalism represented a breach of this boundary. The irony is that these same sporting men did not object to the appearance of other elements of their occupational lives, such as financial audits or Boards of Governors, in their recreational organizations. ${ }^{37}$ Second, professionalism was associated with "playing for pay." ${ }^{\text {"38 }}$ Wage labour was a contentious reality in the decades around the turn of the twentieth century, particularly for men. As Clark Davis notes, "the dominant middle-class construction of occupational success had long glorified economic independence." ${ }^{39}$ However, by the late nineteenth century, most American men could expect to spend their lives as

\footnotetext{
${ }^{33}$ Not everyone agreed. As we will see, for some, "racing machines" were equally the embodiment of professionalism.

${ }^{34}$ Mary O. Furner refers to the late nineteenth century as a "professionalization period" in $A \partial v o c a c y$ and Objectivity: A Crisis in the Profestionalization of American Social Science, 1865-1905 (New Brunswick:

Transaction Publishers, 2011), xi.

${ }^{35}$ Porter and Wagg argue that amateurs "symbolized the detachment of sport from the corrosive influence of the market, competition and technocracy." Porter and Wagg, Amateuritm in Britiwh Sport, 2. ${ }^{36}$ Tara Magdalinski, Sport, Tecbnology, and the Body: The Nature of Performance (New York: Routledge, 2000 ), 16.

${ }^{37}$ This contradictory attitude toward work and leisure is captured by Ross McKibbin's contention that leisure is at once an extension of and compensation for work. Ross McKibbin, "Work and Hobbies in Britain, 1850-1950," in The Working Claw in Modern Britain, ed. Jay Winter (Cambridge: Cambridge University Press, 1983), 127-46.

${ }^{38}$ Bruce Kidd, The Struggle for Canadian Sport (Toronto: University of Toronto Press, 1996), 33.

${ }^{39}$ Clark Davis, "The Corporate Reconstruction of Middle-Class Manhood," in The Middling Sorti:

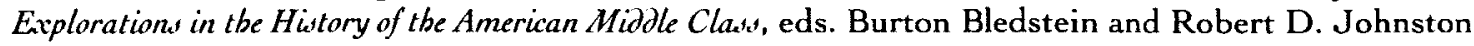
(New York: Routledge, 2001), 201-2.
} 
"salaried employees in bureaucratic hierarchies," beholden to wage labour. "Career ideals," Davis observes, "did not transform in perfect sync with changes in economic and social organization." ${ }^{40}$ Third, professionalism constructed athleticism as a commodity that could be bought and sold, much like wheat or gold, yet another manifestations of industrial capitalism. That opponents of professionalism in the wider world of sport often likened it to prostitution underscores the perceived moral bankruptcy of the professional athlete. ${ }^{41}$

Professionalism's association with the working class and ethnic minorities - two groups that rarely had the time or the means to participate extensively in sport without remuneration - was not coincidental. Amateurism, the ideological counter of professionalism, was as much (if not more) a celebration of masculinity, whiteness, and middle-class status as it was an ideological stance on participation in sport. ${ }^{42}$ Within the world of nineteenth-century sport, 'the words 'amateur' and 'gentleman' were often regarded as interchangeable; indeed, they were often conflated by reference to the 'gentlemen amateur.'”43 Furthermore, as Bruce Kidd notes, "the earliest 'amateur codes' restricted participation on the basis of class and race, reflecting the upper classes' desire to reproduce the social hierarchies of Victorian England and the British Empire and to maintain the primacy of sports as an expression of manly honour and elegant display. ${ }^{\prime \prime 4}$ Even as "upper-class ostentation" gave way to an "ethos of sport as a

${ }^{40}$ Davis, "Corporate Reconstruction of Manhood," 202.

${ }^{41}$ Kidd, Struggle for Canadian Sport, 33.

${ }^{42}$ Amateurism centred on the assumption that one played for no other reason than "the love of the game." It was also associated with sport as a site for building character, for the inculcation of values consistent with middle-class respectability, such as "patriotism, courage, self-reliance, and fair play." Colin Howell, Blood, Sweat and Cheers: Sport and the Making of Modern Canada (Toronto: University of Toronto Press, 2001), 102.

${ }^{43}$ Porter and Wagg, Amateurism in Britws Sport, 4.

${ }^{44}$ Kidd, Struggle for Canadian Sport, 27. 
field of 'civilized' contest and achievement," such hierarchies remained, albeit in a somewhat altered form. ${ }^{45}$ The amateur code, for instance, "required [athletes] to have the leisure to pursue sport on a systematic basis and the means to purchase club memberships, equipment, and travel to out-of-town competitions, while denying them the chance to earn the money to do so from their performances. ${ }^{\text {,46 }}$ Thus, amateurism, as Mary Louise Adams observes, had a circular quality to it: "National championships are institutionalized by upper-class sportsmen as amateur contests; members of the upper classes are the only ones able to expend the time and resources needed for training, and thus it is they who win the honours; once won, these honours come to signify the superiority of the upper classes and to justify the privileges, like freedom from work, that made it possible for them to compete in the first place." ${ }^{\text {47 }}$

In spite of the assumed superiority of amateurism, adherence to the ideal was by no means assured. The organization took a number of steps to counter what it saw as the ever-present threat of professionalism and to uphold the virtues of amateurism. Most directly, it, like other sporting clubs in the period, sought to regulate who could participate in Association races. At the most basic level, participation was reserved for members, and membership was limited to amateurs, who, as I noted in Chapter Two, were predominantly white middle-class men.$^{48}$ Interestingly, although early circulars defined professionals as "any canoeists who...race for money," the organized shied away from offering a clear definition of an amateur. ${ }^{49}$ Canadian canoeist J.N.

\footnotetext{
${ }^{45}$ Kidd, Struggle for Canadian Sport, 28.

${ }^{46} \mathrm{Kidd}$, Struggle for Canadian Sport, 28.

${ }^{47}$ Adams, Artwitic Impressions, 168.

${ }^{48}$ MSCRC, Box 23, Folder 2, Camp Circular for Lake George, 1881. Special invitations could be issued by the Regatta Committee, as in the case of international canoeists.

${ }^{49}$ The bylaws also included a more general statement noting that "Any member who is guilty of ungentlemanly conduct, or of racing for money, shall be liable and may be expelled from the ACA."
} 
McKendrick drew attention to this fact in an 1890 letter to the editor of Forest and

Stream. ${ }^{50}$ The editor agreed, but noted that while "[a] definition of an amateur is

certainly needed...we have never yet seen one that was in any way perfect. ${ }^{.51}$ The difficulty of producing an adequate definition, which itself speaks to the slipperiness of the term, may have underpinned the organization's inaction. In this way, the ACA differed from other sporting bodies that adopted explicit definitions of amateurs such as the oft-cited Montreal Pedestrian Club. ${ }^{52}$ Even the inclusion of an amateur clause in the ACA rules, however vague, was a marked act of boundary work. By the late nineteenth century, amateur was a deeply classed, gendered, and racialized social category that demarcated sporting clubs and amateur athletic associations as white, middle-class, and male institutions.

The decision to increase the length of the encampments from four to fourteen days was also part of the ACA's ongoing offensive against professionalism. ${ }^{53} \mathrm{~A}$ longer encampment placed more emphasis on the annual meeting as a social and recreational space, and sought to limit the time and attention devoted to the races. While some of

William M. Carter, ed., American Canoe Atsociation Yearbook (New Jersey: John L. Murphy Publishing, 1887), 29.

${ }^{50}$ J.N. McKendrick, "The Definition of an Amateur," Forest and Stream, 6 November 1890. McKendrick suggested: "An amateur is any person who has not competed in any open competition or for a stake, public or admission money or entrance fee; or competed with or against a professional for a prize; who has never taught or assisted in the pursuit of any athletic sports as a means of livelihood."

${ }^{51}$ Two years later, the New York Times concurred, "The question of amateur standing in canoeing is a difficult one, and as yet no definition that has been suggested had been at all satisfactory." "Discussed in Canoe Camp," New York Times, 15 August 1892.

52 The Pedestrian Club classified an amateur athlete as one who had "never competed in any open competition or for public money, or for admission money, or with professionals for a prize, public money or admission money, nor has ever, at any period of his life taught or assisted in the pursuit of Athletic exercises as a means of livelihood or is a laborer or an Indian." Howell, Blood, Sweat, and Cbeers, 63.

${ }^{53}$ Recall that at the inaugural meeting in 1880 , the races occupied three of the four days of the encampment. Three years later, then-Commodore E.B. Edwards unveiled a 14-day encampment with only three or four days devoted to racing. Following the 1883 encampment, most years the regatta covered four or five days during the second week of the encampment. There were always exceptions, however. For example, in 1906, the races lasted nine days because of delays and the length of the programme. Perry D. Frazer, "The 1906 Meet and Camp of the American Canoe Association at Sugar Island," Boating (October 1906): 352-4. 
the members responded positively to the new format by spending more time in camp, more common were the canoeists who arrived a day or two before the regatta. ${ }^{54}$ In limiting their time on site to the races, these campers undermined the organizers' efforts to draw attention away from the regatta. Ultimately, the Executive Committee mandated that members wishing to compete be in camp for a minimum amount of time before the start of the regatta. ${ }^{55}$

Organizers also sought to cast the races in a particular light. For example, E.B. Edwards, who was in charge of the 1883 meet, argued in the camp circular that the races should "afford the means of testing in a friendly way the relative merits of various styles of canoes, rig, etc., and furnish a bit of pleasant sport at the end of the camp, rather than...promote the fastest racing in the world, and thus give rise to personal jealousies." ${ }^{56}$ Such comments constructed the regatta as a space of friendly competition as opposed to one of professional contestation. Related to this, the canoeists sought to distance themselves from other water-based sports associated with professionalism such as rowing. ${ }^{57}$ Consider, for instance, the announcement for the 1883 meet on Stony Lake: "In wielding our blades in the clear waters of the Dominion next August, we will do more to promote love for our innocent pastime than all the racing of years can accomplish. Let the college crew, with passage and board paid by subscription, go, like professionals, to race before the fashionable crowds of our

\footnotetext{
${ }^{54}$ Here we see canoeists expressing their preferences for the length of the encampment through their actions in opposition to the wishes of the organizers.

${ }^{55}$ MSCRC, Volume 4, Special Meeting of the Executive Committee, 11 August 1899, and Meeting of the Evecutive Committee, 27 July 1903. This clause was administered unevenly and eventually eliminated. 56 "The Meet," American Canoeist 2, no. 6 (1883): 82.

${ }^{57}$ As Bruce Kidd observes, "stake races, sponsored purses, and gambling on the outcome" were common features of rowing regattas, which were also often financial "bonanzas" for the railway companies that hosted them. Kidd, Struggle for Canadian Sport, 30.
} 
watering-places; but let us remember that we are amateurs purely; and, like gentlemen and canoeists, give to others our experience without cost to them." ${ }^{158}$

A central facet of the ACA's brand of amateurism was "generalism," by which I mean the organization esteemed and promoted the virtues of the canoeist and the canoe that could capably sail and paddle. This orientation is most noticeable in "The Record," a contest introduced at the 1885 meet when it was discovered that "the paddlers were content to...leave the sailing races alone, and the sailors left the paddling races alone." The concern was that "if allowed to go on this way the result would have been finally, paddling machines and sailing machines. ${ }^{59}$ To compete for The Record, canoeists had to enter a canoeing race, a sailing race, and a combined canoeing and sailing race. To place well, they had to be competent sailors and paddlers. The Record was doubly promising because it not only fostered both types of skills, but it also encouraged the development of generalist canoes.

As this last example suggests, more than the payment of athletes threatened the amateur ideal. Equally concerning was the adulteration of the canoe itself:

The yearly meeting together of hundreds of canoeists has stimulated inventors in the effort to approach nearer to the ideal 'perfect canoe.' From year to year new rigs have been devised, and the latest evolution in rigging has been the now famous 'Mohican sail'... Improvements in the model, material, and fittings of canoes have constantly been made.... [t] he best canoes of the association now seem to be beyond the reach of improvement... No man who is not an expert has now the slightest chance of winning in a regatta, and the combination of nerve, quickness, and technical skill shown by our best canoe sailors need only be witnessed to convince any one that canoeing is a worthy sister of yachting. ${ }^{60}$

58 "On Canada," American Canoeitt 2, no. 1 (1883): 1. Unlike commercial sporting endeavours, the ACA never charged spectators for the experience.

${ }_{59}^{59}$ "American Canoe Association," Forest and Stream. 28 August 1884. Other races were introduced with similar ends. See, "The Annual Canoe Meet," New York Evening Post, 27 August 1887; "Paddling Their Own Canoes on the St. Lawrence," Syracuse Daily Standard, 31 May 1896.

${ }^{60}$ MSCRC, Volume 3, Meeting of the Executive Committee, 1890. 
As I noted in this dissertation's Introduction, canoeing enthusiasts in the late nineteenth century struggled to transform the canoe from an "Indian" craft into a respectable middle-class boat, a process I refer to as the whitening of the canoe. Canoeists also laboured to create the "perfect canoe," a project that included new materials, manufacturing techniques, and performance technologies. ${ }^{61} \mathrm{~A}$ newspaper article from 1882, for example, praised the "invention of the Racine process," which "marked a new era in boat building," enabling the production of boats that have a "smooth surface, without ribs, strong, tight, and durable." ${ }^{62}$ This pursuit of perfection, much like the desire for progress that permeated late nineteenth-century society, was a "utopian statement about the future." As the canoe was "improved," so too was the canoeist, and ultimately, society. ${ }^{64}$ The quest for technological perfection was by no means benign, however. As Robert Rydell demonstrates in the context of the fin- $\partial e$ viècle World's Fairs, progress, both in a technological and sociopolitical sense, was "laced with scientific racism."

Regattas, by providing opportunities for "determining the comparative merits of different models and different rigs," were central to the project of creating the

\footnotetext{
${ }^{61}$ A 2011 exhibition, entitled "The Perfect Canoe?," at the Antique Boat Museum in Clayton, NY captured the thrust of this project. As the title suggests, there was no single answer to the question of the perfect canoe. Was it meant for cruising? For racing? For paddling? For sailing? In most cases, the perfect sailing canoe could not be suitably used for paddling, while the ideal cruising canoe was a boon in competition. Such questions highlighted more fundamental divisions in the organization between cruisers and racers that deepened as time went on. However, for much of the period in question, the organization welcomed and sought to appeal to both racers and cruisers, however inadequately.

62 “About Canoeing," The Lowell Daily Courier, 11 May 1882. I also discuss this in this dissertation's Introduction.

${ }^{63}$ Robert Rydell, All the World's a Fair: Visions of Empire at American International Expositions, 1876-1916 (Chicago: University of Chicago Fair, 1987), 4.

${ }^{64}$ Martin Fichman, Evolutionary Theory and Victorian Culture (Amherst: Prometheus Books, 2002). The language and tropes of evolutionary theory pervaded popular culture in this period, offering the AngloAmerican world a new tool for constituting cultural difference and social hierarchies.

${ }^{65}$ Rydell, All the World', 5.
} 
perfect canoe. ${ }^{66}$ Like scientific study - which was gaining purchase in the late nineteenth century - they enabled the observations and experimentations necessary for technological development. ${ }^{67}$ However, regattas also revealed the deep contradictions of this project. Specialized racing canoes were good for little more than competition. The pursuit of the perfect racing canoe, in other words, seemed to undermine the organization's commitment to amateurism because it culminated in the creation of degenerate "racing machines." ${ }^{68}$

That racing canoes were cast in this light is evidence of anxieties about technological modernity, which while not unique to canoe sport, certainly set the field apart from other forms of amateur athletics. As historians have amply documented, the late nineteenth century was awash in references to and images of "the machine," a "complex symbol, increasingly charged with contradictory meanings and implications." 69 "If," as Alan Trachtenberg writes, "the machine seemed the prime cause of the abundance of new products changing the character of daily life, it also seemed responsible for newly visible poverty, slums, and an unexpected wretchedness of industrial conditions. ${ }^{70}$ Even in the World's Fairs that seemed unabashed celebrations of the mechanization of modern life, observers noted "bewilderment and

\footnotetext{
66 "A Year's Work," New York Time', 8 June 1881. Not everyone was convinced such a thing was possible. Professor Edwin Fowler of the Knickerbocker Canoe Club misogynistically opined in a speech to his fellow club members in 1883 , "there is no more perfection in canoes than in wives...there are only convenient compromises." Atwood Manley, Rusbton and Hï, Times in American Canoeing (Syracuse: Syracuse University Press, 1968), 83.

${ }^{67}$ Bernard Lightman, ed., Victorian Science in Context (Chicago: University of Chicago Press, 1997). Lightman argues that the Victorian era is a particularly important period in the history of science because it was when "significant features of the relationship between contemporary science and culture first assumed form." (3)

${ }^{68}$ MSCRC, Volume 3, Meeting of the Executive Committee, 1890.

${ }^{69}$ Alan Trachtenberg, The Incorporation of America: Culture and Saciety in the Gilded Age (New York: Hill and Wang, 1982), 38.

${ }^{70}$ Trachtenberg, The Incorporation of America, 38.
} 
fear." ${ }^{\prime 1}$ Modern machinery, one contemporary astutely noted, was "an incalculable force. ${ }^{172}$ Yet anxieties about the machine appear not to have pervaded other forms of amateur sport in this period in the way they did canoeing. To the contrary, amateur sport was constructed as antithetical to the technological imperative. ${ }^{73}$ This disjuncture is likely a reflection of the dependency of canoeing on such a sizeable instrument that could be manipulated in myriad ways.

The ACA took a number of steps to counter the threat of over-mechanization. First and foremost, it sought to regulate the shape of canoes being entered in races in the hopes that it could prevent the production of racing machines. ${ }^{74}$ For example, the organization mandated that canoes entered into competition "must come within the prescribed limits" of a maximum length of 16 feet and maximum beam of 30 inches, "decreasing the [maximum] length of the canoe one foot for every inch and a half of additional beam. ${ }^{175}$ Sail sizes were similarly constrained.$^{76}$ While commentators admitted that no one size was better than another, they nevertheless felt it necessary to "secure a uniformity" to "greatly simplify the rules and lessen the labors of the regatta committee and measurers." ${ }^{177}$ The Association also instituted regulations pertaining to draft, keels, and centerboards, which, like boat and sail size, altered a canoe's

\footnotetext{
${ }^{71}$ Trachtenberg, The Incorporation of America, 39.

${ }^{72}$ Charles Francis Adams, Jr., as quoted in Trachtenberg, The Incorporation of America, 40.

${ }^{73}$ Magdalinski, Sport, Tecbnology, 16.

${ }^{74}$ Changes to the silhouette and the sail were intended to give canoes greater speed.

${ }^{75}$ George P. Douglass, ed., American Canoe Avoociation Yearbook (Newark: Press of the Holbrook Printing Company, 1894), 14.

${ }^{76}$ In 1884, for example, Class A craft were confined to 50 feet of sail, and Class B craft to 70 feet. These regulations changed numerous times over the following two decades. In 1895, a new type of canoe was introduced that was $15 \times 36$, and a sail limit of 110 square feet. "The Meet of 1884," Foreut and Stream, 8 November 1883. "First Camp Fire of the Canoists [sic]," New York Herald, 13 August 1895.

77 "The Regatta Programme for 1886," Forest and Stream, 8 October 1885. Much as the orgnizers sought to rationalize the landscape, here we see efforts to rationalize the canoe.
} 
performance. ${ }^{78}$ To avoid disqualifications based on size, owners and boat builders alike were encouraged to "know the dimensions of [their] boat, and have her a fraction inside of the measurement, so as to avoid any possibility of dispute. ${ }^{779}$ In limiting the range of possibilities for entries, the regattas served to discipline the boat choices of canoeists. By 1890, Forest and Stream was reporting that the "odd sizes [had] very nearly disappeared from the racing," with the vast majority of canoes measuring 16 feet by 30 inches. ${ }^{80}$ While the ACA may have been successful at creating a standardized canoe, they were unable to prevent the creation of racing machines, which R.B. Burchard argued was an "inevitable result of continued competition." Craft continued to appear at the annual meetings with little use but for racing.

The rules governing boats were not just about curtailing professionalism. They were also about promoting amateurism, but particularly the principle of fair play. ${ }^{82}$ Thus, the racing regulations provided for clearly delineated categories of canoes based on size and type (open, decked). With the exception of one or two open races, canoes competed against craft of comparable size. The result was a complex patchwork of races devoted to various permutations of canoes and rigging with the end goal of creating a level playing field.

Finally, there is the matter of prizes, which, not surprisingly, were a contentious issue for much of this period. At the earliest meets, canoeists competed for

\footnotetext{
${ }^{78}$ Robert Tyson, "The Sailing Regulations of the American Canoe Association," Outing 3, no. 4 (1884): 296.

79 "The Canoes of 1884," Forest and Stream, 4 September 1884. While some recognized the problems inherent in such a position - "The rights of all must be kept in mind" one commentator noted - they maintained, "at this date, the building of odd sizes must be restricted as much as possible." "The Regatta Programme for 1886," Forest and Stream, 8 October 1885.

80 "The ACA Meet: Race Week," Forest and Stream, 28 August 1890.

${ }^{81}$ R.B. Burchard, "The Real Canoeing," Outing 37, no. 1 (1900): 78.

${ }^{82}$ Howell, Blood, Sweat, and Cbeert, 102.
} 
prizes donated by canoe manufacturers or ACA members. At the second encampment, these included "several complete canoes, all ready for work," as well as "useful articles of a canoeist's outfit, such as sails, paddles, flags, $8 \mathrm{c} .{ }^{183}$ As early as 1882 , questions were raised about the suitability of such rewards, given that "racing is not the end of the Association, but only a means of furthering an interest in the sport and improvements in the boats. ${ }^{14}$ Prizes, from this perspective, were thinly-veiled inducements to build the degenerate racing machines that were the province of professionals. Thus, beginning in 1882 , the regatta committee distributed flags. ${ }^{85}$ Such "simple and inexpensive" tokens, the Commodore argued, were "not likely to tempt anyone to the systematic training necessary for an oarsman's race. ${ }^{866}$ Even with the introduction of flags, more substantive awards were not immediately abandoned. At the 1883 meet, which Commodore Edwards claimed would be prize free, competitors in the "impromptu races" during the first week were rewarded with paddles and camping equipment donated by boat builders and canoe clubs. ${ }^{87}$ Beginning in 1886 , there were also a number of expensive cups for which the canoeists could compete. ${ }^{88}$ Like many athletic pursuits in the late nineteenth century, canoeing grappled with the seemingly oppositional values of amateurism and professionalism. The ACA was nothing if not inventive and multi-pronged in its efforts to uphold the amateur

\footnotetext{
83 "Canoeing," The Toronto Daily Mail, 12 July 1881.

84 "Lake George Meet," Forest and Stream, 25 August 1881.

${ }^{85}$ These were solicited from "members and friends" in the months leading up to the encampment. That the committee requested home-made flags rather than "factory-made articles" suggests further ambivalence towards the processes and products of industrial capitalism. "Prizes for 1886," Forest and Stream, 25 February 1886.

86 "The Meet," American Canoeist 2, no. 6 (1883): 82.

87 "ACA Annual Meeting," Peterborough Daily Review', 20 August 1883. A detailed list of donations can also be found in "The Association Meet," Forest and Stream, 6 August 1885.

${ }^{88}$ These were acquired via subscription. The most prominent was the International Challenge Cup, "a silver bowl, 12 inches high and 15 inches in diameter, ornamented around the base with the turtle, bears, frog and other club symbols." "Canoeists in Camp," Auburn Morning Dispatch, 23 August 1886.
} 
ideal and counter professionalizing tendencies. The battle was waged on all fronts, targeting in various ways the competitors, the craft, and the contests. What stands out about the example of the $\mathrm{ACA}$ is the emphasis placed on equipment rather than training or payment for play, although the latter were also concerning for ardent amateurs. The dependency of canoeing on such a sizeable instrument prompted anxieties about technological modernity and the increasing control of machines over different aspects of everyday life, further evidence of the imbrications of sport and society in the late nineteenth century.

Alan Metcalfe argues, "there never was a real difference between amateur and professional. ${ }^{189}$ Rather, we must ask of these two categories (like categories more broadly): How were they deployed by sporting enthusiasts and to what end? In the case of the canoeists, they were part of broader project of community formation that sought to include the right kinds of people, and exclude "others." At the core of this boundary work was the question of fitness: Who was considered "fit" to attend and compete in the ACA regattas? And who was not? Practices of inclusion and exclusion reflected anxieties about the changing place of women, the working class, and immigrants in North American society. Also at the core of the debate between amateurism and professionalism was a tension between the mechanized culture of progress and the "antimodern" culture of fair play. ${ }^{90}$ Clearly, there was no epistemological space at the ACA meetings for sport to be professionalized, mechanized, and "fair."

\footnotetext{
${ }^{89}$ Metcalfe, "Meaning of Amateurism," 33.

${ }^{90}$ I use the term "antimodern" tentatively recognizing that what on the surface appeared to oppose modernity was often deeply entangled in and committed to its development. Sharon Wall, The Nurture of Nature: Childhood, Antimodernium, and Ontario Summer Camps, 1920-1955 (Vancouver: University of British Columbia Press, 2009), 4-5.
} 


\section{Part III - The Regatta}

As a staff writer for Forest and Stream noted in 1886, "It is no light undertaking to manage a series of 20 races in three days, in which the entries aggregate no less than 350, with the necessary measuring, setting up buoys and other matters." ${ }^{11}$ For this reason, a dedicated regatta committee oversaw the races of the American Canoe Association. ${ }^{92}$ The regatta committee was responsible for preparing and publishing the programme, laying out and buoying the courses, organizing prizes, appointing officials, and ruling on protests. ${ }^{93}$

\section{The Programme}

The regatta committee's first responsibility was to revise and circulate the programme for the upcoming meet. This was no easy task given the ever-evolving catalogue of races. ${ }^{94}$ While the content of the programme was ultimately the responsibility of the newly appointed committee, also important were suggestions from the outgoing Executive and regatta committees, and from the membership. ${ }^{95}$ As with

91 “The Meet of 1886: Race Week," Forest and Stream, 2 September 1886.

92 In 1902, the organization further expanded the bureaucracy around the regatta with the creation of a racing board, which had "full charge of all association racing and rules." MSCRC, Volume 4, Meeting of the Executive Committee, 15 November 1902; "Canoe Association Changes," New York Times, 25 October 1903.

${ }^{93}$ See the Chapter IX of the Bylaws, entitled "Duties of the Regatta Committee." Douglass, American Canoe Avociation Yearbook, 13.

${ }^{94}$ The number of races expanded in the period between 1880 and 1910; the list also became more diverse. This expansion took place rapidly at first, from a handful of races at the first meet to 13 at the 1882 gathering, and 22 at the 1883 event. The longest programme was the 1897 meet with thirty races on order. Most years, there were between twenty and twenty-five races on the programme. "American Canoe Association," Forest and Stream, 29 June 1882; "The American Canoe Association," Forest and Stream, 31 May 1883; "Meet of the Canoeists," New York Times, 15 August 1897.

${ }^{95}$ According to the bylaws, the outgoing committee was required to submit a report prior to the fall meeting of the Executive Committee reflecting on the success (or lack thereof) of the recently concluded regatta, and to pass on any potential areas for improvement. Suggestions from the membership, by contrast, were typically solicited when the draft programme was published in the official organs. Douglass, American Canoe Association Yearbook, 14; “The Regatta Programme for 1887," Forest and Stream, 13 January 1887. 
other aspects of organizing, the committee made good on some of the suggestions and ignored others.

There were a number of factors that were taken into account in the creation of the programme. First, the prior success of a race virtually guaranteed its place in the line-up. By contrast, it typically took a few years before the committee would drop a seemingly unsuccessful contest, perhaps to ensure that its failure was not an anomaly. In 1897, for example, the New York Evening Post argued that the unclassified sailing race had been included in the programme since 1890 despite that fact that it had served little purpose in the ensuing years. ${ }^{96}$ Second, the locality and hosts of the meet shaped the programme. For example, during the inland Canadian meets and those hosted by the Northern Division, paddling races were more prominent, as were contests in open canoes. ${ }^{97}$ In part, this reflected the interests of Canadian canoeists. However, it may have also represented efforts on the part of the smaller Canadian contingent to distinguish their regatta programmes from those of their southerly neighbours. This example suggests that the transnationality of the ACA did not preclude the existence and performance of national identities. Third, the programme sought to accommodate new trends in the sport. For example, as canoe clubs began to purchase and race war canoes, the large craft were given their own place in the regatta. ${ }^{98}$

\footnotetext{
${ }^{96}$ The article was equally critical of the gymnastics competition, arguing that it was "useless to all save the canoe-builders, who were called upon to repair the frail boats that had been subjected to such severe handling." "Racing in Canoes," New York Evening Post, 9 November 1897.

97 "Correspondence," American Canoeist 2, no. 1 (1883): 27.

${ }^{98}$ In 1890, the Times claimed: "The novelty of the meet will be a war canoe race, in which the Toronto and Yonkers Clubs, the Red Dragon Club of Philadeplphia, the Kwo-ne-she Club of Trenton, and the Mohicans of Albany will take part." "Fun with Sail and Paddle," New' York Times, 3 August 1890.
} 
Fourth, most programmes were designed to have a broad appeal for competitors in order to encourage participation from a wide range of canoeists. ${ }^{99}$ The organizers of the 1885 regatta, for instance, claimed that their programme provided "for races of all kinds, for those who have never sailed or paddled a canoe, for those who have extreme racing outfits, and for those who have only a cruising boat and rig, but their tendency is strong in encouraging the all round paddling and sailing canoe, and specially to encourage paddling which is apt sometimes to be sacrificed to sailing powers. ${ }^{100}$ Races were constantly being added to the programme to encourage the participation of new contestants. A relay race was included in the 1898 programme, for example, in the hopes that "such an event [would] bring larger delegations of good paddlers to camp, and also increase club rivalry to a greater extent than now exists." ${ }^{\text {101 }}$ Participation was an ongoing concern at the meets, one that only increased in the 1890 s as the number of contestants dwindled. ${ }^{102}$ At the 1886 meet on Grindstone Island, for instance, there were 323 entries for the regatta and 228 starters. ${ }^{103}$ Five years later, there were only 40 names on the entry list. ${ }^{104}$ There are a number of possible explanations for the decline in participation. The New York World cited competition from other small craft, ${ }^{105}$ while Herman Dudley suggested that alternative sports requiring less physical exertion, such as golf and automobile touring, were to

\footnotetext{
${ }^{99}$ The organization's response to declining participation was not limited to introducing new races. They also sought to change the rules. For example, the 1897 regatta committee recommended the abolishment of the one-man one-canoe rule. MSCRC, Volume 4, Report of the Regatta Committee, 1897.

100 "The Association Meet," Forest and Stream, 6 August 1885. Such efforts, like The Record, were also part of the broader commitment to creating well-rounded canoeists.

101 "Racing in Canoes," New York Evening Post, 9 November 1897.

${ }^{102}$ Caspar W. Whitney, "Annual Meet of the American Canoe Association," Harper's Weekly, 2 September 1893; "Dancing at the Camp," New York Times, 19 August 1895.

${ }^{103}$ MSCRC, Volume 3, Annual Meeting, 27 August 1886.

104 “The ACA Meet of 1891," Forest and Stream, 20 August 1891.

105 “Two Weeks of Canoeing," New' York World, 9 August 1896.
} 
blame. ${ }^{106}$ R.B. Burchard pointed to professionalism: "As the requirements for racing have become more exacting because of the proficiency of the few, many have withdrawn from the ranks of racing-canoe sailors." ${ }^{107}$ Certainly, the departure of some of the Canadian canoeists and clubs from the Association following the creation of the Canadian Canoe Association in 1900 was influential, although this was more a slow leak than a mass exodus. ${ }^{108}$ It is unclear what effect recessions or depressions had on the meetings. However, it is possible that the economic downturns that plagued industrialized countries in the early-to-mid 1890s and arguably right through to World War I may have also played a role. ${ }^{109}$

Fifth, the design of the programme was intended to appeal to spectators, highlighting their importance in confirming the regatta as an event. ${ }^{110}$ This is perhaps most evident in the numerous and varied novelty races that were part of the programme at one time or another. ${ }^{111}$ Such contests with their carnivalesque elements also underscored the regatta as spectacle. Most novelty races recalled schoolyard games or fair contests; canoe tug-of-war, hurry-scurry, jousting, hand paddling, and canoe gymnastics were all popular with audiences. ${ }^{112}$ Also common were contests

\footnotetext{
${ }^{106}$ Hermann Dudley Murphy, "Lovers of the Canoe," Boston Evening Transcript, 3 August 1909.

${ }^{107}$ Burchard, "The Real Canoeing," 78.

${ }^{108}$ For example, the war canoe race at the 1899 meet featured seven crews (all from Canada). Five years later, there were only two entries in the same contest. "At the Canoe Camp," Buffalo Morning Expreat, 15 August 1899; "Commodore is Here," The Pout Exprets, 23 August 1904.

${ }^{109}$ Charles Hoffmann, The Depression of the Nineties: An Economic Hittory (Wesport: Greenwood Publishing, 1970).

110 The importance of spectators was also reflected in the organization of the programme. For example, the races for the war canoes, which were considered particularly popular, were held on Saturday at the 1904 meet, while the rest of the events were scheduled for Monday to Wednesday the following week. “American Canoe Association," Watertown Re-Union, 13 August 1904.

III There were usually between five and seven such races in a given year.

${ }^{112}$ During the hurry-scurry race, contestants swam to their canoes, clambered aboard and sailed a prescribed before upsetting their boats, righting them again, and returning to the starting line under sail. "Canoe Racing," The New York Timed, 29 September 1889. During the "tournament," two canoeists faced off against one another from the bows of opposing canoes with long poles in hand. The objective was to
} 
between a canoe or a canoeist and an "unlikely" competitor, such as a skiff, a sneakbox or an "Indian." ${ }^{113} \mathrm{~A}$ successful outcome in such a contest re-affirmed the canoeists' belief in the superiority of their craft or colleague. ${ }^{114}$ Those times when the "underdog" proved victorious - as in the case of the "native in his skiff"115 — called into question established understandings of social and technological superiority, although they rarely dismantled such hierarchies. ${ }^{116}$ Rather, participants and spectators alike found ways to explain the "anomalous" outcome. Novelty races were not just for the spectators. They were also used by the committee to offer a challenge to canoeists and, ultimately, to boost participation. Of course, catering to spectators and participants were not mutually exclusive ends, as the follow comment about a proposed club relay race in 1897 makes clear: "The event will surely prove one of the most interesting of the whole programme, from the spectators standpoint, and it can hardly fail in its purpose in increasing interest in the races generally."117

Finally, the addition of trophy and challenge races were acts of legitimation. Ostensibly intended as an assessment of national difference - observers claimed that

unseat your opponent. "American Canoe Association," New York Herald, 16 August 1886. Canoe gymnastics were introduced at the 1882 meet. The New' York Sun reported that: "These gentlemen walked the entire length of their canoes on deck, stood on their heads in the cock pits, turned back summersaults into the water." "Canoe Racing on Lake George and Trotting in Rochester," New York Sun, 12 August 1882.

113 "The Association Meet," Forest and Stream, 21 August 1884; "The Canoe Beat the Skiff," New' York Times, 15 August 1893; Eckford, "Camp Grindstone," 506. A sneakbox is a small decked "duck-hunting skiff that first appears in South Jersey's backwaters in the mid-nineteenth century." Mary Hufford, "'One Reason God Made Trees': The Form and Ecology of the Barnegat Bay Sneakbox," in Senve of Place: American Regional Cultures, eds. Barbara Allen and Thomas J. Schlereth (Lexington: University Press of Kentucky, 1990), 40-57.

${ }^{114}$ This was certainly true of the following 1884 race: "It is pretty certain from their relative performances that a good canoe has nothing to fear from a sneakbox of anything like equivalent size." "The Association Meet," Forest and Stream, 21 August 1884.

${ }^{115}$ Eckford, "Camp Grindstone," 506. This language of the native versus the canoeists highlights the whiteness of the category "canoeist."

${ }^{116}$ Gail Bederman describes a similar outcome following a prizefight between Jack Johnson (black) and Jim Jeffries (white) in the opening pages of Manlinets and Civilization.

117 "Racing in Canoes," New York Evening Post, 9 November 1897. 
the appeal of the races was that they would "test the comparative merits of the radically different methods of sailing in vogue among American and English canoeists" - the International Challenge Cup, which was introduced in 1886, was a (pale) imitation of the America's Cup. ${ }^{118}$ Nevertheless, the Cup was a highlight of the meet in the late 1880 s and early 1890 s. In addition to positioning the ACA as a national organization of international repute, the race was also the kind of high profile event that drew both competitors and spectators. In 1886, the presence of English canoeists Warrington Baden-Powell and Walter Stewart "brought to the meet many of the best sailors of the association to defend the cup," as well as excursionists from throughout the Thousand Islands. ${ }^{119}$

While canoeists were always quick to offer advice as to how the programme could be improved, it was uncommon for suggestions to be anything but civil. In the late 1890s, things took a decidedly different turn. The first sign of trouble came at the 1897 meet on Grindstone Island, from which the New York Herald reported:

The racing men are at odds with the Regatta Committee because the latter body is strictly enforcing the rules. The rules on which the committee now insist provides that no canoes shall be entered at any one meet by more than one man; that the crew of each canoe shall consist of one man only unless the programme of the regatta states the contrary; that members must paddle or sail their own canoes; and that a canoe which is not owned or used for racing by any other member present shall be deemed to be the canoe of the member bringing it to camp. ${ }^{120}$

The New York Sun added, "For living up to these rules the committee has become unpopular in the camp, especially with the Canadians, who fear that one of their best

\footnotetext{
118 "With Sails and Paddles," New York Herald, 23 August 1886.

119 E.L.F., "The Canoe Meet," Buffalo Daily Courier, 25 August 1886; “The Canoe Fleet Disbanded," New' York Herald, 28 August 1886.

120 "In Canoes at Clayton," New York Herald, 17 August 1897.
} 
paddlers, McDougall, will be disqualified." ${ }^{\prime 21}$ If the ensuing silence is any indication, the canoeists' fears were unfounded. However, tensions re-surfaced two years later. The Sun reported from Hay Island that on a day of light wind the sailors "employed a portion of their spare moments in adverse criticism of the Regatta Committee" for "acting with undue obstinacy in adhering to its programme of races." ${ }^{22}$ The central issue was the committee's decision to forego the trial sailing race, which Association rules mandated was to precede the trophy sailing race. The committee maintained that the trial race, which was intended to limit the field of competitors in the trophy race to 15, was superfluous with such a small number of entries, regardless of the rules. On the day of the trophy race, hostilities reached a head, when "some of the canoeists formed themselves into a 'sailors' union,' protested, and went on strike." ${ }^{23}$ As part of their demands, they urged the regatta committee to resign, a request that went ignored. The Rocbester Democrat Chronicle deemed the race a "flat failure owing to the refusal of the sailing fleet to enter any of the sailing races." In the end, Charles Archibald, of the Ottawa Canoe Club, much like a scab crossing a picket line, "sailed over the course alone and claim[ed] the handsome trophy" for his own. ${ }^{124}$ The rest of the programme appears to have been run, although it is unclear how the dispute affected entries. We should not overlook the deep irony of the canoeists forming a union and going on strike in a period of labour unrest and volatile class relations, just as we cannot ignore the performances of race that were so popular at the meets. ${ }^{125}$

\footnotetext{
121 "Sailing and Paddling Races at the ACA Camp at Clayton," New' York Sun, 18 August 1897.

122 "Canoeing," New York Sun, 10 August 1899. The article blamed the intransigent regatta chairman "who seems to be neither in sympathy with the racing men nor willing to entertain their desires."

${ }^{123}$ W.S. Buell, "The American Canoe Association - The Meet of '99," Outing 35, no. 1 (1899): 88.

124 "Canoe Race Flat Failure," Rocberter Democrat Cbronicle, 13 August 1899.

${ }^{125}$ Richard Schneirov, Shelton Stromquist, and Nick Salvatore, eds., Tbe Pullman Strike and the Crisi of the 1890: Eavays on Labor and Politica (Chicago: University of Illinois Press, 1999).
} 
Perhaps the most visible protest with the farthest-reaching consequences was the founding of the Canadian Canoe Association (CCA) in 1900. There are conflicting reports as to what prompted Canadian canoeists to form the CCA. Canadian papers claimed war canoe teams felt unfairly treated at the 1899 meet. ${ }^{126}$ Forest and Stream, by contrast, maintained that it was a fiscal matter. ${ }^{127}$ Regardless of the motivations, that such examples of open antagonism between the canoeists and the organizing committee/organization have survived suggests that these were not isolated incidents, but were part of ongoing tug-of-war over the form and content of the organization and the programme. They are also further evidence of hierarchies of power within the Association, despite its claims to egalitarianism. Finally, these challenges to the programme reveal the extent to which the "scripts" of the performances were prescriptive but not determinative. In other words, programmes and rules quite openly sought to structure the scenes of the regatta. However, both the "actors" (canoeists) and the "audience" (spectators) could and did negotiate with and within the rules set down for them.

\section{Theatres of Contest}

The broad contours of the regatta landscape changed when the encampment was a mobile event; the shoreline of Long Island, for example, presented a different scene than that of Stony Lake. Even when the meets settled at Sugar Island and there was greater continuity from year-to-year, the landscape was not static. There were, however, common elements to the various theatres of contest: water, land, and buoyed

\footnotetext{
${ }^{126}$ Hoffman, “American Canoe Association," 47.

127 They argued that those canoeists who only wished to compete in the ACA's war canoe races, but did not otherwise have any "special interest in the Association," did not want to have to pay the necessary membership and camp fees, which for a war canoe team could run upwards of $\$ 75$. Given that there were rarely more than two war canoe races at the ACA, the crews felt this was an unreasonable rule. "Canoeing," Forest and Stream, 7 April 1900.
} 
courses. With the exception of the 1880 meet, the ACA regattas always featured two types of courses: a triangular sailing course, and a straightaway paddling course. ${ }^{128}$ As I discussed in Chapters Two and Five, these were usually surveyed in the winter months, along with the campsite. ${ }^{129}$ Surveys were expected to be accurate; the regatta committee was praised when they succeeded and castigated when they did not. ${ }^{130}$ Amongst other things, accurate surveys helped to ensure a level playing field, which fulfilled the amateur aspiration to "fair play." As with yachting races, the surveyed courses were marked off by buoys or stake boats. ${ }^{131}$ These were placed during the first week of the encampment (if not before) so that those in attendance could practice on the course. ${ }^{132}$

The positioning of the courses reflected a number of environmental and social concerns such as tides, current, winds, and spectators. Tides and currents were best avoided in both types of events. However, as I noted in Chapter Three, sailing races were uninteresting without wind, while too much wind impeded paddling contests. Thus, the sailing courses were typically situated out in the open water on the windward side of the encampment with the paddling courses closer to shore on the leeward side. As we see in Figure 8.2, some years the regatta committee created multiple courses in an effort to ensure amenable conditions. Even the best efforts at

\footnotetext{
${ }^{128}$ At the first meet, both paddling and sailing races were run on a straightaway course. "The Canoeists' Convention," New' York Evening Telegram, 5 August 1880.

129 "The Annual Canoe Regatta," Forest and Stream, 21 April 1881; "The Association Meet," Forest and Stream, 21 August 1884; "ACA Regatta Rules, etc. - Suggestions," Forest and Stream, 27 September 1888; "The ACA Meet of 1891: Race Week," Forest and Stream, 27 August 1891.

${ }^{130}$ The importance of accuracy makes the following comment from an account of the 1902 meet somewhat perplexing: "The course was one buoyed out in the day without the formality of a measurement." "War Canoe Race," Auburn Arguw, 19 August 1902.

131 "Canoeing," New York Evening Post, 19 August 1891; Lorgnette, "A Woman," 421-4. 132 "Canoeists in Camp," New York Herald, 2 August 1885; "Arrivals at Canoe Camp," New' York Times, 16 August 1895; "Canoeing," New York Sun, 10 August 1899.
} 
locating the courses did not guarantee environmental cooperation. While they could place the buoys, the committee could not control the wind and water. Equally important was the location of the course relative to the encampment. Races, and by extension the racecourses, were to be visible to spectators. ${ }^{133}$ Thus, paddling courses like those in Figure 8.2 were often located parallel to the shoreline so that the spectators could watch the contests with ease from start to finish. ${ }^{134}$ Sailing races were harder to position because of the triangular shape of the course. Most committees, thus, placed the start/finish line near to the shore.

Much as in Figure 8.1, photographs of the regattas show clusters of people gathered along the shoreline, on hillsides, and in watercraft pursuing the best view. ${ }^{135}$ Spectators appear to have been relatively evenly split between land water. While some claimed that "a much better view of the whole course could be gotten" on the shore, others complained about the difficulty of telling "which is which when the little bits of things are way off over the bay, rounding an outer mark."136 Opera glasses were one solution. ${ }^{137}$ Alternatively, spectators could take to the water to follow the action, both literally and figuratively. ${ }^{138}$ The regattas were social affairs as much as sporting ones. Thus, as important as being able to see the race was one's proximity to friends and family. One young woman revealed, "we appear to be watching the races, though the actual events are often forgotten, as the running fire of talk and laughter plainly

\footnotetext{
${ }^{133}$ MSCRC, Volume 3, Meeting of the Executive Committee, 23 November 1889.

134 "The ACA Meet: Race Week," Forest and Stream, 28 August 1890.

${ }^{135}$ One young woman decided that watching the races from a canoe was advantageous because you had the interesting things pointed out to you, while you "quietly rest in a most comfortable position at one end and let bim do all the work at the other." Flip, "The Lake Champlain Canoe Meet," Outing 11, no. 3 (1887): 264.

${ }^{136}$ Lorgnette, "A Woman," 422; Flip, "Lake Champlain Canoe Meet," 263.

${ }^{137}$ See, for example, NYSHA, 1.1/25, "Watching the Trophy Race from West Shore," 1887.

138 "Canoes on Kill Von Kull," New York Times, 25 June 1882.
} 
attests."139

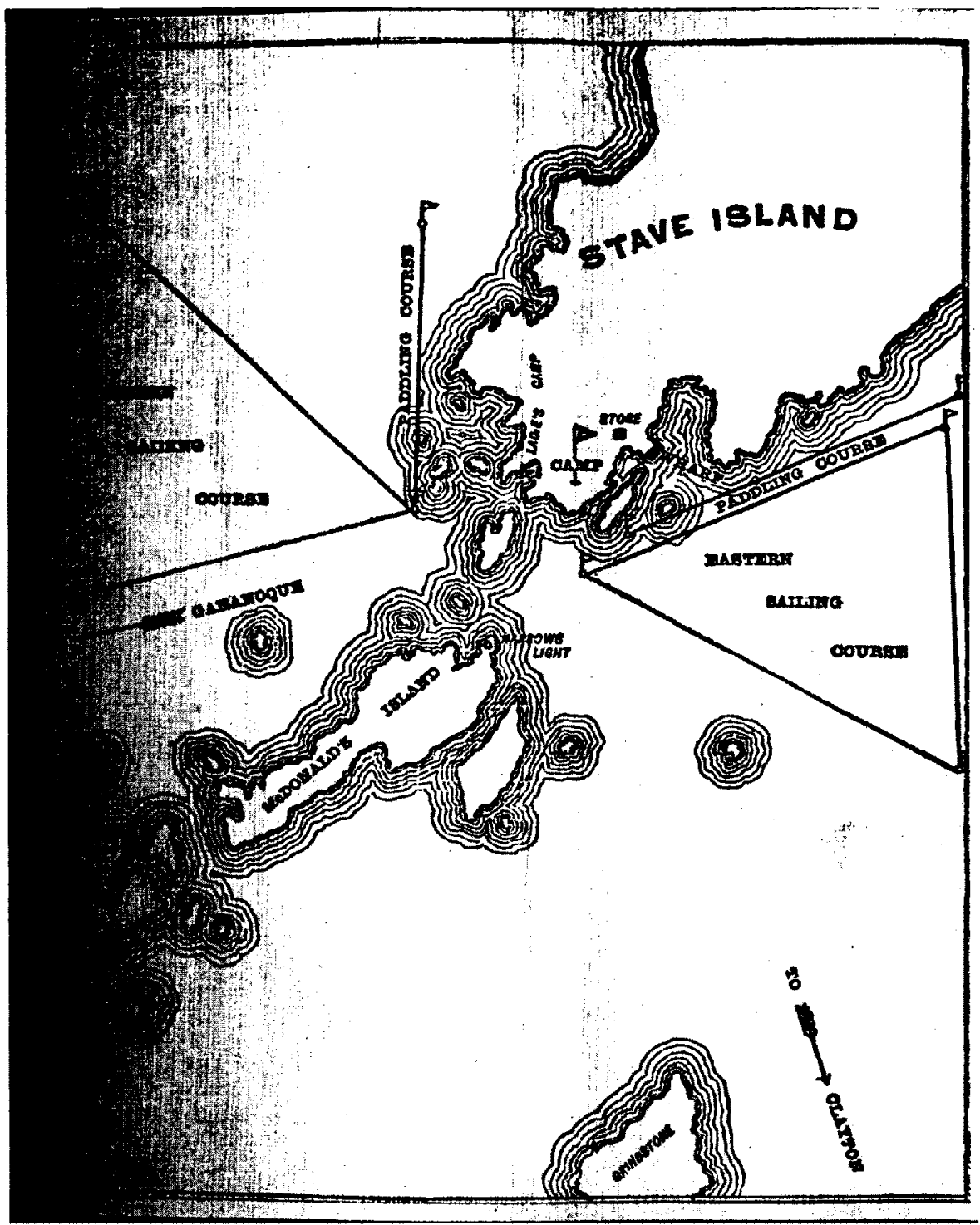

Figure 8.2 - Course map from the 1889 meet on Stave Island. [Source: NYSHA, 1.6/12.]

The Players

The cast of the ACA regattas was large, featuring at times upwards of 2000 performers. ${ }^{140}$ There were three broad roles available: competitor, spectator, and official. These were not discrete entities; most competitors spent time as spectators and

${ }^{139}$ Flip, “Lake Champlain Canoe Meet," 263.

140 "The Thousand Isles," New York Times, 25 August 1889. 
officials often took part in the contests, as racers were one of the few groups willing to officiate. ${ }^{141}$ Women almost exclusively played the role of spectator, although beginning in 1890 , there was usually one or two opportunities on the programme for them to perform as competitors. ${ }^{142}$ This situation was not unique to the ACA. Over the course of the nineteenth century, sport generally "came to be forcefully and graphically depicted as the 'natural' province of males." 143 Women were, in most cases, relegated to the audience and positioned as consumers rather than producers of sport. ${ }^{144}$ Their marginal place reflected nineteenth-century standards of femininity, as well as ideas about women's bodies. ${ }^{145}$ In particular, their participation was circumscribed by the belief that women were not physically capable of demanding physical pursuits or the related notion that vigorous exercise would in some way imperil their femininity and/or reproductive capabilities, which in turn would spell "race suicide" for Anglo-North Americans. ${ }^{146}$ Of course, the late nineteenth century was also the time of the "New

${ }^{141}$ Not everyone was successful at managing their dual role: "There was nominally a Regatta Committee, but its members were generally contestants in the races, and the spectators, in most instances, had to determine who won." "The Canoe Men's Holiday," Neu' York Timed, 14 August 1881.

${ }^{142}$ Even if a contest was absent from the programme there is no guarantee that it did not take place. This is true of the ladies' tilting competition in 1906, which was not part of the formal programme, but for which there is photographic evidence in the NYSHA archive. Thus, it is certainly possible that women were participating in scratch races prior to 1890 , but also in greater numbers than official accounts suggest. The photograph is reprinted in Lawrence E. Zuk, ed., American Canoe Association 100th Anniversary Yearbook (Concord: Minuteman Printing, 1980), 13.

${ }^{143}$ Roberta Park, "Sport, Gender, and Society in Transatlantic Victorian Perspective," The International Journal of the History of Sport 24, no. 12 (2007): 1572. See, also, Kidd, Struggle for Canadian Sport, 26; Bouchier, Love of the Game, 132.

${ }_{144}$ I borrow this phrase from Colin Howell, Nortbern Sandlots: A Social History of Maritime Baseball (Toronto: University of Toronto Press, 1995), 75.

${ }^{145}$ To borrow from Patricia Vertinsky, "medical shibboleths about female physical activity have quite naturally reflected popular beliefs about the nature of women, their biological purpose and their social role." Patricia Vertinsky, The Eternally Wounded Woman: Women, Doctors, and Exercire in the Late Nineteenth Century (Toronto: St. Martin's Press, 1990), 1.

${ }^{146}$ Vertinsky, The Eternally Wounded Woman; Wendy Mitchinson, The Nature of Their Bodies: Women and Their Doctors in Victorian Canada (Toronto: University of Toronto Press, 1991); Helen Lenskyj, "Moral Physiology in Physical Education and Sport for Girls in Ontario, 1890-1930," Proceeding $4: 5 t h$ Canadian Symposium on the History of Sport and Pbysical Education (Toronto: University of Toronto Press, 1982), 139 50 . 
Woman" and the "Gibson Girl," the former embodying physical and political independence and the latter representing a new ideal of beauty that was athletic in its orientation. ${ }^{147}$ Dress reform had begun to release women from the physical constraints of rigid corsets and voluminous petticoats. ${ }^{148}$ There was also a growing cadre of physicians and physical educators who advocated for women's participation in athletics. ${ }^{149}$ Perhaps not surprisingly, their support was often couched in the language and values of white middle-class motherhood. "A reinvigorated motherhood," reformers argued, "would allow the 'fittest' race to expunge weaker strains and take its natural place stop the social order. ${ }^{150}$ Even as their opportunities to be physically active proliferated, women were encouraged to pursue "moderate and lady-like forms of exercise." ${ }^{" 51}$ To do otherwise was to risk the coarsening effects of physical activity. Leisurely paddling, in other words, was preferable to racing. ${ }^{152}$

We can only imagine what might have transpired to prompt the running of a woman's race at the 1890 meet; the regatta report only states that "several extra events were called," including a ladies' paddling race. ${ }^{153}$ Based on extant accounts, we know the audience responded positively to the contest. The New York Times called the event

\footnotetext{
${ }^{147}$ Patricia Marks, Bicycles, Bangs, and Bloomers: The New Woman in the Popular Prest (Lexington: University of Kentucky Press, 1990). The "Gibson girl," Lois Banner argues, was patrician, athletic, and wellproportioned. Lois Banner, American Beauty: A Social History through Two Centuries of the American Idea, Ideal, and Image of the Beautiful Woman (New York: Knopf, 1983).

${ }^{148}$ Kathleen E. McCrone, "Women's Sport and Dress Reform," in Playing the Game: Sport and the Physical Emancipation of Englist Women, 1870-1914 (Lexington: University of Kentucky Press, 1988), 216-46. McCrone notes, "It is difficult now to appreciate fully the extent to which clothing affected the physical activities of Victorian women. Tightly laced corsets, tight-fitting bodices, tight sleeves and arm holes, and long, heavy, flowing skirts severely restricted the movement of the chest, abdomen, arms and legs, and seemed purposely designed to prevent participation in any form of genuine exercise." (219)

${ }^{149}$ Howell, Northern Sandlots, 81-2.

${ }^{150}$ Susan K. Cahn, Coming on Strong: Gender and Sexuality in Twentietb-Century Women's Sport (New York: Free Press, 1994), 28-9.

${ }^{151}$ M. Ann Hall, The Girl and the Game: A History of Women's Sport in Canada (Peterborough: Broadview Press, 2002), 20.

${ }^{152}$ Other acceptable pursuits included croquet, figure skating, golf, and lawn tennis, activities in which "the 'grace and bearing' expected of 'ladies' could be maintained." Kidd, Struggle for Canadian Sport, 27.

${ }^{153}$ MSCRC, Volume 3, Meeting of the Executive Committee, 1890.
} 
"a most exciting and interesting one," 154 in which "the ladies in the winning canoe paddled beautifully, with a powerful, even stroke from the start and deserved all the applause they got from the watching crowd."155 The success of the race is also underscored by the fact that the following year, there were two races for women on the programme: a tandem paddling race and single paddling race. ${ }^{156}$ In the years that followed, races such as these or mixed events were a common if marginal part of the line-up. ${ }^{157}$ The ACA's treatment of women's races says much about the organization's perception of them as athletes, perceptions that fit neatly with contemporary associations between women and athletics. First, women's races were often scheduled outside of the official race days. ${ }^{158}$ Second, they were always classified as "Other" or "Novelty," alongside events such as the "upset race" or "hurry-scurry." 159 Third, women's races were physically shorter than men's contests. ${ }^{160}$ Finally, women's participation was limited to paddling races. Presumably, canoe sailing was seen as a technically demanding sport to which women were ill suited.

154 "The Canoe Men in Camp," New' York Times, 17 August 1890.

${ }^{155}$ The article concluded, "No time was taken, but it is safe to say that not twenty teams of men in the camp could beat it." The failure to note the time is yet another example of the ways in which the women's races were different from the men's. The 1896 meet is somewhat of an anomaly in that two of the four races featuring women were timed events. Thomas H. Stryker, ed., American Canoe Asdociation Yearbook (Rome: Press of the Rome Sentinel, 1896), 60-1.

156 "Canoeists Greatly Interested," New York Time', 25 August 1891. These same races were part of the programme in 1897 and 1898 as well. "Canoeing," Outing 31, no. 1 (1897): 97; "Canoe Races for Women," New York Times, 11 August 1898.

${ }^{157}$ Stryker, American Canoe Astociation Yearbook; MSCRC, Volume 4, Special Meeting of the Executive Committee, 11 August 1899.

${ }^{158}$ At the 1891 meet on Lake Champlain, for example, the women's races were held after the end of the regatta, by which time a good portion of the campers had already left the encampment. "The ACA Meet of 1891: Race Week," Forest and Stream, 27 August 1891.

${ }^{159}$ Similar views existed in other fields of sport. Colin Howell has shown how women's baseball teams were "tolerated because of their 'novelty' or 'entertainment' value rather than from a sense of the legitimacy of their involvement in a more egalitarian social order." Howell, Nortbern Sandlotv, 86.

${ }^{160}$ A women's paddling race typically covering at most a quarter-mile, while men's paddling races were at least a half-mile. 
Not everyone shared the belief that women were less capable canoeists than men. For example, the Syracuse Daily Standard declared the Squaw Point paddlers "very skillful": "They easily paddle five miles an hour and many do much better. When the races take place they push down the trim little canoes to the water, launch the canoes themselves, skip aboard, grasp the paddle and are off. Being light, they fairly fly over the water." Unfortunately, they faced an added challenge, a mysterious "handicap," without which they "would undoubtedly make records for canoeing annals."161 Similarly, the New York Sun observed that the women at the 1894 camp "were not of the type that put on nautical-looking garments and sit demurely on a yacht's deck...On the contrary they could paddle and sail canoes like veterans, could get out on the end of the sliding seat or 'hiker,' and with sails drawing taut and the lee rail awash sneak into the eye of a twenty-knot blow, and with their dainty little craft obedient to their slightest touch on the tiller, laugh at the common sailboats and skiffs that lumber through the heavy seas." ${ }^{162}$ They even have "muscles...hardened by the constant exercise of handling sail and paddle." ${ }^{.163}$ In the next breath, however, the paper assured its readers, " $[t]$ he canoe girl, is nevertheless, as delightful a piece of femininity as exists. Robed in a fetching gown she can pour tea at a 5 o'clock affair in the city with as demure an air as anybody, and without giving a suggestion of the muscle and daredevilry she possesses." In this qualifying statement, we see the author attempting to counter the view that canoeing broadly, but paddling specifically somehow subverts a women's femininity.

\footnotetext{
${ }^{161}$ It is likely that "handicap" refers either to physical strength or menstruation. "Paddling Their Own Canoes on the St. Lawrence," Syracuse Daily Standard, 31 May 1896.

${ }^{162}$ This account is particularly unique for suggesting that women could be competent sailors. Most only addressed them as paddlers.

163 "Canoists [sic] Break Camp," New York Sun, 29 July 1894.
} 
The vast majority of the competitors were not just men they were also white. I have found only a handful of exceptions to this fact, although there may have been others. ${ }^{164}$ At the 1881 meet on Lake George, for example, "an Indian race" in "real old birchbark canoes" was run off Crosbyside. Louis Tahamont and Joseph Dufflin, whom the Times characterized as "a young Frenchman, who [had] grown up among the Indians," won the race and the purse. However, the Timed opined that they did so "without showing extraordinary speed" and that there were " 20 white canoeists on the lake who could easily beat them." 165 Such statements, like those accompanying descriptions of races between a canoe and sneakbox, served to re-orient and re-assure the reader or spectator in the face of information which could subvert one's sense of the world, and its seemingly "natural" hierarchies. Gilllian Poulter has shown in the case of lacrosse how even as "Native players were admired for their skill and physical capacities," they were "considered inferior to white players since these were said to be innate abilities unrelated to intellect."166

Finally, a word is required on "differently abled" competitors, a subject that has received limited attention in the sport history literature. ${ }^{167}$ Although I have only found two explicit (and decidedly brief) examples of disabled or differently abled athletes

\footnotetext{
${ }^{164}$ Novelty races featuring indigenous people were a common practice of urban regattas, as I noted earlier in this chapter. With the exception of 1881 , these appear not to have been common at the ACA regattas. Visible minorities also occasionally took part in scrub races. These were not, however, part of the official space of the regatta.

165 "The Second Day of the Regatta," New York Times, 13 August 1881.

${ }^{166}$ Poulter, Becoming Native, 131.

${ }^{167}$ There are exceptions. See, for example, Fred Mason, "R. Tait McKenzie's Medical Work and Early Exercise Therapies for People with Disabilities," Sport History Review 39, no. 1 (2008): 45-70; Steve Bailey, Atblete First: A History of the Paralympic Movement (London: Wiley, 2008). Scholars working in the broader field of sports studies have been more attentive to disability in sport. See, for example, Karen P. DePauw and Susan J. Gavron, Disability and Sport (Champaign: Human Kinetics, 1995/2005); Jennifer Hargreaves, "Impaired and Disabled: Building on Ability," in Heroines of Sport: The Politices of Difference and Identity (London: Routledge, 2000), 174-214; Nigel Thomas and Andy Smith, Disability, Sport and Society (Abingdon: Routledge, 2008).
} 
participating in the ACA meets, it is imperative that these receive mention to begin the process of recovery. Historians of sport can no longer be silent on the historical place of disability in sport, which has long functioned as a normative field of social relations central to the production of "ability" and "disability" as categories of identification and experience. In the first example, visitors to the 1893 meet on Wolfe Island were treated to a race involving Kenneth Cameron, "a one-armed man sailing a racing canoe with a big spread of muslin."168 That the Timed referred to the event as a spectacle reinforces the disabled body as anomalous, although Cameron's success also highlights his capabilities as an athlete. The second example is less an event than an individual. Paul Butler was a long-time member of the Vesper Boat Club in Lowell, Massachusetts, who participated in a number of ACA races in the $1880 \mathrm{~s}$ and $1890 \mathrm{~s}$. Butler is perhaps best known for his creation of the "sliding-deck seat." 169 This innovation, which enabled Butler to get his weight farther out to windward, accommodated the canoeist's small stature. ${ }^{170}$ Butler reportedly weighed $110 \mathrm{lbs}$. and photographs show that he was at least a head shorter than his fellow competitors. ${ }^{171}$ Moreover, his stooped posture suggests he may have suffered from scoliosis of some sort. This assumption is confirmed by W.P. Stephens: "Small in stature and even a cripple (a hunchback), he was sadly handicapped against the agility of sailors like Vaux and athletes like Dr.

\footnotetext{
168 "The Canoe Beat the Skiff," New' York Time, 15 August 1893.

${ }^{169}$ W.P. Stephens, "The Past and Future of American Canoeing, 1880-1900," Forest and Stream, 6 January 1900.

${ }^{170}$ C. Bowyer Vaux, “The Canoeing of Today,” Outing 16, no. 2 (1890): 135.

${ }^{171}$ Maurice D. Wilt, "Canoeing Under Sail" in Sailing Craft, ed. Edwin J. Schoettle (New York: Macmillian, 1928), n.p.; NYSHA, 1.1/20, Photographs from Grindstone Island, 1886; 1.1/33 Photographs from Lake George, 1888; 1.2/6. Photographs from Jessup's Neck, 1890.
} 
Heighway and W.G. MacKendrick." ${ }^{172}$ In spite of these obstacles and Stephens' assessment, Butler was routinely lauded as a crack canoeist. ${ }^{173}$

While the archive is relatively silent on athletes such as Kenneth Cameron and Paul Butler, contemporaries reported widely on the spectators who, not surprisingly, made up the largest contingent of the regatta cast. At the 1890 meet, Forest and Stream observed, "the waters in all directions were covered with sails before colors, and people crowded into camp from all directions; on foot, in carriages and wagons, in steam launches, sloops, catboats, and yachts." ${ }^{.174}$ Their visibility reflected their importance in confirming the races as events in which competition and fair play were displayed and affirmed as virtues. The spectators were the most diverse socially, drawn as they were from the encampment, the surrounding resorts and cottages, and local communities. While the organization sought to limit access to the encampments, they had little control over the watery landscape of the regatta. Thus, it is likely that those in the audience included individuals who would have otherwise been unwelcome at the ACA meets. Surprisingly for an organization that had separate lists of rules for members, campers, and racers, the ACA never issued a code of conduct for spectators.

Race officials constituted the third and final group of players. Officials at the ACA meetings were, like their colleagues in other sports, a key feature of the bureaucracy of modern sport. ${ }^{175}$ As Colin Howell notes, "Those who promoted sport and codified its rules recognized that players and audiences might lose control in the

\footnotetext{
${ }^{172}$ Stephens, Traditions and Memories, 172.

173 "The Canoe Camp," Lowell Courier, 25 August 1888; "The ACA Meet: Race Week," Forest and Stream, 28 August 1890; McMaster University Archives (MUA), Box 9, File 27, Pauline Johnson, "Sail and Paddle," The Illuwtrated Buffalo Exprese, c. 1893; "Fine Sport in Canoes," New' York Times, 1 July 1895. 174 "The ACA Meet: Race Week," Forest and Stream, 28 August 1890.

${ }^{175}$ Allen Guttmann argues that modern sports owe much to the "scientific world-view." Allen Guttmann, From Ritual to Record: The Nature of Modern Sports (New York: Columbia University Press, 1978).
} 
heat of the fray and that disinterested judges were therefore required."176 In addition to functioning as arbiters of decorum, officials represented a more general fascination with technocracy, order, and time in the nineteenth century. ${ }^{177}$ Much as the officer of the day and his pickets encouraged order in the campsite, the race day officials pursued a similar end during the regatta. ${ }^{178}$ At any given meet, the officials might include: clerks of the course, judges, starters, timekeepers, entry clerks, buoymen, and measurers. ${ }^{179}$ While there is no record of women serving as regatta officials at the ACA, they did take on such roles in other locales. For example, there were women starters and timers at the New York Canoe Club races in $1891 .^{180}$

The clerk of the course was considered the most important official beside the committee chairman. ${ }^{181}$ His primary task was to organize the entries and keep the records of the regatta. Some years, an entry clerk provided assistance by overseeing the registration of the canoeists for competition. Whereas the clerk of the course was ideally the same person for the duration of the encampment, timekeepers and buoymen could be appointed on an ad hoc basis. ${ }^{182}$ The latter were responsible for observing the

\footnotetext{
${ }^{176}$ Howell, Blood, Sweat, and Cheer, 89.

${ }^{177}$ Timothy Mitchell, Colonising Egypt (Berkeley: University of California Press, 1991).

${ }^{178}$ Retaw's account suggests that it could be a demanding role: "On regatta morning,...I was hard at work in the headquarters' tent, classifying entries, answering the questions of anxious racers, and settling disputes about 'totems'." Retaw, Fragment, 3.

179 "The Meet of 1884," Forest and Stream, 8 November 1883; "The Association Meet," Forest and Stream, 21 August 1884; "American Canoe Association," Forest and Stream, 28 August 1884. The line-up of officials depended, in part, on the availability of volunteers. There appears to have been some difficulty in arranging for race officials, particularly amongst the "non-racing men," which may explain the overlap between competitors and officials. "ACA Regatta Rules, etc. - Suggestions," Forest and Stream, 27 September 1888.

180 "A New Idea for a Regatta Committee," Forest an $\partial$ Stream, 30 July 1891.

181 "ACA Regatta Rules, etc. - Suggestions," Forest and Stream, 27 September 1888.

${ }^{182}$ David A. Poe, "The Status of the Clerk of the Course," Forest and Stream, 10 August 1889. If there were extra bodies available, the timekeeper may have also had an assistant.
} 
boats as they passed the buoys, one of the prime sites for "foulings." ${ }^{\text {"183 }}$ According to Forest and Stream, buoymen were central to maintaining order for the course, because they "insure[d] more care in management of canoes in a race, a stricter regard to rules, and also avoid the disagreeable duty of one contestant lodging a protest against another on account of fouling." ${ }^{184}$ Finally, there were measurers, whose job it was to guarantee that canoeists conformed to the size regulations in the racing rules. ${ }^{185}$ The existence of an elaborate system of rules, as well as a cadre of officials responsible for overseeing the smooth running of the races suggests that the regatta, like the encampment more broadly, was threatened by disorder. ${ }^{186}$

\section{The Performance}

With the scene set, the cast of characters in place, and the script posted on the bulletin board, the drama could commence. A typical day at the ACA regatta featured anywhere from one to seven races. ${ }^{187}$ The different contests varied markedly in their temporal and physical length. For example, the half-mile "paddling fours" at the 1897 meet lasted just over five minutes, while the winner of the nine-mile trophy sailing race

\footnotetext{
183 “ACA Regatta Rules, etc. - Suggestions," Forest and Stream, 27 September 1888; "American Canoe Association," Forest and Stream, 28 August 1884.

184 “American Canoe Association," Forest and Stream, 28 August 1884; "American Canoe Association," Forest and Stream, 14 October 1886.

${ }^{185}$ There were very clear instructions about how measurements of the canoe were to be taken. Length, for instance, was ascertained by measuring "between perpendiculars at the fore side of the stem and at the aft side of the stern." Tyson, "Sailing Regulations," 297. George Warder documented the measuring of the canoes for the International Challenge Cup in 1886 in photographs. See, NYSHA, 1.1/22, "Viewing the Corpse," 1886.

${ }^{186}$ Certainly canoeists were consistently finding ways to circumvent the rules, particularly in the sailing races, through the introduction of different riggings, sails, and so on.

${ }^{187}$ Seven races were run on 19 August 1901 at Mudlunta Island and 20 August 1902 at the meet on Cape Cod. "Argonauts Take Canoing [sic] Shield," New York Herald, 20 August 1901; "Canoe Crews' Close Races," New York Times, 21 August 1902.
} 
at the 1896 meet crossed the finish line after one hour, 40 minutes, and 55 seconds. ${ }^{188}$ Whereas paddling races were run consecutively, the organizers often combined the long sailing races by staggering the starting times. Even as commentators thought these attractive, they could also pose problems. At the 1884 meet, for example, as the "leaders of the first division were soon even with the rearguard of the last," it was "difficult to place anyone."189

The order of the races, unlike the content of the programme, which was determined by a variety of factors described above, was largely the product of the weather, something no committee could predict. Thus, it was almost inevitable that the schedule of events would change during the meet to accommodate the weather. In some cases, however, last-minute changes were effected to please the audience. This was true of the 1883 encampment when extra races were added on Friday and Saturday for the large number of visitors in camp. ${ }^{190}$ Although the organizers routinely pronounced, "[p]unctuality will be insisted upon," or "[n]o race will wait for any member," it was not uncommon for individual races or a day's programme to run late. ${ }^{191}$ It is telling, for instance, that at the Lake Champlain races George Pell claimed that the regatta committee "gave the whole fleet the cold shivers on Monday by their promptness, so unlike some former committees."192

188 "Canoeing," New' York Sun, 15 August 1897; "Races at the Canoe Camp," Brooklyn Daily Eagle, 26 August 1896. That some of the sailing races had a three- or four-hour time limit suggests they could run much longer. See, for example, "At the Canoe Camp," New York Sun, 25 August 1896.

189 "The Association Meet," Forest and Stream, 21 August 1884.

190 "The Association Meet," Forest and Stream, 30 August 1883.

191 "Programme of the ACA Regatta," Forest and Stream, 8 January 1885.

${ }^{192}$ Lorgnette, "A Woman," 421. Similarly, the regatta committee report of 1886 expressed delight at the fact that people arrived to their races on time, suggesting that this was also an anomaly. MSCRC, Volume 3, Annual Meeting Minutes, 27 August 1886. 
By the time the first race was called, most canoeists had been at work for at least a couple of hours, preparing their canoes. ${ }^{193}$ The best boats had been oiled down, the rigging perfected, and the captains warmed up. The registered canoeists arrived to the starting line - at the 1894 meet, this was marked off by a "barrel buoy, red and white" and a "row-boat with the red flag hoisted above it"194 - decked out in their racing costumes. As there are no photographs of the women's races, it is difficult to know what they would have worn to compete. The only extant regatta photograph (at least to my knowledge) with female competitors features two women wearing long skirts and long-sleeved blouses in the midst of a jousting duel. ${ }^{195}$ Men were much less constrained. They typically wore striped bathing suits. ${ }^{196}$ For team events, competitors usually had matching costumes. ${ }^{197}$ Paddling races and sailing races were started differently. The former were a cold start, meaning that the canoes were stationary when the official asked, "Are you ready?" and then shouted, "Go." ${ }^{198}$ By contrast, the sailing canoes were already in motion when the race officially started. For this reason, they were provided with a series of flags intended to prepare the racers for the final signal. ${ }^{199}$

193 "The Meet of 1886: Race Week," Forest and Stream, 2 September 1886.

${ }^{194}$ Lorgnette, "A Woman," 421.

${ }^{195}$ Zuk, Anniversary Yearbook, 13. British periodical Field opined in 1891, "No sailor can do his work efficiently with long sleeves, a collared button around his neck, and braces on," and yet women appear to have been expected to compete in such restrictive clothing. "Canoeing Costumes," Field, reprinted in Forest and Stream, 30 July 1891.

196 "Paddling Their Own Canoes on the St. Lawrence," Syracuse Daily Standard, 31 May 1896. Field reported, "brilliant striped jerseys and stocking caps are much in vogue, and knickerbockers are nearly universal" amongst American racing canoeists. "Canoeing Costumes," Field.

${ }^{197}$ NYSHA, 1.2/2, "War Canoe Unk-Ta-Hee," 1889.

${ }^{198}$ Douglass, American Canoe Astociation Yearbook, 17.

199 Although the rules dictated the use of an elaborate flag system, pistols were also used as the starting signal. "Notes About the Meet," Forest and Stream, 20 August 1885; "The ACA Meet: Race Week," Forest and Stream, 28 August 1890. 


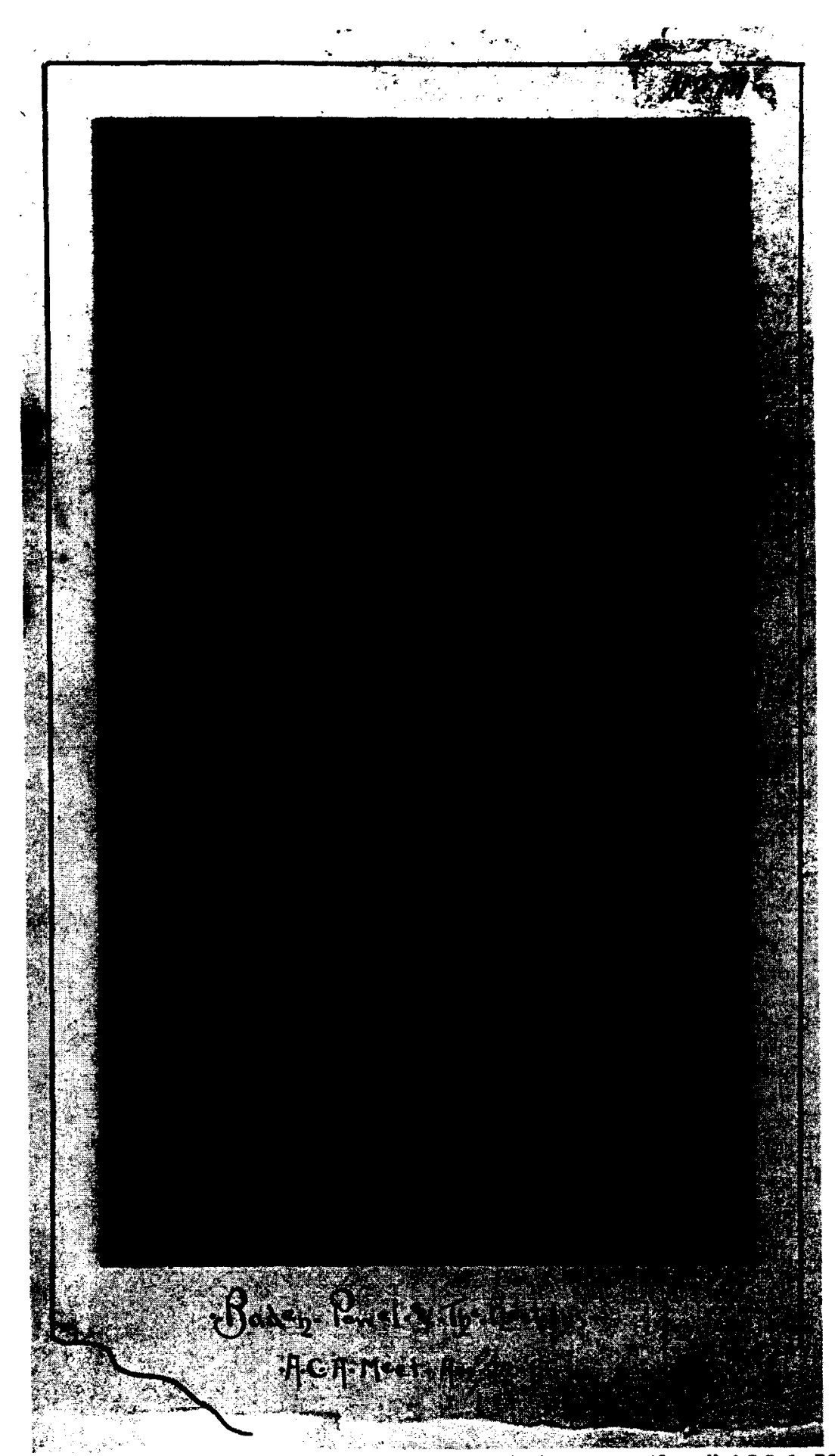

Figure 8.3 - George Warder, "Baden-Powel and the Nautilus," 1886. [Source: NYSHA, 1.1/21.] 


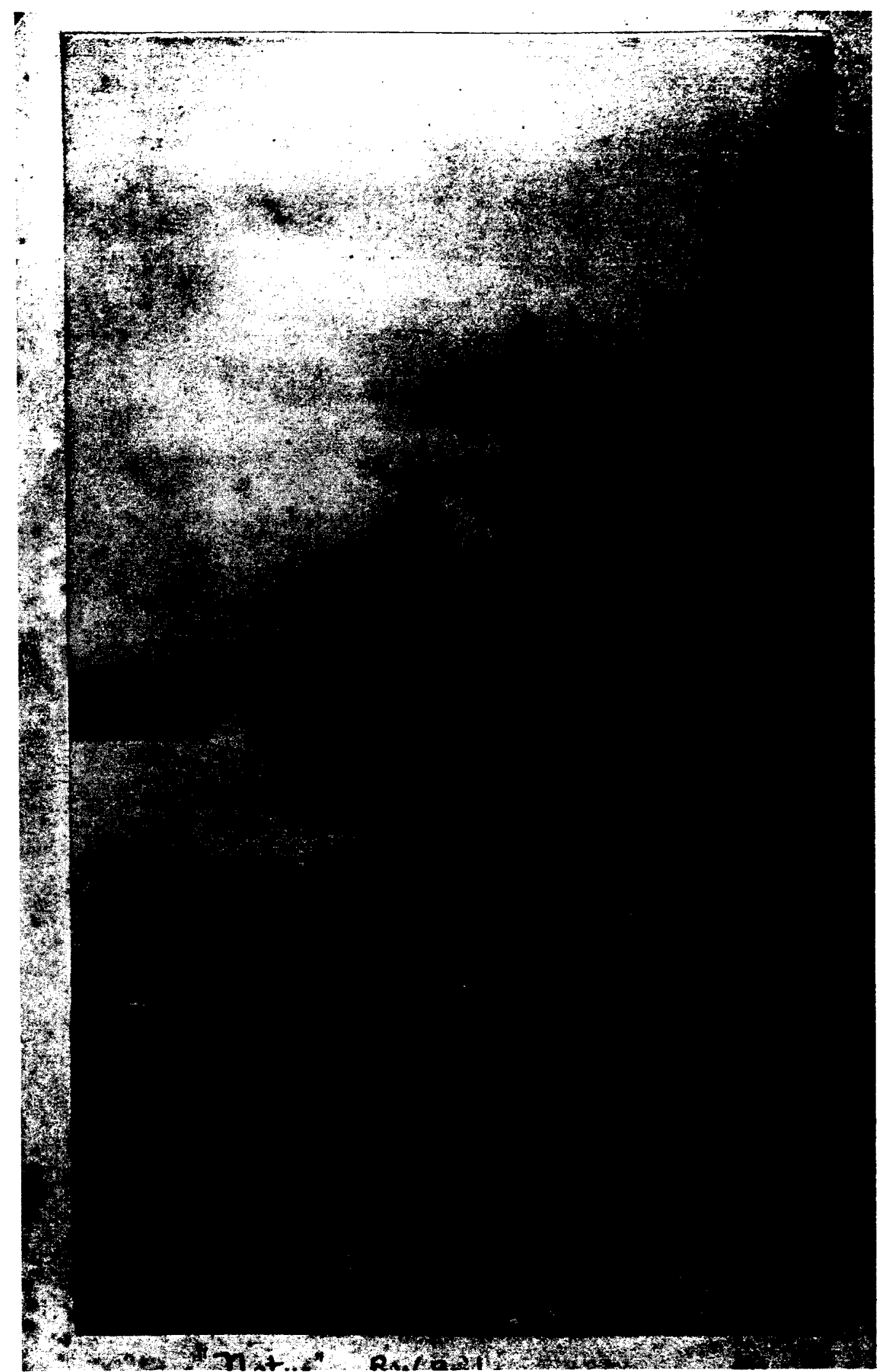

Figure 8.4 - George Warder, "Notus, R.W. Bailey," 1886. [Source: NYSHA, 1.1/22.] 
Competitors occupied a variety of different positions within the canoe during races. The paddling trophy race at the 1891 meet at Willsborough Point provides a good case in point. M.F. Johnson, of Toronto, Ontario, "paddle[d] in a standing position" with his "laced in shoes screwed to the floor boards" and his paddle "about 10ft. long, with spoon blades." Meanwhile, R.G. Muntz, of the Argonaut Boat Club of Toronto, "knelt on one knee" and used a very short paddle (8ft. 9ins.). Finally, Emil Knappe, of the Springfield Canoe Club, sat in the bottom of his boat and used a foot stretcher ${ }^{200}$ Much like their clothing, it is difficult to know how women would have positioned themselves in their canoes. Interestingly, racing form was seen as indicative of national filiation. In the case of paddling races, including the contest captured in Figure 8.1, Canadians were associated with kneeling, while Americans were thought to sit. In sailing races, British canoeists like Warrington Baden-Powell in Figure 8.3 could usually be found tucked in the cockpit of their canoes, while Americans like Reade W. Bailey in Figure 8.4 were typically perched on the deck.

Commentators had a variety of theories as to what determined a canoeist's success. Some highlighted their physical conditioning and form. At the 1884 encampment, for example, Forest and Stream attributed Mr. Johnson's first place finishes in a number of paddling races to his "admirable stroke, long and clean," his "high seat," and "his good condition and powers of endurance." ${ }^{\text {"21 }}$ In tandem or group paddling events, placing well also hinged on teamwork. ${ }^{202}$ Other times, it was a canoeists' craft or rigging. C. Bowyer Vaux owed his first-place finish at the 1885

200 "The ACA Meet of 1891: Race Week," Forest and Stream, 27 August 1891.

201 "The Association Meet," Forest and Stream, 21 August 1884.

${ }^{202}$ Buell, "The Meet of '99," 88. 
regatta to his canoe's "splendid sea going qualities." ${ }^{203}$ While commentators were always making note of new developments in canoes and their rigging, the most up-todate equipment did not necessarily ensure success. At the 1883 meet, for instance, the winner of the novice sailing race boasted "two lug sails and a job, a rig seldom see of late years." In this case, the canoeist won because his boat was "so balanced as to handle perfectly." ${ }^{204}$ Of course, favourable conditions never hurt. At the 1885 meet on Grindstone Island, Mr. Stanton was aided by the winds in the sailing race, "since he had but two tacks to make where other canoes had from four to six laid out for them." ${ }^{205}$

Given that conditions were rarely favourable, more important was the ability to read the environmental situation and respond appropriately. ${ }^{206}$ This was particularly true when the weather was changeable. Whereas contestants in the 1.5 -mile paddling race for sailing canoes at the 1882 regatta were faced with a wind "blowing so fresh from the southward that on the return...the contestants were drenched and their canoes partly filled with water," participants in the next race faced the opposite problem. ${ }^{207}$ Only Commodore Longworth appeared able to make the best of the situation, "while the others, baffled by light winds, struggled behind in constantly varying order." This ability to read conditions was a function of a canoeist's level of experience broadly, but also their knowledge of the specific course. For this reason, scratch or scrub races were an important part of a competitor's introduction to the

\footnotetext{
203 "Notes About the Meet," Forett and Stream, 20 August 1885.

204 "The Association Races at Stony Lake," Forest and Stream, 6 September 1883.

205 "Notes About the Meet," Forest and Stream, 20 August 1885.

${ }^{206}$ The regatta committee provided some assistance by posting "the course and conditions of each race on the bulletin board." Douglass, American Canoe Asvociation Yearbook, 14.

207 "Canoe Racing on Lake George and Trotting in Rochester," New York Sun, 12 August 1882.
} 
racecourses during the first week of the encampment. ${ }^{208}$ Scrub races also provided canoeists with an opportunity to see their fellow sailors or paddlers at work. It was disconcerting for the paddlers at the 1896 meet on Grindstone Island to come up against W.C. Mack of Detroit, "a new and uncertain quantity" because "his practice [was] not taken near the camp, and so the other paddlers [did] not know his gait." ${ }^{209}$ The contestants faced a number of obstacles beyond the weather, both environmental and anthropogenic. For example, during the club fours race at the 1902 meet on Cape Cod, the Winchester boat "got into trouble by a paddle being caught in the sea grass, cramping the boat until she went over and all hands were thrown into the water." ${ }^{210}$ At the 1884 meet, $M r$. Weller's boat was "run down by the steamer $E$. Van Horne, which came across the course as he finished the first round, deliberately running into him in spite of a warning from all on the bank." ${ }^{211}$ Given the chaotic scene of the regattas, it is understandable that the regatta committee found it hard to keep the courses clear of other craft, but also that some years they instituted Police of the Course. ${ }^{212}$ It was not just spectators that posed a challenge, but one's opponents as well. For example, in one race at the 1886 meet, the Wraith and Peggy collided, "carrying away the mainmast of each boat"; the "Sofronia had her rudder unshipped by a collision"; the "Mona broke her deck yoke"; the "Pearl was handicapped by her

\footnotetext{
${ }^{208}$ For example, the New' York Tribune reported in 1902 that "both the Eastern and the Western men promise to show great speed in the races, now that the canoeists are becoming accustomed to the rough water." "Canoe Races on Massachusetts Coast," New' York Tribune, 16 August 1902.

209 "Pleasant Time at the Canoe Camp," New' York Sun, 20 August 1896.

210 "Exciting Contests at the ACA Encampment," Brooklyn Daily Eagle, 19 August 1902.

${ }^{211}$ Thankfully for Weller, his craft "receiv[ed] but little damage," and he went on to win the race. "The Association Meet," Forest and Stream, 21 August 1884.

212 "Last Days of the River Season," Syracure Evening Herald, 30 August 1896; "The Races at Gananoque," Montreal Gazette, 16 August 1899.
} 
leakage"; and the Nautilus impeded by a damaged rudder. ${ }^{213}$ Such collisions occurred frequently in spite of the elaborate rules governing canoeists' behaviour in course. ${ }^{214}$

Although there were officials in place to oversee the fair running of races, canoeists had recourse to lodge complaints if they felt unfairly treated. ${ }^{215}$ Complaints had to be presented in writing within one hour of the end of the race and accompanied by a dollar. Although the money was returned if the protest was successful, the fee discouraged objections, particularly as regatta committees appear to have rarely adjusted their rulings. The protest system functioned like a mini-judiciary. In order to reach a suitable judgment, the Regatta Committee often heard evidence from other contestants or spectators. ${ }^{216}$ If the Committee's position was unanimous, the decision was final. However, if there was some disagreement amongst the members, the canoeist could, with the payment of another dollar, appeal to the Executive Committee. ${ }^{217}$ Despite the perception of transparency and equitability, not all protests

213 "At Grindstone Island," Rocbester Democrat and Cbronicle, 26 August 1886; "The Meet of 1886: Race Week," Forest and Stream, 2 September 1886. It is perhaps surprising given the number of collisions that took place in a given year, that there were not more injuries at the encampments, but $I$ have uncovered very few instances of bodily harm befalling the canoeists. That said, beginning in 1892, the camp staff included a surgeon, and none too soon, for there were two occasions for Dr. Nellis to "stitch up" canoeists that year, although not as the result of a race. "The Camp at Lake Champlain," New' York Evening Pout, 16 August 1892; "The ACA Meet of 1892," Forest and Stream, 25 August 1892.

${ }^{214}$ The racing regulations dictated, for instance, the appropriate method of overtaking another canoe, as well as right of way. They also defined a canoe's "own water." There were a number of infractions that could render a canoeist disqualified from the race. These included accepting "pilotage or direction form any boat or from the shore," and touching a buoy or another canoe ("fouling"). A note in the 1883 Yearbook clarified the former: "This is intended to prevent abuses which might arise from organized coaching and the like. It will not interfere with the inalienable right of encouraging one's friends." Douglass, American Canoe Avociation Yearbook, 16-7; Unknown, American Canoe Association Book (New York: Vaux and Company, 1883), 20.

${ }^{215}$ Protests were not limited to course infractions, but could also address a canoeist's status. For example, at the 1882 meet, a protest was submitted claiming that the winner of the one mile class two junior paddling race, Mr. Johnson of Toronto, ON, already had a challenge cup to his credit. The decision was reversed and the winning prize awarded to the second place finisher, Mr. Emerson. "Canoe Racing on Lake George," New York Sun, 10 August 1882.

${ }^{216}$ The rules also ostensibly provided for conflicts of interest between members of the committee and protest decisions. Douglass, American Canoe Astociation Yearbook, 17.

${ }^{217}$ Douglass, American Canoe Avociation Yearbook, 16. 
were dealt with satisfactorily. At the 1890 meet on Jessup's Neck, for example, the regatta committee failed to post the course for the paddling upset race in advance of the contest. Rather, verbal instructions were given to the canoeists individually. As a result, following the start, "one-half of the men headed one way and the remainder the other. ${ }^{218}$ Two of the competitors who had taken the wrong turn made a verbal protest as soon as the winner's list was posted. This was followed up that evening with a formal protest by the canoeists' home club, the Ianthe of New Jersey. The committee cited procedural oversight, refusing to acknowledge its error and honour the protests because they had not been issued "prior to leaving the boat" and no written protest had been submitted in the hour after the race. The club made a second protest the following day, but once again, the committee declined to even consider their complaint. Whether fair or not, there were in fact few options for canoeists who felt slighted by the regatta committee.

As they made their way around or along the course, the competitors were watched and, in some cases, cheered on by the spectators spread between the land and water. ${ }^{219}$ At the early races on Lake George, periodical accounts suggest that the spectators were particularly engaged in the races. ${ }^{220}$ The diminutive C.B. Vaux of New York, New York, received a standing ovation after he beat the "Giant," Dr. A.E.

218 "The ACA Meet: Race Week," Forett and Stream, 28 August 1890.

${ }^{219}$ They also faced commentary from competitors. Goodsell recalls Paul Butler sitting "idly by in the Wasp calling out to me to be upset so that his club might win." NYSHA, 1.6/2, D.B. Goodsell, $A$ Canoeing Reminiucence (1936), 5.

${ }^{220}$ Even in the early years, not everyone found the races compelling. A Timet reporter at the 1881 meet, for example, did not find the participants particularly skilled. Rather, he hypothesized that the "liliputian sailors" could have been easily put away by "some of our bronzed Long Island fisherman, without any varnish or cushions about their boats." "The Canoe Men's Holiday," New' York Timed, 14 August 1881. 
Heighway of Cincinnati, Ohio, in the upset race. ${ }^{221}$ Race accounts suggest that the canoeists also endured good-natured ribbing from their fellow competitors. D.B.

Goodsell, for example, recalled Paul Butler sitting "idly by in the Wasp calling out to [him] to be upset so that his club might win." 222 Presumably, such commentary was not always pleasant. Later accounts, by contrast, are relatively silent on the spectators' performances. It is possible that this was a function of numbers. R.B. Burchard maintained that at the 1900 meet in Muskoka, "scarce a dozen persons were attracted from the enjoyments of the camp to view the struggle," in spite of the fact that the races were "well contested and spirited." ${ }^{\text {223 }}$ It is also possible that spectators were more subdued.

Interestingly, when the audience receives mention in later years, it is during women's races. For example, the Syracuse Evening Herald reported from the 1896 meet on Grindstone Island, "The events in which the ladies participated excited more than usual interest. The contests though short were watched from start to finish by an eager throng, who with craning necks and shouts of encouragement for the various favorites, cheered the contestants on. ${ }^{224}$ Even at the 1900 meet, with its small crowds, D.J. Howell observed that races in which women took part "aroused more interest among Squaw Pointers than any others. ${ }^{\text {"25 }}$ Work on historical spectatorship is limited, making it difficult to pinpoint the particular appeal of women's races. For men, it may have been the novelty of women's races, although nothing is said of other "novelty"

221 "Canoe Racing on Lake George," New York Sun, 10 August 1882. At another sailing race later that afternoon, the Dot, "gradually but surely drew away" from its competitors and, "amid tremendous applause and blowing of steam whistles." "Canoe Racing on Lake George and Trotting in Rochester," New York Sun, 12 August 1882.

${ }^{222}$ Goodsell, A Canoeing Reminiscence, 5.

${ }^{223}$ Burchard, "The Real Canoeing," 79.

${ }_{224}$ "Last Days of the River Season," Syracute Evening Herald, 30 August 1896.

${ }^{225}$ D.J. Howell, "The International Canoe Meet," The Canadian Magazine 15, no. 6 (1900): 519. 
contests in these accounts. For women, these findings suggest that they particularly enjoyed watching other women compete. ${ }^{226}$

Not all who began the races finished. Usually, competitors bowed out because of injury to their boat or because they capsized. While the latter often proved the end of the race for a participant, it was reportedly quite entertaining for the spectators. ${ }^{227}$ Visitors to the 1883 meet on Stony Lake, for instance, enjoyed watching the boats go "down like tenpins under the rude bowling of old Notus, until but three were left to go over the course. ${ }^{128}$ In some cases, the canoeists were so far behind the pack that they felt it better to exit the race than finish. Leaving a race for whatever reason could strike a blow to the competitor, particularly if they had been favoured to win or if they had travelled a long distance. ${ }^{229}$

The winners of a given contest could usually expect some immediate recognition of their feat. Lorgnette, for example, recalls "going to the cove" following the sailing trophy race to "congratulate the winner" in person. ${ }^{230}$ However, the presentation of prizes was typically saved for a banquet or campfire at the end of the regatta. At the 1881 meet, for example, the canoeists gathered for a seven-course meal in the Crosbyside Hotel dining room. ${ }^{231}$ Following a brief speech by the Commodore,

226 "Lorgnette" confessed that prior to watching a race at Willsborough Point, she had found canoe sailing "an uninteresting subject." In the wake of that race, however, Lorgnette claimed to be able to "uphold the conversation with the zeal of a convert." Lorgnette, "A Woman," 421.

${ }^{227}$ "The Canoe Meeting," New York Times, 20 August 1881.

228 "The Association Races at Stony Lake," Forest and Stream, 6 September 1883.

${ }^{229}$ Lorgnette, "A Woman," 423. As Lorgnette noted, "It must be very irritating to work so long and hard and come so far, and then have to drop out of the race almost at the very start," particularly if one had travelled a great distance.

${ }^{230}$ Lorgnette, "A Woman," 424.

${ }^{231}$ A menu for the meal appears in NYSHA, 1.6/12. 
canoeists (usually women from Squaw Point) bestowed flags, shields or trophies on the deserving canoeists. ${ }^{232}$

\section{Conclusion}

If a curtain could have fallen on the performance that was the yearly regatta of the American Canoe Association, it would have done so following the presentation of the prizes. Instead, the campers either continued their campfire revelries, or they made their way to the fire pit from the mess tent as they did so many other nights. The regatta was at once a unique and typical component of the annual meetings of the ACA. On the one hand, the onset of the races reconfigured the landscapes of the meet, introducing new forms of activity and patterns of movement and interaction amongst the campers. The scale of the races also set the regatta apart; none of the other spectacles on offer at the meetings lasted as long or drew as large a crowd. Yet, for many of the campers, these changes were familiar, part of the yearly ritual of attending the meets. Even those new to the encampments would have noticed that a number of the rhythms of encampment life such as meals in the mess tent and evenings passed by the campfire were little affected by the races. The same could be said of the disciplinary structures in place to govern the encampments and the campers. If anything, efforts to order the encampments were amplified during the regatta with the addition of another set of rules to govern the canoeists' practices. Finally, the regattas while on a larger scale than the other spectacles were still just that: spectacular

\footnotetext{
${ }^{232}$ Women's involvement here may have been a consequence of their role in producing flags. It may also have been a manifestation of their assumed athletic inferiority and the sense that they were better suited to the more decorative role of prize-giving. It certainly had the effect of furthering consituting them as ancillary to competition and not as athletes in their own right.
} 
performances, in which certain scripts were followed and certain characters allowed on stage.

The regatta as performance is confirmed by the myriad ways in which the organizers sought to accommodate spectators including the layout of the course, the content of the programme, and the organization of the schedule. Spectators validated the annual regatta as an event. Competitors likely also played to their audiences, although this is harder to quantify and qualify. As Greg Dening notes, "we sometimes have captive audiences who will endure much to be supportive." ${ }^{\prime 23}$ More often than not, however, the performer must read their audiences' reactions and respond appropriately. That interest in the races waned over the course of this period suggests that the competitors failed somehow in their efforts.

The regattas were unique and typical in other ways as well. For example, the presence of official races on the programme made the ACA meets more than just an encampment; they constituted the event as a space of serious competition with national and international significance, and in doing so legitimized the ACA as a national sporting body, even as it was anything but. However, like organized sport broadly, the regatta highlighted contemporary concerns about amateurism and professionalism. As in these other institutions, the divide between the two categories for the ACA was never clear (if there was one at all). Rather, part of the organization's efforts to promote one and fend off the other worked to constitute what amateur and professional meant to the ACA. Where the ACA appears to have departed from other sporting organizations was in its concerns regarding technology and the mechanization

\footnotetext{
${ }^{233}$ Dening, Performances, 20.
} 
of sport. In addition to its commitment to fair play and opposition to intensive training regimens, the ACA was troubled by the creation of degenerate racing machines. While it is commonplace to speak of the "hard work" involved with sporting competitions, such expressions can obscure the labour that occurs off the playing field or, as in the case of the ACA, the racecourse. In the next chapter, we therefore shift our gaze away from the performances of canoeists, officials, and spectators to examine what made this staging possible. Indeed, the whole enterprise of the encampments including the regatta existed because of the labours, not just of the organizers and members, but of men and women whose presence at the encampments was not officially welcomed, for they were of the wrong class and race of people. These largely invisible historical actors, however, left very visible traces in the landscapes and histories of the ACA meeting. 


\section{Chapter Nine: Producing/Consuming}

Amongst the hundreds of photographs that are part of the American Canoe Association Collection in Cooperstown, New York, is an image produced in 1887 by amateur photographer George Warder of Springfield, Ohio, entitled "Work and Fun in Camp."' As shown in Figure 9.1, the photograph depicts R.W. Gibson of the Mohican Canoe Club (Albany, New York) working on his boat while attending that year's meet on Lake Champlain. The others in the frame wrap themselves in flags and blankets, and strike tableaux-like poses. Although its tone is clearly tongue-in-cheek, the image simultaneously represents the ACA encampments as places of leisure and places of labour. However, it suggests a very narrow understanding of work, as preparation for the races. In other words, the image neglects the myriad other forms of labour that were necessary to the smooth functioning of the annual meetings.

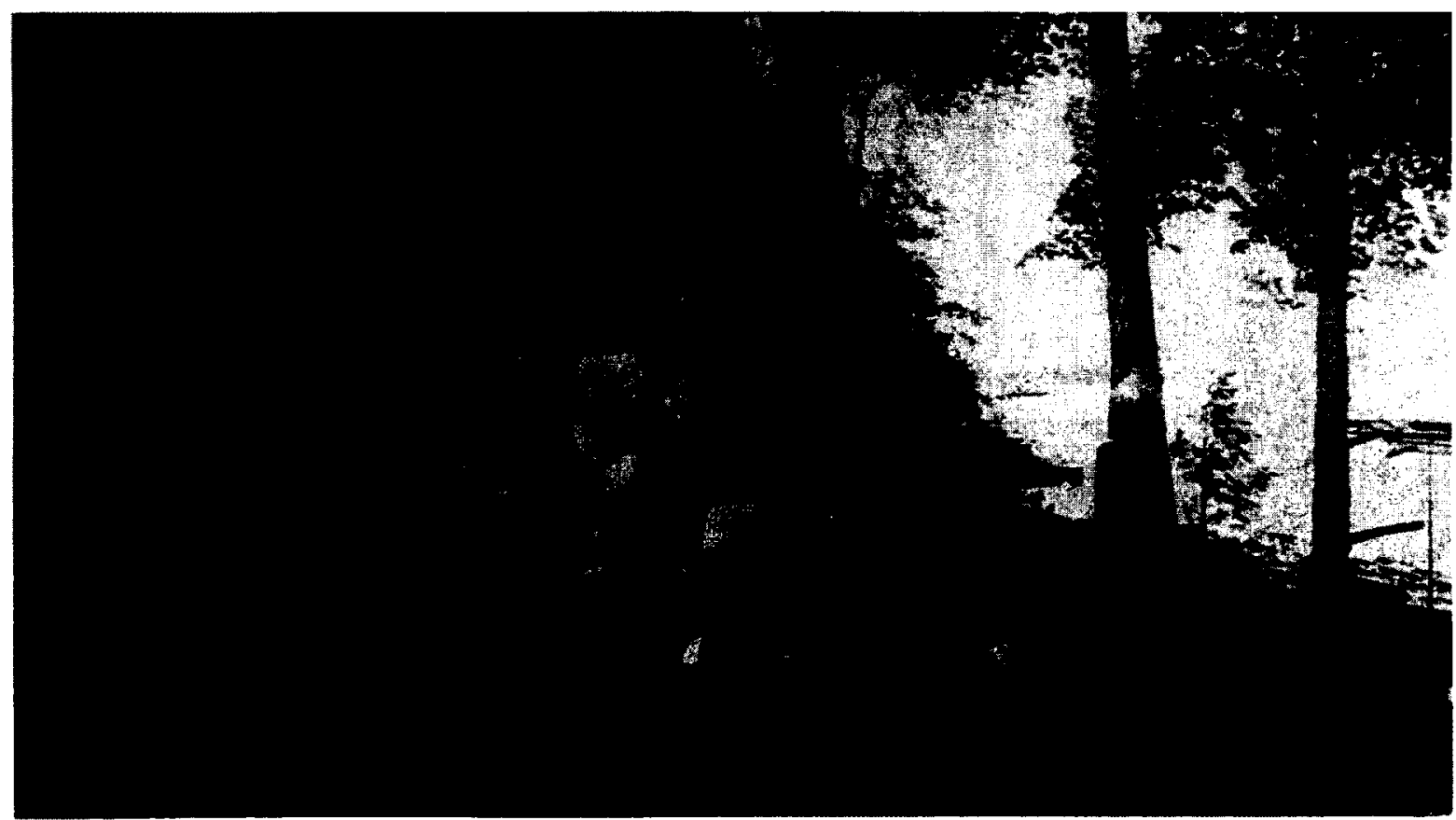

Figure 9.1 - George Warder, "Work and Fun in Camp," 1887. [Source: NYSHA, 1.1/24.]

\footnotetext{
${ }^{1}$ New York State Historical Association (NYSHA), 1.1/24, "Work and Fun in Camp," 1887.
} 
While not disparaging the work of Mr. Gibson and other canoeists, my concerns in this chapter are for work and workers largely excluded from written and photographic accounts of the annual meetings. The ACA encampments never employed the teams of workers that larger vacation enterprises, such as the Saratoga Springs Resort, did. ${ }^{2}$ Nevertheless, the encampments would not have occurred, or at the very least would have looked radically different, without the carpenters, cooks, servers, performers, and general labourers who did the heavy work of construction, maintenance, and service. It is here that this chapter begins. In spite of their importance, these people exist, at best, on the margins of official accounts of the meets; in most cases, they are altogether ignored. While recovery of this labouring past is difficult and admittedly fragmentary, it is nonetheless critical to this dissertation's central concerns with the social and spatial politics of sport/leisure.

This chapter also seeks to complicate the ways in which consumption is understood within the context of the encampments and in the process to uncover another form of work that was common to the meets. In earlier chapters, I discussed the organizers' discursive production of landscapes and experiences, and the ways in which canoeists consumed these vistas and experiences. However, campers were also consumers in a more material sense; among other things, they purchased handicrafts from local Aboriginal people, produce and trinkets from the camp store, boat fittings from canoe builders, and images from commercial photographers. In the second half of the chapter, I turn my attention to those whose labour contributed to the constitution of the encampments as a commercial space. My objective in this chapter, in other

\footnotetext{
${ }^{2}$ Theodore Corbett, The Making of American Retorts: Saratoga Springs, Ballston Spa, Lake George (Piscataway: Rutgers University Press, 2001).
} 
words, is to position the ACA encampments as simultaneously spaces of production and consumption.

Historians of sport have shown how the same activities can be defined as leisure or labour. Such definitions often reflect social position, namely class, gender, and race. Perhaps the best example of this can be found in the extensive literature on hunting, which explores the classed and racialized tensions between hunting as sport and as subsistence, but also between white middle-class male sport hunters and their guides, who were typically Indigenous men or rural whites. ${ }^{3}$ What has remained largely unexplored, however, are the ways in which the sporting practices of the middle and upper classes, but particularly organized sport, have been made possible by the labour of "others," including the working class, women, and visible minorities. ${ }^{4}$ Nor has any significant attention been paid to the other commercial endeavours that sporting competitions supported and encouraged such as the souvenir trade or the sale of sporting equipment.

\footnotetext{
${ }^{3}$ Patricia Jasen, "Chapter Six: Close Encounters," in Wild Tbings: Nature, Culture, and Tourism in Ontario, 1790-1914 (Toronto: University of Toronto Press, 1995), 133-49; Tina Loo, "Of Moose and Men: Hunting for Masculinities in British Columbia, 1880-1939," Wextern Historical Quarterly 32, no. 3 (2001): 296-319; Karl Jacoby, Crimes Against Nature: Poachers, Squatters, Thieves, and the Hidden History of American Conservation (Berkeley: University of California Press, 2001); Scott E. Giltner, Hunting and Fübing in the New' South: Black Labor and White Leisure after the Civil War (Baltimore: Johns Hopkins University Press, 2008); Anne Gilbert Coleman, "The Rise of the House of Leisure: Outdoor Guides, Practical Knowledge, and Industrialization," Western Hütorical Quarterly 42, no. 4 (2011): 436-57.

${ }^{4}$ The intersections between the history of sport and labour history have largely centred on working class leisure or labour organizing/disputes in professional sport. See, for example, Martin H. Blatt and Martha K. Norkunas, eds., Work, Recreation, and Culture: Es'says in American Labor History (New York: Garland Publishing Company, 1996); Lynn Marks, Revivalu and Roller Rinks: Religion, Leiuure, and Identity in Late-Nineteentb-Century Small-Town Ontario (Toronto: University of Toronto Press, 1997); Gerald Gems, "Welfare Capitalism and Blue-Collar Sport: The Legacy of Labour Unrest," Retbinking History 5, no. 1 (2001): 43-58. Historians of tourism have been more attune to questions of labour and leisure. See, for example, Karen Dubinsky, The Second Greatest Disappointment: Honeymooners, Heterosexuality, and the Touritt Industry at Niagara Fallo (Toronto: Between the Lines Press, 1999); Cecilia Morgan, "Porters, Guides, and Middle-Class Tourists," in 'A Happy Holiday': Engliwb Canadians and Trantatlantic Touriwm (Toronto: University of Toronto Press, 2008), 31-58; Thomas G. Andrews, "'Made by Toile'? Tourism, Labor, and the Construction of the Colorado Landscape," Journal of American Hivtory 92, no. 3 (2005): 837-63; LouAnn Wurst. "'Human Accumulations': Class and Tourism at Niagara Falls," International Journal of Historical Archaeology 15, no. 2 (2011): 254-66.
} 
This chapter aims to address these oversights in the literature, while recognizing the challenges that exist to meet such an end. Given the limited attention paid to the workforce in the archive and the decidedly one-sided nature of these accounts, it is difficult for the historian to know with any certainty the extent or the exact ways in which these men and women contributed to encampment life. With the exception of canoe builders and photographers whose class and race position set them apart from other workers, I have yet to uncover accounts of the annual meetings penned by a labourer. ${ }^{5}$ Other scholars in similar predicaments have turned to census material to determine, for example, the number and make-up of workers at hotels and resorts. ${ }^{6}$ However, the men and women employed by the ACA meets were rarely in attendance for longer than a few weeks, which was not enough time to be counted and recorded by census takers. Likewise, efforts to uncover more about people whose names actually receive mention in the archive have proved largely futile. Rather, I am forced to read against the grain of periodical accounts and memoirs, and to pay close attention to those at the edges of photographs to tease out the network of workers and practices that enabled the canoeists to travel, camp, and compete.

Clearly workers were not absent from the meetings of the ACA, but they and the work they performed were largely invisible. As Thomas G. Andrews notes, "It takes work to erase labor from a landscape," which he argues is a testament to the "two distinct but intertwined modes of constructing landscape: as built environments produced by physical labor and as representational spaces produced by cultural

\footnotetext{
${ }^{5}$ This is a common situation. See, for example, Jasen, Wild Tbing', 133.

${ }^{6}$ Wurst, "Human Accumulations," 256-7.

${ }^{7}$ Andrews, "Made by Toile," 837.
} 
work. ${ }^{8}$ What Andrews is documenting in the case of Colorado landscapes at the turn of the twentieth century was not isolated to the west, but was evident in different ways in the "emerging leisure retreats of industrializing America." What had once been understood as sites of labour and production were increasingly being recast as spaces of leisure and consumption. It is a process that continues today: " $[1]$ t has become second nature for many of us to ignore the work that sustains our lives and the labor that constructs the landscapes we inhabit." More than an act of recovery and replacement, this chapter also seeks to understand why labourers and particular kinds of work are invisible in the archive of encampments. ${ }^{10}$

\section{Part I - Labour at the Margins, Marginalized Labour}

\section{Preparations: Local Goods and Services}

Accounts of preparations for the annual meetings emphasize the labours of the committee members. We learn of letters written to government officials, correspondence with railway companies, and surveys undertaken of the campsites and racecourses. What has been largely occluded from these accounts is the extent to which the various organizing committees depended heavily on local resources in the form of both goods and people to ensure the success of the encampments.

One of the first occasions that local people were called on to aid in the preparations was during the surveys. An article describing the survey undertaken for the 1883 meet is, unusually, a relatively thorough account of labour performed by

\footnotetext{
${ }^{8}$ Andrews, "Made by Toile," 840 .

9 Andrews, "Made by Toile," 841 .

${ }^{10} \mathrm{As}$ in Chapter Two, I am interested in the ways in which the archive and historical writing reinscribe dispossession. Of course, the archive in this case reflects both organizational and popular memory. The photographic collection, for example, includes commissioned pieces and personal scrapbooks. In other words, both the ACA and its members are essential to how these folks have been "forgotten."
} 
those outside of the ACA. ${ }^{11}$ According to author Robert Tyson, the regatta committee departed Peterborough at 6.15am on 30 March in a sleigh driven by Joe Vasseur, a "shrewd, good-humored French Canadian." Also in the sleigh was James W. Fitzgerald, Crown Surveyor. Whereas the author had little to say about Fitzgerald, who given his occupation was likely perceived as holding a similar class and race position to Tyson and the other ACA official in the sleigh, Commodore E.B. Edwards, a good size paragraph was devoted to describing Vasseur. Even as Tyson acknowledged that Vasseur was an "excellent teamster," he painted him as simplistic and crude: his English was broken, his commentary obscene. He made special note of Vasseur's recreational pastimes, shooting a "saw-log slide" in "a narrow, log canoe" for "pure reckless fun," a decidedly less rational and respectable canoeing activity than those engaged in by members of the ACA. ${ }^{12}$ Finally, he called into question Vasseur's full humanity, by painting him as a "half-amphibious creature," a consequence of his time working as a river driver in the lumber industry. Tyson's description of Vasseur resonates with J.I. Little's observation that campers visiting Lake Mephremagog in the same period portrayed local men "not as heroic individualists," as was sometimes the case in hunters' accounts of guides, "but as rustic and often amusing folk figures."13

Vasseur was not the only person that the committee engaged that day. Before arriving at Juniper Island, they stopped at the house of Mr. McCracken, a farmer valued for his knowledge of the local environment, but particularly for his familiarity with the "unfailing springs of excellent water near by" that would fulfill the camp's

\footnotetext{
${ }^{11}$ Robert Tyson, "Laying Out the Course on Stony Lake," American Canoeist 2, no. 5 (1883): 66-8.

${ }^{12}$ One of the ideological tenets of middle-class leisure in the nineteenth century was "rational recreation," or recreation with a purpose to improve. Peter Bailey, Leiwure and Claw' in Victorian England: Rational Recreation and the Contedt for Control, 1850-1885 (Buffalo: University of Toronto Press, 1978). ${ }^{13}$ J.I. Little, "Scenic Tourism on the Northeastern Borderland: Lake Memphremagog's Steamboat Excursions and Resort Hotels, 1850-1900," Journal of Hittorical Geograpby 35, no. 4 (2009): 290.
} 
need for fresh water. ${ }^{14} \mathrm{McC}$ racken did more than share his local knowledge, he also lent his bodily skills to the project by acting as the surveyor's assistant to Fitzgerald. It is not clear if the farmer had performed these tasks before. However, Tyson observed, in the paternalistic parlance of contemporary labour relations, that he "proved himself a handy, willing, and cheerful worker. ${ }^{.15}$ Also assisting with the survey was another farmer, Mr. Crow, and his son, Willie; Tyson's report on these two is cursory at best.

The attention paid to Vasseur, McCracken, and the Crows in this recounting of the 1883 surveying trip is uncharacteristic of $\mathrm{ACA}$ accounts, which are more likely to record the activities of members rather than labourers. Thus, in describing the work performed by these men, however vaguely, Tyson was pulling back the cover of obscurity typically ascribed to the people whose work made the encampments possible. How might we explain this anomalous description? Certainly, more attention is paid to work and workers in the early years of the encampments than in later accounts. In part, this likely reflects the routinization of the organization, preparation, and execution of the encampments. ${ }^{16}$ However, I also think the attention paid to this event is a function of the larger story of the survey as a tool of legitimation. ${ }^{17}$ Still in its infancy in 1883 , the ACA meet could only have benefitted from positive associations with the scientific tool, particularly as the organization sought to establish itself as the

\footnotetext{
${ }^{14}$ The account does not provide a first name for McCracken. It is likely that Tyson is referring to W.R. McCracken who arrived on the shores of Stony Lake in 1831. Christine Bentham and Katharine Hooke, From Burleigh to Botcbink: A Community Called Stony Lake (Toronto: Natural Heritage/Natural History, $2000), 72$.

${ }^{15}$ For more on paternalism in industrial labour relations, see Daniel J. Walkowitz, Worker City, Company Town (Urbana: University of Illinois Press, 1978); Patrick Joyce, Work, Society, and Politicy: The Culture of the Factory in Late Victorian England (New Brunswick: Rutgers University Press, 1980); Tamara Haraven, Family and Industrial Time (Cambridge: Cambridge University Press, 1982); Jacquelyn Dowd Hall, James L. Leloudis, Robert Rodgers Korstad, Mary Murphy, Lu Ann Jones, and Christopher B. Daly, Like a Family: The Making of a Soutbern Cottage Mill World (Chapel Hill: University of North Carolina Press, 1987).

${ }^{16}$ As I have noted elsewhere, accounts of the meets became shorter and less detailed over time.

${ }^{17}$ I discuss the deeper significance of the survey in Chapters Two and Five.
} 
national canoeing association. To properly tell the tale of the survey as a travelogue, it required local colour. ${ }^{18}$

More common in the ACA archive are accounts that erase this work altogether. This is perhaps most visible in descriptions of the camp landscape. Despite the organization's claims to inhabiting wild places during the annual meetings, as we know from Chapters Two and Five, much work had been done to produce these landscapes: trees had been cut down, brush removed, paths graded. Yet, few accounts describe how this work was performed or who performed it. That much of this preparatory work was undertaken before the campers arrived on site would have contributed to its invisibility. That said, when it was not carried out to the satisfaction of the campers, notes were made and accusations levelled. ${ }^{19}$ Once judged and committed to "the record," poor performance made the invisible suddenly visible. ${ }^{20}$ In addition to clearing underbrush and constructing walking paths, labourers were engaged in the establishment of the camp infrastructure: digging wells and sinks, constructing the camp wharf, erecting buildings for the mess and camp store, and building tent floors and landing stages for individuals. ${ }^{21}$ Whereas general labourers undertook landscaping duties, skilled carpenters appear to have performed this other work.

\footnotetext{
${ }^{18}$ Vladimir Kapor argues that "by virtue of a 'generic pact' typical of nineteenth-century travelogue and its eye-witnessing mode, local colours came to designate factual accuracy." Vladimir Kapor, Local Colour: A Travelling Concept (Bern: Peter Lang, 2009), 132.

${ }^{19}$ See, for example, descriptions of the 1900 meet on Muskoka, including D.J. Howell, "The International Canoe Meet," The Canadian Magazine 15, no. 6 (1900): 513-20.

${ }^{20}$ This reinforces Andrew's point that if the "small armies of maids, waiters, cooks, and porters... did their jobs properly," they could be overlooked. Cecilia Morgan likewise observes in the case of middleclass Canadians engaged in transatlantic travel that "at times workers in the tourist industry were simply rendered silent." However, a request for a "seemingly undeserved tip" or the provision of wrong information could draw attention. Andrews, "Made by Toile," 848; Morgan, A Happy Holiday, 7. See, also, Dubinsky, The Second Greatest Disappointment, 74-83.

21 "The ACA Meet," Forest and Stream, 31 July 1884; "The Association Meeting," Forest and Stream, 21 August 1884; "The Executive Committee Meeting," Forest and Stream, 18 November 1886; "The ACA Meet, Lake George," Forest and Stream, 23 August 1888.
} 
With the move to Sugar Island, the number of labourers engaged in advance of the meet likely declined. Temporary structures were replaced with more permanent buildings and landscaping became a matter of maintenance rather than yearly reinvention. Nevertheless, there were always unexpected jobs to be performed. For example, in 1908, high water on the St. Lawrence caused a number of the personal docks to be washed away. ${ }^{22}$ The move to Sugar Island, but specifically, concerns about leaving the Association's property unattended, also created a new position: caretaker. The organization hired a local lighthouse keeper, Manley Cross, to watch over the site when the camp was not in session and to perform general maintenance tasks. In the warmer months, Cross was also responsible for signing in visiting members to the site - Sugar Island was to be open to ACA canoeists at all times. ${ }^{23}$

\section{Travelling Assistance}

Each stage of the journey from home to the encampment was facilitated by another's labour. Domestic servants assembled the luggage and kit of the well-to-do. ${ }^{24}$ Domestic service while on the decline was still a relatively common feature of middleclass life in Canada and the United States at the turn-of-the-twentieth century. ${ }^{25} \mathrm{As}$

\footnotetext{
${ }^{22}$ According to the yearbook, "it was necessary to do quite a little work to get the Island in shape." "1908 Meet," in American Canoe Astociation Yearbook, ed. Oscar J. West (Chicago: Press of De Land, Coles and Putnam, 1909), 48.

${ }^{23}$ To be clear, Cross was not a member of the Association. "Secretary Treasurer's Report, 1904" in American Canoe Asvociation Yearbook, ed. H.M. Stewart (Rochester: Morrison's Press, 1905), 47.

${ }^{24}$ A direct reference to this work appears in Paul Vernon's memoirs. Upon taking notice of a "round tin bath tub" at a neighbouring campsite, Vernon was informed by its owner, "I told my man to pack my traps to go camping and he sent this along as is my custom." Trent University Archives (TUA), 83014/2, Paul Vernon, Tales of the $A C A, 1940$.

${ }^{25}$ Susan Williams claims that almost 25 percent of all American households, urban and suburban, had help in 1880. Susan Williams, Savory Suppers and Fastbionable Feasts: Dining in Victorian America (Knoxville: University of Tennessee Press, 1996), 153. See, also, Eric W. Sager, "The Transformation of the Canadian Domestic Servant, 1871-1931," Social Science Hittory 31, no. 4 (2007): 512-3; Theresa M. McBride, The Dometic Revolution: The Modernitation of Housebold Service in England and France, 1820-1920 (New York: Holmes and Meier, 1976), 67.
} 
Magda Fahrni notes, it was a situation of "peculiar tensions." ${ }^{26}$ On the one hand, "service was crucial to the creation of a respectable bourgeois home and lifestyle," a "hallmark" of middle-status. ${ }^{27}$ At the same time, servants, because of their class and race position, were perceived as "dubious intruders into the bourgeois domain."

Domestic service, she concludes, was a "unique spatial process that transgressed the physical segregation of the classes perceived and defended in late- $19^{\text {th }}$-century Canada. ${ }^{" 28} \mathrm{~A}$ similar statement could be made about the encampments, as ostensibly exclusive and segregated spaces that invited the other in, although as lowly labourer rather than fellow canoeist.

Some canoeists and clubs travelled to the encampments with domestic workers. In the 1880s, Paul Butler of the Vesper Boat Club of Lowell, Massachusetts, was accompanied to the encampments by "an old colored man, a body servant of the General, whose duty it was to look after the sails." ${ }^{29}$ Similarly, one of the New York establishments brought their club janitor to the 1884 meet. While it is unclear what his responsibilities were during the meet, he travelled to Grindstone Island in a special car at the forward end of the train that carried the canoes, ostensibly to keep an eye on them, while not coincidentally keeping travellers' eyes free from him. ${ }^{30}$ That there were domestic workers on site is also underscored by the plans to include servants' quarters

\footnotetext{
${ }^{26}$ Magda Fahrni, "'Ruffled' Mistresses and 'Discontented' Maids: Respectability and the Case of Domestic Service, 1880-1914," Labour/Le Travail 39 (1997): 70.

${ }^{27}$ Fahrni, "Ruffled Mistresses," 72.

${ }^{28}$ Fahrni, "Ruffled Mistresses," 70.

${ }^{29}$ W.P. Stephens, Traditions and Memories of American Yactbing: The 50th Anniversary Edition (Brooklin: WoodenBoat Publications, 1989), 173. Butler's father was General B.F. Butler of Lowell, Massachusetts, a member of the US House of Representatives in the 1860s and 1870s, and Governor of Massachusetts in 1883. Leonard C. Schlup and James G. Ryan, eds., Historical Dictionary of the Gilded Age (Armonk: M.E. Sharpe, 2003), 73. D.B. Goodsell also refers to Paul Butler's "valet West" being in attendance at meets in the 1890s. NYSHA, 1.6/2, D.B. Goodsell, $A$ Canoeing Reminiucence (1936), 2. 30 "Canoe Sailors in Camp," New' York Sun, 4 August 1884.
} 
among the permanent buildings on the Sugar Island encampment. ${ }^{31}$ However, servants are almost entirely absent from campers' accounts. As a fact of life for many middleclass, and particularly upper-middle class families, their presence at the encampments was likely unremarkable.

For journeys by train, baggage handlers and porters were a necessity, if a frustrating one. As I noted in Chapter Four, interactions between the canoeists and the baggage handlers were particularly fraught. However, accounts of travel to the encampments are almost universally silent on the role of porters, in spite of the fact that they would have undoubtedly been present in the canoeists' first-class cars. Thomas Andrews observes that by the late nineteenth century, "[1]uxury trains had become domestic spaces where pullman [sic] porters and other men performed precisely the types of feminized and racialized work that travelers were most likely to overlook. ${ }^{\prime 32}$ Andrews also notes that in an earlier age, travellers might have commented on the labour that produced the railroad. However, "a suite of technologies that fundamentally reconfigured the material circumstances of travel" and new scripts created by the tourist industry worked to erase visible traces of these labours. ${ }^{33}$

For those who travelled to the meets by canoe, the assistance of local people was less likely to be overlooked, although their labour was usually framed as an act of kindness rather than work. Travelogues describe the goods purchased from farms bypassed on route, the local people contracted to transport canoes from one body of water to another, the rental of land for tenting, and the appeal for directions when the next stage of the journey was uncertain. Much like descriptions of the labourers at the

31 "A Permanent Camp," Forest and Stream, 18 December 1890.

${ }^{32}$ Andrews, "Made by Toile," 849.

${ }^{33}$ Andrews, "Made by Toile," 846. 
encampments, the canoeists' accounts of interactions with local people along the way to the campsites paint them as "folk"-like. ${ }^{34}$ They note, for instance, the unfamiliar accents, the inappropriate language, and the perceived simplicity of their lives and personalities. Florence Watters Snedeker's slim volume, A Family Canoe Trip, is perhaps the best example of this. The book often reads more like an anthropological expedition than a canoe trip, offering as it does commentary on the many types of people the family encountered along the way. Early on in the trip, for example, Snedeker observed on the roadside, "Instead of Indians, there were lots of farmers' children offering us peaches and apples," who provided "choice pictures for our camera. ${ }^{35}$ She also made note of the mule drivers who worked along the canal, "We became acquainted with our fellow travellers...In face they were less moral than the mules they drove: now a sallow Yankee with a hint of lost estate in his unquiet eyes; now an allbrutal, shaggy foreigner...We found them civil, even obliging. But they whacked their beasts viciously. ${ }^{136}$ She even includes dialogue intended to capture the distinctive cadences of the speaker, but which universally constructs her subjects as uncultured. ${ }^{37}$ Ostensibly, travel brought the canoeists into contact with difference, providing the opportunity for a readjustment of established assumptions. However, more likely, such encounters reinforced notions of difference. Furthermore, they were rarely interpreted as work, but rather as quaint performances of otherness.

\section{During the Meet}

\footnotetext{
${ }^{34}$ Ian McKay, Quest of the Folk: Antimodernism and Cultural Selection in Twentieth-Century Nova Scotia (Montreal: McGill-Queen's University Press, 1994).

${ }^{35}$ Florence Watters Snedeker, A Family Canoe Trip (New York: Harper and Brothers, 1892), 30.

${ }^{36}$ Snedeker, A Family Canoe Trip. 24.

${ }^{37}$ See, for example, the time the family spent with Mr. Windham on Lake George. Snedeker, A Family Canoe Trip, 37-42.
} 
Cindy Aron notes that while early proponents of outdoor living highlighted the opportunity for relaxation, by the end of the nineteenth century, camping advocates were hailing the enjoyment that the work of camping inspired ${ }^{38}$ The ACA appeared to have followed a somewhat different trajectory. By the turn of the century, few of the visitors to the ACA meets did much of the work associated with camping. Tent floors had been built in advance, and in some cases the tents raised. Meals were also cooked and the dishes cleaned by others.

Although much of the work of constructing the encampment took place before the campers arrived, typically one or more of the carpenters remained onsite during the annual meeting to provide assistance. I have only found two direct references to the "camp carpenter," but both suggest their indispensability. For example, an account of the 1889 meet on Stave Island claimed, "Jackman was not only the carpenter, he was the flagpole raiser, fire builder and general utility man of the camp. He was an institution, and if he could be an annual institution that would be a good thing." ${ }^{\prime 39}$ Similarly, at the 1892 meet, handbarrows built by the camp carpenter were praised for aiding canoeists moving boxes and bundles from tent to steamer. ${ }^{40}$ There were also more general labourers on site during the meet that delivered firewood, and carted goods around the camp. ${ }^{41}$

Perhaps some of the most important roles played by workers were in the area of food planning, preparation, and service. Early on, local people were responsible for the kitchen. For example, Mr. Marvin Truesdell, of Hillview, Lake George, served meals

\footnotetext{
${ }^{38}$ Aron, Working at Play, 176-7.

${ }^{39}$ The article described Jackman as an "experienced carpenter with a good staff of assistants." "Snips from Snaps at the '89 Meet," Forest and Stream, 19 September 1889.

40 "The ACA Meet of 1892," Forest and Stream, 8 September 1892.

41 "The Meet of 1884," Forest and Stream, 8 November 1883; "The Executive Committee Meeting," Forest and Stream, 18 November 1886; Forest and Stream, 25 February 1892.
} 
at the 1881 camp for 37 cents each, ${ }^{42}$ while the mess shed on Grindstone Island was under the watchful eye of Mrs. Delaney, whose family had lent a portion of their farm to the canoeists for their encampment. ${ }^{43}$ By the 1890 s, the oversight of meals was increasingly the purview of professionals and also of men. For example, D. McElveney and Sons, a well-known caterer from Albany, New York, was responsible for the food services at a number of the encampments between 1897 and $1910 .^{44}$ That this class of labourer was consistently named suggests a higher status.

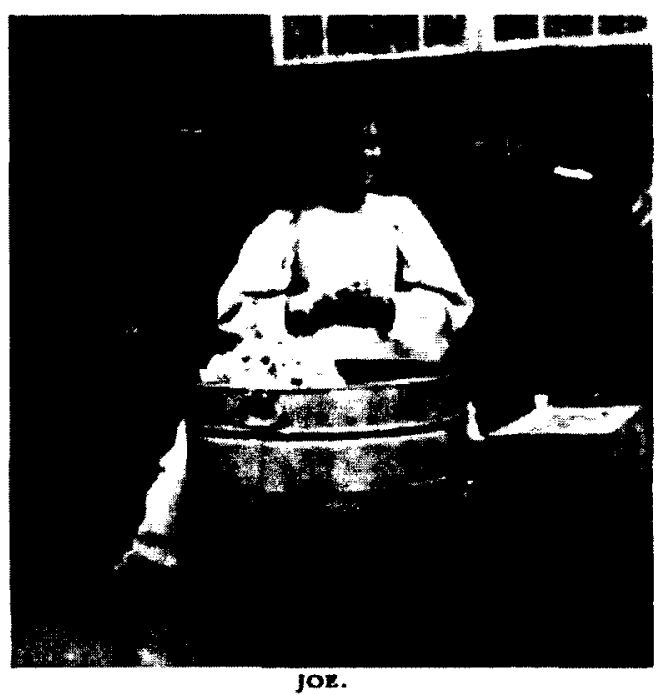

Figure 9.2 - "Joe." [Source: R.B. Burchard, "Back to Grindstone: The Canoe Camp," Outing 29, no. 2 (November 1896): 139.]

Even as the administration of the mess was professionalized, local people, the majority of whom were likely women, continued to work in the kitchen. ${ }^{45}$ The kitchen labourers included the white woman pictured in Figure 9.2 peeling potatoes behind the

\footnotetext{
${ }^{42} \mathrm{He}$ had also offered to furnish straw for bedding at a reasonable price. Mystic Seaport Collections Research Center (MSCRC), Collection 291, Box 23, Folder 2, Camp Circular for Lake George, 1881.

${ }^{43}$ St. Lawrence County Historical Association (SLCHA), Camp Circular for Grindstone Island, 1886.

${ }^{44}$ Amasa Junius Parker, Landmarks of Albany County, New York (Syracuse: D. Mason, 1897), 17-8.

${ }^{45}$ This move to professionalize the oversight of food services while continuing to use marginal labour for supporting tasks in the kitchen and dining hall was echoed in summer camps, although in a somewhat later period. Abigail Van Slyck, A Manufactured Wilderness: Summer Camps and the Shaping of American Youth, 1890-1960 (Minneapolis: University of Minnesota Press, 2006), 137-43.
} 
kitchen shed. ${ }^{46}$ That the photograph is captioned "Joe" suggests that the canoeists knew some of the labourers by name. Local people also served the guests their meals in the dining tent. With the exception of the 1890 meet on Jessup's Neck, the wait staff appears to have been entirely comprised of young white women. ${ }^{47}$ Photographs from the 1898 meet on Stave Island, including Figure 5.3, depict white women sporting matching uniforms and caps. ${ }^{48}$ R.B. Burchard claimed that visitors to the 1896 encampment on Grindstone Island were "served by comely girls from the surrounding country...all prim as schoolmarms." ${ }^{199}$ That servers would be women was out of step with other hotels and resorts in this period. LouAnn Wurst argues that "without exception, the waiters were all men and the domestics were all women" at Niagara Falls' hotels in this same period. ${ }^{50}$ Further clues about the servers are offered by visitors to the encampments, perhaps because of a greater degree of contact between the two groups. Flip, for instance, hypothesized that canoeists at the 1887 meet on Lake Champlain were "waited on by the farmer's daughters." ${ }^{.51}$ Burchard, meanwhile, claims that some were high-school graduates.$^{52}$ D.B. Goodsell's memoir confirms both

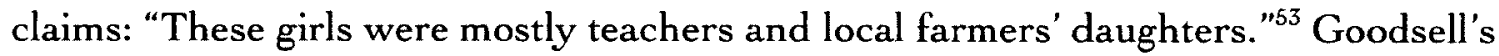
account also suggests that these women were incorporated into the encampments in a way that male labourers, particularly those of colour, were likely not. He recalls, for

\footnotetext{
${ }^{46}$ R.B. Burchard, "Back to Grindstone: The Canoe Camp," Outing 29, no. 2 (1896): 139. The image of "Joe" appeared midway through the article, which chronicles the 1896 meet on Grindstone.

${ }^{47}$ Goodsell's memoirs suggest that the servers at the 1890 meet were men. He recalled that the "waiters were Bowery toughs," a reference to Irish immigrant gangs in New York. Goodsell, A Canoeing Reminiscence, 3. For a brief introduction to the Bowery gangs, see Irving A. Spergel, The Youtb Gang Problem: A Community Approacb (New York: Oxford University Press, 1995), 7.

${ }^{48}$ NYSHA, 1.2/27, "Dinner Time in the Mess Tent," 1898.

${ }^{49}$ Burchard, "Back to Grindstone," 141. See also Forest and Stream, 5 September 1896.

${ }^{50}$ She notes further the racial make-up of these workers: "[T]he vast majority of female workers were white, while most of the males were black or mulatto." Wurst, "Human Accumulations," 257.

${ }^{51}$ Flip, "The Lake Champlain Canoe Meet," Outing 11, no. 3 (1887): 262.

${ }^{52}$ Burchard, "Back to Grindstone," 141.

${ }^{53}$ Goodsell, A Canoeing Reminiscence, 4.
} 
instance, the "dances given for the waitresses of the mess tent." However, according to Burchard, "woe to the luckless Johnny who attempted to be flirtatious," suggesting that at least some female workers maintained a sense of distance from the canoeists. ${ }^{54}$

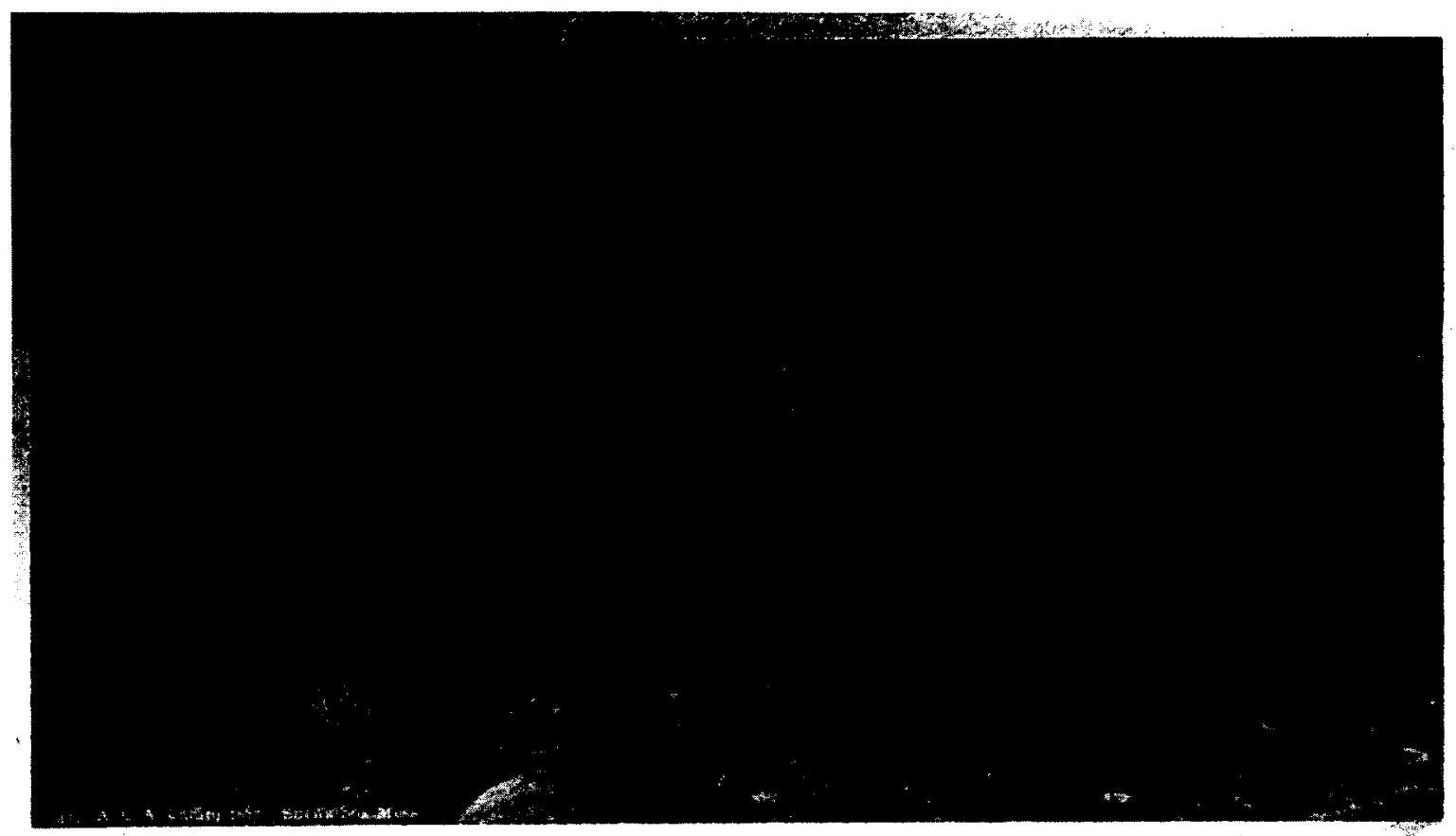

Figure 9.3 - “The Sneak-Box Mess: Camp of the Brooklyn Canoe Club,” 1887. [Source: NYSHA, 1.1/25.]

Not everyone ate at the mess tent. In some cases, the canoeists visited a nearby farmhouse for their meals, further strengthening dependencies on local farms and farmers. ${ }^{55}$ Still others set up a "club mess" and hired a cook. Club cooks came from both near and far. The Brooklyn Canoe Club, for example, employed a man from nearby Kingston to feed them at the 1894 meet on Wolfe Island. ${ }^{56}$ By contrast, in 1887 Frank Baker from the exclusive Down Town Club in New York City oversaw the

\footnotetext{
${ }^{54}$ As I have found no records from the caterers, we have no way of knowing if the servers were instructed to avoid any kind of indiscretion, or if they behaved in this way of their own volition. Certainly the former is not unthinkable in this context.

${ }^{55}$ C. Bowyer Vaux, "Canoe Meet at the Thousand Islands," Outing 14, no. 5 (1889): 348.

${ }^{56}$ Vernon, Tales of the $A C A$.
} 
Brooklyn Club's mess on Lake Champlain. ${ }^{57}$ Some of the cooks had experience working in lumber camps. ${ }^{58}$ Whereas the cooks in lumber camps were authority figures, a point that Ian Radforth makes clear in "The Shantymen," we can presume that at the encampments any authority they may have had ended at the "doors" to the club mess kitchen. ${ }^{59}$ Others were French Canadian, including the "presiding genius" of the Deseronto Canoe Club at the 1890 meet. ${ }^{60}$ Photographs, meanwhile, illustrate the presence of African American men as cooks and/or servants. For example, Figure 9.3 is an image of the Brooklyn Canoe Club at the 1887 meet that bears the following note, “HC Ward (982)...seated in front of colored cook." ${ }^{61}$ I also encountered a photograph of the Knickerbocker Canoe Club at a division meet with an African American boy seated in the foreground. Etched on the back of the image is the following note, "Rastus, the camp chore boy." 62 That such racialized groups were called on to feed and serve the canoeists comes as little surprise; African-American cooks, for instance, were

57 "To Camp on Bow Arrow Point," Brooklyn Daily Eagle, 6 August 1887.

58 "The ACA Meet: Camp Circular," Forest and Stream, 10 July 1890. As Adam Tomczik notes, "a cook prepared and served three gigantic meals for forty to two hundred men," making them valued assets at their camps and elsewhere as well. Adam Tomczik, "He-Men Could Talk to He-Men in He-Men Language': Lumberjack Work Culture in Maine and Minnesota, 1840-1940," Historian 70, no. 4 (2008): 706. Certainly, lumber camp cooks and sea cooks were also favoured choices for overseeing the dining halls at children's summer camps. Van Slyck, A Manufactured Wildernew, 129.

${ }^{59}$ Ian Radforth, "The Shantymen," in Labouring Lives: Work and Worker in Nineteentb Century Ontario, ed. Paul Craven (Toronto: University of Toronto Press, 1995), 229-30.

60 "The ACA Meet: Camp Circular," Forest and Stream, 10 July 1890.

${ }^{61}$ NYSHA, 1.1/25, "The Sneak-Box Mess: Camp of the Brooklyn Canoe Club," 1887. It's not clear whether the black man in the photograph is Frank Baker, as no name is given. It was common practice in turn-of-the-century photographs to name the white subjects, but not the racialized other. Project Naming, a joint initiative of Nunavut Sivuniksavut, the Nunavut Department of Culture, Languages, Elders, and Youth, and Library and Archives Canada seeks to undo some of this colonial erasure by identifying unnamed Inuit in the photographic collections of the national archives. For more information about the project, see: http://www.collectionscanada.gc.ca/inuit/index-e.html.

${ }^{62}$ NYSHA, 1.5/3, Meets and Camps Scrapbook, 1900-1940. 
commonplace at children's summer camps in the United States in the decades around the turn of the century. ${ }^{63}$

Cooks, like other classes of labourers at the camp, received limited attention from the canoeists. When the campers did describe them in any detail, they framed them as sources of amusement, much like Joe Vasseur, the driver for the 1883 survey delegation. For example, the aforementioned cook of the Deseronto Canoe Club was, according to Forest and Stream, "no less celebrated in camp for his bread baking than for his songs by the camp-fire." ${ }^{64}$ The most notorious of the club mess cooks was "the venerable Sergeant Billings" who was in attendance at a number of ACA meetings, including the 1883 encampment on Stony Lake and the 1888 meet on Lake George. ${ }^{65}$ Following the 1883 event, O.K. Chobee opined, "No one who camped with the A.C.A.'s on Juniper Island will forget the stentorian tones with which, each morning, Billings, the cook, strove to arouse the drowsy Mohican and Knickerbocker men who belonged to his mess: 'Breakfast, Morcans! Niggerboggers, breakfast! Dod rat them sleepy Yankees!"66 Such representations of the cooks reinforced their position as others within the white middle-class world of the encampment, but also indicate the permeability of the boundary that surrounded the annual meetings. Even as the canoeists sought to police members and visitors, they allowed "others" access to the encampments as labourers. All this being said, cooks received greater attention in accounts of the meets than other workers on site. Perhaps this is because as I noted in

\footnotetext{
${ }^{63}$ Van Slyck, A Manufactured Wilderness, 129. It's not clear from Radforth's work on lumbering whether or not French Canadians were disproportionately represented amongst the cooks in bush camps. 64 "The ACA Meet: Camp Circular," Forest and Stream, 10 July 1890.

65 "The ACA Meet of 1888: The Camp and the Association," Forest and Stream, 6 September 1888. Billings also receives mention in NYSHA, 1.6/11, "A Trip with the Knickerbockers," 1883-84. ${ }^{66}$ O.K. Chobee, "Echoes from Stony Lake," American Canoeit 2, no. 8 (1883): 115. Billings was also present at the 1888 camp, where he was under the employ of the Kingston Canoe Club. "The ACA Meet of 1888: The Camp and the Association," Forest and Stream, 6 September 1888.
} 
Chapter Seven, food was an important marker of encampment life, even if it was in other ways unremarkable. Assuming this to be true, the work of cooks as preparers of food was foundational to the experience of the annual meetings. The relative visibility of the cooks suggests that not all labourers were perceived as "workers" (and ignored as such) in the same way.

\section{The Labourers}

Given the paucity of records on the subject, it is impossible to offer even a rough estimate of the number of people hired to work at the ACA encampments on a yearly basis. It appears that the cook/caterer was in charge of hiring and paying staff for the kitchen and mess hall, so there is no record of their labour in the ACA accounts. Similarly, some years the responsibility for arranging labour was farmed out to the property owner or a local merchant. In 1887, for example, Mr. Phelps Smith, operator of Foqueet House, agreed to erect the necessary shelters, tables, and benches for the Lake Champlain mess, presumably with the aid of staff from the resort. ${ }^{67}$ In 1910, the Commodore employed W.J. Wing of Gananoque, Ontario, as "camp superintendent." He was "to have charge of all the carpenters and laborers employed by the Association." ${ }^{18}$ The accounts for the 1900 meet in Muskoka are perhaps the most detailed in naming labourers responsible for landscaping or construction. They list payments to nine different individuals, including John Baillie, Mack Gorgon, George McCully, and E. Davidson, for general labour, and one person, A. Chambers,

\footnotetext{
67 "The ACA Meet of 1887," Forest and Stream, 2 June 1887.

${ }^{68}$ NYSHA, 1.6/11, Camp Circular for Sugar Island, 1910.
} 
for blacksmithing. ${ }^{69}$ Attempts to find further information on the names provided have proved unsuccessful.

For many of these labourers, work at the ACA encampments was likely one aspect of a larger household or family economy that existed for rural people on both sides of the border in the late nineteenth century. ${ }^{70}$ Women, in particular, had long played an important economic role in sustaining families through the production of goods, such as butter, buttons, or hats, but also through the sale of their services, such as laundry, and the taking in of boarders. ${ }^{71}$ Joan Jensen goes so far as to suggest that, "farm women expected to undertake work that would bring in money to the household economy. ${ }^{\prime 72}$ Such tasks were important in an era when farms existed at a midpoint on the continuum between subsistence production and the capitalist economy. Farm men were also known to take on wage labour intermittently to supplement their family incomes. ${ }^{73}$ For example, one of the primary sources of seasonal labour for the Ontario lumber camps described by Ian Radforth in Bustworkers and Bosses were agriculturalists. ${ }^{74}$ Conversely, the examples of Joe Vasseur and the camp cooks suggest that the encampments also occasionally provided ancillary work for men engaged in

\footnotetext{
69 "Executive Committee Meeting," Forest and Stream, 3 November 1900.

${ }^{70}$ Nancy Grey Osterud, Bonds of Community: The Lives of Farm Women in Nineteentb-Century New York (Ithaca: Cornell University Press, 1991).

${ }^{71}$ See, for example, Joan M. Jensen, "Cloth, Butter, and Boarders: Women's Household Production for the Market," Review of Radical Political Economice 12 (1980): 14-24; Thomas Dublin, Transforming Women's Work: New England Lives in the Industrial Revolution (Ithaca: Cornell University Press, 1994); Sally Ann McMurry, Tranuforming Rural Life: Dairying Families and Agricultural Change (Baltimore: Johns Hopkins University Press, 1995).

72 Jensen, "Cloth, Butter, and Boarders," 15. Emphasis added.

${ }^{73}$ Joy Parr, "Ontario Agricultural Wage Labour in Historical Perspective," Labour/Le Travail 15 (1985): 91-103. On the same issue in a slightly earlier period and to the east of this study, see Rusty Bittermann, "Farm Households and Wage Labour in the Northeastern Maritimes in the Early $19^{\text {th }}$ Century," Labour/Le Travail 31 (1993): 13-45.

${ }^{74}$ Ian Radforth, Busburorkeri and Bowses: Logging in Nortbern Ontario, 1900-1980 (Toronto: University of Toronto Press, 1987), 27-9.
} 
seasonal resource industries. ${ }^{75}$ Occupational plurality was likely a reality for many of the men and women who worked at the encampments.

Just as accounts of the meets offer few specifics about the individuals whose labour made the encampments possible, they are relatively silent on encounters between the canoeists and the labourers. Some of the organizers' comments hint at tensions between the two groups. For example, following the 1896 meet, a member of the Forest and Stream editorial board opined, "The great difficulty in the choice of a new site each year is that entirely new arrangements for preparing the site, transporting and catering for the members must be made; and thus, under most disadvantageous conditions, the officers have to deal with local men entirely unknown to them. ${ }^{776}$ Similarly, although the ACA publicly praised the relationship they had with the Delaneys of Grindstone Island, there was not universal satisfaction with the arrangement. In 1885 and 1886 , the Executive Committee deemed the bills the family presented to the organization "excessive" and "exorbitant," respectively. ${ }^{77}$ Such interactions were likely frustrating for the Delaneys as well, who may have felt the ACA was trying to undercut them. Moreover, given the canoeists' penchant for pranks and debauchery, the organization may not have always made the best guests. Consider also the following quotation by R.B. Burchard: "The canoemen entered into a friendly alliance with the 'Delaneys'...save for occasional bloodless disputes concerning the propriety of using fencerails for firewood and vagrant chickens for mid-night

\footnotetext{
${ }^{75}$ Radforth shows, for example, how the bulk of the labour in the lumber industry was performed in the winter months Radforth, Busbworkers and Bouses, 26-7.

76 "The American Canoe Association," Forest and Stream, 5 December 1896.

77 "The Executive Committee Meeting," Forest and Stream, 12 November 1885; "The Executive Committee Meeting," Forest and Stream, 18 November 1886.
} 
sacrifices. ${ }^{178}$ The second half of this statement could be read as a jest or it could be interpreted as reflecting a lack of respect on the part of the campers for their hosts and their belongings on Grindstone Island.

\section{Goods}

It was not just labour that the ACA purchased, but goods as well. Local farmers were approached for perishable items such as produce, milk, eggs, and meat to be served in the mess tent and sold in the camp store. ${ }^{79}$ Those years when the organization rented the land from a farmer, this family appears to have supplied a good portion of the fresh produce. For example, in 1887 members were informed, "Farm produce from Mr. Dodds [owner of the land on Bow Arrow Point] will be retailed at the store, and orders for fresh meat will be taken. ${ }^{" 80}$ Area residents were also valued for their wood, both in the form of lumber for the camp infrastructure and as fuel for the nightly campfires. Most of the vendors that the accounts list are men. However, in 1900, the ACA acquired lumber from Mrs. E.C. Wallace. ${ }^{81}$ Here again, we can presume that selling produce and wood was part of a larger and varied economic strategy for local families. Presumably in those areas where there was an established tourist trade, the organizers of the ACA meets tapped into existing supply networks in which local farmers sold "green goods" to the hotels. The story of William Johnson suggests that this could be a precarious occupation. Johnson was drowned in 1896 while en route to a delivery when his boat was cut in two by a steamer. Although he did not service the

\footnotetext{
${ }^{78}$ Burchard, "Back to Grindstone," 139.

${ }^{79} \mathrm{O}$.K. Chobee reported that the 1883 camp was visited daily by a "milkman, a baker, a dealer in fresh butter and eggs, and a post-man." Chobee, "Echoes from Stony Lake," 114.

${ }^{80}$ See, for example, "The ACA Meet of 1887," Forest and Stream, 2 June 1887.

81 "Executive Committee Meeting," Forest and Stream, 3 November 1900.
} 
ACA camps, he died within view of the encampment on Grindstone Island. ${ }^{82}$

The dependency of the ACA on local labour and goods was not unique, but was (and remains) a characteristic of tourist economies more broadly. Dona Brown, for instance, has explored the complex tourist industries that emerged in New England over the course of the nineteenth century to accommodate, feed, and outfit the many visitors to the area. ${ }^{83}$ Similarly, Andrew Watson has illustrated the centrality of lakeside supply networks to meeting the needs and wants of early cottagers and settlers in Muskoka. ${ }^{84}$ On a more intimate level, J.I. Little demonstrates how a small group of "city folk" who summered on Lake Mephremagog around the turn of the century, "relied on the easy-going local men who knew how to build boats and cabins, fix engines, and fulfill other traditionally male tasks that [the campers were] somewhat incompetent at." ${ }^{85}$ With the exception of a handful of ethnographic comments, the fact that campers rarely remarked on the very local economies that sustained them suggests an invisibility of the local to ACA members. This failure to "see" their immediate circumstances calls into question the degree to which the ACA encampments were themselves local phenomenon. Although the canoeists claimed particular affection for sites such as Lake George and Grindstone Island, presumably, this was less a matter of the physical location than the experience of a given meet. The former, for example, was

\footnotetext{
82 "At the Canoe Camp," New York Sun, 17 August 1896; "Ready for the Races," Syracuse Evening Herald, 23 August 1896.

${ }^{83}$ Dona Brown, Inventing New England: Regional Tourism in the Nineteentb Century (Washington: Smithsonian Institution Press, 1995).

${ }^{84}$ In the case of Muskoka, supply boats which travelled from farms/stores to cottages were operated by local merchants or farmers, who sought to extend the reach of their enterprises to immobile cottagers using steam-powered craft. These networks did not only service cottagers, however. They also met he needs of local settlers. Andrew Watson, "Mobility and Sustainability: Lakeside Supply Networks in the Age of Steamboat Navigation, Muskoka Ontario, 1880-1930" (Paper presented at Environments of Mobility in Canadian History, 13-14 May 2011).

${ }^{85}$ Little, "Scenic Tourism," 290.
} 
a formative site for the ACA, the birthplace of the organization, while the latter hosted what were long considered the best meets of the Association's history (1884-1886). In other words, the canoeists' investment in the encampments was more a function of the experience than a particular space/place.

\section{Entertainers}

While the majority of workers present at the encampments were engaged in manual labour, the campers also benefitted from more artistic undertakings. At the 1884 meet on Grindstone Island, for example, “a number of Indians...represented scenes of Aboriginal life," as part of Seavey's spectacle. ${ }^{86}$ Six years later, members of the ACA hired a "Coon Band," entertainment for the camp on a Wednesday afternoon. ${ }^{88}$ The most famous of the ACA performers was E. Pauline Johnson. Her appearance at the 1893 meet in full Indian costume was one of the most unusual and noteworthy aspects of that year's encampment. Spectators watched as "this Indian girl, daughter of a Mohawk chief, stepped into the glare of the red lights, dressed in the ornamental garb of a Mohawk maiden. She tossed back her long black hair, clinched her hands, and recited her own

\footnotetext{
86 "Canoeists Break Camp," New York Sun, 16 August 1884. This appears to be one of the few times, if not the only time, that Seavey used non-ACA members for his spectacle.

${ }^{87}$ Schroeder argues there was a "coon song craze" in the 1890 s. Patricia R. Schroeder, "Passing for Black: Coon Songs and the Performance of Race," Journal of American Culture 33, no. 2 (2010): 139. Major argues "coon" probably came from the Southern belief that all black people were thieves, and raccoons were known to steal food. Clarence Major, ed., Juba to Jive: A Dictionary of African-American Slang (New York: Penguin, 1994), 112. Certainly, its racist connotations are impossible to overlook. ${ }^{88}$ D.B. Goodsell outlined the circumstances as follows, "One evening, led by Lafayette Seavey, we went to Sag Harbor searching for talent to amuse us at the general camp fires. We found four colored men with banjos and guitars who sang and played a song that was new to us - 'Watermellon [sic] Growing on the Vine.' It became popular immediately and we took the quartette over to camp, formed ourselves into a procession and marched around singing the melody." Goodsell, $A$ Canoeing Reminicence, 3. Photographs of the Band were also included in S.R. Stoddard, Glimpset of the ACA (Glens Falls, 1890).
} 
poem, wherein an Indian wife bids her warrior husband go to war with the whites." 89

The New York Times deemed the performance "all very stirring and tragic." 90

Marginal groups also took part in the spectacle of the regatta, as I noted in

Chapter Eight. At the 1881 meet, for example, spectators watched as canoes with local

Indigenous men competed for a purse. ${ }^{91}$ That "Indians" apparently leant some

authenticity to early meets is evident in a letter from Nathaniel Holmes Bishop to a

fellow signatory of the First Call:

Captain Lee Harris, the owner of the little steamer Owl, who is an Adirondack guide, and lives in Caldwell, will 'enthuse' the Indians some half dozen or more who live in the outskirts of the village. He will try to find them birch trees large enough to make canoes, and if we offer a prize for an Indian canoe race, we may coax them into dressing in savage style and putting on the war paint. As their leader is thoroughly Christianized, and the best member of one of our churches, it may require the persuasive eloquence of $\mathrm{Rev} . \mathrm{Mr} . \mathrm{H}-\ldots$ but we must have an Indian canoe race on the Horicon of Cooper, if we have to import the Indians from Canada. ${ }^{92}$

Clearly, Bishop was not interested in the participation of contemporary Native people, but was more concerned with reproducing a mythological and quasi-historical stereotype that would presumably lend some "authenticity" to the event. ${ }^{93}$

The question of participation has long troubled historians studying Aboriginal and African-American performances for white audiences. Scholars in both fields tend to agree that in this period participation in minstrel shows and World's Fairs, to name

\footnotetext{
89 "Around the Pine Camp Fire," New York Times, 20 August 1893.

${ }^{90}$ The reporter's reaction to Johnson is consistent with other commentary of the period, which marveled at the dual identity that Pauline and her mother held. Veronica Strong-Boag and Carole Gerson, "Literature, Performance, and Reception," in Padyling Her Own Canoe: The Times and Texts of E. Pauline Jobnson (Tekabionwake) (Toronto: University of Toronto, 2000), 100-34.

91 "The Second Day of the Regatta," New York Times, 13 August 1881. As I noted in Chapter Eight, Aboriginal men and women had long been performing in canoes for white audiences.

92 "The Canoe Congress," Forett and Stream, 22 January 1880.

${ }^{93}$ I borrow this notion of authenticity from Paige Raibmon, Autbentic Indians: Episodes of Encounter from the Late-Nineteentb-Century Nortbwest Coaut (Durham: Duke University Press, 2005), 3-9.
} 
just two of the more popular venues for racialized performers at the end of the nineteenth century, offered economic benefits for participants. ${ }^{94}$ Such venues also provided opportunities to affirm their culture and "reverse stereotypes" constructed by whites. ${ }^{95}$ In some cases, groups "performed with more irony than their white audiences appreciated, enjoying their status as tricksters by performing expected roles and subverting them." ${ }^{.96}$ In this way, performances were more than "capitulation to the forces of popular consumer culture," they were a "form of political activism," an opportunity "to challenge the racial status quo and thus participate in the creation of modern discourse. ${ }^{97}$ Of course, white audiences likely failed to recognized the complexity of such performances, but rather saw them as confirmations of pre-existing assumptions about the racialized other. As Paige Raibmon notes, even as the Kwakwaka ${ }^{\prime}$ 'wakw performing at the 1893 World's Fair in Chicago "ingeniously combined cultural affirmation and adaptation, they contributed to the identification of Kwakwaka'wakw culture as a static relic of the past." ${ }^{\prime 98}$

The invisibility of work and workers at the annual meetings of the ACA was, in part, a function of the mythology of the encampments, which were framed as spaces of independence in which the canoeist was largely self-sufficient and as events where the real work was undertaken by the organizing committee. Contrary to this mythology,

\footnotetext{
${ }^{94}$ Schroeder, "Passing for Black," 143; Raibmon, Authentic Indianu, 51.

${ }^{95}$ Raibmon, Autbentic Indiant, 72; Schroeder, "Passing for Black," 143.

${ }^{96}$ Schroeder, "Passing for Black," 143.

${ }^{97}$ Schroeder, "Passing for Black," 139. Here, Schroder is citing the pathbreaking work of Louis ChudeSokei, W. T. Lhamon, and Karen Sotiropoulos, which moves beyond simple characterizations of minstrelsy as racism, but rather as performance that "signif[ies] in rich and complex ways." Louis Chude-Sokei, The Laut "Darky": Bert Williamu, Black-on-Black Minutreloy, and the African Diaspora (Durham: Duke University Press, 2006); W.T. Lhamon, Jr., "Whittling on Dynamite: The Difference Bert Williams Makes," in Lìten Again: A Momentary History of Pop Music, ed. Eric Wesibard (Durham: Duke University Press, 2007), 7-25; Karen Sotiropoulos, Staging Race: Black Performers in Turn of tbe Century America (Cambridge, Mass.: Harvard University Press, 2006).

${ }^{98}$ Raibmon, Autbentic Indianu, 72-73.
} 
the canoeists delegated tasks they were incapable of or unwilling to perform to people they could easily overlook: men and women of different socioeconomic and racialized groups. The ACA was not unique in this respect. As Thomas Andrews argues, in the late nineteenth century tourists were set up to ignore the work around them in two ways. First, if the "small armies of maids, waiters, cooks, and porters... did their jobs properly," they would be scarcely noticed. Second, the travel industry "surrounded bourgeois travelers with the sort of labor they were least likely to consider work: the household work of women and the menial labor of racialized others." ${ }^{\prime 99}$ That administrators allowed such groups access to the encampments calls into question the framing of the ACA meets as uniformly white middle-class spaces. Clearly the boundary that the organization sought to police was more permeable when it came to labourers. Although if they were not really "seen," then perhaps the presence of labourers was far more tolerable and, given the normalcy of such relationships in their urban lives, unremarkable. Of course, not all workers were created equal in the eyes of the canoeists, a reality reflected in the variable attention paid to different groups of workers. The ACA was not just a space of material production, but of consumption as well. It is to those individuals whose labour constituted the encampments as a commercial space that we turn in the next section.

\section{Part II - The Encampment as Commercial Space}

At various times in the period between 1880 and 1910, a canoeist could purchase goods from the camp store, views of the encampment from a photographer, handicrafts from indigenous artisans, and canoe parts from a builder. In other words,

\footnotetext{
${ }^{99}$ Andrews, "Made by Toile," 848 .
} 
people consumed more than landscapes, experiences or services at the annual meetings, they also purchased physical goods, some of which made the journey home with them as souvenirs of their time at the encampments. In this part of the chapter, I consider three different groups that peddled their wares at the meets: Aboriginal artisans, commercial photographers, and boat builders. Just as the labourers on site were not created equal, nor were the vendors.

\section{Aboriginal Handicrafts}

The souvenir trade was big business in the late nineteenth century, a consequence of the "rapid growth in tourism during the Victorian era."100 "Making handicrafts" for white travellers was, to borrow from Patricia Jasen, a "principal occupation of Native women along most tourist routes... and a mainstay of the family income in many communities." ${ }^{\text {101 }}$ Although this "doorstep economy" likely gave "poor return for the skill and effort involved," it "provided a significant source of income in locations where older means of survival had been eroded." 102 Furthermore, "the commercialization of Indigenous products helped enable the survival of craft-based, and many women's, knowledge." ${ }^{103}$ Finally, craft production, as a performance of Native culture, was a visible reminder to the colonizer of the continued existence of

${ }^{100}$ Ruth B. Phillips and Christopher B. Steiner, "Art, Authenticity, and Baggage of Cultural Encounter," in Unpacking Culture: Art and Commodity in Colonial and Postcolonial Worlds, eds. Ruth B. Phillips and Christopher B. Steiner (Berkeley: University of California Press, 1999), 9.

${ }^{101}$ Jasen, Wild Things, 70. See, also, Molly Lee, "Appropriating the Primitive: Turn-of-the-Century Collection and Display of Native Alaskan Art," Arctic Antbropology 28, no. 1 (1991): 6-15; Paige Raibmon, "The Practice of Everyday Colonialism: Indigenous Women at Work in the Hop Fields and Tourist Industry of Puget Sound," Labor: Studies in Working-Claw History of the Americas 3, no. 3 (2006): 23-56.

${ }^{102}$ Raibmon, "Practice of Everyday Colonialism," 26; Jasen, Wild Tbings, 97. Other references to Aboriginal handicrafts also appear on pages 50, 70, 95, 98, 118-9.

${ }^{103}$ Raibmon, "Practice of Everyday Colonialism," 26. 
Aboriginal people. ${ }^{104}$

The types of available crafts varied from location to location. In Niagara, Ontario, "offerings included mohair items, "selenite ornaments and bark trifles, curiously ornamented with colored grasses,' leather cigar cases embroidered with 'dyed elk's hair,' [and] beaded moccasins," while in the province's northern communities, such as Killarney and Little Current, the "great quantities of Indian work" included "canoes and boxes made of birchbark and adorned with porcupine quills, baskets, and mats made of grass." ${ }^{105}$ In scholarly circles, products labelled as "tourist arts" have typically "fallen into the ontological abyss of the inauthentic, the fake, or the crassly commercial," thus ignoring the complex meanings and practices associated with the production of souvenirs. ${ }^{106}$ However, as Ruth Phillips and Christopher Steiner observe, "the makers of objects...frequently manipulated commodity production in order to serve economic needs as well as new demands for self-representation and selfidentification made urgent by the establishment of colonial hegemonies." 107

To date, I have only uncovered one reference to Indigenous artisans on site at the ACA encampments. D.B. Goodsell, in his memoirs, makes passing mention of Aboriginal people who sold "baskets and such" at the Willsborough Point meets in 1891 and 1892. ${ }^{108}$ However, Indigenous craftspeople do appear in Florence Watters Snedeker's account of her family's journey to the 1891 meet on Lake Champlain:

\footnotetext{
${ }^{104}$ Melissa Otis-Dixon, "Performing Native Culture: Marketing Art, Acting, and Educating Newcomers in the Adirondacks," (Unpublished paper, 2012).

${ }^{105}$ Jasen, Will Tbings, 50, 97. Jasen does not include any accounts of souvenirs made and sold at any of the reserves on the north shore of Lake Ontario or the St. Lawrence River.

${ }^{106}$ Phillips and Steiner, "Art, Authenticity, and Baggage," 4. In particular, "their production for an external market...conflicts with widespread of authenticity." (9)

${ }^{107}$ Phillips and Steiner, "Art, Authenticity, and Baggage," 4. For example, see the essays in "Part I: Constructing the Other: Production as Negotiation," in Unpacking Culture, 33-83.

${ }^{108}$ Goodsell, $A$ Canoeing Reminiscence, 5.
} 
"Rattling down into the village of Caldwell, we circled the Indian encampment - where the little boy sold his heart to dark maidens for bows and arrows and mimic canoes." 109 Caldwell, which sat at the south end of Lake George, was only a stone's throw from the sites of the $1880-2$ and 1888 meets, suggesting that visitors to those meets may have visited Indian encampments there or that inhabitants of the encampments travelled to the ACA meetings. There were a number of reserves near to other meets as well. For example, travellers to the ACA encampments on the St. Lawrence that came along the river from Montreal or Cornwall would have passed and perhaps even stopped at the "Indian village" of St. Regis/Akewasasne, while visitors to the 1890 meet on Jessup's Neck coming through Southampton may have seen or stopped at the reservation there. ${ }^{110}$ Indigenous artisans did not just wait for customers to come to them, however, some actively pursued consumers, particularly as the market for crafts became glutted in the 1890 s. ${ }^{11}$ Given the prevalence of the souvenir trade in other tourist locations, the proximity of reserves to the meet locations, and the mobility of Indigenous craftspeople, we can presume that Aboriginal artisans were more common at the encampments than the two aforementioned references allow. ${ }^{12}$

As I noted above, the sale of handicrafts was an important source of income for Aboriginal families, but also a means for cultural representation and preservation.

\footnotetext{
${ }^{109}$ Snedeker, A Family Canoe Trip, 33. According to Melissa Otis-Dixon, "Indian encampments" were common around Lake George throughout the nineteenth century. There was also a store in the town run by an Abenaki couple: Angeline Sarah Kaziah-Otondosonne (1851-1925) and her husband Norman Frank Johnson (1852-1919). See, Melissa Otis-Dixon, "Performing Native Culture"; "Basketmaking Indians of Lake George," New' York Timet, 8 September 1912.

${ }^{110}$ Jasen, Wild Things, 70.

${ }^{111}$ Melissa Otis-Dixon, "Performing Native Culture."

${ }^{112}$ With further time, I might be able to document greater involvement by local Aboriginal people. For example, Treaty Indians living on reserves in Canada required the permission of the Indian Agent to leave the reserve. Preliminary searches of the records for the two reserves closest to the St. Lawrence meets, St. Regis and Alnwick, as well as reserves near to Stony Lake and Muskoka have yet to yield favourable results.
} 
What did such souvenirs mean for white consumers? In the most general sense, a souvenir "concretizes or makes tangible what was otherwise only an intangible state." ${ }^{113}$ A souvenir in other words functions as a metonym for an experience, a way to recall a time or place long after it has passed. More specifically, consumers of Indigenous arts, Phillips and Steiner argue, "were motivated both by a genuine admiration for the technical expertise and aesthetic sensibility of non-Western artists and, like the anthropologists, by a romantic and nostalgic desire for the 'primitive' induced by the experience of modernization."114 Consumption was also inspired by a "suspicion of mass manufacturing and mass marketing and the desire to retrieve the authenticity belonging to the rare and the singular lost through new modes of production." ${ }^{115}$ Writing specifically of tourist collectors, Molly Lee contends that members of this group were "collectors by chance, not choice." Moreover, while their “purchase was meaningful as a personal experience... Native people played only a supporting role."116 Like the orientalist material culture so popular at the encampments, Indigenous handicrafts were something exotic. They were also, in the late nineteenth century, perceived as artifacts of a dying race, an idea that as I note elsewhere had profound political consequences. Finally, Indian souvenirs may have captured the "wild-ness" of the canoeists' travels to or the time passed at the annual

\footnotetext{
${ }^{113}$ Beverly Gordon, "The Souvenir: Messenger of the Extraordinary," Journal of Popular Culture 20, no. 3 (1986): 135.

${ }^{114}$ Phillips and Steiner, "Art, Authenticity, and Baggage," 12. They suggest further that the consumption of Aboriginal artifacts was inspired by a "sentimental quest for simplicity." Molly Lee contends that "Native artifacts were metonyms for the people who made them." Molly Lee, "Tourism and Taste Cultures: Collecting Native Art in Alaska at the Turn of the Twentieth Century," in Unpacking Culture, 268.

${ }^{115}$ Phillips and Steiner, "Art, Authenticity, and Baggage," 12.

${ }^{116}$ Lee, "Tourism and Taste Cultures," 269. Souvenirs, Lee adds, "in contrast to collectibles, are only valuable to those who buy them. The curio's resonance comes...from its ability to concretize time and space in a meaningful and substantive fashion." (270)
} 
meetings of the ACA.

\section{The Canoe Builders}

As I noted in Chapter Eight, the regattas at the annual meetings provided welcome opportunities for canoeists to compare the merits of different craft through competition. The same was true for boat builders, for whom the ACA meets were places to see and be seen. ${ }^{117}$ J.H. Rushton's biographer Atwood Manley claimed that the Canton builder returned home after the 1880 meet, "as he was to do after most of the annual meetings, with a pack of new ideas." ${ }^{118}$ Rushton made this point himself in his spring catalogue from 1885: "In the face of a general falling off in trade all over the country, our trade bau largely increaded." The boat builder attributed this success, in part, to attendance at the ACA meets and local meets, where he was able to "observ[e] the success of this or failure of that particular thing; using the knowledge thus obtained to aid us in making our work more perfect." ${ }^{119}$ Canoe meets were also places for selling canoes. ${ }^{120}$ Following the 1881 meet, the Lake George Mirror reported that Rushton and W.P. Stephens, a builder from New Jersey, had "been crowded with work to fill

\footnotetext{
${ }^{117}$ It is not clear how many builders were in attendance at a given meet. We know, however, that at the 1888 encampment on Lake George, the builders in camp included J.H. Rushton of Canton, NY, George Ruggles of Rochester, NY, Nelson Bowdish of Skaneateles, NY, and Mr. Spencer (either of Lowell, MA or Hartford, CT). "The ACA Meet, Lake George," Forest and Stream, 23 August 1888; Atwood Manley, Rusbton and His Times in American Canoeing (Syracuse: Syracuse University Press, 1968 ), 127. ${ }^{118}$ Rushton set up shop in Canton, NY in 1873. Manley, Rubton and His Times, 67.

${ }^{119}$ Manley, Rubton and His Timed, 97.

${ }^{120}$ Although we don't have any accounts of builders commercial practices on site, they likely favoured bringing catalogues over canoes, which were expensive to transport and bulky. Mroeover, were they established, they would have had boats on display in the form of private ownership.
} 
orders. ${ }^{121}$ For Canadian canoe builders, in particular, the encampments provided an entry point to lucrative American markets. ${ }^{122}$

Canoe building was a relatively small industry in 1880 when the ACA first met on Lake George. Peterborough, Ontario had led the way in manufacturing recreational canoes, with the first boat builders setting up shop in the 1860 s. By the 1870 s, there were a number of American builders meeting the demands of the growing number of canoeing enthusiasts south of the border, including Rushton; Stephens; James Everson, of Williamsburg, NY; George Ruggles of Rochester, NY; and Herbert Sprague of Parishville, NY. ${ }^{123}$ These early builders relied on word of mouth and advertisements in outdoor life magazines such as Forest and Stream for much of their marketing. Later, catalogues would prove an important development in their marketing strategies, as would attendance at the ACA meets.

Rushton's involvement with the Association as a canoe builder, from 1880 until his death in 1906, is at once representative and anomalous. ${ }^{124}$ He was certainly one of the more savvy builders to attend the annual meetings, employing a diverse range of marketing strategies to sell his product. He published articles in the leading outdoor magazines of the day, exhibited his boats at international expositions, and toured canoe clubs speaking about boat building, in addition to more traditional advertising

\footnotetext{
${ }^{121}$ As quoted in Manley, Rubton and Hit Times, 71. The belief that the meets would inspire interest in having a canoe is reflected in Commodore Edwards' advisement to Peterborough-area boat builders to have "finished boats on hand" for the 1883 meet on Stony Lake. "Stony Lake Canoe Meet," Peterborougb Examiner, 19 July 1883.

${ }^{122}$ Ken Brown, The Canadian Canoe Company and the Early Peterborougb Canoe Factoried (Peterborough: Cover to Cover, 2011), 15.

${ }^{123}$ Hallie E. Bond, "Paddling for Pleasure in the Northeastern States," in Tbe Canoe: A Living Tradition, ed. John Jennings (Toronto: Firefly Books, 2002), 203.

${ }^{124}$ Manley, Rutbton and Hï Times, 59, 67. Rushton and fellow builder, W.P. Stephens, were charter members of the ACA. Fred Cramphorn, ed., American Canoe Asuociation Yearbook (Manchester: Nutfield Press, 1908), 64.
} 
strategies such as print ads and catalogues. ${ }^{125}$ His relationship with the ACA is also better documented than that of other builders. However, others builders employed similar strategies and made use of the ACA in comparable ways.

First and foremost, Rushton was visible at the ACA encampments, a fact that is revealed in the many references to the builder in accounts of the meets. Where possible, he provided prizes for the regatta or for scratch races. For the inaugural meet, for instance, he donated a canoe valued at $\$ 75$ for the paddling race. ${ }^{126}$ While Rushton's name appears more frequently than his competitors in donation lists for the meets, other canoe builders did the same. ${ }^{127}$ At the 1881 meet, for example, contributions of various shapes and sizes were received from W.P. Stephens, the Racine Canoe Company of Wisconsin, and the Rice Lake Canoe Company. ${ }^{128}$ Second, Rushton made himself useful at the meets. Beginning in 1884, the Canton builder typically set up a large tent on the site, which doubled as a canoe repair shop and a store. ${ }^{129}$ In the first shop, for example, he "offered for display and sale a full line of single and double paddles, oars, masts, sails, and rigging features." ${ }^{130}$ The following year, this tent, which was located near to the Headquarters, was "fitted with a work bench," "a large supply of fittings," and a "competent man...ready to do any kind of repair work." ${ }^{31}$ Forest and Stream declared Rushton's tent a "great convenience" to

\footnotetext{
${ }^{125}$ Manley, Rusbton and Hi Times, 95, 98. According to William Crowley, Rushton produced his first mail-order catalogue around the same time as Montgomery Ward and Sears. William Crowley, Ruston's Rowboats and Canous: The 1903 Catalog in Perspective (Blue Mountain Lake: Adirondack Museum, 1983), viii.

126 "City and Suburban News," New' York Timed, 20 May 1880.

${ }^{127}$ See also "The Association Meet: Regatta Week," Forest and Stream, 13 August 1885.

${ }^{128}$ MSCRC, Collection 291, Box 23, Folder 2, Camp Circular for Lake George, 1881.

${ }^{129}$ Manley, Rubton and Hì Times, 95. See also, "The Meet of 1886," Forest and Stream, 26 August 1886;

"The ACA Meet," Forest and Stream, 19 July 1888; MSCRC, Collection 291, Box 23, Folder 2, Camp Circular for Lake George, 1888.

${ }^{130}$ Manley, Ruston and His Times, 96.

131 "The Association Meet," Forest and Stream, 6 August 1885.
} 
which canoes were carried daily "for repairs or alterations." ${ }^{\text {132 }}$ Although Rushton had initially built his own canoes, it was an unidentified employee from his "Boat Shop" in Canton that performed repair work at the meets. ${ }^{133}$ Rushton was the first to undertake such a project, but in later years other builders followed suit. In 1894, for example, the St. Lawrence River Skiff, Canoe and Steam Launch Company of Clayton, NY had a "repair and supply tent with competent men in charge" at the meet on Wolfe Island. ${ }^{134}$

Rushton and others used the opportunity at the meets to market their products. ${ }^{135}$ The best advertising came on the racecourse in the form of a winning entry. However, builders presumably found other ways to promote their craft. For example, they likely circulated promotional materials such as circulars and catalogues intended to speak for themselves. ${ }^{136} \mathrm{~A}$ review of contemporary trade literature indicates an explicit desire to highlight the quality of the boats being built. However, there is not the degree of emphasis on craftsmanship in this literature that one might expect given the period. T. Jackson Lears has illustrated, for instance, how the growing interest in arts and crafts was one of a host of related and yet divergent responses to anxieties about mass production in the modern age. ${ }^{137}$ If anything, canoe builders emphasized the modernity of their practices. A description of Rushton's

132 "The ACA Meet, Lake George," Forest and Stream, 23 August 1888.

${ }^{133}$ In 1881, Rushton had six men in his employ; by 1887 , that number had grown to roughly twenty. His most trusted assistant was Nelson Brown. Manley argues, no one "contributed more to establishing Rushton's reputation as a builder than did this modest, quiet master craftsman." Manley, Rutbton and Hï, Times, 71, 123, 47.

${ }_{134}$ George P. Douglass, ed., American Canoe Atucciation Yearbook (Newark: Press of the Holbrook Printing Company, 1894), 7 .

${ }^{135}$ Crowley argues that "[p]articipation in the Association provided Rushton with free advertising and allowed him to test and compare his work against that of other builders." Crowley, Rusbton's Rowboat, and Canoes, viii.

${ }^{136}$ I have yet to uncover an explicit description of a builder's activities at the meets.

${ }^{137}$ T. Jackson Lears, "The Figure of the Artisan: Arts and Crafts Ideology," in No Place of Grace: Antimodernitm and the Tranuformation of American Culture, 1880-1920 (Chicago: University of Chicago Press, 1994 [1981]), 60-97. 
factory that appeared in Forest and Stream in 1882, for example, claimed, "Labor-saving machinery of all kinds has been introduced and canoes are now set up and finished wholesale, in fleets at a time." That said, the article is careful to temper this celebration of modernity and mass production by informing readers, "each one receives that personal care and supervision which has given to Rushton's work such an enviable reputation."138

What is clear in the pages of promotional material is that builders made careful use of the ACA's reputation in their marketing. For example, a number of builders referenced Association races in their advertisements, but particularly trophy races. For example, an 1888 advertisement for Charles Piepenbrink of Albany, NY, declared him builder of Notus, the winner of the 1887 sailing trophy. ${ }^{139}$ Some, including Rushton, included scenes from the meets in their catalogues in the form of photographs or sketches. ${ }^{140}$ A number of builders also included "Rule 1" of the ACA's racing regulations - the portion that described measurements - in their catalogues, including the Herald Bros. Canoe Company and the Peterborough Canoe Company. ${ }^{141}$

Clearly boat builders sought to capitalize on the reputation of the organization and to make use of the encampments. However, the ACA also fostered this relationship between the organization, the annual meetings, and canoe manufacturers.

\footnotetext{
${ }^{138}$ Forest and Stream, 6 April 1882, as quoted in Crowley, Rurbton's Rowboat' and Canow, ix. The article continues with a description of the different rooms in Rushton's "factory."

${ }^{139}$ Frederick L. Mix, ed., American Canoe Astociation Yearbook (New York: John C. Rankin Jr., 1888), inside cover. The 1892 issue of the Herald Canoe Company catalogue proudly exclaimed, "At the first ACA meet at Lake George," which you will recall had taken place twelve years earlier, "the Cincinnati Canoe Club sailing some of our canoes and the flat bottomed 'Herald' was to the fore in sailing as well as in paddling qualities." Canadian Science and Technology Museum (hereafter CSTM), L31537, Herald Brot. Rice Lake Canow Catalogue, 1892.

${ }^{140}$ J.H. Rustoton Catalogue, 1886.

${ }^{141}$ CSTM, L31537, Herald Brow. Rice Lake Canoes Catalogue, 1892; CSTM, L31536, The Rice Lake Canoe Company Catalogue, 1900; CSTM, L04497, Peterborough Canoe Company Catalogue, 1892.
} 
For example, a large proportion of the advertisements in the ACA yearbook were for boat builders from both Canada and the United. The 1907 yearbook, for example, had no less than nine advertisements for canoe manufacturers, as well as a number of ads for companies that produced sails, paddles, and fittings. ${ }^{142}$ The ACA also courted boat builders more directly. In 1885, for instance, the organization issued an invitation to boat builders to "visit the camp and make an exhibition of their goods." 143 Similarly, in 1891 , visitors to the encampments were informed that "the different dealers in canoeing outfits" would be "allowed space and opportunity to supply canoe sails, fittings, etc." ${ }^{144}$ The same year, the list of entries at the 1891 meet was accompanied by the make and model of craft so that spectators could link specific boats to a particular builder. ${ }^{145}$ The ACA's efforts to cultivate this relationship with canoe builders extended beyond the meets to include the organization's print material. In the late 1880 s and early 1890s, when coverage of the encampments in the pages of Forest and Stream was at its peak, the yearly reports of the meet included a section devoted to boats and builders that described new models, construction techniques, and purveyors of canoes. $^{146}$

How do we explain this symbiotic relationship? Clearly there were commercial motivations on the part of the builders. Amongst other things, the meets provided opportunities to sell canoes and to improve existing ones. However, builders may have

\footnotetext{
${ }^{142}$ William A. Furman, ed., American Canoe Ausociation Yearbook (Trenton: State Gazette Print, 1907), pasim. Similarly, the 1889 yearbook had eight adverts for canoe manufacturers. George W. Hatton and C. Bowyer Vaux, eds., American Canoe Awociation Yearbook (New York: Nautical Publishing, 1889), pasim. Here again, there is limited attention given to the question of craftsmanship.

143 "The Association Meet," Forest and Stream, 6 August 1885.

144 "The ACA Meet: Camp Circular," Forest and Stream, 10 July 1890.

145 "The ACA Meet of 1891: Race Week," Forest and Stream, 27 August 1891.

${ }^{146}$ See, for example, "The ACA Meet of 1889: Canoes and Fittings," 27 September 1888 and 4 October 1888; "The ACA Meet of 1890-VI," Forest and Stream, 8 January 1890.
} 
also seen their presence at the meets of a "national" canoeing association as adding credibility to their commercial endeavours. Similarly, for the ACA, the presence of canoe companies likely served to further legitimize their project of constructing a national organization for canoeists. Boat builders were also part of the cadre of service providers employed by the ACA, which they seemed to feel would attract visitors and ultimately members. Of course, boat builders' services were likely seen differently than those offered by a barber or general labourer, in no small part because of their present race and class position. To the best of my knowledge, builders were white and middleclass, although the labourers they employed may not have been. ${ }^{147}$

The ACA was not the only event attended by canoe builders promoting their craft, nor was it likely the most important. ${ }^{148}$ Also popular were industrial exhibitions, which as Robert Rydell notes, "provided manufacturing and commercial interests with opportunities to promote the mass consumption of their products."149 Exhibitions, such as these promised a wider audience, but they also exacted a heavy toll from builders. As Manley reveals, "To prepare the exhibit, rent space, ship the display to Chicago, and put a man in charge of it, Rushton had to borrow heavily." ${ }^{150}$ In the uncertain

\footnotetext{
${ }^{147}$ Although a builder like Rushton had, at one time, been a manual labourer, he was now an administrator and salesperson.

${ }^{148}$ Few of the catalogues I reviewed included testimonials, a common marketing strategy in the late nineteenth century. However, a number referenced prizes won at international exhibitions. For example, a Rice Lake Catalogue from 1900 proudly exclaimed that the company had won a gold medal at the Fisheries Exhibition in London in 1883, as well as bronze medals at the following events: Philadelphia Centennial Exhibition (1876), Dominion Exhibition of 1876, Sydney Exposition (1877), Colonial and Indian Exhibition (1886), World's Columbia Exposition (1893), and Paris Exposition (1900). CSTM, L31536, The Rice Lake Canoe Company Catalogue, 1900. For a discussion of testimonial advertising, Marlis Schweitzer and Marina Moskowitz, eds., Tutimonial Advertising in the American Marketplace: Emulation, Identity, Community (New York: Palgrave Macmillan, 2009).

${ }^{149}$ Robert Rydell, All the World's a Fair: Visions of Empire at American International Exposition', 1876-1916 (Chicago: University of Chicago Fair, 1987), 2.

${ }^{150}$ Manley, Rusbton and His Times, 128.
} 
economic climate of the 1890 s, this could prove fatal to a boat builder. ${ }^{151}$ For Rushton, at least, it took "several years to recover his losses and repay the loan." ${ }^{52}$ Perhaps then, the ACA meets represented a safer investment of time and money.

\section{Commercial Photographers}

Aboriginal artisans were not the only group engaged in the souvenir trade at the annual meetings. The encampments were also frequented by those "proletarians of creation," commercial photographers. ${ }^{153}$ Jean Sagne has noted that, in France, "from 1880 onwards, photographers started to follow the crowds as they left town for spas and seaside resorts," convincing hikers "to pose for portraits in their hiking boots, knapsacks on their backs" and persuading "bathers in striped bathing costumes to have their pictures taken in front of painted backdrops showing swelling seas or a port." ${ }^{54} \mathrm{~A}$ similar phenomenon emerged in response to the annual meetings of the ACA, which provided commercial photographers the opportunity to sell portraits of canoe clubs and families, and views of the camp landscapes and activities to members of the organization. ${ }^{155}$ In this way, commercial photographers were manufacturing and selling both a physical product (the photograph) and a more intangible one (memories). ${ }^{156}$

\footnotetext{
${ }^{151}$ Charles Hoffmann, The Depression of the Nineties: An Economic History (Wesport: Greenwood Publishing, 1970).

${ }^{152}$ Crowley, Rusbton's Rowboats and Canoes, ix.

${ }^{153}$ Bernard Edelman, Ledroit Saiui par la Photograpbie (Paris: François Maspéro, 1973), as quoted in Allan Sekula, "Photography Between Labour and Capital," in Mining Pbotograpbo and Otber Pictures, 1948-1968, eds. Benjamin H.D. Buchloh and Robert Wilkie (Halifax: Press of the Nova Scotia College of Art and Design, 1983), 194.

154 Jean Sagne, "All Kinds of Portraits: The Photographers Studio," in A New' History of Pbotograpby, ed. Michael Frizot (Koln: Konneman, 1998), 120.

${ }^{155}$ For example, the Peterborougb Daily Review' reported that the photographers were busy on Sunday afternoon doing portraits of the clubs: Little of Peterborough with the Knickerbockers, and Anderson of Toronto with the Albany clubs. "ACA Annual Meeting," Peterborough Daily Review', 21 August 1883.

${ }^{156} \mathrm{~A}$ discussion of the memory work being performed in the photographs of Stoddard, particularly when placed alongside the images produced by amateur enthusiasts at the meet, would certainly yield fruitful insights as to the ways in which the encampments were imagined and remembered by the canoeists. However, it is outside of the purview of this dissertation.
} 
As Mary Warner Marien notes, "by 1880, photography had been quietly absorbed into the texture of everyday life."157 People of all classes likely had experience with professional photographers in the form of cartes de visit and photograph albums. With the introduction of Eastman's Kodak camera in 1888, photographic practice became accessible to a broader public. ${ }^{158}$ Even with a growing number of amateur enthusiasts, however, professional photographers did not disappear. Although typically associated with studio work, professional photographers also included itinerant commercial photographers who travelled from place-to-place taking pictures for hire. ${ }^{159}$ In contrast with social documentarians who "sought to photograph a way of life," itinerant commercial photographers were motivated, at least in part, "by the potential for sales." 160 Their photographs, in other words, were shaped by their desire to "sell their pictures back to the people they photographed."161

Most of the commercial photographers at the encampments were studio photographers who travelled to the meets in pursuit of economic benefits. ${ }^{162}$ Still others selling their views were canoeists and amateur photographers looking to supplement their incomes while at the annual meeting. ${ }^{163}$ The most prominent photographer at the

${ }^{157}$ Mary Warner Marien, Pbotography: A Cultural History, 2nd ed. (Upper Saddle River: Prentice Hall, 2006), 165.

${ }^{158}$ Marien, Photography, 168-169.

${ }^{159}$ This more informal arm of photographic culture practiced by itinerant practitioners has received less attention than the products and practices of formal photographic culture represented by studios. Sara Spike, "'Photos of the school group of this place and others': An Itinerant Photographer Pictures Rural Education in Nova Scotia, c.1912" (M.A. Thesis: Concordia University, 2009).

${ }^{160}$ Spike, "'Photos of the school group," 39.

${ }^{161}$ Spike, "'Photos of the school group," 39. Photographer Leslie Shedden captures this sentiment perfectly in Sekula, "Between Labour and Capital," 255.

${ }_{162}$ Presumably a good number of these were from the immediate area, such as Mr. Little from Peterborough in 1883.

${ }^{163}$ This group included Lafayette Seavey, who organized a number of the spectacles described in the previous chapter. Occupational plurality was common amongst photographers. See, for example, Carol J. Williams, Framing the West: Race, Gender, and the Pbotograpbic Frontier in the Pacific Nortbwest (New York: Oxford University Press, 2003). 
encampments, however, did not fit into either of these categories. ${ }^{164}$ Born in the foothills of the Adirondacks, Seneca Ray Stoddard had worked as decorative painter before turning to photography in the mid- $1860 \mathrm{~s} .{ }^{165}$ By the time he attended his first ACA encampment in 1881 , he was a relatively well-known photographer throughout the Northeast. ${ }^{166}$ In addition to producing photographs and souvenir albums of the Adirondacks, the Glen's Falls native had authored a series of illustrated guidebooks for the region, which became standard fare for both actual and armchair tourists, including visitors to the meets. ${ }^{167}$ Stoddard's photographs had also been displayed at the Philadelphia Centennial Exhibition of 1876, "where they were seen by thousands of visitors." 168

By 1888, Stoddard had become "a feature of every ACA meet, with his camera, and his request for 'a pleasant expression, now,' or 'quiet, now, for a moment,' or 'rest where you are for another clip.'"169 In part, Stoddard's involvement with the ACA can be understood and explained in economic terms. ${ }^{170}$ The meets provided opportunities for him to sell his images. However, Stoddard also appears to have had a genuine

\footnotetext{
${ }^{164}$ Much has been written about Stoddard's association with the Adirondacks and the wilderness ideal. However, only Stoddard's biographer, Maitland C. De Sormo, has paid any attention to his involvement with the American Canoe Association in Seneca Ray Stodzard: Versatile Camera-Artist (Saranac Lake: Adirondack Yesteryears, 1972). See also, Jeffrey L. Horrell, Seneca Ray Stoddard: Tranuforming the Adirondack Wilderness in Text and Image (Syracuse: Syracuse University Press, 1999); Frank H. Goodyear, III, "A Wilderness for Men: The Adirondacks in the Photographs of Seneca Ray Stoddard," in Gender and Landscape: Renegotiating Morality and Space, eds. Lorraine Dowler, Josephine Carubia, and Bonj Szczygiel (London: Routledge, 2005), 124-42.

${ }^{165}$ Stoddard quickly developed a reputation as a photographer in the Glens Falls area and by the early 1870 s, was selling both individual photographs and souvenir albums of local landscapes to tourists. Horrell, Seneca Ray Stodzard, 43-5. A more thorough treatment of Stoddard's early years can be found in Jeanne Winston Adler, Early Days in the Adirondacks: The Pbotograpbs of Seneca Ray Stoddard (New York: Harry N. Abrams, 1997).

${ }^{166}$ Although Stoddard was at the 1881 meet, he did not join the ACA until 1882.

${ }^{167}$ The first of The Adirondacks Illustrated guidebooks was published in 1873. The guidebooks were revised and reprinted through to 1914.

${ }^{168}$ Horrell, Seneca Ray Stodzard, 45.

${ }^{169}$ C. B. Vaux, "The American Canoe Association, and Its Birthplace," Outing 12, no. 5 (1888): 418.

${ }^{170}$ In reading his photographs, this should be our first consideration. First and foremost, Stoddard sought to produce images, which would resonate with this audience.
} 
interest in canoeing. In addition to his involvement in the ACA, he was a founding member of the Lake George Canoe Club. ${ }^{171}$ He also undertook a number of long canoe cruises, including a three-stage journey between New York and the Bay of Fundy. ${ }^{172}$ With the exception of the 1883 meet on Stony Lake, Stoddard was present at every encampment between 1881 and $1896 .{ }^{173}$ He produced large numbers of images documenting the people, places, and events of these meetings of the ACA, which he then sold to members of the Association. ${ }^{174}$ These same photographs were also circulated in the canoeing press, including the yearbook and official organs of the ACA. While there is little documentation on his commercial practices while on site, he likely set up a tent where he displayed available photographs. ${ }^{175}$ Stoddard also advertised his views in the ACA Yearbooks, as well as in canoeing-related publications such as Forest and Stream. ${ }^{176}$ There is a note, for example, in a September 1882 issue informing subscribers that Stoddard had available "excellent photos of the recent canoe meet at Lake George," which "show all different styles of boats present, the

\footnotetext{
${ }^{171}$ Hallie Bond reports that the club was founded at his house in the winter of 1882 . Bond, Boats and Boating, 112.

${ }^{172}$ Stoddard completed the 2000 -mile cruise over the course of several summers in the mid-1880s, first with his-brother-in-law and occasional assistant, Charles Oblenis, and later with fellow ACA member Roswell B. Burchard. Adler, Early Day, 102.

${ }^{173}$ When he stopped attending, the ACA appointed an official photographer. A.A. Lewis held this post in 1897 and 1898. C.V. Schulyer, ed., American Canoe Association Yearbook (n.p., 1898), 2; Charles P. Forbush, ed., American Canoe Association Yearbook (n.p., 1899), 3.

${ }^{174}$ Other photographers at the meets offered similar good and services, although not to the same degree as Stoddard. For example, a number advertised stock images of the encampments, including Frank $\mathrm{H}$. Foster of Lebanon, NH. It was also common practice for photographers, commercial and amateur, to be commissioned for club pictures. For example, in 1883, the Peterborough Examiner reported that Mr. Little had been in camp taking photographs of the Knickerbockers, while Mr. Anderson did the same for the Toronto clubs. "Stony Lake Canoe Congress," Peterborougb Examiner, 23 August 1883.

${ }^{175}$ I uncovered two images which support this hypothesis. They depict display boards of photographs and Glimpires put together for the 1887 meet. NYSHA, 1.1/29.

${ }^{176}$ There are, for example, advertisements for Stoddard's images in Hatton and Vaux, American Canoe Astociation Yearbook, xxi; Ralph F. Brazer, ed., American Canoe Association Yearbook (New York: n.p., 1891), 73; Charles E. Cragg, ed., American Canoe Atvociation Yearbook (Port Henry: Press of Essex County Publishing, 1895), 80.
} 
camps and canoe islands, the races and the officers." ${ }^{177}$ At other times, he published detailed lists of the individual photographs he had available, as in an 1889 issue of Sail an $\mathrm{Pa} \partial \partial \mathrm{le}^{178}$ In addition to individual photographs, Stoddard produced three souvenir albums of the meets, entitled Glimpses of the $A C A$, in 1887, 1889, and 1890 respectively, which he advertised in Forest and Stream. ${ }^{179}$

As the organization's unofficial photographer for almost two decades, Stoddard was profoundly influential in producing a particular vision of the encampments, an ACA aesthetic if you will. Stoddard, in other words, was performing both the mechanical work necessary in creating photographic images, but also the cultural work that constructed the ACA encampments as competitive, recreational, and social canoeing landscapes. Stoddard effectiveness in framing the experience of the meets is evident in the extent to which canoeists consumed his photographs, but also reproduced his aesthetics in their own images. ${ }^{180}$

James Opp's writing on his family's colour slide images in late twentiethcentury Alberta, while the product of a very different time and place, is nevertheless useful in thinking through the "work" that Stoddard performed as an ACA photographer. ${ }^{181}$ Of particular interest for this chapter are the ways in which Stoddard

177 "Camp Photos," Forest and Stream, 14 September 1882.

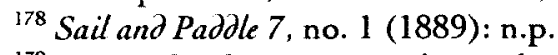

${ }^{179}$ Picture books were popular at the turn-of-the-century, "particularly commemorative books for events of note." They were also part of a photographer's efforts to "continually innovate" as a means of survival. Sara Spike, "Photos of the school group," 23; Williams, Framing the West, 68. An advertisement published in the circular for the 1892 meet at Willsborough Point suggests that Stoddard had plans to produce a fourth edition, although the fact that he was soliciting subscribers suggests early books hadn't been as successful as he had anticipated: "Glimpses of the $A C A$ (1892) will be issued if there are enough subscribers - $\$ 2.00$ per copy. It appears that a fourth Glimpses was never issued. MSCRC, Collection 291, Box 23, Folder 2, Camp Circular for Willoborough Point, 1892.

${ }^{180}$ A review of other scrapbooks included in the ACA Collection proves this point. See, for example, NYSHA, 1.5/4, Thomas Hale Scrapbook; 1.5/6, Walwin Barr Scrapbook.

${ }^{181}$ Opp's work is also suggestive for puzzling over the entanglements of memory and place within the frame of the photograph, which as a result of time will have to be the subject of a future project. James 
contributed to the erasure of labour and labourers from the popular memory of the annual meetings by producing images which elided or obscured such subjects. The ACA that Stoddard constructed was a place of canoe competition, of tent villages, and of play. Even when he documented work, it was easily reimagined as something else. Consider, for example, the two photographs of the "Coon Band" Stoddard included in the 1890 version of Glimpses. ${ }^{182}$ These images suggest the three men are not working, for how could music making be labour. Rather, they are merely amusing the audience of white faces and bodies that surround them in one image or line up to parade behind them in another. It is all play, these photographs suggest, not work. If we spend any time considering the experience from the perspective of the musicians - recall that they had been hired in the nearby town of Sag Habor-however, both the event and Stoddard's photographs take on a very different meaning.

To date, historians of sport have been largely silent on the ancillary industries supported by sporting competitions or events. In this chapter, I have considered the Indigenous artisans, boat builders, and photographers attracted to the encampments by the prospect of economic gain. Even as these different constituencies were selling their wares on site, they did not constitute a uniform group. One of the most remarkable differences is their visibility in the historical record. Boat builders and photographers received significantly more attention in accounts of the meet than Indigenous craftspeople, likely because of their class, race, and, perhaps, gender status. Men like Rushton and Stoddard were, for all intents and purposes, just one of the

Opp. "Finding the View: Landscape, Place, and Colour Slide Photography in Southern Alberta," in Placing Memory and Remembering Place in Canada, eds. James Opp and John C. Walsh (Vancouver: University of British Columbia Press, 2010), 271-90.

${ }^{182}$ S.R. Stoddard, Glimpses of the ACA (Glen Falls, 1890). 
canoeists, members of the exclusive club that was the ACA encampments. By contrast, Aboriginal artisans like the manual labourers described in Part I were outsiders by virtue of their social position.

\section{Conclusion}

In myriad overlapping ways the annual meetings were spaces of production and consumption. Local carpenters and labourers produced landscapes, Indigenous craftworkers produced baskets, and photographers produced images, all of which were consumed by the canoeists. However, it is unlikely that visitors to the encampment would have understood the space and their experiences in these terms. As Dona Brown demonstrates, one of the sleights of hand performed by the tourist industry in the late nineteenth century was to "disguise the commercial relationship" that was at the heart of the touristic practices of consuming landscapes or experiences, so that tourism appeared as an escape from rather than a participant in the creation of "a consumer-oriented society and economy." ${ }^{183}$ To an extent, these acts of conjuring were about ameliorating anxieties about the world industrial capitalism was creating. That the ACA invited commercial vendors such as boat builders and photographers to the meets highlights the contradictions inherent in these practices.

Tourism operators, including the ACA organizers, did more than subsume the performance of consumption in a discourse of authentic experiences. They also obscured the labour that made such experiences possible. Much as in the broader tourist industry and the world of organized sport, the ACA encampments existed in the manner they did because of the work of women, working-class or rural whites, African

\footnotetext{
${ }^{183}$ Brown, Inventing New' England, 6.
} 
Americans, French Canadians, and Indigenous peoples. Ironically, these labourers performed tasks that were either too demanding or too demeaning for the canoeists who continued to think of themselves as independent travellers and sports despite these dependencies. In their efforts to make work and workers invisible, the canoeists sought to maintain the fiction of the encampment as a space for white middle-class men and, to a certain extent, for white middle-class women. This not only reinforced tourism and sport/leisure's apparent remove from the politics of everyday life, but it also ignored the physically and likely at times emotionally demanding contributions that workers made. This oversight further contributed to the already marginal status of the men and women who devoted their time and energies to the encampment.

That I am able to write this chapter at all suggests that the organizers and members were not entirely successful in their efforts to efface work and workers from the historical record of the meetings. In at least one case, a labourer appears to have actively sought to have his presence at the encampment preserved for posterity. In a photograph from the 1887 meet on Lake Champlain that bears much resemblance to "Work and Fun in Camp," the members of the Mohican Canoe Club are gathered once again in a tableau to the left of a decked canoe in full sail. ${ }^{184}$ While the eye is drawn to the scene being performed by the canoeists, a closer look reveals a black man peeking out from behind the sail of the canoe, his eyes trained directly on the camera. In this instance, perhaps, the photograph operates as a scene of resistance to the broader, systemic pattern of historical erasure that one encounters in the archive.

Workers have not only been overlooked in accounts of the ACA encampments. They have also been marginal figures in scholarly writing on the history of sport.

${ }^{184}$ NYSHA, 1.2/26, "Keys, Kanoe, Kaptor, and Kowboy," 1887. 
Whereas historians have capably shown how organized sport through membership systems and amateur clauses (re)produced inequitable social relations in the Victorian era, they have largely ignored the ways in which the sporting practices of the middle and upper classes, but particularly organized sport, were made possible by the work of "others." In this way, sport historians have been complicit in sport/leisure's marginalization of labour, but also in the (re)constitution of social divisions and hierarchies along lines of class, race, and gender. 


\section{Chapter Ten: Conclusion}

There was no official closing ceremony to mark the end of the annual meetings of the American Canoe Association. Rather, the campers drifted away, some leaving as soon as the regatta was finished, others lingering for a few days or even weeks. Trunks were repacked, tents taken down, tent floors disassembled and the wood sold, luggage ferried to the wharf, and good-byes were said. While some were surely heartened by the prospect of a feather bed or a good meal, not a few were saddened by these final tasks. As one author noted, and the caption for Figure 10.1 underlined, "Making camp is delightful. Breaking camp is torture."'

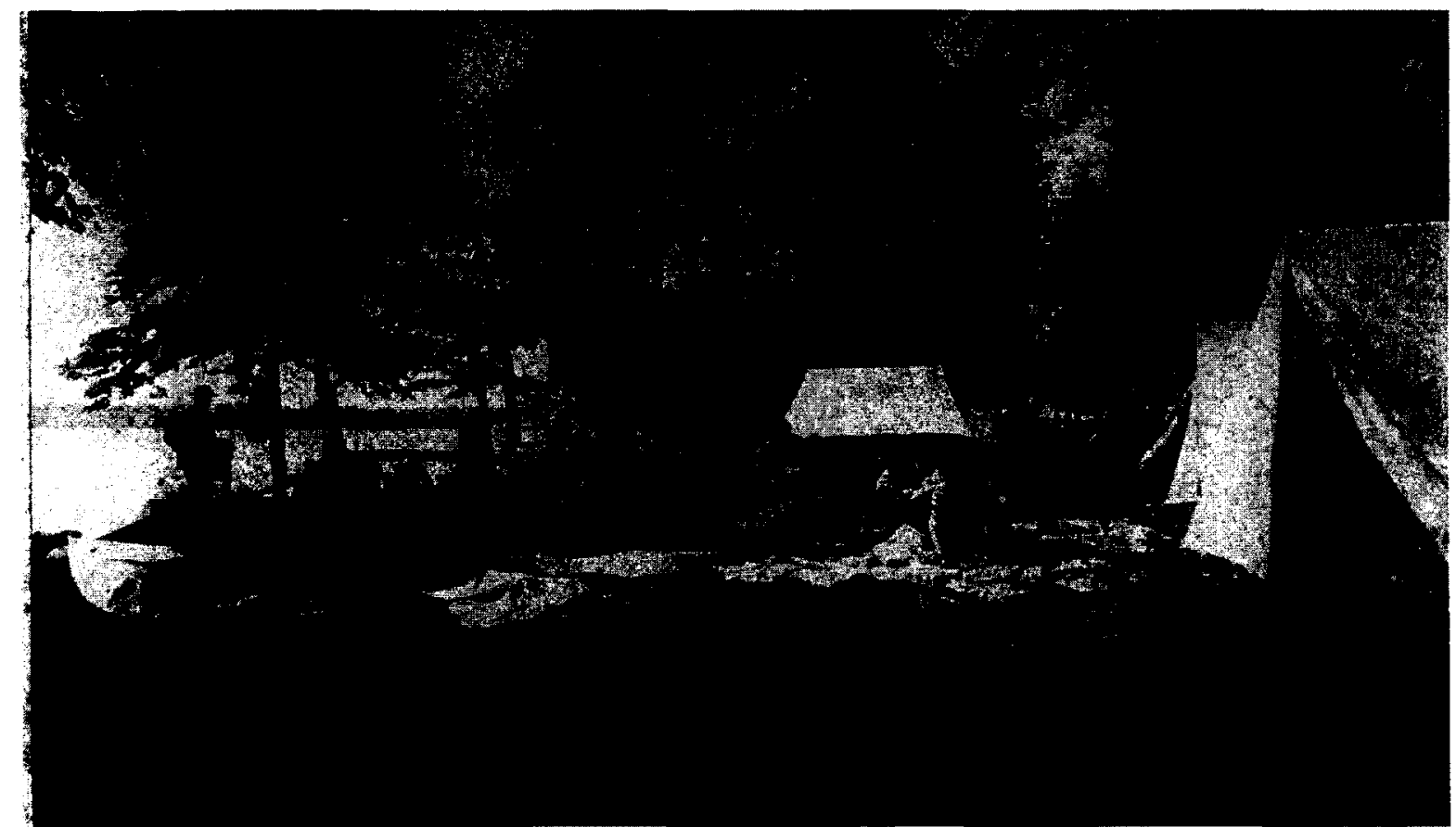

Figure 10.1 - "Packing Up - Sad Day in Camp," 1888. [Source: NYSHA, 1.1/32.]

Accounts of the yearly ACA encampments end almost inevitably on a melancholy note. All of the months of anticipation, the time spent seeking out routes, preparing for the races, packing trunks and boarding trains, and of course, the hours

\footnotetext{
I "The Annual Canoe Meet," New York Evening Post, 27 August 1887.
} 
passed along the shoreline or around the campfire, came quickly to a close, as the following account from Forest and Stream reveals:

No more dismal contrast can be imagined than that presented by a large camp just before and after breaking up. In the morning a row of white and parti-colored tents, each with flags flying, reached from the hill down the shore, while the beach was bright with canoes. At noon a tent or two was still standing at intervals, a few canoes partly packed lay on the beach, and a huge pile of baggage and boats was on the wharf. At sunset the last tent had disappeared, and where the turtle of the Mohicans and the twin cherubs of Springfield had gamboled together a few hours before, the lazy sheep found sweet nourishment on old hats and newspaper, and the patient kine placidly chewed the chromos from beef and tomato cans; while above on the crown of the hill, among the ashes of the camp-fire stood "Uncle Mike," watching the last retreating paddle and wondering whether the canoeists would come back next year to Grindstone. ${ }^{2}$

In the course of a day, what had once been a lively community was suddenly little more than a pile of tent floors waiting to be carted off, and refuse strewn ignobly amongst the trees and grasses. As a reporter from the New York Evening Post noted of the 1887 meet, "but a heap of straw remained, a broken board, a few bottles perhaps, some forgotten or discarded garment - a little trench and badly worn grass mark the spot where but yesterday there was comfort, jollity, life, and a home." ${ }^{\text {3 }}$

In spite of the ephemerality of the campsites, there was something enduring about the experiences of the meets. It lived on in the photographs that canoeists purchased from S.R. Stoddard or took themselves; it was carried home in the form of camp badges and prize flags; it was recalled in the ensuing months in newspaper articles and letters to the editor. ${ }^{4}$ There was also something more intangible about the

\footnotetext{
2 "The Association Meet," Forest and Stream, 6 August 1885. Interestingly, this word picture of the ACA encampments asks us to consider the longer histories of the encampment sites beyond the annual meetings, to inquire about, for example, the workers who stay behind.

3 "The Annual Canoe Meet," New York Evening Post, 27 August 1887.

${ }^{4}$ With more time, I would have considered in greater detail the theme of memory in relation to these events.
} 
experience that the canoeists took with them. Consider the following excerpt from an account of the 1884 meet on Grindstone Island:

Home again; back to desk and counter, to hot and dusty sidewalks, boiled shirt and stiff collar, and the grind of everyday life for another year, with a pleasant but tantalizing memory of last week; idling under the trees; the glorious stir and excitement of racing; pleasant hours by the evening camp-fires; the bright green waters, clear and beautiful, of the St. Lawrence; the deep blue sky, half American half Canadian; free from smoke, except the light blue of the campfire; free from noise, except the distant whistle of a steamer, too far off to be unpleasant until the drone of the city, the rattle of cart and omnibus over stones subside into a refrain of 'Alouette, gentil Alouette,' the brief or ledger fade from view for a moment, and we have a glimpse of camp again. ${ }^{5}$

This quotation speaks to the power of the encampments for the canoeists, but also the particular place memories that the meets invoked. To recall the annual meeting was to be transported to a place of nature, of socializing, and of sport. Yet, even as this author names the St. Lawrence, he is not describing a specific locale, but a feeling that emerged from the encampment, a sense of place based not on a physical location, but on an experience. That the physical backdrops for the encampments varied widely mattered little. The memories invoked are of the shared elements of these spaces: the shorelines, the campfires, the snowy tents tucked in between the trees, the other canoeists. The encampment, in other words, was a composite of layers of social and spatial experiences that crossed time and geography, a place given shape as much by the people - the community of canoeists - and the activities as by the topography of the site.

The encampments were profoundly meaningful events for many who attended. D.B. Goodsell offered the following thoughts in the closing paragraph of his 1936 memoir of his involvement with ACA: "The camps at Sugar Island are remembered as

5 "The Association Meet," Forest and Stream, 21 August 1884. 
the happiest days of my life...It is forty years since my first meet and I still have the same enthusiasm and love of the locality that $I$ had at first and in spite of the fact that $I$ have travelled and seen other places." ${ }^{.6}$ For white middle-class men like Goodsell who would spend their lives working in mid-tier white-collar jobs with little of the independence or satisfaction they believed they were owed as members of a civilized race, organizations like the ACA provided a sense of community in which they could develop valued relationships and achieve success. By contrast, for white middle-class women, the ACA provided a limited freedom from the strictures of urban life. If they wished they could paddle their own canoe and, after 1890, enter into competition as well.

I have no desire to deny the meaningfulness of these experiences. Nonetheless, the construction of meaning for Association members was deeply contingent upon practices of hierarchy and exclusion. Despite its claims to egalitarianism, the ACA barred full membership to women, members of the working class, and people of colour. In doing so, it contributed to the "common-sense" assumption of these groups as inferior, thereby further marginalizing them in contemporary society. It simultaneously shored up the power of white middle-class men. Finally, through its occupation of sites on waterways in Ontario, New York, and New England, the ACA participated in the displacement and dispossession of Aboriginal people, and the transformation of the lives of rural whites.

At the end of this dissertation, I am of the mind that we cannot ignore, escape, or rationalize the politics of class, gender, and race embedded in the origins of

\footnotetext{
${ }^{6}$ New York State Historical Association (NYSHA), 1.6/2, D.B. Goodsell, A Canoeing Reminiscence (1936), 13
} 
amateurism and, thus, in the very fabric of the amateur ideal that inspired so many of the ACA canoeists. Moreover, I am cognizant of the work that this ideal performs in the present day. I think particularly of college sport in the United States and the ways the term "student-athlete," which draws its rhetorical and practical power from the amateur ideal, has enabled the National Collegiate Athletic Association (NCAA) and American universities to profit handsomely from the labours of young, typically black, male athletes, but also to avoid assuming any social responsibility for these athletes. Similarly, the ideal of amateur sport allows countries to pursue nationalist ends in international competition at the expense of underpaid athletes who, in some cases, place their lives at risk.

This dissertation explored the social and spatial politics of sport/leisure in the late nineteenth century within the context of the American Canoe Association encampments. It paid particular attention to the ways in which class, gender, and race shaped access to and experiences of recreation in the Victorian era, but also to the structures that enabled white, middle-class forms of sport, namely industrial capitalism, colonialism, and liberalism. I have argued that the ACA encampments, which were microcosms of sport/leisure in the late nineteenth century, were not divorced from the realms of society, politics, and the economy, but were active participants in the making of a social order that was colonial, capitalist, and liberal.

In addition to this more general line of argumentation, this dissertation makes a number of distinct but related secondary arguments. In Chapter Two, for instance, I make the case for thinking of sporting organizations as another form of nineteenthcentury voluntary association and thus as part of the unfolding liberal social order.

\footnotetext{
${ }^{7}$ Taylor Branch, "The Shame of College Sports," The Atlantic (October 2011): 80-110.
} 
Chapter Three asks scholars to consider how sport historically through its physical emplacement has participated in the displacement and dispossession of already marginal people. In Chapters Four and Six, I encourage historians to think more critically about the ways in which they have understood travel as an extraordinary event that involves a leaving behind of home. The example of the ACA meets is suggestive of the ways in which travel is tethered to urban domestic spaces in both material and imagined ways. Chapter Six also proposes that we need to rethink the extent to which outdoor recreation in the late nineteenth century was a repudiation of the domestic, and by extension, the degree to which middle-class men generally were rejecting domesticity. Chapters Five and Eight offer some indication of the fruits of using the concept of governmentality to understand how sporting spaces and communities are enacted. Specifically, they reveal the insidiousness of liberal political culture in late nineteenth-century sport, and the ways in which the sporting practices of white middle-class men and women were enabled by and made possible these forms of governance in other aspects of everyday life. Finally, Chapter Nine is a call to historians to consider the ways in which marginalized labour has been fundamental to the sporting and leisure practices of the dominant classes and consequently to broaden how we imagine "sportscapes" both in the past and in our own present.

As this brief overview indicates, this dissertation contributes to a number of literatures, including gender history, the history of travel and tourism, environmental history, and labour history. Perhaps most importantly, it has sought to bridge the continuing divide between the history of sport and the discipline of history more broadly, by showing how sport contributes to our understanding of a wide range of historical events and phenomena. The best histories of sport do more than shed light 
on how we played in the past. They also show us how those ways of playing intersected with, reflected, and shaped the spheres of society, politics, the economy, and culture. 


\section{Appendix A: \\ Dates and Locations of the Annual Meetings and Encampments, 1880-1910}

3-6 August 1880 - Crosbyside Park, Lake George 11-13 August 1881 - Canoe Islands, Lake George 8-11 August 1882 - Canoe Islands, Lake George 10-24 August 1883 - Juniper Island, Stony Lake 1-15 August 1884 - Grindstone Island, St. Lawrence River 25 July-8 August 1885 - Grindstone Island, St. Lawrence River 13-27 August 1886 - Grindstone Island, St. Lawrence River 12-26 August 1887 - Bow-Arrow Point, Lake Champlain 10-24 August 1888 - Long Island, Lake George 9-23 August 1889 - Stave Island, St. Lawrence River 8-23 August 1890 - Jessup's Neck, Peconic Bay, Long Island 6-27 August 1891 - Willsborough Point, Lake Champlain 4-25 August 1892 - Willsborough Point, Lake Champlain 11-26 August 1893 - Brophy's Point, Wolfe Island, St. Lawrence/Lake Ontario 13-28 July 1894 - Croton Point, Hudson River 9-23 August 1895 - Bluff Point, Lake Champlain 14-28 August 1896 - Grindstone Island, St. Lawrence River 6-20 August 1897 - Grindstone Island, St. Lawrence River 5-19 August 1898 - Stave Island, St. Lawrence River 4-18 August 1899 - Hay Island, St. Lawrence River 3-17 August 1900 - Birch Point, Lake Rosseau, Muskoka 9-23 August 1901 - Mudlunta Island, St. Lawrence River 8-22 August 1902 - Chatham, Cape Cod 7-21 August 1903 - Sugar Island, St. Lawrence River 5-19 August 1904 - Sugar Island, St. Lawrence River 4-18 August 1905 - Sugar Island, St. Lawrence River 10-24 August 1906 - Sugar Island, St. Lawrence River 9-23 August 1907 - Sugar Island, St. Lawrence River 7-21 August 1908 - Sugar Island, St. Lawrence River 6-20 August 1909 - Sugar Island, St. Lawrence River 12-26 August 1910 - Sugar Island, St. Lawrence River 


\section{Bibliography}

\section{Primary Sources}

\section{Unpublished}

New York State Historical Association (NYSHA)

American Canoe Association Collection

Mystic Seaport Collections Researcb Center (MSCRC)

Collection 291 American Canoe Association

St. Lawrence County Hivtorical Adsociation (SLCHA)

John Henry Rushton Collection

McMaster University (MUA)

E. Pauline Johnson Fonds

Trent University Arcbived (TUA)

83-014 Stoney Lake: American Canoe Association

Library and Archives Canaza (LAC)

MG30-C-27 W.L. Scott Fonds

RG 10 Indian Affairs

R2936 John Harold Micklethwaite Fonds

I also consulted select materials at the: Adirondack Museum (AM), the Canadian Museum of Science and Technology (CSTM), and the City of Toronto Archives (CTA).

\section{Published}

American Canoe Adsociation Yearbook (1881-1910).

Alden, W.L. The Canoe and the Flying Proa, or Cheap Cruiving and Safe Sailing. New York: Harper and Brother Publishers, 1878.

- The Cruise of the Canoe Club. New York: Harper and Brothers, 1883.

Babcock, Louis M. Our American Resorts: For Health, Pleasure and Recreation. Washington: National News Bureau, 1883. 
Barker, Lady Mary Anne. The Bedroom and Boudoir. London: Macmillan, 1878.

Beard, George M. American Nervousness: Its Causes and Consequences. New York: G.P. Putnam's Sons, 1881.

Bishop, Nathaniel Holmes. The Pampat and Andes: A Thousand Miles Walk Across South America. Boston: Lee and Shepard, 1869.

- The Voyage of the Paper Canoe. Boston: Lee and Shepard, 1878.

- Four Months in a Sneak Box. Boston: Lee and Shepard, 1879.

James, Bushrod W. American Resorts. Philadelphia: F.A. Davis, 1889.

Jameson, Anna. Winter Studie and Summer Rambles in Canada. New York: Wiley and Putnam, 1839.

MacGregor, John. A Thousand Miles in the Rob Roy Canoe: On Rivers and Lakes of Europe. London: Sampson, Low, Marlowe and Company, 1866.

Moodie, Susanna. Roughing It in the Bush, or Life in Canada. $2^{\text {nd }}$ ed. London: Richard Bentley, 1852.

Murray, William Henry Harrison. Lake Cbamplain and Its Shores. Boston: De Wolfe, Fiske, and Co., 1890.

Neide, Charles. The Canoe Aurora: A Cruise from the Adirondacks to the Gulf. New York: Forest and Stream Publishing Company, 1885.

Nessmuk, Woodcraft. New York: Forest and Stream Publishing, 1884.

Norcom, Stanley. Grindstone Island: An Island World Remembered. 1993.

Parker, Amasa Junius. Landmarks of Albany County, New York. Syracuse: D. Mason, 1897.

Peverelly, Charles A. The Book of American Pastimes. New York, 1866.

Picturesque Views and Maps of the Muskoka Lakes, Canada. Toronto: Ralph, Smith and Co., 1893.

Possons, Charles H. Lake George and Lake Cbamplain. Glens Falls, 1887.

Retaw, Fragments from the ' 88 Meet. Montreal, 1888. 
Seneca, Canoe and Camp Cookery: A Practical Cook Book for Canoewt, Corintbian Sailors and Outers. New York: Forest and Stream Publishing, 1885.

Snedeker, Florence Watters. A Family Canoe Trip. New York: Harper and Brothers, 1892.

Stephens, W.P. Canoe and Boatbuilding. New York: Forest and Stream Publishing Co., 1883.

Traditions and Memories of American Yachting: The $50^{6}$ Anniversary Edition.

Brooklin: Wooden Boat Publications, Inc., 1989.

Stoddard, S.R. Lake George Illustrated. Albany: Van Benthuysen and Sons, 1882.

- Glimpses of the ACA. Glens Falls, 1887.

- Glimpses of the ACA. Glens Falls, 1889.

- Glimpses of the ACA. Glens Falls, 1890.

- Lake George and Lake Cbamplain: A Book of Today. $20^{\text {th }}$ ed. Glens Falls, 1890.

Sweetser, Charles Humphreys. Book of Summer Resorts: A Complete Guide for the Summer Tourist. New York: Evening Mail Office, 1868.

Sweetser, M.F. Soutbwestern New Hampsbire. Boston and Maine Railroad, 1890.

Thoreau, Henry David. Cape Cod. Boston: Ticknor and Fields, 1865.

Tocqueville, Alexis de. Democracy in America, Vol. 1 [1835]. Edited by Phillips Bradley. New York: Knopf, 1980.

Turner, Frederick Jackson. "The Significance of the Frontier in American History." In Annual Report of the American Historical Association for the Year 1893, 188-227. Washington: Government Printing Office, 1894.

Vaux, C. Bowyer. Canoe Handling. New York: Forest and Stream Publishing, 1885.

Wilhelm, Thomas. A Military Dictionary and Gazeteer. Rev. ed. Philadelphia: L.R. Hamersly and Co., 1881.

E. Zuk. Lawrence, ed. American Canoe Association 100tb Anniversary Yearbook. Concord: Minuteman Printing Corp., 1980.

Newspapers and Periodicals

American Canoeidt (1882-1887) 
Forest and Stream (1873-1910)

New York Times (1872-1910)

Outing Magazine (1884-1900)

Note: Included here are newspaper and periodical sources that I consulted in depth. Any other newspapers or magazines I drew material from are cited in the footnotes.

\section{Secondary Sources}

Adams, Annmarie. "The Eichler Home: Intention and Experience in Postwar Suburbia." Perspectives in Vernacular Arcbitecture 5 (1995): 164-78.

Architecture in the Family Way: Doctors, Howed, and Women, 1870-1900. Montreal: McGill-Queen's University Press, 1996.

Medicine by Design: The Architect and the Modern Hospital, 1893-1943. Minneapolis: University of Minnesota Press, 2008.

- and Stacie Burke. "Not a Shack in the Woods': Architecture for Tuberculosis in Muskoka and Toronto." Canadian Bulletin of Medical History 23, no. 2 (2006): 429-55.

Adams, David Wallace. Education for Extinction: American Indiand and the Boarding School Experience, 1875-1928. Lawrence: University Press of Kansas, 1995.

Adams, Mary Louise. The Trouble with Normal: Postwar Youtb and the Making of Heterosexuality. Toronto: University of Toronto Press, 1997.

- "Death to the prancing prince': Effeminacy, Sport Discourses and the Salvation of Men's Dancing." Bozy and Society 11, no. 4 (2005): 63-86.

- Artivtic Impressions: Figure Skating, Masculinity, and the Limits of Sport. Toronto: University of Toronto Press, 2011.

Adleman, Jeremy, and Stephen Aron. "From Borderlands to Borders: Empires, Nation-States, and the Peoples in Between in North American History." American Historical Review 104, no. 3 (1999): 814-41.

Adler, Jeanne Winston. Early Dayv in the Adirondacks: The Photographo of Seneca Ray Stodzard. New York: Harry N. Abrams, 1997.

Agnew, Jean-Christophe. "A House of Fiction: Domestic Interiors and the Commodity Aesthetic." In Consuming Visions: Accumulation and Display of Goods in America, 1880-1920, edited by Simon J. Bronner, 133-55. New York: W.W. Norton, 1989. 
Alexander, Lewis M. "The Impact of Tourism on the Economy of Cape Cod, Massachusetts." Economic Geography 29, no. 4 (1953): 320-26.

Allison, Lincoln. Amateurism in Sport: An Analyais and a Defence. London: Frank Cass, 2001.

Andrews, Thomas G. "'Made by Toile'? Tourism, Labor, and the Construction of the Colorado Landscape." Journal of American Hiatory 92, no. 3 (2005): 837-63.

Armstrong, James, and David M. Williams. "The Steamboat and Popular Tourism." The Journal of Transport History 26, no. 1 (2005): 61-76.

Aron, Cindy S. Working at Play: A History of Vacations in the United States. New York: Oxford University Press, 1999.

- "The Evolution of the Middle Class." In A Companion to Nineteentb-Century America, edited by William Barney, 178-91. New York: Blackwell, 2000.

Bailey, Peter. “'A Mingled Mass of Perfectly Legitimate Pleasures': The Victorian Middle Class and the Problem of Leisure." Victorian Studied 21, no. 1 (1977): 7-28.

- Leivure and Clavd in Victorian England: Rational Recreation and the Contest for Control, 1830-1885. Buffalo: University of Toronto Press, 1978.

-. "Leisure, Culture and the Historian: Reviewing the First Generation of Leisure Historiography in Britain." Leisure Studies 8, no. 2 (1989): 107-27.

Bailey, Steve. Athlete First: A History of the Paralympic Movement. London: Wiley and Sons, 2008.

Baker, Lee D. From Savage to Negro: Antbropology and the Construction of Race, 1896-1954. Berkeley: University of California Press, 1998.

Baldwin, Andrew. "Ethnoscaping Canada's Boreal Forest: Liberal Whiteness and Its Disaffiliation from Colonial Space." The Canadian Geographer 53, no. 4 (2009): 427-43.

Bale, John. Sport, Space and the City. London: Routledge, 1993.

—. Landscaped of Modern Sport. Leicester: Leicester University Press, 1996.

-. Sportu Geography. $2^{\text {nd }}$ ed. New York: Routledge, 2002 [1989].

—, and Mike Cronin, eds. Sport and Postcolonialium. Oxford: Berg, 2003.

Banner, Lois. American Beauty: A Social History through Two Centuries of the American Idea, Ideal, and Image of the Beautiful Woman. New York: Knopf, 1983. 
Beasley, Diane. "Walter Dean and Sunnyside: A Study of Waterfront Recreation." M.A. Thesis: University of Toronto, 1995.

Bederman, Gail. Manliness and Civilization: A Cultural History of Gender and Race in the United States, 1880-1917. Chicago: The University of Chicago Press, 1995.

Belisle, Donica. Retail Nation: Department Stored and the Making of Modern Canada. Vancouver: University of British Columbia Press, 2011.

Benidickson, Jamie. Ideness, Water, and a Canoe: Reflections on Paddling for Pleasure. Toronto: University of Toronto Press, 1997.

Benson, Susan Porter. Counter Cultures: Sales-women, Managers, and Customers in American Department Stores, 1890-1940. Urbana: University of Illinois Press, 1986.

Bentham, Christine, and Katharine Hooke. From Burleigh to Boscbink: A Community Called Stony Lake. Toronto: Natural Heritage/Natural History, 2000.

Berger, Molly. Hotel Dreamu: Luxury, Tecbnology and Urban Ambition in America, 1829-1929. Baltimore: Johns Hopkins University Press, 2011.

Billington, Ray Allen. Frederick Jackson Turner: Historian, Teacber, Scbolar. New York: Oxford University Press, 1973.

Bittermann, Rusty. "Farm Households and Wage Labour in the Northeastern Maritimes in the Early $19^{\text {th }}$ Century." Labour/Le Travail 31 (1993): 13-45.

Blair, Peggy J. Lament for a First Nation: The Williams Treaties in Soutbern Ontario. Vancouver: University of British Columbia Press, 2008.

Blanchard, Mary W. "Boundaries and the Victorian Body: Aesthetic Fashion in Gilded Age America." The American Historical Review 100, no. 1 (1995): 21-50.

Blanton, Casey. Travel Writing: The Self and the World. New York: Routledge, 2002.

Blatt Martin H., and Martha K. Norkunas, eds. Work, Recreation, and Culture: Evsays in American Labor History. New York: Garland, 1996.

Blunt, Alison, and Robyn Dowling. Home London: Routledge, 2006. , and Ann Varley. "Introduction: Geographies of Home." Cultural Geographiet 11 , no. 3 (2004): 3-6.

Bond, Hallie E. Boats and Boating in the Adirondacks. Syracuse: Syracuse University Press, 1998. 
—. "Paddling for Pleasure in the Northeastern States." In The Canoe: A Living Tradition, edited by John Jennings, 194-211. Toronto: Firefly Books, 2002.

- Joan Jacobs Brumberg, and Leslie Paris. A Paradise for Boys and Girls: Cbildreno Camps in the Adirondacks. Syracuse: Syracuse University Press, 2006.

Bouchier, Nancy B. For the Love of the Game: Amateur Sport in Small-Town Ontario, 18381895. Montreal: McGill-Queen's University Press, 2003.

Boykoff, Jules. “The Anti-Olympics.” New Left Review 67 (2011): 41-59.

Branch, Taylor. "The Shame of College Sports." The Atlantic (2011): 80-110.

Braun, Bruce. The Intemperate Rainforest: Nature, Culture and Power on Canada'd West Coast. Minneapolis: University of Minnesota Press, 2002.

Brealey, Ken G. "Mapping Them 'Out': Euro-Canadian Cartography and the Appropriation of the Nuxalk and Ts'ilhqot'in First Nations' Territories, 1793-1916." Canadian Geographer 39, no. 2 (1995): 140-56.

Brenan, Dan, Robert L. Lyon, and Hallie E. Bond, eds. Canoeing the Adirondacke with Nessmuk: The Adirondack Letters of George Wasbington Sears. Blue Mountain Lake: Adirondack Museum/Syracuse University Press, 1993.

Brickell, Katherine, and Ayona Datta, eds. Translocal Geograpbies: Spaced, Placed, Connections. Burlington: Ashgate, 2011.

Brody, David. Visualizing American Empire: Orientalium and Imperialism in the Pbilippines. Chicago: University of Chicago Press, 2010.

Brown, Dona. Inventing New England: Regional Touridm in the Nineteentb Century. Washington: Smithsonian Institution Press, 1995.

Brown, Ken. The Canadian Canoe Company and the Early Peterborougb Canoe Factoried. Peterborough: Cover to Cover, 2011.

Brownlie, Robin Jarvis. A Fatberly Eye: Indian Agent, Government Power, and Aboriginal Revistance in Ontario, 1918-1939. Don Mills: Oxford University Press, 2003.

Brucken, Carolyn. "In the Public Eye: Women and the American Luxury Hotel." Wintertbur Portfolio 31, no. 4 (1996): 203-20.

Burton, Antoinette, ed. After the Imperial Turn: Thinking With and Through the Nation. Durham: Duke University Press, 2003. 
- ed. Arcbive Stories: Facts, Fictions, and the Writing of History. Durham: Duke University Press, 2005.

Buzard, James. The Beaten Track: European Touriom, Literature, and the Ways to "Culture," 1800-1918. Oxford: Clarendon Press, 1993.

Bynum, William F. Science and the Practice of Medicine in the Nineteenth Century. Cambridge: Cambridge University Press, 1994.

Cahn, Susan K. Coming on Strong: Gender and Sexuality in Twentieth-Century Women's Sport. New York: Free Press, 1994.

Carter, Paul. The Road to Botany Bay: An Exploration of Landacape and Hivtory. New York: Knopf, 1988.

Certeau, Michel de. The Practice of Everyday Life. Translated by Steven Rendell. Berkeley: University of California Press, 1984 [1980].

Cevik, Gulen. "American Style or Turkish Chair: The Triumph of Bodily Comfort." Journal of Design History 23, no. 4 (2010): 367-85.

Chalip, Laurence. "The Cogency of Culture in Sport Tourism Research." Journal of Sport and Tourism 15, no. 1 (2010): 3-5.

Chartier, Roger. “Culture as Appropriation: Popular Cultural Uses in Early Modern France." In Understanding Popular Culture: Europe from the Middle Ages to the Nineteentb Century, edited by Steven L. Kaplan, 229-53. Berlin: Mouton, 1984.

Chen, Xiaobei. “'Cultivating Children as You Would Valuable Plants': The Gardening Governmentality of Child Saving, Toronto, Canada, 1880s-1920s." The Journal of Historical Sociology 16, no. 4 (2003): 460-86.

Cieply, Stefan K. "The Uncommon Man: Esquire and the Problem of the North American Male Consumer, 1957-63." Gender and History 22, no. 1 (2010): 161-78.

Cole, Jean Murray. “Kawartha Lakes Regatta." In Nastawgan: The Canadian Nortb by Canoe and Snowsboe, edited by Bruce W. Hodgins and Margaret Hobbs, 203-10.

Toronto: Dundurn Press, 1987.

Coleman, Anne Gilbert. "The Rise of the House of Leisure: Outdoor Guides, Practical Knowledge, and Industrialization." Western Historical Quarterly 42, no. 4 (2011): 436-57.

Colville, Quintin. "Corporate Domesticity and Idealised Masculinity; Royal Naval Officers and Their Shipboard Home, 1918-1939." Gender and History 21, no. 3 (2009): 499-519. 
Conlin, Paul. "The Cold War and Canadian Nationalism on Ice: Federal Government Involvement in International Hockey During the 1960s." Canadian Journal of the History of Sport 25, no. 2 (1994): 50-68.

Corbett, Theodore. The Making of American Resorts: Saratoga Springs, Balleton Spa, Lake George. Piscataway: Rutgers University Press, 2001.

Cowan, Ruth Schwartz. "The 'Industrial Revolution' in the Home: Household Technology and Social Change in the $20^{\text {th }}$ Century," Tecbnology and Culture 17 , no. 1 (1976): 1-23.

Craig, Lee A., and Matthew T. Holt. "Mechanical Refrigeration, Seasonality, and the Hog-Corn Cycle in the United States, 1870-1940." Explorationd in Economic History 45, no. 1 (2008): 30-50.

Craik, Jennifer. Uniforma Exposed: From Conformity to Transgression. Oxford: Berg, 2005.

Crane, Diana. Fasbion and it, Social Agendas: Clast, Gender, and Identity in Clotbing. Chicago: University of Chicago Press, 2000.

Cranz, Galen. “Women in Urban Parks.” Signs 5, no. 3 (Spring 1980 Supplement): S80-5.

Cresswell, Tim. On the Move: Mobility in the Modern Western World. London: Routledge, 2006.

- and Gareth Hoskins. "Place, Persistence, and Practice: Evaluating Historical Significance at Angel Island, San Francisco, and Maxwell Street, Chicago." Annalo of the Association of American Geographers 98, no. 2 (2008): 392-413.

- and Peter Merriman, eds. Geograpbies of Mobilities: Practices, Spaces, Subjects. Burlington: Ashgate, 2011.

Cromley, Elizabeth Collins. "Sleeping Around: A History of Beds and Bedrooms." Journal of Design History 3, no. 1 (1990): 1-17.

—. "Transforming the Food Axis: Houses, Tools, Modes of Analysis," Material History Review 44 (1996): 8-22.

Cronon, William. Nature's Metropolid: Chicago and the Great West. New York: W.W. Norton, 1991.

Crouch, David. "Places Around Us: Embodied Lay Geographies in Leisure and Tourism." Leisure Studied 19, no. 2 (2000): 63-76.

Crowley, William. Rusbton's Rowboats and Canoes: The 1903 Catalog in Perspective. Blue Mountain Lake: Adirondack Museum, 1983. 
Cruikshank, Ken, and Nancy Bouchier. “'Dirty Spaces': Environment, the State and Recreational Swimming in Hamilton Harbour, 1870-1946." Sport History Review 29, no. 1 (1998): 59-76.

Cunningham, Patricia A. Reforming Women'd Fasbion, 1850-1920: Politicd, Healtb, and Art. Kent: Kent State University Press, 2003.

Curtis, Bruce. The Politics of Population: State Formation, Statistics, and the Census of Canada, 1840-1875. Toronto: University of Toronto Press, 2001.

"Review of Governmentality and the Mavtery of Territory in Nineteentb-Century America." The American Historical Review 107, no. 5 (2002): 1544-5.

Davidoff, Leonore, and Catharine Hall. Family Fortunes: Men and Women of the Englisb Middle Class, 1780-1850. Rev. ed. London: Routledge, 2002.

Davies, Megan. "Night Soil, Cesspools, and Smelly Hogs on the Streets: Sanitation, Race, and Governance in Early British Columbia." Histoire Sociale/Social History 38, no. 75 (2005): 1-36.

Davis, Clark. "The Corporate Reconstruction of Middle-Class Manhood." In The Midzling Sorts: Explorations in the History of the American Middle Class, edited by Burton Bledstein and Robert D. Johnston, 201-16. New York: Routledge, 2001.

Davis, Janet M. The Circus Age: Culture and Society Under the American Big Top. Chapel Hill: University of North Carolina Press, 2002.

Dawson, Michael, and Catherine Gidney. "Persistence and Inheritance: Rethinking Periodisation and English Canada's 'Twentieth Century.'" In Contesting Clio's Craft: New Directions and Debates in Canadian History, edited by Christopher Dummitt and Michael Dawson, 47-74. Vancouver: University of British Columbia Press, 2008.

Deloria, Philip J. Playing Indian. New Haven: Yale University Press, 1998.

Dening, Greg. Mr. Bligh's Bad Language: Pasdion, Power and Theatre on the Bounty. Cambridge: Cambridge University Press, 1992.

- Performances. Chicago: University of Chicago Press, 1996.

DePauw, Karen P. and Susan J. Gavron. Disability and Sport. $2^{\text {nd }}$ ed. Champaign: Human Kinetics, 2005 [1995].

De Sormo, Maitland C. Seneca Ray Stoddard: Versatile Camera-Artist. Saranac Lake: Adirondack Yesteryears, 1972. 
Dimeo, Paul. "Review of Sports Tourism: Participants, Policy and Providers." Tourism Management 29 (2008): 603.

Dodd, Christopher. The Story of World Rowing. London: Hutchinson, 1991.

Dohmen, Renate. “The Home in the World: Threshold Designs and Performative Relations in Contemporary Tamil Nadu, South India." Cultural Geographies 11 (2004): 7-25.

Douglas, Ann. The Feminization of American Culture. New York: Knopf, 1977.

Doyle, Don H. "The Social Functions of Voluntary Associations in a NineteenthCentury American Town." Social Science History 1, no. 3 (1977): 333-55.

Drayton, Richard. Nature'd Government: Science, Imperial Britain, and the 'Improvement' of the World. New Haven: Yale University Press, 2000.

Dubinsky, Karen. The Second Greatest Disappointment: Honeymooners, Heterosexuality, and the Tourist Industry at Niagara Falls. Toronto: Between the Lines Press, 1999.

Dublin, Thomas. Transforming Women's Work: New England Lives in the Industrial Revolution. Ithaca: Cornell University Press, 1994.

Dunkin, Jessica. "The stories we tell': Locating Nature, Gender and Place in the Poetry of Mary Edgar and Glen Bernard Campers." M.A. Research Essay: Carleton University, 2008.

- "Manufacturing Landscapes: Place and Community at Glen Bernard Camp, 1924-1933." Histoire Sociale/Social History 45, no. 89 (2012): 79-113.

Dyreson, Mark. "Sport History and the History of Sport in North America." Journal of Sport Hiwtory 34, no. 3 (Fall 2007): 405-14.

Edwards, P.K. Strikes in the United States, 1881-1974. New York: St. Martin's Press, 1981.

Egan, Michael. "Wrestling Teddy Bears: Wilderness Masculinity as Invented Tradition in the Pacific Northwest." Gender Forum 15 (2006). Accessed 19 March 2012: http://www.genderforum.org/issues/gender-roomours-i/wrestling-teddy-bears/.

Erdozain, Dominic. The Problem of Pleasure: Sport, Recreation, and the Crisis of Victorian Religion. Woodbridge: Boydell Press, 2010.

Erickson, Bruce. "Canoe Nation: Race and Gender in the Making of a National Icon." Ph.D. Dissertation: York University, 2009. 
Fahrni, Magda. "'Ruffled' Mistresses and 'Discontented' Maids: Respectability and the Case of Domestic Service, 1880-1914," Labour/Le Travail 39 (1997): 69-97.

Falasca-Zamponi, Simonetta. Fasciut Spectacle: The Aestbetics of Power in Musdolini's Italy. Berkeley: University of California Press, 1997.

Fee, Elizabeth, Theodore M. Brown, Jan Lazarus, and Paul Theerman. "Baxter Street Then." American Journal of Public Health 92, no. 5 (2002): 753.

Ferry, Darren. Uniting in Measures of Common Good: The Construction of Collective Liberal Identitied in Central Canada, 1830-1900. Montreal: McGill-Queen's University Press, 2008.

Fichman, Martin. Evolutionary Theory and Victorian Culture. Amherst: Prometheus Books, 2002.

Field, Russell. "Constructing the Preferred Spectator: Arena Design and Operation and Consumption of Hockey in 1930s Toronto." International Journal of the Hivtory of Sport 25, no. 6 (2008): 649-77.

Flaumenhaft, Mera. The Civic Spectacle: Edsays on Drama and Community. London: Rowman and Littlefield Publishers, 1994.

Foucault, Michel. Discipline and Punish: The Birtb of the Prison. Translated by Alan Sheridan. New York City: Vintage Books, 1977.

. The History of Sexuality, Volume 1: An Introduction. Translated by Robert Hurley. New York: Random House, 1978.

- Power/Knowledge: Selected Interviews and Otber Writing, 1972-1977. Edited by Colin Gordon. New York: Pantheon, 1980.

- "The Subject and Power." Critical Inquiry 8, no. 4 (1982): 777-95.

- "Governmentality." In The Foucault Effect: Studies in Governmentality, edited by Graham Burchell, Colin Gordon, and Peter Miller, 87-104. Chicago: University of Chicago Press, 1991.

Fox, Richard Wrightman, and T. Jackson Lears, eds. The Culture of Consumption: Critical Edsays in American History, 1880-1980. New York: Pantheon, 1983.

Francis, Martin. "The Domestication of the Male? Recent Research on Nineteenthand Twentieth-Century British Masculinity." The Historical Journal 45, no. 3 (2002): $637-52$.

Frank, Stephen M. Life with Father: Parenthood and Masculinity in the Nineteentb-Century American North. Baltimore: Johns Hopkins University Press, 1998. 
Franklin, Adrian, and Michael Crang. "The Trouble with Tourism and Travel Theory." Tourist Studies 1, no. 1 (2001): 5-22.

Franks, C.E.S., Michael Hawes, and Donal MacIntosh. "Sport and Canadian Diplomacy." International Journal 43, no. 4 (1988): 665-682.

Freund, Daniel. "The Battle for a Brighter America: A Social History of Natural Light, 1850-1935." Ph.D. Dissertation: Columbia University, 2008.

Furner, Mary O. Advocacy and Objectivity: A Crisis in the Profesdionalization of American Social Science, 1865-1905. New Brunswick: Transaction Publishers, 2011.

Gamm, Gerald, and Robert D. Putnam. “The Growth of Voluntary Organizations in America, 1840-1940." Journal of Interdisciplinary History 29, no. 4 (1999): 511-57.

Gammon, Sean, and Gregory Ramshaw, eds. "Special Issue: Placing Heritage in Sport Tourism." Journal of Sport and Tourism 10, no. 4 (2005): 225-334.

Garcia, Raul Sanchez and Antonio Rivero Herraiz. "Governmentality' in the Origins of European Female PE and Sport: The Spanish Case Study, 1883-1896." Sport, Education, and Society (2011): 1-17.

Gassan, Richard H. "The First American Tourist Guidebooks: Authorship and the Print Culture of the 1820s." Book History 8 (2005): 51-74.

The Birth of American Tourism: New York, the Hudson Valley, and American Culture. Amherst: University of Massachusetts Press, 2008.

Geller, Peter. Northern Exposures: Photographing and Filming the Canadian North, 1920-45. Vancouver: University of British Columbia Press, 2004.

Gems, Gerald. "Welfare Capitalism and Blue-Collar Sport: The Legacy of Labour Unrest." Retbinking History 5, no. 1 (March 2001): 43-58.

Gibbins, Roger, and Loleen Berdahl. Western Visions, Western Futures: Perspectives on the West in Canada. $2^{\text {nd }}$ ed. Toronto: University of Toronto Press, 2003.

Gilkeson, Jr., John H. Middle-Class Providence, 1820-1940. Princeton: Princeton University Press, 1986.

Gilner, Scott E. Hunting and Fisbing in the New Soutb: Black Labor and White Leisure after the Civil War. Baltimore: Johns Hopkins University Press, 2008.

Goldstein, Daniel M. The Spectacular City: Violence and Performance in Urban Bolivia. Durham: Duke University Press, 2004. 
Goodyear, III, Frank H. "A Wilderness for Men: The Adirondacks in the Photographs of Seneca Ray Stoddard." In Gender and Landscape: Renegotiating Morality and Space, edited by Lorraine Dowler, Josephine Carubia, and Bonj Szczygiel, 124-42. London: Routledge, 2005.

Gordon, Beverly. "The Souvenir: Messenger of the Extraordinary." Journal of Popular Culture 20, no. 3 (1986): 135-46.

Gorn, Elliot J. The Manly Art: Bare-Knuckle Prize Fighting in America. Ithaca: Cornell University Press, 1986.

Graham, Sara Hunter. Women Suffrage and the New Democracy. New Haven: Yale University Press, 1996.

Graham, Stephen, and David Wood. "Digitizing Surveillance: Categorization, Space, Inequality." Critical Social Policy 23, no. 3 (2003): 227-48.

Greer, Allan, and Ian Radforth, eds. Colonial Leviatban: State Formation in Mid. Nineteentb-Century Canada. Toronto: University of Toronto Press, 1992.

Grier, Katherine C. "Imagining the Parlor, 1830-1880." In Perspectives on American Furniture, edited by Gerald W. R. Ward, 205-39. New York: W. W. Norton for the Henry Francis du Pont Winterthur Museum, 1988.

Culture and Comfort: Parlor Making and Middle-Clavs Identity, 1850-1930. London: Smithsonian Institution Press, 1997.

Gunn, Simon. "From Hegemony to Governmentality: Changing Conceptions of Power in Social History." Journal of Social History 39, no. 3 (2006): 705-20.

Gutman, Herbert G. Work, Culture, and Society in Industrializing America: Estsays in American Working-Claws and Social History. New York: Knopf/Random House, 1976.

Guttmann, Allen. From Ritual to Record: The Nature of Modern Sports. New York: Columbia University Press, 1978.

-Women's Sports: A Hiwtory. New York: Columbia University Press, 1991.

- "Berlin, 1936: The Most Controversial Olympics." In National Identity and Global Sports Events: Culture, Politics, and Spectacle in the Olympics and Football World Cup, edited by Alan Tomlinson and Christopher Young, 65-82. Albany: State University of New York Press, 2006.

Haddad, John R. "The Wild West Turns East: Audience, Ritual, and Regeneration in Buffalo Bill's Boxer Uprising." American Studies 49, no. 3/4 (2008): 5-38. 
Hague, Cliff. "Planning and Place Identity." In Place Identity, Participation and Planning, edited by Cliff Hague and Paul Jenkins, 2-14. New York: Routledge, 2005.

Haldrup, Michael. "Laid-Back Mobilities: Second Home Holidays in Time and Space." Tourium Geographies 6, no. 4 (2004): 434-55.

Hall, M. Ann. The Girl and the Game: A History of Women's Sport in Canada. Peterborough: Broadview Press, 2002.

Hall, Jacquelyn Dowd, James L. Leloudis, Robert Rodgers Korstad, Mary Murphy, Lu Ann Jones, and Christopher B. Daly. Like a Family: The Making of a Soutbern Cottage Mill World. Chapel Hill: University of North Carolina Press, 1987.

Halperin, David M. "Sex before Sexuality: Pederasty, Politics, and Power in Classical Athens." In Hidden from History: Reclaiming the Gay and Lesbian Paut, edited by Martin Baumi Duberman, Martha Vicinus, and George Chauncy, Jr., 37-53. New York: NAL Books, 1989.

Halttunen, Karen. "From Parlor to Living Room: Domestic Space and the Culture of Personality." In Consuming Visions: Accumulation and Display of Goods in America, 18801920, edited by Simon J. Bronner, 157-89. New York: W.W. Norton, 1989.

Handelman, Don. Models and Mirrors: Towards an Antbropology of Public Events. Cambridge: Cambridge University Press, 1989.

Hannam, Kevin, Mimi Sheller, and John Urry. "Editorial: Mobilities, Immobilities and Moorings." Mobilities 1, no. 1 (2006): 1-22.

Haraven, Tamara. Family and Industrial Time. Cambridge: Cambridge University Press, 1982.

Hargreaves, Jennifer. Heroines of Sport: The Politics of Difference and Identity. London: Routledge, 2000.

Harley, J.B. The New Nature of Maps: Essays in the History of Cartography. Edited by Paul Laxton. Baltimore: Johns Hopkins University Press, 2002.

Harris, Cole. Making Native Space: Colonialism, Resistance, and Reserves in Britist Columbia. Vancouver: University of British Columbia Press, 2002.

Haun-Moss, Beverly. "Layered Hegemonies: The Production and Regulation of Canoeing Desire in the Province of Ontario." Topia 7 (Spring 2002): 39-55.

Hawley, Emily C. Annale of Brookfield, Fairfield County, Connecticut. Brookfield, 1929.

Hermer, Joe. Regulating Eden: The Nature of Order in the North American Parks. Toronto: University of Toronto Press, 2002. 
Heron, Craig. The Canadian Labour Movement: A Brief History. $2^{\text {nd }}$ ed. Toronto: J. Lorimer, 1996.

- Booze: A Distilled History. Toronto: Between the Lines Press, 2003.

- , and Steven Penfold. The Worker's Festival: A History of Labour Day in Canada. Toronto: University of Toronto Press, 2005.

High, Steven. Industrial Sunset: The Making of North America's Rust Belt, 1969-1984. Toronto: University of Toronto Press, 2003.

—. "Placing the Displaced Work: Narrating Place in Deindustrializing Sturgeon Falls, Ontario." In Placing Memory and Remembering Place in Canada, edited by James Opp and John C. Walsh, 159-86. Vancouver: University of British Columbia Press, 2010.

Hillier, Bill, and Julienne Hanson. The Social Logic of Space. Cambridge: Cambridge University Press, 1984.

Hinsley, Curtis M. "Zunis and Brahmins: Cultural Ambivalence in the Gilded Age." In Romantic Motives: Essays on Antbropological Sensibility, edited by George W. Stocking, Jr., 169-207. Madison: University of Wisconsin Press, 1989.

Hobsbawm, Eric. The Age of Revolution: 1789-1848. New York: New American Library 1962.

—. The Age of Capital, 1848-1875. New York: Scribner, 1975.

- The Age of Empire, 1875-1914. New York: Pantheon, 1987.

Hoffman, Ronald. “The History of the American Canoe Association, 1880-1960." Ph.D. Dissertation: Springfield College, 1967.

Hoffmann, Charles. The Depression of the Nineties: An Economic History. Wesport: Greenwood Publishing, 1970.

Hoganson, Kristin. "Buying into Empire: American Consumption at the Turn of the Twentieth Century." In Colonial Crucible: Empire in the Making of the Modern American State, edited by Alfred McCoy and Francisco Antonio Scarano, 248-59. Madison: University of Wisconsin Press, 2009.

Hooke, Katharine N. From Campsite to Cottage: Early Stoney Lake. Occasional Paper 13. Peterborough: Peterborough Historical Society, 1992.

Horrell, Jeffrey L. Seneca Ray Stoddard: Transforming the Adirondack Wildernede in Text and Image. Syracuse: Syracuse University Press, 1999. 
Horsman, Reginald. Race and Manifest Destiny: The Origins of American Racial AngloSaxonium. Cambridge, Mass.: Harvard University Press, 1981.

Howell, Colin. Nortbern Sandlots: A Social History of Maritime Baseball. Toronto: University of Toronto Press, 1995.

Blood, Sweat and Cheers: Sport and the Making of Modern Canada. Toronto: University of Toronto Press, 2001.

"Borderlands, Baselines, and Big Game: Conceptualizing the Northeast as a Sporting Region." In New England and the Maritime Provinces: Connections and Comparisons, edited by Stephen J. Hornsby and John G. Reid, 264-79. Montreal: McGill-Queens University Press, 2005.

Hufford, Mary. “'One Reason God Made Trees': The Form and Ecology of the Barnegat Bay Sneakbox." In Sense of Place: American Regional Cultures, edited by Barbara Allen and Thomas J. Schlereth, 40-57. Lexington: University Press of Kentucky, 1990.

Hunt, Alan. "Regulating Heterosocial Space: Sexual Politics in the Early Twentieth Century." Journal of Historical Sociology 15, no. 1 (2002): 1-34.

Hutton, George V. The Great Huddon River Brick Industry: Commemorating Three and One Half Centuried of Brickmaking. Fleischmann: Purple Mountain Press, 2003.

Jacoby, Karl. Crimes Against Nature: Poacherd, Squatters, Thieves, and the Hidden History of American Conservation. Berkeley: University of California Press, 2001.

Jasen, Patricia. Wild Things: Nature, Culture, and Tourism in Ontario, 1790-1914. Toronto: University of Toronto Press, 1995.

Jensen, Joan M. “Cloth, Butter, and Boarders: Women's Household Production for the Market." Review of Radical Political Economics 12 (1980): 14-24.

Jessup, Lynda. "The Group of Seven and the Tourist Landscape in Western Canada." Journal of Canadian Studies 37, no. 1 (Spring 2002): 144-79.

Johnson, Benjamin H., and Andrew R. Graybill, eds. Bridging National Borders in North America: Transnational and Comparative Histories. Durham: Duke University Press, 2010.

Johnson, Susan Lee. "Bulls, Bears, and Dancing Boys: Race, Gender, and Leisure in the California Gold Rush." Radical Hivtory Review 60 (1994): 5-37.

Johnston, C. Fred. "Canoe Sport in Canada: Anglo-American Hybrid?" In Canexus: The Canoe in Canadian Culture, edited by James Raffan and Bert Horwood, 59-72.

Toronto: Betelguese Books, 1988. 
100 Years of Champions: The Canadian Canoe Adsociation, 1900-2000. Kingston:

Canadian Canoe Association, 2003.

Johnston, Matt. "National Spectacle from the Boat and from the Train: Moulding Perceptions of History in American Scenic Guides of the Nineteenth Century." University of Toronto Quarterly 73, no. 4 (2004): 1021-35.

Jones, Karen. "Review of Trafficking Subjects." English Studies in Canada 31, no. 4 (2005): 235-7.

Jordan, Ben. "'Conservation of Boyhood': Boy Scouting's Modest Manliness and Natural Resource Conservation, 1910-1930." Environmental History 15 (2010): 612-42.

Joudrey, Susan L. "The Expectations of a Queen: Identity and Race Politics in the Calgary Stampede." In The West and Beyond: New Perspectives on an Imagined Region, edited by Alvin Finkel, Sarah Carter, and Peter Fortna, 133-55. Edmonton: Athabasca University Press, 2010.

Joyce, Patrick. Work, Society, and Politicd: The Culture of the Factory in Late Victorian England. New Brunswick: Rutgers University Press, 1980. The Rule of Freedom: Liberaliom and the Modern City. London: Verso, 2003.

Kaika, Maria. "Interrogating the Geographies of the Familiar: Domesticating Nature and Constructing the Autonomy of the Modern Home." International Journal of Urban and Regional Research 28, no. 2 (2004): 265-86.

Kapor, Vladimir. Local Colour: A Travelling Concept. Bern: Peter Lang, 2009.

Kealey, Gregory S. Toronto Workers Respond to Industrial Capitalism, 1867-1892. Toronto: University of Toronto Press, 1991.

-Workers and Canadian Hidtory. Montreal: McGill-Queen's University Press, 1995.

Kerber, Linda K. "Separate Spheres, Female Worlds, Woman's Place: The Rhetoric of Women's History." The Journal of American History 75, no. 1 (1988): 9-39.

Keyssar, Alexander. The Right to Vote: The Contested History of Democracy in the United States. New York: Basic Books, 2009.

Kidd, Bruce. The Struggle for Canadian Sport. Toronto: University of Toronto Press, 1996. 
Kilner, Lisa. "Narrating Indigenous-Settler Histories: Native Cultural Representations at the 1988 Calgary Olympic Winter Games." M.A. Research Essay: Carleton University, 2009.

Kimmel, Michael S. "Consuming Manhood: The Feminization of American Culture and the Recreation of the Male Body, 1832-1920." Michigan Quarterly Review 33 (1994): 7-36.

The History of Men: Evsays in the History of American and British Masculinities. Albany: State University of New York Press, 2005.

Knight, William. “'Our Sentimental Fisheries': Angling and State Fisheries Administration in $19^{\text {th }}$ Century Ontario." M.A. Thesis: Trent University, 2006.

Korinek, Valerie. Roughing It in the Suburbs: Reading Chatelaine Magazine in the Fifties and Sixties. Toronto: University of Toronto Press, 2000.

Krause, Sydney. "Penn's Elm and Edgar Huntly: Dark 'Instruction to the Heart." American Literature 66, no. 3 (1994): 463-84.

Kruger, Arnd, and William J. Murray, eds. The Nazi Olympics: Sport, Politics, and Appeasement in the 1930\%. Champaign: University of Illinois Press, 2003.

Kyle, Donald G. Sport and Spectacle in the Ancient World. Oxford: Blackwell, 2007.

Leach, William. "Strategists of Display and the Production of Desire." In Consuming Vitions: Accumulation and Display of Goods in America, 1880-1920, edited by Simon J. Bronner, 99-132. New York: W.W. Norton, 1989.

Kimmel, Michael S. Land of Desire: Merchant, Power, and the Rise of a New American Culture. New York: Pantheon, 1993.

Lears, T. Jackson. No Place of Grace: Antimodernism and the Tranuformation of American Culture, 1880-1920. Chicago: University of Chicago Press, 1994 [1981].

Lee, Molly. "Appropriating the Primitive: Turn-of-the-Century Collection and Display of Native Alaskan Art." Arctic Antbropology 28, no. 1 (1991): 6-15.

- "Tourism and Taste Cultures: Collecting Native Art in Alaska at the Turn of the Twentieth Century." In Unpacking Culture: Art and Commodity in Colonial and Postcolonial Worlds, edited by Ruth B. Phillips and Christopher B. Steiner, 267-81. Berkeley: University of California Press, 1999.

Lefebvre, Henri. The Production of Space. Translated by Donald Nicholson-Smith. Oxford: Blackwell, 1991 [1974]. 
Lemke, T. "The Birth of Bio-politics: Michael Foucault's Lectures at the College de France on Neo-Liberal Governmentality." Economy and Society 30, no. 2 (2001): 190207.

Lenskyj, Helen J. "Moral Physiology in Physical Education and Sport for Girls in Ontario, 1890-1930." In Proceedings: 5th Canadian Symposium on the History of Sport and Physical Education, 139-150. Toronto: University of Toronto Press, 1982.

Inwide the Olympic Industry: Power, Politics, and Activism. Albany: State University of New York Press, 2000.

The Best Olympics Ever? Social Impacts of Sydney 2000. Albany: State University of New York Press, 2002.

Lightman, Bernard, ed. Victorian Science in Context. Chicago: University of Chicago Press, 1997.

Lindsay, Peter L. "The Impact of Military Garrisons on the Development of Sport in British North America." Canadian Journal of History of Sport and Pbysical Education 1, no. 1 (1970): 33-44.

Linton, Marilyn R. The Ballast Island Cbronicles: A History of the Western Canoe Association and ILYA Beginnings. Linwood: M.R. Linton, 1994.

Lisle, Benjamin D. “'We Make a Big Effort to Bring Out the Ladies': Visual Representations of Women in the Modern American Stadium." International Journal of the Hittory of Sport 28, no. 8/9 (2011): 1203-18.

Little, J.I. "Scenic Tourism on the Northeastern Borderland: Lake Memphremagog's Steamboat Excursions and Resort Hotels, 1850-1900." Journal of Historical Geography 35, no. 4 (2009): 716-42.

. "Life without Conventionality: American Social Reformers as Summer Campers on Lake Memphremagog, Quebec, 1878-1905." Journal of the Gilded Age and the Progressive Era 9, no. 3 (2010): 281-311.

Littmann, William. "The Production of Goodwill: The Origin and Development of the Factory Tour in America." In Constructing Image, Identity and Place: Perspectives in Vernacular Architecture, IX, edited by Alison K. Hoagland and Kenneth A. Breisch, 71 84. Knoxville: University of Tennessee Press, 2003.

Logan, Thad. The Victorian Parlour: A Cultural Study. Cambridge: Cambridge University Press, 2001.

Loo, Tina. "Of Moose and Men: Hunting for Masculinities in British Columbia, 18801939." Western Historical Quarterly 32, no. 3 (2001): 296-319. 
Love, Christopher. A Social History of Swimming in England, 1800-1918: Splasbing in the Serpentine. London: Routledge, 2008.

Mackintosh, Phillip Gordon. "'The development of higher urban life' and the Geographic Imagination: Beauty, Art, and Moral Environmentalism in Toronto, 19001920." Journal of Hiotorical Geograpby 31 (2005): 688-722.

and Richard Anderson. "The Toronto Star Fresh Air Fund: Transcendental Rescue in a Modern City, 1900-1915." Geographical Review 99, no. 4 (2009): 539-62.

and Clyde R. Forsberg. "Performing the Lodge: Masonry, Masculinity, and Nineteenth-Century North American Moral Geography." Journal of Historical Geography 35 (2009): 451-72.

MacLeod, David I. Building Character in the American Boy: The Boy Scouts, YMCA and Their Forerunners, 1870-1920. Madison: University of Wisconsin Press, 1983.

Macnaghten, Phil, and John Urry. "Bodies of Nature: Introduction." Body and Society 6, no. 3-4 (2000): $1-11$.

Magdalinski, Tara. Sport, Technology, and the Body: The Nature of Performance. New York: Routledge, 2000.

Maier, Charles S. "Consigning the Twentieth Century to History: Alternative Narratives for the Modern Era." American Hitorical Review 105, no. 3 (2000): 807-31.

Major, Clarence, ed. Juba to Jive: A Dictionary of African-American Slang. New York: Penguin, 1994.

Mangan J.A., and Roberta J. Park, eds. From 'Fair Sex' to Feminism: Sport and the Socialization of Women in the Industrial and Post-Industrial Era. London: Frank Cass, 1987.

Manley, Atwood. Rubton and His Timet in American Canoeing. Syracuse: Syracuse University Press, 1968.

Marien, Mary Warner. Pbotograpby: A Cultural History. 2nd ed. Upper Saddle River: Prentice Hall, 2006.

Marks, Lynne. Revivals and Roller Rinks: Religion, Leisure, and Ientity in Late-NineteentbCentury Small-Town Ontario. Toronto: University of Toronto Press, 1997.

Marks, Patricia. Bicycles, Bangs, and Bloomers: The New Woman in the Popular Press. Lexington: University of Kentucky Press, 1990.

Markula, P. and R. Pringle. Foucault, Sport and Exercise: Power, Knowledge and Transforming the Self. London: Routledge, 2006. 
Marsh, Margaret. “Suburban Men and Masculine Domesticity, 1870-1915." American Quarterly 40, no. 2 (1988): 165-86.

Suburban Lives. London: Rutgers University Press, 1990.

Martschukat, Jürgen. "'The Necessity for Better Bodies to Perpetuate Our Institutions, Insure a Higher Development of the Individual, and Advance the Conditions of the Race': Physical Culture and the Shaping of the Self in Late Nineteenth and Early Twentieth Century America." Journal of Historical Sociology 24, no. 1 (2011): 472-93.

Massey, Doreen. “Places and Their Pasts.” History Worksbop Journal 39 (1995): 182-92.

Mason, Fred. “R. Tait McKenzie's Medical Work and Early Exercise Therapies for People with Disabilities." Sport Hittory Review 39, no. 1 (2008): 45-70.

Maynard, Steven. "Rough Work and Rugged Men: The Social Construction of Masculinity in Working-Class History." Labour/Le Travail 23 (1989): 159-69.

McBride, Theresa M. The Domestic Revolution: The Modernisation of Housebold Service in England and France, 1820-1920. New York: Holmes and Meier, 1976.

McCrone, Kathleen E. Playing the Game: Sport and the Pbysical Emancipation of English Women, 1870-1914. Lexington: University of Kentucky Press, 1988.

McCuaig, Louise, and Richard Tinning. "HPE and the Moral Governance of P/leisurable Bodies.” Sport, Education and Society 15, no. 1 (2010): 39-61.

McIvor, Heather. Women and Politict in Canada. Peterborough: Broadview Press, 1996.

McKay, Ian. Quest of the Folk: Antimodernism and Cultural Selection in Twentietb-Century Nova Scotia. Montreal: McGill-Queen's University Press, 1994.

- "The Liberal Order Framework: A Prospectus for a Reconnaissance of Canadian History." Canadian Historical Review 81, no. 4 (2000): 617-645.

McKibbin, Ross. "Work and Hobbies in Britain, 1850-1950." In The Working Clawd in Modern Britain, edited by Jay Winter, 127-46. Cambridge: Cambridge University Press, 1983.

McManus, Sheila. The Line Which Separates: Race, Gender, and the Making of the AlbertaMontana Borderlands. Edmonton: University of Alberta Press, 2005.

McMullin, Thomas A. "Revolt at Riverside: Victorian Virtue and the Charles River Canoeing Controversy, 1903-1905." The New England Quarterly 73, no. 3 (2000): 482-94. 
McMurray, David. "Rivaling the Gentleman in the Gentle Art: The Authority of the Victorian Woman Angler." Sport History Review 39, no. 2 (2008): 99-126.

McMurry, Sally Ann. Transforming Rural Life: Dairying Familied and Agricultural Change. Baltimore: Johns Hopkins University Press, 1995.

McNairn, Jeffrey L. The Capacity to Judge: Public Opinion and Deliberative Democracy in Upper Canada, 1791-1854. Toronto: University of Toronto Press, 2000.

Melosi, Martin V. The Sanitary City: Urban Infrastructure in America from Colonial Times to the Present. Baltimore: Johns Hopkins University Press, 2000.

Metcalfe, Alan. Canadian Learns to Play: The Emergence of Organized Sport, 1807-1914.

Toronto: McClelland and Stewart, 1987.

-. "The Growth of Organized Sport and the Development of Amateurism in Canada, 1807-1914." In Not Just a Game: Evsays in Canadian Sport Sociology, edited by Jean Harvey and Hart Cantelon, 33-50. Ottawa: University of Ottawa Press, 1988.

- "The Meaning of Amateurism: A Case Study of Canadian Sport, 1884-1970." Canadian Journal of the History of Sport 26, no. 2 (1995): 33-48.

Michael, Mike. "These Boots Are Made for Walking...: Mundane Technology, the Body and Human-Environment Relations." Body and Society 6, no. 107 (2000): 107-26.

Michalski,. David. "Portals to Metropolis: $19^{\text {th }}$-Century Guidebooks and the Assemblage of Urban Experience." Tourist Studies 4, no. 3 (2004): 187-215.

Miller, Dan. “The Charles River Canoe.” Wooden Canoe 30, no. 3 (2007): 8-15.

Milloy, John. A National Crime: The Canadian Government and the Revidential Scbool Sydtem. Winnipeg: University of Manitoba Press, 1999.

Mills, Sara. Discourses of Difference: An Analyois of Women's Travel Writing and Colonialism. London: Routledge, 1991.

Milne-Smith, Amy. "A Flight to Domesticity? Making a Home in the Gentleman's Clubs of London, 1880-1914.” Journal of British Studies 45 (2006): 796-818.

" "Club Talk: Gossip, Masculinity and Oral Communities in Late NineteenthCentury London." Gender and History 21, no. 1 (2009): 86-106.

L London Clubland: A Cultural History of Gender and Clasd in Late Victorian Britain. New York: Palgrave Macmillan, 2011.

Miron, Janet. Prisons, Asylums, and the Public: Institutional Visiting in the Nineteenth Century. Toronto: University of Toronto Press, 2011. 
Mitchell, Timothy. The Rule of Experts: Egypt, Techno-politics, Modernity. Berkeley: University of California Press, 2002.

—. Coloniwing Egypt. Berkeley: University of California Press, 1991.

Moffat, Eva L. The Ancestors of Daniel Freeman Britton of Westmoreland and Gananoque, 1808-1807. n.p., 1953.

Moores, Ted. "From Forest to Factory: Innovations and Mass Production." In The Canoe: A Living Tradition, edited by John Jennings, 162-93. Toronto: Firefly Books, 2002.

Montgomery, David. The Fall of the House of Labor: The Workplace, The State, and American Labor Activiom, 1865-1925. Cambridge: Cambridge University Press, 1987.

Morgan, Cecilia. 'A Happy Holiday': Englist Canadians and Transatlantic Tourism.

Toronto: University of Toronto Press, 2008.

Nash, Catherine. "Irish Placenames: Postcolonial Locations." Transactiond of the Institute of Britisb Geographers 24, no. 4 (1999): 457-80.

Nash, Linda. Inescapable Ecologies: A History of Environment, Disease, and Knowledge. Berkeley: University of California Press, 2006.

Nash, Roderick. Wildernedd and the American Mind. New Haven: Yale University Press, 2001 [1967].

Neubauer, John. Cultural History After Foucault. Piscataway: Aldine Transaction, 1999.

O'Brien, Jean M. Firsting and Lasting: Writing Indians out of Existence in New England. Minneapolis: University of Minnesota Press, 2010.

Oliver, Jeff. "On Mapping and Its Afterlife: Unfolding Landscapes in Northwestern North America." World Archaeology 43, no. 1 (2011): 66-85.

Opp, James. "Finding the View: Landscape, Place, and Colour Slide Photography in Southern Alberta." In Placing Memory and Remembering Place in Canada, edited by James Opp and John C. Walsh, 271-90. Vancouver: University of British Columbia Press, 2010.

Osterud, Nancy Grey. Bonds of Community: The Lives of Farm Women in NineteenthCentury New York. Ithaca: Cornell University Press, 1991.

Otis-Dixon, Melissa. "Performing Native Culture: Marketing Art, Acting, and Educating Newcomers in the Adirondacks." Unpublished paper, 2012. 
Otter, Chris. The Victorian Eye: A Political History of Light and Vision in Britain, 1800-1910. Chicago: University of Chicago Press, 2008.

Palmer, Bryan. A Culture in Conflict: Skilled Workers and Indutrial Capitalism in Hamilton, Ontario, 1860-1914. Montreal: McGill-Queen's University Press, 1979.

Working Class Experience: Retbinking the History of Canadian Labour, 1800-1991.

Toronto: McLelland, 1992.

Parenteau, Bill, and Richard W. Judd. "More Buck for the Bang: Sporting and the Ideology of Fish and Game Management in Northern New England and the Maritime Provinces, 1870-1900." In New England and the Maritime Provinces: Connections and Comparisons, edited by Stephen J. Hornsby and John G. Reid, 232-51. Montreal: McGill-Queens University Press, 2005.

Paris, Leslie. Children's Nature: The Rise of the American Summer Camp. New York: New York University Press, 2008.

Park, Roberta. "Sport, Gender, and Society in Transatlantic Victorian Perspective." The International Journal of the History of Sport 24, no. 12 (2007): 1570-1603.

Parr, Joy. "Ontario Agricultural Wage Labour in Historical Perspective." Labour/Le Travail 15 (1985): 91-103.

Peiss, Kathy. Cbeap Amusements: Working Women and Leiwure in Turn-of-tbe-Century New York. Philadelphia: Temple University Press, 1986.

Perry, Adele. On the Edge of Empire: Gender, Race, and the Making of Britwb Columbia. Toronto: University of Toronto Press, 2001.

Peters, Michael A., A.C. Besley, Mark Olssen, Susanne Maurer, and Susanne Weber, eds. Govermentality Studies in Education. Rotterdam: Sense Publishers, 2009.

Peterson, J. "The City Beautiful Movement: Forgotten Origins and Lost Meanings." Journal of Urban History 2 (1976): 415-34.

Phillips, Ruth B. and Christopher B. Steiner. Unpacking Culture: Art and Commodity in Colonial and Postcolonial Worlds. Berkeley: University of California Press, 1999.

Podruchny, Carolyn. Making the Voyageur World: Travelerd and Traderd in the North American Fur Trade. Toronto: University of Toronto Press, 2006.

Pope, S.W. "Amateurism and American Sports Culture: The Invention of an Athletic Tradition in the United States, 1870-1900." International Journal of the History of Sport 13, no. 3 (1996): 290-309. 
Porter, Dilwyn, and Stephen Wagg, eds. Amateurium in Britisb Sport: It Matters Not Who Won or Lost? London: Taylor and Francis, 2007.

Poulter, Gillian. Becoming Native in a Foreign Land: Sport, Visual Culture, and Dentity in Montreal, 1840-1885. Vancouver: University of British Columbia Press, 2009.

Pratt, Mary Louise. Imperial Eyes: Travel Writing and Transculturation. $2^{\text {nd }}$ ed. London: Routledge, 2008.

Price, Derek, and Liz Wells. "Thinking About Photography: Debates, Historically and Now." In Photography: A Critical Introduction, $4^{\text {th }}$ ed., edited by Liz Wells, 27-34. London: Routledge, 2009.

Putney, Clifford. Muscular Cbristianity: Manbood and Sports in Protestant America. Boston, Mass.: Harvard University Press, 2003.

Radforth, Ian. Busbworkers and Bosdes: Logging in Nortbern Ontario, 1900-1980. Toronto: University of Toronto Press, 1987.

- "The Shantymen." In Labouring Lives: Work and Workers in Nineteentb Century Ontario, edited by Paul Craven, 204-277. Toronto: University of Toronto Press, 1995.

Raffan, James. Bark, Skin, and Cedar: Exploring the Canoe in Canadian Experience. Toronto: Harper Collins, 1999.

- and Bert Horwood, eds. Canexus: The Canoe in Canadian Culture. Toronto: Betelguese Books, 1988.

Raibmon, Paige. "Living on Display: Colonial Visions of Aboriginal Domestic Space." BC Studies 140 (2003): 69-89.

Autbentic Indians: Episodes of Encounter from the Late-Nineteenth-Century Nortbwest Coast. Durham: Duke University Press, 2005.

- "The Practice of Everyday Colonialism: Indigenous Women at Work in the Hop Fields and Tourist Industry of Puget Sound." Labor: Studiev in Working-Clave History of the Americas 3, no. 3 (2006): 23-56.

Rendell, Jane. “The Clubs of St. James's: Places of Public Patriarchy - Exclusivity, Domesticity and Secrecy." The Journal of Architecture 4 (1999): 167-89.

Richter, Amy. Home on the Rails: Women, the Railroad, and the Rive of Public Domesticity. Chapel Hill: University of North Carolina Press, 2005.

Roberts, M.J.D. “Between Fame and Eccentricity: John 'Rob Rob' MacGregor, Almost Eminent Victorian." History Atutralia 2, no. 2 (2005): 36-1-36-8. 
Roche, Maurice. Mega-Events and Modernity: Olympics and Expos in the Growth of Global Culture. London: Routledge, 2000.

Roedigger, David R. Working Toward Whiteness: How America's Immigrants Became White; The Strange Journey from Ellio Idland to the Suburbs. New York: Basic Books, 2005.

Rogal, Samuel J. The American Pre-College Military School: A Hiwtory and Comprebenoive Catalog of Institutions. Jefferson: McFarland, 2009.

Rose, Gillian. Feminium and Geography: The Limits of Geographical Knowledge. Minneapolis: University of Minnesota Press, 1993.

Rose, Marilyn J. “Emily Pauline Johnson." In The Dictionary Of Canadian Biography Online. Accessed 2 December 2011: http://biographi.ca/009004-119.01e.php?id $\mathrm{nbr}=7476$.

Rose, Nikolas. "Governing Advanced 'Liberal' Democracies." In Foucault and Political Reason, edited by Andrew Barry, Thomas Osborne, and Nikolas Rose, 37-64. Chicago: University of Chicago Press, 1996.

- Powers of Freedom: Reframing Political Thought. Cambridge: Cambridge University Press, 1999.

Rose-Redwood, Reuben. "Rationalizing the Landscape: Superimposing the Grid upon the Island of Manhattan." M.A. Thesis: Pennsylvania State University, 2002.

- "Governmentality, Geography, and the Geo-Coded World." Progress in Human Geography 30, no. 4 (2006): 469-86.

Rosen, George. A History of Public Health. New York: MD Publications, 1958.

Rosenzweig, Roy. Eight Hours for What We Will: Workers and Leisure in an Industrial City. Cambridge: Cambridge University Press, 1983.

- and Elizabeth Blackmar. The Park and the People: A History of Central Park. Ithaca: Cornell University Press, 1992.

Rothman, Hal K. "Selling the Meaning of Place: Entrepreneurship, Tourism, and Community Transformation in the Twentieth-Century American West." Pacific Historical Review 65, no. 4 (1996): 525-57.

Roy, Wendy. "Visualizing Labrador: Maps, Photographs, and Geographical Naming in Mina Hubbard's $A$ Woman's Way tbrougb Unknown Labrador." Studies in Canadian Literature 29, no. 1 (2004): 13-34. 
Rubies, Joan Pau. "Travel Writing and Ethnography." In The Cambridge Companion to Travel Writing, edited by Peter Hulme and Tim Youngs, 242-60. New York:

Cambridge University Press, 2002.

Rudy, Jarrett. The Freedom to Smoke: Tobacco Consumption and Identity. Montreal: McGillQueen's University Press, 2005.

Rupp, Leila J. “Toward a Global History of Same-Sexuality." Journal of the History of Sexuality 10, no. 2 (2001): 287-302.

Rydell, Robert. All the World'd a Fair: Visions of Empire at American International Expositions, 1876-1916. Chicago: University of Chicago Fair, 1987.

Sager, Eric W. "The Transformation of the Canadian Domestic Servant, 1871-1931." Social Science History 31, no. 4 (2007): 509-37.

Sagne, Jean. "All Kinds of Portraits: The Photographer's Studio." In A New Hivtory of Photography, edited by Michael Frizot, 102-22. Cologne: Konneman, 1998.

Said, Edward. Orientalism. New York: Vintage Books, 1978.

. Culture and Imperialium. Toronto: Random House, 1993.

Saxton, Alexander. The Rive and Fall of the White Republic: Class Politics and Mavs Culture in Nineteentb-Century America. London: Verso, 2003.

Schaffner, Cynthia V.A. and Lori Zabar. "The Founding and Design of William Merrit Chase's Shinnecock Hills Summer School of Art and the Art Village." Wintertbur Portfolio 44, no. 4 (2010): 303-50.

Schivelbusch, Wolfgang. The Railway Journey: The Industrialization of Time and Space in the Nineteentb Century. Berkeley: University of California Press, 1986.

Schlup, Leonard C., and James G. Ryan, eds. Historical Dictionary of the Gilded Age. Armonk: M.E. Sharpe, 2003.

Schneirov, Richard, Shelton Stromquist, and Nick Salvatore, eds. The Pullman Strike and the Critit of the 1890: Easays on Labor and Politics. Chicago: University of Illinois Press, 1999.

Schneirov, Richard, James L. Huston, and Rebecca Edwards. "Forum." The Journal of the Gilded Age and Progressive Era 5, no. 3 (2006): 189-240.

Schoolman, Morton, and Alvin Magid. Reindustrializing New York State: Strategies, Implicationd, Cballenges. Albany: State University of New York Press, 1986. 
Schrodt, Barbara. "Problems of Periodization in Canadian Sport History." Canadian Journal of History of Sport 21, no. 1 (1990): 65-76.

Schroeder, Patricia R. "Passing for Black: Coon Songs and the Performance of Race." The Journal of American Culture 33, no. 2 (2010): 139-53.

Schultz, Stanley K. and Clay McShane. "To Engineer the Metropolis: Sewers, Sanitation, and City Planning in Late-Nineteenth-Century America." The Journal of American History 65, no. 2 (1978): 389-411.

Schuster, David. Neurasthenic Nation: America's Searcb for Health, Happiness, and Comfort, 1869-1920. New Brunswick: Rutgers University Press, 2011.

Schweitzer, Marlis, and Marina Moskowitz, eds. Testimonial Advertising in the American Marketplace: Emulation, Identity, Community. New York: Palgrave Macmillan, 2009.

Scobey, David M. Empire City: The Making and Meaning of the New York City Landocape. Philadelphia: Temple University Press, 2003.

Scott, James C. Seeing Like a State: How Certain Schemes to Improve the Human Condition Have Failed. New Haven: Yale University Press, 1998.

Sears, John F. Sacred Places: American Tourist Attractions in the Nineteentb Century. New York: Oxford University Press, 1989.

Sekula, Allan. "Photography Between Labour and Capital." In Mining Pbotograpbs and Otber Pictures, 1948-1968, edited by Benjamin H.D. Buchloh and Robert Wilkie, 193268. Halifax: Press of the Nova Scotia College of Art and Design, 1983.

Sellars, Richard West. Preserving Nature in the National Parks: A History. New Haven: Yale University Press, 1997.

Shannon, Brent. "Fashion, Masculinity, and the Cultivation of the Male Consumer in Britain, 1860-1914." Victorian Studies 46, no. 4 (2004): 597-630.

Sigler, William F., and John W. Sigler. Fisbes of the Great Basin: A Natural History. Reno: University of Nevada Press, 1987.

Simpson, Mark. Trafficking Subjects: The Politics of Mobility in Nineteentb-Century America. Minneapolis: University of Minnesota Press, 2005.

Slotkin, Richard. "Buffalo Bill's 'Wild West' and the Mythologization of the American Empire." In Cultures of United States Imperialism, edited by Amy Kaplan and Donald E. Pease, 164-81. Durham: Duke University Press, 1993. 
Smalley, Andrea L. '“Our Lady Sportsmen': Gender, Class, and Conservation in Sport Hunting Magazines, 1873-1920." Journal of the Gilded Age and Progresdive Era 4, no. 4 (October 2005): 355-380.

Smith, Susan W. A History of Recreation in the Thousand Islandy. Parks Canada, 1974.

Smith-Maguire, Jennifer. "Michel Foucault: Sport, Power, Technologies and Governmentality," In Theory, Sport and Society, edited by Joseph Maguire and Kevin Young, 293-314. Oxford: Elsevier Science, 2002.

Smock, John C. "Geologico-Geographical Distribution of the Iron Ores of the Eastern United States." Engineering and Mining Journal 37 (March 1884): 130-144.

Soja, Edward W. Postmodern Geograpbies: The Reawertion of Space in Critical Social Theory. London: Verso, 1989.

Spain, Daphne. Gendered Space. Chapel Hill: University of North Carolina Press, 1992.

Spergel, Irving A. The Youtb Gang Problem: A Community Approach. New York: Oxford University Press, 1995.

Spike, Sara. "Photos of the school group of this place and others': An Itinerant Photographer Pictures Rural Education in Nova Scotia, c.1912.” M.A. Thesis: Concordia University, 2009.

Spurr, David. The Rhetoric of Empire: Colonial Discourse in Journalism, Travel Writing, and Imperial Administration. Durham: Duke University Press, 1993.

Stanley, Meg. "More Than Just a Spare Rib But Not Quite a Whole Canoe: Some Aspects of Women's Canoe-Tripping Experiences, 1900-1940." In Using Wildernesd: Essays on the Evolution of Youtb Camping in Ontario, edited by Bruce E. Hodgins and Bernadine Dodge, 51-60. Peterborough: The Frost Centre for Canadian Heritage and Development Studies, 1992.

Stevens, Peter A. "Getting Away from It All: Family Cottaging in Postwar Ontario." Ph.D. Dissertation: York University, 2010.

Stocking, George W. Victorian Antbropology. New York: Free Press, 1987.

Stoddart, Mark. “Constructing Masculinized Sportscapes: Skïng, Gender, and Nature in British Columbia, Canada." International Review for the Sociology of Sport 46, no. 1 (2011): 108-24.

Stoler, Ann Laura. "Making Empire Respectable: The Politics of Race and Sexual Morality in Twentieth-Century Colonial Cultures." Cultural Politica 11 (1997): 344-73. 
Carnal Knowledge and Imperial Power: Race and the Intimate in Colonial Rule.

Berkeley: University of California Press, 2002.

Stover, John F. American Railroads. Chicago: University of Chicago Press, 1997.

Stradling, David. The Nature of New York: An Environmental History of the Empire State.

Ithaca: Cornell University Press, 2010.

Strauss, David. "Toward a Consumer Culture: 'Adirondack Murray' and the Wilderness Vacation." American Quarterly 39, no. 2 (Summer 1987): 270-286.

Strong, John A. The Montaukett Indians of Eastern Long Idland. Syracuse: Syracuse University Press, 2001.

Strong, Pauline Turner. "Cultural Appropriations and the Crafting of Racialized Selves in American Youth Organizations: Towards an Ethnographic Approach." Cultural Studies - Critical Metbodologies 9, no. 2 (2009): 197-213.

Strong-Boag, Veronica, and Carole Gerson. Paddling Her Own Canoe: The Times and Texts of E. Pauline Jobnson (Tekabionwake). Toronto: University of Toronto Press, 2000.

Surtees, Robert J. “Land Cessions, 1763-1830." In Aboriginal Ontario: Historical Perspectives on the First Nations, edited by Edward S. Rogers and Donald B. Smith, 92121. Toronto: Dundurn Press, 1994.

Sutter, Paul. Driven Wild: How the Fight Again Automobiles Launched the Modern Wildernesd Movement. Seattle: University of Washington Press, 2002.

Swanson, Ryan A. "I Never Was a Champion at Anything': Theodore Roosevelt's Complex and Contradictory Record as America's 'Sports President'." Journal of Sport History 38, no. 3 (Fall 2011): 425-46.

Swiencicki, Mark. "Consuming Brotherhood: Men's Culture, Style and Recreation as Consumer Culture, 1880-1930.” Journal of Social History 31, no. 4 (1998): 773-808.

Taft, Robert. Photograpby and tbe American Scene. New York: Dover, 1964.

Tchen, John. New York Before Cbinatown: Orientalism and the Shaping of American Culture. Baltimore: Johns Hopkins University Press, 1999.

Thomas, Nigel, and Andy Smith. Disability, Sport and Society. Abingdon: Routledge, 2008.

Thompson, E.P. "Time, Work-Discipline, and Industrial Capitalism." Past and Present 38, no. 1 (1967): 56-97. 
Thorpe, Jocelyn. Temagami's Tangled Wild: Race, Gender and the Making of Canadian Nature. Vancouver: University of British Columbia Press, 2012.

Toll, Robert C. Blacking Up: The Minstrel Sbow in America. New York: Oxford University Press, 1974.

Tolles, Jr., Bryant F. Resort Hotelo of the Adirondacks: The Arcbitecture of a Summer Paradide, 1850-1950. Lebanon: University Press of New England, 2003.

Tomczik, Adam. "'He-Men Could Talk to He-Men in He-Men Language': Lumberjack Work Culture in Maine and Minnesota, 1840-1940." Historian 70, no. 4 (2008): 697 715.

Topolski, Jerzy. "Periodization and the Creation of Narrative Wholes." Storia della Storiografia 37 (2000): 11-16.

Tosh, John. A Man's Place: Masculinity and the Middle-Clasd Home in Victorian England. New Haven: Yale University Press, 1999.

Trachtenberg, Alan. The Incorporation of America: Culture and Society in the Gilded Age. New York: Hill and Wang, 1982.

Trigger, Bruce. “The Original Iroquoians: Huron, Petun, and Neutral." In Aboriginal Ontario: Historical Perspectives on the First Nations, edited by Edward S. Rogers and Donald B. Smith, 41-63. Toronto: Dundurn Press, 1994.

Turner, James Morton. “From Woodcraft to 'Leave No Trace': Wilderness, Consumerism, and Environmentalism." Environmental Hittory 7, no. 3 (2002): 462-84.

Turner, Victor Witter. The Forest of Symbols: Aspects of Ndembu Ritual. Ithaca: Cornell University Press, 1967.

Unwin, P.T.H. Wine and the Vine: A Historical Geography of Viticulture and the Wine Trade. London: Routledge, 1991.

Urry, John. "Social Networks, Travel and Talk." Britwh Journal of Sociology 54, no. 2 (2003): 155-75.

Valencius, Conevery Bolton. The Healtb of the Country: How American Settlers Understood Themselves and Their Land. New York: Basic Books, 2002.

Valverde, Mariana. The Age of Light, Soap, and Water: Moral Reform in Englisb Canada, 1885-1925. Toronto: University of Toronto Press, 2008 [1991].

van Gennep, Arnold. The Rites of Passage. London: Paul, 1960 [1909]. 
Van Slyck, Abigail. "The Lady and the Library Loafer: Gender and Public Space in Victorian America." Wintertbur Portfolio 31, no. 4 (Winter 1996): 221-42.

"Kitchen Technologies and Mealtime Rituals: Interpreting the Food Axis at American Summer Camps, 1890-1950." Technology and Culture 43, no. 4 (2002): 668 92.

_ . "Housing the Happy Camper." Minnesota History 58, no. 2 (2002): 68-83.

—_. A Manufactured Wilderness: Summer Camps and the Shaping of American Youth, 1890-1960. Minneapolis: University of Minnesota Press, 2006.

Venne, Muriel Stanley. "The 'S' Word: Reclaiming 'Esquao' for Aboriginal Women." In Unsettled Pasts: Reconceiving the West through Women's History, edited Sarah Carter, Lesley Erickson, Patricia Roome, and Char Smith, 123-28. Calgary: University of Calgary Press, 2005.

Vertinsky, Patricia. The Eternally Wounded Woman: Women, Doctors, and Exercise in the Late Nineteentb Century. Toronto: St. Martin's Press, 1990.

"A 'Sense of Place': Reading the Landscape of Sporting Life." International Sport Studies 23, no. 1/2 (2001): 11-23.

- and John Bale, eds. Sited of Sport: Space, Place and Experience. London:

Routledge, 2004.

- and Sherry McKay, eds. Disciplining Bodies in the Gymnasium: Memory, Monument and Moderniom. London: Routledge, 2004.

Walden, Keith. Becoming Modern in Toronto: The Industrial Enbibition and the Sbaping of a Late Victorian Culture. Toronto: University of Toronto Press, 1997.

Walkowitz, Daniel J. Worker City, Company Town. Urbana: University of Illinois Press, 1978.

Wall, Sharon. “Totem Poles, Teepees, and Token Traditions: 'Playing Indian' at Ontario Summer Camps, 1920-1955." Canadian Historical Review 86, no. 3 (2005): 51344.

The Nurture of Nature: Cbildbood, Antimoderniom, and Ontario Summer Camps, 1920 1955. Vancouver: University of British Columbia Press, 2009.

Walsh, John C. "Landscapes Of Longing: Colonization And The Problem Of State Formation In Canada West." Ph.D. Dissertation: University of Guelph, 2001.

- "Performing Public Memory and Re-Placing Home in the Ottawa Valley, 1900-1958." In Placing Memory and Remembering Place in Canada, eds. James Opp and 
John C. Walsh, 25-56. Vancouver: University of British Columbia Press, 2010.

- and Steven High. "Rethinking the Concept of Community." Histoire Sociale/Social History, 32, no. 64 (1999): 255-74.

Wamsley, Kevin B. and David Whitson, "Celebrating Violent Masculinities: The Boxing Death of Luther McCarty." Journal of Sport History 25, no. 3 (1998): 419-31.

Warren, Louis. Buffalo Bill's America: William Cody and the Wild West Show. New York: Alfred A. Knopf, 2005.

Watkins, Mel. "Foreward." In Inside the Minstrel Mask: Readings in Nineteentb-Century Blackface Minutreloy, edited by Annemarie Bean, James Vernon Hatch, and Brooks Macnamara, ix-x. Hanover: University Press of New England, 1996.

Watson, Andrew. "Mobility and Sustainability: Lakeside Supply Networks in the Age of Steamboat Navigation, Muskoka Ontario, 1880-1930." Paper presented at Environments of Mobility in Canadian History Workshop, 13-14 May 2011.

Weigold, Marilyn E. The Long Idland Sound: A History of Its People, Places, and Environment. New York: New York University Press, 2004.

Weir, Robert E. Class in America: An Encyclopedia. Westport: Greenwood Press, 2007.

Whaley, Gray S. Oregon and the Collapse of Illabee: U.S. Empire and the Transformation of an Indigenous World. Chapel Hill: University of North Carolina Press, 2010.

Wheatley, E. "Disciplining Bodies at Risk: Cardiac Rehabilitation and the Medicalization of Fitness." Journal of Sport and Social Isules 29 (2005): 198-221.

Wiebe, Robert. The Searcb for Order, 1877-1920. New York: Wang, 1967.

Williams, Carol J. Framing the West: Race, Gender, and the Photographic Frontier in the Pacific Nortbwest. New York: Oxford University Press, 2003.

Williams, Gareth. "Popular Culture and the Historians." In Making History: An Introduction to the History and Practices of a Discipline, edited by Peter Lambert and Phillipp Schofield, 257-68. London: Routledge, 2004.

Williams, Susan. Savory Suppers and Fasbionable Feasts: Dining in Victorian America. Knoxville: University of Tennessee Press, 1996.

Willis, J., and R. Wettan. "Social Stratification in New York City Athletic Clubs, 1865-1915." Journal of Sport History 3, no. 1 (1976): 45-63.

Whitson, David, and Donald Macintosh. "The Global Circus: International Sport, Tourism, and the Marketing of Cities." Journal of Sport and Social lodues 20, no. 3 (1996): 
278-95.

Wilson, Alexander. The Culture of Nature: North American Landscapes from Disney to the Exxxon Valdez. Toronto: Between the Lines Press, 1990.

Wilson, William H. The City Beautiful Movement Baltimore: Johns Hopkins University Press, 1989.

Wilt, Maurice D. "Canoeing Under Sail." In Sailing Craft, edited by Edwin J.

Schoettle, n.p. New York: Macmillian, 1928.

Wiltse, Jeff. Contested Waters: A Social History of Swimming Pools in America. Chapel Hill: University of North Carolina Press, 2007.

Wurst, LouAnn. "Human Accumulations': Class and Tourism at Niagara Falls." International Journal of Historical Arcbaeology 15, no. 2 (2011): 254-66.

Youngs, Tim. Travel Writing in the Nineteentb Century: Filling in the Blank Spaces. London: Anthem Press, 2006.

Zakus, Dwight. “A Genesis of the Canadian Sport System in Pierre Trudeau's Political Philosophy and Agenda." Sport History Review 27, no. 1 (1996): 30-48. 